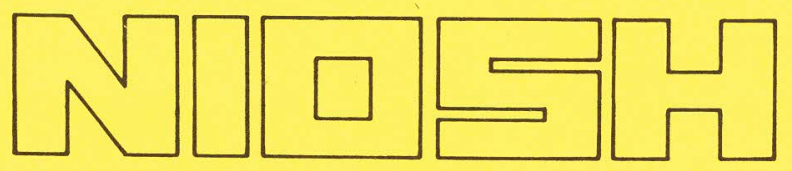

\title{
Proceedings of the Symposium on
}

\section{Occupational Health Hazard Control Technology in the Foundry and Secondary Non-Ferrous Smelting Industries}




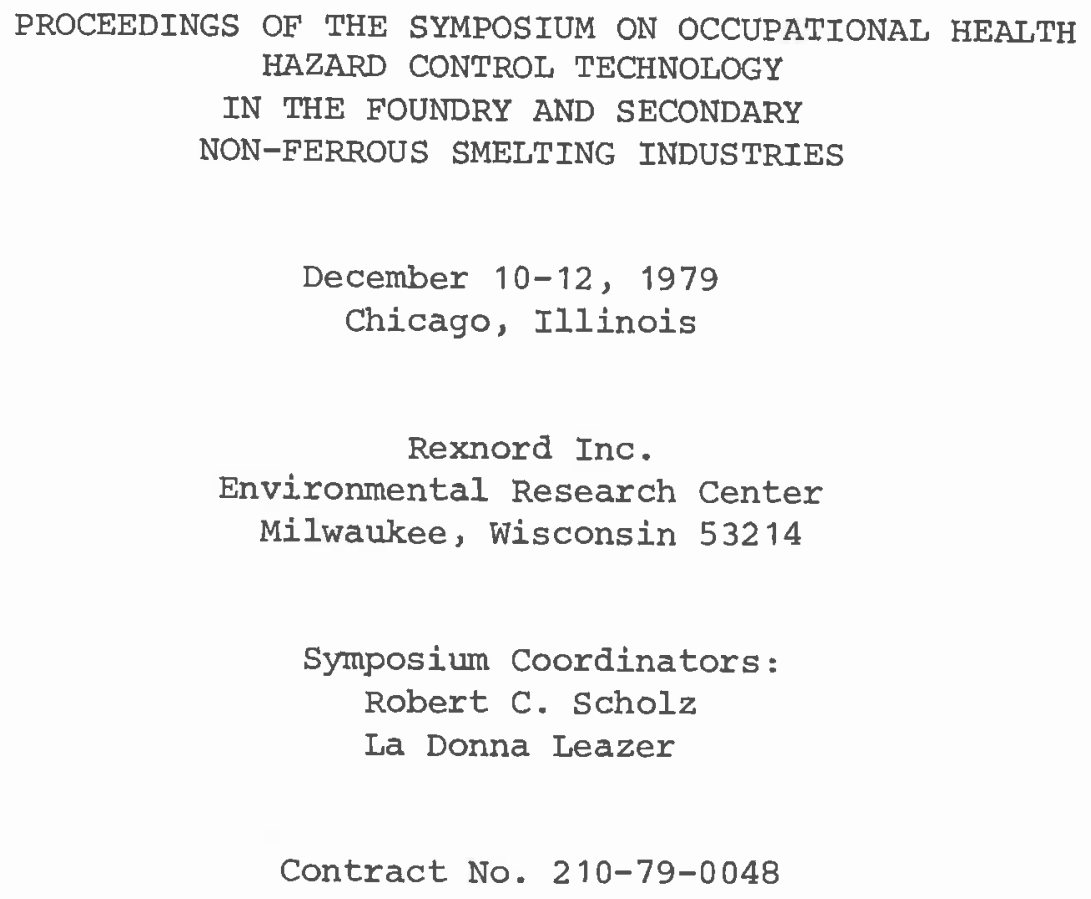

August 1981 
DISCLA:IMER

Mention of company names or products does not constitute endorsement by the Institute for Occupational Safety and Health.

NIOSH Project Officer: Dennis O'Brien

Project Manager: Robert C. Scholz

DHHS (NIOSH) Publication No. 81-114 
ABSTRACT

The purpose of this symposium was to present up-to-date information on control technology to reduce or eliminate worker exposures to chemical and physical agents in foundries and secondary non-ferrous smelters. The emphasis in the symposium was placed on data from in-place and functioning control systems as well as research results, primarily in the areas of control of air contaminants, noise, and vibration. The methods of reducing worker exposures that were discussed include substitution of less hazardous materials, processes, or equipment; process or worker isolation; ventilation; process monitoring; and work practices. In addition, the findings of recently completed studies of control technology in the foundry and secondary non-ferrous smelting industries sponsored by the National Institute for Occupational Safety and Health (NIOSH) were described and discussed.

The symposium was open to all individuals in both the private and public sectors. The goal was to elicit interchange of useful information among all groups with an interest in the health of workers. Technical speakers and panelists represented experts from throughout the United States, as well as the United Kingdom, Sweden, and Denmark. The symposium was three days in length; the first two days were devoted to foundries and the third day to non-ferrous secondary smelters. The total program drew nearly 500 people from a wide variety of backgrounds in both the public and private sectors, including OSHA, NIOSH and EPA, industry and industrial associations, labor unions, universities, consultants, equipment and material suppliers, industrial nurses and insurance companies, among others.

All of the technical presentations, with the exception of the descriptions of the NIOSH Technology Assessments of the Foundry and Secondary Non-Ferrous Smelting Industries, were submitted by the authors for publication. The descriptions of the NIOSH studies were not included here because all of that information is already included in reports published by NIOSH. Discussion on the technical papers, as well as panel discussions at the end of each day, were all transcribed and are presented here. Questions, answers and commentary have been minimally edited, and presenters have had the opportunity to review their presentations and responses. 

CONTENTS

Abstract. ........................................ $\ldots i$

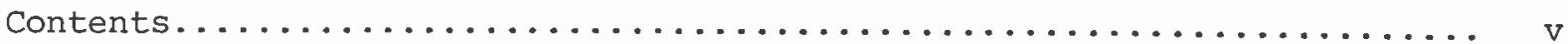

Acknowledgements...........................................

OCCUPATIONAL HEALTH HAZARD CONTROL TECHNOLOGY IN FOUNDRIES

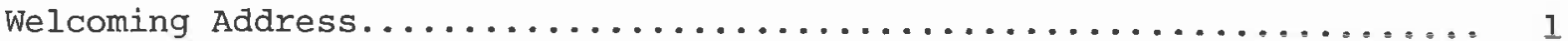

W. Haag, Director, Div. of Physical Sciences \& Engineering, NIOSH

Cincinnati, Ohio

The Foundry - Its Real Potential Health Hazards...................

G. Tubich, Tubich and Associates

Grand Rapids, Michigan

Some Design Criteria For Reducing Dust During The

Cleaning And Finishing of Iron Castings..........................

F. Shaw, British Cast Iron Research Association

Birmingham, England

Swedish Improvements In Cleaning of Castings With Regard

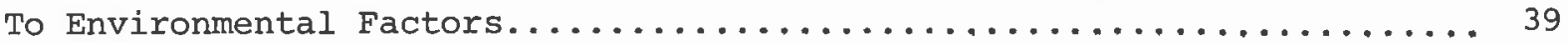

I. Svensson, Svenska Gjuteriföreningen, (Assoc. of Swedish Foundries) Jönköping, sweden

Pelton Casteel's New Cleaning Room............................

J. Scheid, Manager of Engineering, Pelton Casteel

Milwaukee, Wisconsin

High Velocity, Low Volume Dust Capture During

Grinding Using Portable Tools...............................

A. Katko, Manager, Dust Control, Hoffman Air \& Filtration Systems

Syracuse, New York 
New Technology For Improved Foundry Environments.............. 82

S. Hoenig, Professor, Dept. of Electrical Engineering, Univ. of Arizona

Tucson, Arizona

Determination \& Money, A Successful Foundry Safety \& Health Program... 121 H. McVey, Safety Director, Lynchburg Foundry

Lynchburg, Virginia

Panel Discussion on Chemical Binders-Past, Present \& Future........ 136 Moderated by G. Tubich, Tubich and Associates

Grand Rapids, Michigan

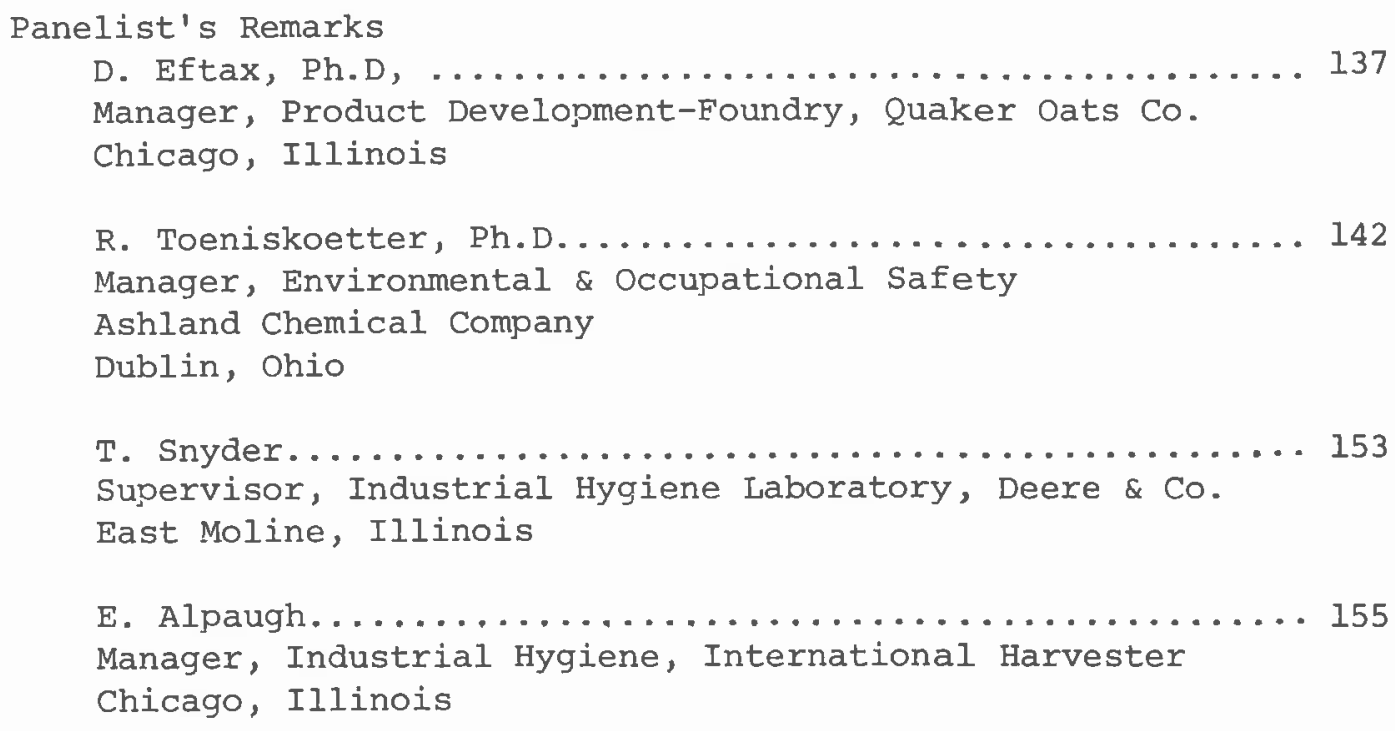

Meeting Air Quality Standards In The Foundry Industry A Study of Four Pennsylvania Foundries.................... 188 J. Davis, Assistant Professor of Industrial Engineering Center for Air Environment Studies The Pennsylvania State University

v. Irwin, Research Assistant Center for Air Environment Studies The Pennsylvania State University 
K. Knott, Assistant Professor of Industrial Engineering The Pennsylvania State University

Characterization of Particulates And Lead In A Brass Foundry

Using A Close Capture Exhaust System........................... 204

R. Jacko, Ph.D, PE, Associate Professor of Environmental Engineering

School of Civil Engineering, Purdue University

West Lafayette, Indiana

R. Overmyer, President

Hawley Division, Envirotech Corporation

Indianapolis, Indiana

A New Incentive: Payback Costs of Environmental Control In The

Melting Shop By Adding Heat Recovery Systems................. 222

J. Gutierrez, Airecon Manufacturing Corp.

Cincinnati, Ohio

Methods of Noise Control In The Foundry, Problems And Limitations..... 230

W. Ihde, Consulting Engineer, SV Engineering

Hinsdale, Illinois

A Summaxy of Chipping And Grinding Noise Research At

Rensselaer Polytechnic Institute........................... 238

H. Scarton, W. Kennedy, C. Caplan, J. Lacey, and K. Gaylo

Laboratory for Noise Control Research

Mechanical Engineering, Aeronautical Engineering \& Mechanics Dept.

Rensselaer Polytechnic Institute

Troy, New York

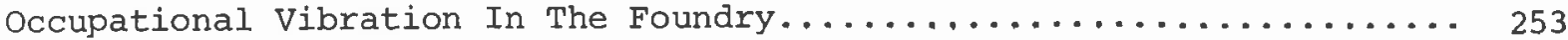

D. Wasserman, Chief, Bioacoustics Section

Physical Agents Effects Branch, NIOSH

Cincinnati, Ohio

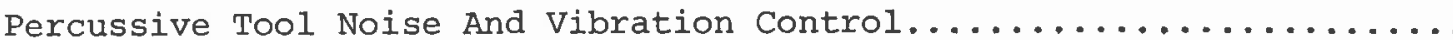

$\mathrm{E}$, Auerbach, Manager, Acoustics and Vibration

Ingersol-Rand Company

Easton, Pennsylvania 
Announcement of A New Health Study On Nickel And Chromium Exposure In Foundries.......................... 272 W. Dybvad, Corporate Director, Loss Control, The Duriron Co., Inc. Dayton, Ohio

Panel Discussion on Health Hazard Control Technology

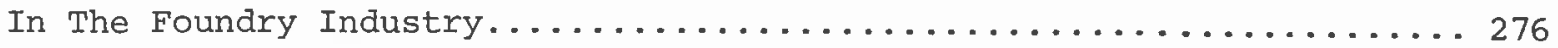
Moderated by D. O'Brien, Industrial Hygienist Control Technology Research Branch, NIOSH Cincinnati, Ohio

Panelist's Remarks

W. Huelsen, Director, Environmental Affairs.......... 277 American Foundrymen's Society

Des Plaines, Illinois

J. Williams, Vice President, Grede Foundries.......... 280

Milwaukee, Wisconsin

J. Brown, Industrial Hygienist............... 283 International Molders and Allied Trades Union Cincinnati, Ohio

Z. Sadauskas, Industrial Hygienist............. 286 OSHA Training Institute

Des Plaines, Illinois

F. Mirer, Ph.D, Industrial Hygiene Consultant......... 289 Social Security Department, International Union, UAW Detroit, Michigan

Questions, Answers and Commentary................. 292

OCCUPATIONAL HEALTH HAZARD CONTROL TECHNOLOGY IN SECONDARY NON-FERROUS SMELTERS

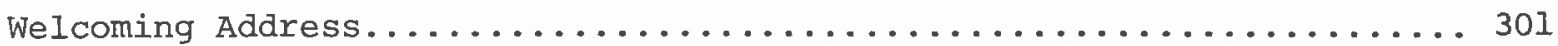

J. Talty, PE, Chief, Control Technology Research Branch

Div. of Physical Sciences and Engineering, NIOSH

Cincinnati, Ohio 
Questions, Answers and Commentary

Health Hazard Control Technology Assessment of The Secondary

Non-Ferrous Smelting Industry.......................... 303

R. Vandervort, Group Leader

D. Burton, Manager, Occupational Safety \& Health Div. Radian Corp.

Salt Lake City, Utah

Lead Smelter Design For Exposure Control...................... 306

N. Gram, Metallurgist, Paul Bergsoe \& Son

Denmark

Environmental And Occupational Protection In The Secondary

Lead Industry....................................

A. Craig, Jr., Industrial Environmental Research Laboratory, EPA

Cincinnati, Ohio

R. Vandervort, D. Burton, Radian Corporation

Salt Lake City, Utah

R. Coleman, Jr., Texas Metals

Austin, Texas

Work Practices And Administrative Controls - Lessons Learned From

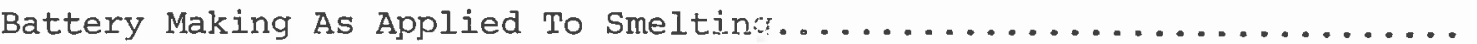

W. Pallies, Director of Environment, Safety and Health

ESB Ray-O-Vac Management Corp.

Philadelphia, Pennsylvania

Use of Downdraft Booth Design In Removing Toxic Dusts From

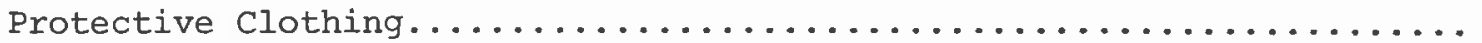

C. Dungey, Environmental Specialist, ASARCO

Tacoma, Washington

Engineering Controls -- only The Beginning.................. 367

V. Jacobson, Gopher Smelting Co., Inc.

St. Paul Minnesota

K. Caplan, President

Industrial Health Engineering Associates, Inc.

Minneapolis, Minnesota

Prevention of High Lead Levels Through Employee Training Programs.... 373

L. Norman, Director

Industrial Safety and Health Consultants

Jackson, Tennessee 
Panel Discussion on Health Hazard Control Technology In The

Secondary Non-Ferrous Smelting Industry...................... . . . . . . . Moderated by $\mathrm{R}$. Hughes, Chemical Agents Control Section Control Technology Research Branch, NIOSH Cincinnati, Ohio

Panelist's Remarks

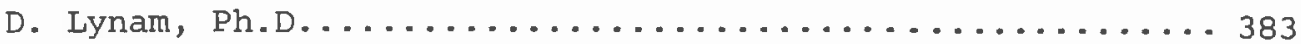
International Lead Zinc Research Organization, Inc. New York, New York

M. Cassady, Industrial Hygienist.................. 386 U.S. Department of Labor/OSHA

Salt Lake City, Utah

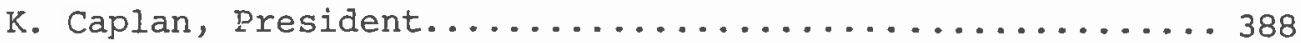
Industrial Health Engineering Associates

Minneapolis, Minnesota

P. Hitcho, Industrial Hygienist................... 390 United Steelworkers of America Pittsburgh, Pennsylvania 


\section{ACKNOWLEDGEMENTS}

Deep appreciation is extended to the technical authors and panelists who contributed their expertise and time to prepare written and oral presentations for the symposium. These individuals are truly representative of that class of busy professionals who still take time and do their part to advance everyone's knowledge of occupational health matters.

The large attendance at the symposium was gratifying and it was due primarily to the cooperation that governmental groups and private associations gave in "spreading the word". A number of associations in the foundry and secondary non-ferrous smelting industries sent the program brochures to their membership along with their periodic newsletters; others included announcements within the newsletters themselves. Announcements were also made at group meetings.

The program was moderated by two industrial hygiene professionals at NIOSH, who are deeply involved in control technology programs aimed at eliminating worker hazards, Mr. Dennis O'Brien and Mr. Robert Hughes. 

OCCUPATIONAL HEALTH HAZARD CONTROL TECHNOLOGY IN FOUNDRIES

\author{
WELCOMING ADDRESS \\ Walter Haag \\ Director, Division of Physical Sciences and Engineering, NIOSH \\ Cincinnati, Ohio
}

On behalf of the Institute and its Director, Dr. Anthony Robbins, I would like to welcome you to this Symposium on Control Technology in the Foundry and Secondary Non-ferrous Smelting Industries.

As most of you know, NIOSH has been given responsibility under the Occupational Safety and Health Act of 1970 to conduct research and develop criteria for preventing the exposure of workers to harmful chemical and physical agents. Within NIOSH, the Division of Physical Sciences and Engineering is responsible for control technology research, as well as for research and technical support in sampling and analysis.

A primary goal of NIOSH is to prevent occupational disease. In order to achieve this objective there must be an awareness of potential problems. There must also be knowledge of options for solving these problems and of constraints which would influence the choice of these options. Finally, there must be action to solve these problems. The success of this action depends on the degree of commitment to the timely solution of the problem, and the support, cooperation, and partjcipation of employers, employees, and Government.

To expand the knowledge of available options for the solution of occupational health problems and the constraints influencing the selection of these options, NIOSH has sponsored a series of industrywide control technology evaluation projects. The goal of these evaluations or assessments is to stimulate the private sector to prevent hazardous exposures of their workers and to establish a catalog of solutions by documenting successful application of control measures. These studies look for the best control techniques practiced by different companies and encourage the dissemination of knowledge across industries. Where we identify gaps in existing technology, we will encourage and support research to find answers. In addition to the studies completed on foundries and secondary smelters, NIOSH has finished studies on the plastics and synthetic resins industries and on dry cleaning establishments. Studies on cotton processing, pesticide manufacturing, aluminum reduction, coal gasification and liquefaction, spray painting, tire manufacturing and pulp and paper production are either well underway or nearing completion.

Foundries and secondary smelters were among the first industries studied in this program, for several reasons. First, both industries employ 
processes using substances long recognized as health hazards. Control measures for these hazards were known to exist, but no systematic study of the effectiveness of these methods had been undertaken. Second, the majority of foundries and secondary smelters are small businesses, lacking the total resources to develop information on the prevention of occupational exposures on their own. Third, since World War II, revolutionary changes have taken place in the processes and equipment available for use in these industries both here and abroad. Lastly, both industries are being challenged by the international community and must begin to do something about it.

The foundry and secondary smelter studies saw their beginning in late 1976. The studies were performed primarily through in-plant evaluations of existing control methods. At the outset it was apparent that studies conducted in a limited number of plants would not be able to assess all of the various processes and associated control measures in use. As a follow-up to these studies, NIOSH is conducting this symposium to enable representatives from industry, labor, and government to contribute additional solutions to occupational exposure problems not investigated in the NIOSH studies, to assist in the dissemination and provide a vehicle for discussion of the NIOSH foundry and secondary smelter studies, and, perhaps most importantly, to stimulate an interchange of ideas and solutions among participants. Our intention is that participation in the symposium should extend not just to the speakers, but to all other interested individuals who can contribute to a constructive exchange of information on these areas through floor discussions and the special panel discussions planned at the close of each day. Such a cross-fertilization of ideas can lead to significant progress. We hope that each participant will leave here with new and innovative ideas for solving the problems with which we are faced.

I would like to take this opportunity to commend the managers and employees of the foundries and secondary smelters who participated in the NIOSH control technology studies. Their cooperation is a testimony to their commitment to the prevention of occupational disease, and an invaluable assistance to NIOSH in the performance of its public mandate, the protection of the health of the working person.

I look forward to the presentations and discussions of the next three days as the beginning of a continuing partnership in stimulating the development and use of new and innovative technology to better protect our Nation's greatest resource, its workforce. 
THE FOUNDRY - ITS REAL POTENTIAL HEALTH HAZARDS

George E. Tubich

Tubich and Associates

Grand Rapids, Michigan

\section{ABSTRACT}

Silica, carbon monoxide, and metal fume are high priority health hazards in foundries. Noise and vibration, heat stress, illumination, and ionizing and non-ionizing radiation are physical agents with high priorities. A priority list is presented for foundry areas from a ventilation standpoint; the cleaning and finishing area tops the list. Looking at priorities among types of metals cast, the high temperature (ferrous) alloys have the highest priority. Ferrous foundries also account for the greatest majority of foundry workers. The reduction of the silica hazard will be achieved by the use of ventilation approaches; substitute sands for silica do not appear to be a long term solution.

Silica dust exposure is the major potential foundry hazard. Carbon monoxide is a major potential hazard in cupola operations. Foundrymen must be aware of its sources, symptoms, and treatment in case of emergency.

Metallic fume problems are greatest in processes in which the metal is molten, e.g., melting, pouring, welding, arc air, and less in abrasive grinding operations. The degree of potential health hazard associated with fume is dependent on the type of metal being cast.

The question of the formation of cancer agents during thermal decomposition of mold and core binders and additives is a subject for ongoing research.

Noise and vibration are not discussed here because they are handled in-depth in succeeding presentations.

Heat stress effects can be reduced by training workers to maintain their water and salt balances.

Good illumination affects productivity as well as safety and health.

The use of ionizing radiation is rigidly regulated in the foundry.

\section{INTRODUCTION}

The foundry, as well as many other industries, has a wide variety of potential health hazards. These have been classified as chemical and physical risks; at times they may occur simultaneously. It is virtually impossible to develop a list or priority classification that is accurate and precise at all times because of the many variable factors involved. However, when 
proper consideration and evaluation is given to the variable factors, number of people involved, concentration factors, and degree of toxicity, an order of priority can be developed which may serve as a useful guide.

For the foundry, the following chemical hazards appear to be of real significance.

1. Silica.

2. Carbon monoxide and certain other products of thermal decomposition.

3. Certain metallic fume and particulate - lead, manganese, chrome, nickel, etc.

There are some who believe trat the physical risks are of secondary importance as compared to the chemical risks'because of the type or nature of impairments. In the foundry the following physical conditions are of importance:

1. Noise and vibration.

2. Heat stress.

3. Illumination.

4. Ionizing and non-ionizing radiation.

Let no one be misled in any way by the above statement about the importance of various foundry risks for under certain conditions either the chemical risk or the physical risk may be of real significance. It would be well for all of us to reflect on John Donne's quotation - "Any man's death or injury diminishes me".

FACTORS INVOLVED IN DEVELOPING AN OCCUPATIONAL DISEASE

In one way or another a combination of some or all of the following factors may have the potential to produce an occupational disease:

1. Toxicity of material.

2. Concentration in breathing zone.

3. Particle size.

4. Length of exposure.

5. Individual susceptibility.

Particle size is perhaps the factor least understood by foundrymen. In order that silica dust can be inhaled into the deeper parts of the lungs to produce a health effect, it must be in the respirable range. There are several classifications of a specific respirable range; many consider particles that are 10 microns and less to be respirable. Particles larger than 10 microns are referred to as non-respirable and are removed from the body by the upper respiratory and lung clearance mechanisms.

The following facts concerning particle sizes are presented to provide some understanding of dealing with very small particles:

1. The respirable dust ( $<10$ micrometers) which is a health hazard is much smaller than the diameter of a human hair (40 micrometers). 
2. The limit of visibility extends down to about 40 micrometers, which helps to hide the presence of the respirable dust.

3. In still air, a 1 micrometer silica particle will settle less than $0.5 \mathrm{~m}$ in an hour. This emphasizes the ability of respirable dust to persist in the foundry general environment.

POTENTIAL HEALTH HAZARDS BY OPERATION

In the foundry there are certain basic operations where excessive exposures to airborne contaminants are most frequently encountered, particularly when ventilation controls are ineffective or non-existent. The principal operations where ventilation control or approved personal protective equipment is almost a must in every case because of inherent problems are listed below, in a broad order of priority:

1. Cleaning and finishing.

2. Sand systems.

3. Shakeout and core knockout.

4. Material handling systems.

5. Melting and pouring*.

6. Molding and coremaking.

This order that has been developed cannot be accurate and precise at all times because of the many variable factors involved. However, when proper consideration and evaluation are given to these variable factors, e.g., the number of people involved and the toxicity of the contaminant, an order of priority can be a very practical guide. This order applies only to chemical factors and not physical factors.

In terms of the type of foundry, priorities would be:

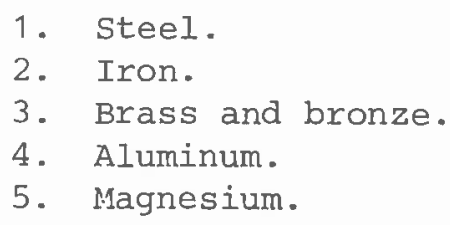

It may be noted that risk potential is considered to be greater in the higher temperature alloys.

Bureau of Labor Statistics (BLS) data for May, 1979 gives the estimated number of foundry production workers as follows:

$$
\begin{array}{ll}
\text { 1. Ferrous } & 201,800 \\
\text { 2. Non-ferrous } & \frac{84,300}{286,100}
\end{array}
$$

BLS has issued a projection that the rise in production workers from 1976 to 1985 will be about 15 percent or 43,000 . Of this amount 30-40 percent will be in growth and the remainder for replacement.

*Priority listing may vary according to type of metal cast. 
Information on the distribution of foundry production workers by operation is fragmentary, and is estimated below:

$\begin{array}{lr}\text { 1. Cleaning and finishing } & 70,400 \\ \text { 2. Sand systems } & 4,600 \\ \text { 3. Shakeout and core knockout } & 10,900 \\ \text { 4. Material handling systems } & 24,700 \\ \text { 5. Melting and pouring } & 29,800 \\ \text { 6. Molding and coremaking } & 116,800\end{array}$

CHEMICAL RISKS

Silica

Virtually all of the above production workers have a certain degree of exposure to silica dust and, dependent on operation, may have varying exposures to other contaminants. Accordingly, it seems evident that silica dust is the major problem and controlling the silica exposures will in many instances control other exposures.

From time immemorial silicosis has been a continuing problem in the foundry industry. It is unfortunate that there is no recent study data on the incidence of silicosis in the foundry. The last published data was in 1950. This study revealed that approximately 10 percent of the workers had some degree of silicosis. Today, it can only be assumed that improvements in the foundry over the past 30 years have brought about some reduction in the incidence of silicosis.

On a number of occasions it has been suggested that a non-silica aggregate, e.g., aluminum silicate, chromite, olivine or zircon, be substituted for silica. However, based on usage and production capabilities this is not reasonable. Today, the foundry industry uses some 10 million tons of silica sand each year. The total production of all non-silica aggregates is barely 500,000 tons per year. In addition, the cost of non-silica aggregates is approximately 4-6 times that of silica sand. The NIOSH study of health hazard control technology in foundries records many approaches to controlling silica dust. These should be thoroughly reviewed and applied or modified to fit the particular problem. Also, dilution ventilation with proper distribution of make-up air and approved personal protective equipment should be considered.

Carbon Monoxide

Carbon monoxide $(\mathrm{CO})$ is one of the oldest poisons known to man, and men have been subjected to it ever since the first fire was kindled. Until there is a better understanding of $\mathrm{CO}$, it will continue to be a problem.

Today, it has been determined that the potential for exposure to co of employees at the workplace is greater than that for any other chemical or physical agent. Not only is $\mathrm{CO}$ an important industrial poison, but it is also the greatest single non-industrial hazard, for it is readily found in the home, automobile, and other places. $C O$ is a colorless, 
odorless, tasteless, noncumulative, and non-irritating gas. All of these properties increase its danger, for an individual will not realize when he is being exposed.

Sources of Carbon Monoxide--

Carbon monoxide will be given off wherever there is incomplete combustion of a carbonaceous material. Therefore, gas, oil, kerosene, wood, coal, coke, core and mold additives, resin binders, and many other organic materials will emit $\mathrm{CO}$, the amounts depending on combustion efficiency. There is an old expression that says, "Where there is smoke, there is fire". Remember it in this way, "Where there is smoke, there is carbon monoxide".

The cupola is the major source of CO generation in the foundry. About 8 times more $\mathrm{CO}$ is emitted from a cupola than particulate matter. While much of the $\mathrm{CO}$ is either burned or emitted into the atmosphere, there is ample leakage at the charging and bottom doors and iron and slag spouts to produce significant $C O$ exposures. Typical $C O$ concentrations from the cupola and other foundry operations are shown in Table 1. This data was compiled from a number of different studies and represents conditions of poor to good control measures.

Table 1. Range of carbon monoxide concentrations in certain foundry operations.

\begin{tabular}{lcc}
\multicolumn{1}{c}{ Location } & No. of readings & Range of CO, ppm* \\
\hline Charging deck & 100 & $10-600$ \\
Iron and slag spout & 60 & $15-200$ \\
Floor level - cupola & 53 & $10-300$ \\
Pouring green sand molds & 75 & $25-600$ \\
Pouring resin bonded molds & 50 & $25-400$ \\
Shell core molding & 25 & $10-75$ \\
\hline
\end{tabular}

Absorption of $\mathrm{CO}--$

There are certain factors which enter into the absorption of $\mathrm{CO}$ :

1. Concentration of $\mathrm{CO}$.

2. Length of exposure.

3. Rate and depth of respiration.

4. Amount of exertion.

5. Altitude, temperature, humidity and air movement.

6. State of health, e.g., age, size, smoking habits, emphysema, anemia, coronary heart disease.

Carbon monoxide is classified as a chemical asphyxiant because it produces its harmful effects by cutting off the oxygen or fresh air supply from tissues of the body. Ordinarily, the oxygen that is inhaled is carried from the lungs by the red blood cells to all parts of the body. This combination with the red blood cells is very important, for just breathing oxygen is not enough to maintain life. The oxygen must combine with the red blood cell and circulate through the blood stream and be carried to all parts of 
the body. Unfortunately, CO can combine with the hemoglobin of the red blood cells to form a relatively stable compound, carboxyhemoglobin ( $\mathrm{COHb}$ ), which deprives the body of its oxygen. This action of $C O$ results in more persons succumbing to acute $C O$ poisoning than any other single toxic agent except alcohol.

The phrase "percentage of blood saturation" is commonly used in discussions concerning $\mathrm{CO}$ poisoning and can be defined as the percentage of hemoglobin of the blood combined with $\mathrm{CO}$ instead of oxygen. The symptoms of poisoning more or less parallel the blood saturation level and are shown in Table 2 .

Table 2. Symptoms of carbon monoxide poisoning related to the percentage of blood saturation of $\mathrm{CO}$.

\begin{tabular}{|c|c|c|}
\hline $\begin{array}{r}\text { Perc } \\
\text { blood }\end{array}$ & $\begin{array}{l}\text { centage of } \\
\text { saturation }\end{array}$ & Symptoms \\
\hline & $0-10$ & None. \\
\hline & $10-20$ & Tightness across forehead, possible headaches. \\
\hline & $20-30$ & Headache, throbbing in temples. \\
\hline & $30-40$ & $\begin{array}{l}\text { Severe headache, weakness, dizziness, dimness } \\
\text { of vision, nausea, vomiting and collapse. }\end{array}$ \\
\hline & $40-50$ & $\begin{array}{l}\text { Same as previous item with more possibility } \\
\text { of collapse and syncope, increased pulse and } \\
\text { respiration. }\end{array}$ \\
\hline & $50-60$ & $\begin{array}{l}\text { Syncope, increased respiration and pulse, } \\
\text { coma with intermittent convulsions. }\end{array}$ \\
\hline & $60-70$ & $\begin{array}{l}\text { Coma, with intermittent convulsions, de- } \\
\text { pressed heart action and respiration, } \\
\text { possible death. }\end{array}$ \\
\hline & $70-80$ & $\begin{array}{l}\text { Weak pulse and slowed respiration, respiratory } \\
\text { failure and death. }\end{array}$ \\
\hline
\end{tabular}

The symptoms decrease in number with the rate of blood saturation. When high concentrations of $\mathrm{CO}$ are inhaled, the employee may not experience any of the symptoms shown in Table 2 but may suddenly collapse. Death in these cases is due to paralysis of the respiratory center. Heavy work or exercise and high temperature and humidity with little or no air movement tend to increase respiration and heart rate and consequently result in more rapid absorption of $\mathrm{CO}$.

Sometimes $\mathrm{CO}$ does not work as quickly as this, but its effects are just as deadly. Often the first symptoms of lower concentrations, e.g., tightness across forehead, headache, throbbing in temples, dizziness, nausea, vomiting, are confused or misinterpreted as the symptoms of other illnesses. However, CO absorption is continuing and unless recognized, its serious effects progress to the same end results.

Treatment--

Prevention is always the best way to deal with accidents, but sometimes they happen despite our best efforts to foresee all possibilities. When they do occur, knowing what to do and acting quickly can save a life. This 
is especially true in cases of acute co poisoning where time is of the utmost importance. These are the steps to take:

1. Remove the victim to fresh air immediately - avoid extremely cold locations. If breathing has stopped or is irregular; begin artificial respiration at once.

2. Call a doctor immediately. Also send for an ambulance service or rescue squad, fire or police department, for special equipment to help revive the victim. However, do not wait for this help to arrive; start first aid without delay.

3. Continue artificial respiration when the emergency equipment arrives, providing both kinds of treatment at the same time until natural breathing returns, unless otherwise directed by a physician. Continue artificial respiration for two hours or more if natural breathing is not restored.

4. Continue application of oxygen, as provided through the emergency equipment, for 15 to 30 minutes after natural breathing returns. This will assist in quickly ridding the blood of $\mathrm{CO}$.

5. Keep the victim warm with blankets or other covering. After the victim begins to breathe again, keep him still, warm and quiet, to stave off any danger of shock.

6. Aid circulation by rubbing the arms and legs. The sooner proper circulation is restored, the sooner the patient will recover.

7. Avoid use of stimulants such as coffee or tea, since these may strain the heart.

8. See that the patient has rest and plenty of time to recover slowly to avoid any strain on the heart.

\section{Prognosis--}

In most cases of $\mathrm{CO}$ poisoning, recovery takes from a few hours to several days. All the damage done in these cases takes place during the time the gas is combined with the blood causing anoxia in the tissues. If this anoxia is both prolonged and severe, there is a possibility that a degenerative process may occur in the brain giving rise to after-effects. These aftereffects depend on the area of the brain affected and the extent of the degeneration. If the anoxia has not been too severe or prolonged, there may only be irritation of the brain cells without degeneration. In this case, the symptoms will disappear leaving no after-effects. However, if a degeneration is once set up in the brain, it may remain stationary or 
become progressively worse, ending in death. Sometimes, in cases where the degeneration becomes progressively worse, after the blood has been entirely freed of the $\mathrm{CO}$, there may be a period of time during which the victim has apparently recovered from the acute effects of the gas, only to have a relapse with severe after-effects.

Once the brain cells have degenerated, they are never regenerated and the effects produced become permanent. The after-effects manifest themselves in the form of loss of memory, paralysis, amnesia or other mental disorders and are most liable to occur in those of advanced years or in those having coronary heart disease. The number of victims suffering after-effects is extremely low in comparison to the number of victims severely asphyxiated.

Regardless of how high the percentage of saturation of the blood has been, practically all the $\mathrm{CO}$ is eliminated in 8-10 hours, but a small amount of $\mathrm{CO}$ may remain in the blood for a much longer time. Once the blood has been freed of $\mathrm{CO}$, the red blood cells are found to not be destroyed or altered in any way and they immediately resume their normal function.

\section{Metallic Fume and Particulate}

The degree of potential health hazards associated with fume and particulate is dependent upon the type of metal being cast. Some of the more significant metals are lead, manganese, chromium and nickel. Metallic fume can be encountered at melting, pouring and the various types of welding and brazing operations. Some of these operations may also emit carbon monoxide, nitrogen dioxide and other contaminants. The particulates liberated during grinding operations are usually not as significant as the fume because particulates from most grinding operations are usually of a large particle size.

Coal Tar Pitch Volatiles

There appears to be increasing evidence of carcinomas of the respiratory system in foundrymen. While there are no straightforward conclusions as to a single etiological agent or agents, there are strong suspicions that agents responsible may be formed during the thermal decomposition of a wide variety of organic additives and binders used in the foundry processes. Possible explanations are:

1. The presence of unidentified carcinogens in the air.

2. Synergism between various contaminants.

3. Different exposure in the 1940 's.

4. Smoking habits of the worker.

There is little question that before an unequivocal answer is possible much additional work will be required of the many parameters involved. One study on this matter is now being conducted by NIOSH. 
PHYSICAL RISKS

Noise and Vibration

A number of excellent papers on this topic are to be presented in these sessions. Accordingly, no comments on this subject will be presented.

Heat Stress

A big step toward maintaining the efficiency and well being of foundry workers exposed to heat can be achieved by an uncomplicated education program of teaching these workers to drink enough water and consume enough salt to replace that lost through sweating. This will combat the problem of worker fatigue caused by heat exposure. Although rapid strides have been made in the mechanization of foundry operations, worker fatigue still ranks as one of the critical factors in productivity. Studies have shown the following:

1. Failure of the body to get enough water during the working day is one important reason for heat fatigue.

2. A worker's thirst is not a reliable indicator of the amount of water he needs to avoid fatigue.

3. Most workers consume only two-thirds of their hourly requirement.

4. To get enough water, workers must force themselves to drink water even when they aren't thirsty.

The human body is a self-regulating mechanism which automatically demands the water it needs to make up for losses due to exertion and heat exposure. For many workers, however, there is a time lag in thirst, which allows the fatigue cycle to begin. The worker ends up being less efficient than he need have been for a good part of the day, and leaves the job more tired than necessary.

\section{Illumination}

Light and lighting are so universally applicable, controllable, and essential, however, they have been so grenerally neglected from every viewpoint of seeing. Good illumination is a vital factor in health and safety and productivity. The best worker with the best eyes, equipped with the best tools, becomes unsafe and inefficient when handicapped by poor illumination. The benefits of good illumination cannot be over-emphasized particularly when consideration is given to the fact that the cost is minimal when compared to many other in-plant control systems.

Ionizing Radiation

Those foundries using this type of radiation are uzually regulated by state agencies and must adhere to rigid control programs accordingly and only due to adverse situations is this a significant problem. 
To be successful in any control program there is a great need to develop and carry out a well-planned preventive maintenance program for all control equipment and a sound housekeeping program. Those foundries that have been most successful in achieving a good environmental control program have found these two factors to be most essential.

\section{AIR BALANCE}

Another factor that requires serious consideration is the air balance. If there is a great difference between the amount of air exhausted as compared to the amount of air supplied, the effectiveness of the control systems will be reduced. A frequent mistake with the air supply systems is poor location and distribution.

Most often the supply air should be introduced at no higher than $2.5-3 \mathrm{~m}$ (8-10 ft) above the floor level and so located that it will not be quickly removed by a nearby exhaust system. Proper air balance is a most important factor in achieving good control.

\section{RECIRCULATION}

The energy costs involved with exhausting heated room air to the outside is receiving a great deal of attention. NIOSH has conducted several seminars and investigations into this matter and their publications are available. In addition, the AFS recirculation comnittee will, within the next several months, have available further study data conducted at foundries.

\section{COMMENTARY}

The foundryman, through his technology, has created a wealth of new methods and materials. This has taken up so much of his total time, effort and ingenuity as to leave him little opportunity to learn what might be the ultimate effects upon himself. The foundryman, as well as many others, derives an undue comfort from the crude statistics that the people in no previous society have been known to die young in such small numbers and to live old in such large numbers. The easy conclusion is that we are healthier now than ever before and that modern life holds no serious threat to health. However, if we examine these statistics carefully, we find that we have extended the unproductive extremes of infancy and senility.

In law, the suspect is innocent until his guilt is proved beyond reasonable doubt. In the protection of the health of foundrymen such absolute proof often comes too late. To wait for this proof is to invite disaster or at least to suffer unnecessarily in the period of waiting. Today, a considerable amount of significant work is available on foundry control technology. Evidence that better working conditions and better equipment are essential to the production of quality products and attractive to the highest type of workman is now conclusive. The present problem, therefore, is not to convince management of the need but to show management that the time is now. 
QUESTIONS, ANSWERS AND COMMENTARY

Question (P. Maganus, Milwaukee Valve Company, Inc.) :

You. indicated that illumination is a most economical inplant safety measure on the basis of the defective vision that the employees seem to have in the foundry industry. Is this true only in the foundry industry?

(Editor's note: In his verbal presentation Mr. Tubich indicated that illumination is a good area where health, safety, and productivity can be improved. He said to consider two points:

1. Illumination is probably the cheapest of all inplant control measures.

2. Of the 40 and older population, 50-90\% have defective vision of some sort).

Answer (G. Tubich):

The diminishing of vision with age is true for the entire population. When we're talking about investments, I am contrasting the amount of money necessary to improve illumination with the much higher amounts necessary to, for example, ventilate a cleaning and finishing operation. 
SOME DESIGN CRITERIA FOR REDUCING DUST DURING

THE CLEANING AND FINISHING OF IRON CASTINGS

\author{
F. M. Shaw \\ British Cast Iron Research Association \\ Birmingham, England
}

\begin{abstract}
A wide variety of available methods for reducing worker exposure to respirable silica dust during the cleaning and finishing of castings are described and discussed. Emphasis is placed on methods which reduce the amount of sand burn-on and the amount of cleaning and finishing necessary. Casting precleaning is discussed, including the advantages and limitations of the various methods. One by one, exhaust methods are described and discussed for each of the manual cleaning and finishing processes. It is indicated where automation may help to reduce the dust hazard and simplify control. It is concluded that dust control during cleaning and finishing goes a lot further than ventilation.
\end{abstract}

\title{
INTRODUCTION
}

The cleaning and finishing department of a foundry generally generates the most potentially dangerous dust because of the high concentrations of silica dust which can exist if proper precautions are not taken. Experience in UK iron foundries shows that the lung disease, pneumoconiosis, caused by mixed dusts containing respirable silica, is not a problem. From this we may conclude that present day dust control standards are generally adequate from a health point of view.

When considering dust control it is important that all aspects are fully considered, ranging from casting cleanliness to adequate exhaust rates. This paper discusses the main points to be borne in mind.

REDUCING AND/OR SIMPLIFYING CLEANING AND FINISHING REQUIREMENTS

The amount of metal to be removed should be reduced to a minimum by attention to the molding and coremaking equipment. Wherever possible, by agreement rith the customer, excess metal should be left on the casting either because it will be machined off subsequently or because it does not detract from the utility of the casting.

Methods of achieving minimum cleaning and finishing requirements or making the job easier include: 
1. Pattern and corebox equipment must be accurate. In the case of high production castings there is the opportunity for alterations as the result of production experience to reduce flash.

2. Parting lines and core prints can often be located to make the flash easier to remove.

3. Joint line flash can be 'designed' to ease removal as shown in Figure 1; it will be seen that the 'fin" is part of the pattern(2).

4. Using barrel shotblast units where possible rather than conveyor units as the former are very effective in removing flash during the cleaning operation.

5. Definning cores by dropping shot or chain on them (1). The process is suitable for certain high production cores (Figure 2).

Using these and other practices the Volvo skövde Foundry was able in three years to reduce typical cleaning times as follows (2):

$\begin{array}{ll}4 \text { cylinder car block } & 60 \text { percent } \\ 6 \text { cylinder lorry block } & 48 \text { percent } \\ \text { cylinder head - car } & 27 \text { percent } \\ \text { cylinder head - lorry } & 46 \text { percent }\end{array}$

PROPER MOLDING AND COREMAKING PRACTICE

In the ideal case, sand properties and molding techniques should be such that sand strips cleanly from the surface leaving only superficial amounts of sand to be removed from the casting. If sand burns on to the casting, it becomes almost impossible to clean automatically. When exploring the reasons for sand burn-on, the refractoriness of the sand, the additives used and the type of mold coating used (if any) should be looked at. Burn-on is more likely with the silicate processes than with others since refractoriness is reduced by the silicate additions. Mold coatings are essential when silicate processes are used. Where burn-on occurs the quality and adhesion of the coating is suspect. The subject of sand technology is obviously too wide to discuss here. Suffice it to say that burn-on is possible if sand control is poor.

A similax defect having a different cause is metal penetration into the sand resulting in patches of mixed metal and sand on parts of the casting which only chipping will normally remove. One cause of metal penetration is the insufficient ramming of molds so that the sand is soft and of low compaction, especially at the bottom of re-entrant portions of a casting. Where this happens the molding process and the machines used need to be examined.

EFFICIENT CASTING PRE-CLEANING

Most castings are ground and when metal is removed some of the sand cast surface is also removed. Even when castings have been well shotblasted, the 

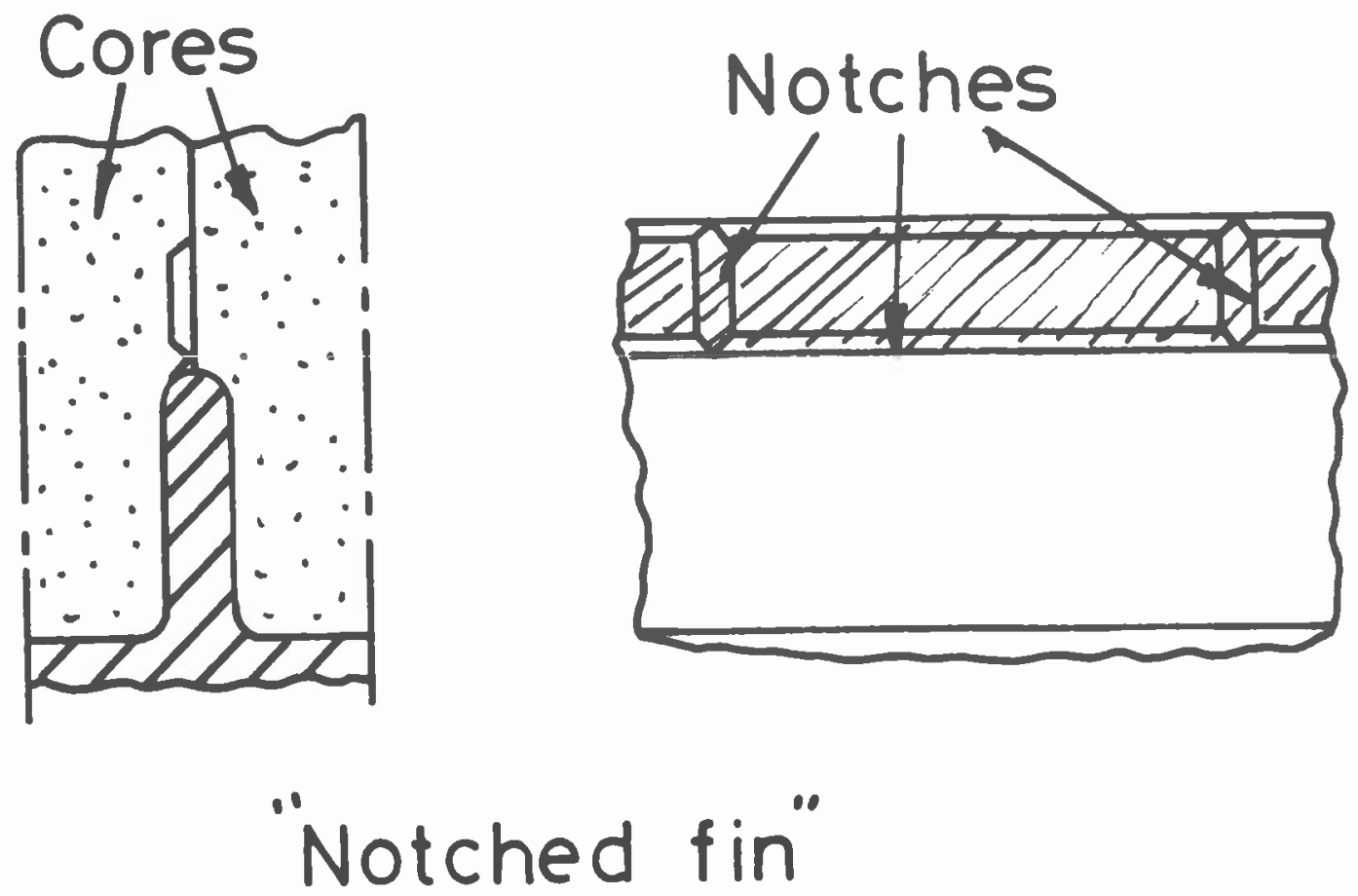

Figure 1. Casting fin design to facilitate removal.

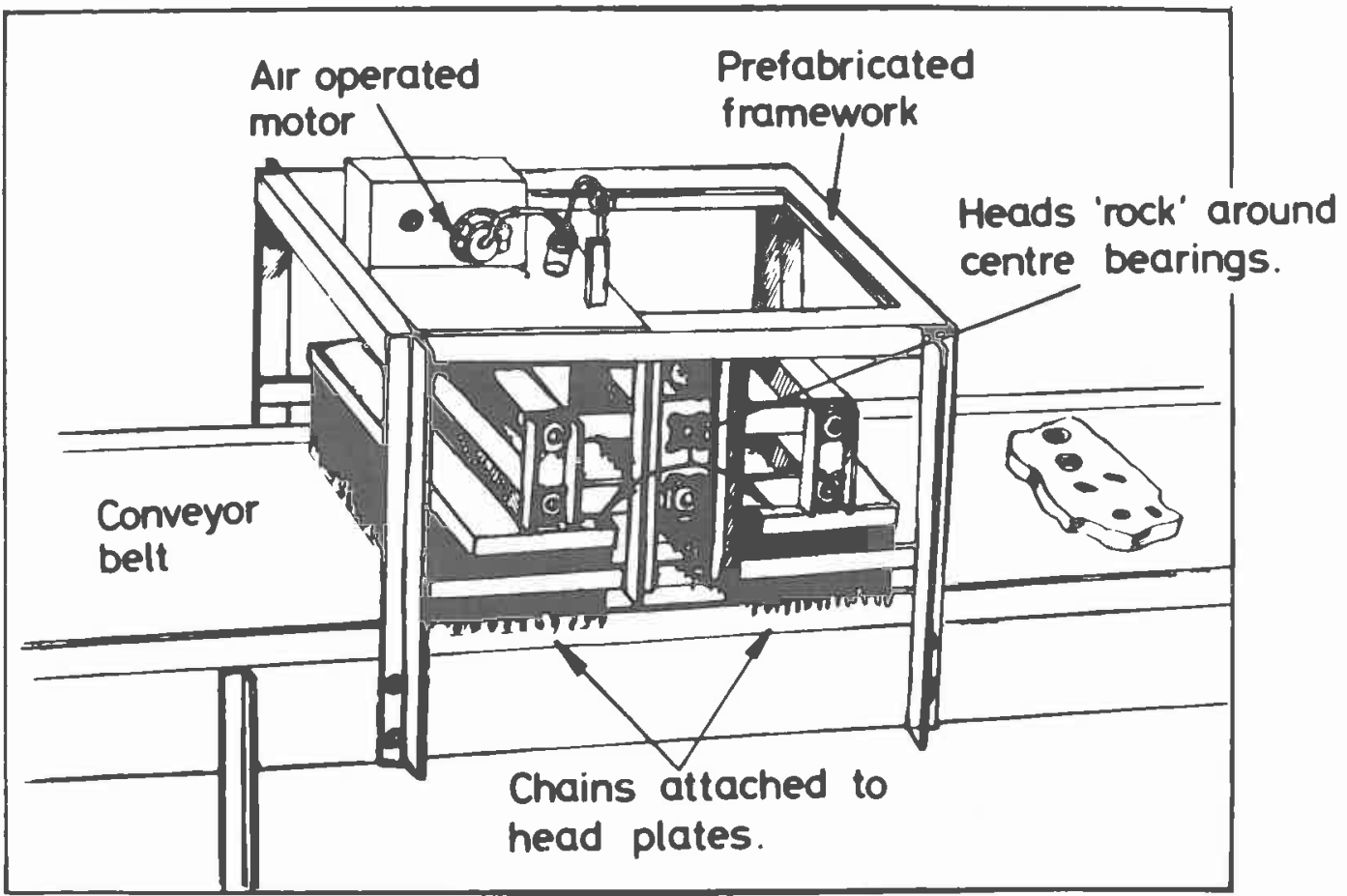

Figure 2. Chain definning machine for removal of flash from cores. 
surface will still contain some silica from the molding sand. On grinding, this silica is shattered and part of it becomes airborne. It is important, therefore, to pre-clean castings as well as possible prior to metal removal processes, otherwise the dust generated could well be beyond the capacity of the control system.

The achievement of foundry dust concentrations below the TLV, therefore, depends in many cases on efficient, prior cleaning of castings. By examining the respirable dust in the grinding/chipping areas a rough conclusion can be drawn on the efficiency of casting cleaning. If the respirable dust contains over 10 percent silica then the degree of cleaning is suspect and should be examined. We would normally expect nearer 5 percent silica if cleaning is good.

Shotblasting

Most castings are cleaned in one of the many designs of shotblast units now available and it is doubtful if any other process will make major inroads into their use. Shotblasting sand castings with metal shot is an excellent way of generating heavy clouds of high silica content dust. The process therefore must be well controlled by enclosure and exhaust to a dust collector. It may be of interest that sandblasting is forbidden in UK as is the recirculation of extracted cleaned air from any shotblasting process. We have found that properly maintained centrifugal shotblast units exhausted at the rates recommended by the manufacturers are seldom a cause of appreciable dust in the cleaning room. Where appreciable amounts of airborne dust with high silica content $(>20 \%)$ are found in cleaning rooms, it is usually possible to trace this to one or more of the following factors:

Leaking seals on the shotblast unit.

Insufficient exhaust caused by blocked ducts.

Insufficient exhaust caused by 'blinded' fabric filters.

\section{Salt Bath Process}

The most efficient and expensive means of removing silica from internal and external casting surfaces is to use one of the salt bath processes. For a few specialized castings, such as hydraulic valve castings, it may be done as part of the production process. It cannot, however, be considered as a general method for cleaning all castings.

\section{Acid Pickling}

Hydrofluoric acid will dissolve silica and some castings are pickled in mixed hydrofluoric/sulphuric acids prior to galvanizing where a very clean surface is required. General use of the process would result in a very difficult waste disposal problem.

\section{Other Cleaning Systems}

A number of little used processes also exist which may eventually be adopted on a wider scale. In electrohydraulic spark cleaning, underwater spark 'explosions' cause shock waves to loosen and remove sand. Ultrasonic 
cleaning is a recognized cleaning method but not readily adaptable to large scale casting cleaning. Castings may be vibrated in a bed of cleaning media and, while this is a good system of internal cleaning, it has little general applicability. For many years some castings were cleaned by a jet of high pressure water containing sand, but the use of this process has declined and it is doubtful if it will be used again even though it allows the recovery of sand removed.

VENTILATED METAL REMOVAL PROCESSES

Having done all that is practically and economically possible to remove traces of mold materials from castings in all but a few cases they then need to be processed to remove surplus metal. Dust evolution during metal removal is roughly proportional to the quantity of metal removed, provided surface sand has been largely cleaned off.

Automatic Grinding

Where large numbers of castings, particularly small ones, are being produced, it is often economic to use automatic cleaning and finishing machines. These machines are limited in the range of castings which any one of them can handle, and require a set of jigs for each casting. To be economical, therefore, there must be enough work for each machine and sufficient numbers of each casting to justify the jigs, and sufficient castings in a batch to justify fitting the jigs. It is generally accepted that a machine is not worth setting up for less than a two-hour run. The machines can grind from 200 to 1,200 castings per hour. Figures 3 and 4 show some typical machines used for malleable fittings. At BCIRA we have developed a simple grinding machine (Figure 5) for small round parts such as valve seats and burner caps. The machine uses a removable plate with cut-outs mounted on an indexing table to transport the castings to a position between a single, simple, replaceable jig and a support table in front of and slightly above a grinding-wheel. The jig is lowered to clamp the casting, and the clamping action continues, bringing the flash-line to the center line of the wheel. Then the casting is rotated to remove flash and ingate. Indexing of the table replaces the ground casting and ejection is automatic; casting feed can be manual or automatic. Castings $40 \mathrm{~mm}$ in diameter can be cleaned at the rate of 1000 per hour. Replacement of the jig enables a limited range of castings to be handled, and replacement of the jig and table plate greatly extends the range.

The point to be made is that it is usually cheaper, cleaner, and more accurate to use automatic machines for removing metal from long run castings.

One problem is the variability of flash even on castings which are mass produced. To ensure that all surplus metal is removed, an automatic grinder needs to grind all joint lines even if no flash is present. An alternative to fully automatic cleaning and finishing which may well prove to be the most economical and productive is a combined $\mathrm{man} / \mathrm{machine}$ operation. A man inspects a casting a:d removes the variable flash present and an automatic machine then performs the removal of runners and risers. The automatic machine may be located in the foundry, or it could be the first operation in the subsequent machining of the casting. 

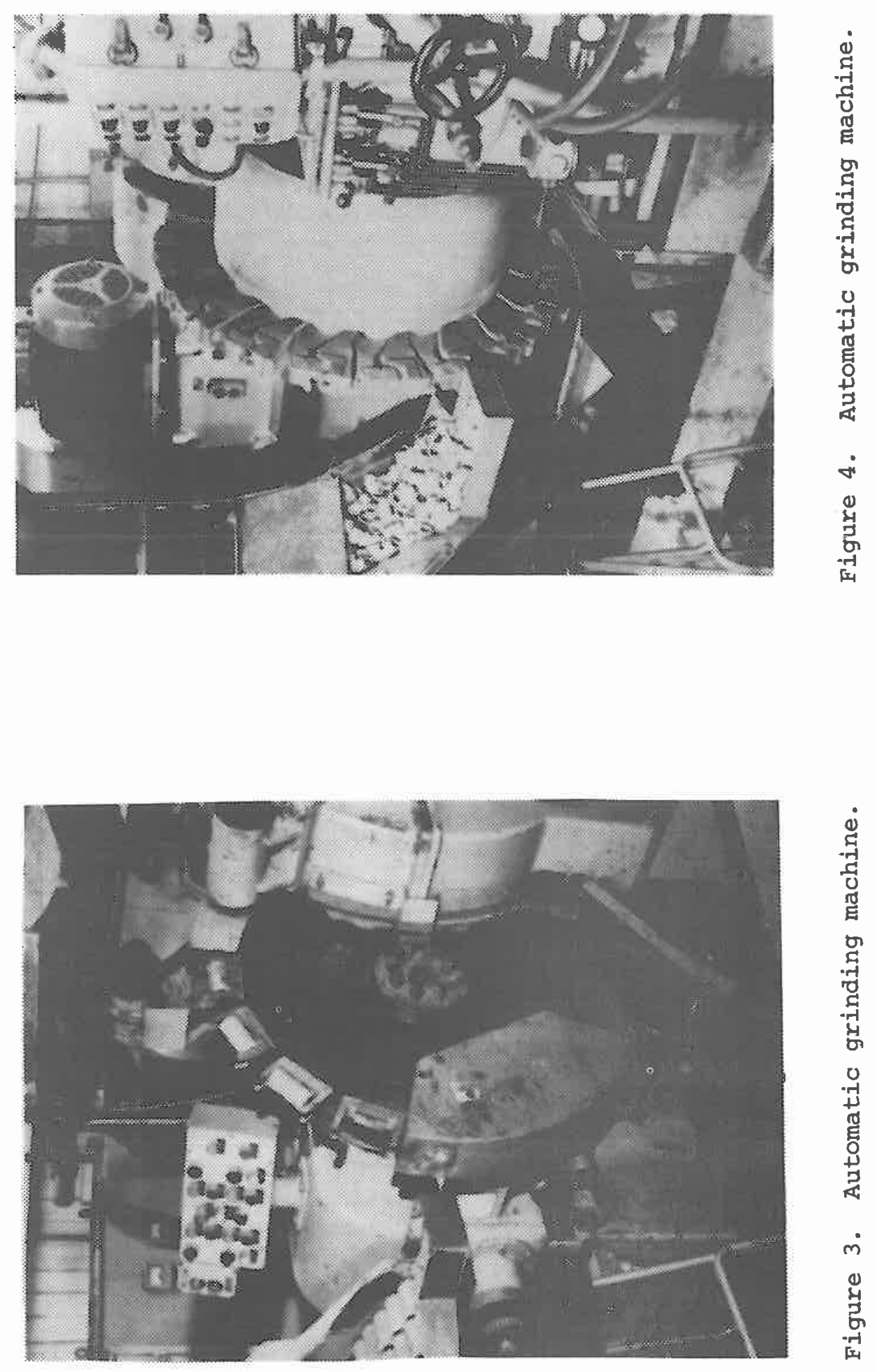


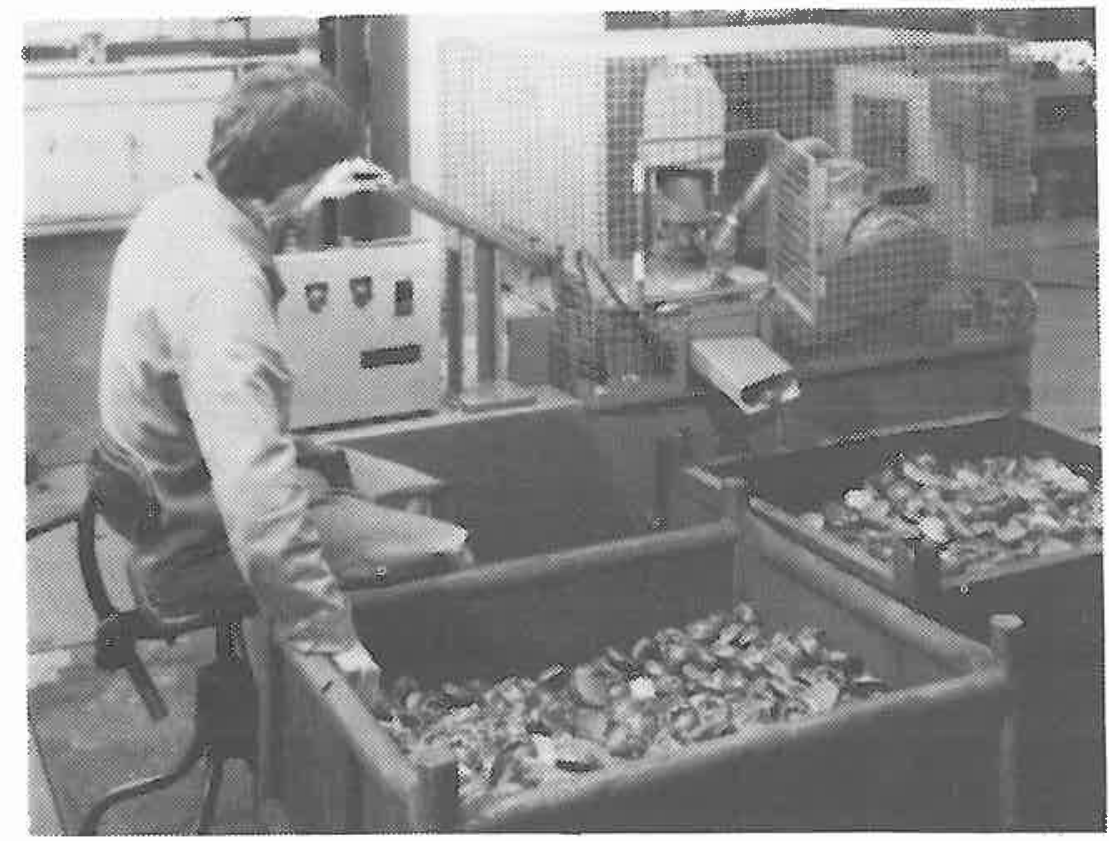

Figure 5. BCIRA designed machine for automatically grinding small circular castings.

\section{Pedestal Grinding}

Most small castings are ground by being hand held on pedestal grinders, though in some instances, particularly for malleable castings, pressure bars may be used to increase the rate of metal removal. Metal removed is around one percent of casting weight for grey iron castings and two percent for malleable. Grinding speeds have increased over the last decade or so and grinders in general now run at either 48 surface $\mathrm{m} / \mathrm{sec}$ (9500 surface $\mathrm{ft} / \mathrm{min})$ or 63 surface $\mathrm{m} / \mathrm{sec}(12,500$ surface $\mathrm{ft} / \mathrm{min})$. There seems to have been a swing away from the "super high speed" grinder running at 81 surface $\mathrm{m} / \mathrm{sec}(16,000$ surface $\mathrm{ft} / \mathrm{min})$. The amount of dust escaping from pedestal grinders will depend primarily on the rate of metal removed, the wheel speed and the dust control system used. In the UK it is usual practice to enclose the wheel as far as possible and to use perforated work rests as shown in Figure 6 . With well enclosed wheels running at 48 surface $\mathrm{m} / \mathrm{sec}$ (9500 surface $\mathrm{ft} / \mathrm{min}$ ) or less, an exhaust rate of $1525 \mathrm{~m}^{3} / \mathrm{hr}(900 \mathrm{cfm})$ on a $61 \mathrm{~cm}$ (24 in.) diameter wheel has proven in practice to keep dust levels in grinding shops to below the TLV. There are, of course, exceptional castings where the control may not be so good while removing excess metal from certain positions, e.g., when grinding pipe flange faces when wheel air may go down the pipe carrying dust away from the exhaust system. In such cases the castings might have to be ground on a ventilated cleaning and finishing bench.

When running at 63 surface $\mathrm{m} / \mathrm{sec}(12,500$ surface $\mathrm{ft} / \mathrm{min})$ dust control becomes more difficult but, nevertheless, during foundry tests, a $2130 \mathrm{~m}^{3} / \mathrm{hr}$ $(1250 \mathrm{cfm})$ exhaust rate on $61 \mathrm{~cm}$ (24 in.) wheels was sufficient to keep dust levels in a grinding shop to below the TLV. 


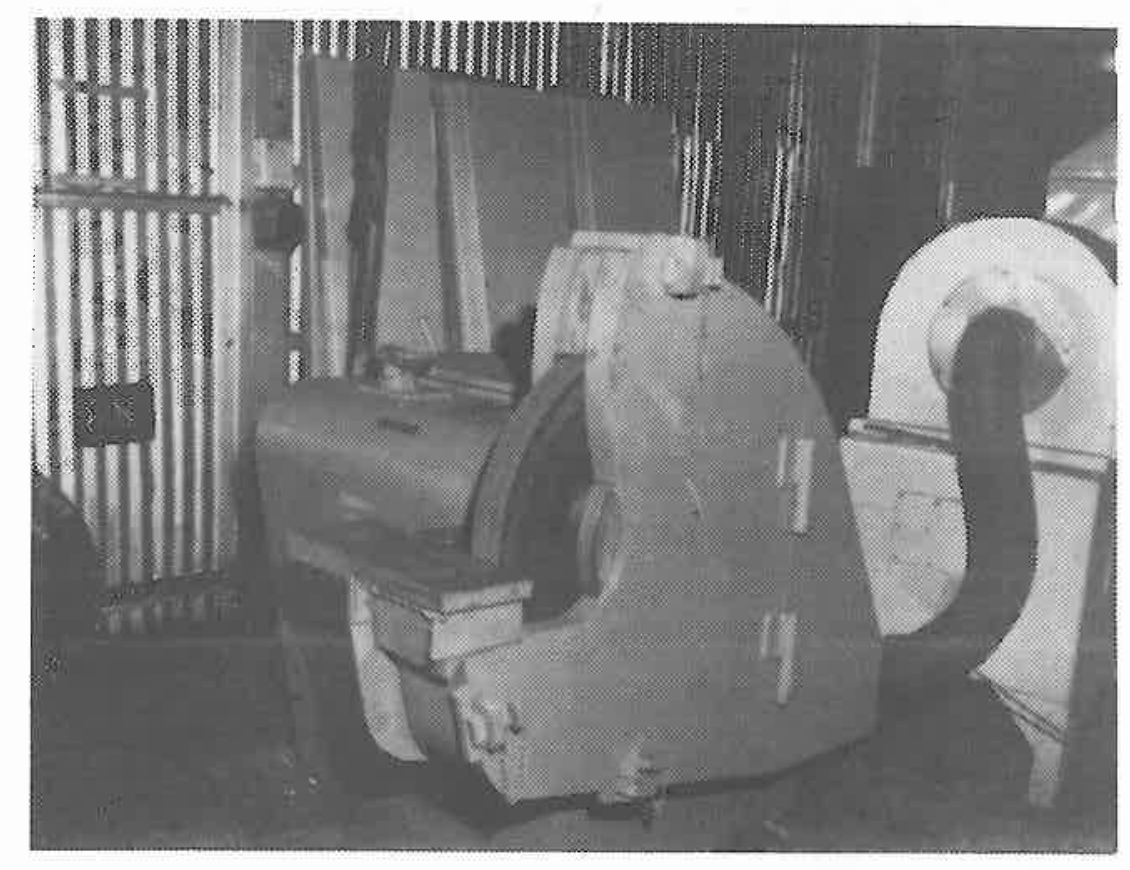

Figure 6. Pedestal grinder with well enclosed wheel.

\section{Portable Hand Grinding}

Medium sized castings, defined as those too heavy or awkward to grind on pedestal grinders but capable of being lifted by hand or with a light hoist, are ground by taking the grinder to the casting. The grinder is smaller, lighter, and lower powered than a pedestal grinder.

The Health and Safety Executive (HSE) in the UK usesa design figure of $1.0 \mathrm{~m} / \mathrm{sec}(200 \mathrm{ft} / \mathrm{min})$ for the air speed entering the hood of a ventilated bench. This figure is much higher than is used in most other parts of the world. We believe it to be a good general design figure in most cases but there are exceptions. For light grinding using, for example, $8 \mathrm{~cm}$ ( 3 in.) diameter or smaller wheels, a lower figure is adequate. However, for dirty castings, ground with a $20 \mathrm{~cm}$ ( 8 in.) grinder held with the spark stream directed out of the hood, it may be insufficient.

In many cases the castings to be ground are difficult to support and hold and many unsafe and otherwise undesirable improvisations are resorted to. New techniques have, therefore, been developed using rapidly adjustable holding or packing devices. One such development in the Fetlock casting support system, shown in Figures 7 and 8 . The unit consists of a table covered with pins upon which the casting is placed, depressing the pins. Movement of a lever locks the pins, which hold the casting where it has been placed rigidly enough for cleaning and finishing to be carried out. Dust control is taken care of by an exhaust.hood. The Fetlok is suitable for hand-grinding and also chipping. 

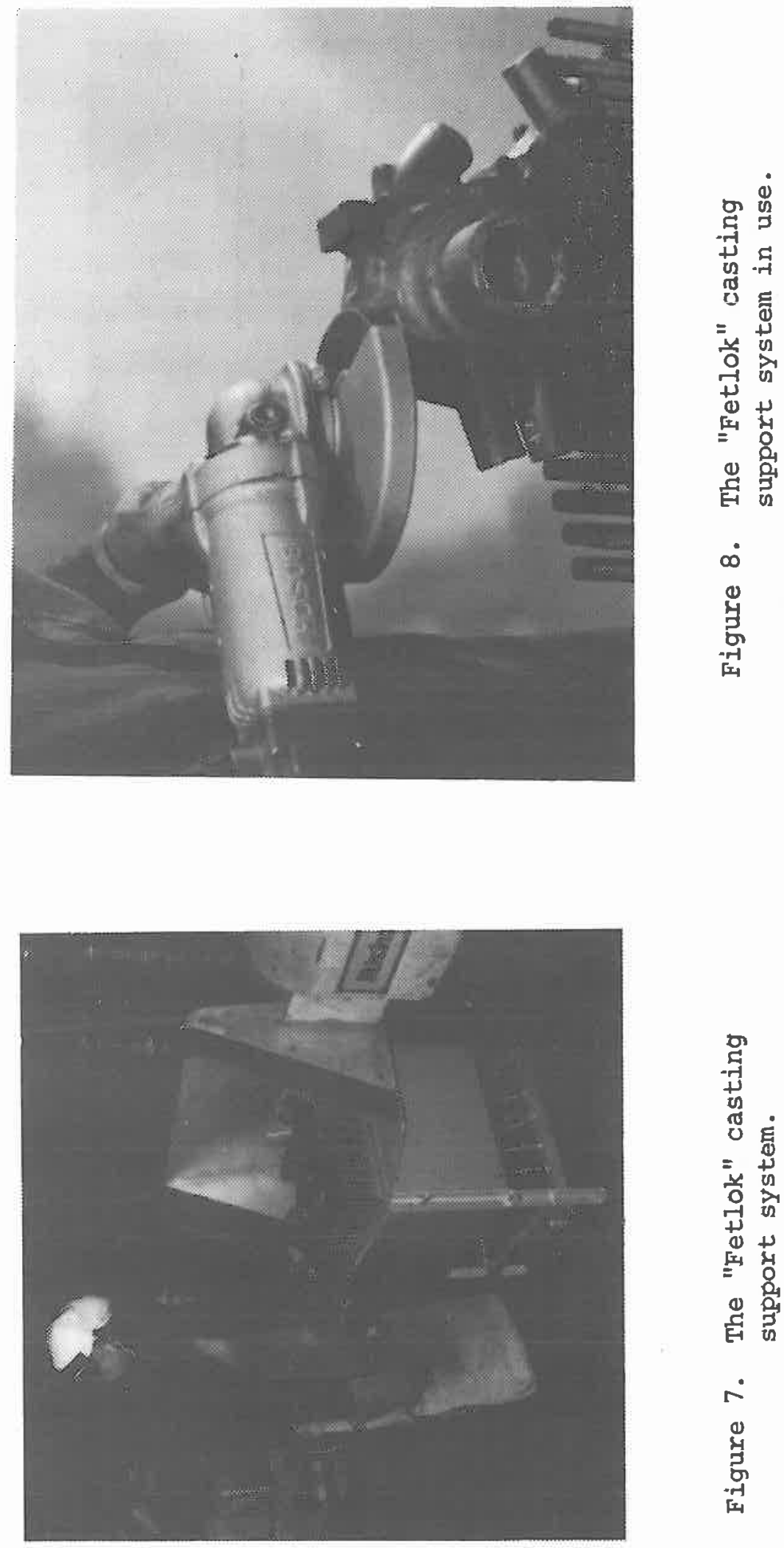

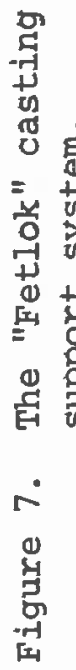


For castings which are too heavy for easy manual lifting, manual handing may be overcome in various ways. One is to put the casting on a turntable, which allows the operator to move the casting periodically; an alternative is the BCIRA fettling-hood, as seen in Figure 9. This hood allows the operator to work around the casting in the natural manner, using his shoulder to push the hood around as he moves. A further advantage of the fettling-hood is that the hood itself controls the air flow past the casting, giving more efficient dust control for a lower air exhaust rate than with a grinding booth. This results in a lower operating cost, because of the reduced power requirement and the reduced heating required for the lower volume of make-up air necessary.

Portable Grinding in Booths--

Castings too large and heavy for benches are frequently ground in booths. Here the casting is at or near floor level, preferably on a turntable as shown in Figure 10. Notice that the booth is retractable for placing the castings on the turntable. With large booths there is a possibility for the operator to move between the casting and the extraction point, thus exposing himself to the dust. Easy means of turning the casting around are, therefore, considered essential to make this method of working unnecessary.

Again the HSE in the UK asks for an inlet air speed to the booth of $1.0 \mathrm{~m} / \mathrm{sec}$ (200 ft/min).

An interesting design of booth used in the volvo skövde foundry is shown in Figure 11.

Combination Bench/Booths--

Some castings are too heavy to lift onto a bench until runners and risers have been removed or they have been separated from a spray. What often happens is that the operator removes the runner system or breaks up a spray of castings on the floor in front of a bench with virtually no operative dust control. Once castings are on the bench, dust control is good. BCIRA has developed a combined bench/booth concept to meet this situation, shown in Figure 12. Initial work takes place on the floor (Figure 13) in front of the lower ventilation slot, and final grinding takes place on the hench (Figure 14). The air flow is diverted from one position to the other by means of a simple lever.

Swing Frame Grinding

Metal can be removed by swing frame grinders far more quickly than when using hand held grinders. Their disadvantage is lack of flexibility in grinding position and only top surfaces can be ground easily. Dust control is probably best achieved by mounting the grinder so that it is in a booth and cannot be used outside the front face. Exhaust sufficient to produce a velocity of $1.0 \mathrm{~m} / \mathrm{sec}(200 \mathrm{ft} / \mathrm{min})$ into the booth face will normally achieve the TLV when working on "clean" castings. 

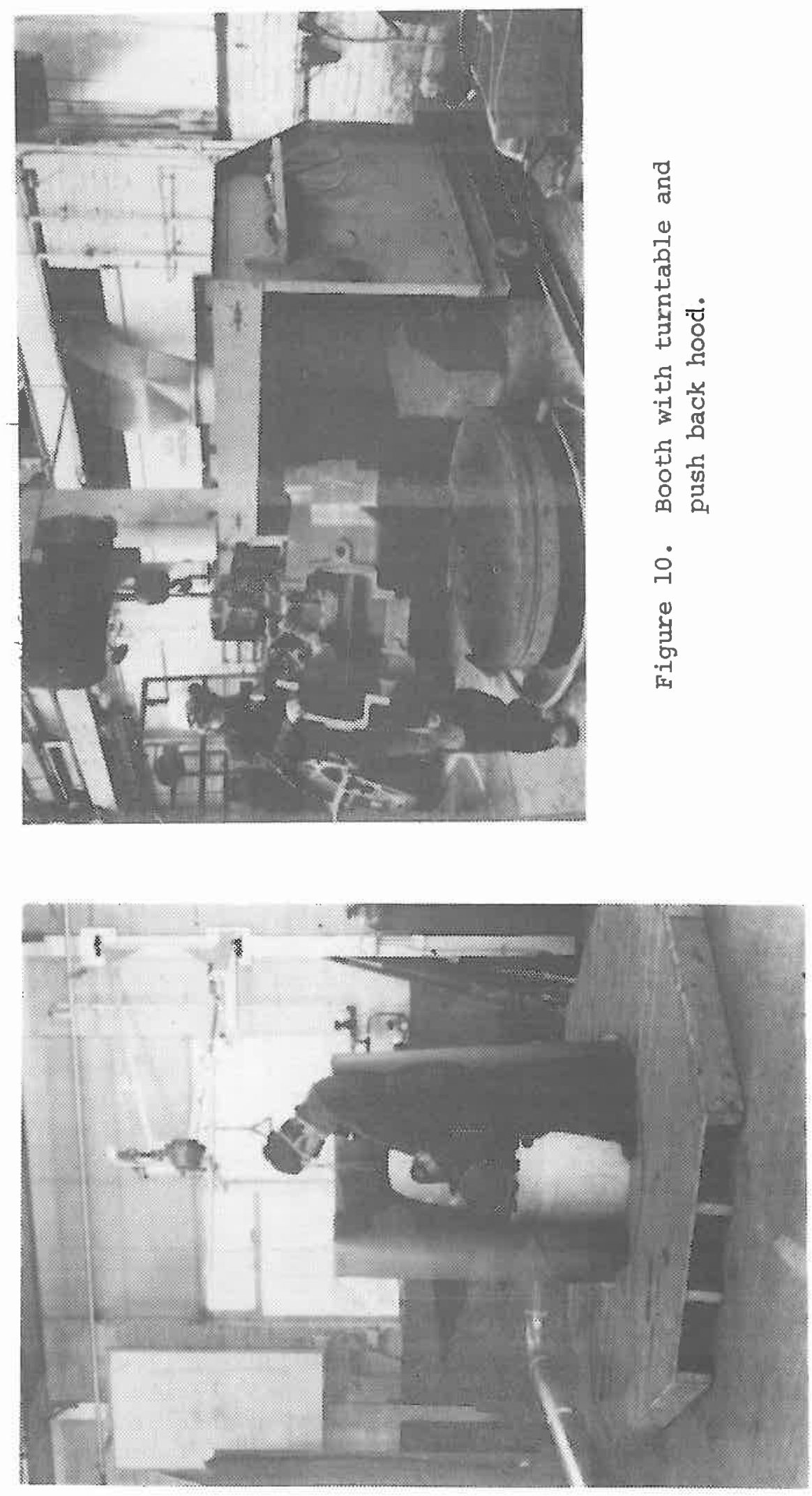

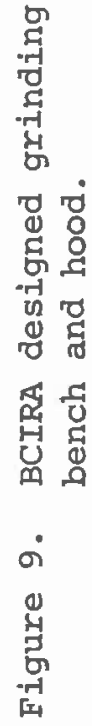




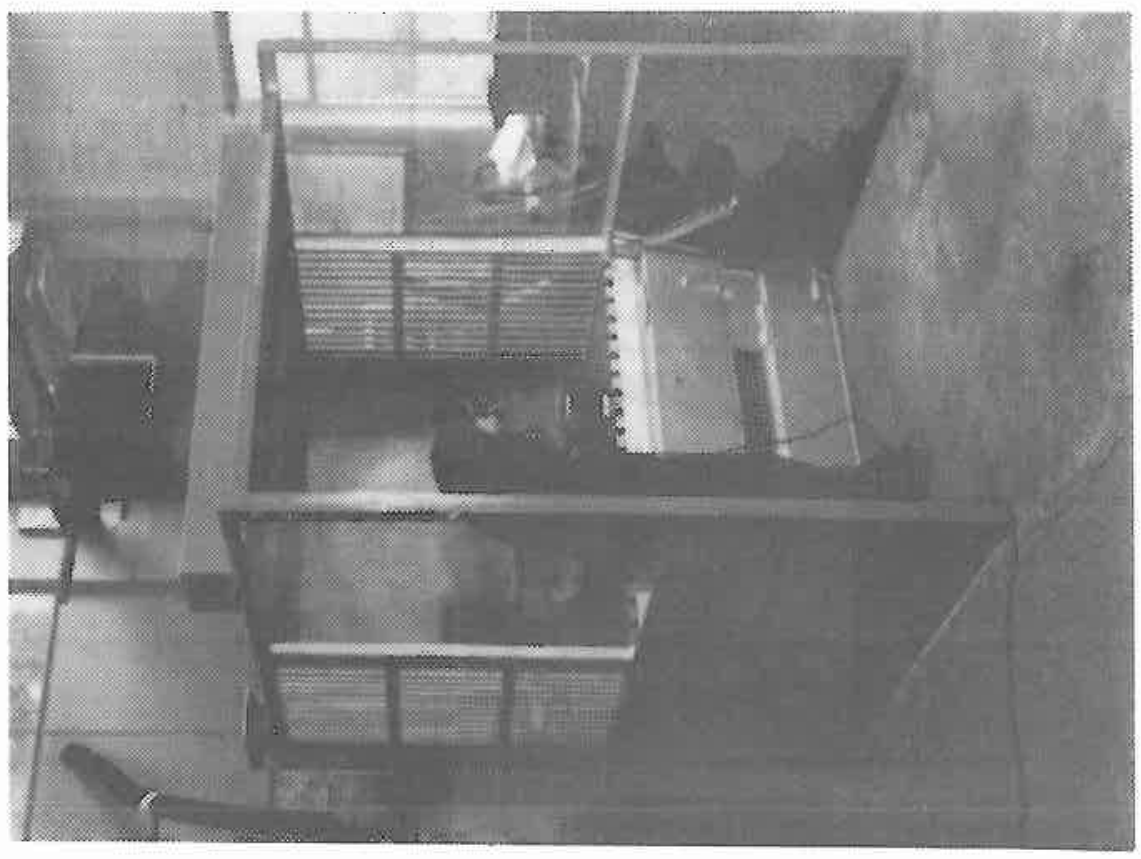

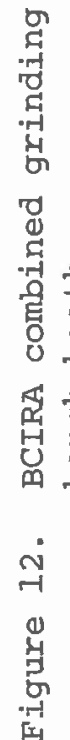

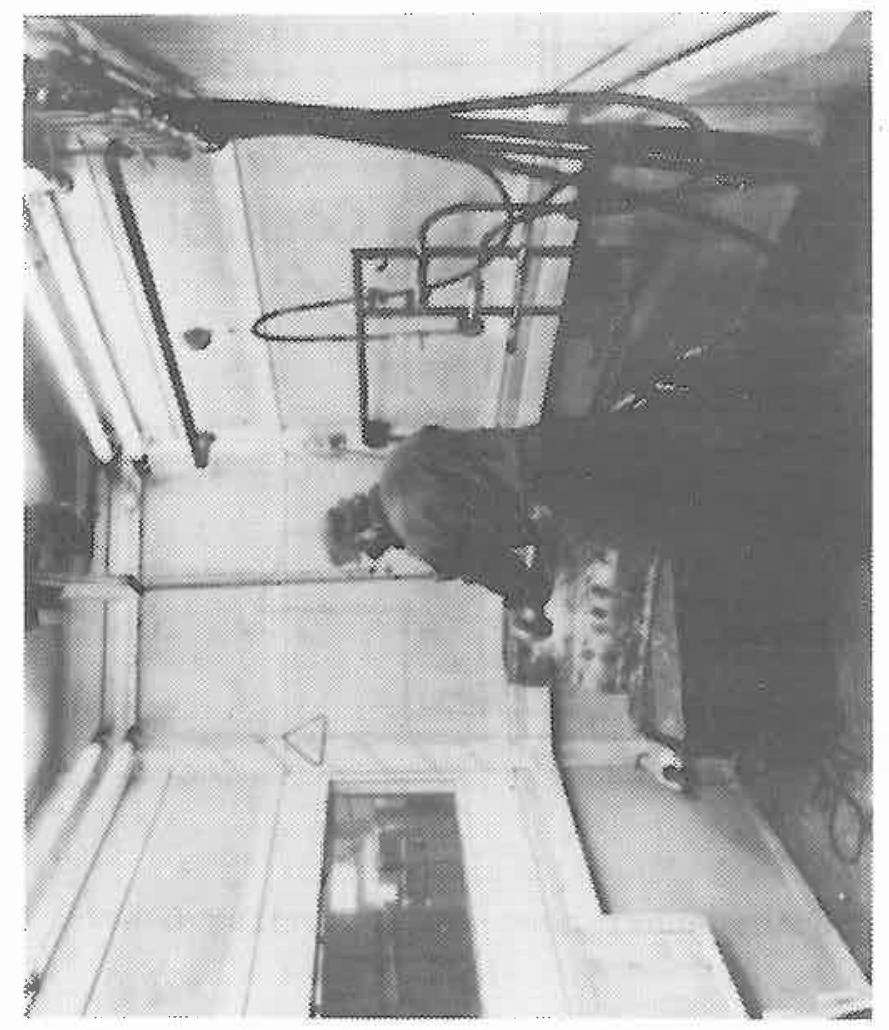

$\frac{9}{8}$

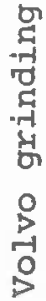

-

荡 


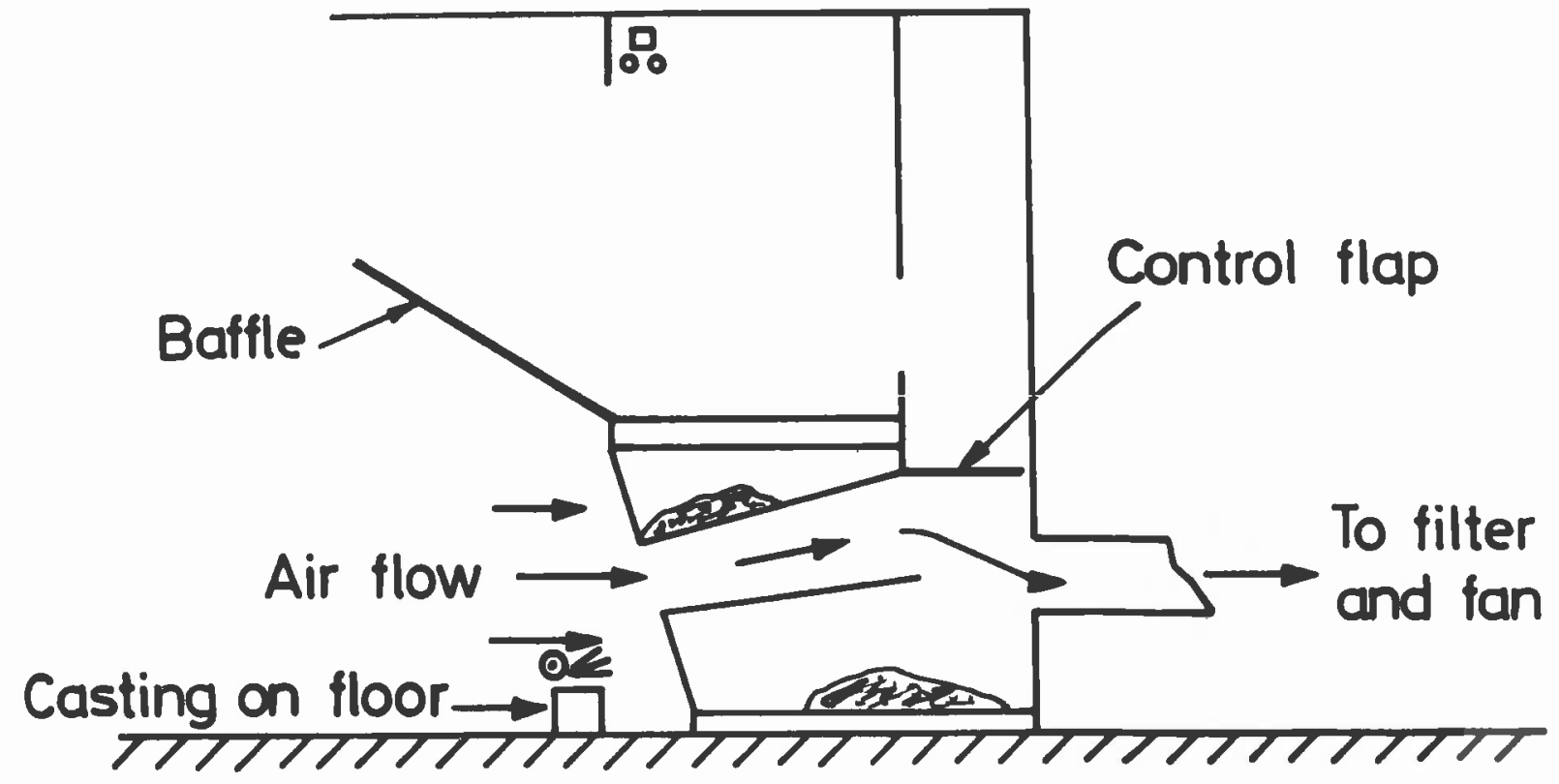

Figure 13. BCIRA combined unit used as a grinding booth.

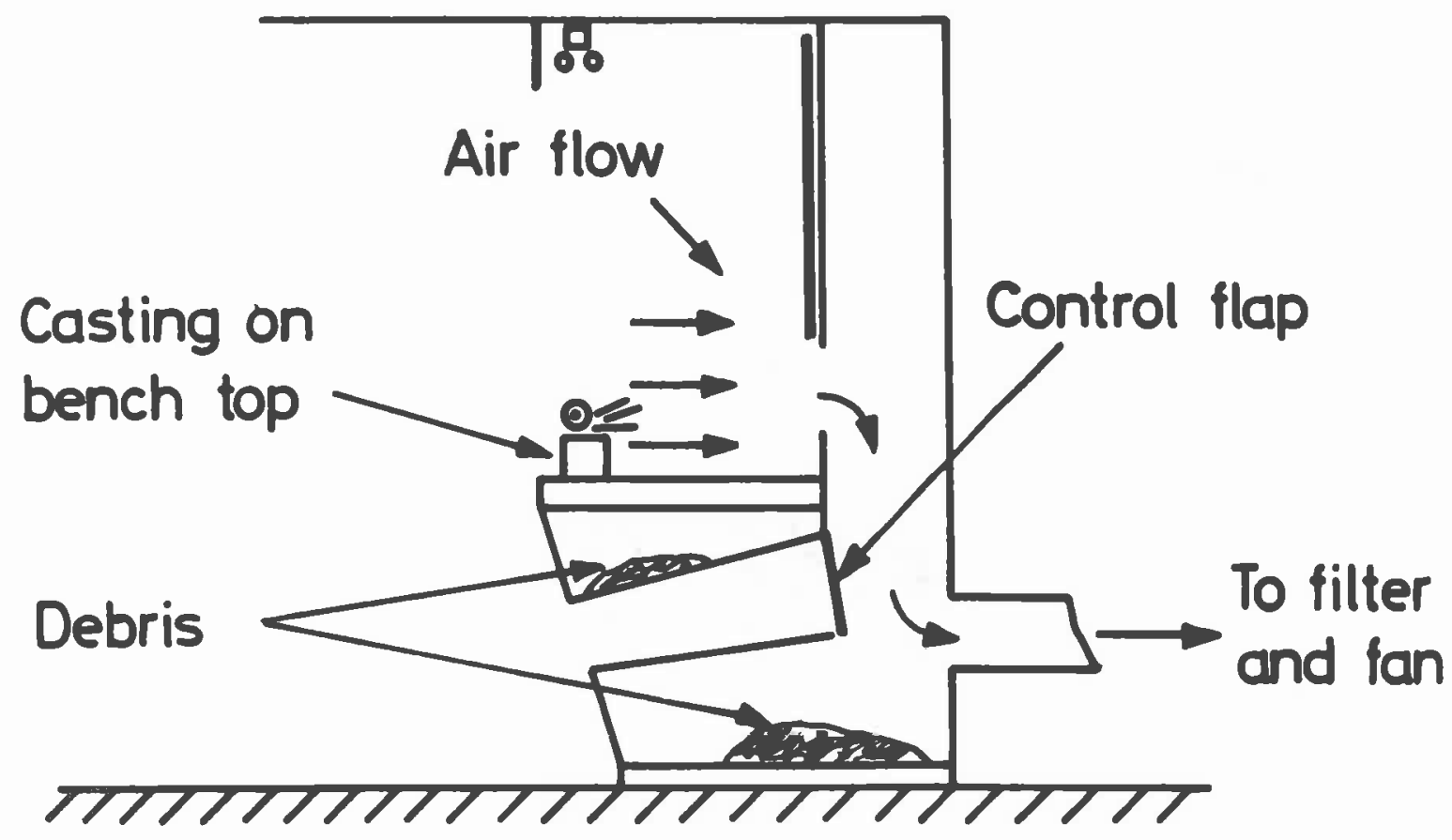

Figure 14. BCIRA combined unit used as a grinding bench. 
In some cases exhaust is applied to the swing frame grinder itself by means of flexible hoses. Recommended exhaust rates for swing frame grinders fitted with integral exhaust hoods are:

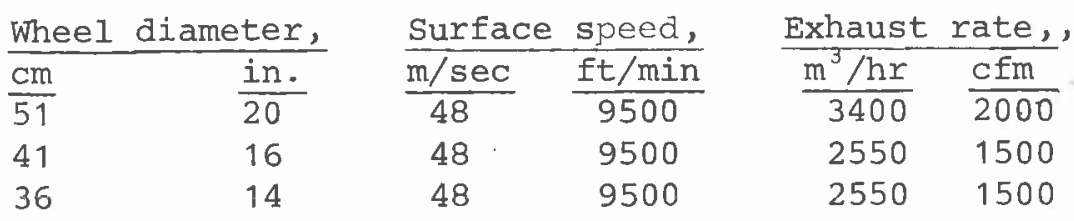

Little experience is available for wheels running at higher speeds but undoubtedly the above exhaust rates would need to be increased by at least $850 \mathrm{~m}^{3} / \mathrm{hr}(500 \mathrm{cfm})$.

An advantage of using a booth instead of grinder exhaust is that the booth also contains the large amount of heavy particles which no exhaust hood fitted to the grinder can completely capture. Booths therefore make housekeeping easier as the booth floor merely needs cleaning out, preferably by a vacuum cleaner at the end of the shift.

\section{Grinding Very Large Castings}

Large castings are frequently ground in large booths which use very high air exhaust rates. It is desirable to apply dust control directly to the cleaning and finishing tool and, as a result, use less air. The high velocity, low volume (HVLV) system was designed for this purpose. It has three main drawbacks: the exhaust hose is an added burden to the operator, efficient exhaust depends on the operator using the tool in the correct manner (which may entail his using only a small area of the grinding wheel), and the exhaust hoods require adjustment as the wheel wears. These shortcomings have been overcome by a new BCIRA development known as Freshold (Figure 15). The object was to make lighter work of grinding by supporting the weight of the grinder with a balancer, but as soon as this was done it became clear that there was an opportunity to incorporate better dust control than that provided by the HVLV method. The support system allows the use of a largebore exhaust pipe, which in turn allows a higher exhaust rate using a low power fan, compared to the expensive high-power exhauster required for HVLV. The increased exhaust rate gives better dust control over the full grinding area of the wheel. For instance, the $23 \mathrm{~cm}$ (9 in.) disc grinder shown in Figure 16 can be used over the whole exposed segment of the wheel with good dust control. The cup-grinder (Figure 17) can be used over its full face, from the new wheel stage until it is worn out, without the need for adjustment of the exhaust hood. The supporting jib is designed so that it cannot be overloaded or damaged by an overhead crane.

For external grinding the present system is easy to use, and offers good dust control even when using the highest-power hand grinders available. The air flows required are up to $1445 \mathrm{~m}^{3} / \mathrm{hr}(850 \mathrm{cfm})$. 

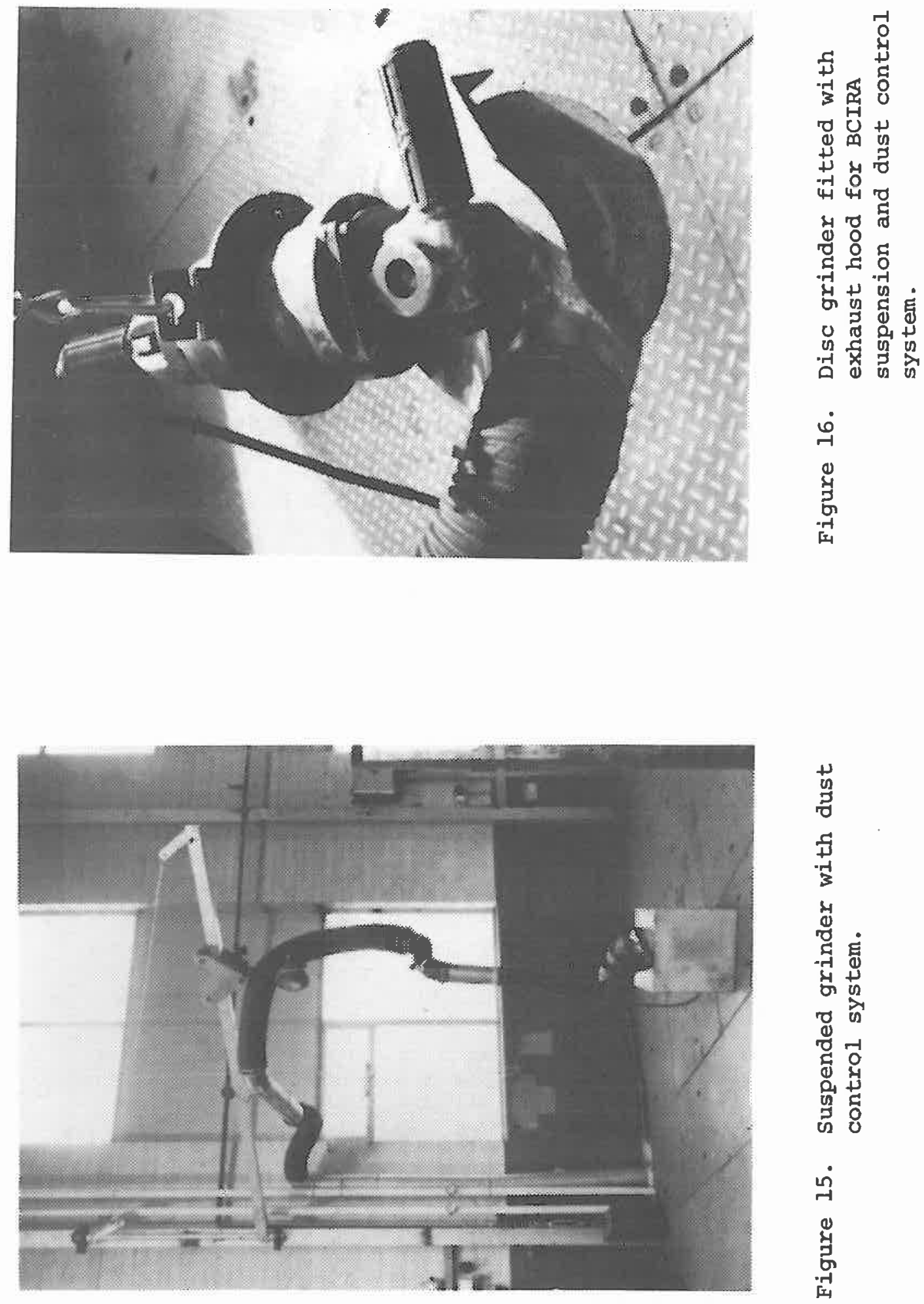

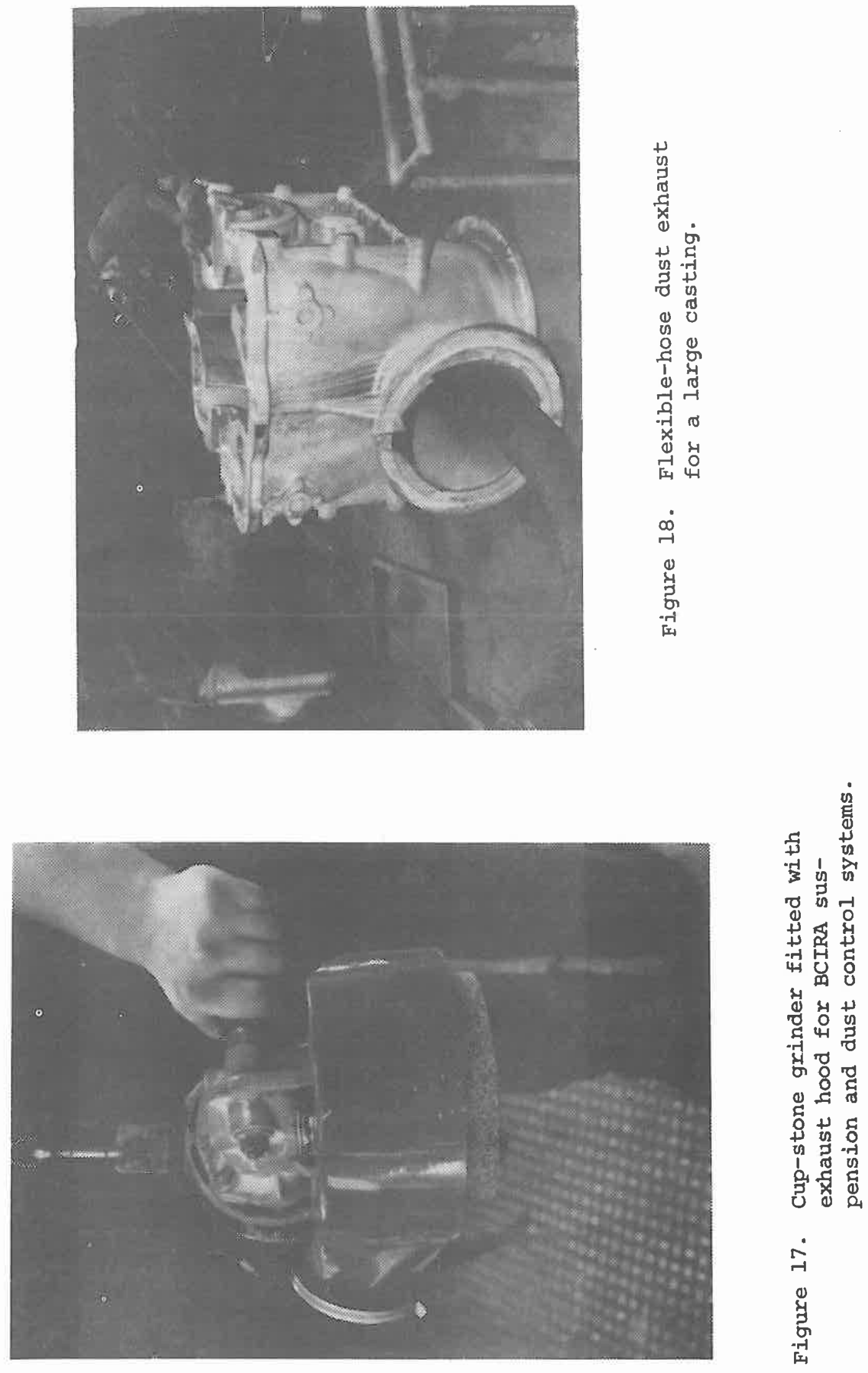
Internal Work--

When grinding or chipping the internal surfaces of large castings it is difficult to provide dust control on the tools themselves.

Svensson and Thyberg have experimented with flexible exhaust ducts simply placed inside the casting (Figure 18) (4). The duct is believed to have been exhausted at a rate of $3060 \mathrm{~m}^{3} / \mathrm{hr}(1800 \mathrm{cfm})$ with the following effect on operator breathing zone respirable dust concentrations:

Exhaust on: $1.8 \mathrm{mg} / \mathrm{m}^{3}$

At the time this satisfied the Swedisn dust concentration criteria, but probably would not do so now. With a somewhat greater exhaust air flow, perhaps $5100 \mathrm{~m}^{3} / \mathrm{hr}(3000 \mathrm{cfm})$ the system has a good chance of achieving the ACGIH TLV in a number of internal grinding applications. The simple expedient of providing flexjble exhaust ducts inside the casting being cleaned may therefore satisfy control requirements in many cases where previously control was not achieved. BCIRA has carried out similar work on ingot molds (Figure 19) (5). The ingot molds were ground internally with the operator sometimes working inside the casting.

It was found that if an air velocity of at least $0.76 \mathrm{~m} / \mathrm{sec}$ (150 ft/min) could be induced through the ingot mold, the dust clouds generated by grinders and pneumatic chisels could, with one exception, be exhausted from the mold without passing through the breathing zone of the worker. The exception is the situation where the worker is inside the mold with a grinder or pneumatic chisel upwind of his breathing zone.

The situation sometimes arises when a right-handed worker is working on the bottom left-hand corner of the ingot mold. If this situation cannot be avoided, the worker should wear an approved respirator until he returns to a working position such that the grinder or pneumatic hammer is downwind of his breathing zone.

The air exhaust can be coupled to the top of an open-top or bottle-top ingot mold by a flexible hose and a vertical baffle plate mounted on a low trolley. Alternatively, the flexible hose, fitted with a suitable inlet hood to reduce the air flow resistance of the system, could be inserted at the top of the mold and held in position by magnets fitted to the hood. The top end of the mold could then be sealed as completely as possible by a weighted canvas curtain. In the case of closed end molds and bottom poured molds with a greater cross-sectional area than $0.18 \mathrm{~m}^{2}\left(2 \mathrm{ft}^{2}\right)$, the exhaust has to be achieved by inserting the flexible hose well up the mold from the open end.

Of limited application for large casting grinding is the semi-automatic Gabelin grinder developed specifically for ingot molds (6). Changing to this grinding system (Figure 20) separates the operator from the operation and allows simple dust control to be fitted (Figure 21) on the same lines as that used by BCIRA for hand grinding of ingot molds. 


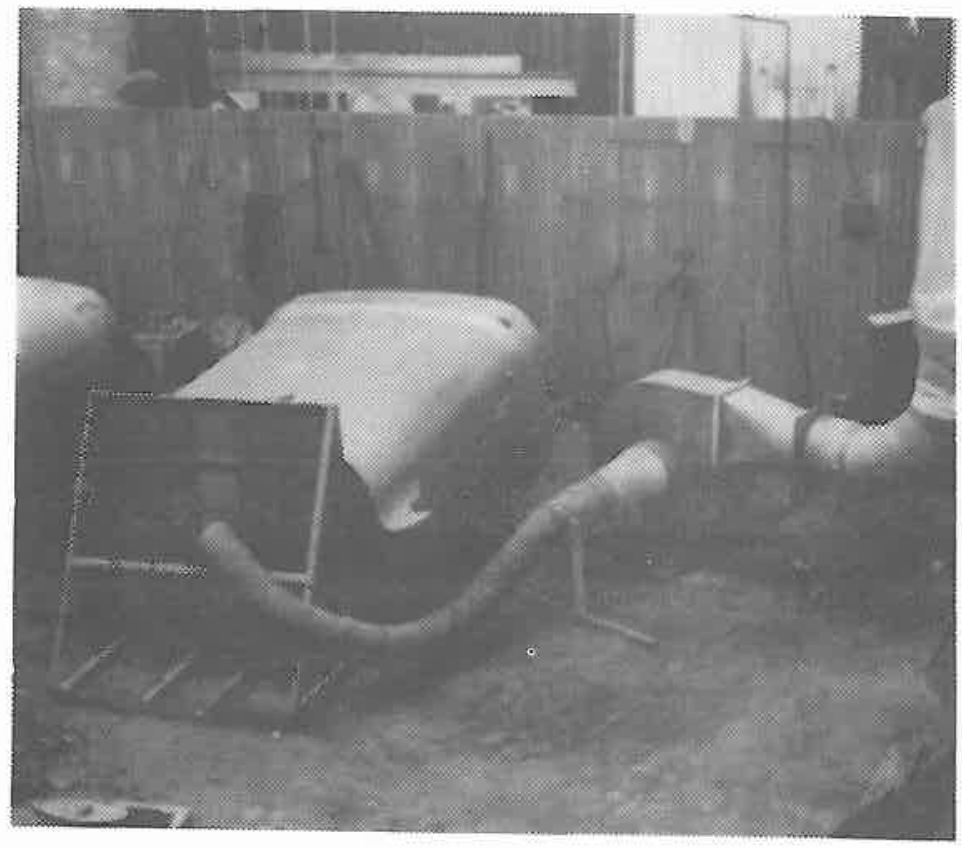

Figure 19. Dust control system for ingot mold hand grinding operation.

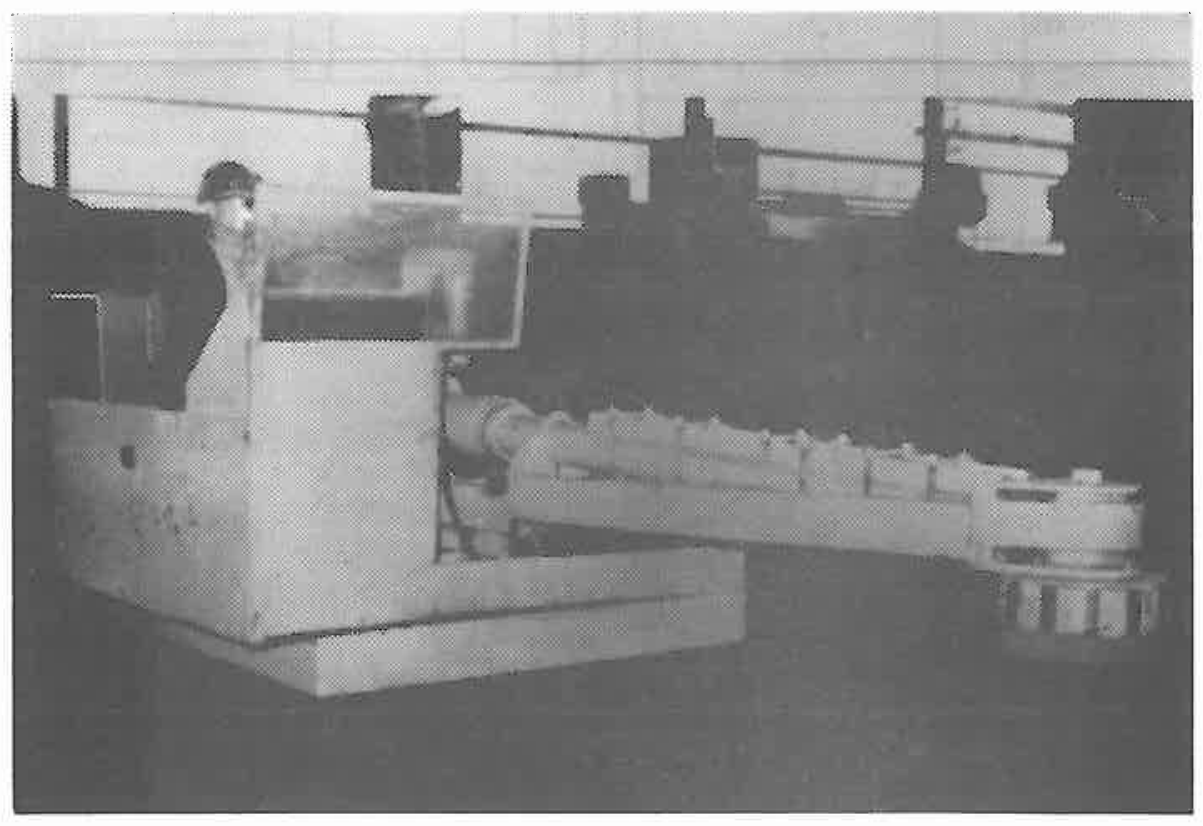

Figure 20. Gabelin grinder for ingot molds. 


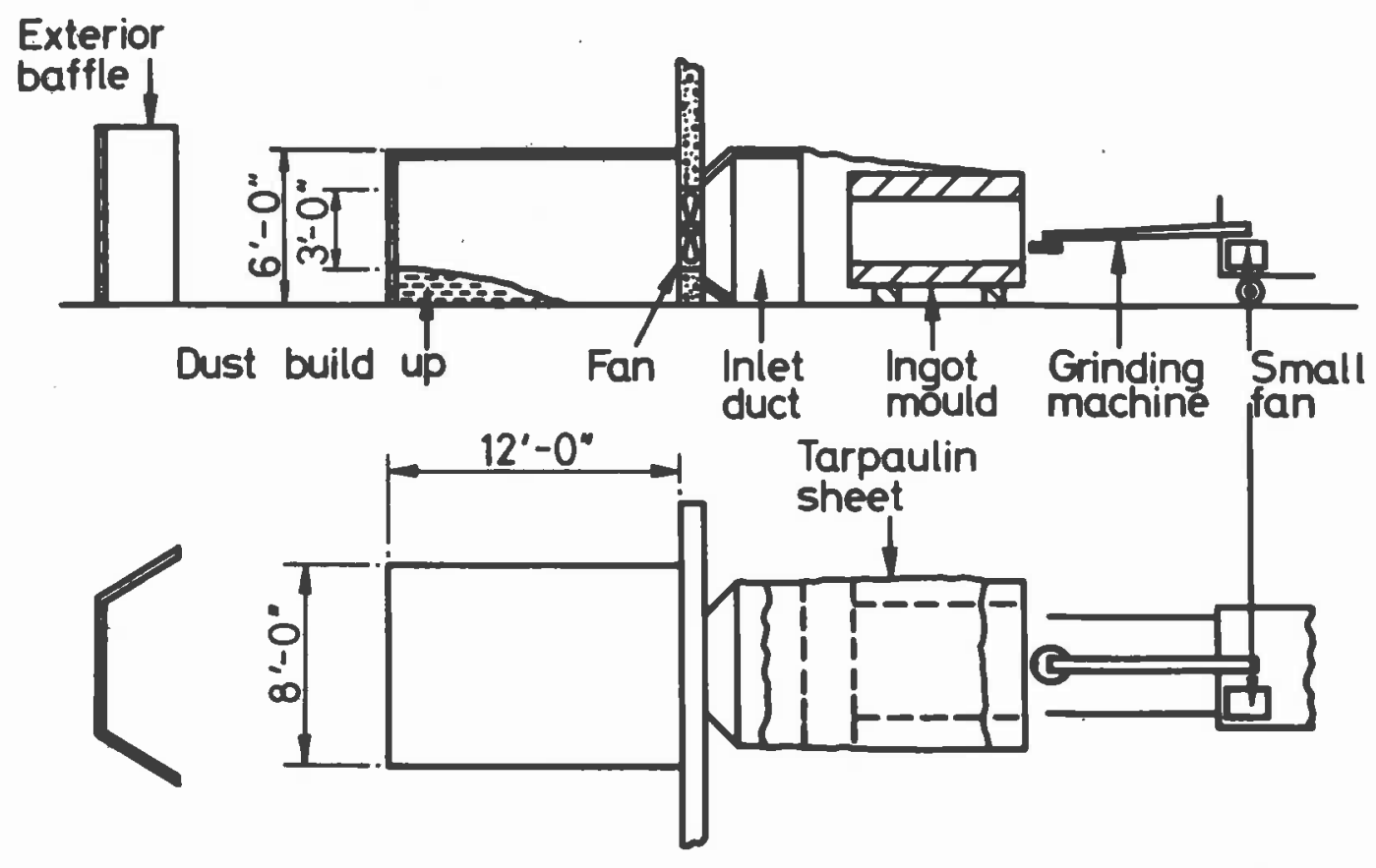

t. Simple settling chamber used on Gabelin grinder.

Figure 21. Dust control system for Gabelin grinder. 
Further work using a "snorkle" (Figure 22) with the duct placed inside a casting showed the hand grinder dust to be under control. Figures 23 and 24 were taken using intensive light beams to show up dust clouds. No dust is visible in Figure 24, but admittedly, this does not prove that none could have been found by sampling. Nevertheless, the visual evidence strongly suggests that the dust levels achieved would be acceptable.

Robots and Servo Arms

Technology has allowed the use of robots for grinding. A Swedish application for grinding gear boxes is shown in Figure 25. Here, as in most applications to date, the operator first inspects and then places the casting to be ground onto a jig on one edge of a turntable. While he is doing this the robot, beyond a protective screen, is grinding the previous casting according to its pre-recorded program. The turntable is rotated, changing the castings, and the operator inspects the finished casting as he removes it from the $j i g$. The advantages of a robot or servo arm is that it separates the operator from the job and makes dust control easier. Servo arms allow the operator to control the tool so that no programming is required and jobbing work can be accommodated.

One of these servo-arms is controlled by manipulating a smaller arm or master unit, the movements of which the larger working arm or slave unit follows (Figure 26). This unit is easier to control than the more usual lever-operated manipulators, particularly for intricate operations. The units can be servo-operated with force feedback so that the pressure applied to the work can be gauged. This makes the unit suitable for fitting to a grindex or a chipping hammer (Figure 27).

In spite of the obvious advantages of robots, it seems unlikely that they will find wide scale acceptance in the immediate future.

Other Methods of Metal Removal

Some castings can have surplus metal removed by clipping or broaching. One application of clipping is shown in Figure 28 (1). SG iron rocker arms are placed in a die and automatically pushed through into a bin. The operator merely feeds castings into an eight die machine. No dust is generated and the resulting castings are more accurate than if hand ground.

Friction band sawing is possible where a high speed saw belt, $51 \mathrm{~m} / \mathrm{sec}$ $(10,000 \mathrm{ft} / \mathrm{min})$ surface speed, generates heat to soften the metal being cut which is then swept away by the belt motion. These saws are quite capable of cutting gray iron castings at the rate of $1.0 \mathrm{~cm} / \mathrm{sec}(0.4 \mathrm{in.} / \mathrm{sec})$ through $1.2 \mathrm{~cm}(0.5$ in.) thick sections. Abrasive belts are now more attractive than they were 10 years ago, while water jetting, laser cutting and cryogenic metal removal are possibilities for the foundry of the future. But for some time we are likely to rely on grinding and chipping for removing metal from the majority of castings. 

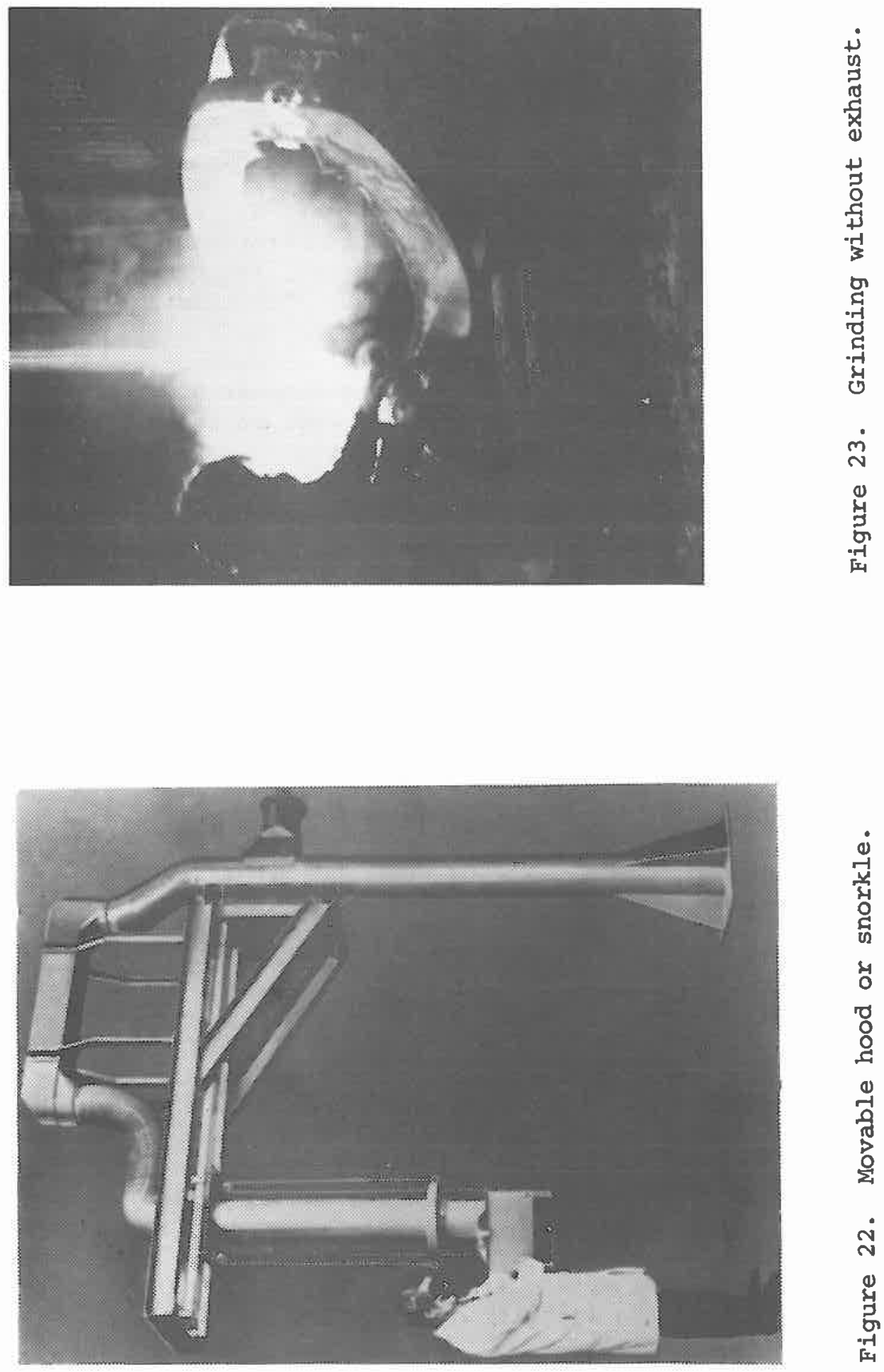

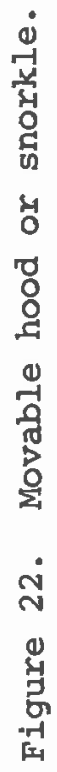



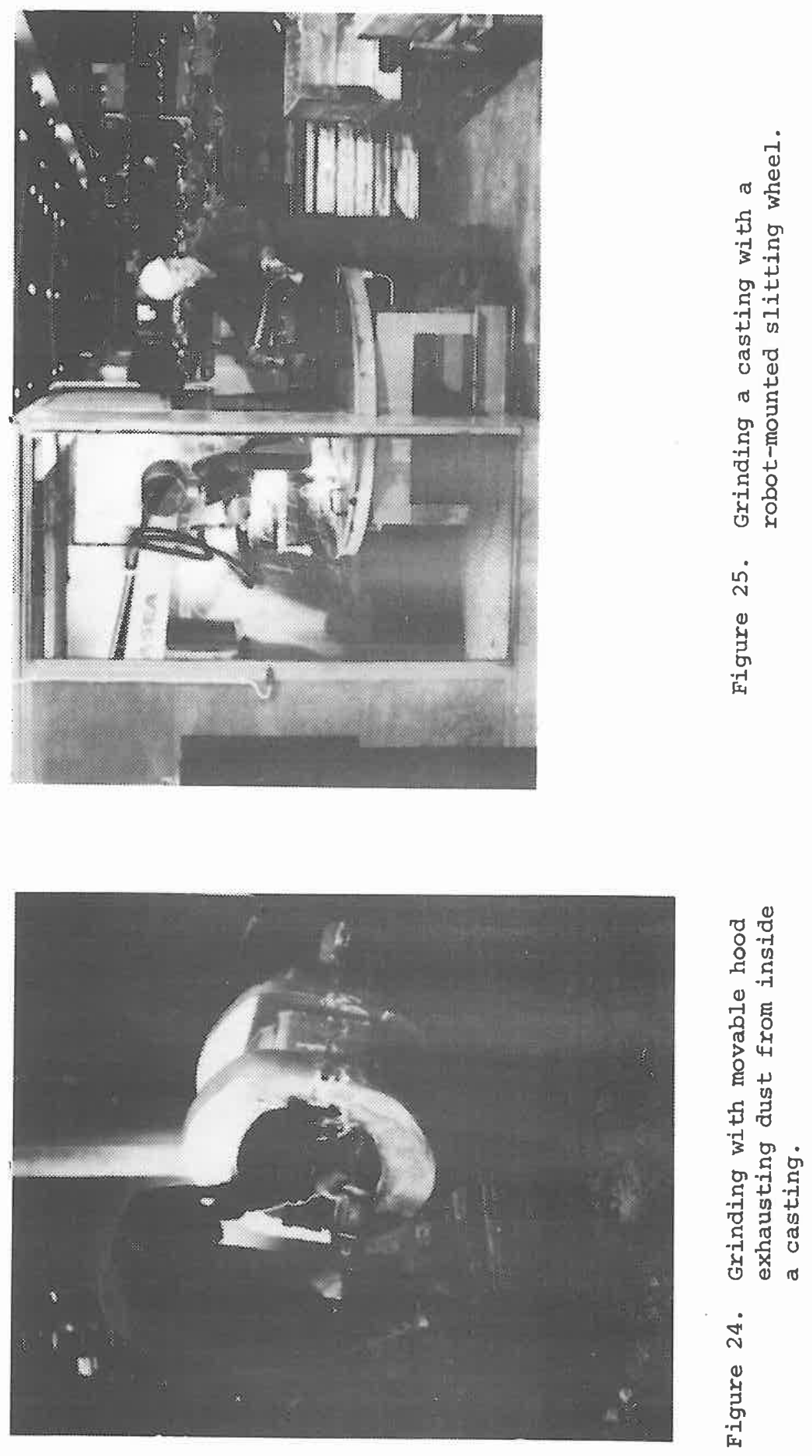


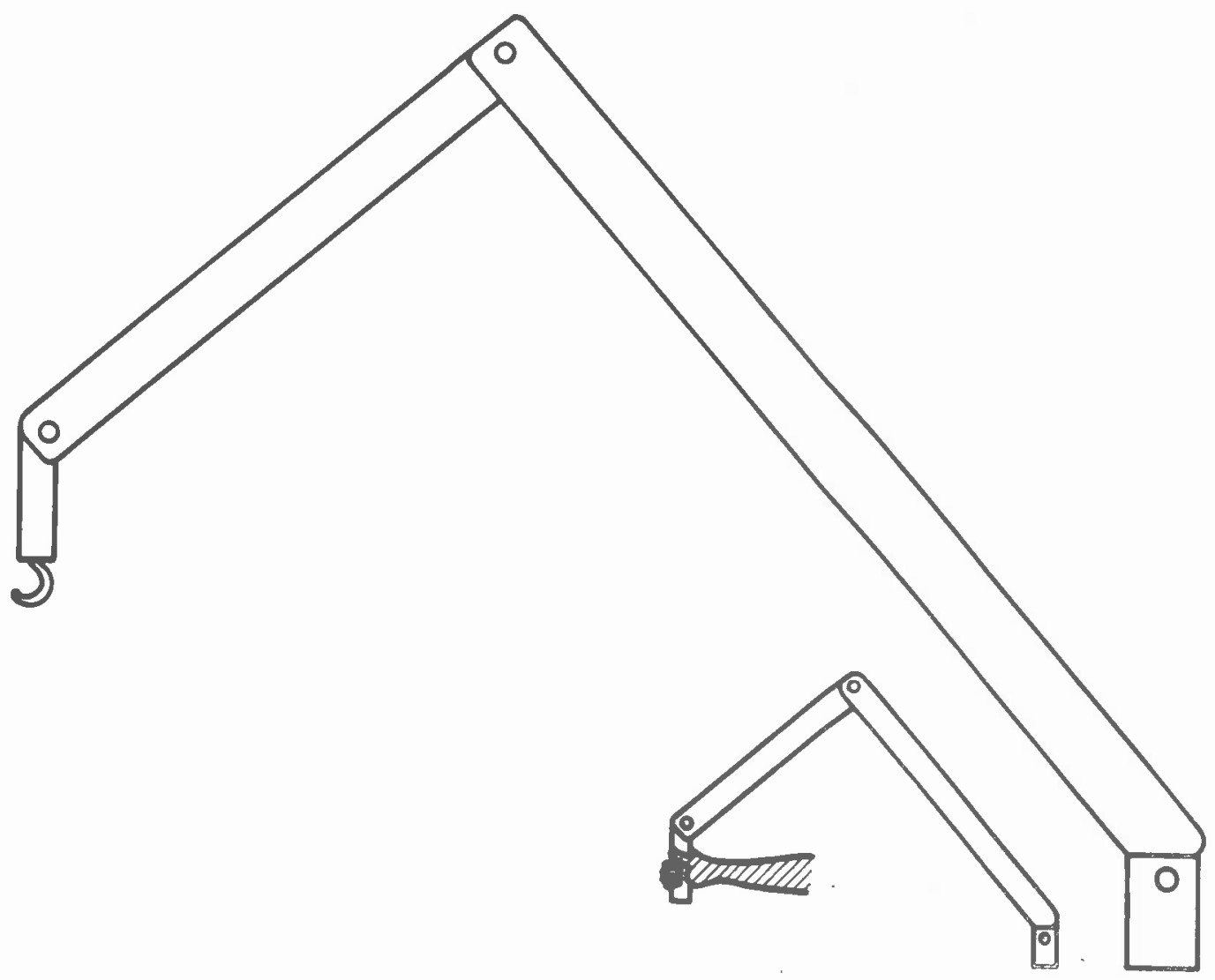

Figure 26. Servo-arm control using a master/slave system with spatial co-ordination. 


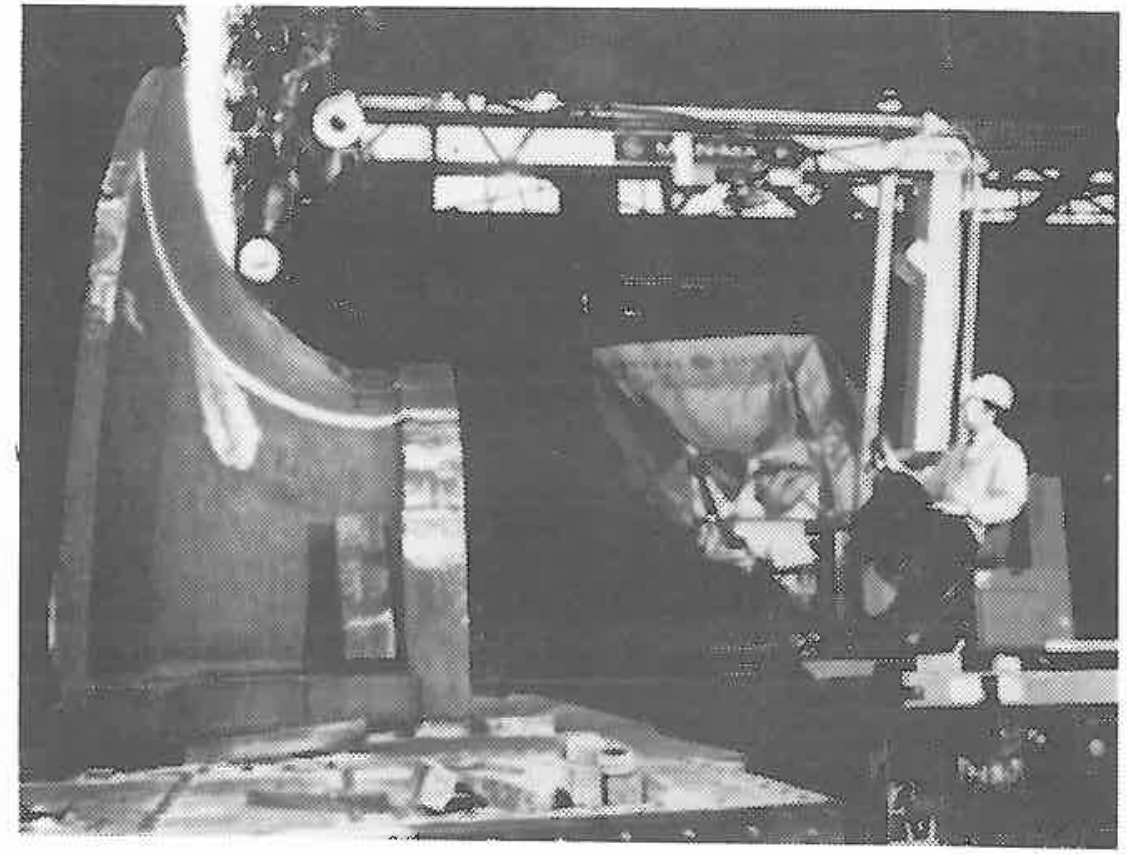

Figure 27. Grinder mounted on a servo-arm.

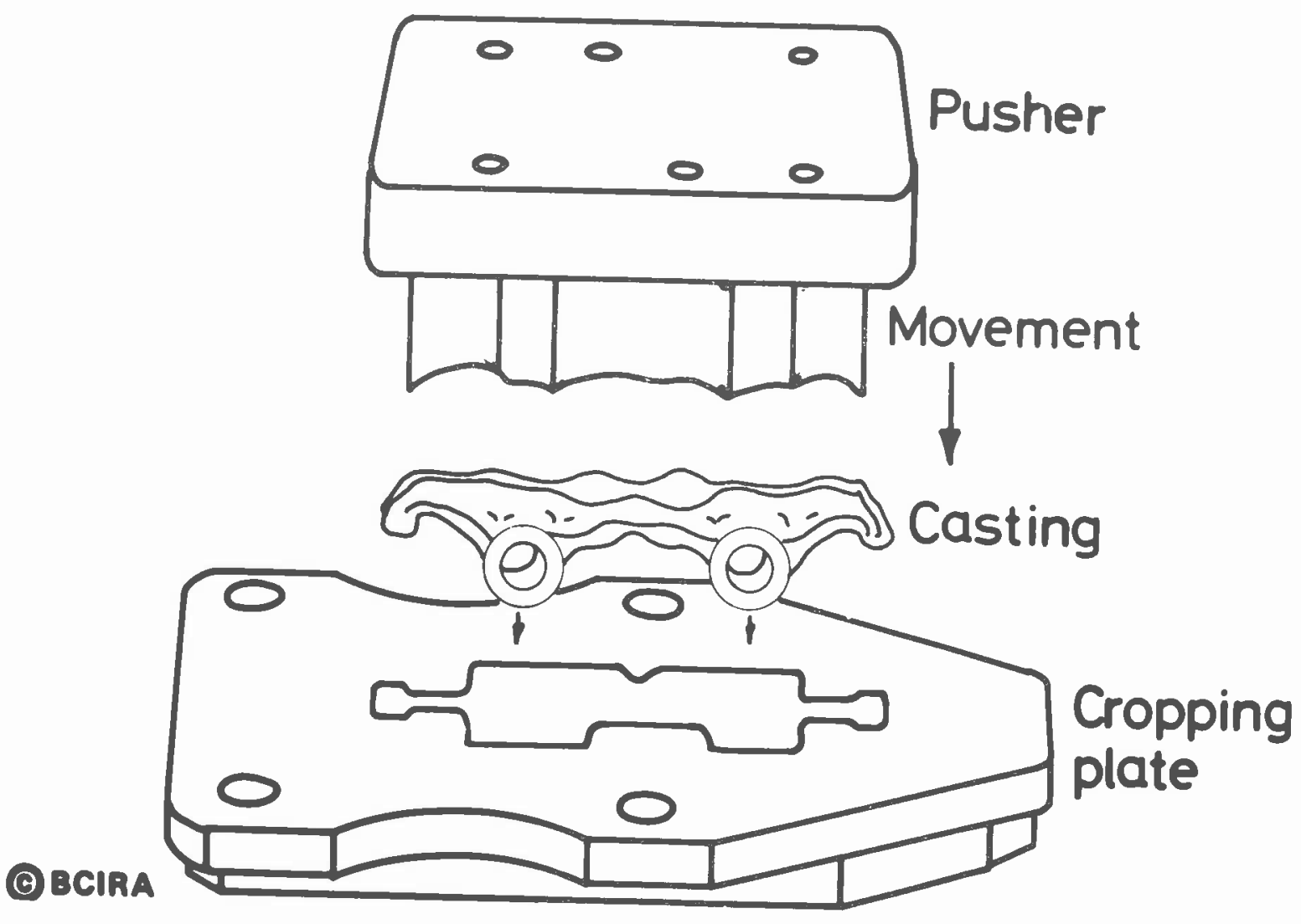

Figure 28. Casting with broach for clipping. 
The two major points made throughout this paper are that:

1. Dust control is not simply a matter of hoods and air extraction.

2. Metal removal is not merely the unthinking use of grinding and chipping.

The whole process of casting production pre-cleaning and grinding methods need to be reconsidered.

\section{REFERENCES}

1. Cruikshank, A. A., An Automotive Supplier - Customer Viewpoint of the Fettling and Cleaning of Iron Castings, BCIRA Conference on Fettling and Cleaning of Iron Castings, University of Nottingham 1974, September 24-26, Paper 3.

2. Saxin, R., Reduction in Fettling Costs by Improved Foundry Practice, BCIRA Conference on Fettling and Cleaning of Iron Castings, University of Nottingham, 1974, September 24-26, Paper 6.

3. Health and Safety Executive Foundry Dust Control, Second Report of the Sub-Committee on Dust and Fume, HMSO 1975, 25 pp.

4. Svensson, I., and Thyberg, B., Improvements in Working Conditions in Fettling Shops - A Report on Recent Swedish Investigations, BCIRA Conference on Fettling and Cleaning of Iron Castings, University of Nottingham, 1974, September 24-26, Paper 22.

5. Dewell, P., and Higgins, R. I., Unpublished work at BCIRA.

6. Glass, A. W., Semi-Automatic Fettling of Ingot Molds and Bottom Plates, BCIRA Conference on Fettling and Cleaning of Iron Castings, University of Nottingham, 1974, September 24-26, Paper 19. 


\title{
SWEDISH IMPROVEMENTS IN CLEANING OF CASTINGS WITH REGARD TO ENVIRONMENTAL FACTORS
}

\author{
Ingemar Svensson, Svenska Gjuteriföreningen \\ (Association of Swedish Foundries) \\ Jönköping, Sweden
}

\section{ABSTRACT}

The results of a number of research and development projects undertaken in Sweden during 1972-78 is reported. The major breakthrough has been the development and demonstration of mechanized manipulators and robots which separate the worker from the immediate vicinity of casting finishing operations. Automation and isolation simplify ventilation and noise and vibration control and reduce the effort while speeding up the process.

Guidelines for the use of ventilated work enclosures are also presented. Other research and development includes: substitution of hydraulic for pneumatic tools; and high velocity, low volume exhaust hoods.

\section{INTRODUCTION}

During the last decade there has been a demand made for better working conditions in foundries. In particular, the problems in today's cleaning and finishing operations are environmental, technical, and economical. Many cleaning operations are very labor-intensive and expensive. It is becoming increasingly more difficult to recruit workers for these jobs and turnover is very high. In many Swedish foundries, the turnover in the cleaning room is the highest for the whole foundry. Even in times of labor surplus in industry as a whole, it has still been very difficult to recruit workers for cleaning rooms. As a result of this, environmental improvements can be seen as essential if profitability is to be maintained.

PROBLEMS IN THE CLEANING ROOM

The environmental problem that is most often associated with the cleaning room is the high content of dust in the air breathed. Most Swedish foundries today have invested so much money in ventilation measures that, at most working places, the dust level lies well below the current limit value.

Noise is another common environmental problem in the cleaning room. There are not many foundries that are able to keep noise at the limiting level now in force in Sweden, i.e., $85 \mathrm{dBA}$.

Vibration is a third environmental problem that has attracted much attention during recent years. Above all the pneumatic chipping hammer causes high 
vibrations which result in "white fingers".

A fourth environmental problem in the cleaning room is back injuries due to the frequent manual lifting of heavy castings. One way of coping with this problem is to install lifting aids and other material handling provisions. Other environmental concerns in the cleaning shops are the monotonous work and bad lighting which can lead to unsafe work performance.

\section{POSS IBLE COUNTER MEASURES}

A very important question for all foundries today is, "What shall we do in order to achieve improved working conditions and reduced costs in the cleaning room?"

I think the measures to be taken first are the following (Figure 1):

1. Preventive measures to decrease or eliminate the need for casting cleaning.

2. Introduction of new and effective cleaning methods and equipment.

3. Environmental measures to decrease worker exposure to hazards.

These measures must be implemented together. If a step is taken to increase production, the environmental implications must be taken into consideration. The same type of thinking is applied when a new machine is developed: environmental and technical aspects are always taken into consideration at the same time.

\section{PREVENTIVE MEASURES}

When attempting to solve problems in the cleaning room, one should always first consider the question of whether the operation cannot be completely or partially eliminated through preventive measures. These preventive measures can be taken during casting design as well as during work preparation and production. The cleaning operations should always be taken into consideration when locating feeders and gating systems. If possible both feeders and ingates should be located on easily accessible surfaces of the casting. Another preventive measure to be taken is to make the fit between the mold and the core so tight that no fins are formed during pouring. However, this can be difficult, especially when producing castings in large quantities, as there are risks of other faults. Vacuum molding is advantaceous in order to avoid fins.

The use of knock-off cores should also be considered as a measure to reduce the necessity for cleaning and finishing. Tests made in Sweden with knock-off cores of graphite and ceramic fiber materials have produced positive results. One advantage with these thin knock-off cores is that they may be given a form that corresponds completely to the casting surface. Without making the cleaning work more difficult, the feeders can be located on either flat or curved surfaces.

It should be noted that in certain cases it may be possible to decrease or entirely eliminate cleaning work. Surfaces are often cleaned by grinding 


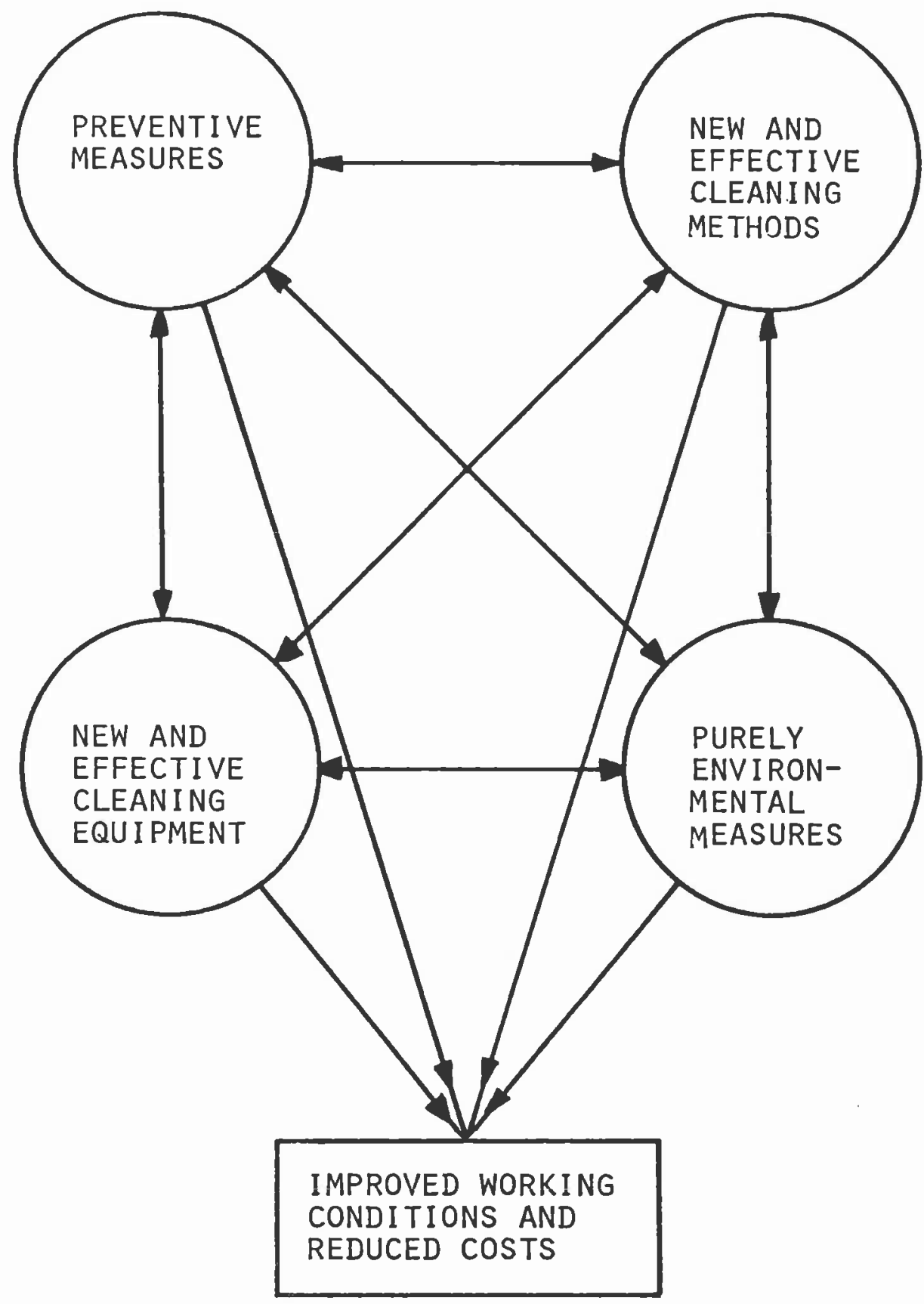
Figure 1. Measures to be taken in order to get improved working conditions
and reduced costs in the cleaning room. 
even if they are to be later machined. In the future more attention must be given to the relationship between casting cleaning operations and subsequent machining. Close cooperation between foundry and customer is important in this regard. Many swedish foundries, especially jobbing foundries, have already made progress in discussions with their customers on the question of cleaning castings. Solutions have been reached that are economically and environmentally advantageous for both the foundry and the customer.

NEW AND EFFECTIVE CLEANING METHODS

An extensive development project has been carried out by Svenska Gjuteriföreningen in collaboration with several of its member companies. This development work has mainly concentrated on the use of manipulators and industrial robots and on the use of shear pressing.

Use of Manipulators and Industrial Robots

The word manipulator in the following section designates a remotely controlled device used to reposition a casting or a tool. An industrial robot is a manipulator which is not continuously supervised and controlled; it follows a preset program. The robot obviously cannot think but is a machine that follows relatively simple movement patterns set by a human being. In contrast to a manipulator, an industrial robot does not need an operator.

When choosing between a manipulator and an industrial robot the extent and complexity of the manipulations, as well as the weight and dimensions of the castings, are of importance. Figure 2 gives broad guidelines for the fields of application of manipulators and robots and also includes a third class of devices: specially built mechanical handling device. As the latter name implies, these devices are designed specifically for a particular handling operation. The boundaries between the application ranges for the three different types of devices are not well-defined and vary from case to case. The manipulator is normally the best alternative for short or medium runs and for large castings. With increased size of runs the robot becomes a viable alternative, provided the weights and dimensions of the castings are not too large. The programming and the necessary jigs and fixtures require that there be long runs before a robot will be feasible. It is important to note that it is not the number of castings handled at one point in time that is the determining factor for the selection of a robot but rather the total number of a casting run over a period of time. Castings may be handled on different occasions with the use of the same robot program. For really large runs, e.g., automotive castings, the robot is usually no longer the best alternative, and it is possible to design special handling equipment for the application. Special handling equipment can be designed for use both with manipulators and industrial robots. It may use a manipulator for short non-recurrent series of castings or for specialty work or it may use an industrial robot for recurrent medium sized runs.

Development work in Sweden has shown that both manipulators and industrial robots can be valuable tools for improving the working conditions in cleaning 
rooms. Manipulators of different types have been installed to solve problems at swing grinding operations. Three of these will be described in the following section. Industrial robots are also in use in some Swedish cleaning rooms and will be described below.

Manipulator Equipped with Force Feed-Back Coupling--

At a Swedish steel foundry, a manipulator with force feed-back (Figure 3) is used for grinding medium to large steel castings, The manipulator is of American origin and is manufactured by General Electric under the name of Man-Mate. In Europe, the manipulator is produced in France under license and called Andromat.

The manipulator is operated with one-hand control (compare aircraft control) and has six degrees of freedom. The operator's movements of the steering arm are amplified and duplicated by the working arm. The steering and working arms are interconnected with a servo system with force feedback which makes a two-way communication between operator and work possible. This means that the operator continuously feels the weight of a load or the resistance of the grinding tool on a reduced scale, about 1:100. The manipulator has a lifting capacity of $270 \mathrm{~kg}$ and a lifting radius of $5 \mathrm{~m}$. Force feedback is used on three of the six degrees of freedom, i.e., rotary movement of the manipulator and the radial and vertical movement of the arm.

The movements of the tool head in the other three degrees of freedom are controlled by different pushbutton controls on the steexing arm handle. These movements include rotation, bending, and side tilting.

An hydraulic motor with a grinding wheel and a grinding casing has been installed into the tool head of the manipulator. The casing is designed to prevent flying debris if the wheel should burst. The hydraulic motor develops $30 \mathrm{~kW}$ of power and is run by a separate hydraulic pumping system. The hydraulic motor of the grinding machine is started and stopped from the control station on the manipulator. It is also stopped automatically when the operator leaves the control seat.

Because a force of up to $10,000 \mathrm{~N}$ may be applied to the grinding wheel, a grinding wheel of very high quality, i.e., hot-pressed and very hard, must be used. The peripheral speed of the wheel is $45 \mathrm{~m} / \mathrm{s}$ and its dimensions are about $50 \mathrm{~mm}$ wide $\mathrm{x} 300 \mathrm{~mm}$ in diameter. The rotation of the wheel is such that the material removed is thrown forward and is captured by a ventilation hood. The grinding pressure is easily felt at the control handle and may be varied as required. It is also easy for the operator to tell by feel when the grinding wheel has gone past the edge of the casting. The hydraulic motor of the grinding wheel is powerful enough to maintain a constant number of revolutions, irrespective of grinding pressure.

Figure 3 shows the grinding of a casting weighing about $400 \mathrm{~kg}$. The manipulator is being used for grinding away the remainders of feeders and gating systems and fins. Due to the high grinding pressure the grinding time was decreased to a third or a fourth of the time required previously. The learning time was also short; after not more than one or two hours, full production speed was attained. 


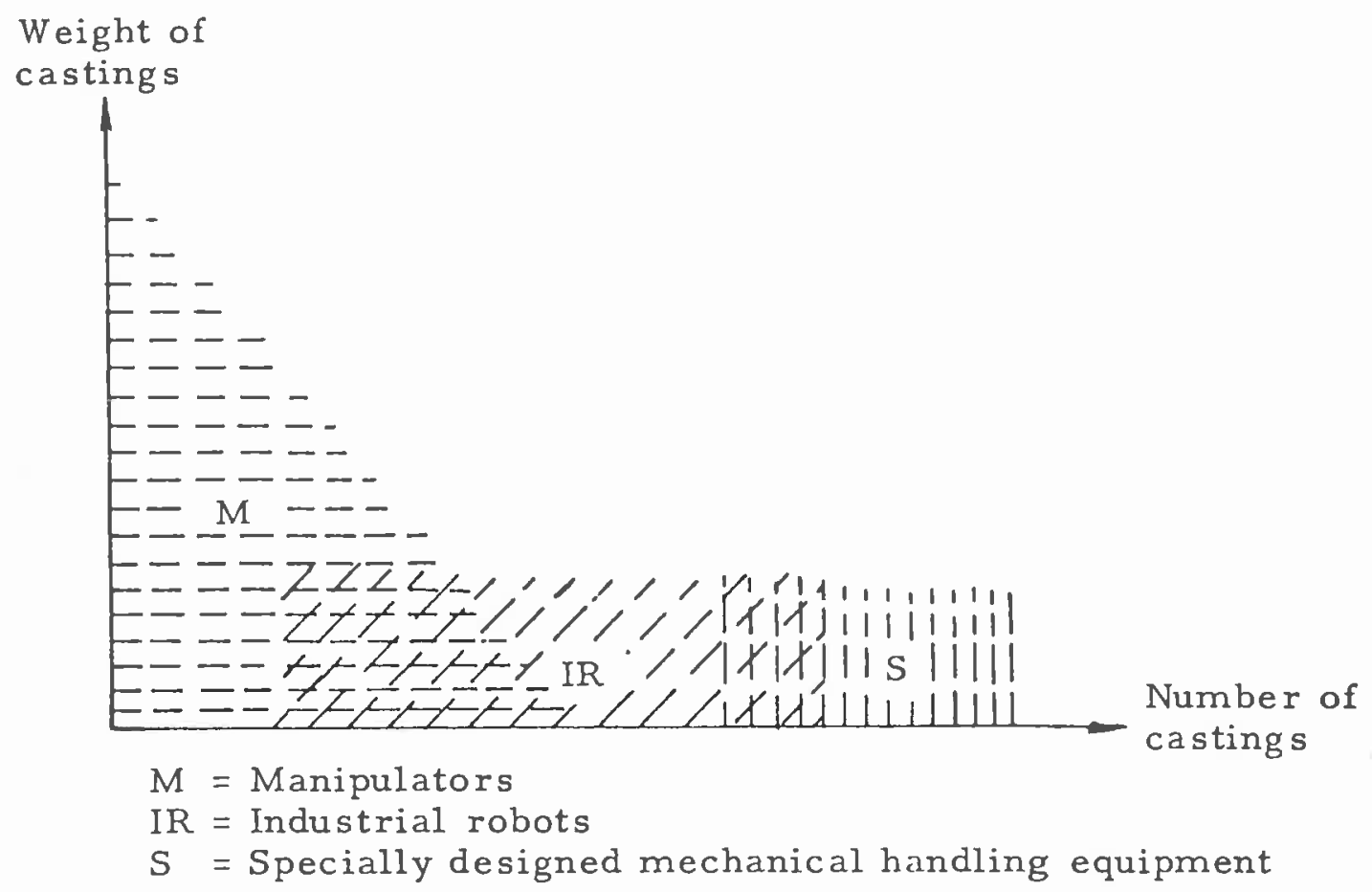

Figure 2. Application fields for manipulators, industrial robots, and specially designed mechanical handling equipment.

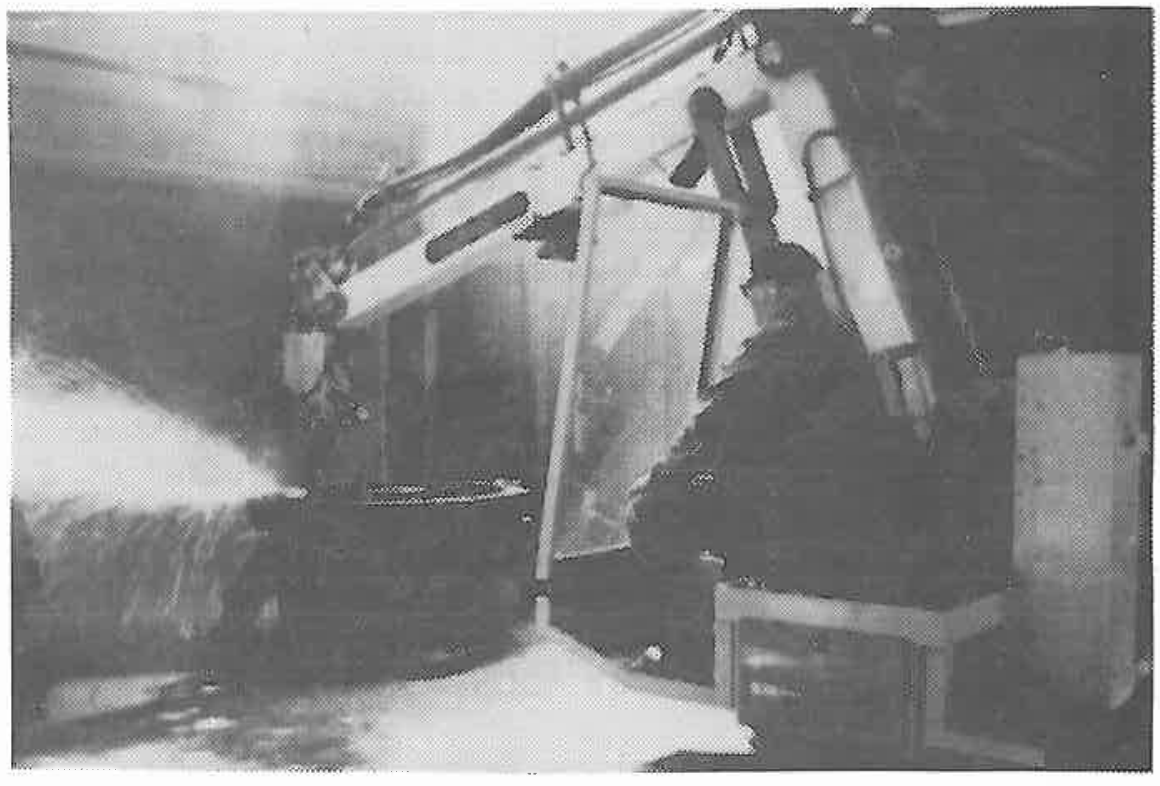

Figure 3. The Andromat manipulator. 
Electro-Hydraulically Controlled Manipulator for Swing Grinding--

Figuxe 4 shows an electro-hydraulically controlled manipulator used for grinding of a plane surface. The operator controls the manipulator from an enclosed, ventilated, and acoustically lined booth. All controls in the booth are located on two consoles to the right and left of the operator. The manipulator can also be operated from a mobile control unit outside the booth.

The castings to be ground are placed on an electrically driven truck and transported onto a rotating table in the grinding room. Truck and casting can thus be rotated in the horizontal plane to the desired position.

During grinding the pressure may vary from 300 to $3000 \mathrm{~N}(30-300 \mathrm{kp})$ regulated through electronic conversion of the applied power of the grinding motor. The grinding unit is suspended in similar fashion to an overhead crane. During grinding work the unit performs a pendulating movement whose maximum angular displacement is $\pm 45^{\circ}$. The rotational speed of the grinding wheel is $1870 \mathrm{rpm}$ which corresponds to a peripherical speed of $60 \mathrm{~m} / \mathrm{s}$ when using a new grinding wheel. The unit can be inclined $45^{\circ}$ in one direction and be turned maximally $\pm 45^{\circ}$ for the pendulating movement.

Complicated, curved, spherical, and cylindrical surfaces can be ground while maintaining constant pressure of the grinding wheel against the workpiece. The grinding wheel follows the outline of the workpiece during the pendulating movement. Figure 5 shows the difficult grinding of turbine blades with the manipulator.

When grinding is finished, the truck with the workpiece is taken out of the room and unloaded. Changeover time for castings is about 15 minutes.

A heavy turntable is built into the floor under the manipulator. It is dimensioned for a maximum point load of $100 \mathrm{kN}(10 \mathrm{Mp})$ and a total bearing strength of $200 \mathrm{kN}(20 \mathrm{Mp})$. It is driven by two motors at $0.5 \mathrm{r} / \mathrm{min}$ corresponding to a peripherical speed of $6 \mathrm{~m} / \mathrm{min}$. with a table diameter of $4000 \mathrm{~mm}$.

The machine is provided with equipment that minimizes the risks involved in wheel breakage. If the grinding wheel slips over the ends of the casting during the work, the load on the wheel is immediately lowered by the built-in control of wheel pressure. If the pressure controls do not function or if the wheel were to be exposed to a higher load than intended, operation will be automatically shut down.

An exhaust hood, located adjacent to the manipulator removes dust in an exhaust flow of $10,000 \mathrm{~m}^{3} / \mathrm{h}$. Another exhaust hood with a capacity of $5000 \mathrm{~m}^{3} / \mathrm{h}$ is located at the grinding wheel head and is connected to a wet scrubber. Makeup air is introduced through inlets located above the door of the grinding room. In the operator booth there is a separate intake of fresh air with temperature regulation.

Heavy manual work has been eliminated by using the manipulator. It is possible today to employ women and handicapped workers for the operation. 


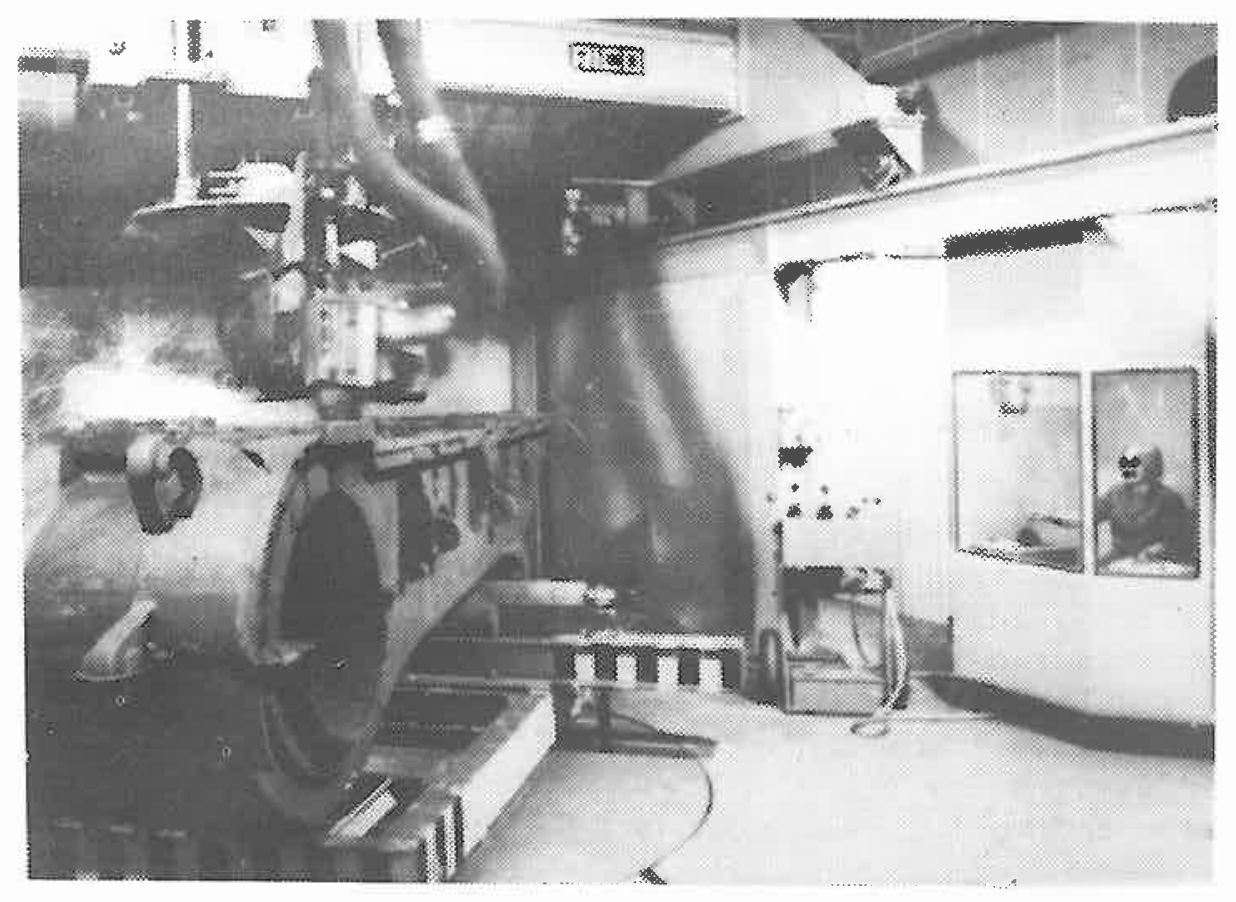

Figure 4. Grinding of flat surfaces with an electro-hydraulically controlled manipulator.

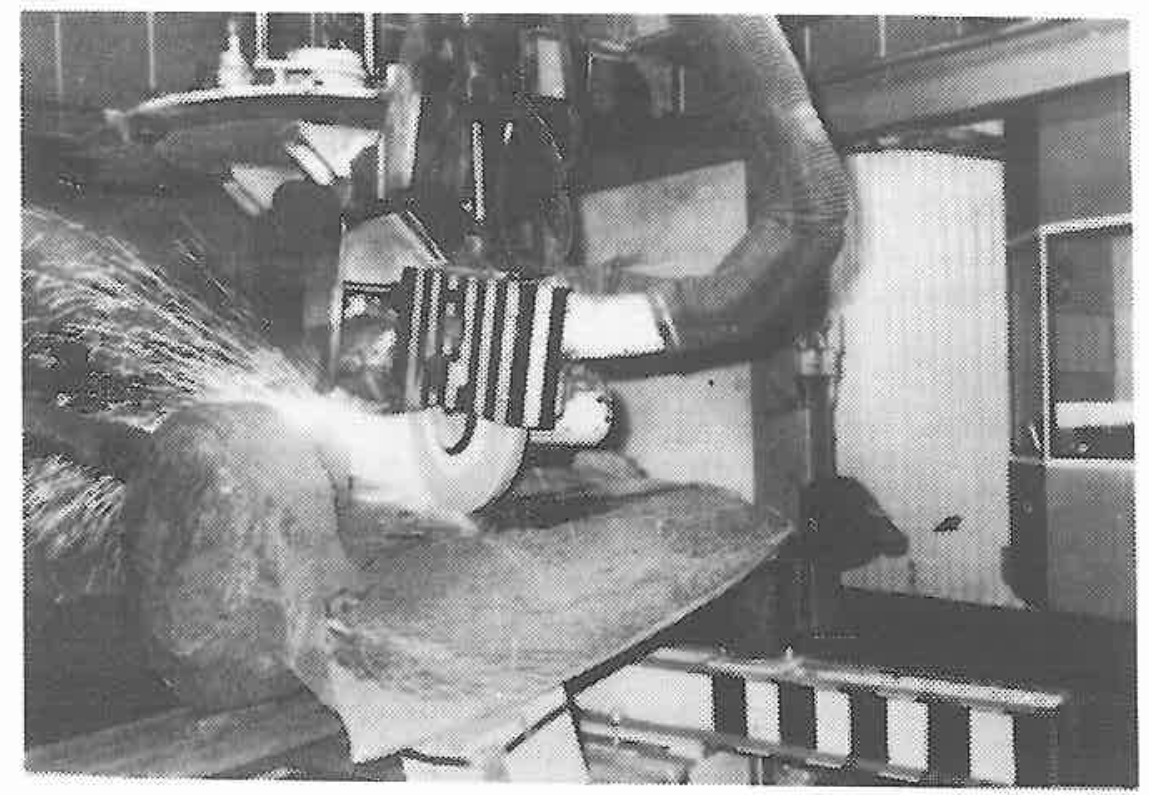

Figure 5. Grinding of turbine blades with the electro-hydraulically controlled manipulator. 
Pneumatically Controlled Manipulator for Swing Grinding--

As in the case of the electro-hydraulic manipulator, the pneumatically controlled manipulator is also suspended like a travelling crane (Figure 6). The grinding unit of the manipulator can move horizontally in cross movements as well as up and down. It can also be given a bevelled movement and can move around a horizontal axis, making possible the grinding of curved surfaces. The working area of the manipulator is about $1 \times 1 \mathrm{~m}$.

Movements in two horizontal directions as well as the bevelled movement are achieved by pneumatic motors in chain drive systems. Vertical movement is accomplished through a combined hydraulic-pneumatic system. The speed of all movements can be varied continuously within high and low speed ranges. The controls are located on a panel.

A considerably higher pressure can be attained than during manual swing grinding. As the grinding wheel travels over the surface of the casting, constant pressure is applied while variations in height up to about $100 \mathrm{~mm}$ are accommodated.

The grinding machine requires $15 \mathrm{~kW}(20 \mathrm{hp})$ of power and operates at $2820 \mathrm{rpm}$. The grinding capacity of the manipulator is greater than that of a manual grinding machine.

In order to protect the operator from noise and dust, a small booth has been erected beside the manipulator. From this booth the whole process is remote-controlled. It is provided with an inlet of pre-heated fresh air.

During grinding the castings are located on a truck on rails on a turntable. It would be comparatively easy to provide the truck with a motor to achieve the back and forth and turning movements. The truck could also be provided with a lifting device for the raising and lowering of the work table.

Robots for Grinding and Pneumatic Chipping-In order to determine the feasibility of using industrial robots for the grinding of castings, a Trallfa robot was tested in a large iron foundry in southern Sweden in the spring of 1974. The results of the test were promising. Further tests were performed with a more rigid robot made by ASEA. These latter results were so satisfactory that this robot is now being used in production cleaning operations in some Sredish foundries.

The ASEA robot has a lifting capacity of $60 \mathrm{~kg}$ and 5 degrees of freedom of motion. The robot has a separate programming unit with a memory capacity of four programs. The programming capacity is normally 250 position instructions; programs are easily modified. The robot moves in straight line patterns through a series of preprogrammed motions. Practical experience has shown that the distance between the points should not exceed $40 \mathrm{~mm}$, otherwise the deviation from the ideal straight line will be too great. The program capacity permits steering both from point to point and in a curved line. The programing unit itself is portable in order to facilitate the programming of the robot. The unit may be used for several robots and also for manual operation of robots. 


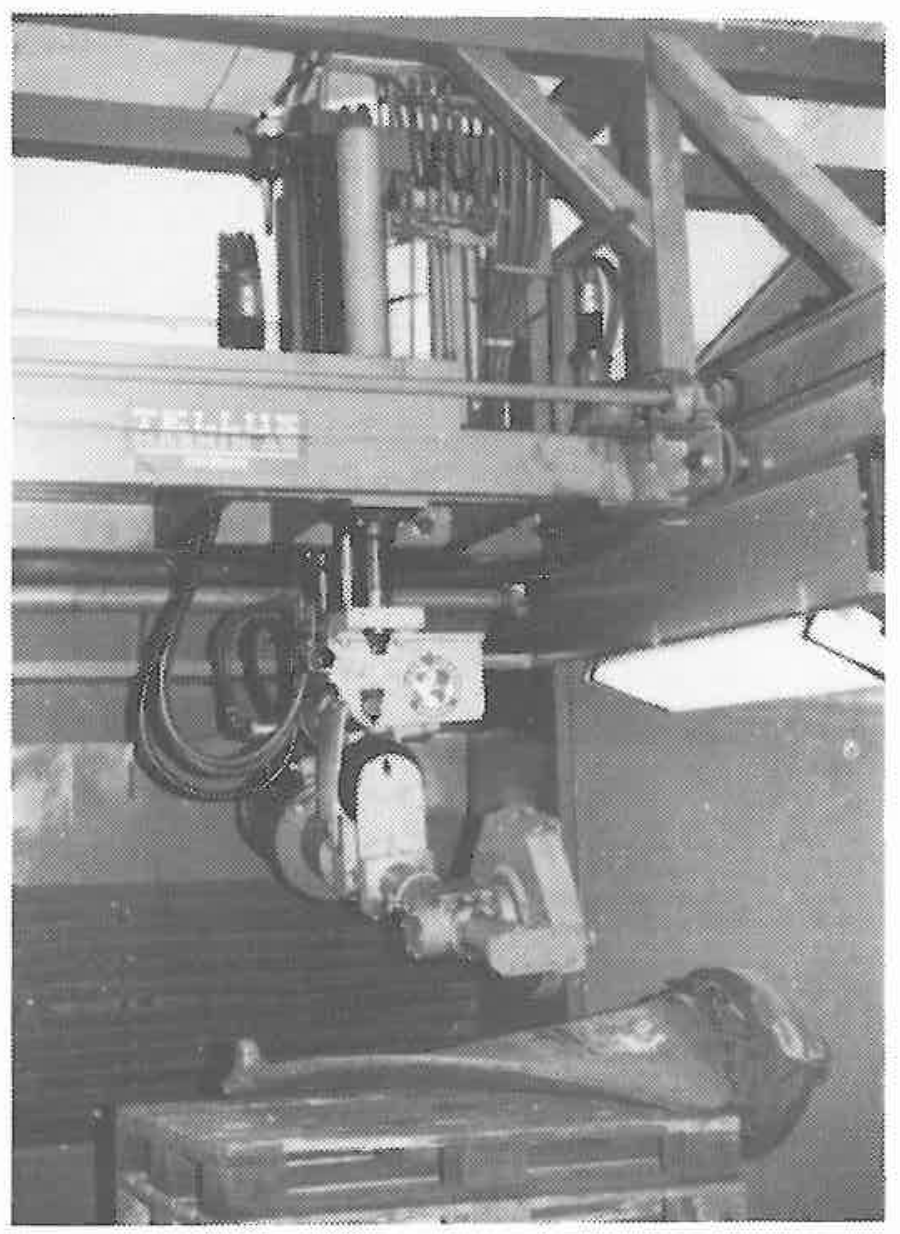

Figure 6. Pneumatically controlled manipulator for grinding of castings.

At the foundry where the development work took place, special equipment was designed for the robot: a revolving work table, a holder for the work piece, and a holder for the tools. In order to protect the operator against grit, dust, and sparks, a shield of transparent plastic has been inserted between the working area of the robot and the work station of the operator. The table is provided with a slotted exhaust located under the table.

For straight grinding a grinding wheel is attached to a separately built holder which is, in turn, attached to the robot arm (Figure 7). 


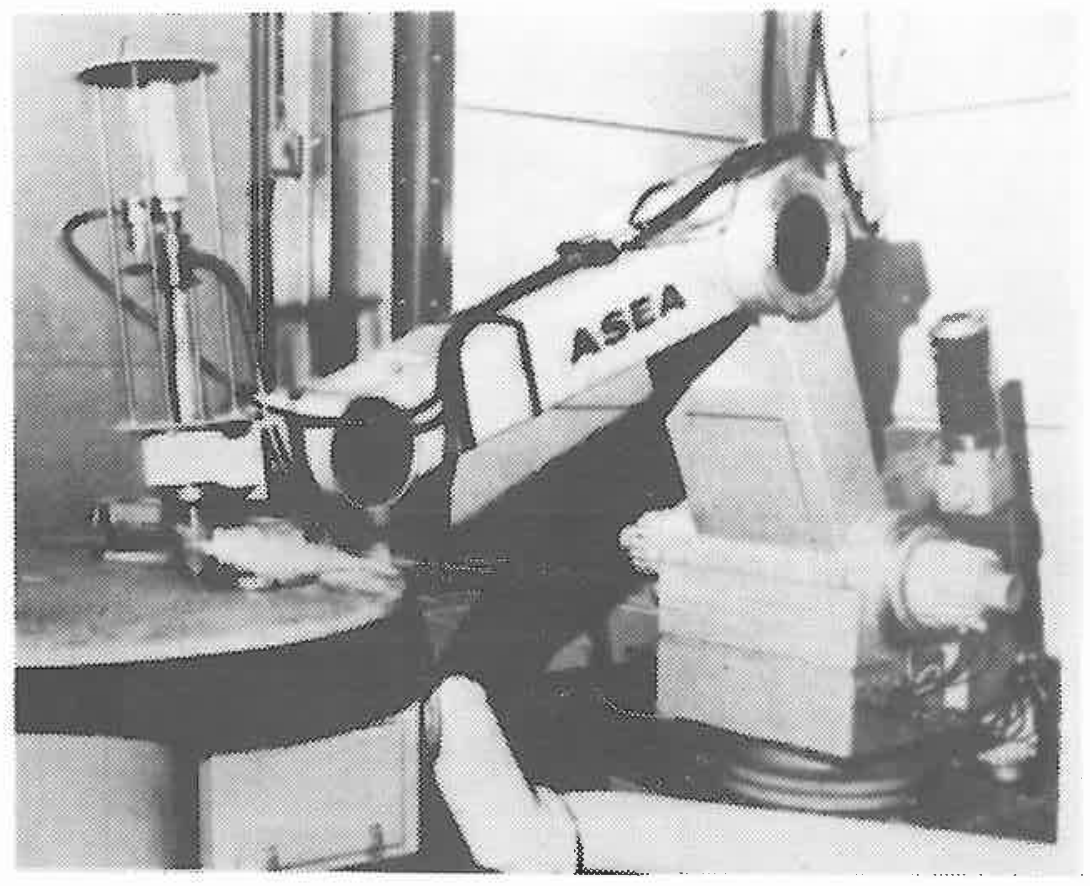

Figure 7. Use of industrial robot for straight grinding of castings.

When setting up the michine's program, a grinding wheel with a diameter of $40 \mathrm{~mm}$ was used, while during actual work the diameter was $50 \mathrm{~mm}$. The difference in diameters plus the elastic holder resulted in an adequate grinding pressure against the work piece. The life of the grinding wheel is calculated to be two hours efficient grinding time, which corresponds to 50-80 castings.

Cup grinders could also be inserted into the specially designed holder. The grinding machine travels in two guides and the necessary pressure is achieved with the aid of a pressure cylinder. The pressure in the air cylinder is set to a level which provides sufficient force to ensure that the wheel always cuts, and its force is constant. As the robot advances the wheel to the casting and begins its pattern of movement, any variations in size and position of the component from what may be termed "nominal" are taken up by the compound slide, which is free to back the wheel off, or advance it, while still maintaining thrust for the cut. Figure 8 shows the machine at work.

Some ASEA robots are also used in the cleaning room of a Swedish steel foundry. Here one of the two robots is used for cutting off risers, and one for grinding. For removing risers (Figure 9) the robot applies a powerful spindle with a large diameter cut off wheel driven by an hydraulic motor. In this application, the robot incorporates a sensor which detects the moment when the cut off disc touches the casting, an event which obviously can vary from work piece to work piece. As soon as contact is "felt", the cycle of the robot is initiated. 


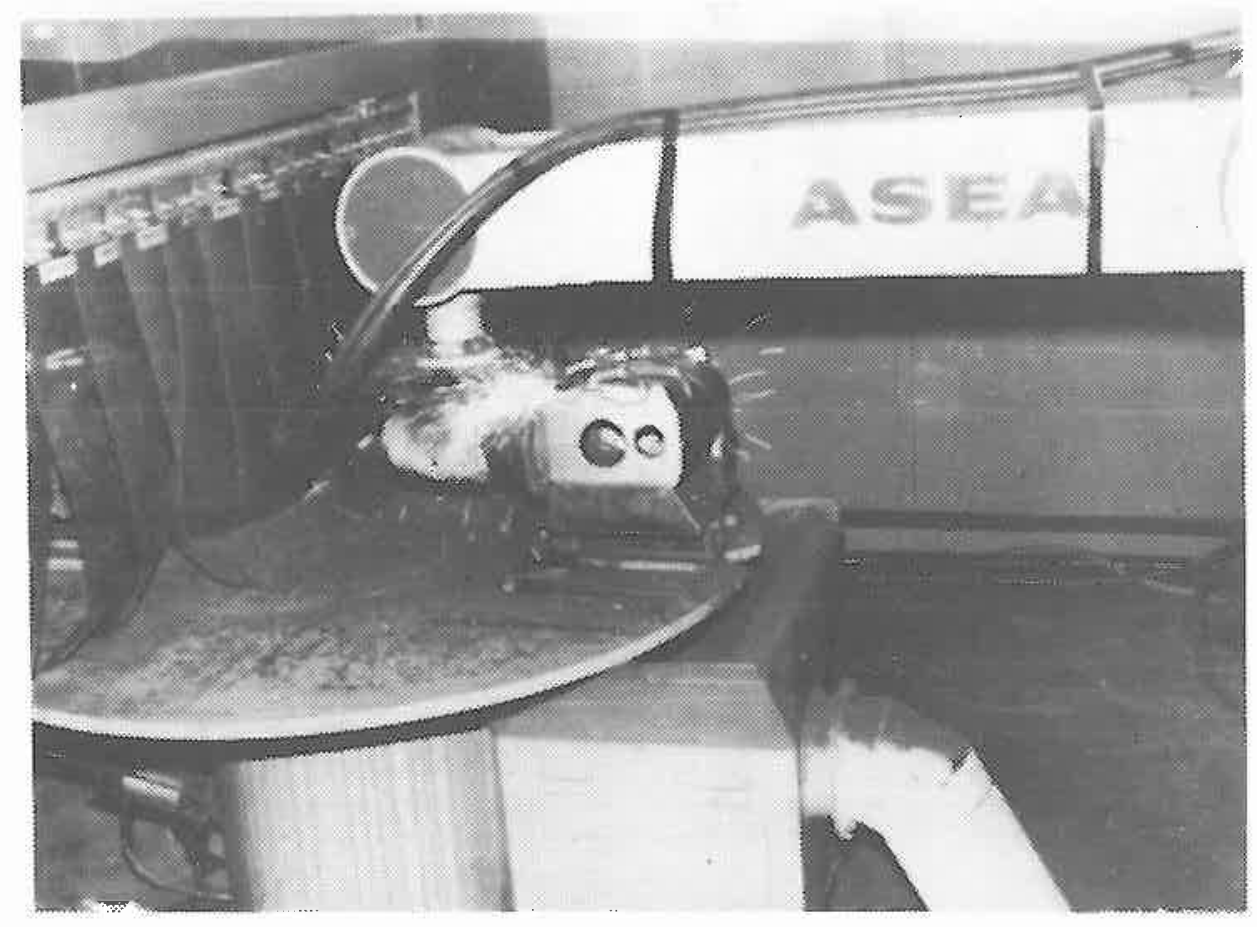

Figure 8. Robot grinding with a cup grinding machine.

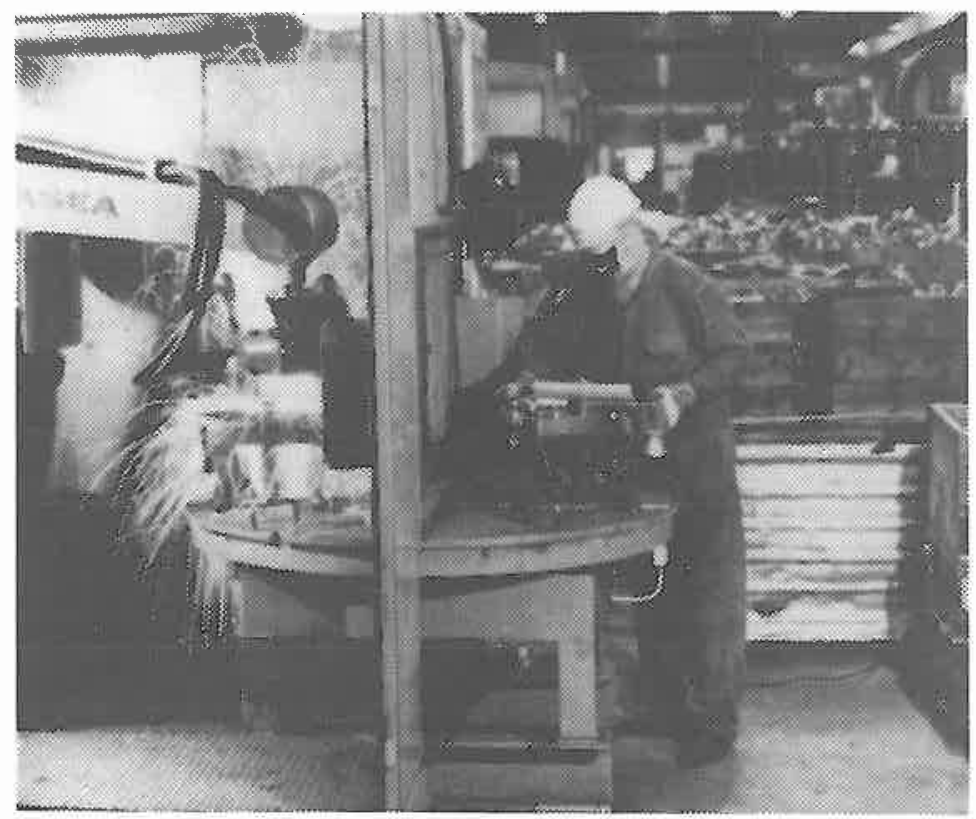

Figure 9. Removing of risers on steel castings by an industrial robot. 
The point of contact is also used as a means of monitoring the reduction in diameter of the disc as wear takes place. As the disc reduces in diameter the cut off stroke of the robot is automatically extended. The controller also recognizes the minimum diameter below which it is not safe to use the wheel, and withdraws the robot to an idle position when this point is reached. For the grinding application with this robot, a spindle and burr is substituted for the cut off wheel, and a fresh program is inserted into the controller. The complete installation is housed in a cubicle, and a $180^{\circ}$ indexing table is provided for loading and unloading.

Tests have also been made with the ASEA robot on chipping. A chipping hammer (Atlas Copco RRC 33) was elastically attached to the robot arm with a special holder (Figure 10). During chipping the casting was held in a jig. The tests showed that chipping, too, can be satisfactorily performed with an industrial robot. This application, however, has not yet been used in real working conditions.

As a result of this development work it is possible to state that the use of industrial robots during certain cleaning jobs is a practical proposition, with an increase in production of 20 to 40 percent possible. An important advantage is the obvious improvement of the working environment when the worker is removed from the immediate vicinity of the dust source and when the main part of the heavy and monotonous work is relieved.

Manipulators and Industrial Robots from an Economic Point of View

It is difficult to evaluate manipulators and industrial robots economically because of the large number of factors involved. It is evident, however, that a normal investment calculation does not show that the installation of a robot is always profitable. One should not,

however, always adhere strictly to economic assessments when investments of this sort are discussed. Often it is of paramount interest to solve difficult environmental problems. Due to stringent governmental regulations concerning the environment and shortness of labor in some countries, installations of robots and manipulators may be the only way of getting a certain type of work done. Another factor to remember when evaluating economic feasibility of using robots and manipulators is the ever-increasing cost of ventilation. If, for instance, a dusty operation can be performed by remote control with a manipulator, the need for ventilation will be reduced. The cost to temper makeup air will also be reduced.

When estimating the costs of a manipulator or robot installation, the costs of the necessary accessories must be taken into account. Often these costs are as great as the cost of the manipulator or the robot itself. The cheapest robot or manipulator does not always produce the most cost-effective system when everything is considered.

A further cost item that must not be forgotten is the cost for service and maintenance and, owing to the advanced electric and pneumatic equipment involved, it may be necessary to give the workers special training. 


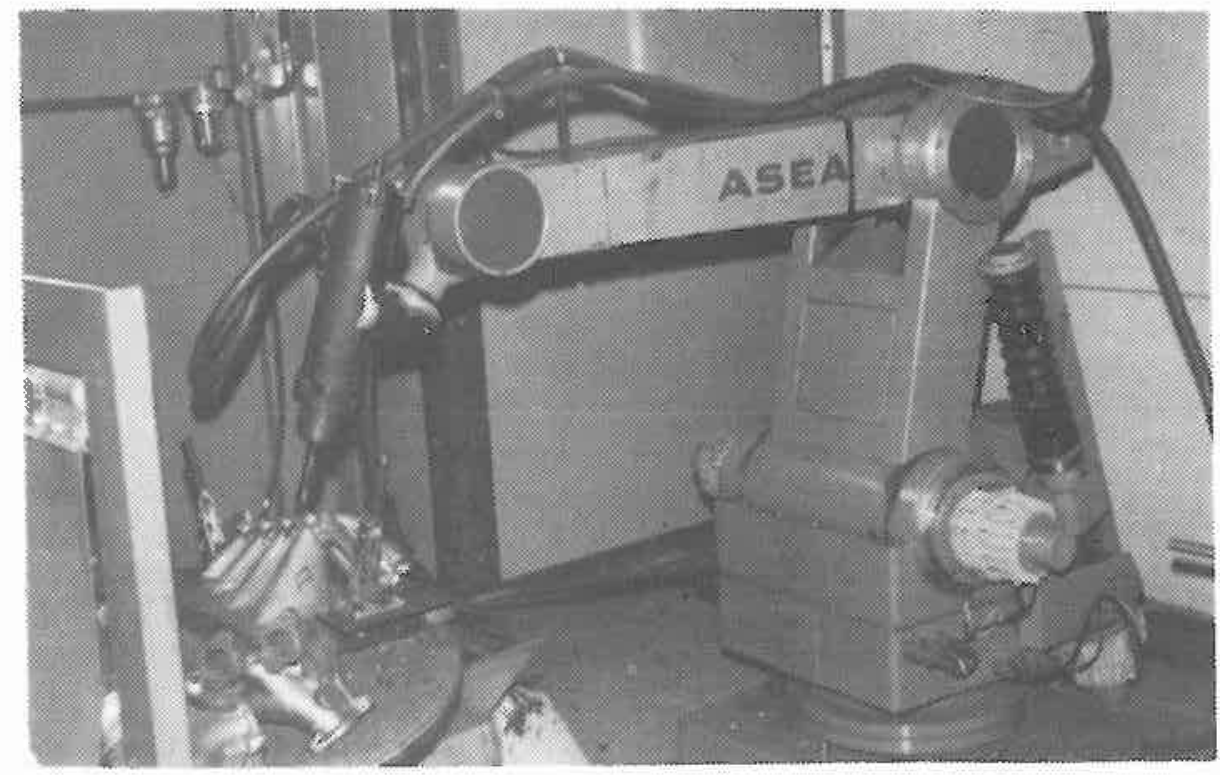

Figure 10. Pneumatic chipping with an industrial robot.

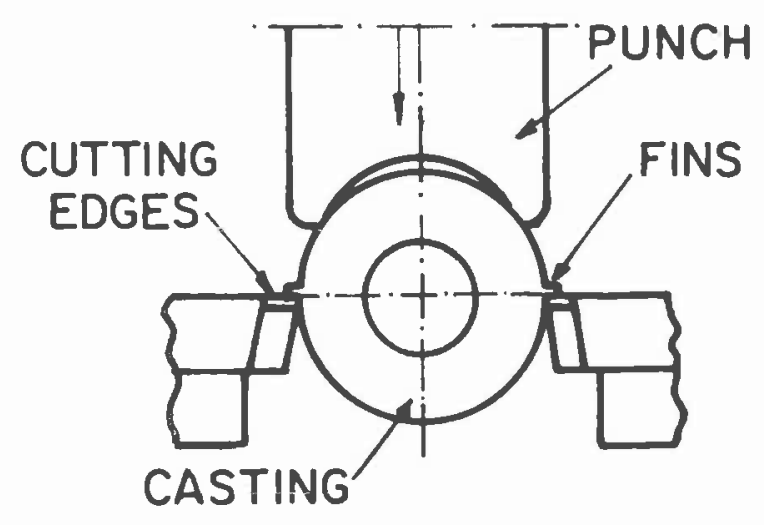

Figure 11. Shear pressing of flash on a simply shaped casting. 
Shear pressing signifies the removal in a press of flash, feeders, and ingate rests. Up to now, the method has been used by foundries primarily for the cleaning of die castings.

For castings of simple geometric design a process such as shown in Figure 11 may be used. A punch fixed to the runner of the press moves the casting past the cutting edge, which shears away the flash. It is also possible to locate the cutting edges on the runner. The latter technique is used in Figure 12, showing the cleaning of a gear case. This method has turned out to be the most efficient method of cleaning castings with complicated geometry. The casting is located in a fixture on the pressing table and is held in place with the aid of an extra cylinder in the runner.

When geometry is complicated, it is generally impossible to perform all the deflashing with one single tool in one direction of movement; several tools in several directions must be used. Only flash that is projected in the direction of the tool can be removed.

During development and testing of the shear pressing technique, the following advantages have been identified.

1. Less dust formation, noise, and exposure to vibrations, and improved ergonomic conditions compared with conventional cleaning methods.

2. Increased productivity resulting in lower cleaning costs.

3. Insensitivity variations in the amount and size of flashes.

4. Better quality of work.

5. Less energy consumption than conventional cleaning due to lower ventilation demands.

6. Easy process to mechanize.

Measurements of the work environment before and after introduction of shear pressing have shown very drastic reductions in the amount of dust produced at shear pressing and reductions of 20-25 dBA in noise level.

High cost reductions have also been achieved. For long runs the costs have in some cases been reduced to one fourth of that for conventional cleaning.

Of course, shear pressing also suffers from certain disadvantages. The following are the most important:

1. The relatively high investment cost demands a certain minimum length of the production run to justify the tool cost. When cleaning not too complicated castings, a number of 1500-2000 per year will represent the lowest limit.

2. The delnand placed on the tools is high. 
3. Placing the casting in a press may be felt as a monotonous job, justifying further automation.

4. Interior cleaning is difficult to perform.

NEW AND EFFECTIVE CLEANING EQUIPMENT

Very few other innovations have been developed during recent years. Instead, already existing equipment is steadily being further developed and improved.

Hydraulic Grinding

Manual grinding machines are good examples of cleaning equipment that has not changed very much over the years. In sweden, hand grinders are as a rule driven by compressed air; electric grinders are an exception. A power source that is expected to be more widely used in the future is hydraulic power. Tests done in sweden with this sort of equipment have shown positive results. A hydraulic grinder would have considerable advantages over a pneumatic tool, particularly in that the hydraulic tool is more powerful and the speed is not effected by load. Cutting times may therefore be reduced and longer life of the grinding wheels may be expected. Another essential advantage is that the hydraulic tools get somewhat warm when used in contrast to the pneumatic ones, which grow cold. Operators who have been testing hydraulic grinders have said that they like them just for this reason. From the point of view of vibration it is medically advantageous that the machines are warm; the risk of injury is lower.

\section{Casting Fixtures}

When cleaning castings it is important to be able to hold the casting firmly and handle it efficiently. In Sweden a machine has been developed for fastening and handling castings during cleaning (Figure 13). The castings are held between movable pegs which are locked in a special patented way. Development of this type of tool is ongoing. 


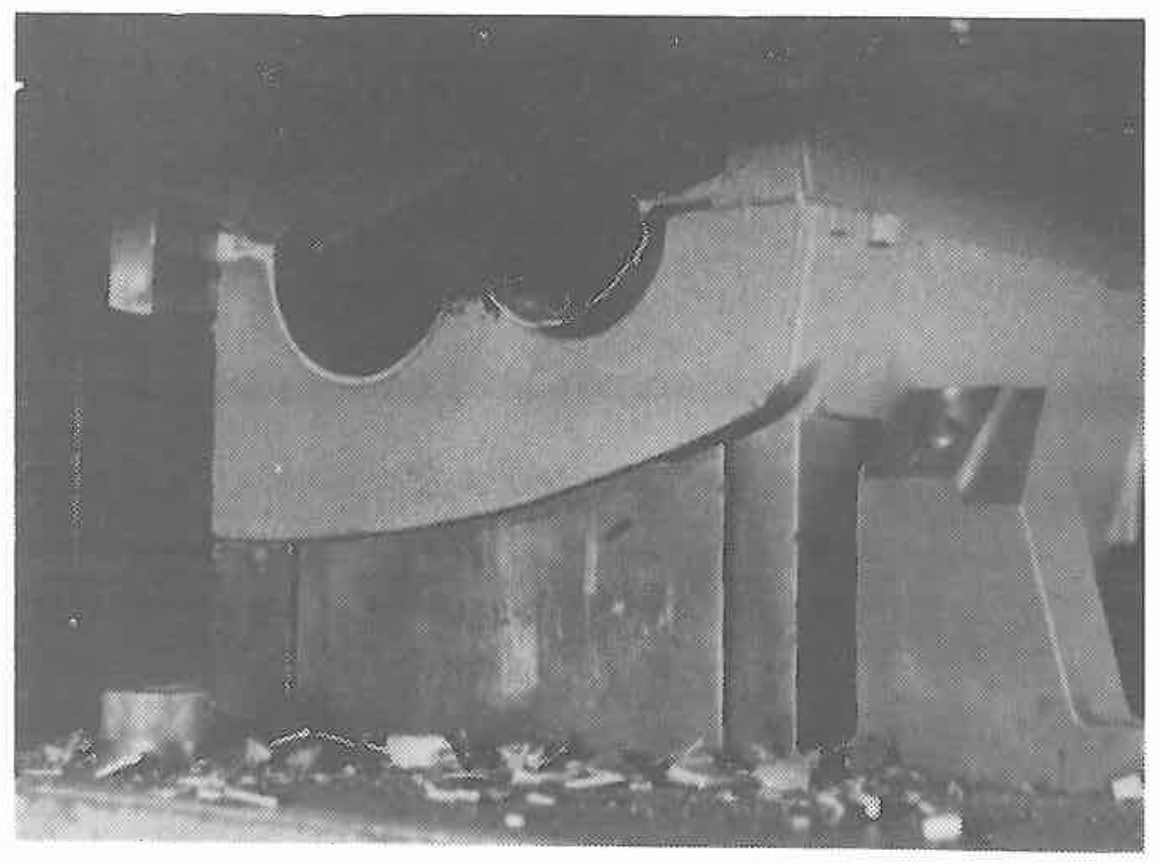

Figure 12. Shear pressing of a gear case.

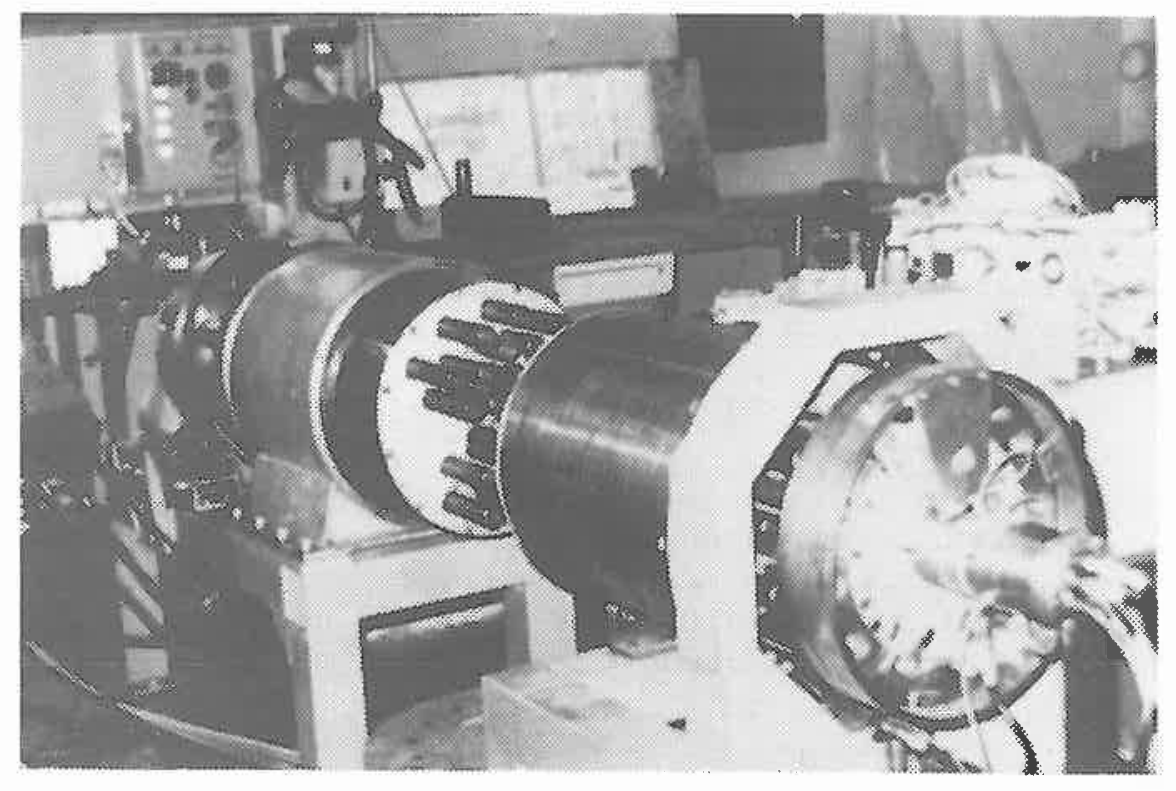

Figure 13. Fastening and handling equipment for castings during cleaning. 
Cleaning Booths

Many Swedish foundries have installed enclosed booths during recent years, resulting in a considerable improvement of working conditions. Figures 14-18 show some examples of cleaning booths in use. The hexagon booth in Figures 17 and 18 was introduced first. Experience with this method and other development work hare resulted in other types of cleaning booths. Experience has shown that the following requirements should be taken into consideration when designing a satisfactory cleaning booth.

1. Cleaning booths must provide sufficient ventilation so that dust concentrations are well below the hygienic limit value. The supplier should be asked to show test results from dust measurements made in the booth on similar work, thus demonstrating that dust concentrations should be sufficiently low.

2. The booth must be built in such a way that noise from surrounding processes does not cause levels in the cabin to rise above $85 \mathrm{dBA}$ and preferably not above $80 \mathrm{dBA}$.

3. The worker in the cleaning booth must not feel locked up or isolated but should have a chance to contact and collaborate with his fellow-workers. Methods of booth surveillance for accident detection should be implemented.

4. The dimensions of the booth must allow the worker to move around freely. The floor surface must be at least $15 \mathrm{~m}^{2}$. The booth should be furnished with a drop-leaf table and chair. The height of the booth should be at least $2.4 \mathrm{~m}$.

5. The booth must be equipped with satisfactory non-glaring lighting. Tlie luminance should be maintained at least at 700 lux. The electrical fittings must be equipped with protective plates made of a material which grinding debris cannot damage.

6. It must be possible to transport castings in and out of the booth in an efficient way.

7. The booth must be rugged and suitable for a foundry environment.

8. Color, light reflectivity, and perforation of the walls must not irritate the eyes or cause glaxe. It must also be easy to clean the wall material.

9. If fresh air is brought in through the ceiling, the downward speed should not be less than $0.25 \mathrm{~m} / \mathrm{s}$ and not more than $0.5 \mathrm{~m} / \mathrm{s}$. With lower speed air dust removal is insufficient and with higher speeds, drafts on workers is the result. If air is drawn in from surrounding space, the air velocity should be about $0.5 \mathrm{~m} / \mathrm{s}$ through the cabin door. A separate intake for aix is desirable. The operator should be able to regulate the temperature from inside his booth. 


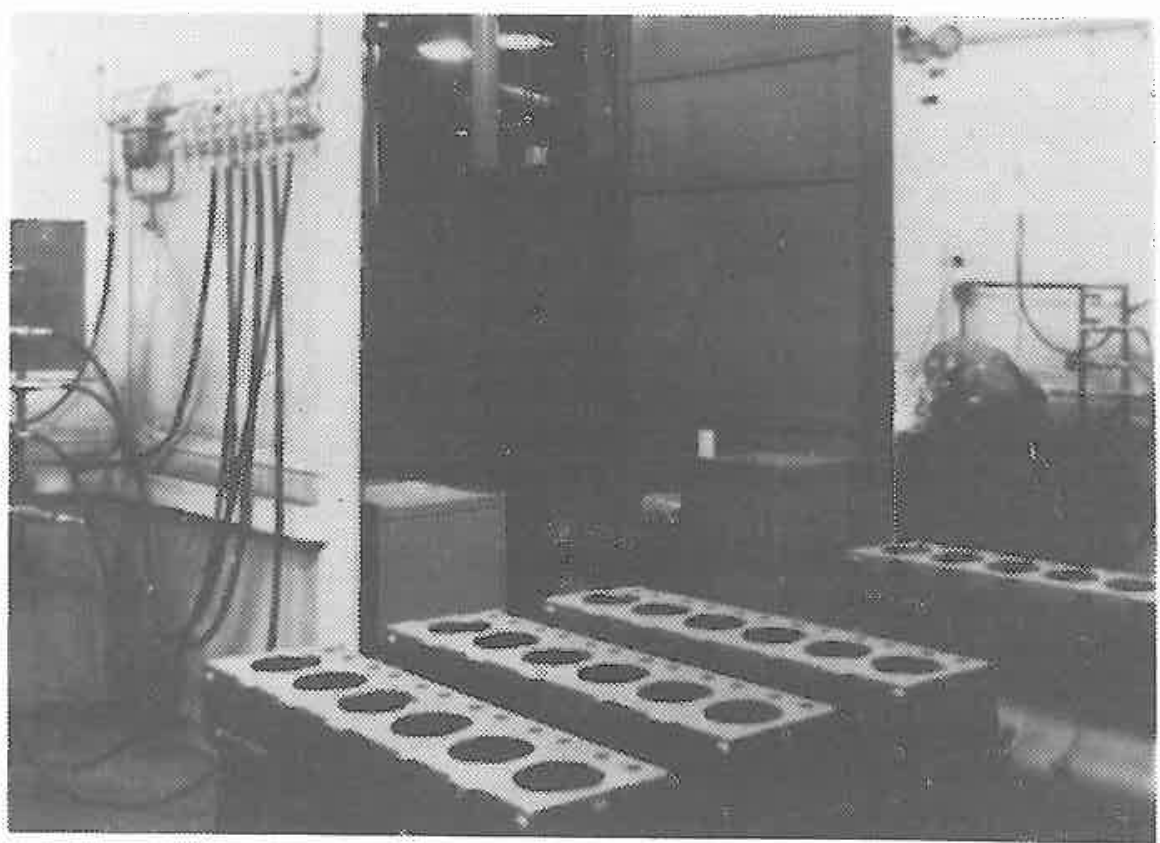

Figure 14. Hexagonal cleaning booth for cleaning of castings such as diesel engine blocks.

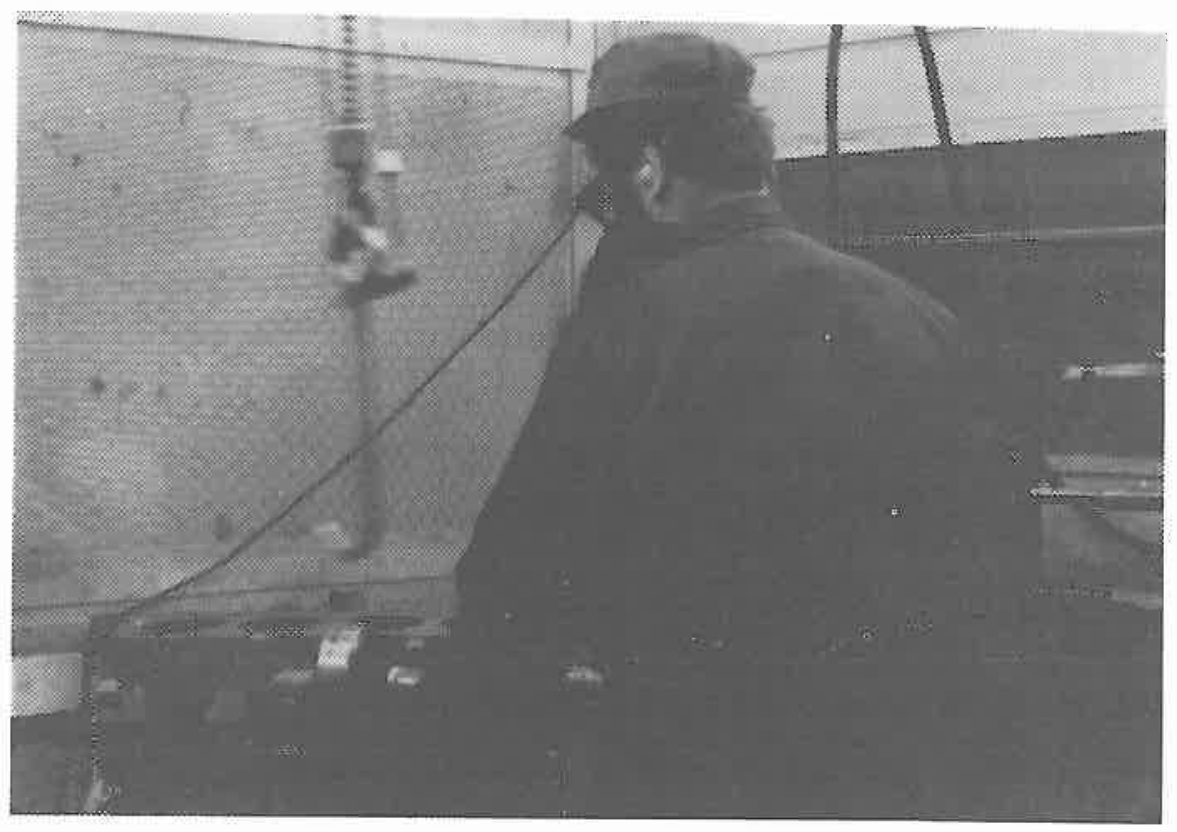

Figure 15. Interior of the cleaning booth in Figure 14. 


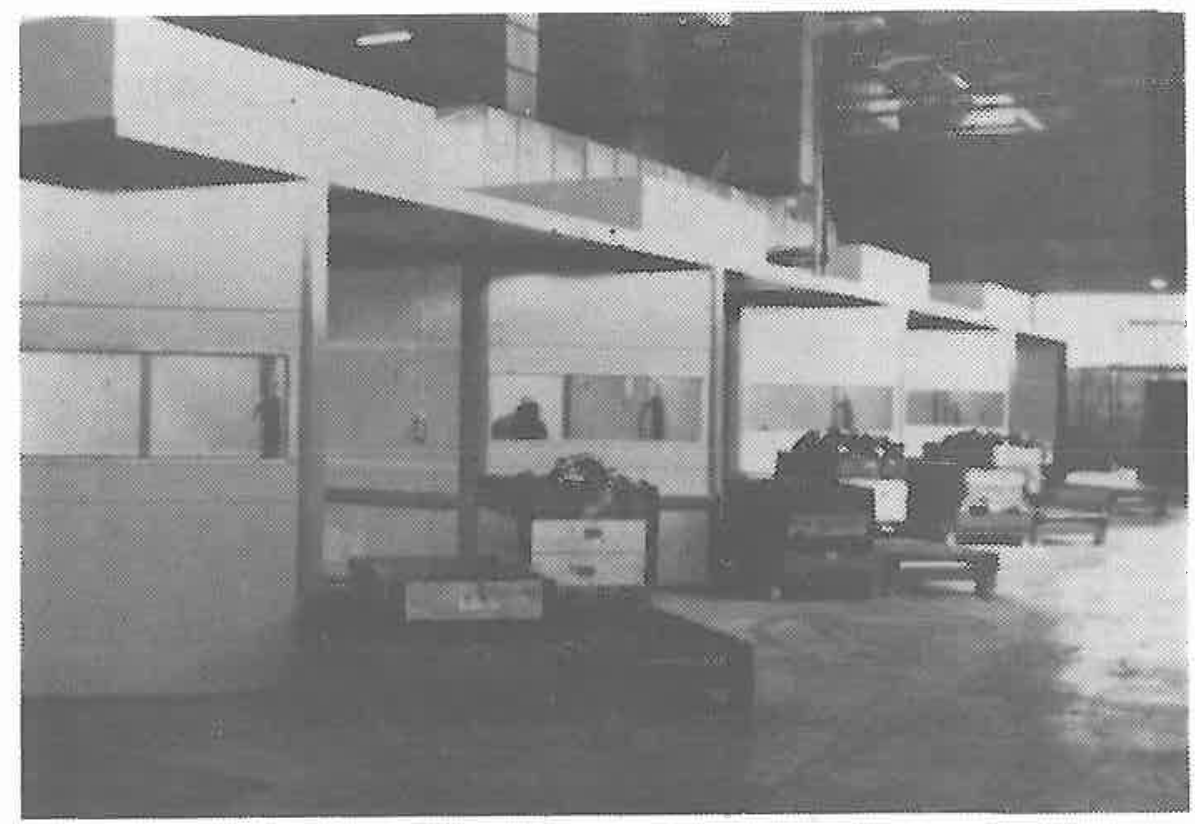

Figure 16. Cleaning booth for smaller castings.

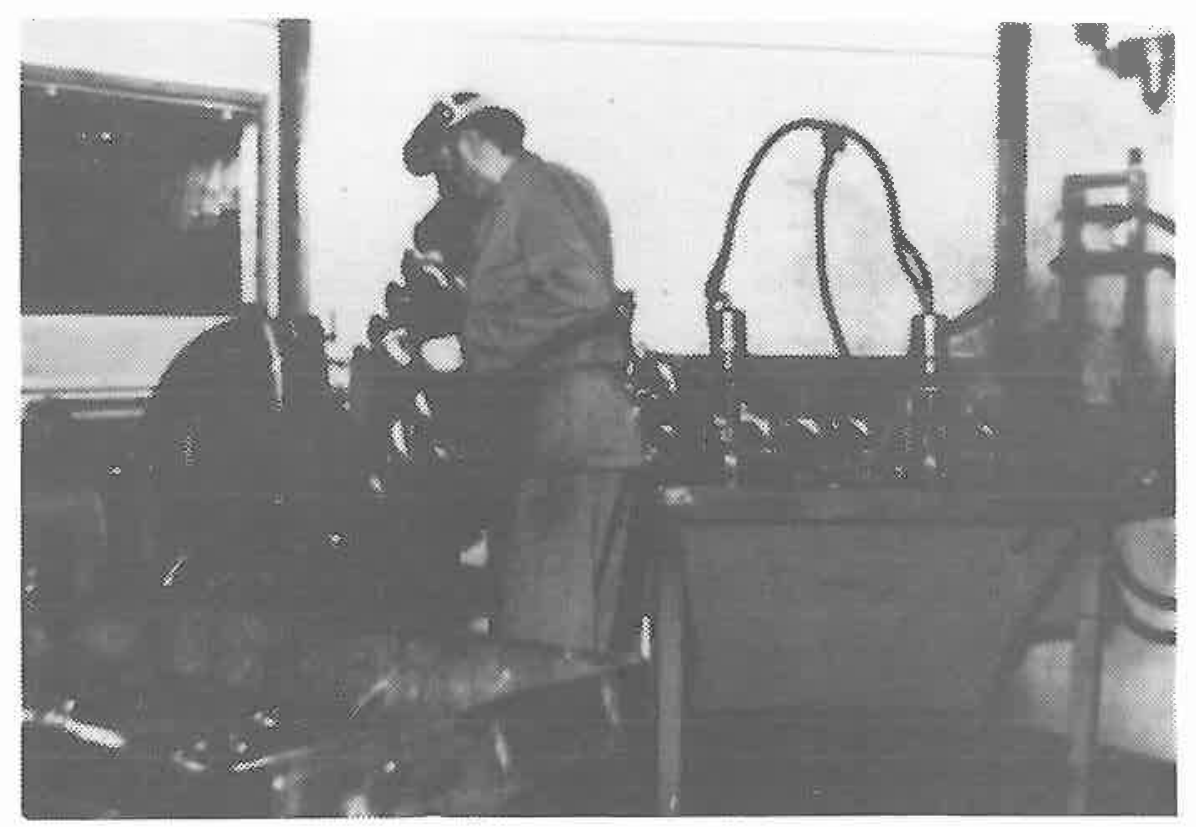

Figure 17. Interior of the cleaning booth in Figure 16. 


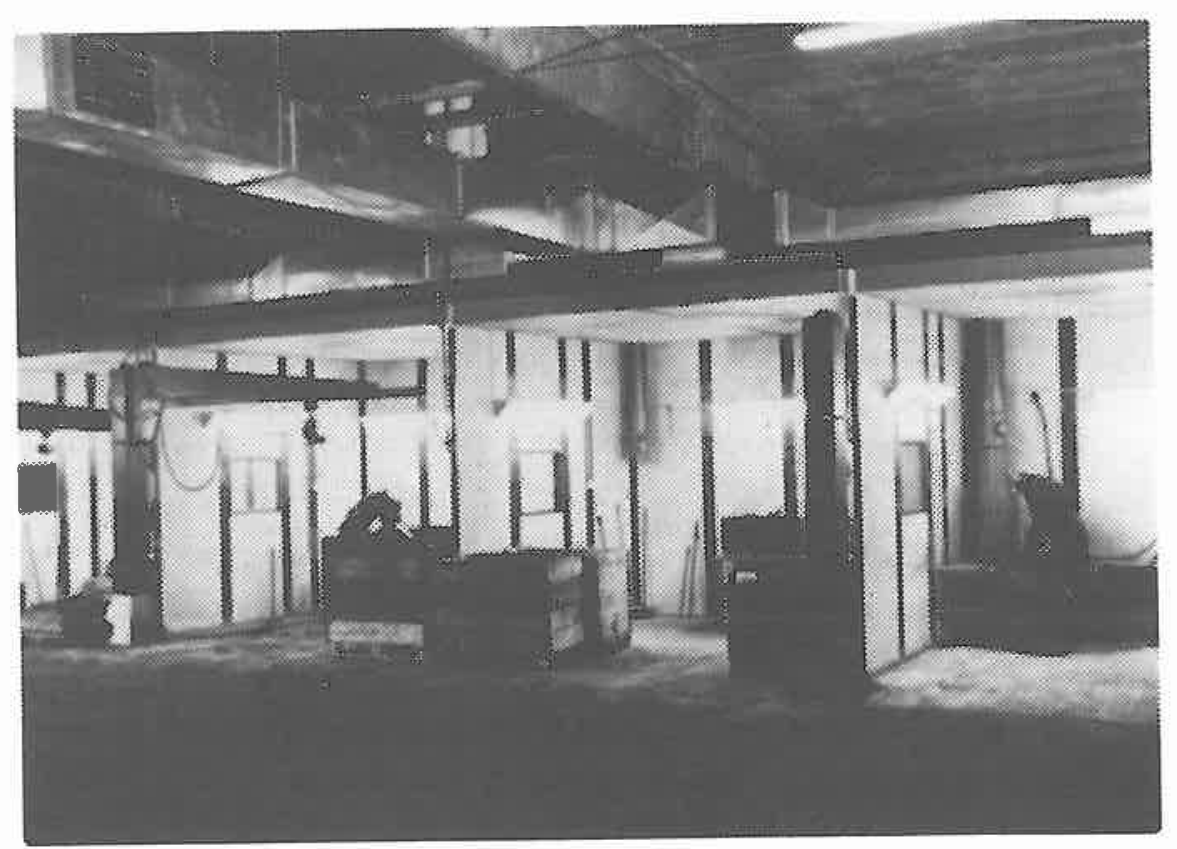

Figure 18. Another type of cleaning booth.

10. A working bench or table should be fixed onto or located near a wall with an exhaust hood. Close proximity between bench and wall is important to prevent work from being done between the exhaust hood and the table, in which case the dust produced must travel through the breathing zone before entering the hood.

11. The space under the cleaning bench and the cleaning table should be large enough to allow large pieces of iron to be collected there.

The cleaning booth in Figure 14 and 15 consists of a framework of steel, to which wall units are attached. The frame consists of six corner posts held together by transverse members. The walls are noise-absorbing and are built. of prefabricated module panels consisting of $1.5 \mathrm{~mm}$ of sheet steel, $80 \mathrm{~mm}$ of noise absorbing glass fiber wool, and $1.5 \mathrm{~mm}$ perforated plate on the inside. In one of the walls there is a window of tempered glass. The roof of the enclosure is similarly built of prefabricated panels.

Ventilation is provided by fresh air blown in through the perforated ceiling of the enclosure. The air is distributed in such a way that an almost laminar flow passes the breathing zone of the worker. The air is exhausted through the work bench.

Castings are transported in and out of the booth using a pneumatic hoist on a monorail. Compressed air lines are supported at head level from behind the operator for ease of movement (Figure 15). In the cabin there is a seat and a small folding table, both fixed to the wall. The light directad on the castings is about 1000 lux. The amount of dust in the cabin has been measured and it has been shown that the respirable percentage of quartz in the worker's breathing zone is about one sixth of the limit value now in 
effect. Before the reconstruction of the work station, when ventilation was arranged with exhaust in the walls but without a controlled supply of fresh air, the respirable percentage of quartz was so high that a respirator had to be worn by the worker.

The general noise level in the part of the cleaning department where the new cleaning booth has been installed has been reduced by about 20 dBA. The noise level in an unused booth from work carried out in neighboring enclosures is about 75-80 dBA. Thus it is possible for the worker to take off the hearing protection during work pauses without risk of hearing damage. When he is working, however, the ear protectors must be used.

Exhaust Hoods on Hand Grinding Machines

In dust control design the general rule is that dust should be collected as near the source as possible. This is especially important for hand grinding machines, which are very difficult from the point of view of ventilation. During grinding, air currents which can disperse dust are caused by release of heavy particles and by the rotation of the grinding wheel. With pneumatic tools the exhaust air from the tool makes the situation even worse. Extensive development work has been carried out with hand grinders in order to collect the dust as close to the source as possible by applying ventilation to the tool itself. This is difficult because good flexibility and lightness are necessary while, at the same time, the worker must be able to see the grinding area easily.

When collecting dust from hand grinding tools through source ventilation the so-called high velocity, low volume (HVLV) system is the best. The tools are fitted with hoods around the grinding wheels. A comparatively powerful exhaust system is connected to the hood demanding the use of special fans or ejectors. The power increase needed is comparatively small because the air flow rates are small and the total cost of heating fresh air is reduced.

Svenska Gjuteriföreningen, in collaboration with a member company and a supplier company, recently carried out a development program during which efficient exhaust hoods for different types of hand grinding tools were developed and tested (Figures 19-21).

For surface grinders (not shown) an exhaust hood is used consisting of a plastic case which surrounds the grinding wheel and rotates with it. Air is exhausted between the case and the grinding wheel.

An exhaust hood has also been developed for a chipping hammer (Figure 22). It consists of a suction nozzle with provisions for preventing large particles to be sucked into the exhaust tube. The nozzle is positioned by a figure "8" device consisting of two steel rings welded together. The chisel is inserted through one of the rings and the nozzle hood through the other.

A special swinging arm to support the suction tube and the compressed air line has been developed within this project. A vacuum valve has also been developed which shuts off the suction to the machine when it is not in use. 


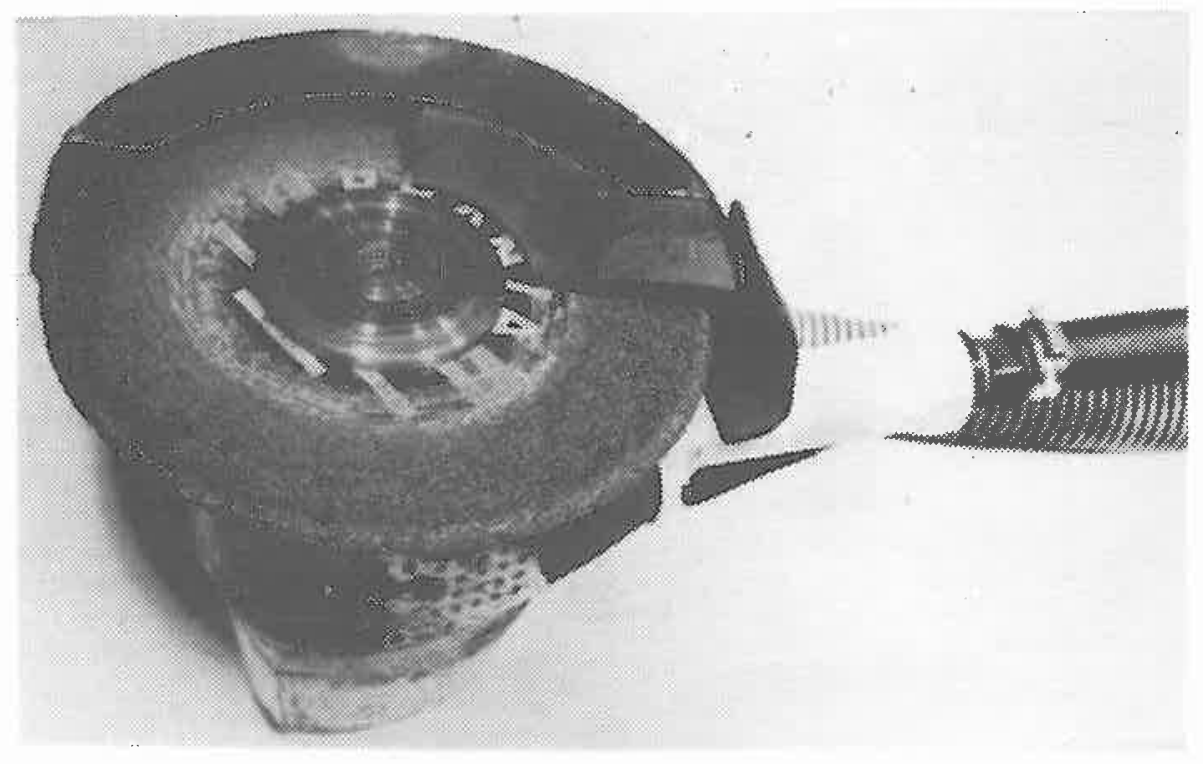

Figure 19. A cutting wheel equipped with an exhaust hood inside the shield.

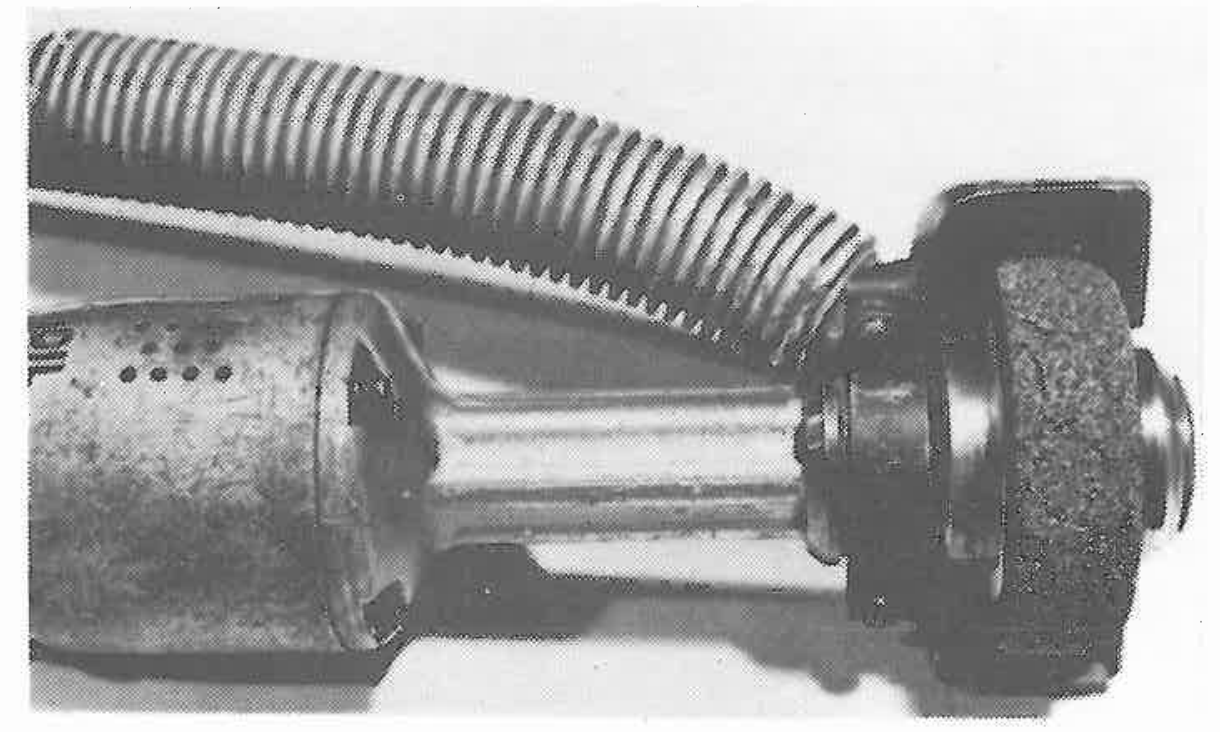

Figure 20. Straight grinding machine equipped with an exhaust hood. 


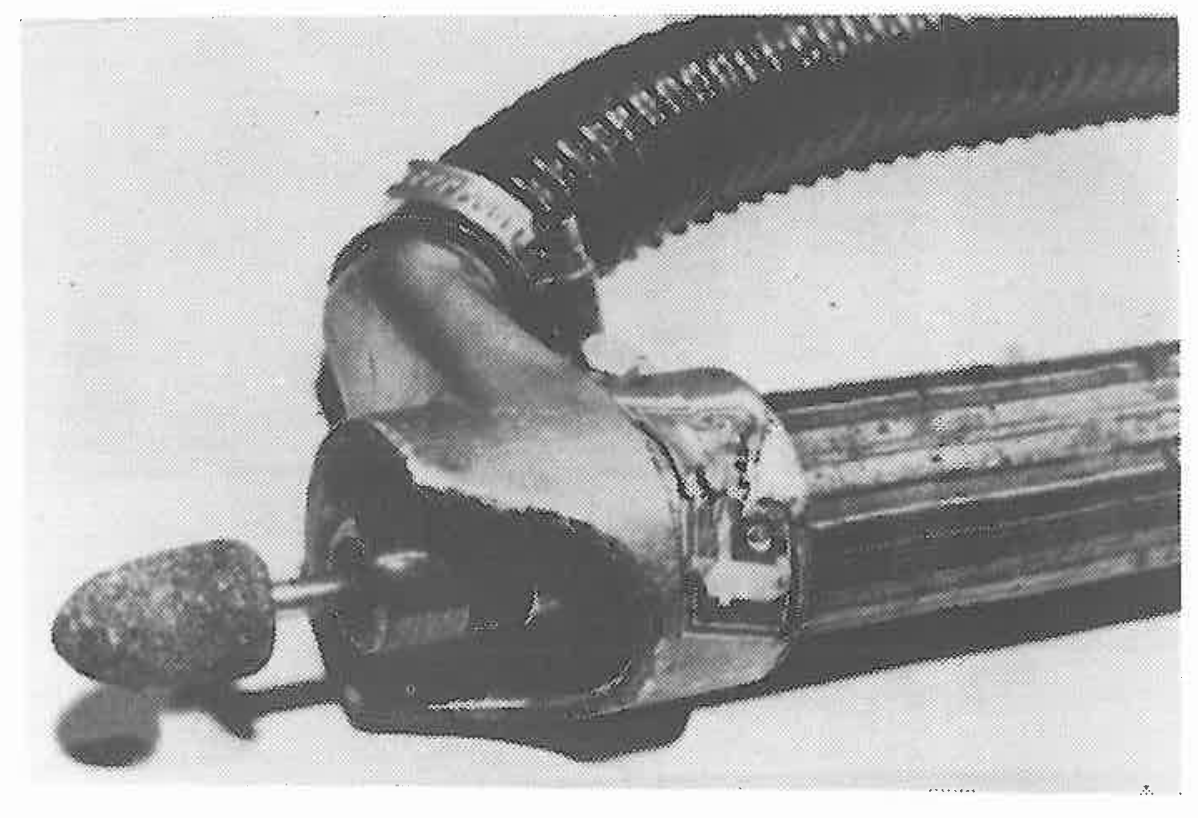

Figure 21. Straight grinding machine equipped with an exhaust hood.

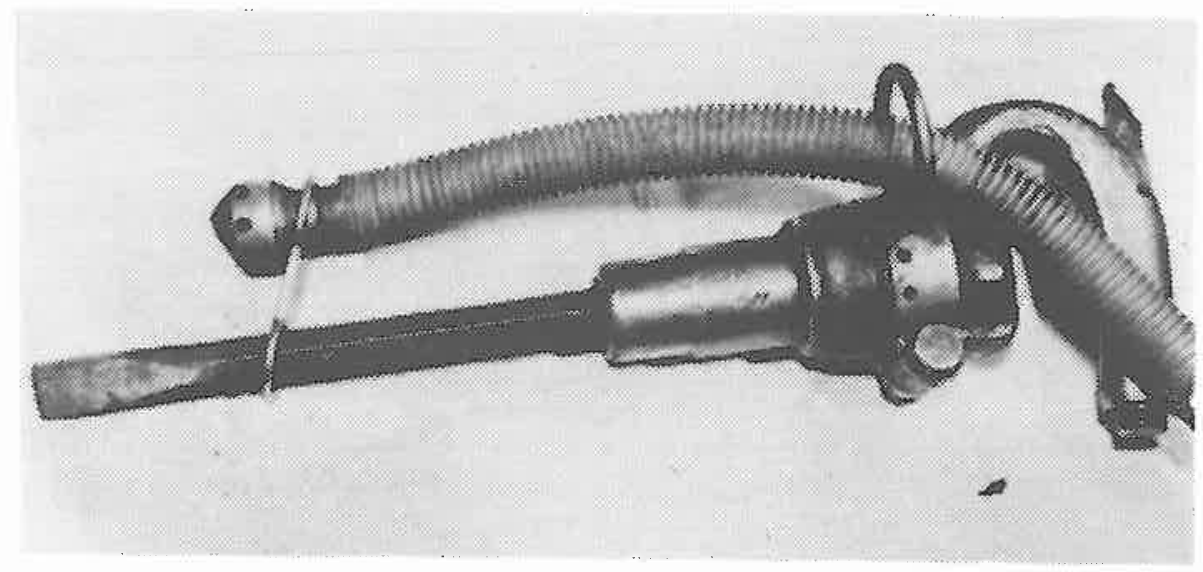

Figure 22. Chipping hammer equipped with an exhaust device. 
Tests during actual cleaning operations showed that the use of the spot suction devices reduced dust concentration considerably.

Prospective Developments for the Future

Continued development is expected in the field of manipulators and industrial robots. In the future, many manipulators will probably be equipped with force feedback. Developmental work on industrial robots is continuing in many parts of the world. For the foundry industry a robot with a capacity for "recognizing" is desired for handling castings after the shakeout operation on automatic molding lines and transporting them to an appropriate automatic cleaning machine. Robots are needed that are able to lift heavy weights, perform work more accurately, and have a larger programming capacity, which will certainly be possible with new computer techniques. With a better programming capacity it will be possible to have the robot perform a number of tasks simultaneously.

New and effective cleaning equipment is sought which can reduce the need for specialized work booth enclosures.

\section{ACKNOWLEDGEMENTS}

This report is based on the results from a number of development projects in Sweden during the years 1972-1978. The costs have partly been borne by the companies taking part in the work and also in part by grants from the Swedish Board for Technical Development and the Swedish Work Environment Fund. The different projects have been initiated, coordinated, and evaluated by the Association of Swedish Foundries with help of an advisory committee.

The author thanks the companies which have taken part in the projects and given exhaustive information.

Numerous persons have taken part in the work and the author sincerely thanks them all, including Mr. Lars Villner, Director, Mr. Bertil Thyberg, Research Manager, and other employees at the Association of Swedish Foundries for valuable advice and help in the work. 


\title{
PELTOIN CASTEEL'S NEW CLEANING ROOM
}

\author{
James Scheid \\ Manager of Engineering, Pelton Casteel \\ Milwaukee, Wisconsin
}

ABSTRACT

Pelton Casteel has incorporated provisions into its new cleaning and finishing facility to reduce exposure of workers to silica dust and metal fume to below allowable limits. This has been accomplished with ventilated, encapsulating booths. Special provisions in the design resolved potential problems of safety and worker acceptance. The booths were acoustically lined and partial seals were installed across openings. Although hearing protection is still needed in the booth, the noise outside the booths has been reduced to below 90dBA. Exhaust from abrasive grinding operations has been filtered and returned to the plant in winter to conserve energy. An opacity monitor signals upset conditions and automatically stops recirculacion.

\section{INTRODUCTION}

With the celebration of Pelton's 50th anniversary, it was announced that a decision was made to expand the facilities to twice the capacity of the existing foundry. This decision was based on customer demand, the desire to grow and add new products, and a need to update the existing facility. Based on a feasibility study it was decided to separate cleaning and finishing, heat treating, inspection, and shipping operations into a separate facility. Castings are delivered to the new facility after removal of sprue, gates and risers.

The plant is divided into two sections, based on the size of castings processed. Castings which weigh up to $22 \mathrm{Kg}$ (50 lb) are finished on the "small side" and larger castings up to $1360 \mathrm{Kg} \mathrm{(3,000} \mathrm{lb)} \mathrm{are} \mathrm{finished} \mathrm{on}$ the "large side".

\section{BOOTH DESIGN AND CONSTRUCTION}

Safety Considerations

Ventilated and acoustically lined booths are used to encapsulate the grinders, finishers, and arc air and welding operators (Figures 1-3). It was decided to have more than one person per booth for safety reasons and also so that the worker would not feel isolated. With individual booths there is the possibility that a serious injury or illness would go unnoticed until the foreman looked in on the worker or until the end of a shift. Windows also help to relieve the feeling of isolation and facilitate monitoring the worker's well-being. 


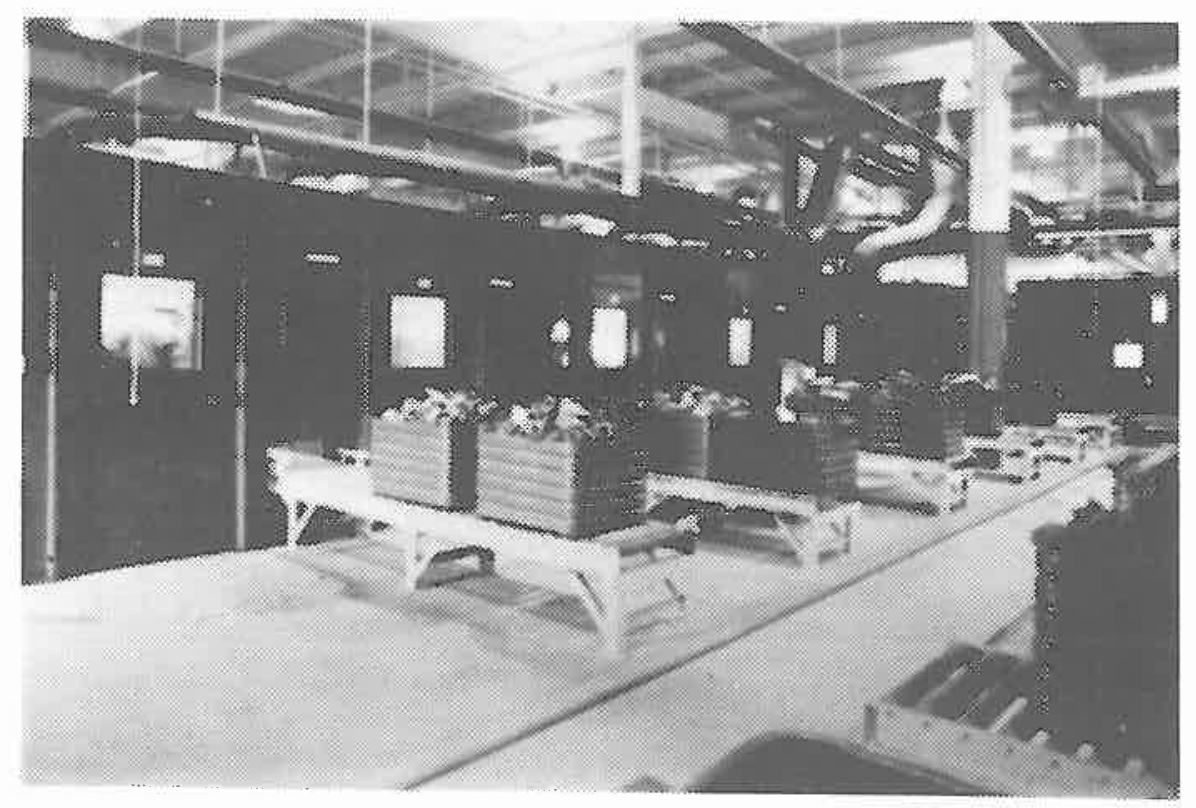

Figure 1. Row of small casting booths showing the inlet conveyors and casting bins.

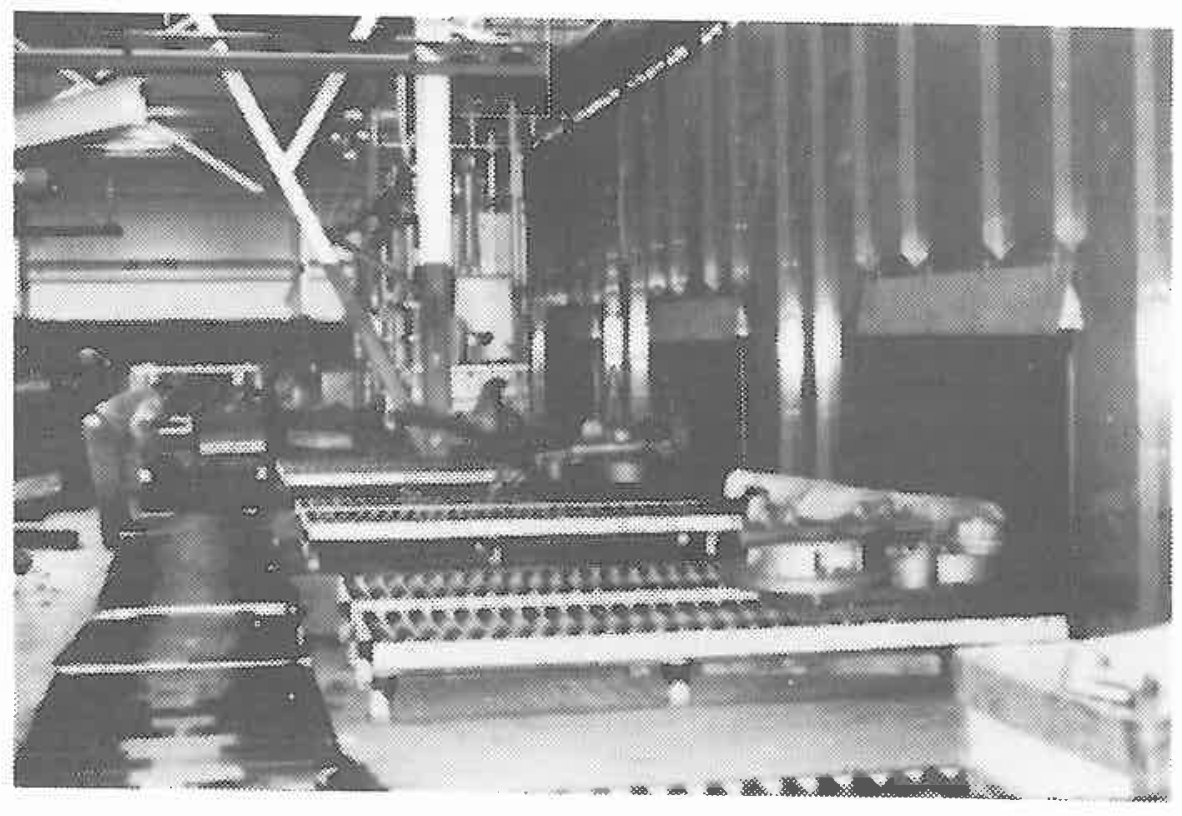

Figure 2. Large casting booths showing the inlet conveyors and castings ready to be processed. 


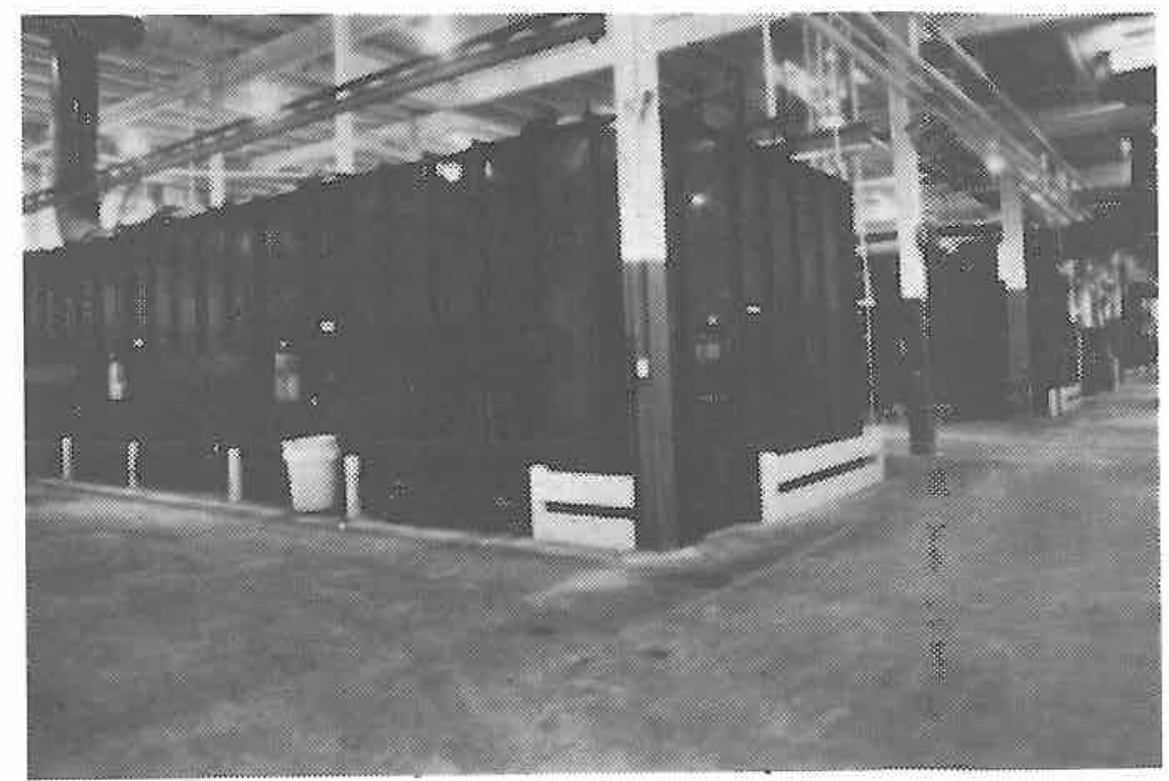

Figure 3. Dishcarge side of large casting booths.

\section{Materials of Construction}

The booths are totally enclosed and are constructed from sheet metal with sound deadening walls of $3.8 \mathrm{~cm}$ (1.5 in.) fiberglass finished on the inside with a perforated protective liner. Rubber flaps over the casting inlet and outlet openings in the booth help to cut down noise loss through these openings.

\section{Material Handling Provisions}

There is a roller conveyor running straight through and projecting out both sides of the booths which process small castings. Bins full of castings ready to be pushed into these booths are shown in Figure 1.

The booths in which large castings are processed are also supplied using a roller conveyor (Figure 2). However, this conveyor terminates just inside the booth. Castings are loaded from the conveyor onto the workbench using an overhead hoist. After processing, the castings are loaded with the hoist onto a heat treat rack just inside the outlet opening of the booth. The heat treat racks are removed from the booths using fork lift trucks.

\section{Ventilation Provisions}

All processing stations within the booths are ventilated. Stand grinders have evacuated exhaust hoods. The remainder of the work, i.e., abrasive grinding with portable tools and casting repair using arc air and welding, is ventilated with side exhaust hoods at the back of each bench. Figures 4 and 5 show the exhaust hoods for welding and grinding of small castings, respectively. The exhaust flow rates for all of the cleaning and finishing processes within booths as well as for miscellaneous processes outside of booths in need of ventilation is presented in Table 1. 


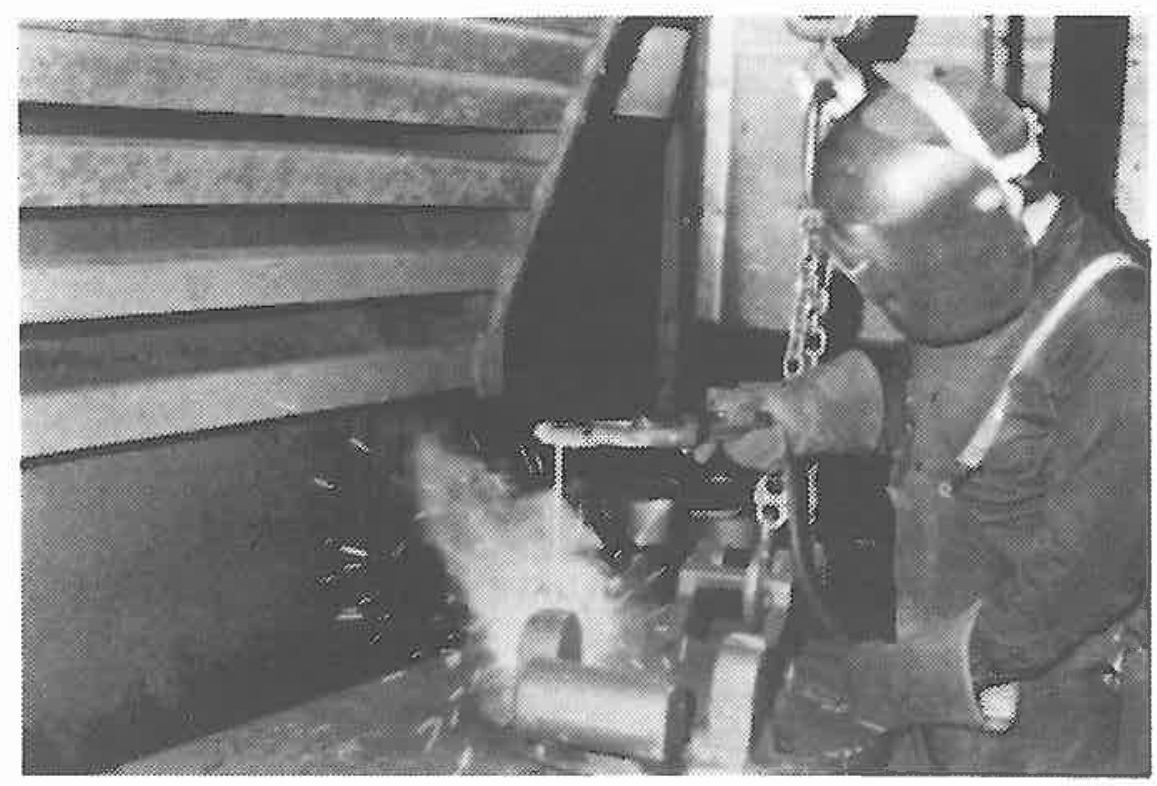

Figure 4. Fume control by side draft hood duging'welding on small castings in a booth.

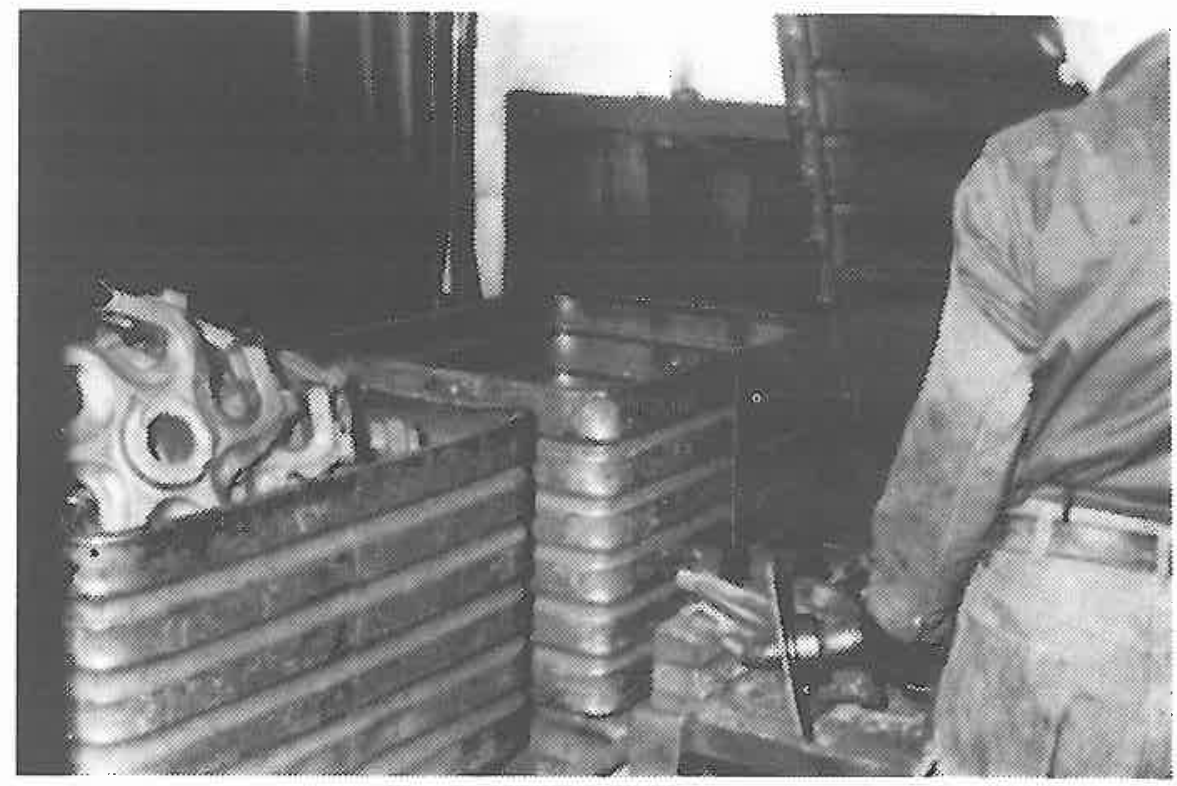

Figure 5. Bench grinding in samll booth with exhaust capture behind bench. Note rubber flaps sealing booth opening. 
In some of the booths air is introduced above and behind the worker (indoor air in winter, outdoor air in sumer) to provide additional control of the air quality in the breathing zone and comfort ventilation.

Exposure Sampling Results

The results of recent personal sampling for silica in abrasive grinding operations are presented in Table 2. All of the exposures on the "small side" were below OSHA permissible exposure limits (PEL); all but one on the large side were below the PEL.

Results of air sampling for metals are presented in Table 3 . The highest values of iron oxide, at the OSHA permissible exposure limit, were found during arc air on large castings. Arc air of small castings and welding produced lower levels of iron oxide. Copper fume was controlled below allowable limits in both arc air and welding.

Table 1. Exhaust air flows from cleaning room processes.

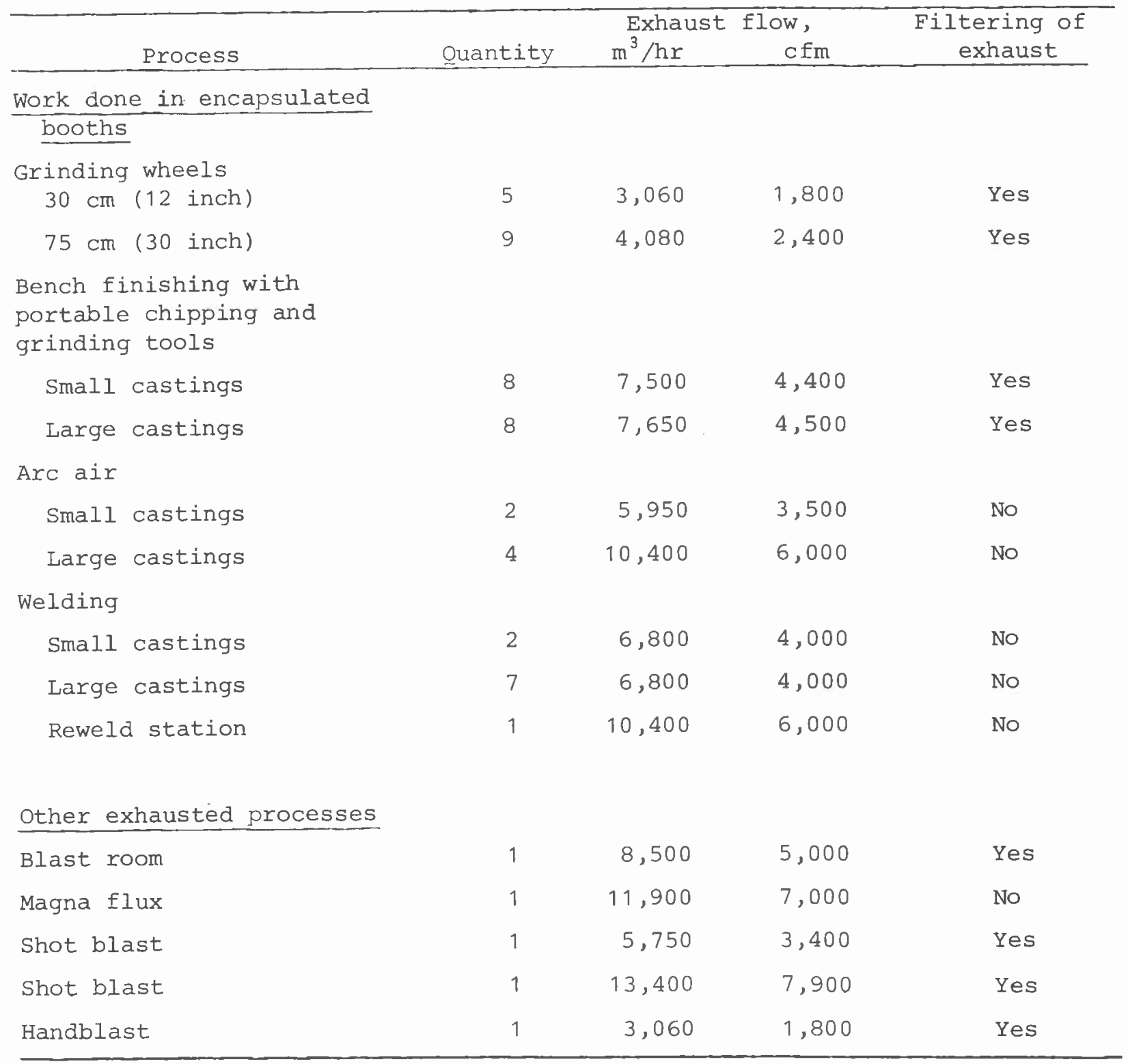


Table 2. Results of personal sampling for silica in abrasive operations.

\begin{tabular}{|c|c|c|c|c|}
\hline Process & $\begin{array}{l}\text { Respirable } \\
\text { or } \\
\text { total dust }\end{array}$ & $\begin{array}{c}\text { Exposure, } \\
\mathrm{mg} / \mathrm{m}^{3}\end{array}$ & $\begin{array}{l}\mathrm{PEL}, \\
\mathrm{mg} / \mathrm{m}^{3}\end{array}$ & $\begin{array}{c}\text { \& } \\
\text { Quartz } \\
\end{array}$ \\
\hline \multicolumn{5}{|l|}{ "Small side" } \\
\hline \multicolumn{5}{|l|}{ Grinding wheels } \\
\hline $30 \mathrm{~cm}$ (12 inch) & Respirable & 0.24 & 0.67 & 13.0 \\
\hline $75 \mathrm{~cm}$ (30 inch) & Respirable & 0.63 & 1.54 & 4.5 \\
\hline $75 \mathrm{~cm}$ (30 inch) & Respirable & 0.42 & 1.01 & 7.9 \\
\hline $75 \mathrm{~cm}$ (30 inch) & Respirable & 0.29 & 5.0 & $<1$ \\
\hline $75 \mathrm{~cm}$ (30 inch) & Respirable & 0.52 & 5.0 & $<1$ \\
\hline $75 \mathrm{~cm}$ (30 inch) & Total dust & 2.03 & 15.0 & $<1$ \\
\hline Bench finishing & Respirable & 0.55 & 1.41 & 5.1 \\
\hline Bench finishing & Respirable & 0.56 & 1.59 & 4.3 \\
\hline $\begin{array}{l}\text { Bench finishing } \\
\text { "Large side" }\end{array}$ & Total dust & 1.38 & 15.0 & $<1$ \\
\hline Bench finishing & Respirable & 0.72 & 1.45 & 4.9 \\
\hline Bench finishing & Respirable & 2.26 & 2.13 & 2.7 \\
\hline Bench finishing & Respirable & 0.51 & 1.59 & 4.3 \\
\hline Bench finishing & Total dust & 9.20 & 15.00 & $<1$ \\
\hline Arc air & Total dust & 8.8 & 15.0 & $<1$ \\
\hline Welding & Total dust & 4.72 & 15.0 & $<1$ \\
\hline
\end{tabular}


Table 3. Results of personal sampling during air and welding.

\begin{tabular}{lcccc}
\hline \multicolumn{1}{c}{ Process } & \multicolumn{2}{c}{ Iron oxide } & & \multicolumn{2}{c}{ Copper } \\
\cline { 5 - 5 } "Small side" & & & & \\
\hline Arc air & 6.35 & 10.0 & 0.030 & 0.100 \\
"Large side" & & & & \\
Arc air & 10.92 & 10.0 & 0.064 & 0.100 \\
Arc air & 9.27 & 10.0 & 0.058 & 0.100 \\
Welding & 2.18 & 10.0 & 0.020 & 0.100 \\
Welding & 4.00 & 10.0 & 0.040 & 0.100 \\
\hline
\end{tabular}

Recirculation of Cleaned Exhaust Air

All of the exhaust from the abrasive grinding operations in the encapsulated booths, along with selected other exhausts, are fed to a modular shakertype baghouse. The total baghouse capacity is $204,000 \mathrm{~m}^{3} / \mathrm{hr}(120,000 \mathrm{cfm})$ and the air-to-cloth ratio is $3: 1$.

To save energy the air discharged from the baghouse is recirculated back into the plant during winter through four long plenums with distribution grilles. The plenums are mounted high in the plant along the walls (Figure 6). Upstream of each of the four plenums a monitor (Joy Mfg. Company) measures and records dust opacity (Figure 7 ). If readings exceed a preset trigger level, an alarm sounds and the baghouse discharge air is automatically redirected to the outdoors. Problems experienced so far which have resulted in the alarm sounding and the air bypassing are:

1. Fouling of glass on the opacity monitor.

2 . Broken bags in the dust collector.

Carbon monoxide has been monitored and found not to be a problem during recirculation.

\section{General Exhaust}

Reversible fans and large plenums are used to either exhaust general plant air or supply fresh air, depending on the time of year and plant environmental conditions (Figure 8).

\section{Noise Measurements}

The use of encapsulated booths for manually processing castings has resulted in the noise level in the general area outside the booths to be reduced below $90 \mathrm{dBA}$. Inside the booths, readings when the exhaust system alone was running (no work being done) ranged from 78-82 dBA. Noise levels were measured at $87 \mathrm{dBA}$ at a work station in a booth when work was not being done at that work station, but was being done in the other part of the booth. Dressing stand grinder wheels was found to lower noise levels by 5 dBA. 

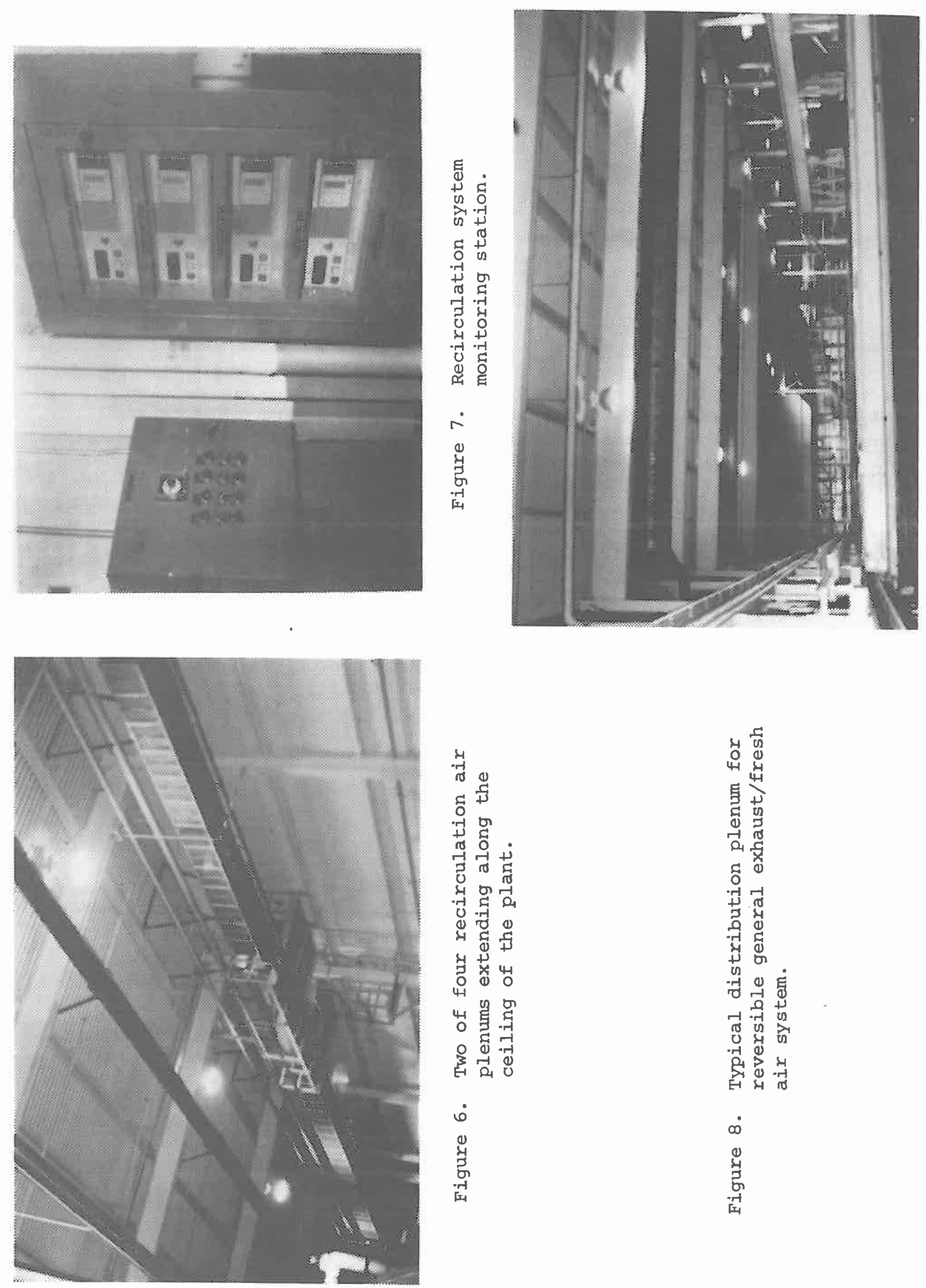

त्

대

㸵聶

음

วิ

남

匝

덩 क्

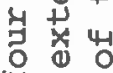

4

出苞罡

워

蛋落

ம

荘

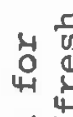

둔

羿

다영

ธี

式 겅

จำ

牙

吕骂

नी

ठิ

究总资

$\dot{\infty}$

氙 


\title{
HIGH VELOCITY, LOW VOLUME DUST CAPTURE \\ DURI.NG GRINDING USING PORTABLE TOOLS
}

\author{
Andrew A. Katko \\ Manager, Dust Control \\ Hoffman Air \& Filtration Systems \\ Syracuse, New York
}

\section{ABSTRACT}

The high velocity, low volume dust capture method has been shown to be effective in controlling dust during chipping and grinding of castings using portable tools. Two inplace and functioning systems are described, as well as the ways that worker objections to use of the systems were overcome to the point where the workers don't want to perform their job without this dust control method in operation.

\section{THREE IMPORTANT DESIGN FACTORS}

Time does not permit me to go into the design aspects of a high velocity, low volume dust control system here. Suffice it to say that there are no magical formulae, etherial air quantities, or mystic knowledge necessary to design a successful high velocity, low volume system. A working system is made up of three separate but interrelated factors: engineering, common sense, and system compatibility. An explanation of the above can best be made by describing two working high velocity, low volume dust control systems in foundries and what went into their development.

\section{THEORY OF OPERATION}

The high velocity, low volume method of dust control is based on the principle of getting a small nozzle or a suction hood within $1.3 \mathrm{~cm}$ (one-half inch) of the source of dust generation. The air entering this nozzle must be moving fast enough to overcome the velocity of dust generation and effect capture of dust particles. This is the unique high velocity concept of picking up dust at the source. A velocity sufficient to do this is termed the capture velocity, defined as:

Air velocity at any point in front of the nozzle or hood necessary to overcome opposing air currents and to capture the contaminated air at that point by causing it to flow into the hood.

Much of the dust that we attempt to capture is respirable (less than 10 micrometers in diameter) and capable of entering and being retained in the lungs. Many times this "culprit" is not visible unless it is spotlighted using a high intensity lamp, strong flashlight, or some similar lighting device. The 
remainder of the dust is usually visible to the naked eye and is made up of what we call heavy particles, which, although airborne, lose their velocity quite rapidly and fall to the floor at a short distance from the source. We are not nearly as concerned with heavy particles as we are with respirable dust. But a good hood design on a tool used by a sensible operator will eliminate the respirable dust and also a great majority of the "heavies".

\section{HOOD DESCRIPTIONS}

Before discussing the application of the high velocity, low volume dust capture method to the cleaning and finishing of castings, a few of the capture hoods that are used in those systems will be described.

Figure 1 shows a cone grinder hood which provides an equal distribution of exhaust all around the abrasive tool. The closeness of the hood to the tool is adjustable. In this as in all the other figures, the hose connections are shown but the hoses are not attached. This hood attaches to a $3.8 \mathrm{~cm}$ ( 1.5 inch) diameter hose. The hood is sturdy enough for the worker to grip it in one hand and the tool itself in the other to give him better control in its use.

Figure 2 is a $15.2 \mathrm{~cm}$ ( 6 inch) cupstone grinder; this hood takes a $5.1 \mathrm{~cm}$ (2 inch) diameter hose. The hood on the chipping hammer in Figure 3 is not as awkward as it looks. This hood is used in the second example which follows. It takes a $3.8 \mathrm{~cm}(1.5$ inch) diameter hose and has rotational and axial adjustments.

It was necessary to construct the hood in this manner because the worker grips the chisel with one hand to properly guide the tool. The adjustability of the hood allows him to change bits readily, and to compensate for either a longer or shorter chipping chisel. Figure 4 shows a $17.8 \mathrm{~cm}$ ( 7 inch) cut-off disc hood. Here the outer edge of the disc is used for cutting pieces off the casting, slicing bolts, etc. The four holes in the end of the hood are not for picking up dust, though they do capture some at that point. They are placed at that point to enable even air flow through the hood to prevent heavy spot wear. This tool takes a $5.1 \mathrm{~cm}$ ( 2 inch) diameter hose. Figure 5 shows a $17.8 \mathrm{~cm}$ ( 7 inch) grinder hood. Here the worker uses mainly the front bottom quarter of the tool. This hood also is adjustable to some extent to accommodate workers who grip the tool in slightly different fashions.

\section{SYSTEM 1}

Description of Problem

This foundry uses a standard coke-fired cupola operation to melt mixed foundry cast scrap in one heat a day, producing anywhere from 72-90 metric tons $(80-100 \mathrm{~T})$ of castings a day. The castings weigh between $272-1130 \mathrm{~kg}$ $(600-2500 \mathrm{lb})$ each.

The cleaning room in this facility is on a high volume, production line basis. Eight to ten workers are constantly grinding, chipping, and 


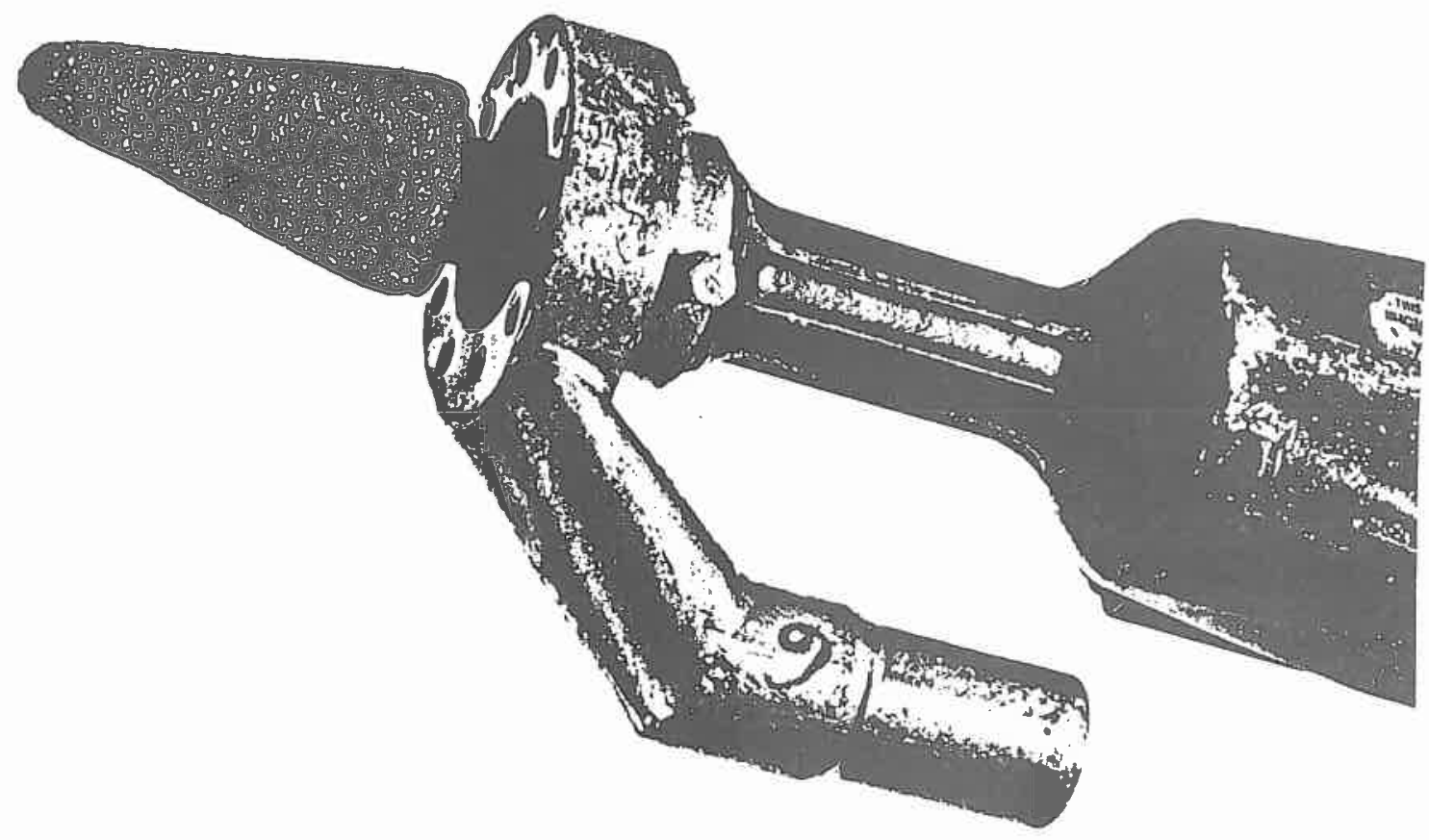

Figure 1. Cone grinder hood.

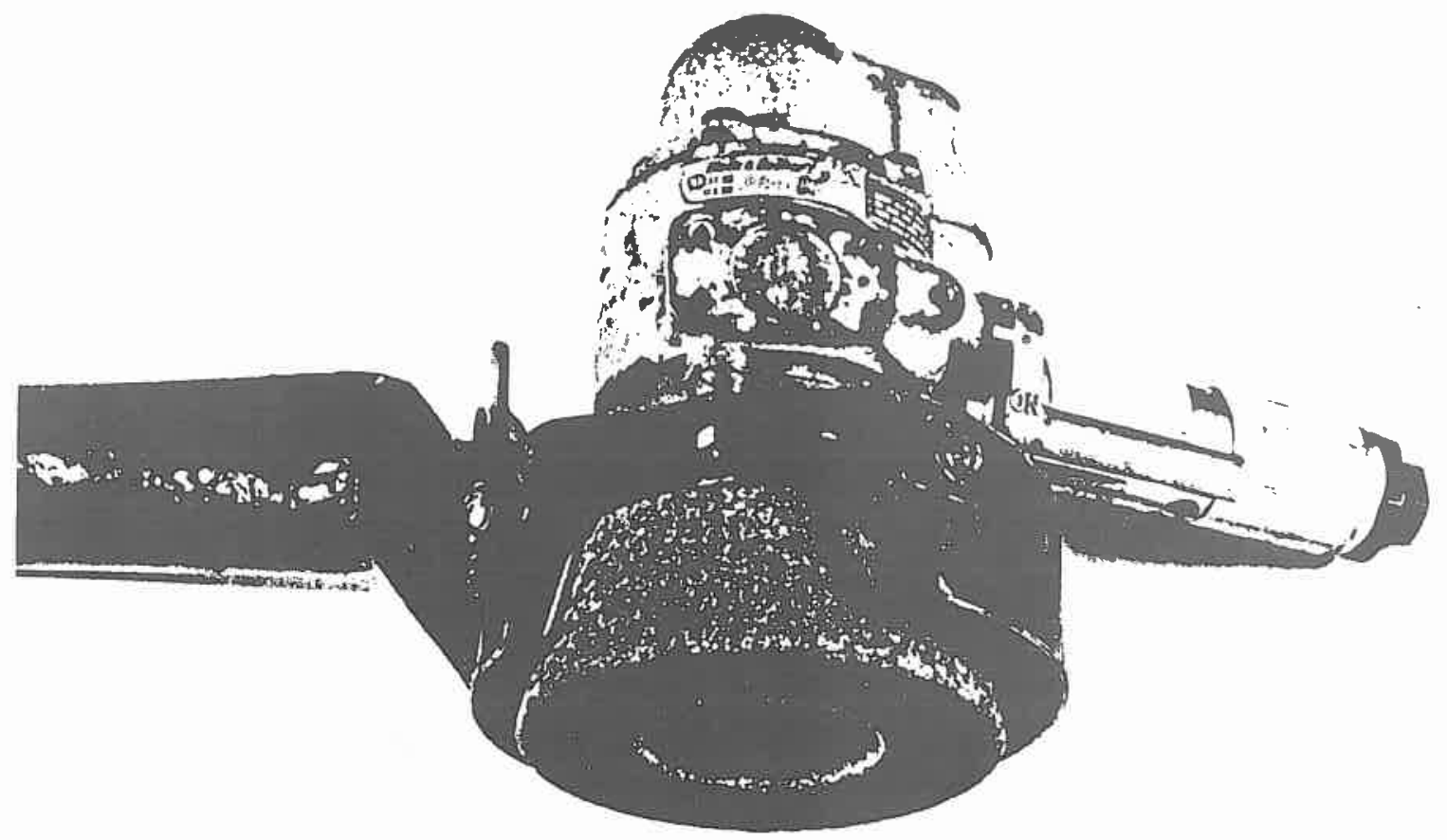

Figure 2. Cupstone grinder hood. 


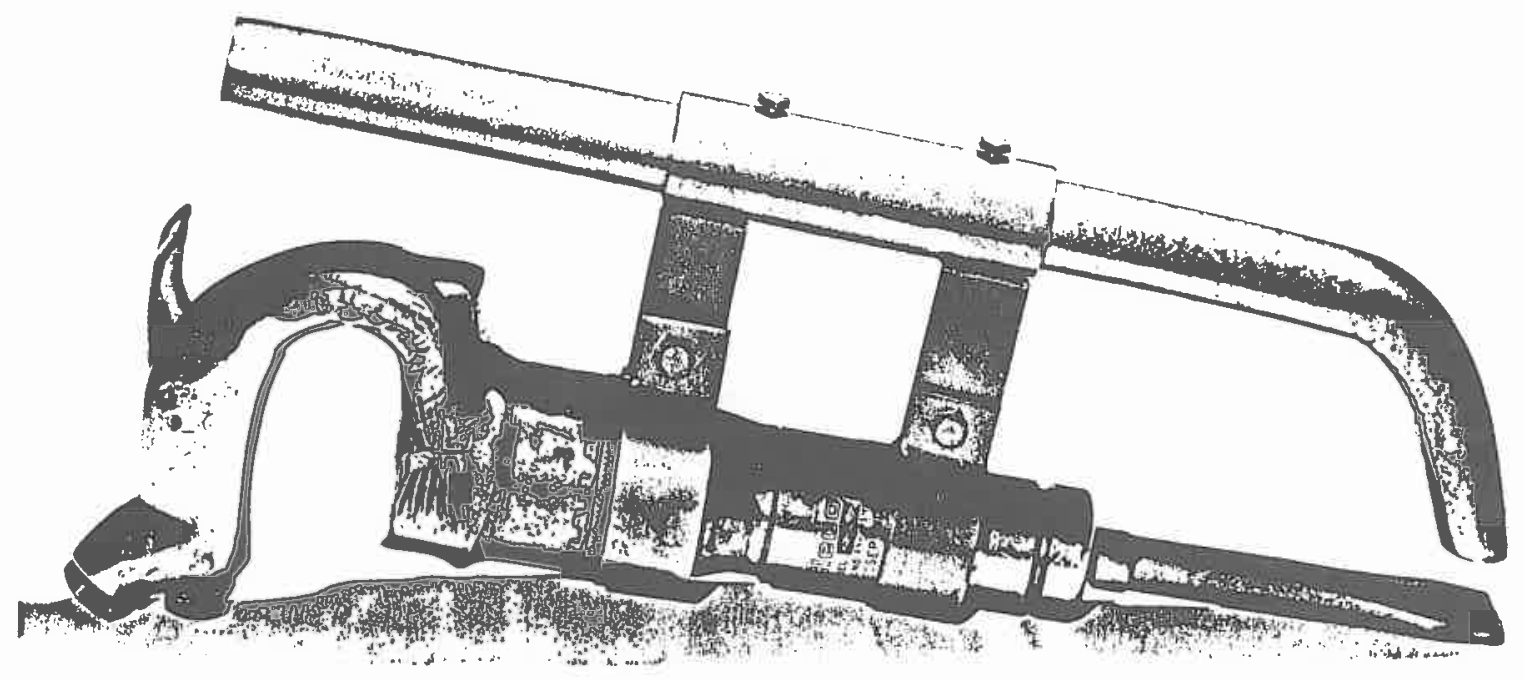

Figure 3. Hood on chipping hammer.

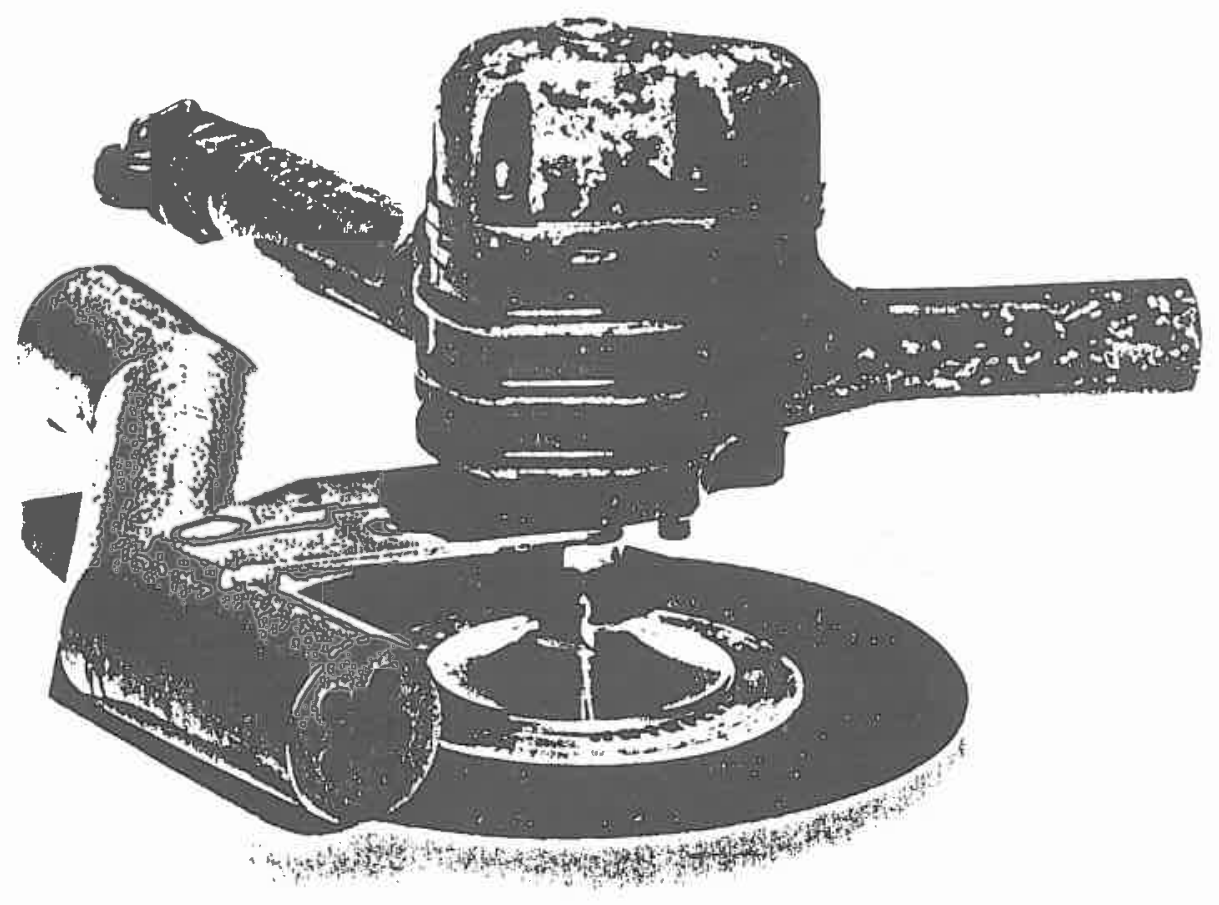

Figure 4. Cut-off disc hood. 


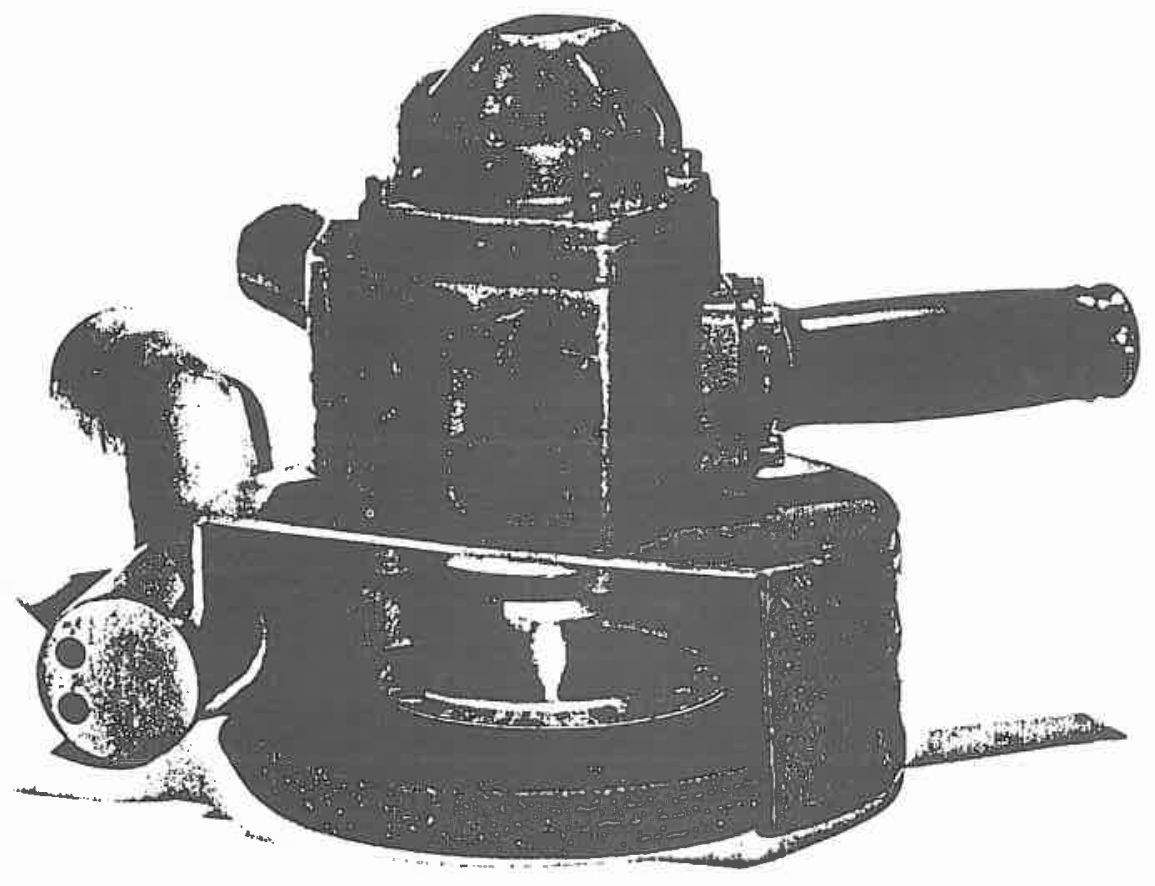

Figure 5. Disc grinder hood. 
finishing these large castings. The room itself is approximately $12.2 \mathrm{~m}$ (40 ft) wide by $18.2 \mathrm{~m}$ (60 ft) long with a $6.1 \mathrm{~m}$ (20 ft) ceiling. Before the system was put into operation, it was impossible to see from one end of the room to the other because of the dust. Other workers in the facility would carefully avoid this area when going from one section of the foundry to the other even though it meant a longer walk and sometimes going outside in the cold weather. When the system was originally designed, hoods were proposed for the cupstone grinder, chipping hammer, and the cone grinders. The $15.2 \mathrm{~cm}$ ( 6 inch) cupstone grinders generate upwards of $80 \%$ of the dust in the area. Grinding dust generated by the use of the chipping hammers, cone grinders and the moving of the castings made up the remainder of the dust problem.

\section{System Description}

From our observation of the cleaning room process and our previous knowledge we designed a $15 \mathrm{~cm}$ ( 6 inch) cupstone grinder hood to draw $340 \mathrm{~m}^{3} / \mathrm{hr}$ (200 cfm) and have a hood loss of $3.72 \mathrm{~cm} \mathrm{Hg} \mathrm{(1.5} \mathrm{inch} \mathrm{Hg})$. The chipping hammer hood was designed for $220 \mathrm{~m}^{3} / \mathrm{hr}(130 \mathrm{cfm})$ and a $\left.6.2 \mathrm{~cm} \mathrm{Hg} \mathrm{(2.5} \mathrm{inch} \mathrm{Hg}\right) \mathrm{loss}$. The cone grinder was designed for $255 \mathrm{~m}^{3} / \mathrm{hr}(150 \mathrm{cfm})$ and a $7 \mathrm{~cm} \mathrm{Hg}$ (2.8 in. Hq) loss. The exhaust hoses were fairly short in length averaging $3-3.6 \mathrm{~m}$ $(10-12$ ft) long.

Due to the abrasiveness of the material that is picked up and the high transport velocities schedule 40 pipe was used with cast iron drainage fittings for the remainder of the ducting leading to the air cleaner. These fittings are easily replaced when worn and also have the advantage of ready access for cleaning. The heavy duty piping system is connected to a large Vacumatic separator which filters out approximately $0.76 \mathrm{~m}^{3}\left(27 \mathrm{ft}^{3}\right)$ of iron dust in one week's operation. In this particular instance a separator with an extended shell length was used to give more than normal storage volume. No preseparator was necessary, however, the filtration section did contain heavy duty dacron bags and had an air to cloth ratio of approximately 6 to 1. The bags were cleaned by a pneumatically operated Vacumatic shaker which automatically shook the bags at a preset timed cycle.

This vacuum system was also used for reclaiming sand and for general casting cleanup throughout the facility.

Resolution of Operational Problems

The hoods furnished for the chipping hammer and the cone grinder did work satisfactorily but in a number of cases they prevented the worker from properly doing the job, requiring a design modification to be used in those special cases. It was necessary for the chipping hammer to get into long bolt holes some $25-30 \mathrm{~cm}(10-12$ inch) deep and no incumbrance could be tolerated around the shaft of the chipping chisel. The problem was solved very successfully by affixing a heavy duty magnet to the hose and placing the suction inlet off of the tool but very close to the vicinity where the chipping work was being done. The same method was used for the cone grinder. 
Another early problem which was overcome was worker acceptance. The hose and the hood on the $15.2 \mathrm{~cm}$ ( 6 inch) cupstone grinder did pose a handling problem to the workers at first; but within a very short period of time, they adapted to the situation after they realized the benefits they were receiving by using the dust control system. The workers had been told at the outset that they must use the system, that it was a necessary part of their jobs and, if they wished to retain their jobs, the system must be used. Strong words, yes, but words that paid off in the long run. After a few weeks of operation, the system was shut down for minor repairs and adjustments and the amount of grumbling and complaining while the system was down was something quite gratifying to hear.

Effect on Dust Levels

The main reason for the installation of the above system was to reduce the level of silica dust in the cleaning room to a level that would be acceptable to OSHA. After the system was installed and running for a few months, OSHA returned and found that what had been an intolerable workplace before, now met the OSHA requirements.

SYSTEM 2

The second system, at another foundry cleaning room operation, involved the use of chipping hammers, disc grinders, cut-off wheels and cone grinders on castings ranging from a few hundred kilograms to well over the ten metric ton range. All of these tools were fitted with high velocity, low volume exhaust hoods. The total high velocity, low volume dust control system consisted of two equal 56 kilowatt (75 hp) systems, each having its own separator and air cleaner with the storage shell volume increased as in the previous system. Each system was designed for $23 \mathrm{~cm} \mathrm{Hg} \mathrm{(9} \mathrm{inch} \mathrm{Hg}$ ) of vacuum at approximately $3740 \mathrm{~m}^{3} / \mathrm{hr}(2200 \mathrm{cfm})$ each. A modulating bleed system was installed to keep each of the centrifugal exhausters out of the surge range when only a few of the inlets were active.

One of the two systems was connected through a primary separator which is placed in the shot blast area of this foundry. Here the suction was used for retreiving the shot and depositing it in the primary separator for reuse. The rest of this high velocity, low volume dust control system was connected into the inlet of this preseparator. Both secondary separators and the exhausters were located outdoors and, as in the previous system, the bags were automatically shaken by the Vacumatic separator at frequent intervals to remove the accumulated dust.

The system was designed for 12 active inlets; at times there could be six operators on one casting. Accommodating this mode of operation necessitated the use of hoses around $7.5 \mathrm{~m}$ ( $25 \mathrm{ft}$ ) long. In order to cut down the friction loss in the hose and still provide the flexibility of working freely on and around a large casting, as well as reducing the total horsepower required to operate the system, the $3.8 \mathrm{~cm}$ ( 1.5 inch) hose attached to the chipping hammer or the cone grinder was connected to $5.5 \mathrm{~m}(18 \mathrm{ft})$ of heavy duty $5.1 \mathrm{~cm}$ ( 2 inch) hose which could be laid along the foundry floor. The larger hose resulted in a lower transport velocity and thus a lower friction loss 
Proper hood design is essential for the high velocity, low volume system to be effective. Before a dust control hood is designed and built, the use that the operator makes of the tool must be carefully evaluated, including how the tool is held, what portion of the tool is utilized for certain tasks and what types of castings are being processed.

The information compiled should be discussed with the operator and the supervisor including the effects that particular practices will have on the ability to capture toxic dusts. The purpose of the system should be explained in advance, as well as the personal benefits to the worker and the need for cooperation if the project is to be successful. No matter how well we engineer, design and install a system, if the operator is against it, it will never work properly.

The use of a high velocity, low volume system is not limited to hand held tools. Swing frame grinders, cut-off wheels, and pedestal grinders also lend themselves to this approach.

SYSTEM FLEXIBILITY

One must also take into consideration when evaluating the benefits of a high velocity, low volume dust control system that it also provides the foundry with a vacuum cleaner for housekeeping and maintenance.

In conclusion I would like to quote a foundry user of a high velocity, low volume system: "This system, in addition to increasing productivity, has a definite effect on product quality. With dust removal at the source, the workers have a clear unobstructed view of the work piece and they don't have to wear cumbersome dust respirators.

QUESTIONS, ANSWERS, AND COMMENTARY

Question (F. Boelter, OSHA):

I've heard many foundrymen say that the greatest problem with the HVLV system is it works fine on flat surfaces but doesn't work at all on curved surfaces. Can you respond to that?

Answer (A. Katko):

Yes. If you could construct the ideal hood, it would pick up everything if the surface of the workpiece is flat. When the surfaces to be cleaned are 
curved, some of the heavy particles will escape capture. If the tool is used properly and if it is the proper tool for the job then most of the heavy particles would be captured along with the respirable dust when working on curved surfaces.

In some foundries a single tool is used for three or four jobs. When this procedure is followed the tool may produce dust in a variety of ways which are difficult to control with a single hood technique.

I repeat, proper use of high velocity low volume hoods on portable tools requires that the right tool be used for each particular operation. When this is accomplished, worker acclimation to the hoods is simplified.

Question (J. Calhoun, White Consolidated Industries, Inc.):

Are you saying that the dust in the area is reduced or just the dust in the small sphere to which the worker is exposed?

Answer (A. Katko) :

With each hood the dust in the area that the worker is working in is reduced. In the cleaning room, if there are seven or eight people working with tools with hoods on them, the area can be brought down within OSHA limits without any problems. Of course, there is other dust generated in the plant. Forklift traffic can cause substantial amounts of airborne dust. This and other sources besides the cleaning and finishing operation contribute to background dust levels.

Question (J. Calhoun):

Let's assume that the background dust level is well below the permissible exposure limit. Have tools with the high velocity, low volume devices been tested under such a condition on a pilot basis on the same day at the same location, some with and some without hoods, so that a direct measurement of this technique's effectiveness could be obtained?

Answer (A. Katko):

Yes. And it has been successful. We have done it in our own foundry and in our test lab.

When a high velocity, low volume system is installed after we have had a chance to survey the application right from the start, we will gurantee the results of the system. But, then, again, I think what's in everybody's mind is: I have a tool, can it work on mine? It may not. In one of the examples I just presented we had to take the hoods off some of the tools in that foundry and use a magnet to position the suction hose close to the point of dust generation to overcome an interference problem.

Question (R. Crane, Duraloy Blaw-Knox, Inc.) :

I noticed in the examples the absence of what I call a horizontal grinder. Do you have any hood applications for that type of a grinder? 
Answer (A. Katko):

Yes, quite a few on horizontal grinders, cone grinders and even radial wheel grinders.

Question (G. Cusamano, Aer-X-Dust Corp.) :

Have you any sound level readings on that depressed center wheel in terms with that sharp cut-off on the air entry?

Answer (A. Katko):

No, we do not have sound level ratings on that specific tool. We do have them on others, which we've tested in our lab. We do not have sound ratings of tools out on the job.

Only once has someone come back to us because of a noise complaint and we fixed it. In most cases the noise is less than that generated by the tool without a hood. 
NEW TECHNOLOGY FOR IMPROVED FUUNDRY ENVIRONMENTS

\author{
Stuart A. Hoenig, Professor \\ Department of Electrical Engineering \\ University of Arizona \\ Tucson, Arizona
}

\title{
ABSTRACT
}

This paper presents the results of recent research at the University of Arizona on methods for control of dust, fume, vapor and smoke. The dust reduction systems are based on the discovery that industrial dusts are naturally charged as they disperse into the air. These dusts can be induced to agglomerate and fall out by exposure to small quantities of oppositely charged water fog.

Control of smoke, vapors, fume, etc., has been done with a variety of new and improved electrostatic techniques. Particular attention has been aimed at welding smoke and the control of diesel exhaust particulates. Other applications have involved the developmest of an "electrostatic fence" designed to "push" smoke and dust toward a hood or other collector. Electrostatic systems can also be used for demisting and the control of sulfur dioxide. Laboratory and industrial studies of the above technologies will be discussed in the paper.

\section{INTRODUCTION}

Improvement of foundry working conditions has been an important goal of health professions for many years and a great deal has been done to reduce the hazards of the foundry environment. Nevertheless, we must recognize that high temperatures, toxic gases, metallic fume and respiratory dusts are still sources of injury to foundry workers. The problem is complicated by the obvious need to maintain economical operations while improving the foundry environment; a closed foundry does little for the ex-worker's health or the nation's gross national product.

In the discussion below we will consider the work doie at the University of Arizona in the development of new devices to improve working conditions in the foundry. Where possible data and/or photographs of equipment in action will be presented. However, there are a number of operating systems where the plant owners have insisted that no mention of their installation be made. 
Dust and smoke are serious foundry problems particularly in grinding, arc washing, silica unloading, sand handling and shakeout areas. In most cases the hoods or other dust control systems are located above the worker's head, virtually insuring that the dust will go past the worker before it gets to the collection system. This situation and our knowledge that dust respirators are relatively ineffective suggests that efforts be made to suppress the dust at the point of generation.

The University has been working on the application of charged fog for this purpose for some years with support from the Environmental Protection Agency and the American Foundrymens Society. This work has demonstrated that most, if not all, respirable dusts are electrostatically charged as they are dispersed into the air and that the dusts can be induced to agglomerate and fall out by exposure to appropriately charged water fog* (1). The use of charged fog provides several advantages. The fog and the dust particles are attracted to one another leading to rapid wetting and agglomeration. The electrostatic charging process encourages rapid breakup of large water drops into smaller droplets. This makes for more efficient use of water and reduces the quantity of liquid needed for dust suppression. It might be noted that minimal water use is important for two reasons: first, it reduces the problems with mud formation and the hazard of rusting metal components; second, it reduces the total consumption of water which is becoming ever more important in the water short Southwest.

\section{APPLICATIONS TO DUST CONTROL}

Hand Grinders and Sanders

Hand grinders and sanders are an example of devices where dust must be controlled on the device itself if operator dust exposure is to be reduced. A system for this purpose is shown schematically in Figure 1. The unit has been installed on an operational hand grinder by the ARO Company of Bryan, Ohio and is shown in operation in Figure 2. Some of the results with this system in the grinding and sanding modes are shown in Figures 3 and 4 . There was a significant reduction in respirable dust and operator comments indicated that it is possible to grind more rapidly without the danger of "grinding burn". Prototype models of this unit are under test at several industrial organizations. In one automobile company it proved possible to grind lead solder (used as a body filter) without dust masks because the lead dust was reduced below the OSHA limit. This had never been possible with conventional dust control systems. It should be noted that the quantity of water used is quite small $(0.8 \mathrm{gal} . / \mathrm{hr})$ so that there is no problem with mud or a wet floor. The wetted dust is deposited in the grinding area where it remains in large clumps and can be swept up for removal.

\footnotetext{
*The charged fog guns are manufactured and sold by the Ritten corporation,
} 40 Rittenhouse Place, Ardmore, Pennsylvania 19003, (215) 896-0900. 
Swing grinders are another example of a foundry system that is not amenable to conventional control by hoods because of the vertical suspension and the need for constant movement over the work. There have been some systems for providing water to the work by high pressure diffusion into the sides of the grinding wheel itself but the devices are quite expensive (some $\$ 20,000$ per installation) and the high pressure pumps require extensive maintenance.

In Figure 5 we show a system that can be attached to a conventional grinding wheel to provide a flow of finely divided water droplets to the wheel-work interface. The addition of the coanda effect lip shown in Figure 5 is an important part of the system since it insures that the water droplets will cling to the wheel in spite of the high centrifugal forces developed by the rotating wheel.

This system has been tested on a limited scale in the laboratory where there was every evidence of a significant reduction in fine "float dust". The operator noted that it was possible to grind at a much faster rate because of the cooling effect of the water flow.

Control of Dust During Transfer Operations

Sand and material transfer operations are frequent sources of dust that may be difficult to control with hoods. In Figure 6 we show an application to a dust dumping system from a fly ash hopper. The irritating dust normally blows directly into the plant through the door shown in Figure 6 (upper photograph). With the fog generator (Fogger II) "on" (lower photograph) the dust is completely suppressed.

Another problem in sand operation is "boil up" during dumping; this was simulated with the apparatus shown schematically in Figure 7 . An experiment to show how the system worked in practice resulted in the photographs of Figures 8 and 9. In Figure 8 the fog generator (Fogger I) was "off", in Figure 9 the fogger was "on" and the dust suppression was quite significant.

Other applications of the fogging system have been made on foundry shakeout. The results with foggers mounted over the shakeout area were very satisfactory but company policy forbade the taking of photographs. An application to a sander is shown in Figure 10; in one case (left photo) the system was "off" and there was significant dust blown about the room. In the right hand photograph the fogger was "on" and dust suppression was quite effective.

Bag splitting and dumping of silica powder is a frequent source of employee exposure. In Figure 11 we show data taken at a West coast foundry bag splitting room. This data was taken by company personnel and the reduction of dust exposure on the workman is of particular significance. We should note here that silica dust is known to be negatively charged (1) and the fog used in the experiment was positively charged so that rapid wetting and agglomeration would be expected to occur. 
Another silica experiment involved a sand car unloading system. The setup is shown schematically in Figure 12; the results, using positive fog, are shown in Figure 13. There was a significant reduction in respirable dust and an even larger reduction of silica. Once again this effect could have been anticipated from the knowledge that silica dust has a high negative charge.

Control of Carbonaceous Fume and Particulates

Fumes of this type are among the most persistant and dangerous in the foundry. In some cases the fumes are due to burn-off of coke used as a binder in mold formation. Other fumes are generated by the combustion of residual oil on metal scrap. Electrical techniques for the control of oil smoke will be discussed below. Here we shall note that charged fog is quite effective for the control of coke fume and particulates. Typical results are shown in Figures 14 and 15. In Figure 14 we show the effect of charged fog on particulates where a significant reduction in dust level was observed with (t) charged fog. The data of Figure 15 was taken to observe the effect of charged fog on benzene solubles. The analysis involved a low cost gas chromatograph that did not provide details about the absorbed materials but it was clear that the benzene solubles were significantly reduced by (+) charged fog.

Electrostatic control techniques for control of tarlike particulates have been another area of interest and here we might note that the usual tube and wire electrostatic precipitator (ESP) is quite effective. The major problem in the use of ESP systems has been the removal of the deposited material since it cannot be shaken off. We have been looking at the design of a tube and wire ESP with an inner rotating liner; as the tars are deposited on the liner it rotates beneath a scraper that picks up the tars and carries them, via an internal worm, to a storage container. The first application of this area of technology has been in the control of diesel engine particles. In Figure 16 we show some recent results with a small diesel engine exhausting into a tube and wire ESP. Not only was there a huge reduction in the fine particulate level, we also noted significant agglomeration as demonstrated by the upward trend of the "voltage on" curve for larger particulates. We feel that this is very encouraging since there should be no problem catching these larger particulates with a cyclone system.

This summarizes the work on dust control to date. We have continued with the development of larger fog guns designed to "throw" the fog some distance against the wind. Other systems for use in high temperatures or corrosive environments have been developed and are in application (2). The University and Aerovironment Incorporated of Pasadena, California are engaged in an Environmental Protection Agency support effort to adapt a spinning cup fog generator for use on a front loader and factory sweeper. At the moment the spinning cup fog thrower is undergoing Phase 1 testing at an off-campus site.

The spinning cup system has several advantages; there are no nozzles to clog even if dirty or contaminated water is used, the system is much simpler than conventional nozzles technology, and the spinning cup can vaporize 
water at any flow rate limited only by the power of the driving motor. A drawing of the current spinning fog thrower is shown in Figure 17 and a photograph of the system in action is shown in Figure 18 .

Control of Welding Smoke and Fume

Arc washing makes use of typical welding components using extra heavy currents to "wash" an arc over the surface and vaporize metal tags, risers, etc. The smoke and metal fume present a control problem because the operator moves around the work and the presence of cranes in the area makes it difficult to mount effective hoods. We have been looking into several techniques for the control of welding fume and smoke; the first was the application of charged fog. In this experiment we felt that it was necessary to not only show that the fog would reduce the pollution but that it did not interfere with the operator or the quality of the weld.

The experimental setup is shown in Figure 19. The welder was a Miller Electric Company, Model 35s, continuous wire unit. The operator was asked to work on cold rolled plate in a normal manner. He was questioned after the experiment about the quality of the weld and the effect, if any, of the charged fog on the working environment.

Typical results with the system are shown in Figure 20. There was a significant reduction in the solid particulates and the operator indicated that the charged fog did not affect his work or the quality of the weld. Turning back to Figure 20 , we might note that the reduction in particulates was encouraging, but there was little effect on the visible smoke and fume. This was expected as fume particulates are typically some 0.3 micrometers in diameter and are not easily caught by the much larger (20 micrometer) water droplets.

Other Smoke and Fume Control Systems

For general fume and smoke collection we have developed a new series of electrostatic "pushing" and "catching" apparatus that we refer to as an electrostatic fence. A schematic drawing of a system of this type is shown in Figure 21. For operation the needles are run at a high voltage to generate electrons which in turn produce oxygen negative ions. These ions pass through the grounded screen and charge dust particles; the dust particles are then "pushed" away by the electrostatic field of needles. A system of this type can be used to push dust or smoke toward a reversed system that is operated as a collector. A photograph of a system of this type operating on lead fume is shown in Figure 22. Lead fume is normally very difficult to collect with conventional electrostatic or baghouse systems. It is clear that the electrostatic fence can collect this material quite effectively.

Another application of electrostatic technology involves the use of large scale electrostatic screens to "push" smoke or fume from the point of generation to a collection system. An example of where this might be needed is shown in Figure 23 where the smoke from a copper converter goes up to the smelter roof rather than being caught in the hood positioned behind the 
converter. We would envision an electrostatic pusher system of the type shown in Figure 24 for this application. The screen would normally be rolled up like a window shade and would be released and turned on when needed. A small scale unit of this type is shown in action in Figure 25. In this case an aerosol of ammonium chloride was blown toward the system. In the upper figure the system is "off" and the dust, $3.3 \mathrm{~m} / \mathrm{sec}(650 \mathrm{ft} / \mathrm{min})$ goes right through. In the lower photograph the system is "on" at some 12,000 volts and the dust is blown backwards. We have developed the necessary technology to make flexible units of this type in almost any size; further application depends upon a commitment by the industry.

Hoods are popular systems for collecting dust, fume and smoke but in many cases they cannot be applied properly because of crane movements in the area. What is needed is a hood that can be collapsed (like a hoop skirt) or hoisted out of the way when the crane comes by. Another problem with hoods in foundries is the weight and bulk of the motor-fan systems needed to draw air into the hoods. It would be most advantageous to have a collapsible hood that can be "driven" by some method other than the usual mechanical fans.

In Figure 26 we show a demonstration model of an electrostatic hood. The system consists of a grounded outer shell and an inner high voltage element. In the photograph on the left the unit is "off" and the smoke passes through the side of the hood. In the photograph on the right the unit is "on" and the smoke is forced out the top. A hood of this type could easily be made of chain mail mesh and metal rings (like a hoop skirt) with an elephant trunk attached to the top to carry off the collected dust, smoke, etc. As the crane moves past, the hood would be collapsed or drawn up out of the way. Once again the design and application of large scale systems of this type is dependent on the response of the industry.

Still another example of an electrostatic system in action is shown in Figure 27. Here the objective was the condensation of vapors. vapors can be induced to condense and coagulate in a strong electrostatic field gradient and we suggest that this technique can be used to remove a variety of oil smokes and water droplets from a gas stream. In Figure 27 the vapor (from heated mineral oil) is coming from the left; in the upper photograph the field is off and the smoke simply moves out of the system. In the lower photograph the field is on at $-12 \mathrm{kV}$ and the vapor is condensed and deposited inside the collector. We have obtained similar results with a variety of other vapors.

\section{Electrostatic Demisting Technology}

Many foundry pollutants are composed of steam or water vapor mixed with various gases or particulates. These mists are difficult to remove from air by conventional impaction demisters especially when fan power to accelerate the gas to high velocity is limited. We have been investigating the application of electrostatic techniques for demisting with the system shown schematically in Figure 28. In a system of this type the mist droplets are forced to pass through a strong electrostatic field. The high dipole moment of the water droplets results in their being drawn to 
the needles where coalescence takes place. The coalesced droplets are then forced to the wall by the electrostatic field. The system is shown "off" and "on" in Figure 29 with the mist coming from the right. It is clear that with the field "on" the moisture is totally coalesced. Similar results have been obtained with ammonium chloride particles. It is important to note that this electrostatic coalescing system operates with very low power levels and increases in efficiency as the flow velocity decreases. This is in contrast to the operation of a typical impaction demister where efficiency decreases as the flow velocity drops.

\section{CHARGED FOG TECHNIQUES FOR CONTROL OF SULFUR DIOXIDE}

Control of $\mathrm{SO}_{2}$ has proved to be one of the most difficult and expensive problems for smelters, foundries and power plants. Present EPA technology calls for the injection of calcium carbonate water mixtures to form calcium sulfate slurries that must ultimately be disposed of by burial. The slurry technique has other problems beyond the mere cost of the materials, in that the injection results in a significant reduction in gas temperature as the water evaporates and the dry $\mathrm{CaCO}_{3}$ is heated. This in turn can lead to a reduction in stack draft and plume rise which may be the cause of furthe $r$ EPA citations or loss in plant efficiency.

We have been investigating the use of charged water fog for the simultaneous reduction of $\mathrm{SO}_{2}$ and fly ash in a simulated stack environment. We suggest that the $\mathrm{SO}_{2}$ will be absorbed by the water droplets and that the water droplets will induce the fly ash to agglomerate thereby removing both the fly ash and the $\mathrm{SO}_{2}$ from the environment. If the quantity of water is small the loss of sensible heat from the flue gases will be quite low and the agglomerated fly ash particles will be dry so that disposal can take place without any hazard to groundwater supplies.

In this connection it is important to note that the reaction of $\mathrm{SO}_{2}$ and water is not limited by the usual solubility relationships; experiments at Georgia Tech have indicated that when charged water droplets are present the absorption of $\mathrm{SO}_{2}$ is significantly enhanced (3). There is still some question as to the mechanism involved here but the authors of Reference 3 suggest that when a droplet is electrostatically charged the surface is altered and the number of absorption sites is greatly increased. Further research is needed to verify this concept.

The application of this technology might have important consequences for the foundry, power and smelter industries and for this reason we have performed experiments in the Anaconda supported stack simulation facility shown in Figure 30. Typical results with charged fog and copper smelter fly ash are shown in Figure 31 where we have plotted the reduction in $\mathrm{SO}_{2}$ and fly ash as a function of operating temperature. It is.clear that there is a significant reduction in both pollutants until the temperature exceeds $250^{\circ} \mathrm{C}$. At high temperatures there is a loss of water, by evaporation, before the droplets can contact the $\mathrm{SO}_{2}$ and there may well be some release of $\mathrm{SO}_{2}$ from the fly ash particles since they were supplied by a copper smelter. 
It would seem that this technique offers the opportunity to reduce both $\mathrm{SO}_{2}$ and fly ash without the costly technology associated with the $\mathrm{CaCO}_{3}$ system.

\section{DEVELOPMENT OF LOW COST DUST TESTING APPARATUS FOR FOUNDRY APPLICATIONS}

One of the problems in industrial dust control is the lack of small, low cost, instrumentation that can be given to environmental health personnel for in-plant testing. In most cases where filter cassettes are used it is necessary to send them to the laboratory for dessication and weighing before the data can be generated. This makes it difficult to test new dust control systems where on-line information would allow for on-the-spot adjustments.

At the University we have been developing a hand held optical system designed to accept the filtex cassettes normally used for dust testing. Typical operation involves putting a clean cassette into the optical reader and setting the battery driven lamp so that the scale reads $100 \%$. A dust sample is taken and the used cassette is placed in the reader to determine how much dust is normally present. Then the dust control system is activated and another cassette is exposed and inserted into the reader; the difference between the second and third readings is a direct measure of the reduction in dust level. The cassettes can still be sent to the laboratory for the usual drying and weighing procedures to serve as a check on the optical system; we have found that the correlation between the two techniques is very good. If necessary a calibration curve can be provided to convert the optical dust density readings into typical $\mathrm{mg} / \mathrm{m}^{3}$ dust densities. In Figure 32 we show typical test results where a number of dusts were tested for their optical absorption. The general response was quite linear suggesting that the optical dust tester might find a wide use in industry. The system is being tested in selected industries at the present time. We anticipate a retail sale price of under $\$ 200$. This cost will include a simple hand operated pump to draw dust laden air through the cassette. Alternatively the usual battery driven pump, supplied for personnel sampling, could be used.

\section{SUMMARY}

We suggest that modern technology can be used to significantly reduce the personnel hazard in the foundry industry. In some cases, e.g., charged fog, the technology has already been demonstrated and is in daily use. Other techniques have not emerged from the laboratory environment and need further development. The transfer of these new systems from the university to industry will require not only the financial support of the foundry industry but patience and cooperation as the new devices go through the usual "teething problems".

\section{REFERENCES}

1. Hoenig, S. A., "Use of Electrostatically Charged Fog for Control of Fugitive Dust Emissions", EPA-600-7-77-131, November 1977. Available from NTIS, springfield, Virginia 22161. 
2. Hoenig, S. A., "Fugitive and Fine Particle Control Using Electrostatically Charged Fog", EPA-600-7-79-078, March 1979. Available from NTIS, Springfield, Virginia 22161.

3. Matteson, M. J., Gardenia, P. J., "Mass Transfer of Sulfur Dioxide to Growing Droplets", Env. Sci. and Tech., 8, No. 1, pp. 50-55, 1974.

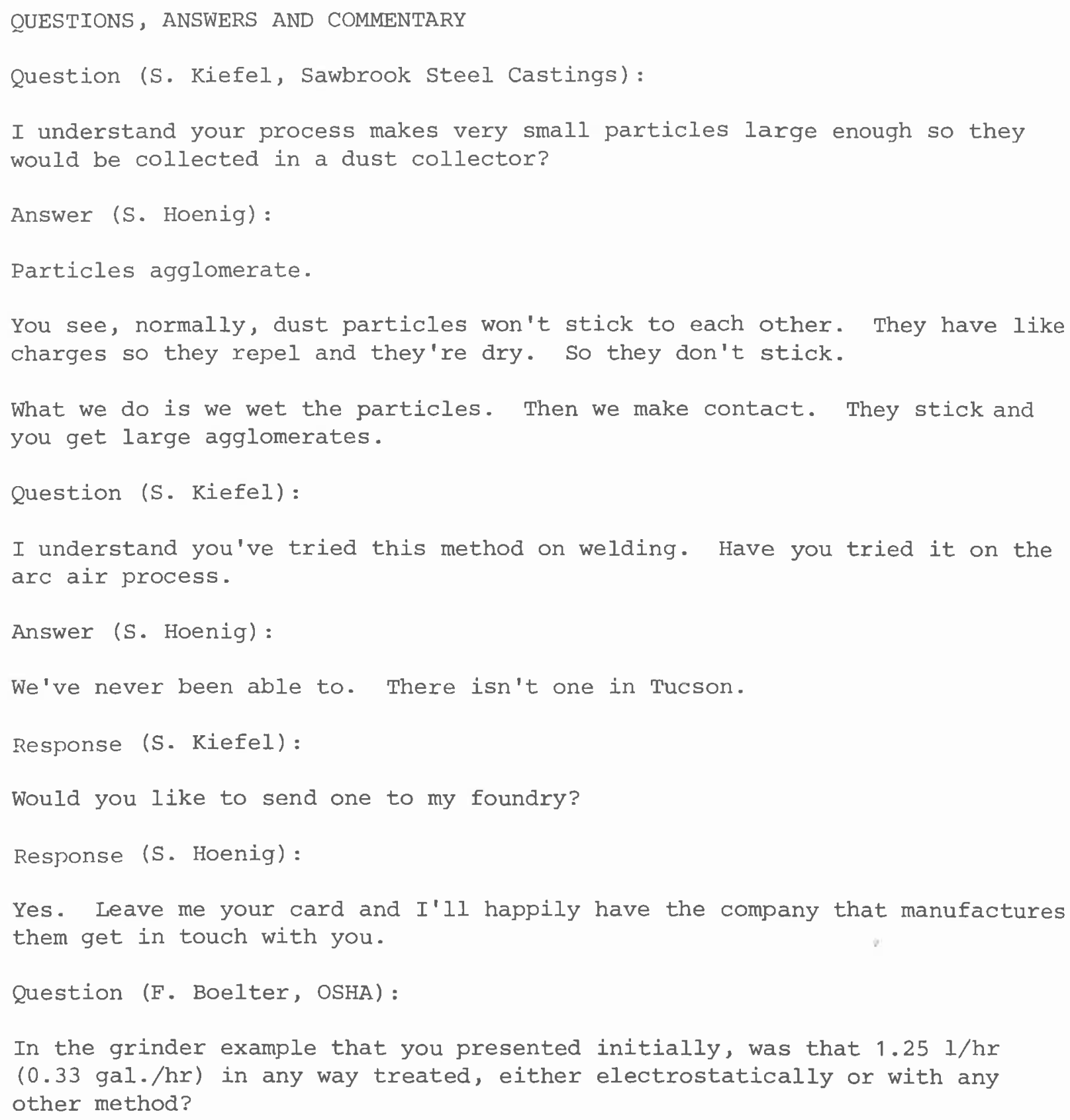


Answer (S. Hoenig):

No. In that experiment there was no electrostatic effect.

Question (F. Boelter):

In some foundries that I've visited, that are presently using the fogging devices in the pit areas to control the respirable dust. I've discussed with them the idea of using that particular grinder. However, they voiced tremendous concern about rusting problems that might occur.

Answer (S. Hoenig):

I think the answer is that they have to get used to the idea that a lot of water is not being used.

We went through this with a cement company and finally I said "why don't you put a bag of cement out and we'll fog in the area. If the cement turns to concrete, I'll buy it from you". That demonstration finally convinced them.

The method doesn't use a lot of water. If it rains there is more humidity in the plant coming in with the incoming air than will ever be gotten from the fog guns or the grinder.

Comment (F. Boelter):

I think Stan Kiefel's suggestion is a good idea because the arc air process involves compressed air, which many times has some water in it, to begin with. Perhaps it could be treated in some fashion.

Question (G. Mosher, American Foundrymens Society):

In your work with your fogger and the coke oven emissions do you analyze your samples for polynuclear aromatics? And, if so, were they reduced?

Answer (S. Hoenig):

The only instrument we had available to us was a small gas chromatograph, which just handled the benzene. We've just never had access to a better gas chromatograph for that experiment.

Question (H. Scarton, Rensselaer Polytechnic Institute):

Can you comment on the cutting efficiency of the grinding?

Answer (S. Hoenig):

One thing that was commented on at the automobile company, and has also been commented at local foundries, is that they couldn't burn the work. No matter how hard they leaned on that grinder, they couldn't burn the work. When grinding is done dry, burning is quite easy. 
Question (H. Scarton):

Often times arc air metal gouging is done on hot castings for metallurgical reasons. Might the fog tend to cool the casting or does it represent an insufficient quantity of moisture to cool the casting?

Answer (S. Hoenig):

We were concerned about that on welding. Our observations were that the fog evaporated completely before it ever got to the work.

I think that's one thing we have to restrain people on. They want to turn the fog gun up all the way and that's just the wrong way to go at it. It is better to start with only as much as necessary.

Question (G. Cusamano, Aer-X-Dust Corporation):

Are the commercially available fog guns switchable as far as polarity goes? If they are used in a situation where there is a mixture of liquid hydrocarbons and particulate all the way down to a very fine particle size range, and if it is not certain which polarity will produce the best results, it would be helpful to switch back and forth.

Answer (S. Hoenig):

The foggers that are commercially available are switchable. On the large spinning fog thrower we just have a fixed power supply, but that could be switched too.

Comment (C. Anderson, DOFASCO, Canada):

At this time of year we're worried about freezing.

Response (S. Hoenig):

At steep Rock, near sudbury, they wanted to run with ethylene glycol. We convinced them that was a bad idea; ethylene glycol is quite toxic in vapor form. Instead they're running with glycerine. Their comment was: it really sticks. It's a little expensive, but glycerine is the only chemical that I can think of that is good antifreeze and is approved for all rectal, dermal, and internal applications. There aren't many chemicals you can say that about these days. 


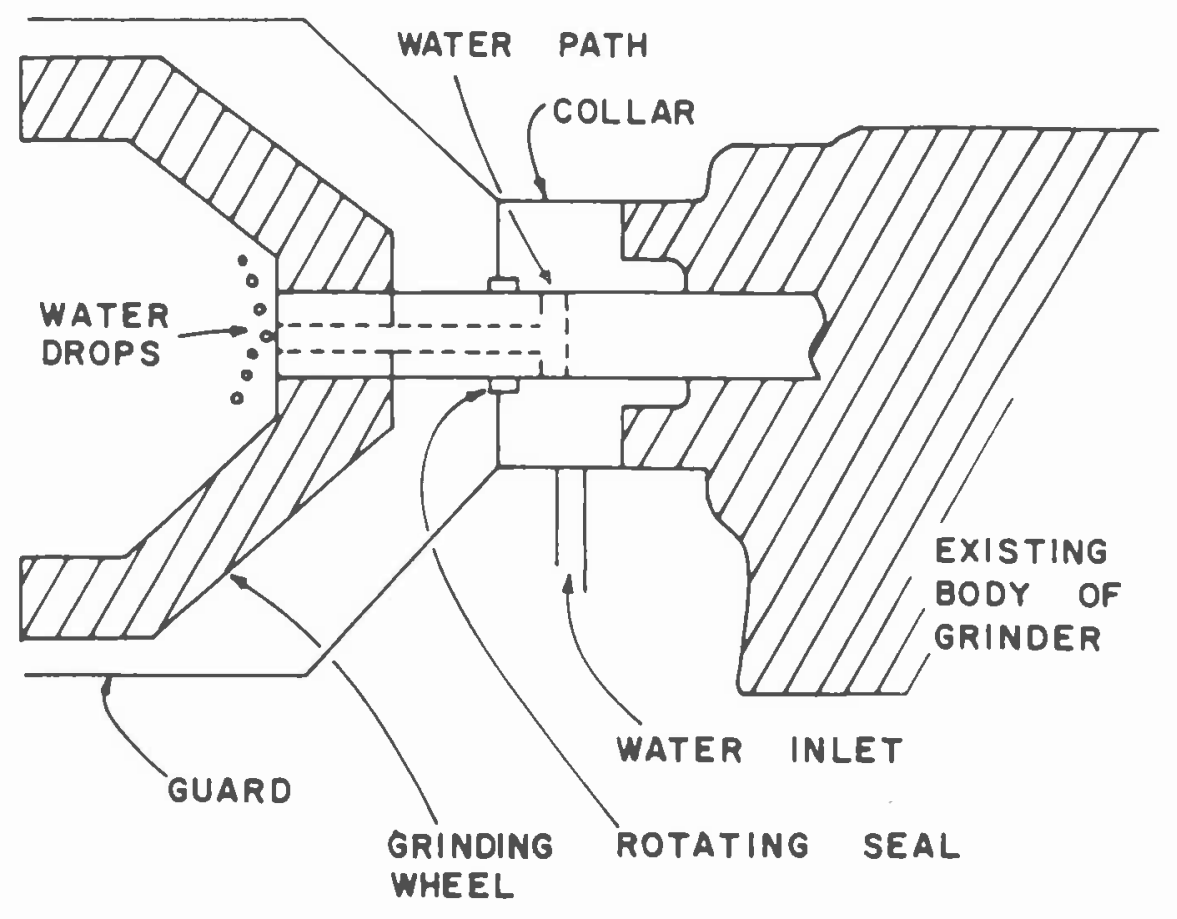

Figure 1. Modification of typical hand cup grinder to provide for dust control by water addition.

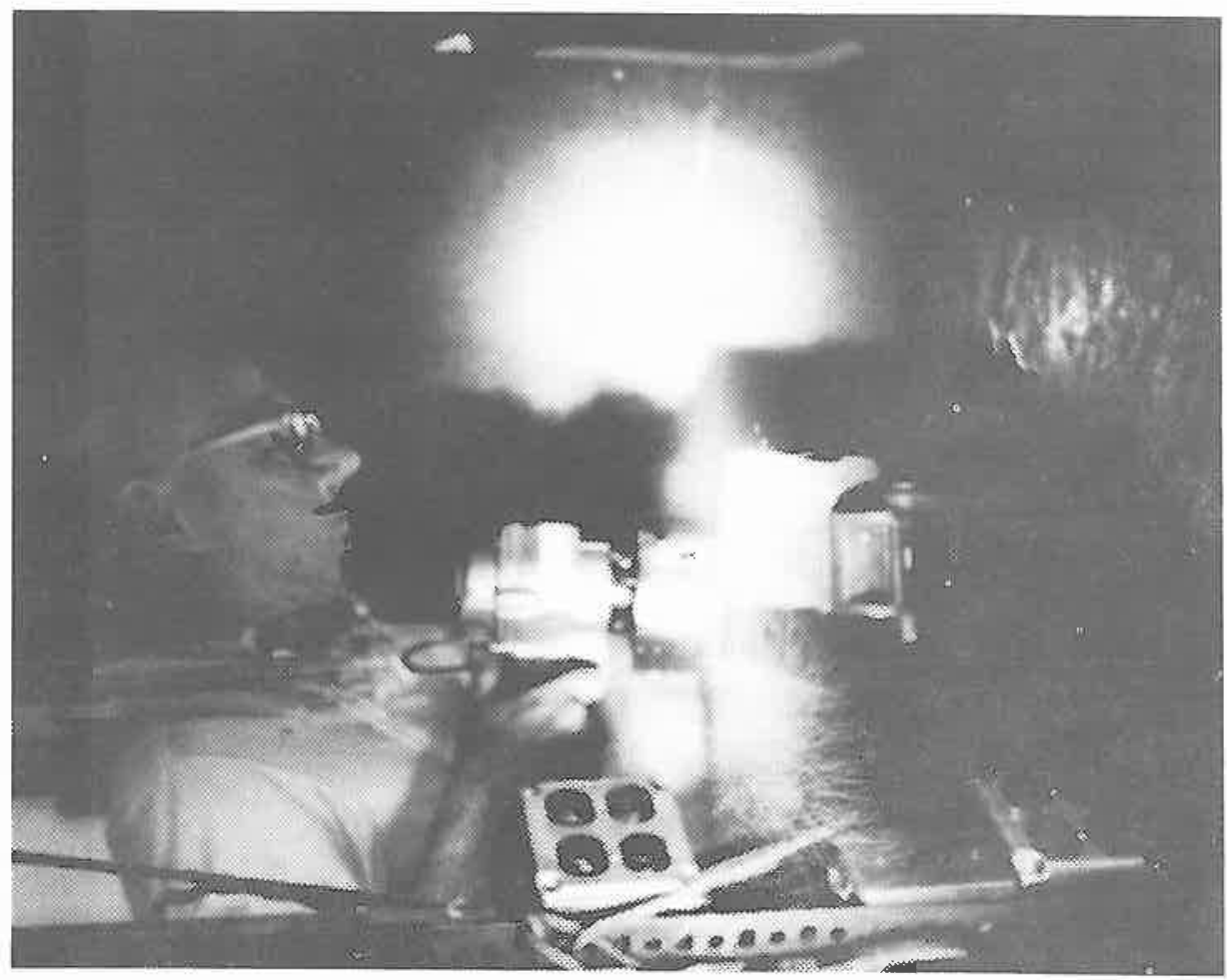

Figure 2. Dust controlled cup grinder in operation. 


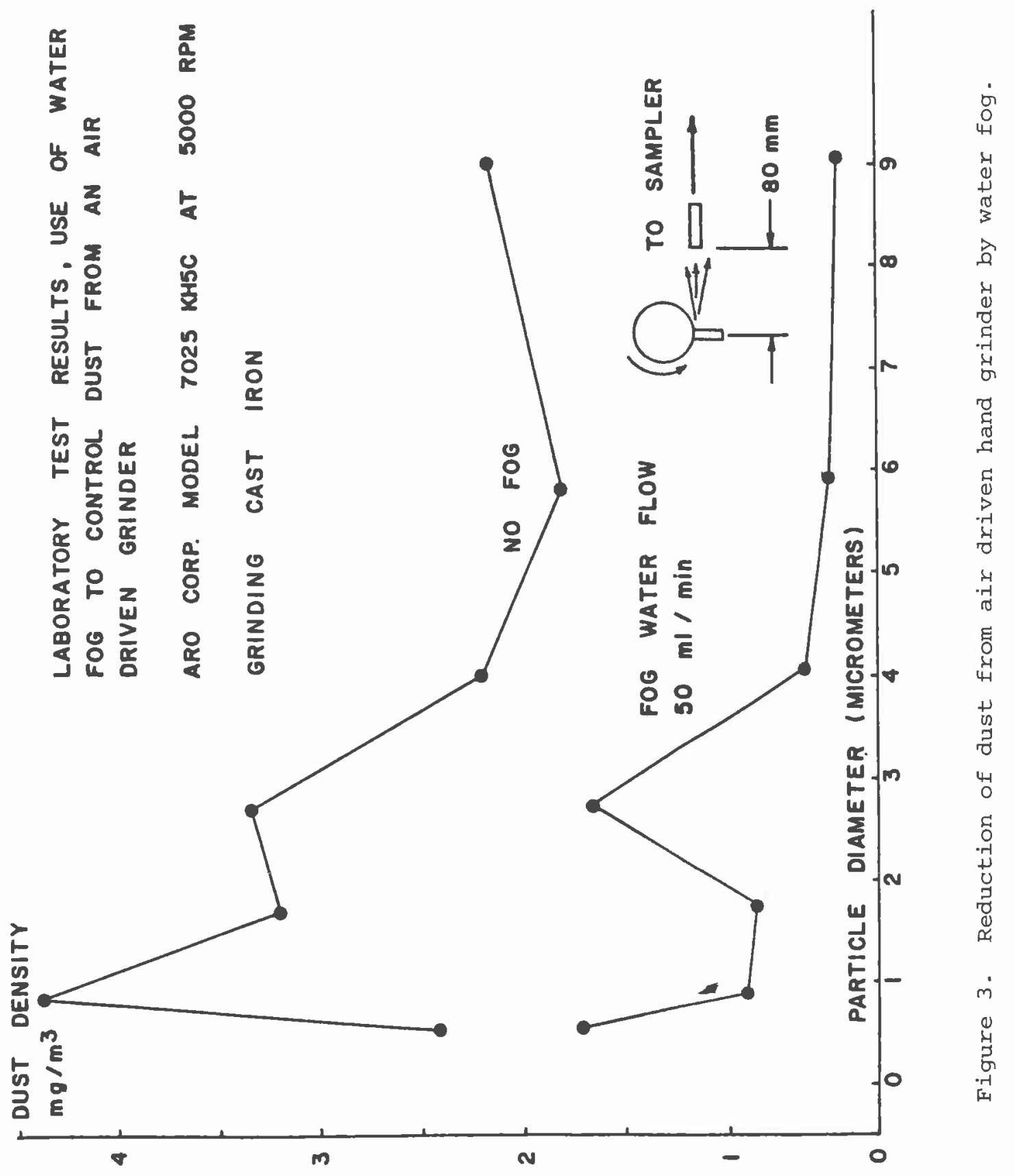




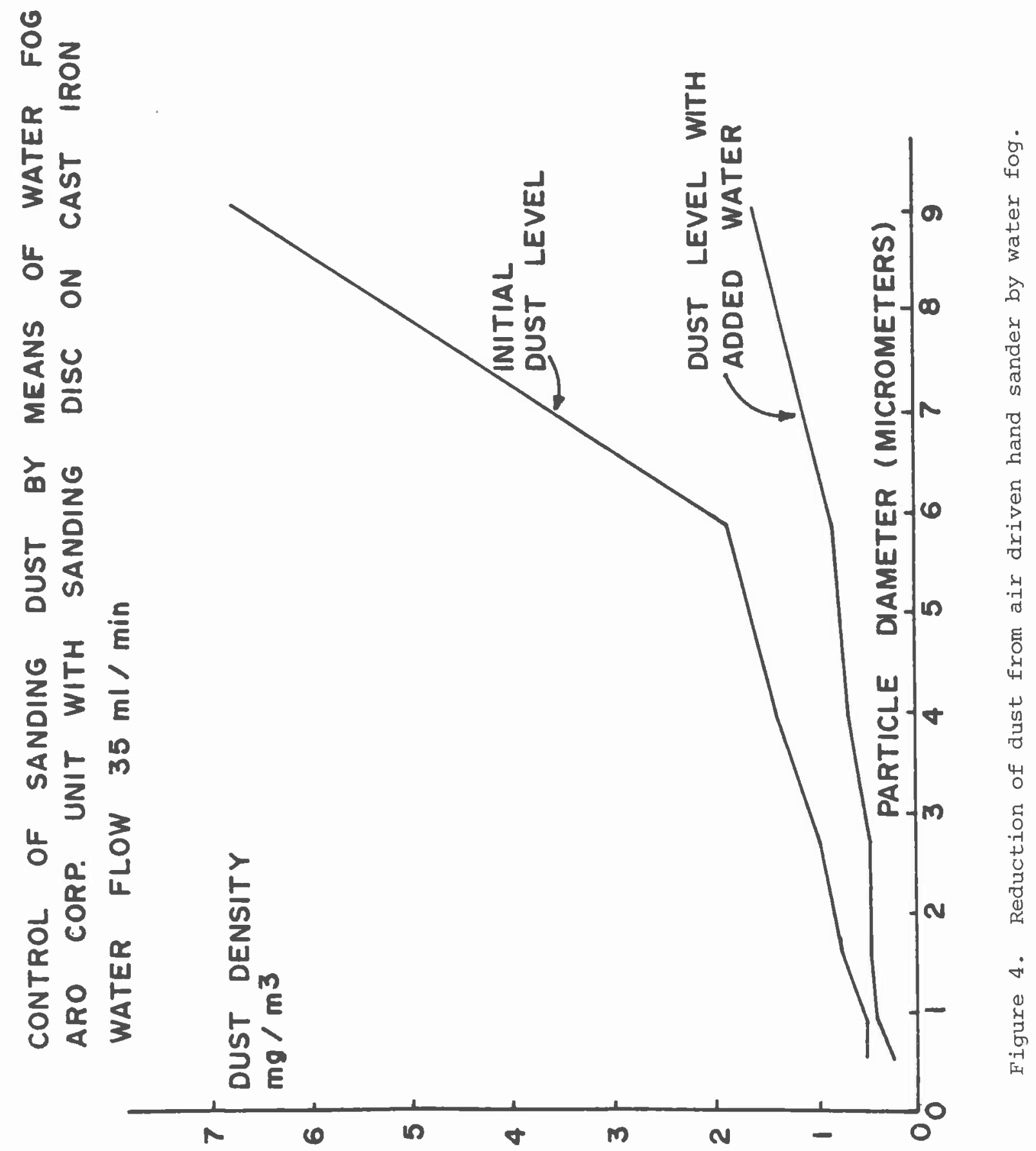




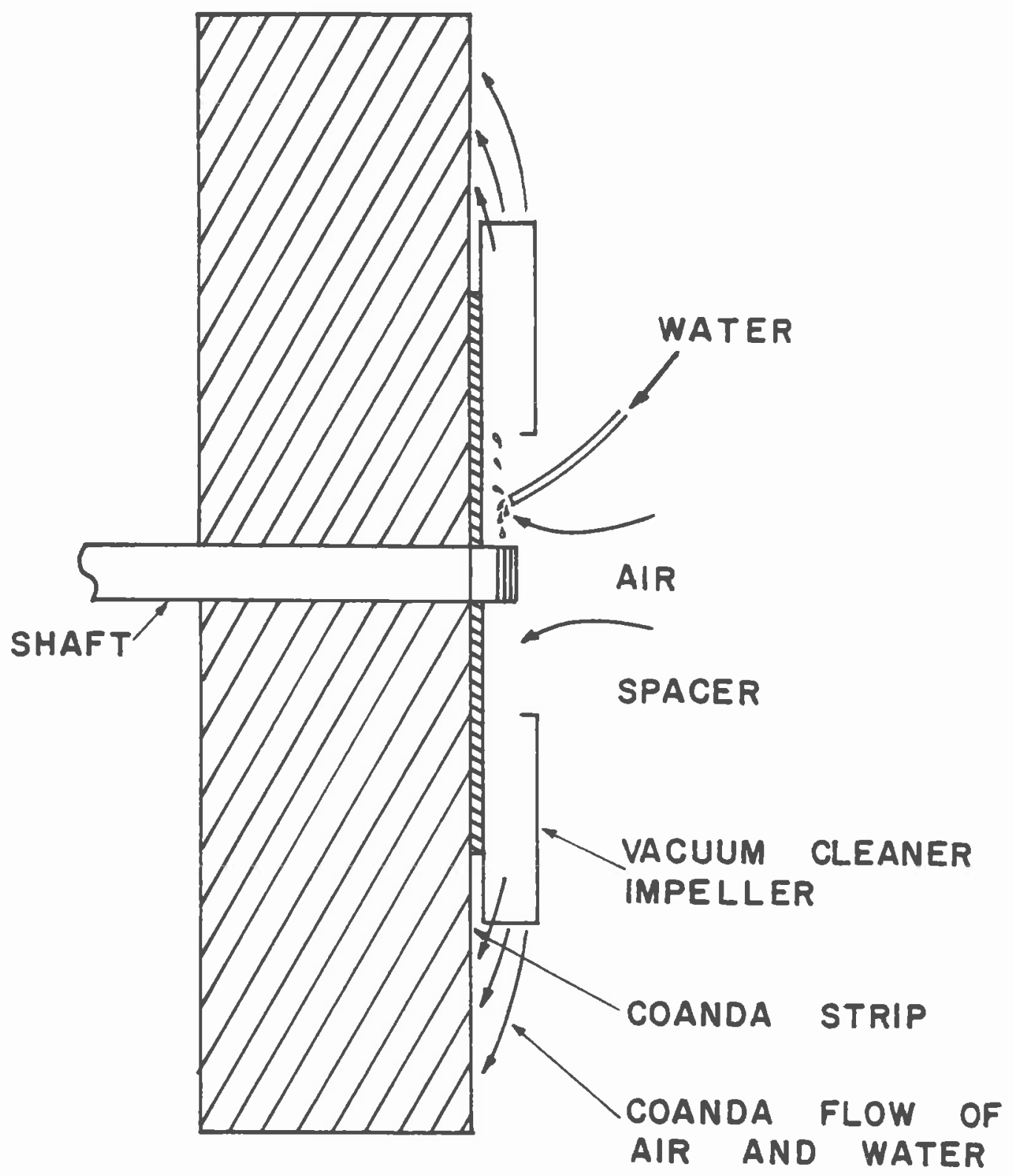

Figure 5. Schematic drawing of dust control system for large grinding wheel. 

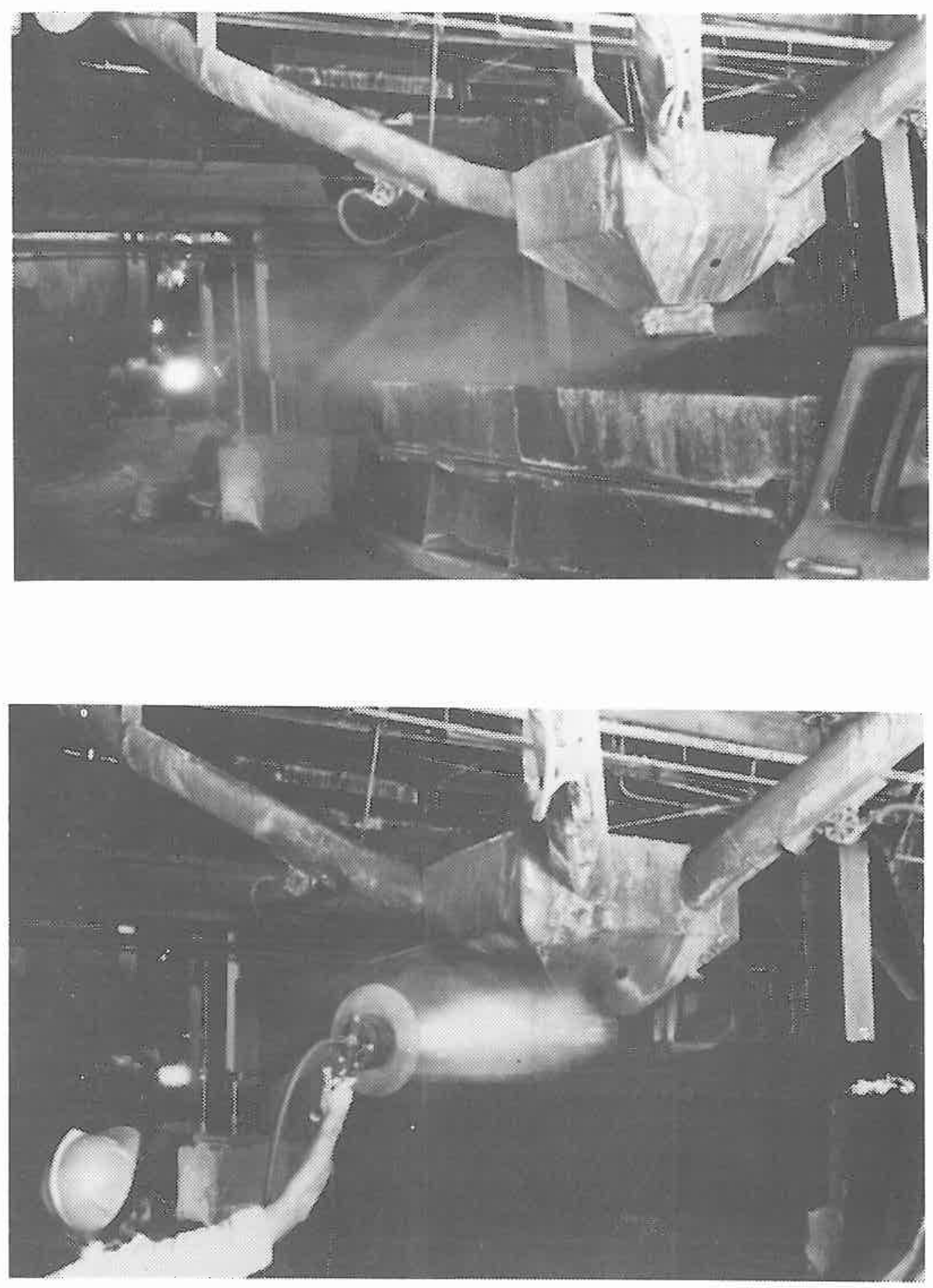

Figure 6. Control of hopper dumping with charged fog. 


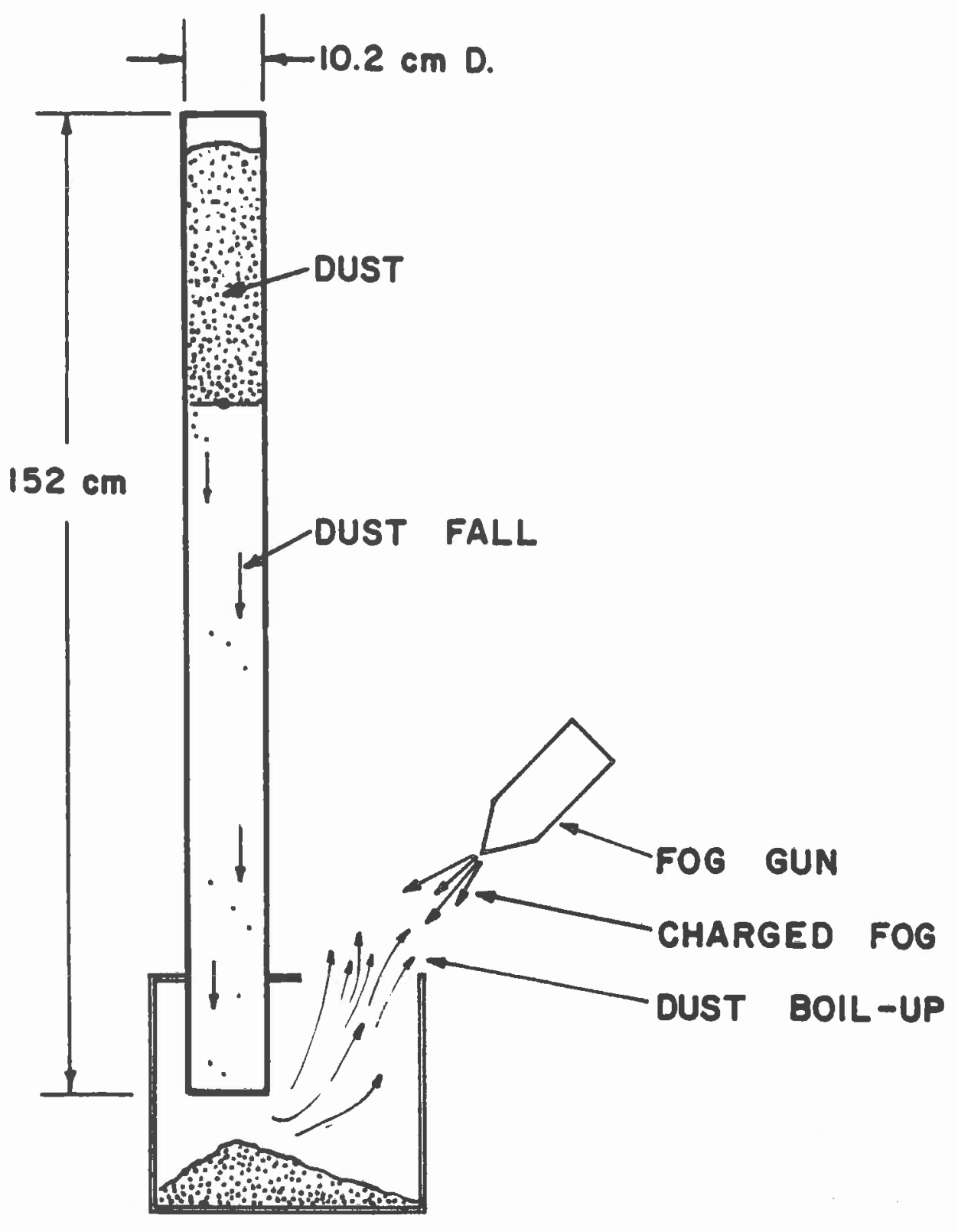

Figure 7. Application of charged fog to the control of dust boil-up. 


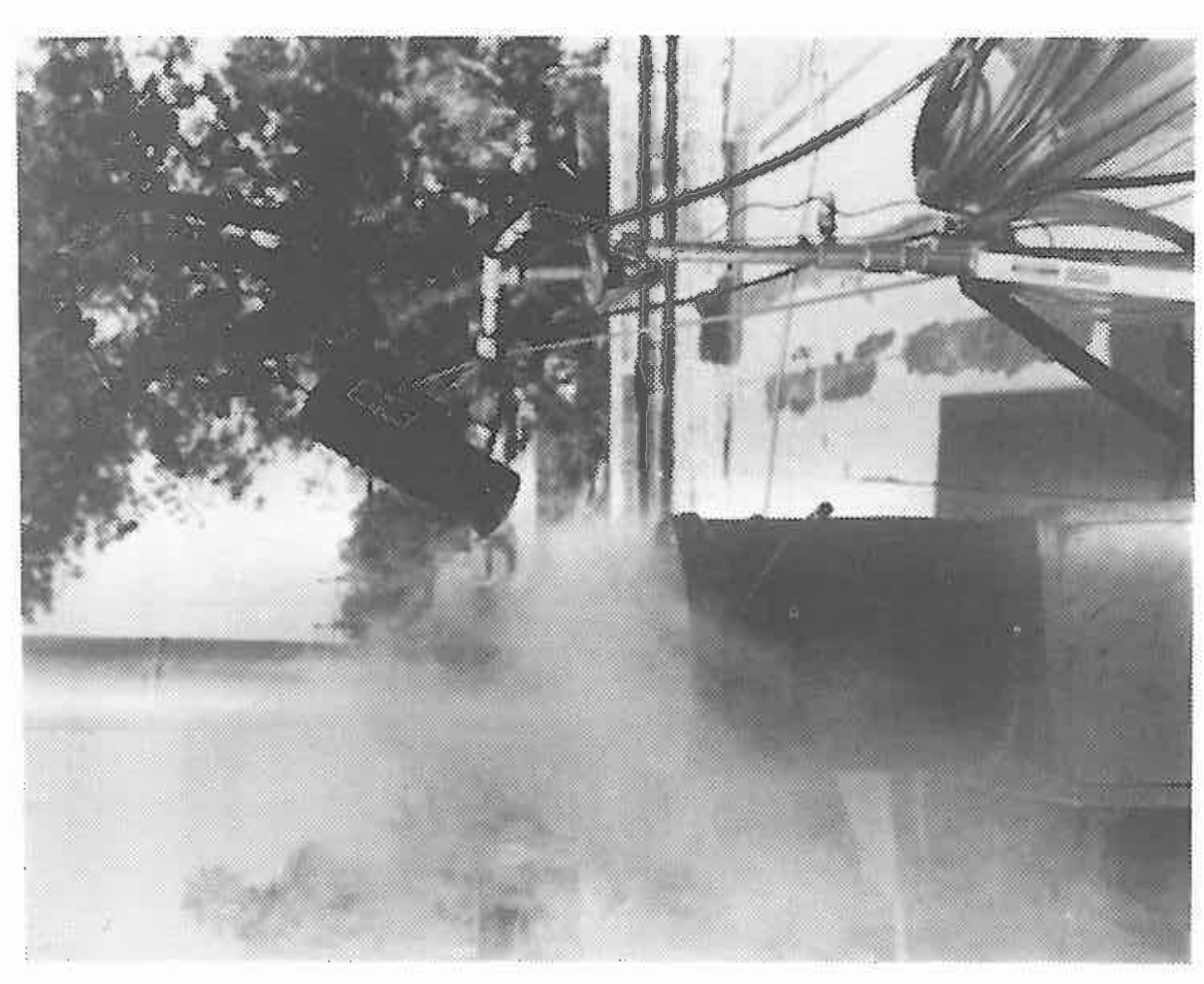

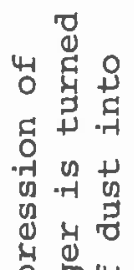

م

in 4

岁造营

प द व

茨出

त

역 茎

ग

岱整考

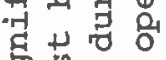

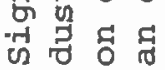

a

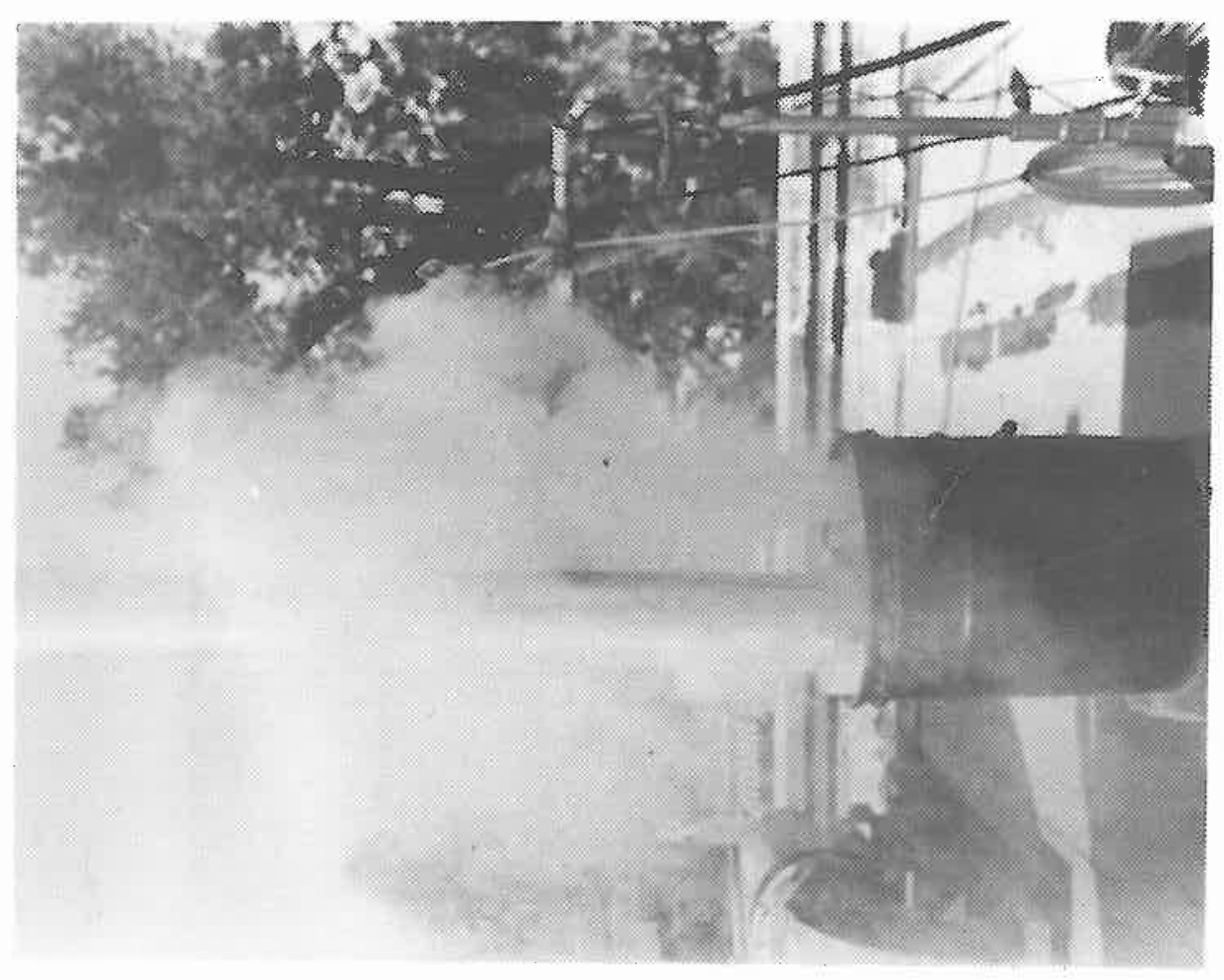

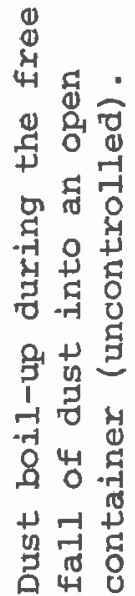

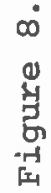




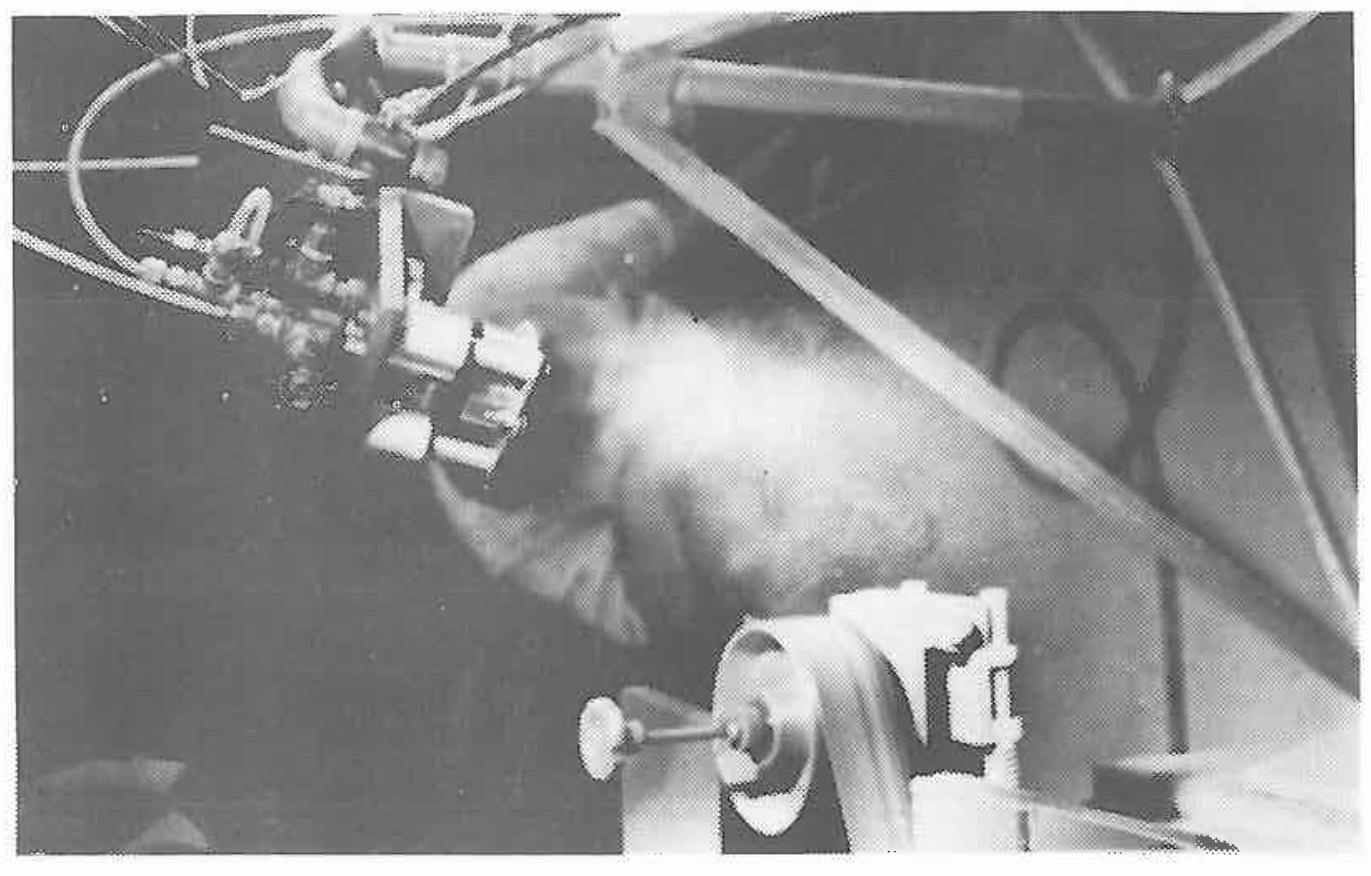

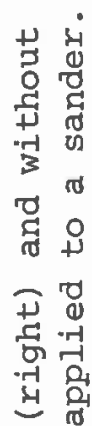

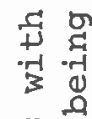

뎡 잉

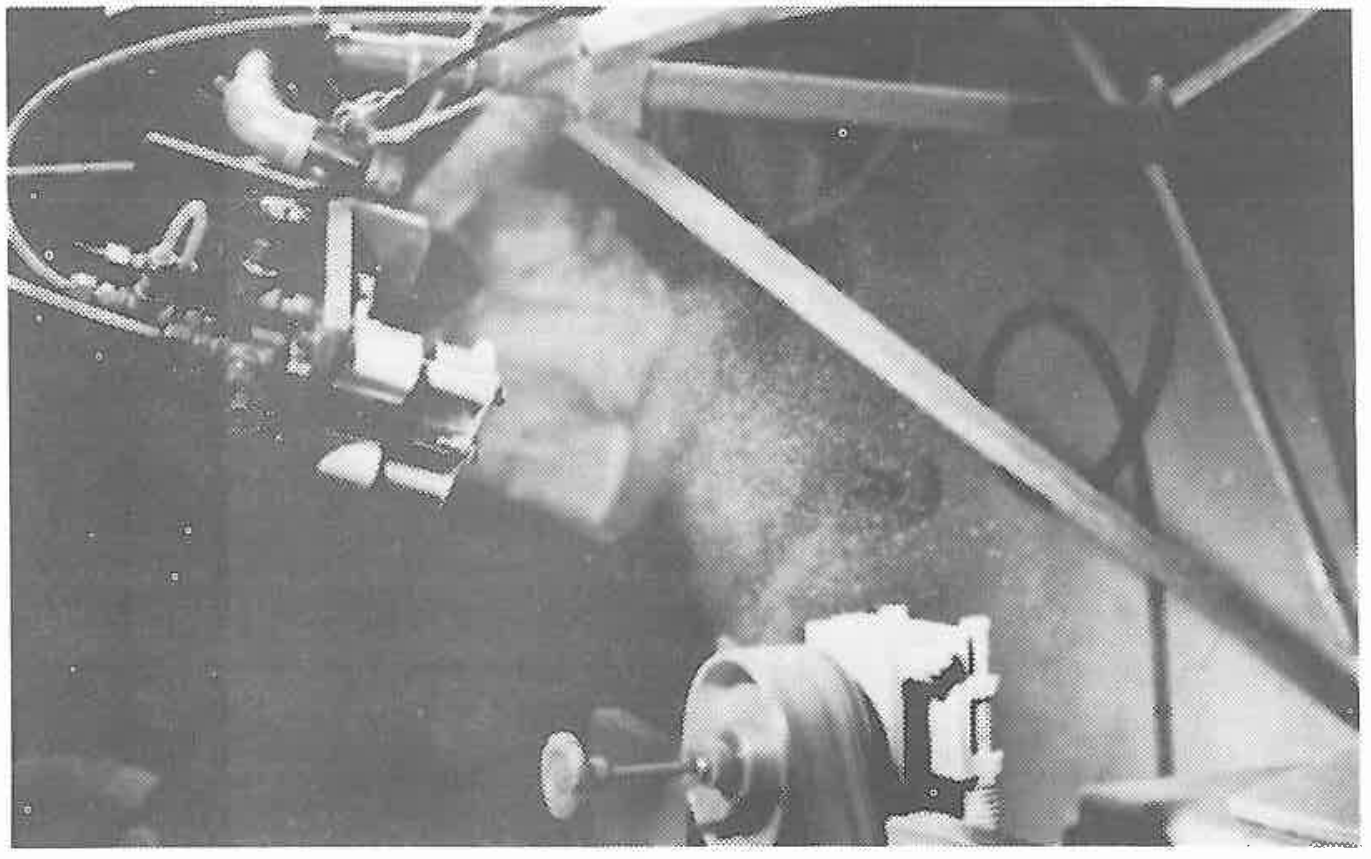

त्र

4

오

욤당

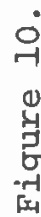




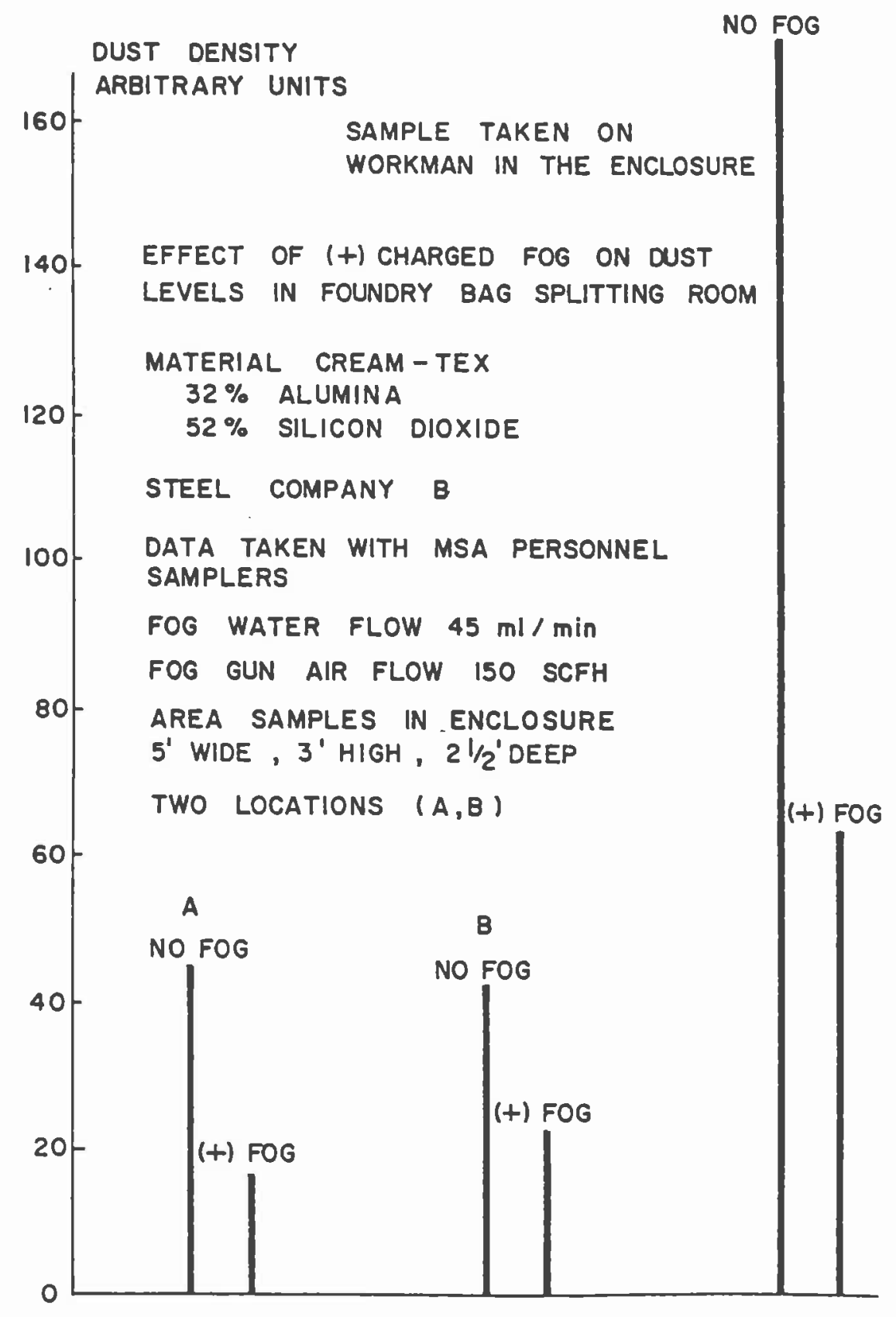

Figure 11. Bag splitting room dust density with and without charged fog. 

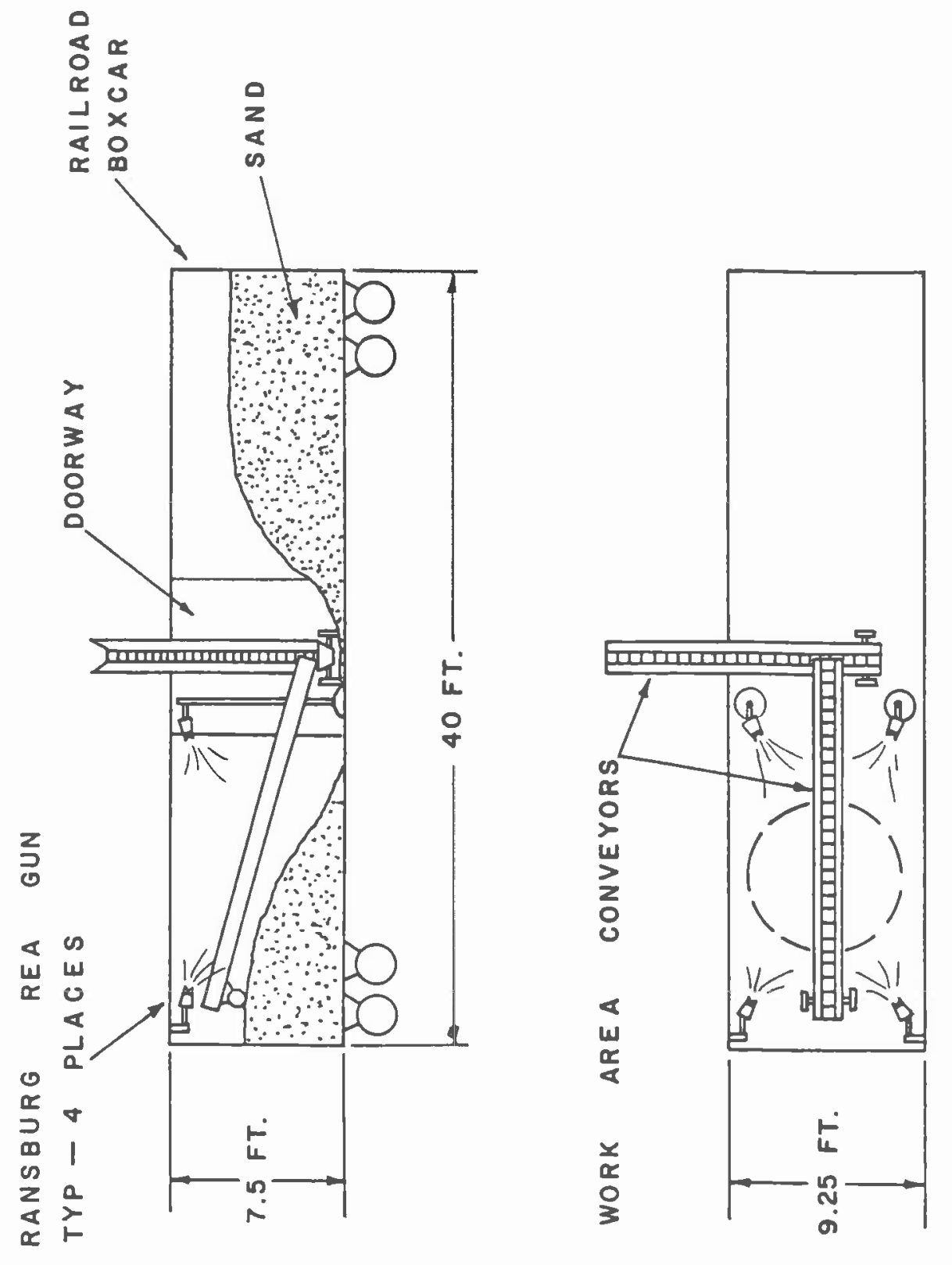

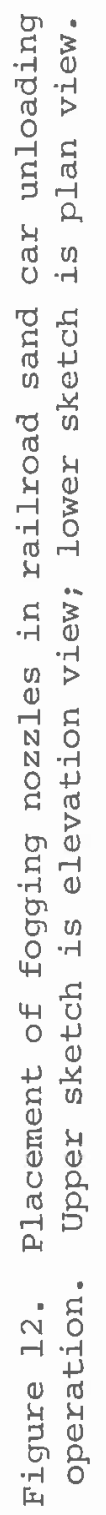




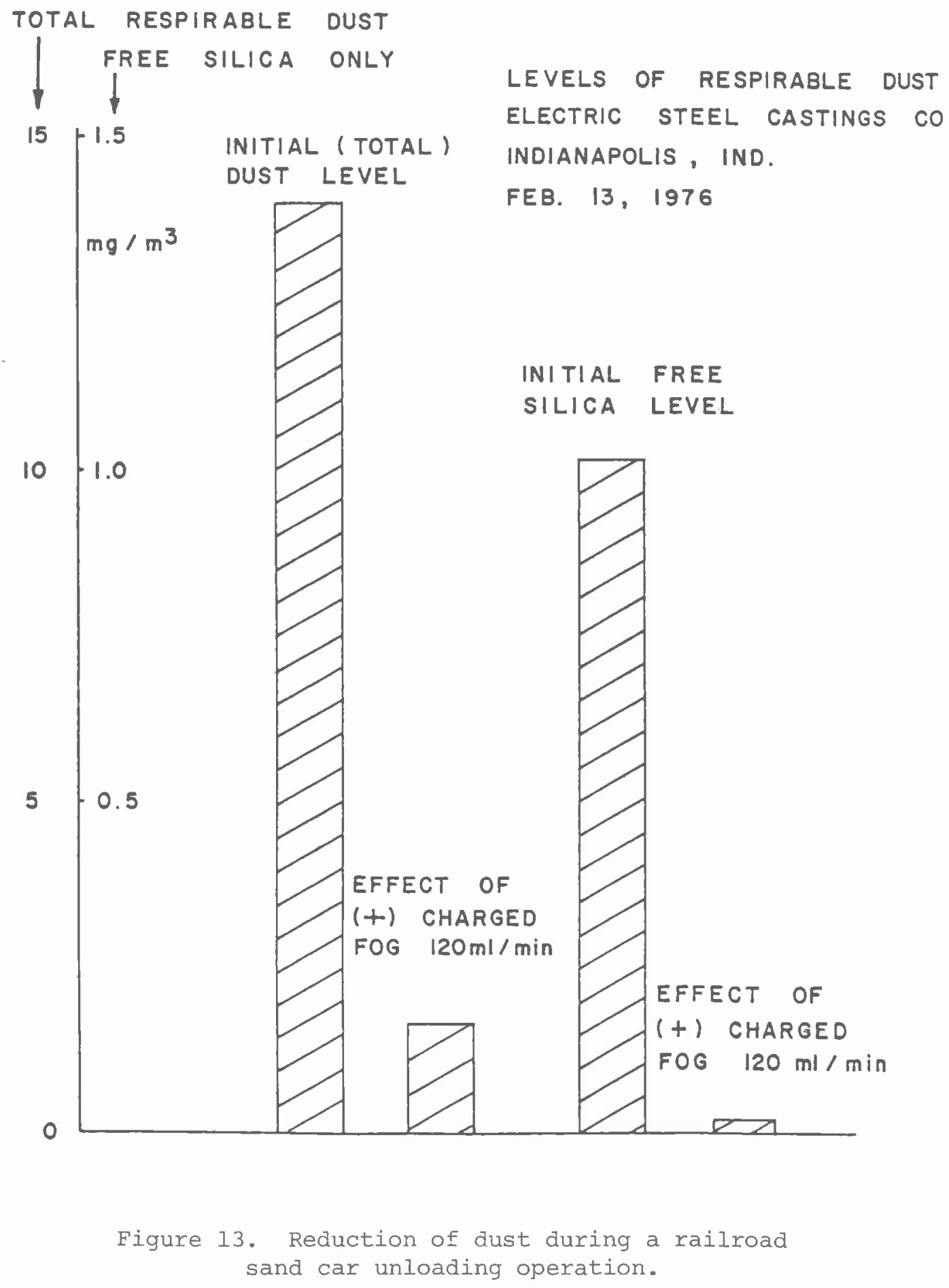




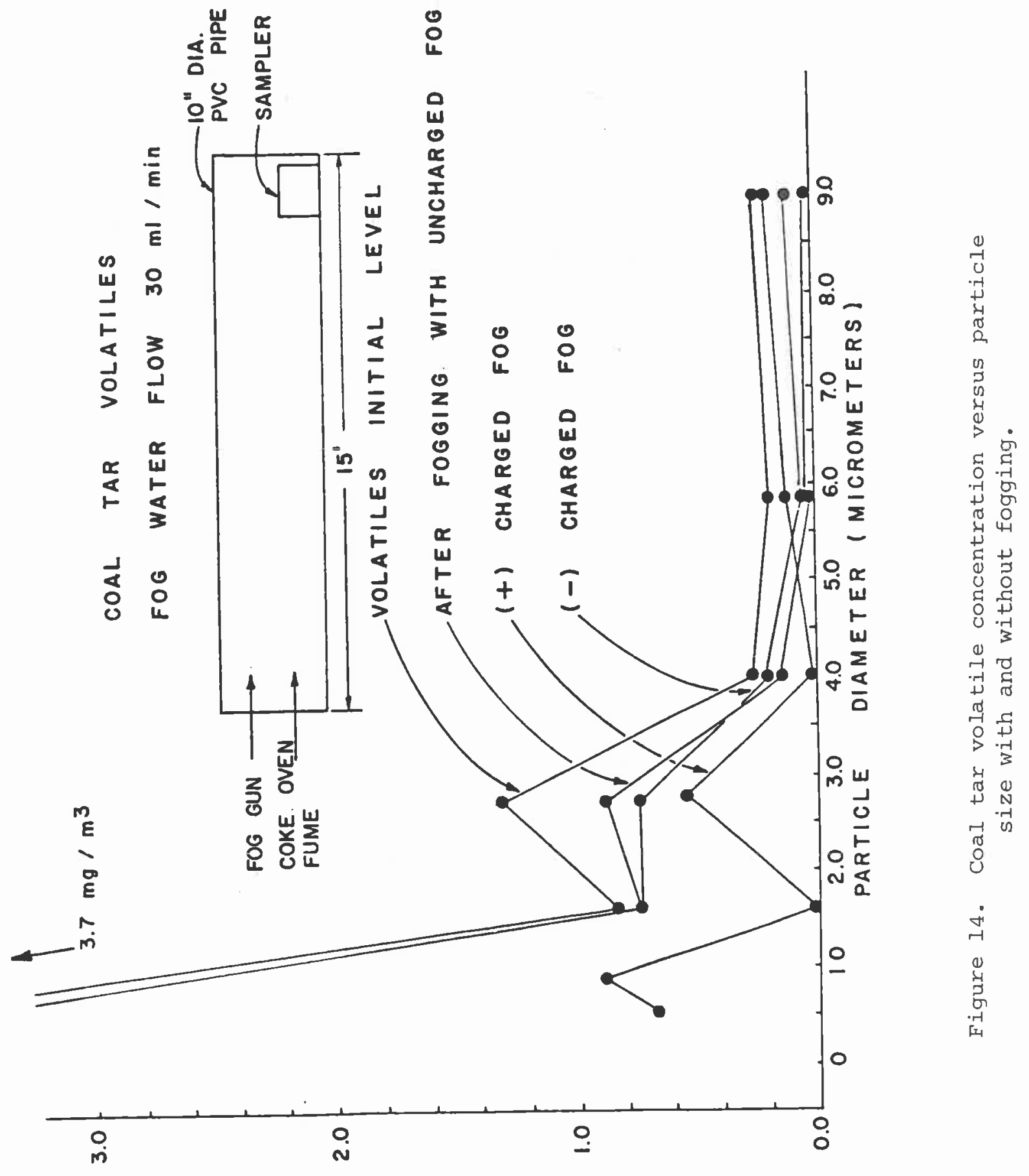




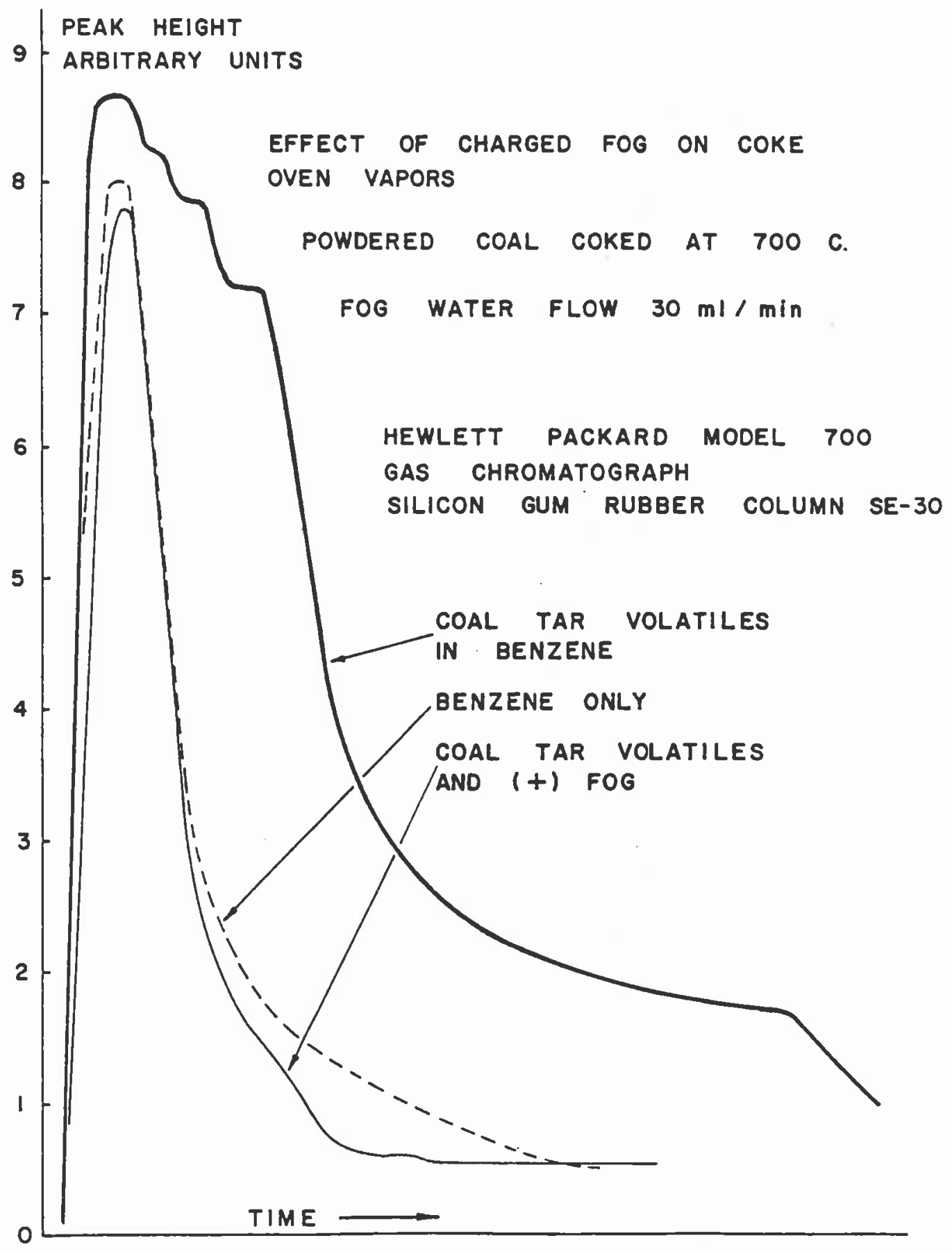

Figure 15. Effect of charged fog on coke oven emissions. 
LABORATORY EXPERIMENTS CONTROL OF DIESEL EXHAUST PARTICULATES BY MEANS OF ELECTROSTATIC TECHNIQUES, AIRFLOW VELOCITY 200 FPM $(60.8 \mathrm{~m} / \mathrm{min})$, CORONA VOLTAGE $-20,000 \mathrm{~V}$.

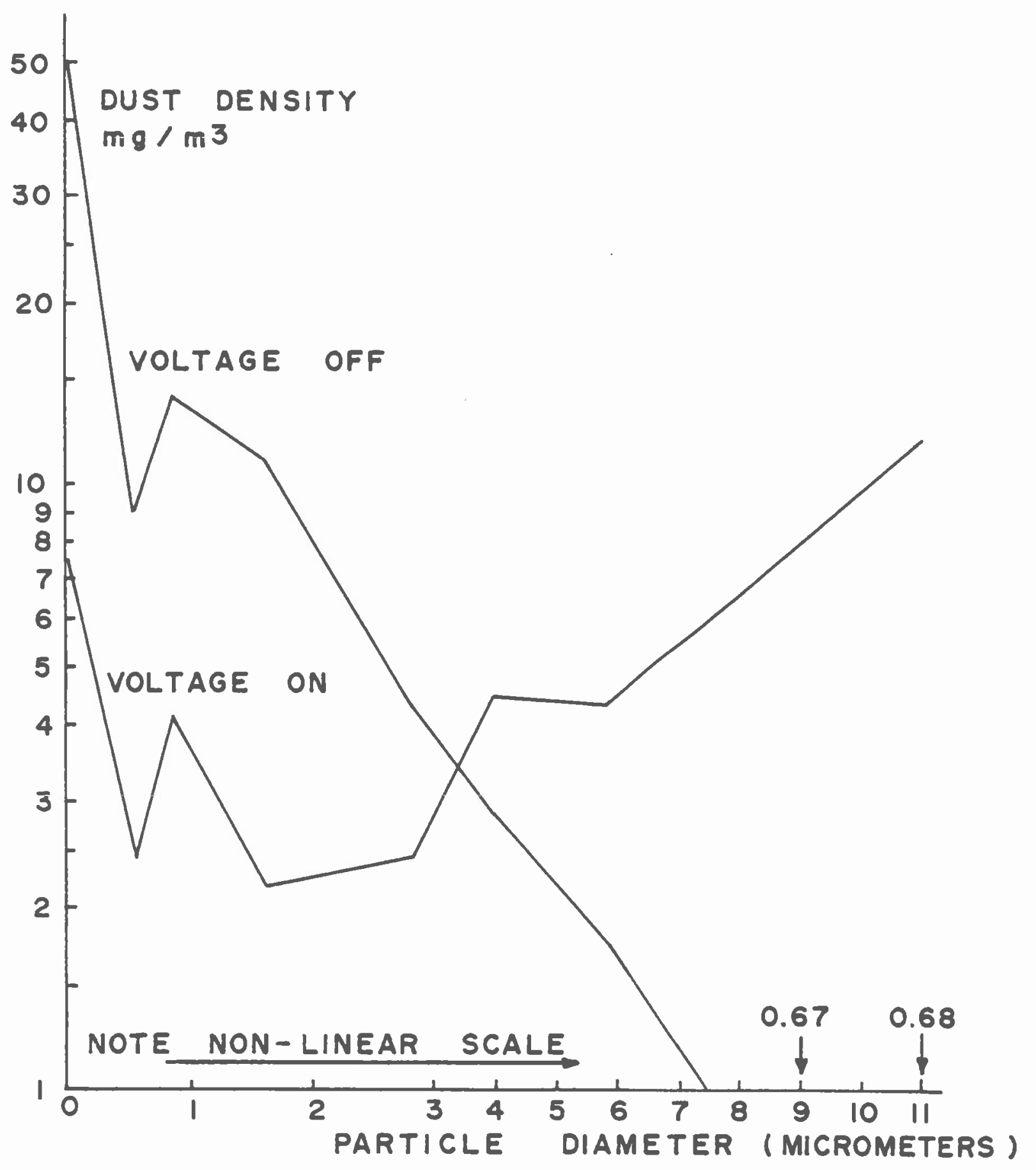

Figure 16. Control of diesel particulate through electrostatic techniques. 


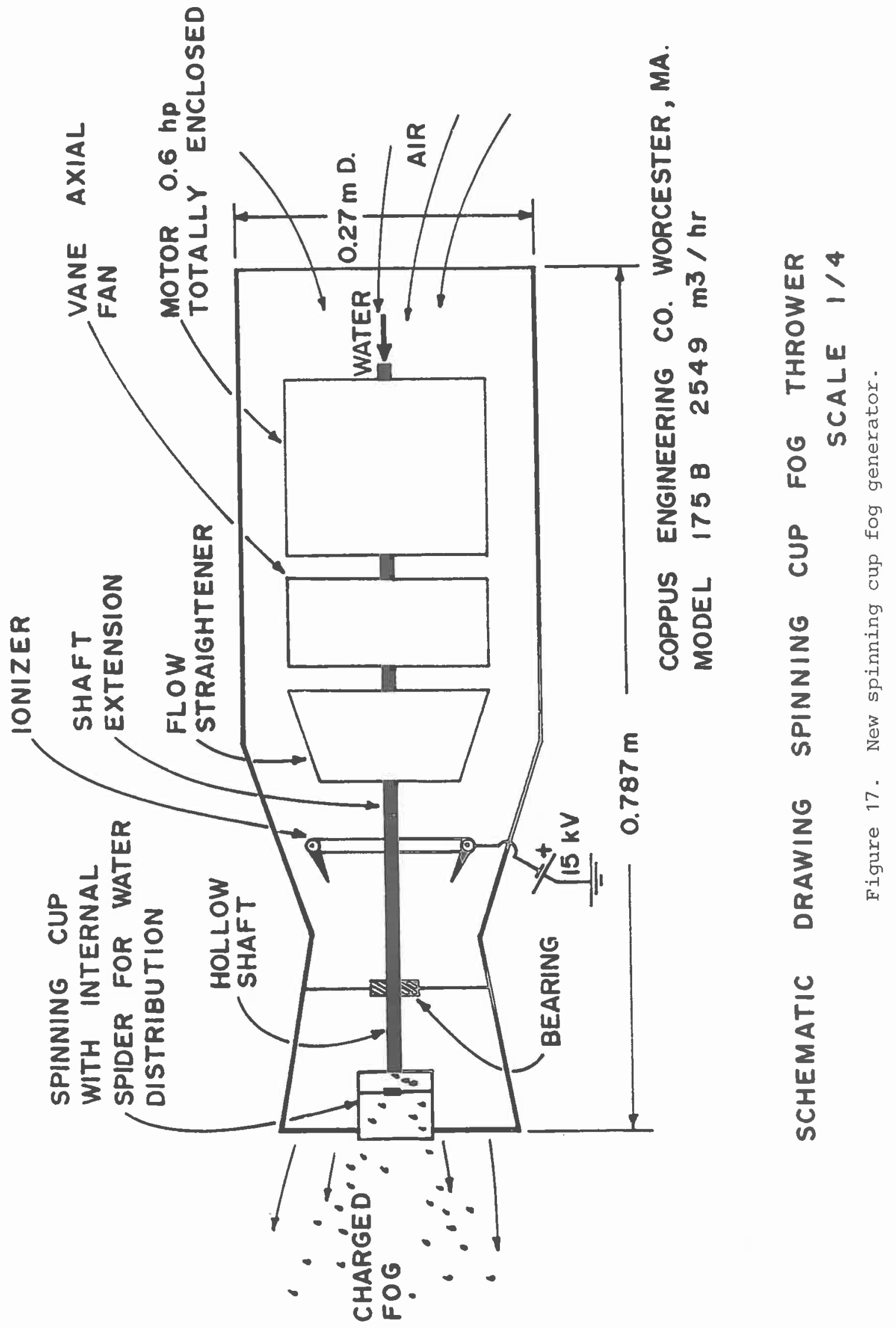



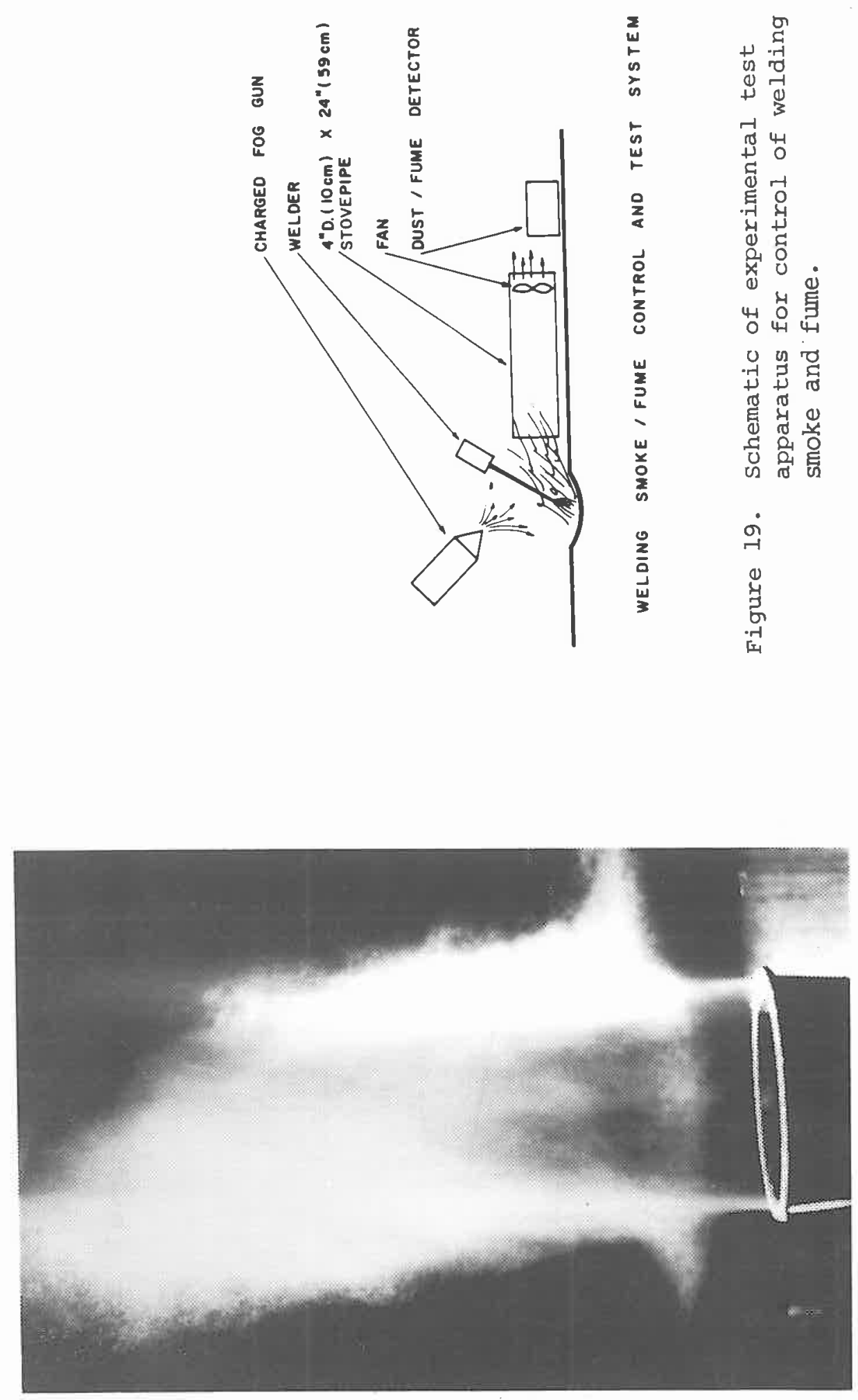

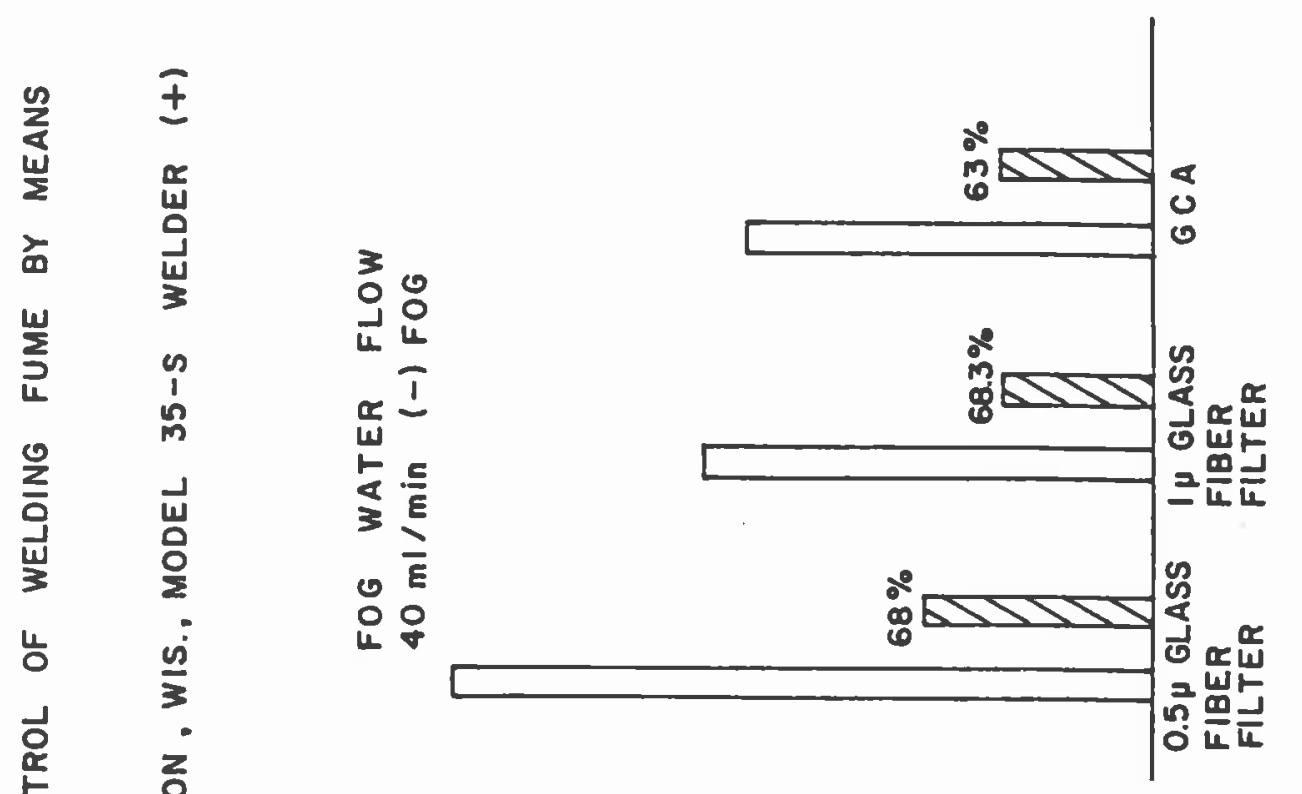

它昆岂

ธัㅇำ

뜨응

$\propto \frac{\pi}{2} \sigma \pi$

㔯方 山占

0 0 ]

는 인

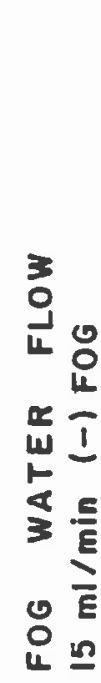

$\propto$

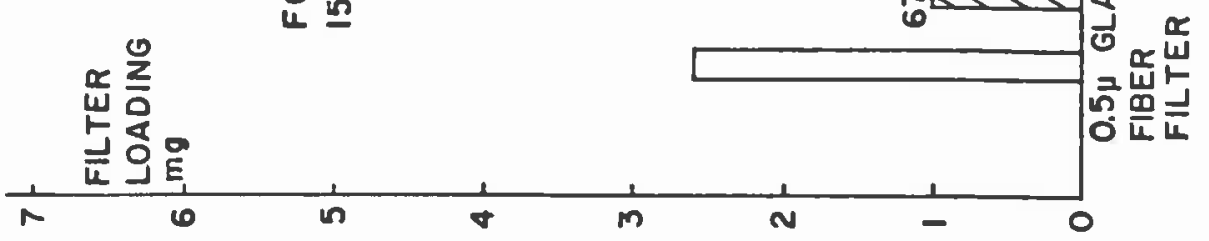




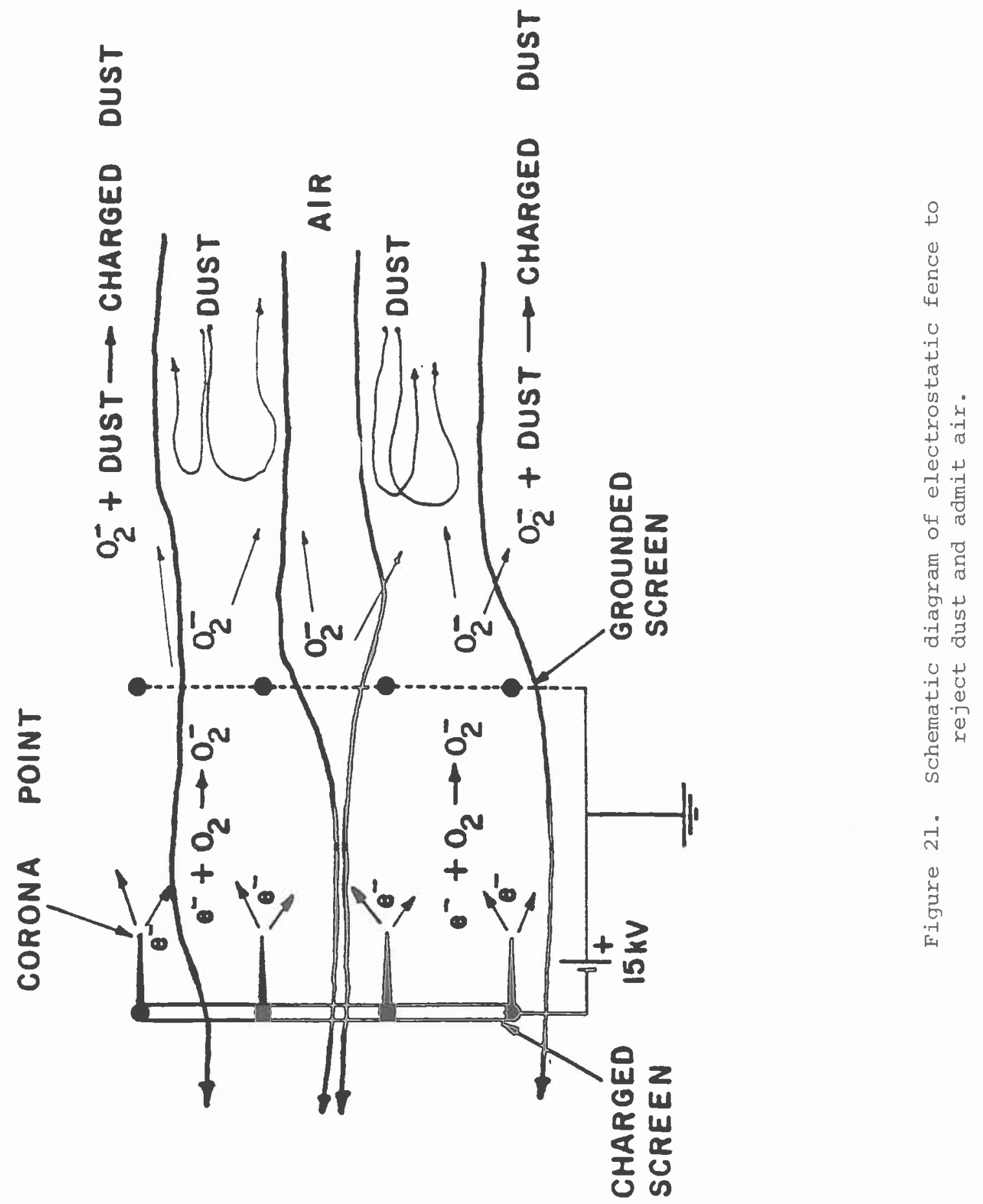



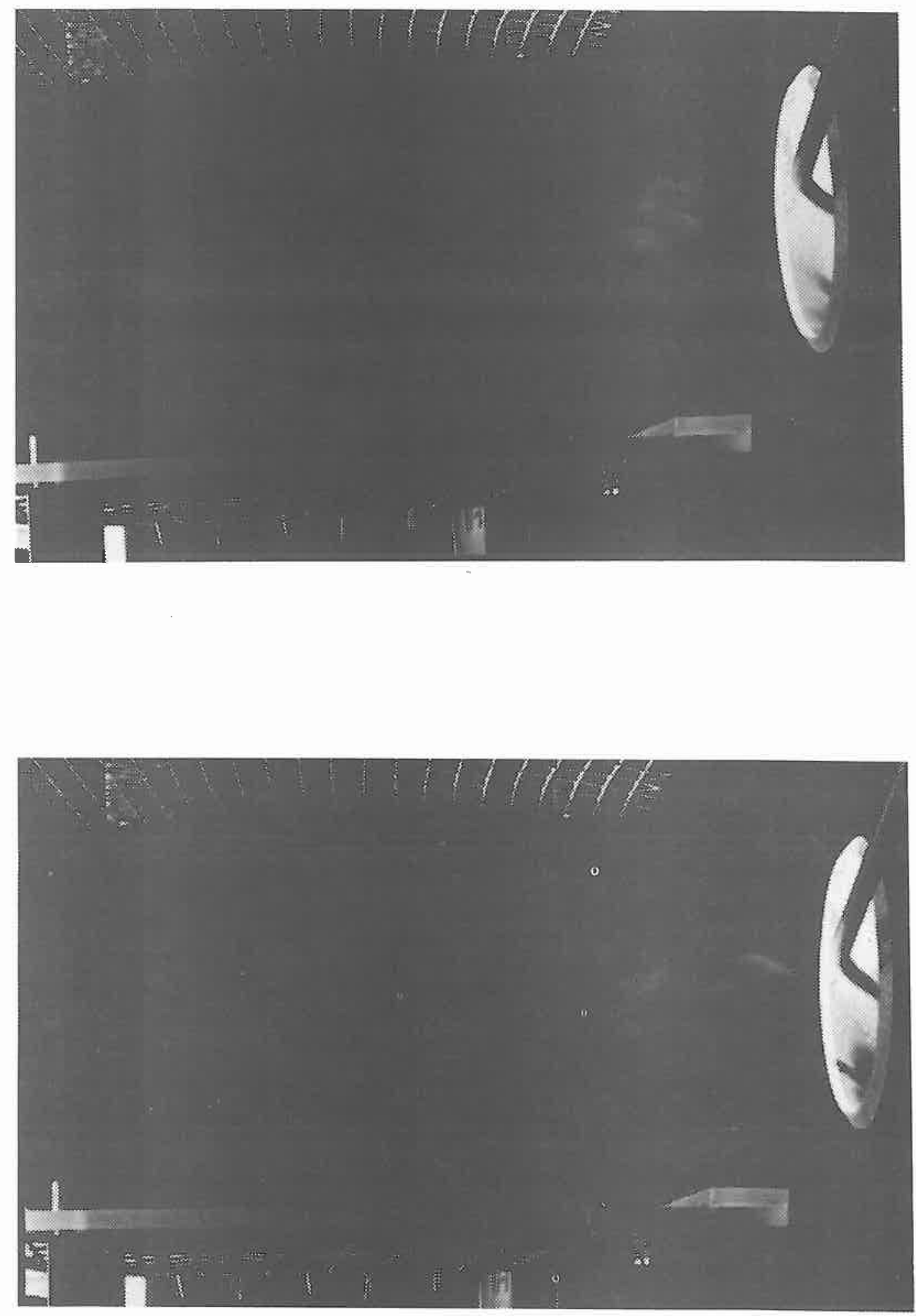


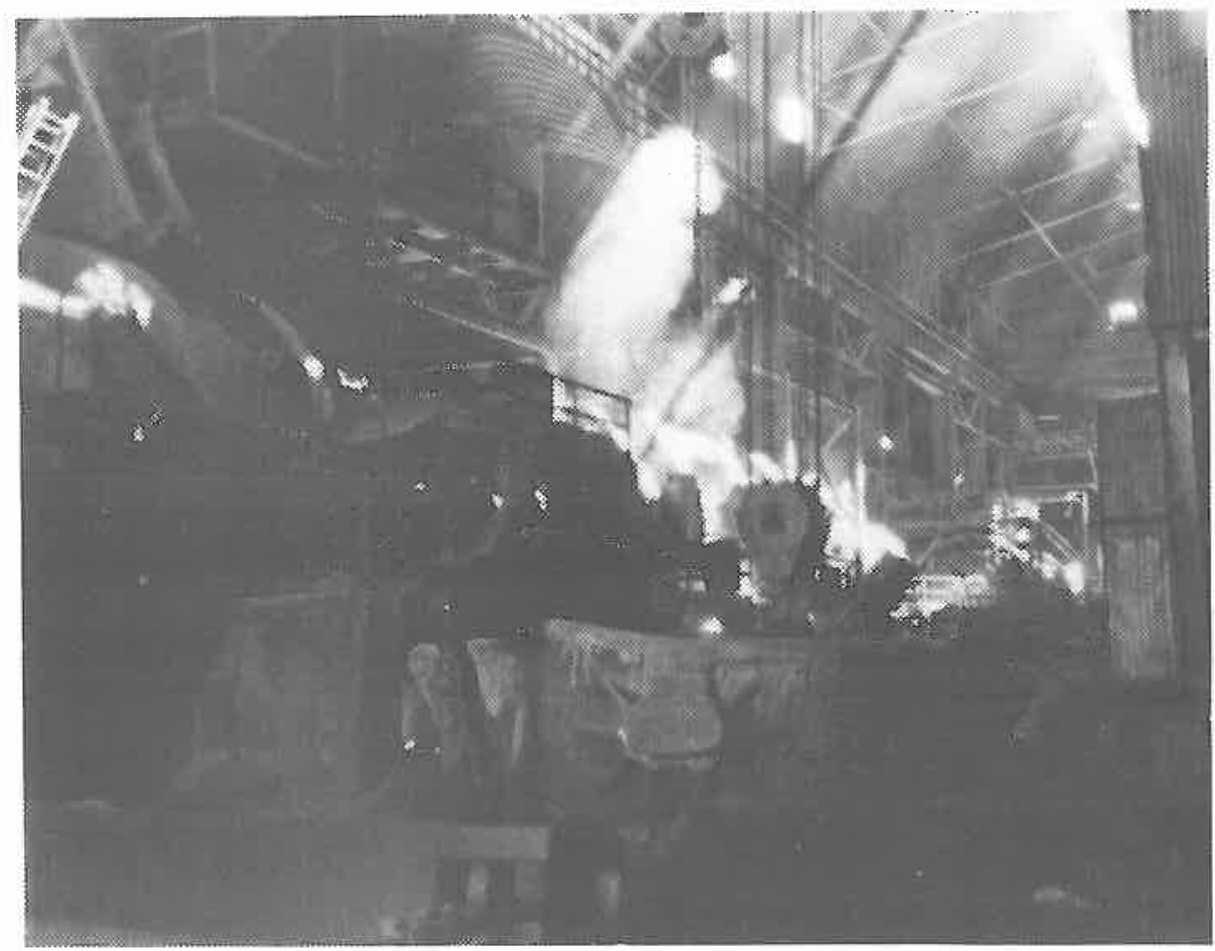

Figure 23. Smoke generation of copper smelter converter.

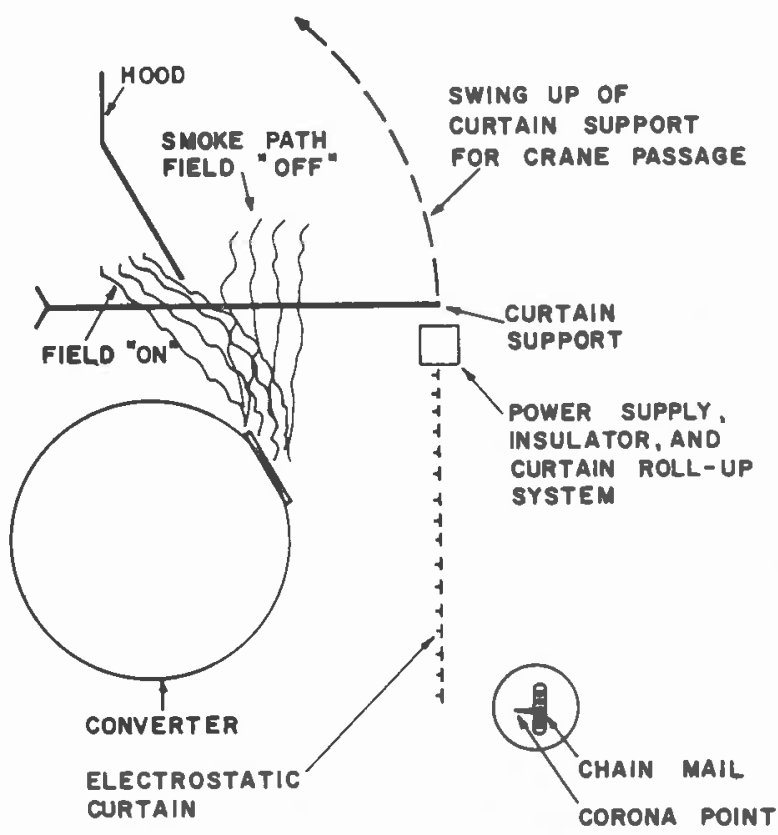

Figure 24. Electrostatic curtain system for copper smelter converter. 

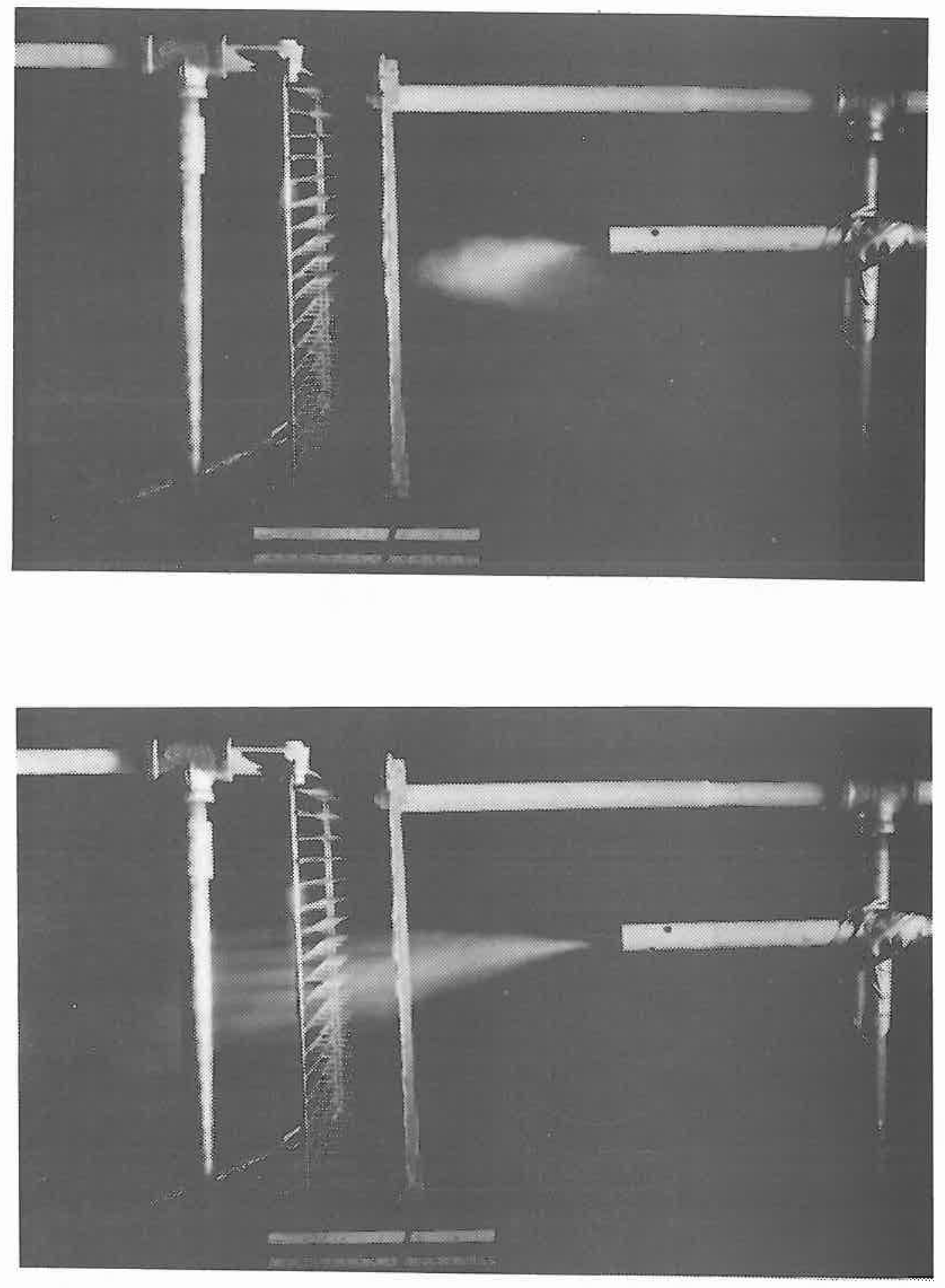

Figure 25. Electrostatic dust fence off (upper) and on (lower). 


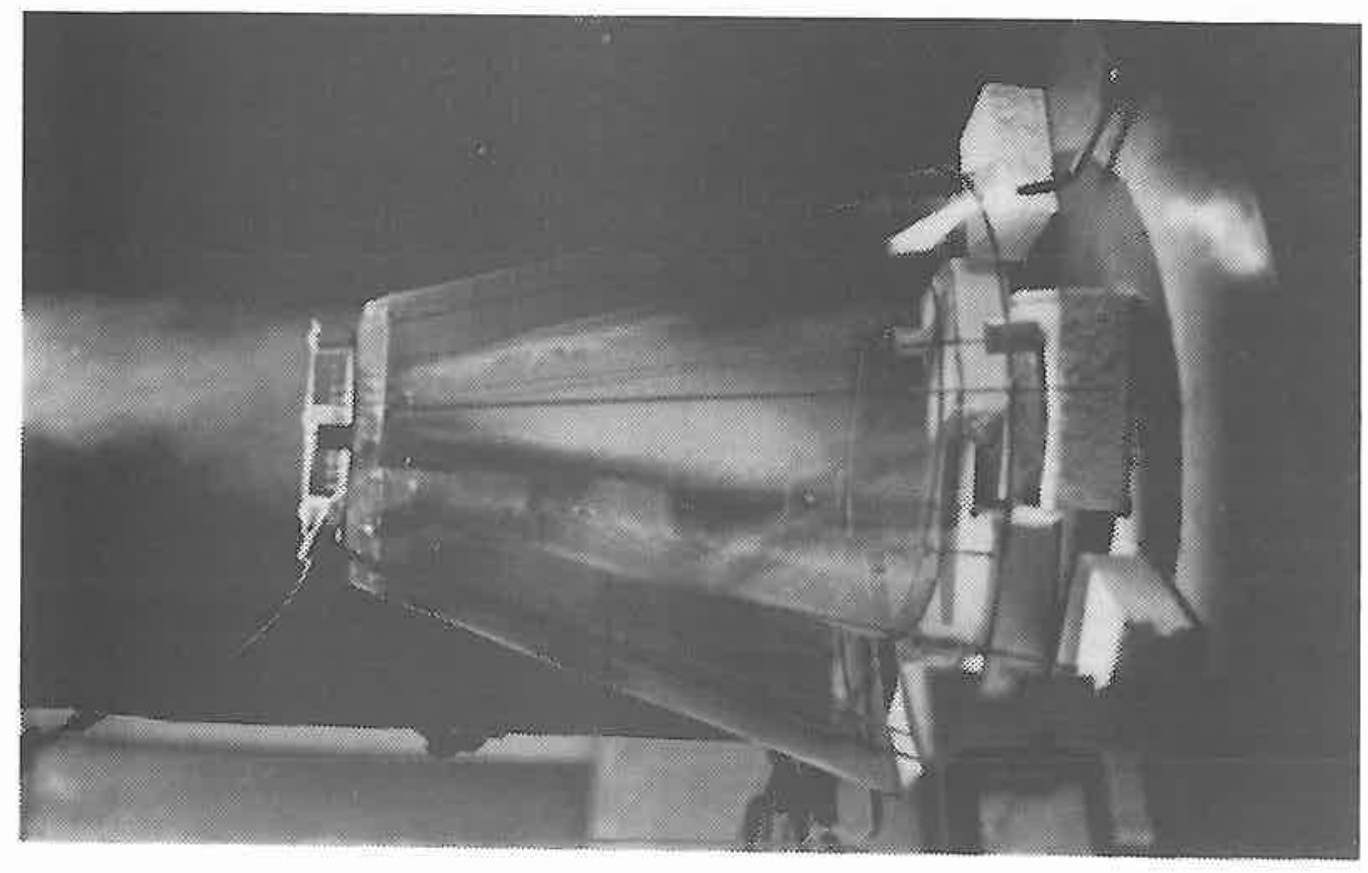

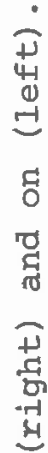

出

8

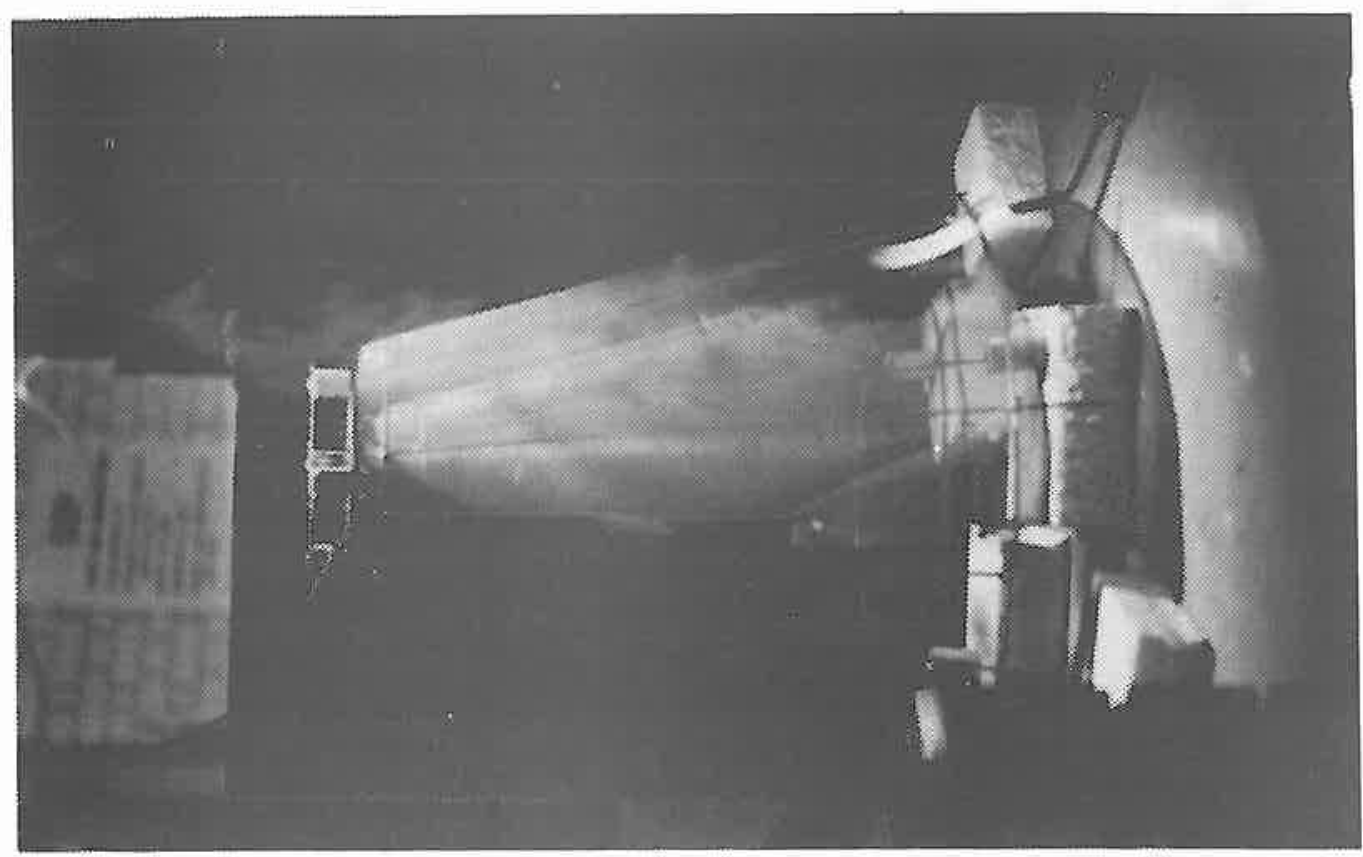




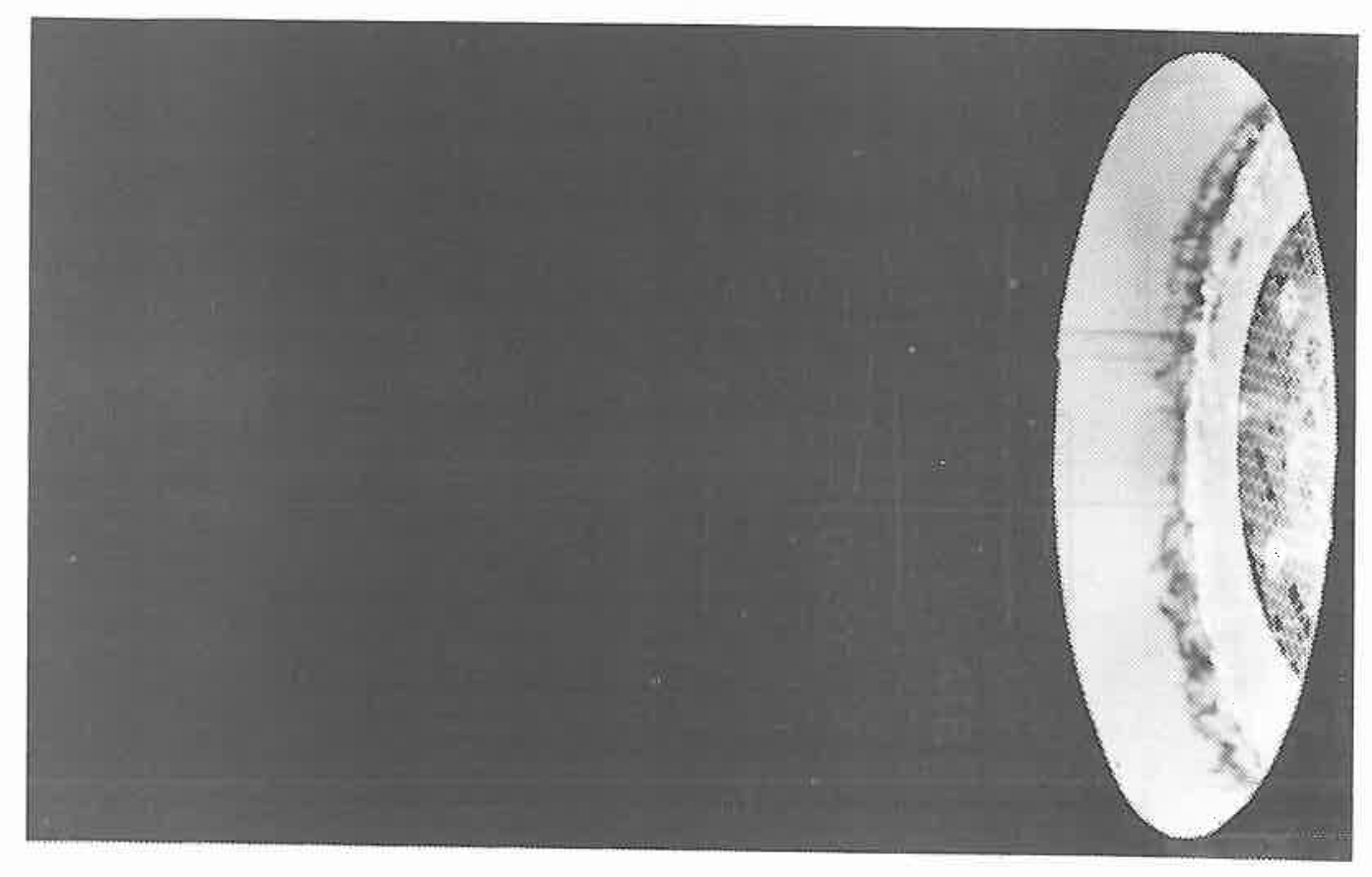

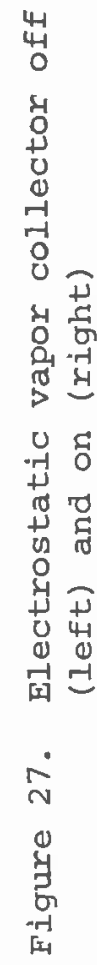




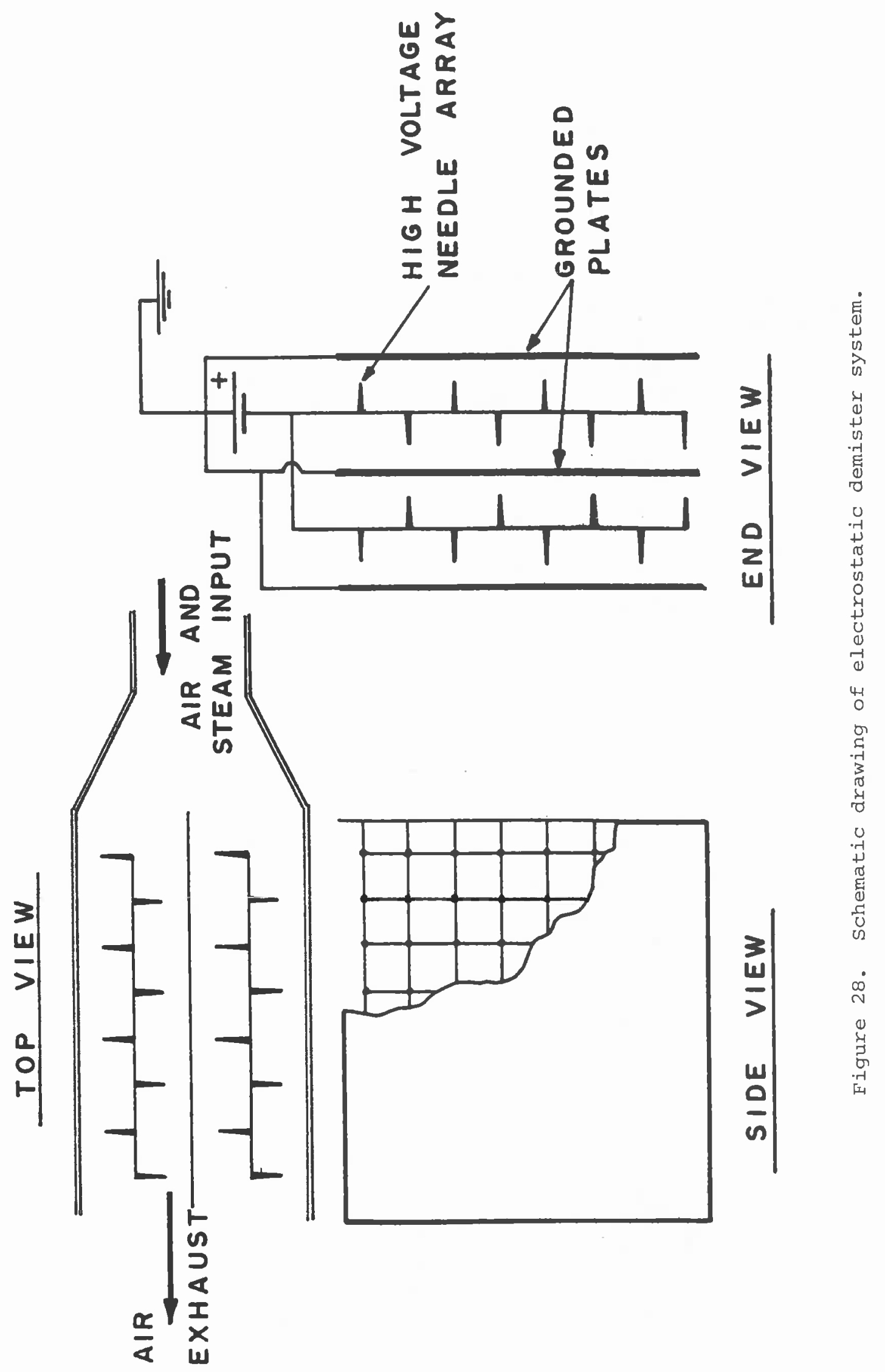



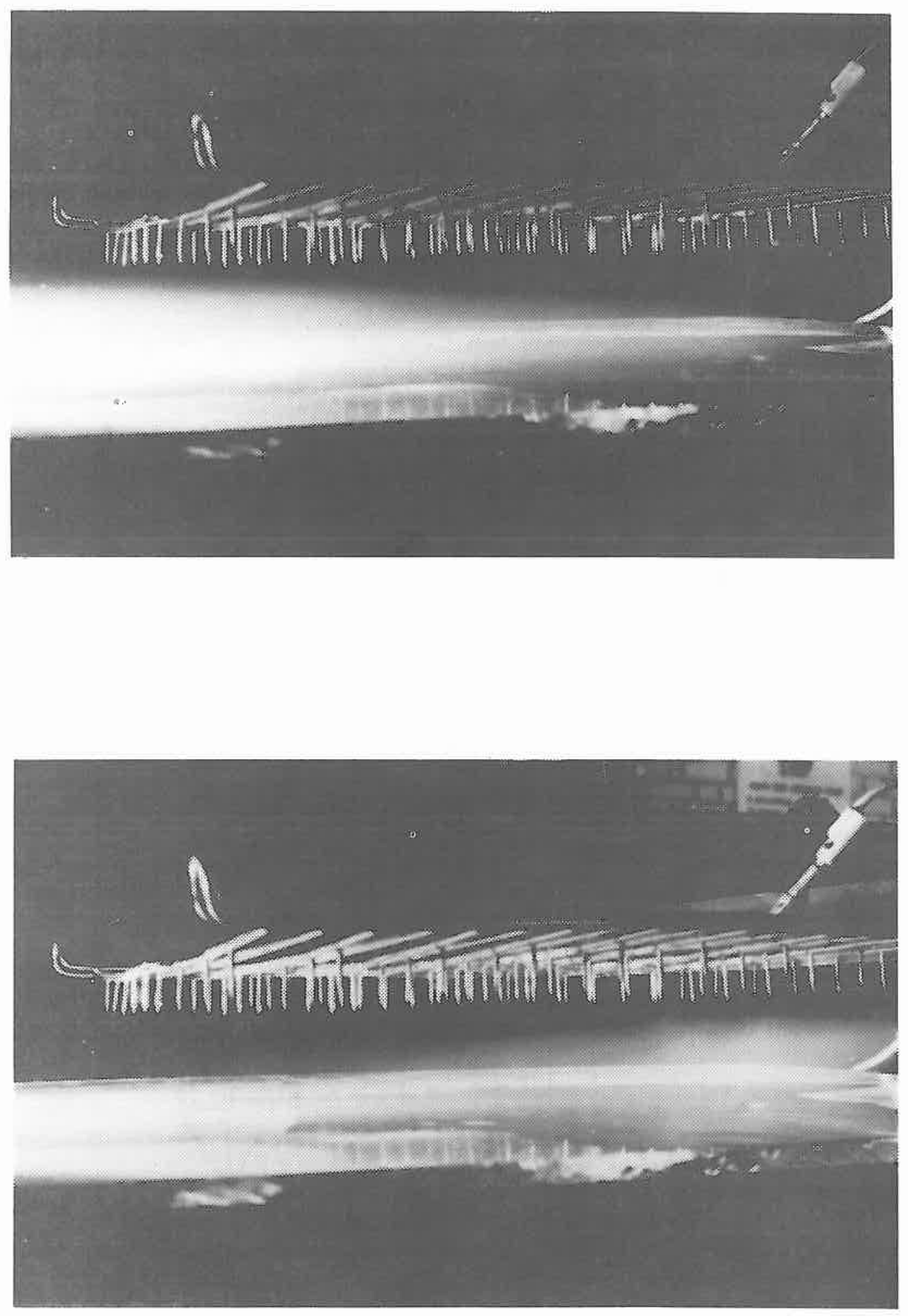

Figure 29. Electrostatic demister system off (upper) and on (lower). 


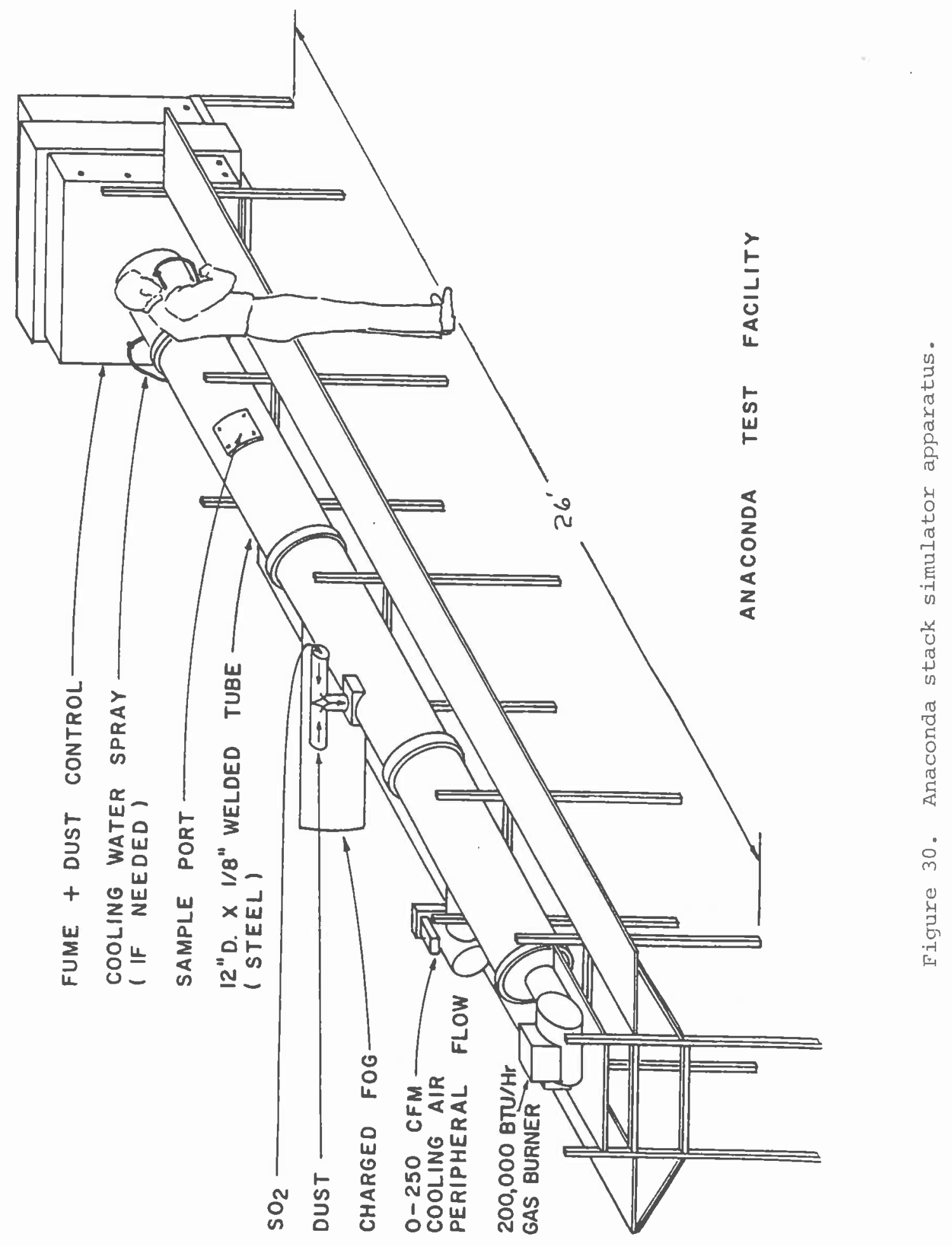




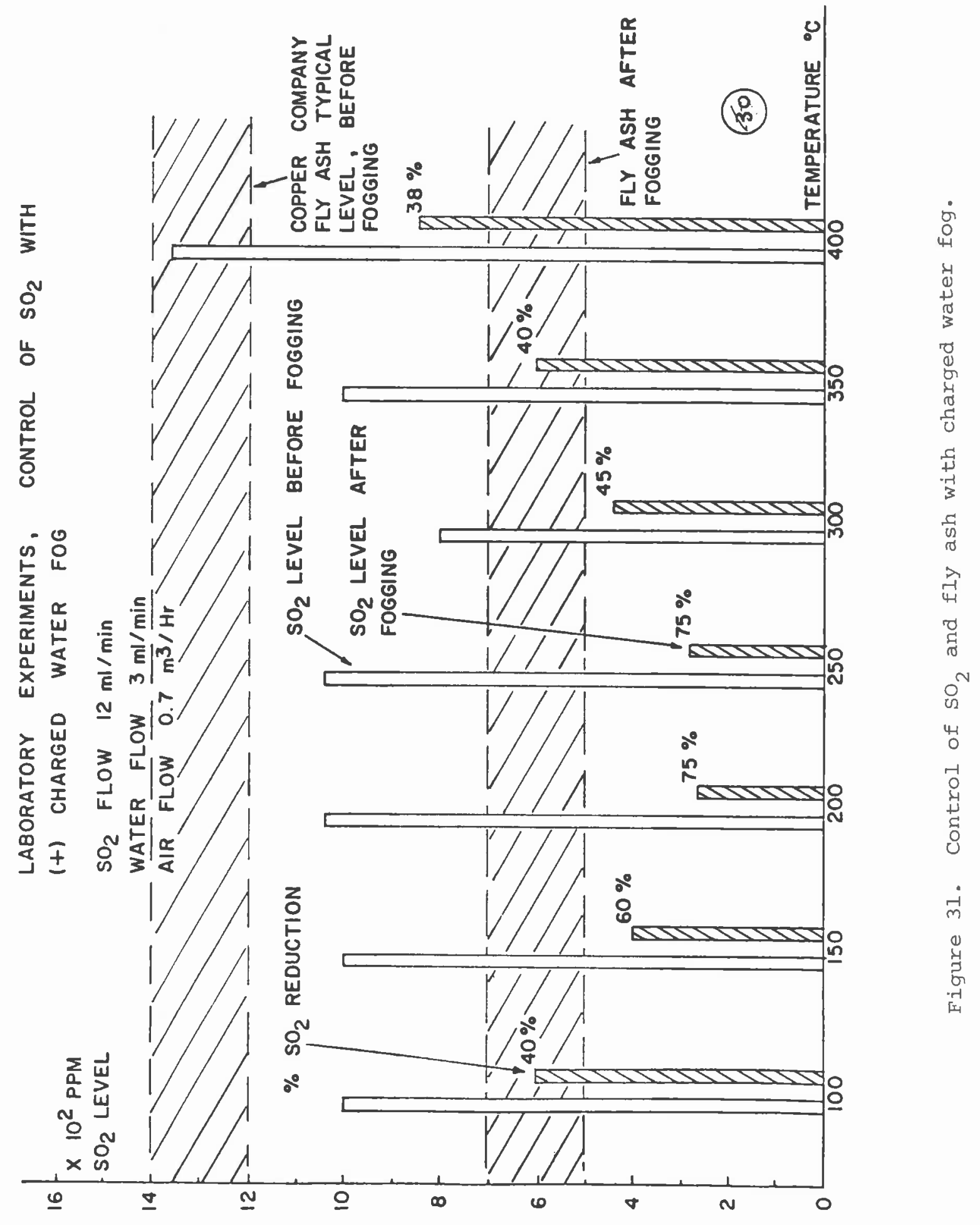




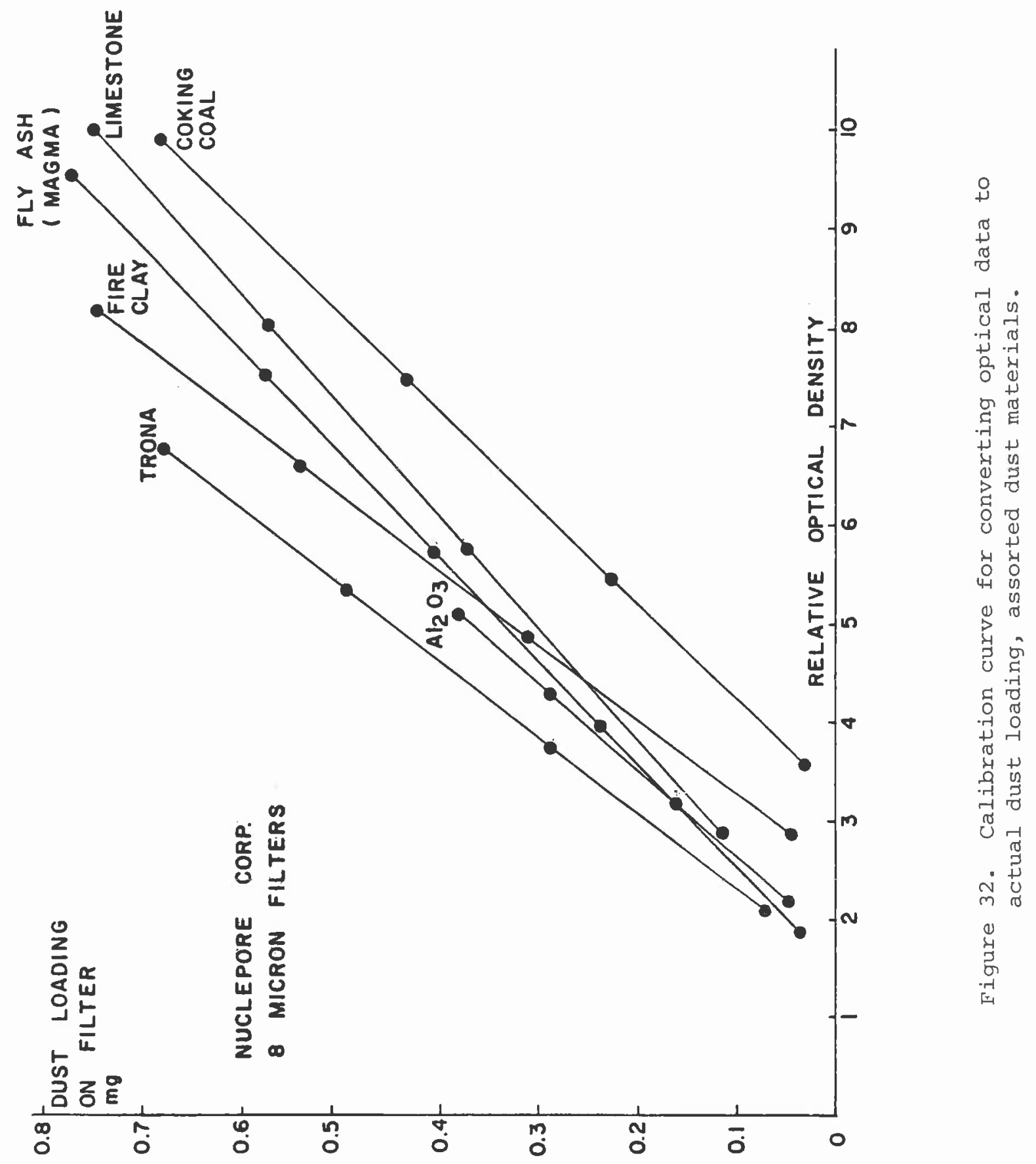




\author{
DETERMINATION ANT̃ MONEY, \\ A SUCCESSFUL FOUNDRY SAFETY AND HEALTH PROGRAM \\ H. Don McVey, Safety Director \\ Lynchburg Foundry \\ Lynchburg, Virginia
}

\begin{abstract}
To be successful, a safety and health program must be multi-faceted and include a number of essential elements: top management support, employee training and incentives, high visibility, enforced rules, self-inspection, health surveillance and good housekeeping. Lynchburg Foundry Company has found that besides all these essentials the two main ingredients underlying success are determination and money. The results that have been achieved in terms of lower compensation costs, fewer fines, higher efficiency, and satisfaction of the moral obligation toward employees, have made the program at Lynchburg Foundry well worth the effort.
\end{abstract}

\title{
INTRODUCTION
}

Summarizing a multi-faceted safety program in thirty-five minutes is almost an impossible job. In my allotted thirty-five minutes I will highlight the points that I feel are most viable in what I consider a successful foundry safety and health program.

For those of you not familiar with Lynchburg Foundry, let me provide a brief background. We presently have three plant sites: Lynchburg, Archer Creek (located outside of Lynchburg) and Radford, Virginia. We employ approximately forty-five hundred people at the three facilities and at a general office building.

\section{FOUNDRY DESCRIPTIONS}

In all three plant locations we are busy using cupolas to melt iron and induction holding furnaces to insure temperature, consistency and surge capabilities. We are busy making molds in green sand with jolt-squeeze machines, sandslingers, and automatic molding machines. We also do extensive molding using the hot box shell method. Cores going into these molds are made utilizing oil sand, shell, no-bake and TEA isocure processes, as well as the new sulfur dioxide technique.

Shake-out methods include automatic punch-out, the traditional vibrating table, and oscillating conveyors. The shake-out process is followed by the traditional knocking-off of gates and risers with hammers. The 
blasting of castings at all three facilities is similar in that they use a cabinet blast for large castings and barrel blasts for small castings.

Inspection, some painting, oil dipping, and shipping are all carried out in a somewhat traditional fashion.

In the midst of all the aforementioned activity, we are continuing to build new facilities for increased capacity. We are also examining at our Research Facility, new technology to reduce energy consumption and costs, and to improve the quality of our castings. Extensive use of quality control methods such as sonic testing for nodularity and mass $x$-ray is necessary in order to comply with new product safety regulations.

COMPREHENSIVE SAFETY AND HEALTH PROGRAM

In the haste for production, expansion, cost reduction, new method trial and quality assurance, it is important not to ignore the hazards involved with casting methodology including innumerable safety and health concerns, among them:

Equipment guarding and lockout Material handling - manual and automated Personal protective equipment Noise

\author{
Dust, fume, and gases \\ Yr-rays \\ Heat \\ Fire control
}

Setting up a comprehensive safety and health program that will assure each employee of a place to work that is free of recognized hazards is a formidable task in the foundry and one that I feel can be accomplished only by determination and money and, I might add, lots of both.

The program we have implemented at Lynchburg Foundry is based upon a proven set of precepts or requirements:

1. Management conmitment from the president to the front line supervisor.

2. High visibility.

3. Employee training.

4. Establishment of safety and health rules and their rigid enforcement.

5. Thorough machine guarding and maintenance programs.

6. Self-inspection procedures in both safety and health areas.

7. Closely monitored housekeeping program.

8. Comprehensive system of lockout.

9. Comprehensive health surveillance program.

10. Inclusion of employee incentives and recognition.

It is to these facets that I will direct my following remarks since their accomplishment is where most of my energies are directed. 
First, let me talk about management commitment, or maybe a better word would be determination. This must start at the top of an organization. If the emphasis that the president of an organization places on safety and health is passive, the tenor of the whole safety and health program will carry the same emphasis throughout the management ranks. Our president, Gerry Robertson, starts every management meeting with comments concerning our safety program. He has gone on record stating his profound determination to reduce accidents and occupational illness to zero, if that is possible.

Mr. Robertson has placed heavy responsibilities for safety on all lower levels of management. The conduction of safety meetings, new employee training, housekeeping, and accident records are all weighed when a performance appraisal is being assessed. When the pay a person receives for his work is directly tied in to the effectiveness that he has exhibited in boosting his area of responsibility from a safety standpoint, one usually gets results.

Strong endorsement is also made in communicating our program. The consistent circulation of safety statistics and the posting of accident descriptions and investigative results at all facilities is common practice. Company and plant newspapers carry safety information in every issue.

Top management's commitment is further exemplified by the approval of funds for monitoring equipment, machine guarding, recognition programs, and the hiring of personnel to carry out such programs.

At each of our plants we have a safety director and a full time registered nurse who is supported by a staff of highly trained first aid technicians (Figure 1). Our first aid facilities are new and well equipped. The personal attention paid to our employees goes a long way in conveying the Company's interest in their health and well being.

\section{High Visibility}

Visual evidence of an active and viable safety and health program should be apparent in every facet of work activity. When the worker arrives at the plant, the first thing to catch his or her eye is our large safety sign (Fig. 2) displaying the week's safety slogan, the number of days worked without a lost time accident, and a light illuminated to indicate either that no lost time accidents have occurred within the last twenty-four hours (green light), or that one has just happened within that time frame (red light). As the worker enters the assignment area, a clean orderly work station will signify the housekeeping program in action. He or she will be greeted by a supervisor exemplifying the properly adorned foundry worker with hard hat, side shield safety glasses, and metatarsal guarded shoes and will see signs indicating hazards unique to certain areas. Plant bulletin boards will contain postings of lost time accidents not only at this plant but also at the other two plants. Statistical profiles will also be posted showing how we presently stand in our safety program compared to our 
DivisionAL

SAFETY DiRECTOR
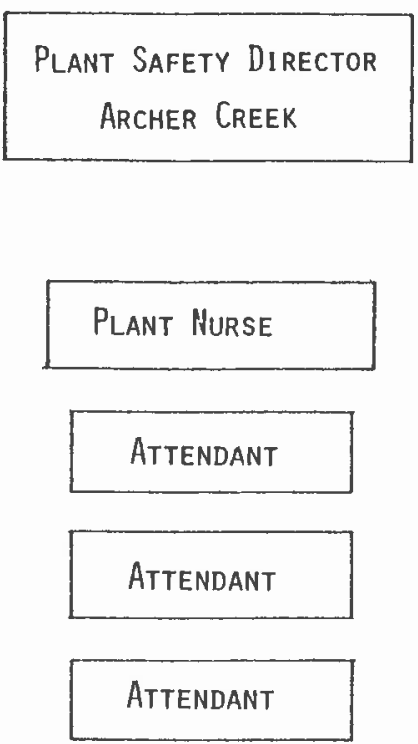
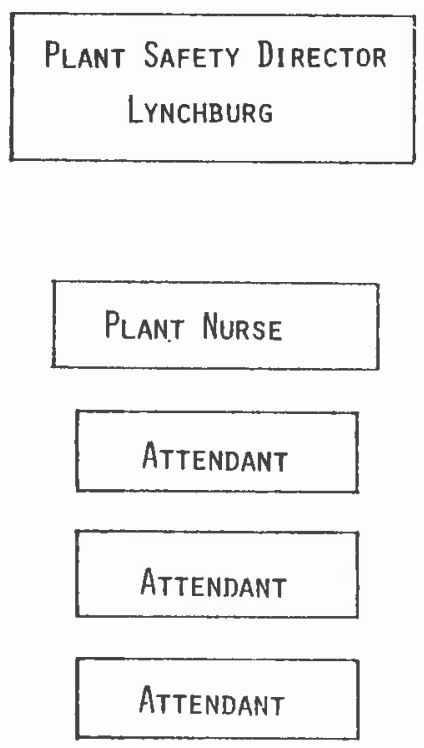
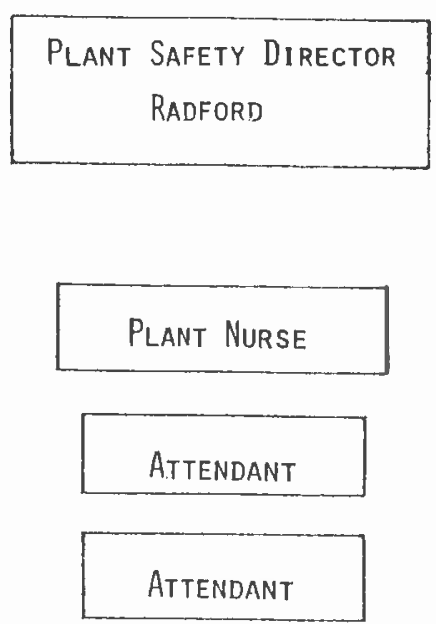

Attendant

Figure 1. Safety and health staff at Lynchburg Foundry.

predicted goals. As the worker turns to the machine control panel at the particular work station, he or she is greeted by a sign containing the step-by-step procedure for lockout of that equipment (Figure 3). Work aisles are clearly defined with lines or with neatly stacked rows of boxes. Thus we believe that high visibility is of paramount importance in a good safety program.

Employee Training

Employee training in the safety and health field is a neverending process. It has to begin when the individual is hired and the hazards of foundry work are carefully explained (Figure 4). Plant rules and regulations and the required use of safety equipment and its proper maintenance are taught. The worker's supervisor will then cover the job hazard analysis, one of which has been made up for each job in the foundry. Experienced co-workers then are assigned so the individual can be carefully watched as he learns. Monthly safety meetings are required of everyone and these are carefully planned and enriched by the Safety Directors at each plant. Supervisors, too, get indepth training in all facets of safety and environmental health. One of the most successful supervisory training programs we have used has been the General Motors program which emphasizes observation for unsafe conditions and unsafe acts. Specialized training has been set up covering lift truck operation, crane operations, manual materials handling, OSHA compliance, and the conduction of meaningful safety meetings. 


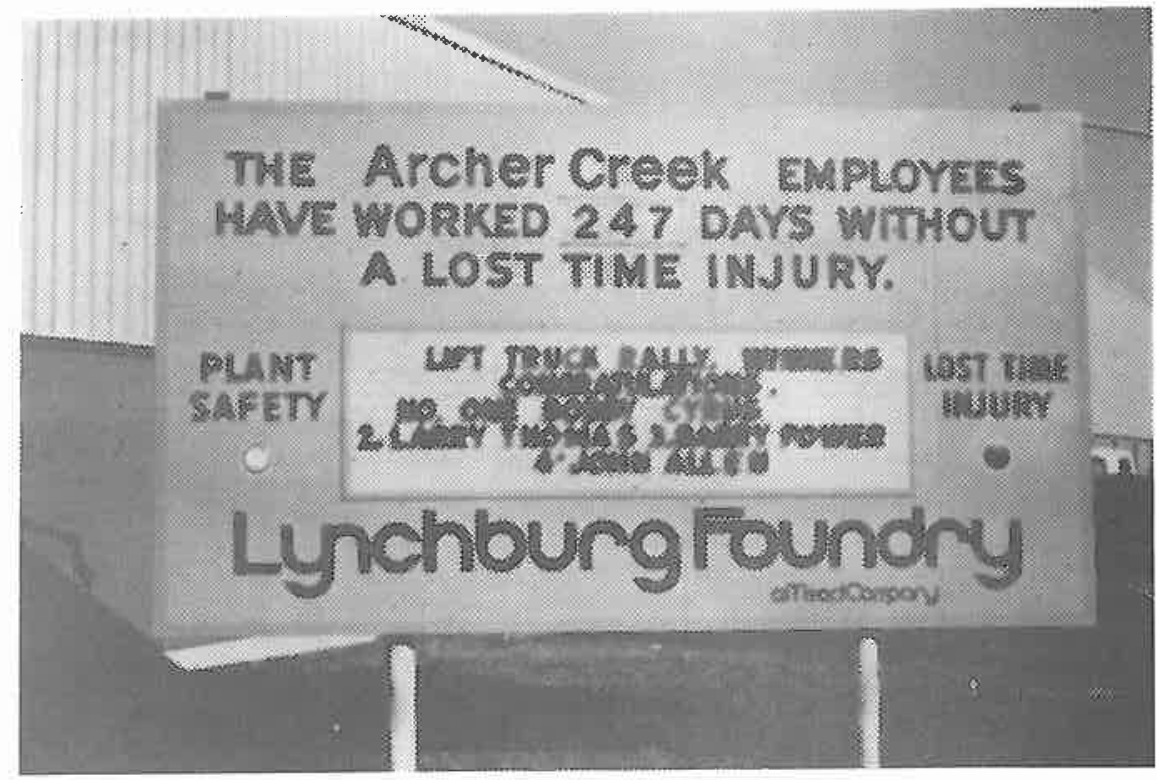

Figure 2. Large safety sign greeting workers as they arrive.

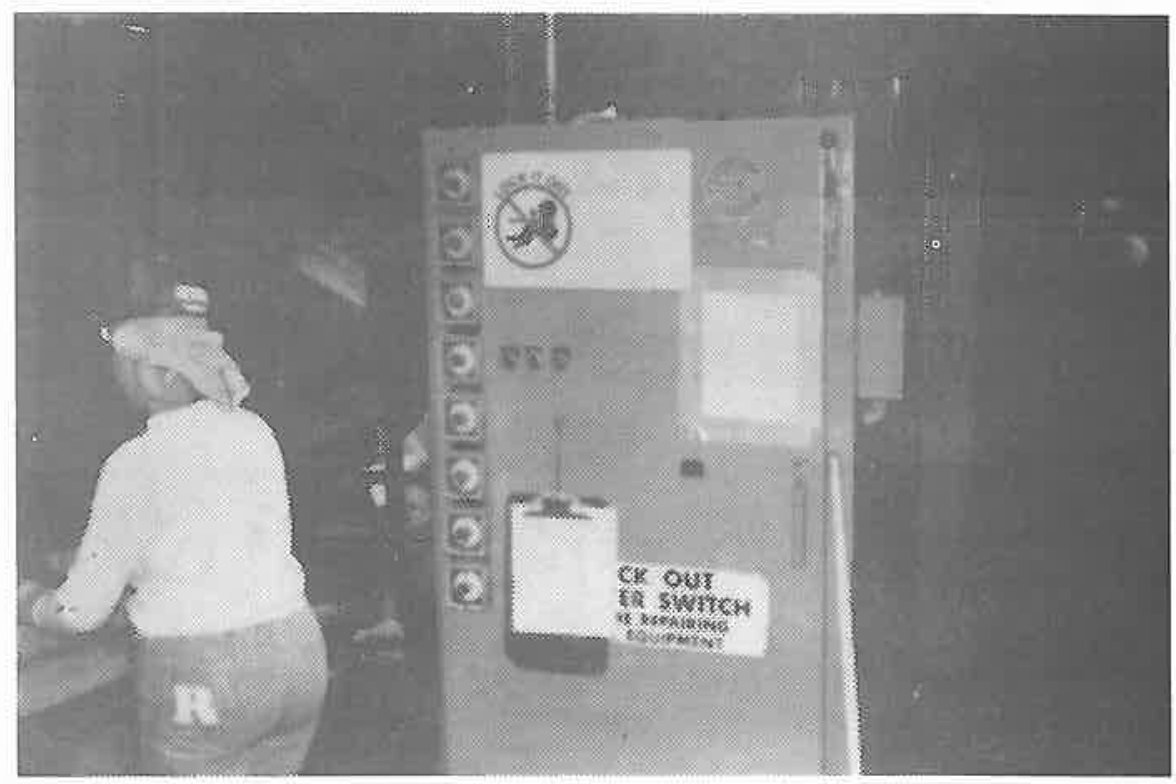

Figure 3. Sign warns workers and repairment to lock-out equipment before performing maintenance or repairs. 


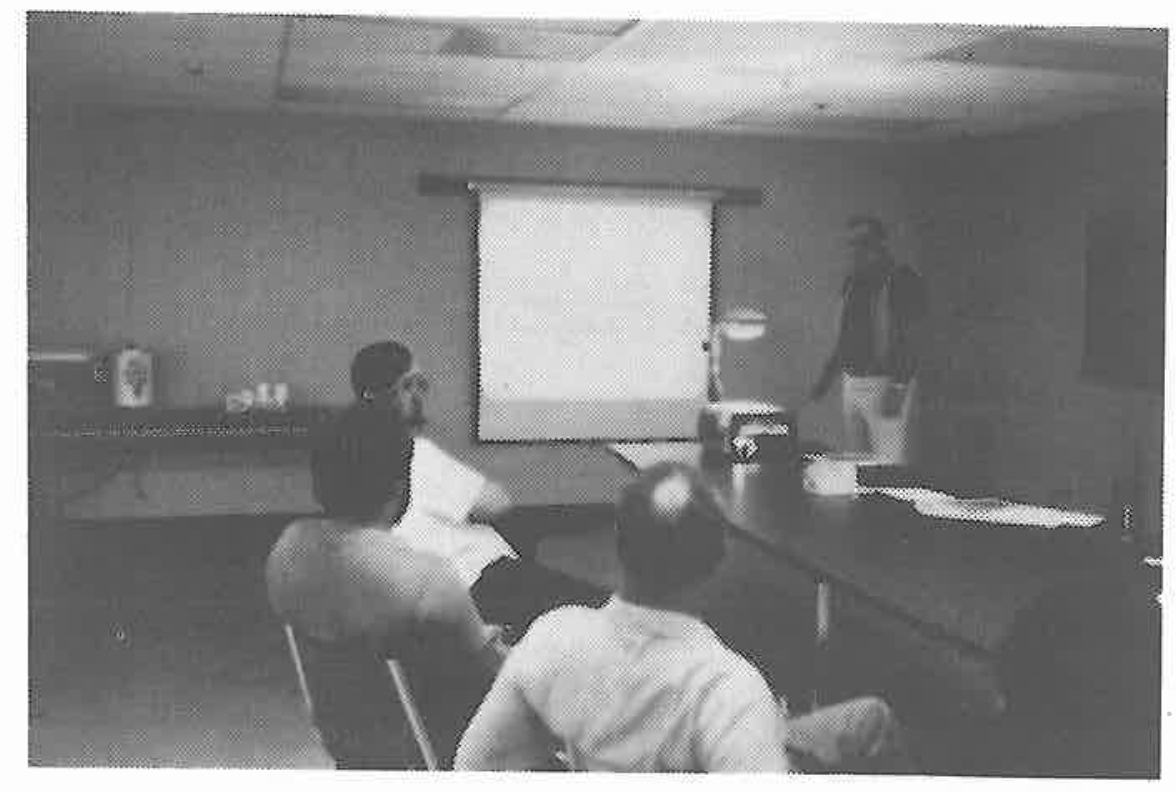

Figure 4. Job hazards are explained and safe procedures are taught before the new worker starts the assignment

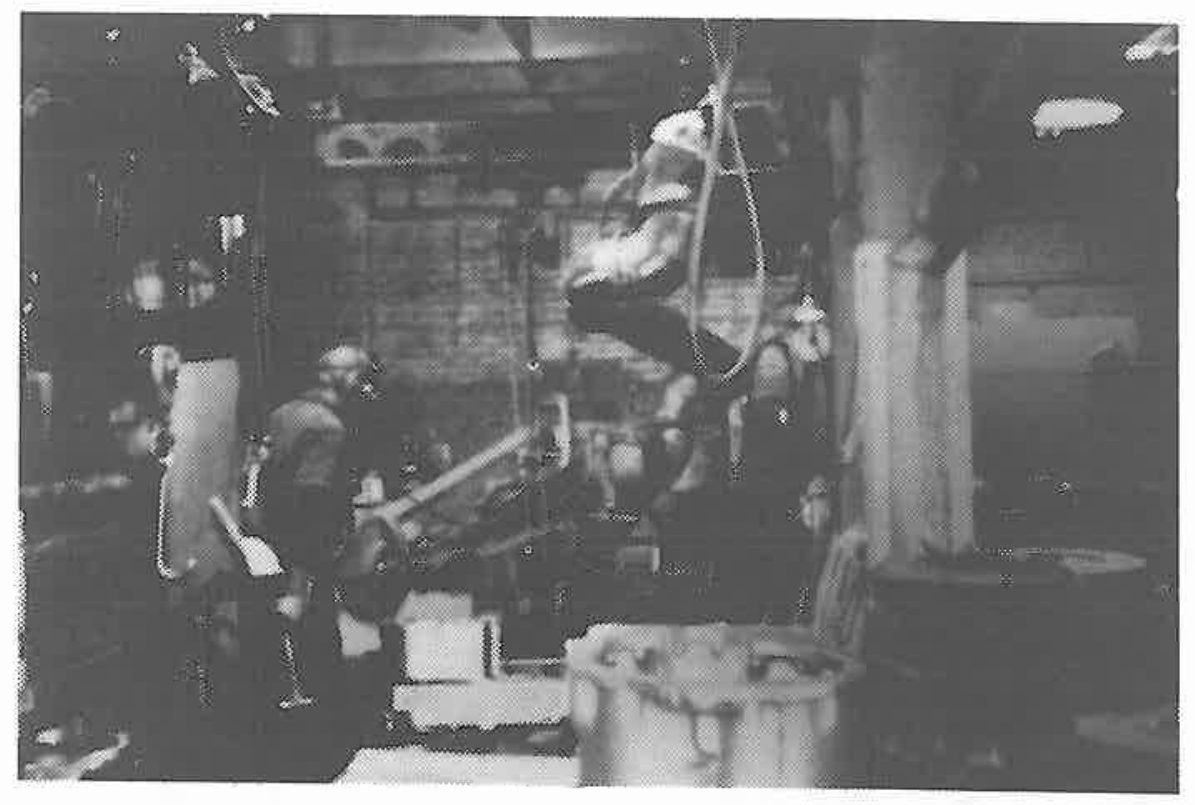

Figure 5. Machine mounted hood captures dust during swing grinder operation. 
Establishment and Enforcement of Safety and Health Rules

Compliance with machine guarding and environmental standards has represented one of the toughest aspects of the safety program to achieve. Explicit standards have not been written to cover all situations and in many cases technology does not exist that will enable us to meet all environmental standards. The evidence of our attempts, though is everywhere:

1. In our push-pull downdraft systems where we can clean small castings

2. In our self-filtering Wolverine booth system.

3. In our Hawley Travel Vent systems mounted on swing frame grinders (Fig. 5).

4. In the guarding of a dump station.

5. In guards to protect workers from overhead loads (Figure 6).

6. In punch-out devices that eliminate the need for dropping hot cupola bottoms (Figure 7).

7. In our everyday crane inspection reports.

8. In our special safety work order system which is monitored by top management and also prioritized by them.

Lockout Procedures

One of the most critical factors that we have discovered contributing to a successful safety program has been a well documented and strongly enforced lockout system. Signs posted by the controls of every machine describe all factors involved with lockout. The ZES (Zero Energy State) system is the theory that we use where all sources of energy are shut off and locked including the bleed off of pressurized hydraulic and air lines. Failure to follow the described lockout procedures is grounds for immediate dismissal.

Self-Inspection

Self-inspection is becoming more critical for all industry to set up and utilize as almost everyday, it would seem, a new health hazard is being discovered with regard to a long-used chemical. At Lynchburg Foundry we use several self-inspection techniques:

1. A bi-lateral committee meets monthly to discuss problems of safety and health and concludes its meeting with a comprehensive inspection of portions of the plant.

2. An unsafe acts observation program is administered in which foremen and supervisors record and take action on the spot when they see an unsafe act committed. These unsafe acts are reported at weekly cost meetings.

3. People in all our facilities are trained in the techniques of monitoring. We presently have on order $\$ 18,000$ of monitoring equipment that should provide the basis of a very thorough monitoring system. In the past we have used the monitoring services of our compensation carrier, the Mead Corporate Hygienist, and the Virginia Voluntary Compliance officials. Self environmental 


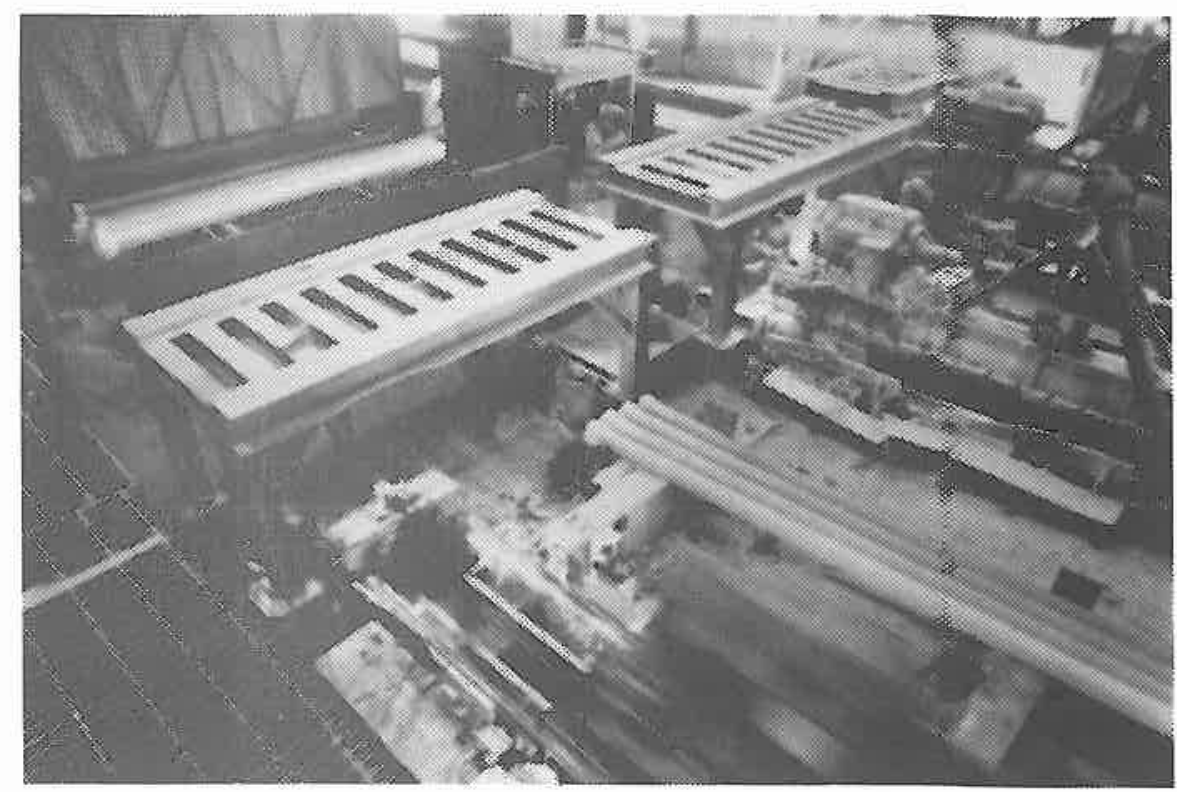

Figure 6. Rugged structural guards (center of picture) protect workers from overhead crane loads.

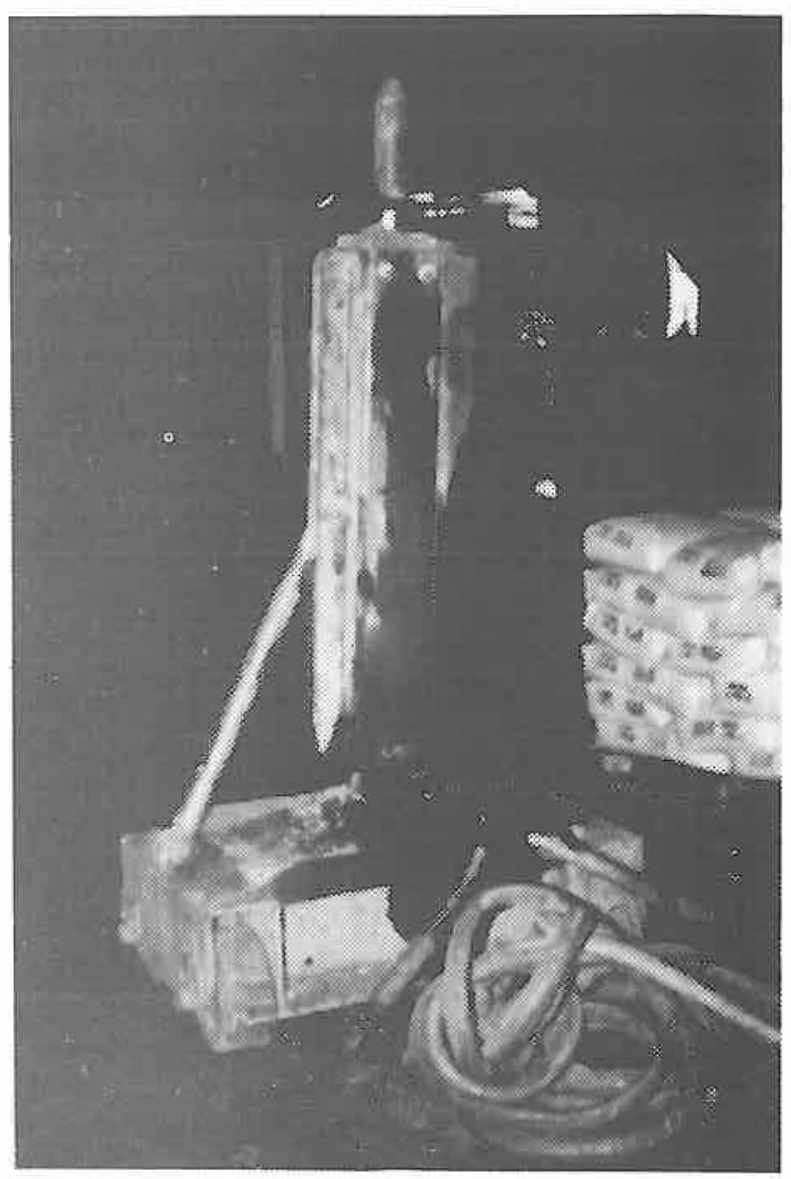

Figure 7. Punch-out device to eliminate the need for dropping hot cupola bottoms. 
monitoring programs are a vital portion of any foundry operation as this conference will bring out.

When our monitoring uncovers problers, jnterim measures must be taken. First, we notify affected employees of the situation and, if necessary, install personal protective equipment. Ve have made it a practice to recommend personal protective equipment such as respirators even in conditions below the TLV limits. Where levels of hazardous materials such as silica dust are found to be at or above the TLV, rigid enforcement of protective equipment is invoked (Figure 8). Where respirator programs are required, selection, cleaning, repair, and storage programs must be placed into effect.

In the meantime, the engineering department will be notified of the conditions in the area and will immediately begin to work on remedies for the situation. Where special expertise is required, consultants are brought in. Our primary use of consultants has been in the area of noise control. From these studies come capital project requests requiring corporate approval if large amounts of money are jnvolved. The final step is then the actual purchase and installation of control systems.

Health Surveillance

This conference attests to all of the hazards that foundry work can impose on one's health. Even with all of the suggested controls in action we know that parts will wear out and machines will get out of adjustment. In addition, new products will involve new hazards. Therefore, an important part (and also an expensive part) of our safety and health program involves health surveillance. Our health surveillance begins with pre-employment physical examinations to determine that individuals are sound physically before they get involved in a labor-intensive industry such as ours. We will even give physical exams for individuals going from a more sedentary type of job into a physically demanding role, especially if there is any question of physical ability.

Our hearing conservation program is always in action. Where noise tests reveal high levels, hearing protection is then required and enforced. Baseline audiograms are given to all new employees and hearing checks are made annually on all employees (Figure 9). These audiograms are conducted by the plant nurses and first aid attendents who have been trained and certified by Hearing Control Noise Control Inc. (HCNC) of Philadelphia. Audiogram interpretations, machine calibrations, and noise surveys are all conducted by them.

Also, under the topic of health surveillance is a new program of chest x-rays started by Lynchburg Foundry this year. We have a mobile unit with an $x$-ray machine designed strictly for chest x-raying. (Figure 10). It spends one-third of the year at each of our plants providing chest x-rays for those people who have worked in high dust areas in the years before extensive control programs were installed. Chest $\mathrm{x}$-rays are also given to other employees who desire them. X-rays are processed at the general office building and interpreted by a physician. This program, I might add, has been very successful in identifying the onset of other diseases than those just 


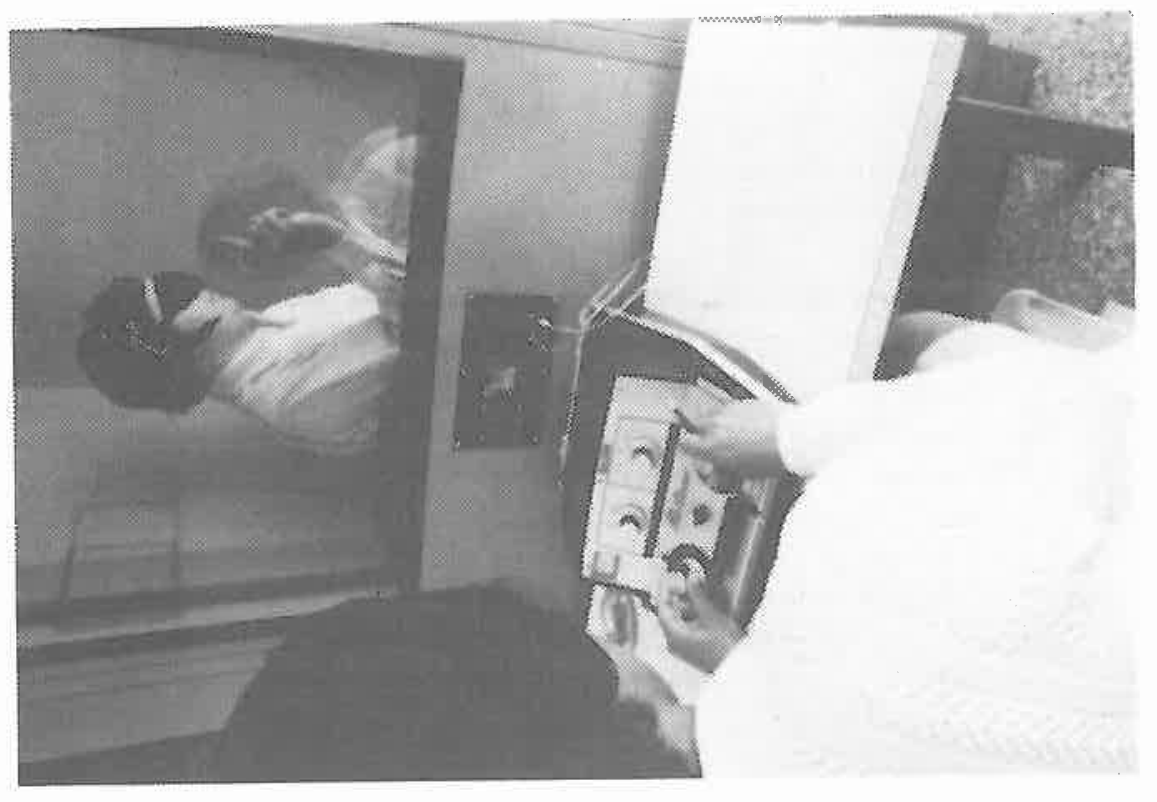

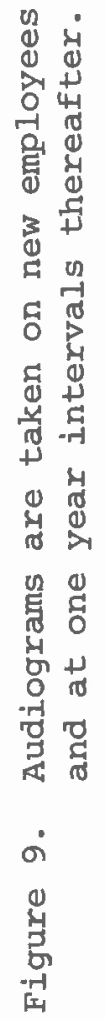

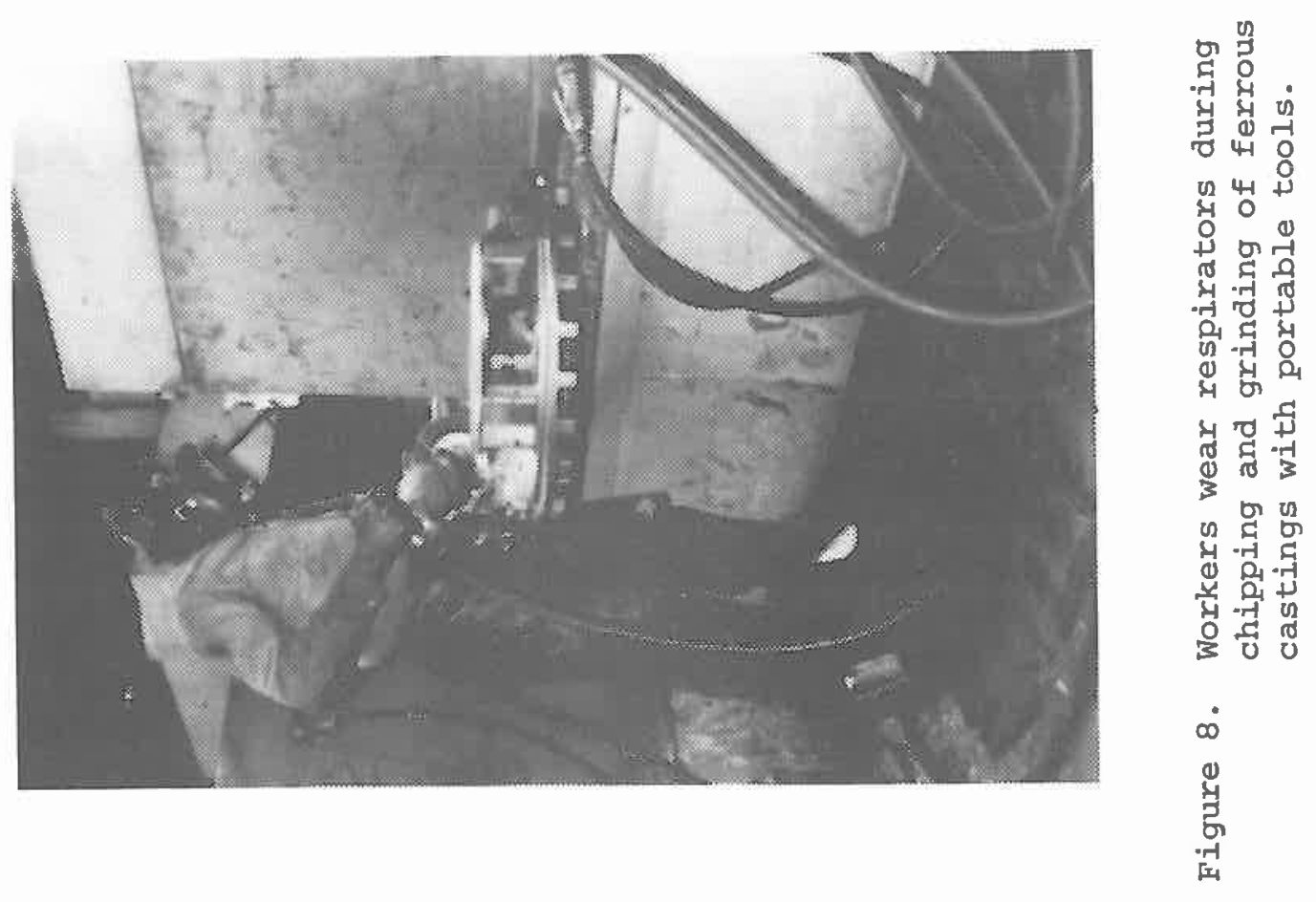




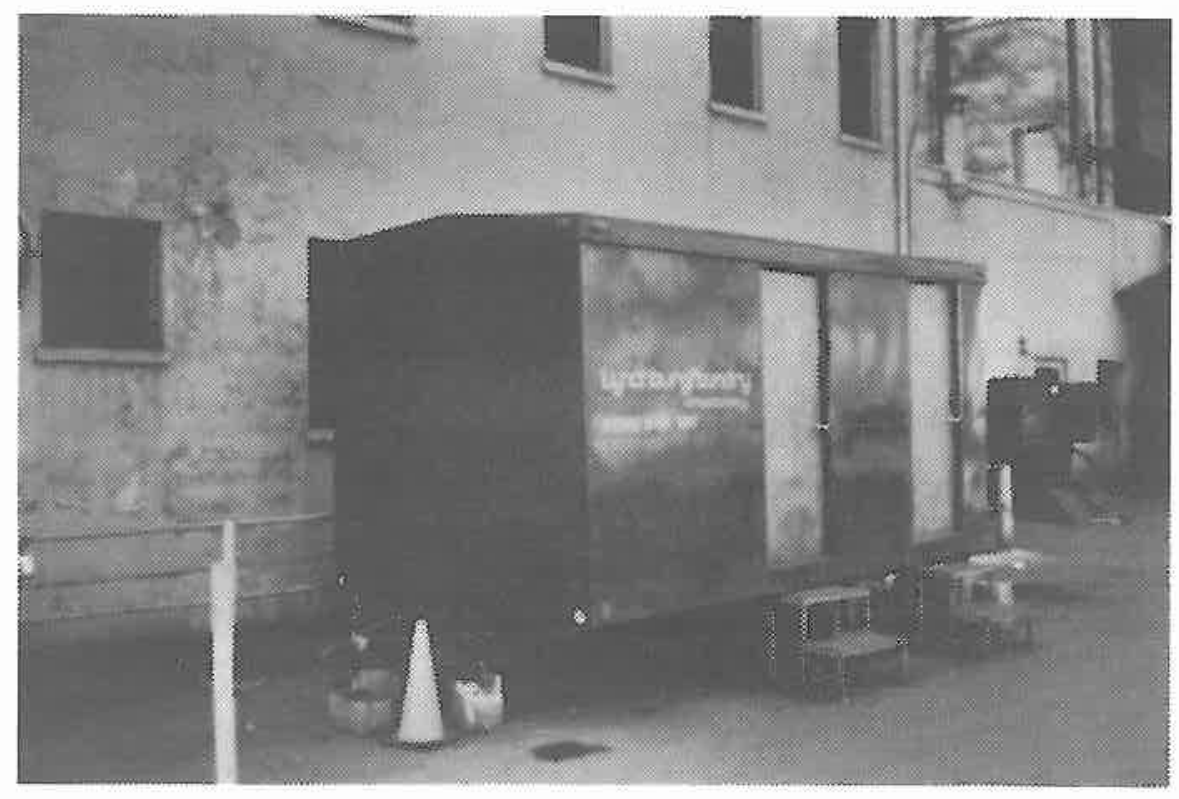

Figure 10. Mobile x-ray unit.

related to the respiratory tract. Conditions such as aneurisms, enlarged hearts, and bone deteriation have also been found. As yet, none of the diseases found have been occupational in nature.

The Foundry, as well as Mead Corporation as a whole, offers annual hypertensive screening as another health surveillance tool critical to the health of all employees. A doctor's treatment of high blood pressure in our employees is strongly supported by daily monitoring and the overseeing of proper medication intake at our first aid units (Figure 11).

As most of you are aware, eye problems are quite common to any foundry operation. One of our most successful preventive programs has not only been safety glasses and goggles but preventive eye checks at the end of each shift (Figure 12). Here the plant nurse or first aid attendent examines the eyes of those people working in high dust areas, cleans out particles when found and washes dirt and dust found on eyelashes and eyebrows.

Housekeeping

Housekeeping has always been a difficult program to keep active in our foundry. Work that is inherently dirty and work that is very difficult seems to breed careless housekeeping. We have utilized inspection teams and incentives for winning departments, but have met with marginal success. One of the most successful approaches, though, that we have found in setting up a good housekeeping system is a very hard-nosed attitude towards it by top management and an occasional and unannounced visit by our president to our plant facilities. Extensive paint-up and fix-up campaigns have generated pride within departments and now housekeeping seems to no longer be the problem it once was. 


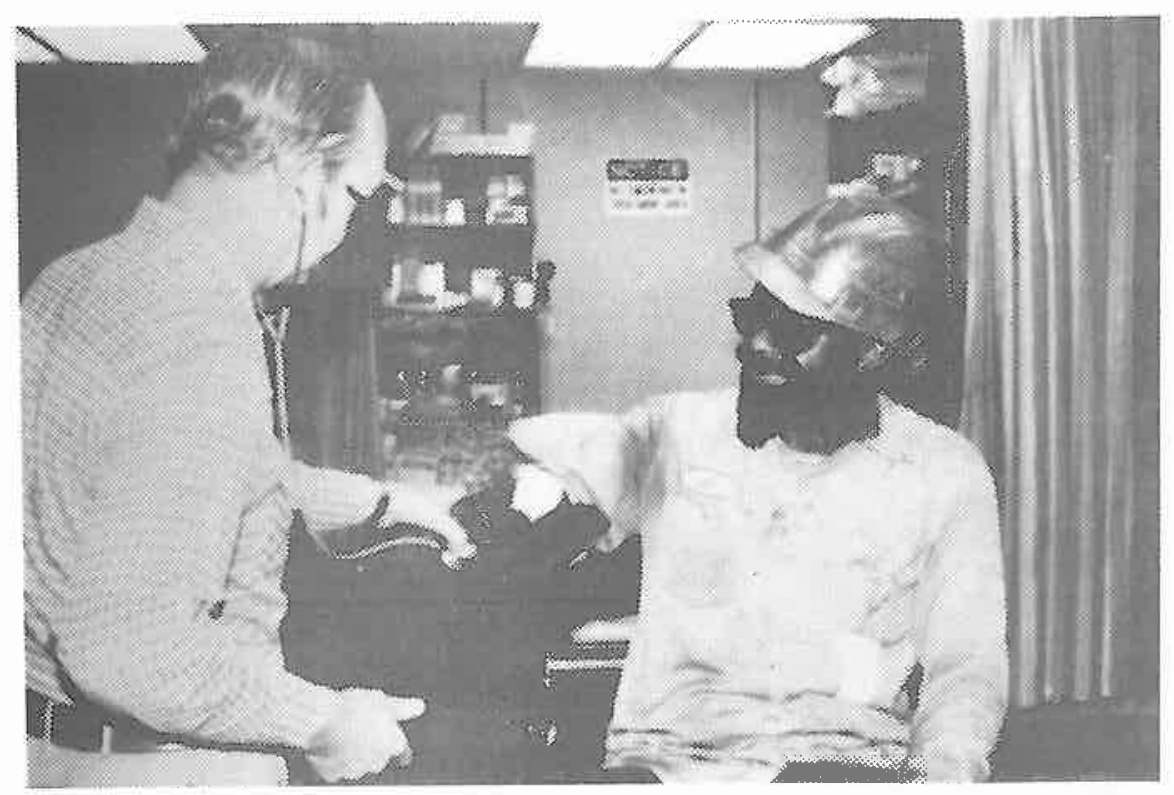

Figure 1l. Blood pressure check.

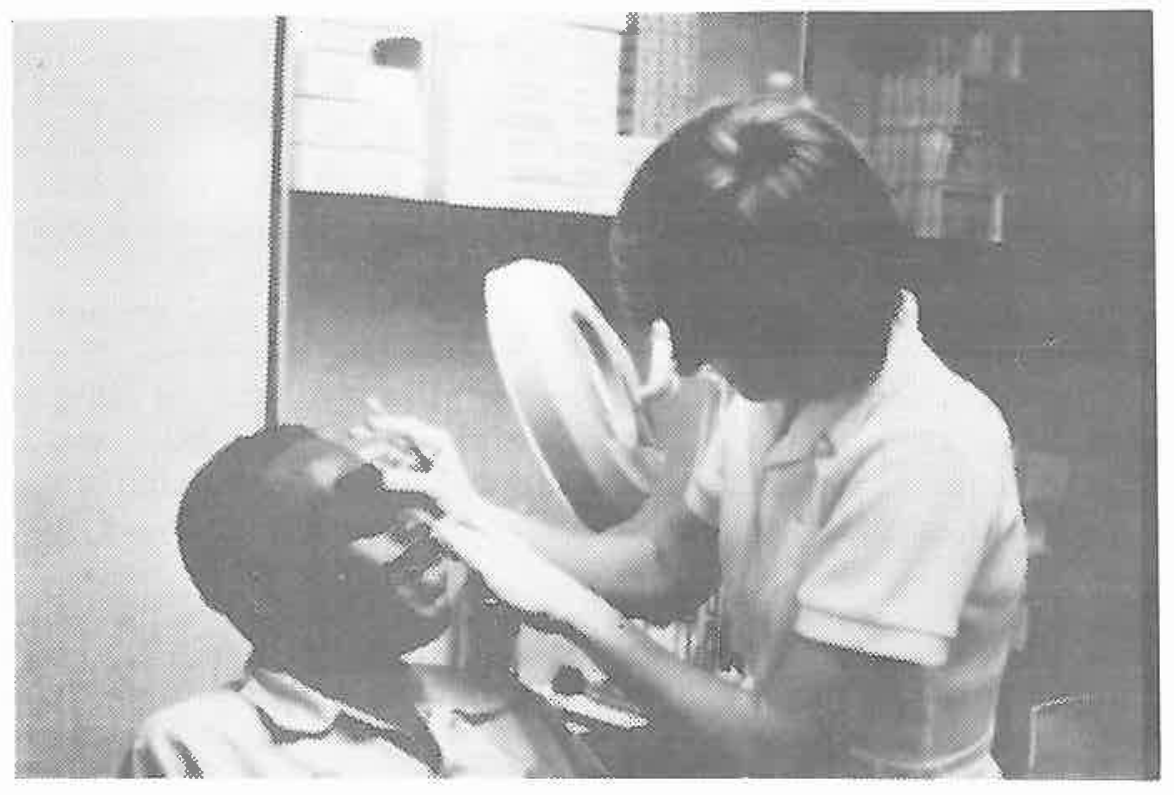

Figure 12. Preventive eye check at end of shift. 
Along with all of the items I have discussed and illustrated as part of a good comprehensive safety and health program, I firmly believe that one more needs to be included, and that is incentive. We have set up incentive programs at all of our facilities and firmly believe that it helps keep safety in the minds of our employees. Our most commonly used incentive programs are:

Gift Awards - A gift award system that is based upon the amount of time of exposure that employees are subject to. The time factor varies from 2 to 12 months depending upon conditions and types of work involved.

Steak Dinners - When a million manhours of accident free time is realized, everyone gets to enjoy a steak dinnex cooked by professionals over charcoal grills (Figure 13).

Performance Appraisal - An integral part of all management performance appraisals is the safety and health record of individuals working within the department. This evaluation directly affects the amount of pay that the individual will receive in the coming year and thus a

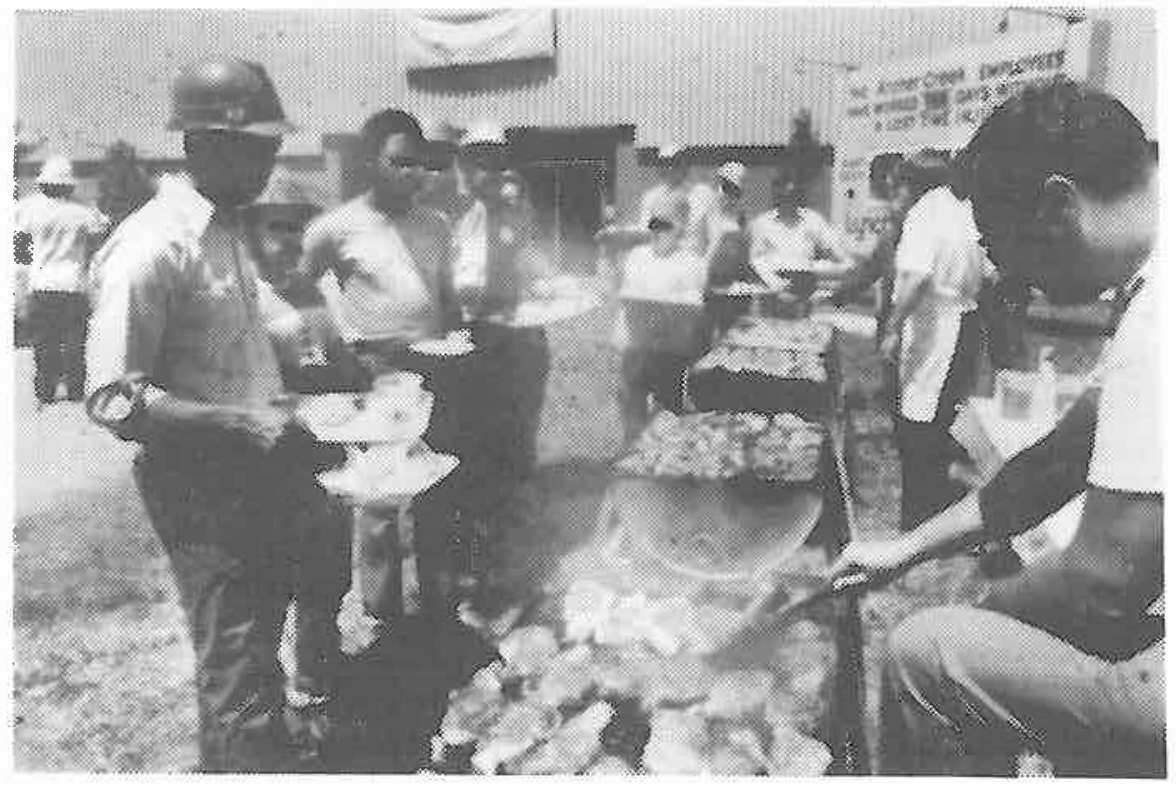

Figure 13. Rewards (steak dinners) for safe performance are used as incentives. 
strong incentive is created to enforce those rules and regulations which have been set by us.

Recognition - We recognize good safety performance by giving out five year award pins and by advertising program activities in our company newspapers and on our large safety signs.

Profit by Mistakes - When things don't go right (and occasionally they don't), we also circulate negative recognition. A lost time accident description is recorded on a pink sheet of paper entitled with large letters "WHERE WE HAVE FAILED". This sheet is posted on bulletin boards throughout the entire company where individuals can read about the accident that has befallen a fellow employee and hopefully benefit from the situation by avoiding similar circumstances.

\section{Costs and Benefits}

You have heard me describe here the determination and sometimes hardnosed attitude taken by management with regard to the safety and health program. You have heard me talk about portions of the program that are obviously expensive (up to $\$ 9,000$ for one steak dinner). But let's take a close look at some of the justification:

Lower Compensation Costs - Workers's compensation costs for Lynchburg Foundry over the years of $1975-1978$ have ranged from $\$ 21.00$ per thousand manhours worked to $\$ 65.00$ per thousand manhours worked less than the Virginia Foundry averace set up by the Industrial Commission (Figure 14). This has meant retro-nayments from our compensation insurer in excess of a quarter of a million dollars per year.

Fewer Fines - There have been few OSHA citations, and fines have been minimal because of our demonstrated concern for safety and health and the gravity of the violations found.

Higher Efficiency - Surveys have revealed improved attitudes on the part of workers toward the foundry as a good place to work. Employees have recognized caring attitudes toward them as individuals. As employee attitude has improved, so has efficiency. Our standards experts have documented molding efficiency levels in certain operations as high as 124 percent over the norm of 100 percent.

Satisfying Our Moral Obligations - Concern for the health and well being of all employees should be the backbone of any safety and health program and certainly reflects justification for any expenditures of money and efforts to insure employee well being. Unfortunately, with the complexities of today's indistrial systems, new technology, and new chemical compounds that are part of this technology, few industries have the expertise to diagnose all of the hazards and institute all of the control necessary to insure a workplace free of recognized hazards. 


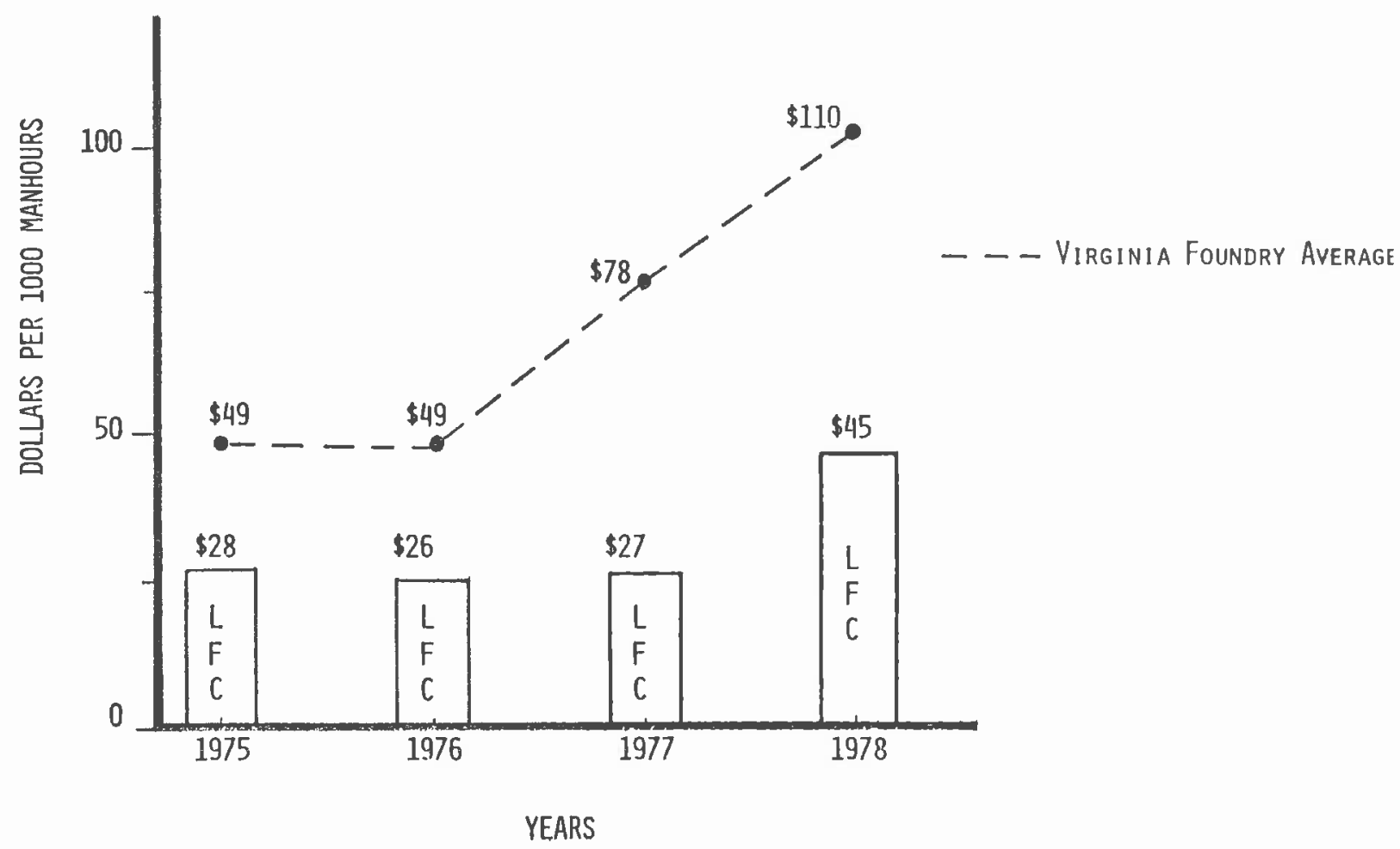

Figure 14. Recent history of lower worker's compensation costs paid out by Lynchburg Foundry Company as a result of its safety and health program.

In conclusion, if you want a sound safety and health program, I think you can now readily see that it takes two main ingredients: determination, from top management down to the leadman on the production line; and money, for all of the guarding, control systems, monitoring and surveillance programs. Team these factors up with some well-defined systems administration and you will have a successful foundry safety and heal.th program. 
PANEL DISCUSSION ON CHEMICAL BINDERS - PAST, PRESENT AND FUTURE

\author{
Moderated by George Tubich \\ Tubich and Associates \\ Grand Rapids, Michigan
}

\title{
INTRODUCTION
}

The purpose of the chemical binder panel was to provide a forum for comments, questions, and interchange of information concerning the potential hazards involved with the use of chemical winders in mold and coremaking and control measures to reduce or eliminate these hazards. Two members of the panel represented manufacturers of chemical binder systems and/or oomponents and two others represented the users of the binder systems.

Prior to the open floor discussion each of the panelists presented short introductory remarks. To facilitate audience involvement and discussion, written questions had been requested from the audience from the beginning of the symposium. The text of the panel incorporates both the introductory remarks of the panelists and the discussions, comments and questions. 
PANELIST'S REMARKS

CONTROL TECHNOLOGY FOR FURFURYL ALCOHOL - BASED SYSTEMS:

THE FURAN NO-BAKE PROCESS

\author{
Daniel S. P. Eftax, Ph.D \\ Manager, Product Development - Foundry \\ Quaker Oats Company \\ Chicago, Illinois
}

\title{
INTRODUC'LION
}

The recent NIOSH report on foundries presented the available technology to control exposure to potential physical and chemicals agents (1). Three chemically bonded sand processes were covered: phenolic shell molding, furan hot box coremaking, and phenolic urethane cold box coremaking. In addition, case histories on each of the above processes were presented.

In this presentation the no-bake chemically bonded sand process will be covered, that is, the process by which cores and molds are produced at room temperatures. I will identify controls and precautions that are recommended to improve the quality of the workplace environment when utilizing furan foundry binder systems, i.e., binders based on furfuryl alcohol. The comments will be specific for the furan no-bake process since the major outlet for furfuryl alcohol is the no-bake process.

In certain respects, the controls recommended for the furan no-bake process may be applicable to other furan processes that are utilized in the foundry: hot box, cold box, and warm box.

SYSTEM COMPONENTS

\section{Binders}

The composition of a furan no-bake binder varies depending on the performance required in a particular foundry. Furfuryl alcohol content may vary from 45\% up to nearly 100\%, and may be present as a monomer or in a prepolymerized form, or blends thereof. Other ingredients may include urea, formaldehyde, urea-formaldehyde polymers, phenolic materials, water, and possible other additives. In addition, small amounts of silanes ( 0.1 to $0.3 \%$ ) are added to ensure high tensile strength under conditions of high humidity. Formulations include nitrogen-free, formaldehyde-free, water-free types, as well as binders with varying proportions of any or all of the additives mentioned above. The main constituent is furfuryl alcohol. The binder is placed on the sand after the catalyst has been added to the sand and mixed. 
Furan no-bake catalysts are generally proprietary mixtures of acids and solvents, and, at times, color-coding dyes. The two main types of acid are: phosphoric acid and aromatic sulfonic acids (benzene-, toluene-). Common sólvents are water and/or methanol. The catalyst is always placed on the sand first, followed by the binder.

\section{PRECAUTIONARY MEASURES/CONTROLS AND PERSONAL PROTECTION}

The following are recommendations to minimize the potential for, and exposure to, hazards associated with furan no-bake systems. Recommendations for the mixing, molding, and coremaking areas are presented first, followed by pouring, cooling and shakeout.

Mixing, Molding and Coremaking

Potential hazards involve air contaminants and skin and eye contact. The air contaminants of industrial hygiene concern and their osHA permissible exposure limits (PEI) are:

Furfuryl alcohol (50 ppm);

Formaldehyde (for furan binders that are formulated with formaldehyde)

(3 ppm);

Toluene (from free toluene in the toluenesulfonic acid catalyst) (200 ppm);

Benzene (may arise from the use of benzene sulfonic acid catalyst) (10 ppm).

1. Do not directly mix binder and catalyst. The reaction is violent unless sand is present to absorb a significant amount of released heat.

2. Use protective equipment when handling the binders, catalysts, and mixed sand (gloves, aprons, long-sleeved shirts, sacety glasses). In general, furan binders are slightly irritating to the skin, slightly toxic dermally, and severely irritating to eyes. The catalysts are potentially more hazardous to skin and eyes than the binders. The mixed sand is a much less potential hazard than the binders and catalysts since it is about $98 \%$ sand, and sand is regarded as inert.

A series of Ames tests on furfuryl alcohol and representative furan binders indicated that they were not mutagenic or carcinogenic (2).

3. Use high purity rounded silica sands (AFS GFN $55 \pm 10 ; 3$ or 4 screen). Rounded sands generally require much lower levels of binder and catalyst than subangular or angular sands; lowest levels of binder and catalyst are thus attained.

4. Use sand at $21-32^{\circ} \mathrm{C}(70-900 \mathrm{~F})$ (new and/or reclaimed). Higher sand temperatures result in larger amounts of volatiles being emitted and lower levels of catalyst being used. Lower sand temperatures have an opposite effect: lower amounts of volatiles and higher levels of catalyst. Each foundry arrives at its own optimum 
compromise with respect to sand temperature, depending on ventilation controls and process requirements.

5. Use functional exhaust fans on the mixer and in the work areas, with air circulation away from the employees' stations. Fans will control gases (from the binder system) and silica dust (from the sand or mixer). The use of continuous-type sand mixers minimizes employee contact with binder and catalyst.

6. Use binders that are free or contain less than $0.5 \%$ free formaldehyde; use catalysts that do not contain volatile solvents. Furfuryl alcohol is a high boiling liquid with a low vapor pressure; when catalyzed it polymerizes to a non-volatile solid. Furan binders are reactive and do not contain volatile or non-reactive solvents.

Pouring, Cooling and Shakeout

Organic binders are composed primarily of carbon, hydrogen, and oxygen, which, under optimum conditions of combustion, should decompose into carbon dioxide and water. However, these optimum conditions are not present in a foundry mold filled with molten metal in the presence of such things as core washes, adhesives, and exothermics. The following two recommendations are considered important in improving the quality of the air at pouring:

1. Use the lowest possible levels of binder and catalyst. Low percentages of binder result in decreased amounts of decomposition products on pouring and lower levels of potential volatile material in the reclaimed sand. In addition to improved air quality at pouring, low binder consumption provides the added benefit of greater economy.

2. Provide adequate ventilation. Air quality at the pouring station can be substantially improved by any ventilation arrangement that will effectively prevent the decomposition gases from entering the breathing zone of the personnel in the pouring area.

Test Data for Decomposition Products--

A long series of volatile decomposition tests by various organizations has concluded that the major volatile decomposition product of foundry binder systems that is of any serious concern is carbon monoxide (CO) (4). Binder systems evaluated in these studies included hot box, shell, silicates, all the various no bakes, and also green sand. The other major volatiles, carbon dioxide and water, were not of serious concern environmentally.

Laboratory experiments showed that the type of decomposition products emitted during pouring depends on the specific binder and catalyst used. Furan no-bakes that are nitrogen-free decomposed into carbon dioxide, carbon monoxide, hydrocarbons, and traces of formaldehyde. Binders that contain urea emitted minimal amounts of nitrogen-containing compounds (ammonia, hydrogen cyanide) in addition to the above gases. Sulphur-containing catalysts (sulphonic or sulphuric acids) predictably decomposed into sulphurcontaining gases, e.g., sulphur dioxide, and hydrogen sulfide. The fate of 
phosphoric acid has not been fully documented; ammonium phosphate is believed to be an intermediate with binders containing urea. It is reasonable to assume that phosphoric acid eventually shows up as 'phosphate'.

The amount of volatiles depends on the sand-to-metal ratio and the level of the binder system used: lower sand-to-metal ratios and/or heavier metal sections and higher levels of binder system result in larger quantities of volatiles being evolved.

When the laboratory test concentrations and the toxicities of individual gases are compared to one another, carbon monoxide stands out as a possible problem in poorly ventilated foundries. Many operating variables can affect the type and amount of volatiles, but if the carbon monoxide level is maintained within the acceptable standard (50 ppm, $55 \mathrm{mg} / \mathrm{m}^{3}$ ), all other trace gases will most likely be either below the OSHA permissible exposure limits or below the detectable limit (4).

Recently, there has been some publicity regarding benzo(a) pyrene (BAP), a suspected carcinogen that is found in coke oven emissions, char broiled meats, in automobile exhausts, in cigarette smoke, in metal pouring of green sand molds, etc. (5). The question was raised whether BAP could possibly form during the decomposition of a furan no-bake binder. The testing that has been conducted to date indicates that BAP is not a problem with furan no bakes; this confirms the results obtained by an independent research institute that examined, besides furan no bakes, other types of foundry binder systems.

FOUNDRY MEASUREMENTS

Mixing Area

Since October, 1976 under foundry operating conditions, the quaker Oats Company has made measurements for furfuryl alcohol, formaldehyde, toluene, and benzene vapor levels in about 40 foundries pouring from 5 to over 100 tons of ferrous metal per day; with a strip time of 2-30 minutes; using continuous mixers of $45-363 \mathrm{~kg} / \mathrm{min}(100-800 \mathrm{lb} / \mathrm{min})$; at sand temperatures of $18-55^{\circ} \mathrm{C}\left(65-130^{\circ} \mathrm{F}\right)$; at pouring temperatures of $1290-1620^{\circ} \mathrm{C}\left(2350-2950^{\circ} \mathrm{F}\right)$; using a variety of sands: 100\% new, 100\% reclaimed, in various mixtures.

All the foundries tested to date have shown levels of less than 50 ppm of furfuryl alcohol; about half of the breathing zone measurements were less than $5 \mathrm{ppm}$. Formaldehyde levels averaged about $1 \mathrm{ppm}$ for those furan binders formulated with formaldehyde. Toluene and benzene measurements were about $1 \mathrm{ppm}$.

Independent sampling in European foundries has confirmed our values since all of their results showed less than $50 \mathrm{ppm}$ of furfuryl alcohol $(6,7,8)$. This also holds true for OSHA measurements in several U.S. foundries $(9,10)$. 
In the pouring areas of foundries, carbon monoxide and sulfur dioxide (for systems using sulfonic acids) were found to be the major gases of interest. Furfuryl alcohol levels were generally below 1 ppm.

Generally, breathing zone levels below standards were recorded for carbon monoxide and sulfur dioxide in adequately ventilated pouring areas. The carbon monoxide levels varied, depending on the time and place of measurement. As expected, higher values were obtained immediately following pouring. In those foundries that used a sulfonic catalyst for curing the core or mold, sulfur dioxide levels averaged around 1 ppm (OSHA PEL = 5 ppm).

\section{REFERENCES}

1. An Evaluation of Occupational Health Hazard Control Technology for the Foundry Industry, USDHEW (NIOSH) Publication No. 79-114, October 1978.

2. Quaker Oats Data, unpublished.

3. NIOSH Criteria Document on Furfuryl Alcohol, U.S. Department of Health, Education and Welfare, HEW Publication No. (NIOSH) 79-133, March 1979.

4. Scott, W. D., Bates, C. E., and James, R. H., Chemical Emissions from Foundry Molds, AFS Transactions, Vol. 85, 1977 (77-98).

5. Scott, W. D., Carcinogenic Possibilities in Foundry Operations, Foundry M\&T, December 1978 (48-55).

6. L. Johnson and B. Thyberg, Influence of Organic Binders on the Atmosphere in Fo'dndries, Svenska Gjuteriforeningen, BCIRA International Conference University of Warwick, 1976.

7. M. Virtamo and A. Tossavainen, Gases Formed from Furan Binding Agents, Scand. J. Work Environ. and health 2 (1976); suppl. 1. 50-53.

8. V. B. Danilov, V. V., Tarasov and Y. M., Mamatov, Chemical Air Pollution from Sands Containing "Furitol-125", Castings Production, October 1976, p. 430 (Translation from Liteinoe Proizvodstvo, 1976, 10, p. 37).

9. Apol, A: Western Foundry Company, Tigard, OR, Health Hazard Evaluation Determination Report No. 73-116-85, Cincinnati, U.S. Dept. HEW, PHS, Center for Disease Control, NIOSH, 1973, 4 pp.

10. Burton, D. J., and Rivera, R. O.: May Foundry, Salt Lake City, UT, Health Hazard Evaluation Determination Report No. 72-10-15, Cincinnati U.S. Dept. HEW, PHS, Center for Disease Control, NIOSH, 1972, 7 pp. 
PANELIST'S REMARKS

URETHANE FOUNDRY BINDERS - AN INDUSTRIAL HYGIENE APPRAISAL

R. H. Toeniskoetter, Ph.D

Manager, Environmental \& Occupational Safety

Ashland Chemical Company

Dublin, Ohio

\section{INTRODUCTION}

Three types of urethane binders are used by foundries: alkyd-isocyanate no-bake; phenolic-urethane no-bake; and phenolic-urethane cold box. The alkyd-isocyanate no-bake was introduced in 1965; the phenolic-urethane cold box in 1968, and the phenolic-urethane no-bake in 1970. Usage of these binders has grown steadily since their respective introductions to the foundry industry. In 1979, approximately one hundred million pounds of urethane binders will be consumed by the United States Foundry Industry, and an additional one hundred million pounds throughout the rest of the world. Since their introduction in 1965, over five hundred million pounds of urethane binders have been consumed by the United states Foundry Industry with an equal amount being used elsewhere in the world.

This rapid increase in the use of these types of binders can be attributed to their many desirable characteristics for production foundry operations. Urethane foundry binders provide ease of handling, excellent coremaking and molding properties, high productivity, excellent casting quality, good energy conservation and favorable environmental and ecological characteristics. The foundry industry has enjoyed a good safety and health record in the use of these binders. Because of their chemical makeup, however, urethane binders can present potential occupational hazards if misused. By providing adequate safety and health information and guidance on their use, Ashland Chemical Company has been able to assist foundries in adapting these binder processes to their operations without excessive difficulties or safety/health problems.

\section{COMPOSITION AND USE}

Urethane binders are three-part systems consisting of polyol, polymeric isocyanate and catalyst components. In the presence of the catalyst, the polyol combines chemically with the polymeric isocyanate to produce a highly cross-linked urethane bond. Specific components of the three types of urethane binders are shown in Table 1. Part A of the alkyd-isocyanate system consists of an alkyd resin dissolved in an aliphatic hydrocarbon solvent. These are usually modified with a petroleum hydrocarbon resin. Part A's of alkyd-isocyanate binders are similar to core oils. Part C of the alkyd- 


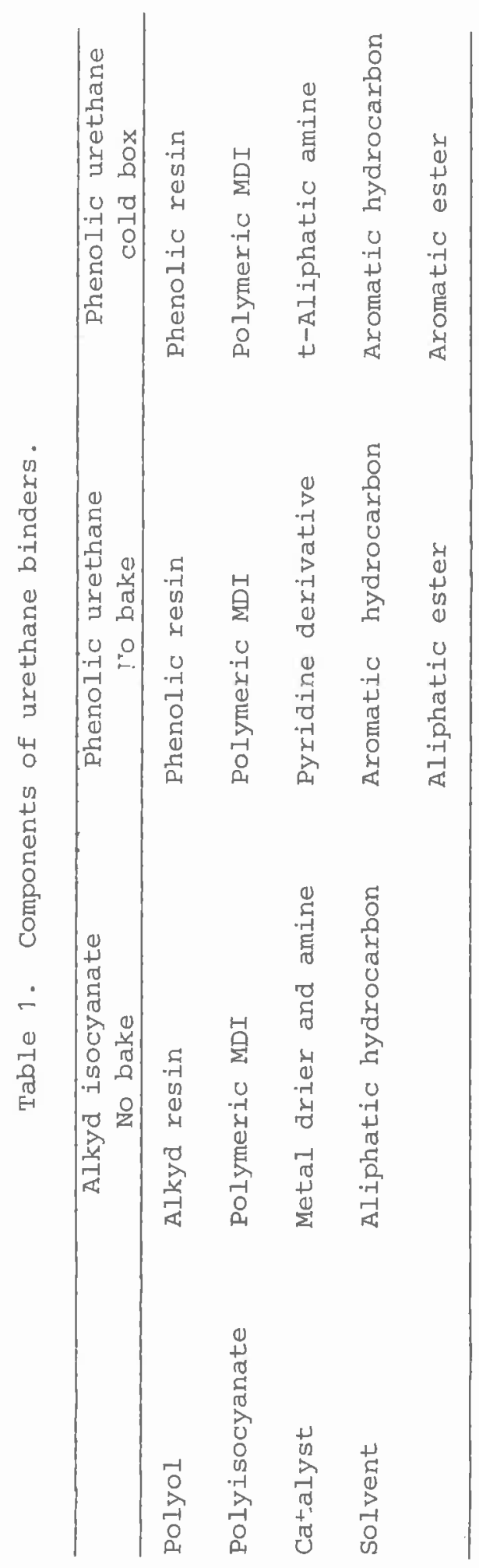


isocyanate system is a polymeric isocyanate of the methylene bis phenylisocyanate (MDI) type. It is a dark colored liquid of moderate viscosity and extremely low vapor pressure. Part $B$ of the alkyd-isocyanate system is the catalyst. It contains a metal drier to facilitate the final oxidative-polymerization of the binder and also an amine catalyst for the urethane reaction which provides the initial.set or curing.

The phenolic-urethane no-bake system uses a phenol-formaldehyde resin (phenolic resin) dissolved in solvent as the polyol component. The isocyanate component is a polymeric MDI dissolved in solvent. The catalyst is a low volatility pyridine derivative which may be supplied neat or dissolved in solvent depending on the use characteristics desired. Solvents used in these phenolic urethane components are high boiling aromatic petroleum hydrocarbons and aliphatic esters.

The phenolic urethane cold box binder system is similar to the corresponding no-bake. Part I is a phenol formaldehyde resin dissolved in a solvent blend which consists of highboiling aromatic petroleum hydrocarbons and esters. Part II is the polymeric MDI in aromatic petroleum hydrocarbon solvent. The catalyst for the phenolic urethane cold box system can be either triethylamine (TEA) or dimethylethylamine (DMEA). These catalysts are provided in liquid form but are vaporized into a stream of air, nitrogen or carbon dioxide and introduced into the sand/binder mixture as a gas.

The alkyd-isocyanate and the phenolic urethane binders are no-bake systems. After polyol, polymeric isocyanate and catalyst components are mixed together on sand, a spontaneous chemical reaction occurs and results in hardening, or cure, of the sand mass. No external heat is required. Settling or curing times with the alkyd-isocyanate no-bake range from ten minutes to one hour or more and as a result of these working characteristics this type of binder is generally used for larger core or mold work, or where high production rates are not desired. The phenolic urethane no-bake is a very fast setting system providing strip times in the range of 3 to 8 minutes. This fast setting characteristic allows the phenolic urethane no-bake to be used on high production lines for cores or molds.

The phenolic urethane cold box binder system is designed primarily for high production coremaking or molding where curing can be controlled by an external triggering agent. The triggering agent in this case is the gaseous catalyst, triethylamine or dimethylethylamine, which is introduced into the sand binder mix as a vapor. As this gaseous amine is absorbed into the resin system, the curing reaction is initiated and occurs almost instantaneously. Cured cores or molds can then be ejected from the core box or pattern within a matter of seconds. The phenolic urethane cold box system is readily adapted to fast machine production of cores and molds.

\section{POTENTIAL EMISSIONS}

Table 2 shows the potential emissions that need to be considered when using urethane binders. Permissible Exposure Limits (PEL's) are shown where applicable. Whether a potential exposure problem could exist in the use of a urethane binder is dependent on the nature of the operation and the 
Table 2. Potential emissions from urethane binders.

\begin{tabular}{|c|c|c|}
\hline Emission & PEL (OSHA) * & Source \\
\hline Phenol & 5 ppm-skin & $\begin{array}{l}\text { Volatilization } \\
\text { Decomposition }\end{array}$ \\
\hline Formaldehyde & 3 ppm & $\begin{array}{l}\text { Volatilization } \\
\text { Decomposition }\end{array}$ \\
\hline Solvent & Various & $\begin{array}{l}\text { Volatilization } \\
\text { Decomposition }\end{array}$ \\
\hline MDI & $0.02 \mathrm{ppm} \mathrm{C}$ & $\begin{array}{l}\text { Volatilization } \\
\text { Decomposition }\end{array}$ \\
\hline Triethylamine & $25 \mathrm{ppm}$ & Volatilization \\
\hline Dimethylethylamine & & Volatilization \\
\hline Carbon monoxide & $50 \mathrm{ppm}$ & Decomposition \\
\hline Carbon dioxide & $5,000 \mathrm{ppm}$ & Decomposition \\
\hline Hydrocarbons & Various & Decomposition \\
\hline Hydrogen cyanide & 10 ppm & Decomposition \\
\hline Ammonia & $50 \mathrm{ppm}$ & Decomposition \\
\hline Smoke & & Decomposition \\
\hline
\end{tabular}

*Permissible exposure limit. 
particular stage of the foundry process involved. When sand is being mixed with binder materials, the volatile components can evaporate into the work environment. Similarly, volatiles can be produced while the sand-binder mix is being worked in preparation of the core or mold. Once the binder has set or cured, the components are chemically or physically entrapped and emissions by volatilization are extremely low.

During mixing, molding, coremaking and other operations prior to cure of the binder, the principal volatile component from the alkyd-isocyanate system is the aliphatic petroleum hydrocarbon solvent. Because this material has a low vapor pressure and a PEL of $500 \mathrm{ppm}$, exposure has not been a problem. When phenolic urethane binders are mixed with sand, potential emissions of phenol, formaldehyde and the solvent components are possible. These emissions are greatest for operations employing a high speed continuous mixer which sprays sand from the mixing chamber at a high rate. High sand temperature can increase the potential emissions. At such an operation, the operator stands close to the mixer discharge and works the sand onto the pattern or into the core box. Exposures under such working conditions can be significant and one usually needs to conduct a monitoring survey to establish the levels of airborne contaminants in the work environment. General exhaust in the work area may be adequate to control exposures below permissible exposure limits, however, when exposures are excessive further local ventilation is necessary. Exhaust ventilation at the discharge port of the mixer can be quite effective.

Organic isocyanates are toxic chemicals. They are respiratory irritants and potential sensitizers. The OSHA PEL for organic isocyanates is only $0.02 \mathrm{ppm}$ (ceiling) and NIOSH has recommended lower exposure limits. Recognizing potential problems as a result of organic isocyanate exposure, urethane foundry binders are only formulated with the polymeric forms of MDI. The vapor pressure of these polymeric forms of MDI is in the neighborhood of $0.000024 \mathrm{mmHg}$ at $75^{\circ} \mathrm{C}$. With such a low vapor pressure, it is extremely unlikely that vapor concentration in a work area where no heat is involved could reach the PEL level of $0.02 \mathrm{ppm}$. Extensive monitoring of foundry mixing, coremaking and molding stations by Ashland Chemical Company and others has confirmed the very low likelihood of isocyanate exposure being a problem at these operations. In fact, essentially all monitoring results have been near or below the detectable limit of $0.002 \mathrm{ppm}$ at such work stations.

Cold box coremaking presents a potential exposure hazard from the triethylamine or dimethylethylamine catalyst. These compounds are irritants of the mucous membranes and have very strong, unpleasant odors. They are also known to cause edema of the corneal membranes which results in blurred vision or the "blue haze" effect. Triethylamine has an OSHA established PEL of $25 \mathrm{ppm}$. Dimethylethylamine has no established PEL but based on limited data its toxicological properties appear similar to that of triethylamine which it resembles structurally and chemically. We recommend that exposures at the work station should be controlled to well below $10 \mathrm{ppm}$ for either triethylamine or dimethylethylamine. Control of exposures to below $10 \mathrm{ppm}$ is needed at any rate to provide a relatively pleasant work station free of strongly obnoxious odor. The odor thresholds for triethylamine and dimethylethylamine 
appear to be in the range of 1 ppm or less.

During pouring, cooling and shakeout operations involving urethane cores or molds, a wide range of degradation and volatile products are produced. These have been generally described in the published literature (1). As with any organic foundry binder, the range of thermal degradation products is quite broad and attempts to measure the full range of potential exposures in an operating foundry would be a task of great magnitude. We suggest that the initial focus should be on insuring that smoke and carbon monoxide levels are maintained within reasonable and acceptable limits. The composition of smoke from decomposing foundry binders is largely unknown at this time. Where urethane binders are used it is also important to ensure that levels of organic isocyanates are within exposure limits, MDI is formed at very low levels as a result of the thermal degradation processes occuring in urethane binders. Concentrations of MDI in excess of the 0.02 ppm PEL are possible when the work place has inadequate ventilation. Experience has shown that, with a reasonable amount of local and general exhaust ventilation, the exposure levels to MDI can be kept well below the established or recommended exposure limits.

\section{MONITORING PROGRAM}

Captive foundries and many independent jobbing foundries have capable industrial hygiene and safety staffs. As a supplier of foundry products, Ashland Chemical Company provides safety and health information to its customers in the form of material safety data sheets, labels, technical brochures and through seminars and personal communications. Foundries with in-house capabilities generally conduct their own monitoring surveys and establish engineering controls to ensure healthful work environments which at least meet minimum standards for occupational exposures. Foundries without in-house capabilities, especially in the industrial hygiene area, need support to recognize and evaluate potential exposure hazards and for recommendations regarding engineering controls and work practices. Ashland provides such a service by sending a qualified Industrial Hygienist to customer foundry plants to conduct preliminary monitoring surveys. The scope of such surveys is always tailored to the particular operation involved and the nature of the binder products that are employea. Results of such monitoring surveys are reported to appropriate foundry management along with interpretations as to the significance of the data and recommendations regarding engineering controls that should be considered. Frequently, followup surveys are conducted to ensure that engineering controls that were implemented are doing the job intended. Thereafter, we expect the foundry organization to follow up with any further required actions and to establish an ongoing program for monitoring their in-plant environment. Ashland's function here is that of technical service and is intended to assist the customer in recognizing and evaluating potential problems. It is not a substitute for a foundry's own in-house program in the areas of industrial hygiene or safety. We strongly recommend that foundries unable to provide this in-house capability should retain suitable outside help in the form of a consultant or independent laboratory. 
An initial summary of results of monitoring surveys in our customer plants was reported in 1974 (2). There was evidence at that time of potentially significant exposures to MDI in the foundry work environment. Exposures above the permissible exposure limit for MDI, however, were found only at pouring, cooling or shakeout stations.

Since that time, our ongoing program for inplant monitoring has established significant new data as is summarized in Tables $3,4,5$, and 6 . It is most noteworthy that in 29 iron and steel foundries using urethane binders, of a total of 203 samples taken for MDI measurement, only four samples showed airborne contaminant levels in excess of $0.02 \mathrm{ppm}$. Our measurements for MDI always include a simultaneous measurement for aromatic amine, calculated as methylene bisaniline (MBA) because organic amines are known interferences in the isocyanate determination. Of 185 samples collected in 28 foundries, 183 showed levels of MBA less than $0.1 \mathrm{ppm}$. The remaining two samples indicated levels of $\mathrm{MBA}$ in the range 0.1 to $0.2 \mathrm{ppm}$.

In the last few years, there has been expanded use of the phenolic urethane cold box system for production of cores to be used in gravity-fed, permanent mold aluminum casting applications. In these automated operations, cores are placed in the permanent molds which are at temperatures in the range of $316-427^{\circ} \mathrm{C}\left(600-800^{\circ} \mathrm{F}\right)$. After the mold closes, it is automatically poured and opened for ejection of the casting after a rather short solidification time of 1-2 minutes. Under these conditions, considerable thermal degradation of the core binder occurs. Because temperatures are relatively low, most of the degradation products escape unburned to the work environment. Smoke and decomposition products can be quite heavy as the casting is removed from the permanent mold and inspected prior to being placed on the cooling conveyor. Monitoring surveys have shown that the MDI concentration in these smokes can exceed $0.02 \mathrm{ppm}$. In eight foundries, of a total of 42 samples taken, 23 showed concentrations in excess of the PEL for MDI. Similarly, the concentrations of MBA were found to be correspondingly high, with seven of 40 samples showing levels in the range of 0.1 to $0.2 \mathrm{ppm}$ and two samples being in excess of $0.2 \mathrm{ppm}$.

This data from the monitoring surveys in these new aluminum casting operations exposed a new potential hazard. Since these were all new operations, initial recognition of a potential problem was the observation of heavy smoke during the casting pickup and inspection operation. The results of our monitoring surveys alerted foundry management to the potential problem. In all cases actions have been, or presently are being, taken to bring these situations under control. Installation of suitable local exhaust ventilation has been effective in reducing these exposures to well below permissible exposure limits. While engineering controls were being implemented, foundry management prudently curtailed operations, required use of appropriate respirators for workers, or took other temporary control measures at these work stations. We believe that by prompt action on the part of foundry management, and Ashland as a supplier, this potential hazard was quickly recognized, evaluated and suitable engineering controls implemented. 
Table 3. Summary of monitoring data for MDI/MBA*; iron and steel foundries.

\begin{tabular}{lrr}
\hline & MDI & MBA \\
\hline Total foundries & 29 & 28 \\
Total samples & 203 & 185 \\
No. in range N.D. to $0.005 \mathrm{ppm}$ & 185 & \\
No. in range $>0.005$ to $0.02 \mathrm{ppm}$ & 14 & \\
INo. in range $>0.02$ ppm & 4 & 2 \\
No. in range N.D. to $0.1 \mathrm{ppm}$ & & 0 \\
No. in range $>0.1$ to $0.2 \mathrm{ppm}$ & & \\
No. in range $>0.2$ ppm & & \\
\hline
\end{tabular}

*MDI = Methylene bisphenyl-isocyanate.

${ }^{*}$ MBA $=$ Methylene bisaniline.

Table 4. Summary of monitoring data for $\mathrm{MDI} / \mathrm{MBA}$; aluminum foundries.

\begin{tabular}{lrr}
\hline & MDI & MBA \\
\hline Total foundries & 8 & 7 \\
Total samples & 42 & 40 \\
No. in range N.D. to $0.005 \mathrm{ppm}$ & 8 & \\
No. in range $>0.005$ to $0.02 \mathrm{ppm}$ & 12 & 31 \\
No. in range $>0.02$ ppm & 23 & 7 \\
No. in range N.D. to $0.1 \mathrm{ppm}$ & & 2 \\
No. in range $>0.1$ to $0.2 \mathrm{ppm}$ & & \\
No. in range $>0.2$ ppm & & \\
\hline
\end{tabular}

*MDI $=$ Methylene bisphenyl-isocyanate.

${ }^{*}$ MBA $=$ Methylene bisaniline. 
Table 5. Summary of monitoring data for phenol; iron, steel and aluminum foundries.

\begin{tabular}{lr}
\hline Total foundries & 25 \\
Total samples & 102 \\
No. in range N.D. to $1 \mathrm{ppm}$ & 95 \\
No. in range $>1$ to $5 \mathrm{ppm}$ & 6 \\
No. in range $>5 \mathrm{ppm}$ & 1 \\
\hline
\end{tabular}

Table 6. Summary of monitoring data for TEA/DMEA; iron, steel and aluminum foundries.

\begin{tabular}{lr}
\hline Total foundries & 27 \\
Total samples & 210 \\
No. in range N.D. to $5 \mathrm{ppm}$ & 100 \\
No. in range $>5$ to $10 \mathrm{ppm}$ & 34 \\
No. in range $>10$ to $25 \mathrm{ppm}$ & 51 \\
No. in range $>25 \mathrm{ppm}$ & 25 \\
\hline
\end{tabular}


At mixing stations utilizing the phenolic urethane no-bake, exposures to phenol, formaldehyde and solvent vapors are the principal concerns. Our monitoring surveys have established that exposure levels to solvent vapors are generally well below the respective permissible exposure limits. Phenol exposure also appears not to be a problem. In 18 foundries, 90 samples were collected for phenol and in 85 of those the phenol concentration was less than $1 \mathrm{ppm}$. Five other samples showed concentrations in the range of 1-5 ppm and none were in excess of $5 \mathrm{ppm}$. Airborne formaldehyde at sand mixing stations employing phenolic urethane binders is difficult to monitor because of interference from phenol. Because of this interference, we have not been able to obtain monitoring data using long-term sampling techniques. Results from Dräger Tube measurements have indicated that the concentrations of formaldehyde at a phenolic urethane sand mixing station seldom exceed the permissible exposure limit of $3 \mathrm{ppm}$. In those few instances where formaldehyde levels did exceed $3 \mathrm{ppm}$, we were usually able to trace a potential problem to the use of hot sand which would increase the rate of evolution of formaldehyde. In those cases, suitable recommendations were made to foundry management to control the temperature of the sand going to the mixers more carefully.

A final potential exposure to be considered is that of triethylamine or dimethylethylamine at phenolic urethane cold box coremaking operations. One monitoring program has taken us to 27 foundries where 210 samples have been collected. A summary of the ranges of data obtained is shown in Table 6 . Approximately $12 \%$ of the samples showed concentration levels in excess of $25 \mathrm{ppm}$ with an additional 25\% of the samples being in the range of 10 to 25 ppm. High amine levels at a phenolic urethane cold box work station are usually the result of leaking fittings, inadequate core box seals or excessive use of the amine catalyst. When this monitoring data was reported to foundry management, steps were taken to improve the engineering controls on the work operation. As a result, in almost all cases these excessive exposures were quickly brought under control. We continue to work with any of the foundries that have remaining problems.

\section{SUMMARY}

Urethane foundry binders are well established in production foundry operations. During 14 years of use and consumption of over 500 million pounds throughout the world, the record with regard to safety and health problems has been excellent.

Because of the composition of urethane binders, some potential hazards due to chemical exposures exist. Ashland Chemical Company has strived to provide its customers with adequate safety and health information regarding these products and to assist them in establishing safe operations. We have also provided extensive technical service by conducting monitoring surveys and working with foundry management to correct problem areas. Foundry management has done its part in recognizing that potential hazards could exist in the use of these products and has been diligent and prudent in taking management actions and effecting engineering controls to ensure safe and healthful work environments for its employees. 
Monitoring data obtained during our surveys has established a history regarding contaminant levels in the foundry work environment and techniques for their control. It is expected that this program will continue and be of further value to the foundry industry in its continuing efforts to maintain safe working environments for its employees.

\section{REFERENCES}

1. Scott, W. D., Bates, C. F., and James, R. H., "Chemical Emissions from Foundry Molds", Trans. Ar. Foundrymen's Society, 85, 203-208 (1977).

2. Toeniskoetter, R. H., and Schafer, R. J., "Industrial Hygiene Aspects of the use of Sand Binders and Additives", The Working Environment in Iron Foundries, University of Warwick, March 22-24, 1977, England. 


\author{
PANELIST'S REMARKS \\ APPROACH TO THE USE OF DIMETHYLETHYIAMINE (DMEA) \\ Thomas M. Snyder \\ Supervisor, Industrial Hygiene Laboratory \\ Deere and Company \\ East Moline, Illinois
}

\title{
PROBLEMS WITH CATALYST
}

When using the phenolic urethane cold box process, we have most of our problems with the use of the catalyst. In our case it is DMEA. In my introductory remarks I will describe how we have approached its use.

You have already heard from Dr. Toeniskoetter in his presentation about an allowable exposure limitation for DMEA. We have been dealing with a $25 \mathrm{ppm}$ recommended standard. However, (and I go along with this recommendation), we try to control below ten parts per million.

DATA FILING SYSTEM

We have quite a bit of information on the acute toxicity of DMEA and I've talked to several different users across the country and I've compiled all I've learned. Those of you who use this product know what the effects of overexposure are: blurred vision and upper respiratory tract irritation. There is also a potential for skin irritation.

Unless I am greatly mistaken, there is very little known about the chronic toxicity of DMEA.

We have done some computer studies which involved different organizations across the United States. And, frankly, we have found that there just isn't that much currently written about the chronic or long-term use of dimethylethylamine.

\section{FOUR PHASE PROGRAM}

Because of a lack of information we can generate quite a few problems for ourselves. In trying to handle those problems we've set up a program for the proper utilization of this particular catalyst. That program involves four different items: one of them, and the first, is our own company's experience. Where have we been? And where do we want to go as far as the use of it? 
The second item is the ventilation that we apply wherever DMEA is used. As a specific example, most of our present coremaking operations have a push-pull type ventilation system, pushing and pulling air across the core box itself. In addition to that system we have installed local exhaust to the core box, which then passes through a scrubbing system. There are several different scrubbers on the market right now such as wet scrubbers and packed towers; we utilize a wet scrubber.

The third item in our program is a complete handling and training program. It goes into effect from the time that we accept a shipment of the particular catalyst until the time it's used in the core machine. It extends all the way to disposal of the shipping container, as well as any type of maintenance procedures that are involved in its use in that core box.

The last thing that we do is probably the most important. It's something that, to my knowledge, we're the only ones doing right now. We have constructed a medical program to go along with the use of DMEA. The medical program primarily involves two areas: environmental surveillance and comparison of environmental data to actual physical examinations given to the employees that are exposed to this chemical. This is done on an annual basis for all employees and complaints are handled immediately as they come up.

Included in the physical examination is an $\mathrm{x}$-ray, an electrocardiogram, a pulmonary function study, a complete blood count, and a bio-chemical profile.

To date we have seen nothing adverse on these physical examinations that could possibly be attributed to the use of DMEA. However, we have detected some other abnormalities in individuals that may have gone unchecked were it not for this physical.

With the use of the push-pull ventilation systems and the scrubber exhaust, I've never collected an air sample where the exposure to DMEA was greater than 2 ppm; on the average it's been in the vicinity of one part per million or less. 
Panelist's Remarks

USE OF PHENOLIC URETHANE BINDER SYSTEMS

\author{
Edwin L. Alpaugh \\ Manager, Industrial Hygiene \\ International Harvester \\ Chicago, Illinois
}

\title{
INTRODUCTION
}

We have been using phenolic urethane binders for the past 10-13 years; their usage in the past 3-4 years has been expecially heavy. Throughout this period we have had very few environmental problems with them.

I am in agreement with remarks that Dr。 Toeniskoetter has just made about potential hazards。 Air sampling data taken at pouring stations and casting hook-out stations, where one would expect to find methane biphenyl diisocyanate (MDI), simply have not shown it to be a problem. Fortunately, nearly all of these work stations are well-ventilated and that probably has a lot to do with it.

In the process of properly using the phenolic urethane binder systems and setting up proper ventilation control, we have overcome some problems which I would like to share with you today.

ODOR PROBLEM DUE TO EXCESSIVE SAND TEMPERATURES

One problem involved sand temperatures above the limits recommended by the Ashland Chemical Company. The problem occurred during very hot weather in a foundry using a phenolic urethane binder system (Pepset ${ }^{R}$ ). Two coremakers complained about a rather unpleasant odor coming off the cores. As an interim measure, a fan was utilized at the work station which eliminated the complaints. When cooler weather arrived the problem disappeared, giving us time to implement a localized exhaust ventilation solution before the following summer.

\section{LEAKAGE OF CATALYST GASES}

The major problem with the phenolic urethanes has been leakage of trithylamine and dimethylethylamine (DMEA) gases from the core boxes because of seal problems. It doesn't take a big leak in the seals to cause a problem because the breathing zone of the coremaker is usually close to the core box. Maintenance alone is not sufficient to solve the problem - auxiliary localized ventilation is also required. 
In one situation auxiliary ventilation was provided in the form of an exhausted "donut". As part of the ventilation provisions, a local exhaust takeoff was added at the bench where the coremaker places the cores after they are taken from the core blower. This is illustrated in Figures 1 and 2. Catalytic gas is not completely purged within the core box and residual gases continue to be emitted during core removal and handling. A third source of exposure to catalytic gases was also eliminated when leaky gas line valves were replaced with more reliable valves.

In another case the problem was solved by enclosing and ventilating the entire core machine as shown in Figures 3 and 4 . There are only two openings in this enclosure: one in back for maintenance access which is kept closed during normal operation (Figure 3), and another at the core removal station where the operator stands (Figure 4). Exhaust from the enclosure causes an indraft at the front opening which prevents escape of catalytic

gas from inside the enclosure, as well as helping to capture residual gases emitted during core handling.

\section{EXPOSURE DURING MANUAL SHAKEOUT OPERATIONS}

Normally, the smoke liberated when the cope is removed after the pouring and partial cooling of large castings can be controlled by local exhaust ventilation. Because of an unusual situation at a cope shakeout consisting of two work stations, one on each side of the line (Figure 5), there was concern about possible exposure of the inside "hook-out" employee to MDI. A large capacity local exhaust hood near the work station (Figure 6) captured most of the smoke, but because of the low Threshold Limit value for MDI $(0.02 \mathrm{ppm}$ Ceiling), it was necessary to make sure that concentrations were not exceeding this limit. The two employees periodically rotate jobs so that total exposure time on the "hook-out" job is only four hours. There is almost no exposure to smoke on the "outside" job. A number of breathing zone samples on the "hook-out" employee gave results that did not exceed the TLV for MDI. Because two samples approached the TLV, the local ventilation system was modified by increasing the volume pulled by the large hood and bringing in fresh air to blow across the "hook-out" station and into the duct, a kind of push-pull technique. 


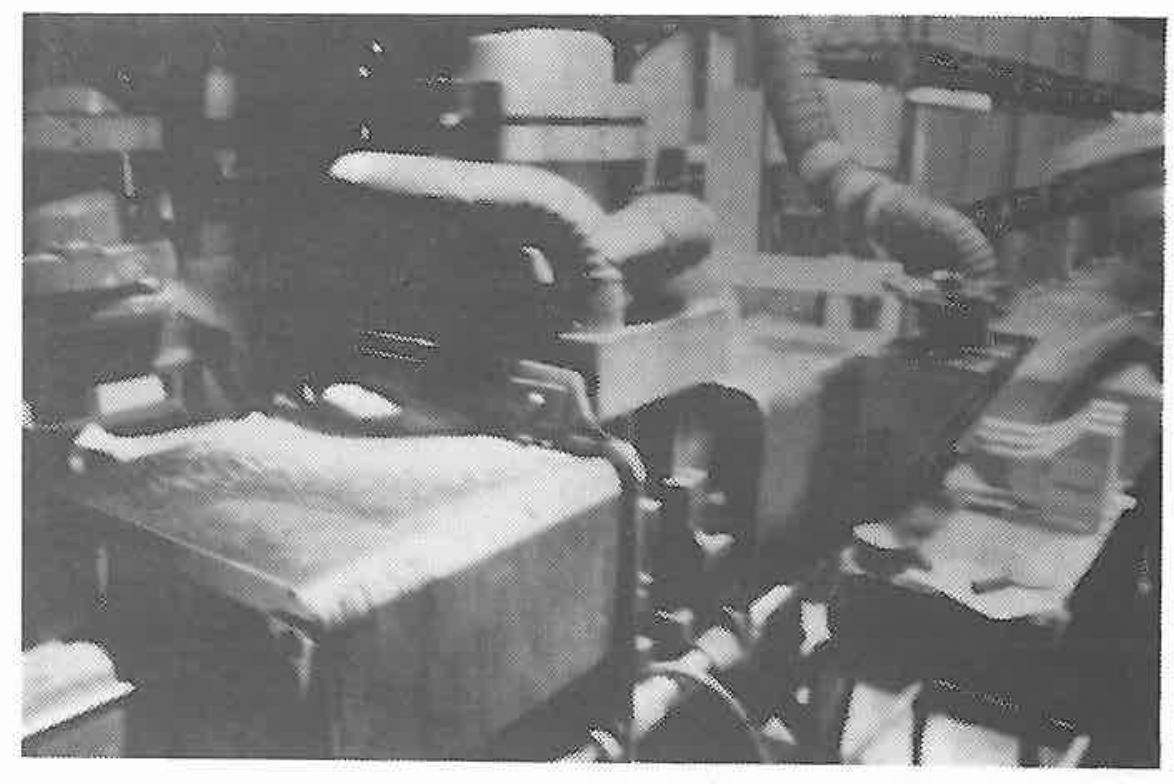

Figure 1。 Local ventilation of catalytic gases around the core box and at the core placing station of a cold box operation.

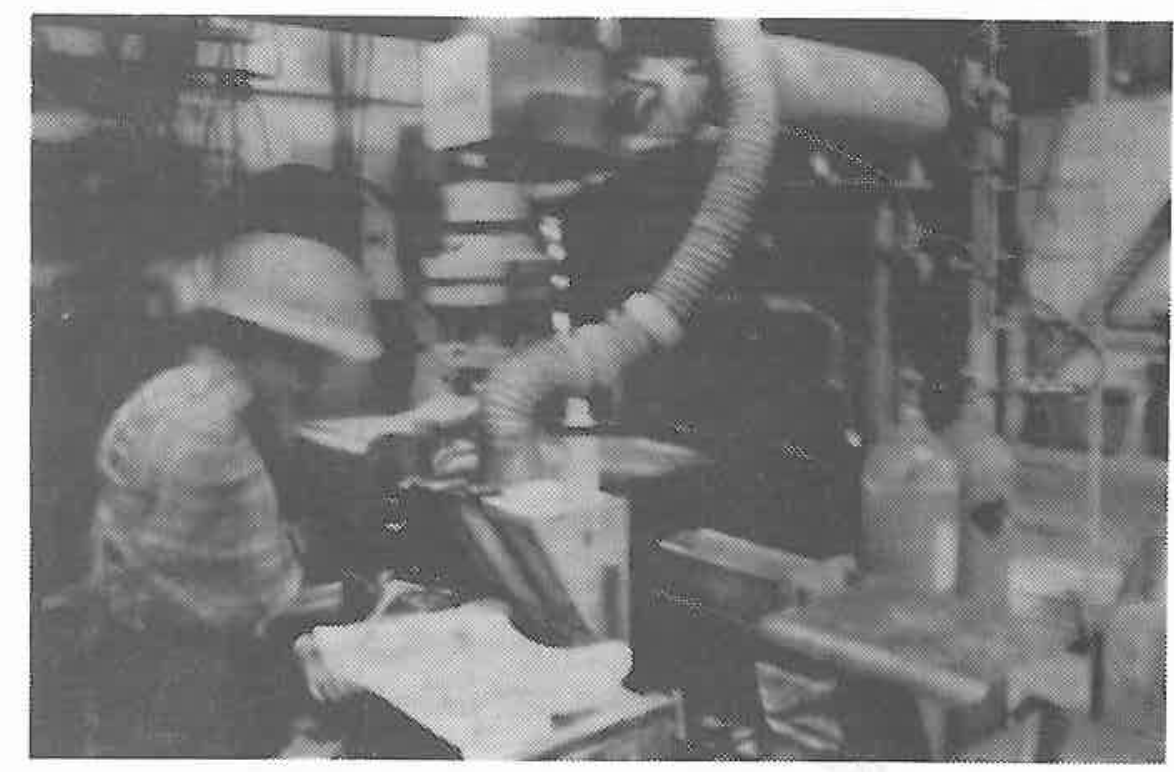

Figure 2. Local hood at core placing station captures residual gases which continue to be emitted after coremaking. 

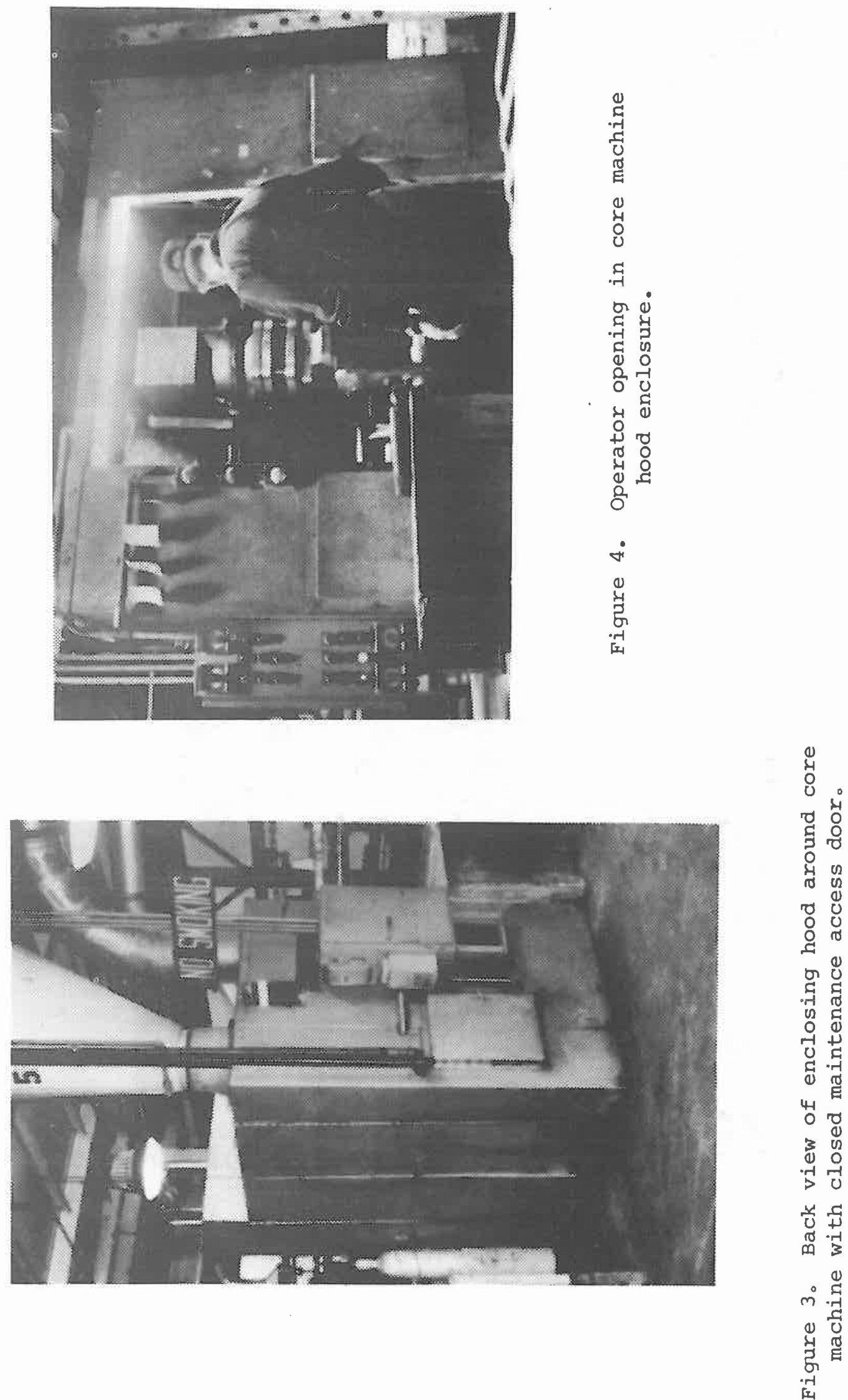


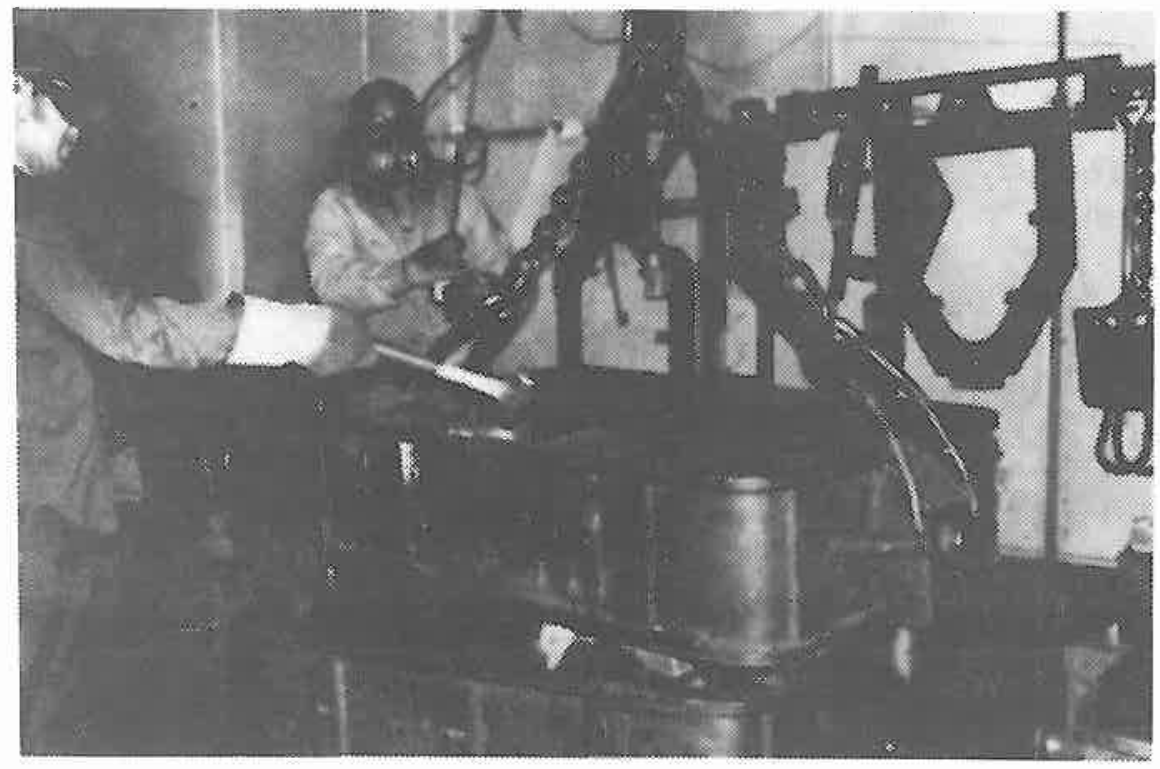

Figure 5. Cope removal operation showing workers on either side of the mold.

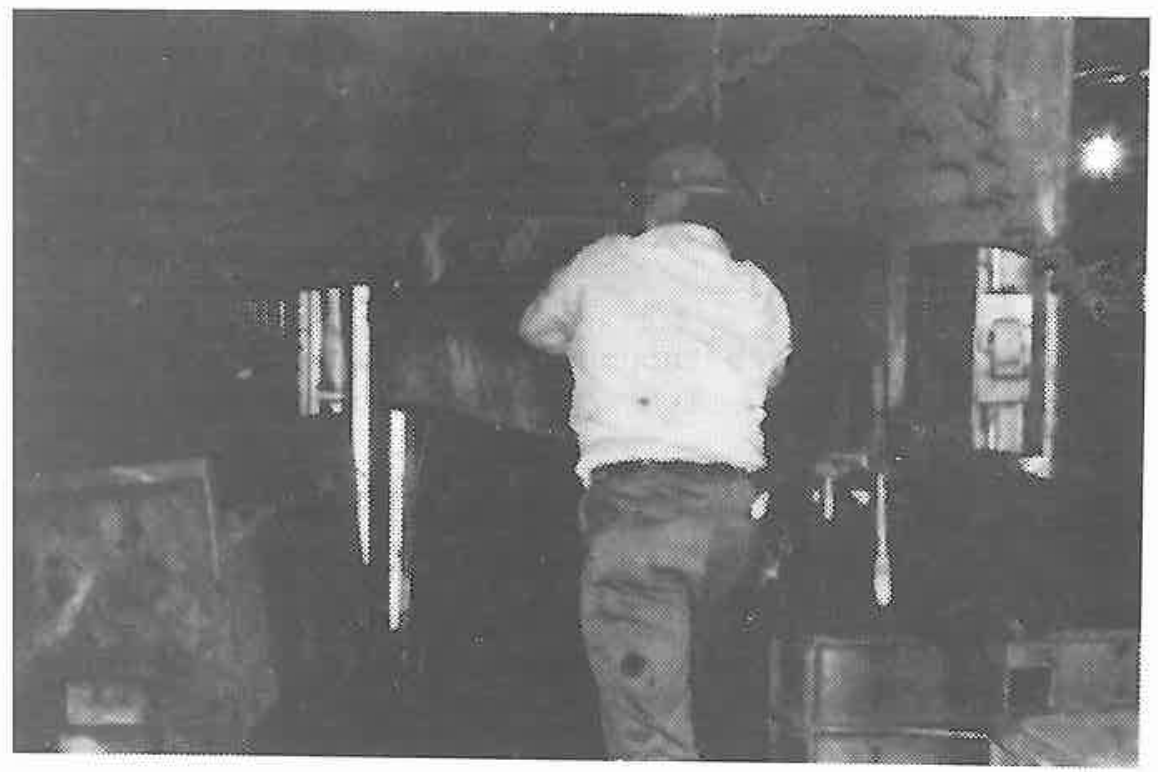

Figure 6. Local hood captures the majority of smoke emitted during cope removal. 
Question (F. Mirer, United Auto Workers):

My question is for Mr. Toeniskoetter, and it is about the urethane binders. I'd like to ask him to recommend an industrial hygiene strategy.

We've just been receiving some complaints from a production foundry that's just gone into the major use of the cold box phenolic urethane process. The foundry has already measured for exposure to methylene bisphenyl isocyanate (MDI) on the pouring line and shakeout. We have been told that it's nondetectable. Do you have any recommendation for other industrial hygiene sampling we should request from the employer?

Answer (R. Toeniskoetter):

It sounds like you are on the right track because if I were looking at an industrial hygiene strategy in a foundry using a phenolic urethane, I'd look for the isocyanates at pouring, cooling, and shakeout.

Now you say you have done that and you are not able to detect anything. Then the next thing to be concerned about would be the amine release at the coremaking station. Now that's really almost more of an engineering problem than an industrial hygiene problem because, if the amine levels are high, it means that the engineering and the maintenance are poor. Maintenance on the core box seals is a thing you are going to have to push.

The only other thing I think you might be concerned about would be the mixing operation. The chances are at this foundry that they're mixing in a muller. If they are and if they've got the muller normally contained with some ventilation, that would probably not be a problem.

Question (F. Mirer):

Getting back to my question, even though the sampling data showed MDI to be nondetectable, the fact of the health complaint remains for the worker at the pouring and shakeout operation. What chemical are we to look for next that may have caused harmful exposure to this worker so that we can attempt to control it?

Response (R. Toeniskoetter):

Have you measured carbon monoxide there?

Response (F. Mirer):

I don't know if carbon monoxide has been measured, however, the problem was respiratory irritation, so it must be something else.

Response (R. Toeniskoetter):

Well, in my opinion, the three things to be concerned about at a shakeout operation or a cooling area would be carbon monoxide, MDI, and smoke. There will be a lot of particulate, and we don't know very much about the chemical nature of that particulate. 
Comment (F. Mirer):

I'd also like to make an observation. We've looked into the problems with dimethylethylamine (DMEA) exposure in the Deere foundries and I think the program that they have instituted is a good program of medical surveillance combined with environmental surveillance.

What we now have is some basis, if the results hold up into the future, that a 1 ppm average exposure to DMEA appears to be a no-effect level for DMEA.

It would be very good for this industry in the future to document this kind of control strategy and this type of result. Of course, we're going to have to look into the future to see if that no-effect level stands up.

We must be careful to correlate a known exposure level with our apparent knowledge of what the health effect is. In one operation I'm familiar with, there were no exposure measurements as high as $10 \mathrm{ppm}$, yet we in the international union received complaints. So it does raise a question about whether a $10 \mathrm{ppm}$ limit is adequate.

Response (T. Snyder):

Thank you Dr. Mirer, for the complinent. I would like to build on that a little. If other data does exist much like the kind that I presented to you and these things could possibly be shared, this may be done starting here today.

Question (J. Hamer, Esco Corporation):

My questions are for Tom Snyder: How much does your medical surveillance physical cost you? And can you tell us a little bit more about the programs that you are using to train your people to handle the various binder compounds, materials you might have, and how the procedures work?

Answer ( $T$. Snyder):

I can't give you a specific cost because there are so many inclusions that I don't know about - lost production and so forth.

In each one of the installations where we have dimethylethlamine (DMEA) in use, we have a training manual which is divided into several sections. The first section deals with the transport and handling of DMEA. For example, where is it stored? Who inspects it when it comes in? Who takes it to its area of use and what route do they use in transporting it? Because DMEA has a lower explosive limit of 1.5 percent, we're worried about people smoking around it, so we transport on an off-shift. Who does the transporting? What should that individual know if a forktruck punctures a drum of DMEA? The operator obviously would need some kind of respiratory protective equipment and there's a whole section that deals with the use of respirators in accordance with the OSHA standard. 
What, then, happens when a drum of DMEA gets to the area where it's used? We obviously can't use 210 liters $(55 \mathrm{gal}$.) of it at one time, so there is some storage near the point of usage. Who, then, takes the material from that storage area and puts it into the actual gasing unit? Grsing units are another source of catalyst contamination if the controls are set improperly. If the core box is over-pressurized core box seals can be blown out. We deal with potential problems like that in the handling program.

The training manual includes first aid instructions and the procedures of the physical exan. workers are told of the results of both the physical exam and the environmental sampling.

Question (J. Hamer):

How do you get the people together? Do you have training sessions? Do you do it at safety meetings? Do you just have those groups of people that are involved and have a specific training session for them?

Answer ( $T$. Snyder):

At the start of this program we covered everyone who was involved with DMEA. Now, when anyone new comes into the affected areas, the personnel department notifies the safety department, who then in turn conducts the training.

Question (S. Rabinovitz, JRB Associates):

When you measure the isocyanate levels from the Isocure (B) cold box at the shakeout area, I was wondering whether the heat would change the form of the isocyanate from possibly aromatic to aliphatic, and thus the Marcali method wouldn't pick it up. Do you measure with the Marcali method? And, if you do, have you looked into what forms of isocyanate might occur other than aromatic?

Answer (R. Toeniskoetter):

We do use a modified version of the Marcali - modified to make the simultaneous amine measurement. I don't know if any aliphatic isocyanates could be formed. I suppose it would remotely be possible, but we have no data on that. We're working on a high-pressure liquid chromatography procedure which would sort ou'. the various isocyanates, but we don't have data as yet.

Question (M. Cohen, University of Illinois):

You stated, Dr. Eftax, that industrial hygiene surveys in forty foundries showed that benzo(a) pyrene (BAP) was not a problem. I'm not exactly sure what that means. Does that mean that you didn't detect any BAP? And, in that case, what was the sensitivity of your sampling and analytical procedures? Or does that mean you detected BAP at levels that you considered not to be hazirdous for exposure? In that case, what is your threshold for safe exposure to BAP? 
BAP was not tested in forty foundries, furfuryl alcohol was measured in forty foundries. BAP was measured, I believe, in three foundries. I believe the statement that it was no problem originated from the fact that our analytical chemists told us it was below a certain limit. I don't have the figures in front of me, but I would be very happy to get them for you.

I neglected to mention in my presentation that a recent NIOSH criteria document has been put out on furfuryl alcohol; I believe the number is 79-133.

Question (M. Cavanagh, OSHA):

I have an observation and a question.

Hopefully, time will bear out the optimistic opinion that the use of the cold box processes is not a health hazard. My question would perhaps be best addressed to $\mathrm{Dr}$. Toeniskoetter; it deals with the potential for nitrosamine formation with some of the catalysts as they're moved into the hot processes in the foundry.

Answer (R. Toeniskoetter):

The cold box process uses a tertiary aliphatic amine. In the cold box coremaking there is no heat involved at the core station; nevertheless, there is an amine, a tertiary amine. But the other half to formation of a nitrosamine would be nitrogen oxide. The reaction between the nitrogen oxide and the tertiary amine without heat would be an extremely slow reaction.

If amine drifts into a hot area that contains any nitrogen oxide, I suppose there would be a possibility there for nitrosamine formation. However, we do know that OSHA investigated this in one foundry and, after coming in two or three times, concluded that there was no nitrosamine present.

Question (F. Boelter, OSHA):

My question is directed at Dr. Toeniskoetter, but first an observation for you. My understanding is not the same as yours as to what has happened in that particular foundry. We were barred from doing further investigation by that foundry, exercising their constitutional rights. It's my understanding that the Isocure (3) process that was in use there has been removed because it had been found to be something not worth pursuing.

Now, here is my question. With the optimistic attitudes that you have put forward about the use of chemical binding systems and the relatively short life that they have had in the foundry industry, and further, with your comment on the unknown nature of many of the compounds that are involved here, at what point along the way do you think we'll have enough knowledge? 
And, secondly, what kind of studies are you doing to back up your claims that there are no hazards or that the hazards are relatively minor? Have you done animal studies? What kind of toxicity studies - chronic or acute are you actually involved with?

Answer (R. Toeniskoetter):

I think we were pexhaps talking about different foundries with that nitrosamine study. There was a report in Modern Castings magazine, I think the last issue, describing a foundry that a local OSHA official had investigated for nitrosamine. The OSHA official concluded that there was none present.

In answer to your question regarding toxicological studies, we do from time to time have studies underway primarily of an acute or sub-acute nature. We don't have any chronic studies underway on any of these chemicals.

Moderator:

I might add that NIOSH is currently doing a study to determine the effect of these organic decomposition products using animal experiments. I believe that study is about half done. There has also been a fair amount of research done in the continental countries and in Canada that may add more knowledge to this area.

Answer (D. Eftax):

Quaker Oats has a chemicals division, so naturally I view myself as part of the chemical industry. Most of the toxicological data on furfuryl alcohol is referred to in the NIOSH criteria document and there are ongoing studies. We have made Ames tests on five strains and the results were negative, indicating that the basic furan compounds are not mutagenic and carcinogenic.

Response (F. Boelter):

My primary concern in the foundry industry is not necessarily with the compounds that are used in the binder systems but rather in the decomposition products. There is very little known about these - very little known about what contaminants are there, to what extent people are being exposed, and what kind of long term problems there might be. If NIOSH has put any of that in their criteria documents, I'd be very interested to read it.

Response (D. Eftax):

The American Foundrymen's Society has supported a number of studies at Southern Research Institute and the foundry industry, through FEMA, has supported some studies. They are a matter of public record and can be found in the American Foundrymen's Society transactions, starting in the early seventies. Decomposition products were measured in simulated foundry casting operations and decomposition products were classified as major, minox and trace. 
Just to put things into perspective, I'd like to address the question of benzo(a)pyrene (BAP) which is all around us. The question is: When does this substance become a potential hazard? Well, there are two schools of thought. One says if it is present it's a hazard; another school says there has to be a certain lower limit below which there is no problem. It's a question that's not going to be answered very quickly.

When we're talking about controlling substances to below detectable limits we must remember that analytical methodology and detection devices improved so much over the years that we are now detecting not only parts per million but parts per trillion of materials that have been around us all along without us realizing it.

The foundry has improved its environment not only as far as the aggregate is concerned but also as far as binders are concerned and as far as safety and health of the employee. In the past cereal binders vere used that contained carbon in higher levels than they are using in the current, "organic", no-bake binders.

Now everything is a process of improvement. Millions of tons of $\mathrm{SO}_{2}$ and $\mathrm{CO}$ are generated, not by the foundry industry, but by the electrical industry and by burning gasoline and fossil fuels. Nitrogen compounds and BAP are also produced by those sources. That's a matter of record.

Response (J. Brown, International Molders and Allied Workers Union):

One of my biggest workloads is to deal with problems coming from the chemical binder systems, primarily pyrolysis products from the pouring floors. We don't find these as innocuous as you seem to say.

Response (D. Eftax):

Nobody said that these decomposition products are innocuous. I think what this symposium is trying to do is put forth an interchange of ideas to share what everybody has found in the past through a learning curve on how to control these decomposition products.

I think the suppliers and the foundry industry have made great strides in pinpointing and identifying the various potential hazards and then determining when they become actual hazards.

Question (F. Mirer):

One of the things I took away from this morning's discussion on cleaning rooms is that silica burn-in, the embedding of silica to the metal surface of the casting, is one of the major sources of silica dust exposure in the cleaning room and would be a very fruitful area to attack in trying to control silica exposures in the cleaning room. Do your companies have any ongoing research into the effects of the various mold binding agents on burn-in and, perhaps, some ideas for future work that would reduce this problem? 
Answer (T. Snyder):

We do have some research going on in that area, specifically related at this point to a productivity factor. Obviously, the kind of core that is put in a mold is going to have a great effect on the quality of casting produced.

Answer (E. Alpaugh):

I don't know how much research is going on, but I do know that foundries make every effort to prevent burned-in sand. It's costly and, if bad enough, can produce scrap. There is a continuing effort going on to minimize burned-in sand.

Answer (G. Mosher, American Foundrymen's Society):

There are ongoing technical committees at the AFS which are examining the effect of various binder systems on surface defects in castings. The problem at this point is that there is no basic understanding at this time of what creates burned-in/burned-on sand. So all we can do is test various binders to see which ones create greater surface defects than others.

\section{Moderator :}

Here is a question from the question box:

We dump forty tons of phenolic BSA (benzene sulfonic acid) no-bake sand a week. Can we have a leaching problem of phenols and benzenes?

Answer (D. Eftax):

It's not a furan system, but I might comment.

It's hard to say "yes" or "no"; I think I will say "perhaps", mainly because of the phenolic component. Phenol is an organic compound and is biodegradable under ideal conditions into carbon dioxide and water. Under non-ideal conditions it goes to methane, water, carbon monoxide, etc. Assuming nature has ample opportunity to take care of that, there should not be a problem from the phenol. However, if phenol should get into the water supply of a community that chlorinated in order to kill some bacteria, then there is a possibility of some chlorinated phenols being formed which have a very low odor threshold. In that instance, yes, there is a possibility of some problem.

Moderator :

The other question was pepset problems, ventilation and fume removal. Answer (R. Toeniskoetter):

I think they might be talking about a problem that they may have experienced 
where Pepset $\mathbb{R}$ (phenolic urethane) is being mixed with sand in a high-speed mixer.

Certainly there could be fume produced during such an operation: formaldehyde fume, and there could be solvent vapors.

Sometimes, depending on the throughput of the sand mixer, general rentilation will be adequate to control the levels of those contaminants. If not, local ventilation will be required at the discharge of the mixer.

Another point which I made earlier and Ed Alpaugh alluded to is the sand temperature. We strongly recommend that the sand temperature should never be above $29^{\circ} \mathrm{C}\left(85^{\circ} \mathrm{F}\right)$. If the temperature gets much above that the amount of these emissions will begin to increase very rapidly and a problem could result. 
SOME DESIGN CRITERIA FOR REDUCING DUST WHEN HANDLING CLAY BONDED SAND

\author{
F. M. Shaw \\ British Cast Iron Research Association \\ Birmingham, Englanc
}

\title{
ABSTRACT
}

This paper discusses methocs whereby dust emissions may be reduced and exhaust control facilitated by consideration of dust reducing measures during the design of the foundry. The quantity of dust emitted during transport and handling of molding sand is closely relatod to the moisture content of the sand. Several ways are available to restore the moist condition as soon as possible after shakeout:

1. A small muller may be added immediately after shakeout.

2. Water may be added directly to the sand on the conveyor.

3. Excess moist system sand may be produced, much of which is mixed with dry sand at shakeout and recycled (Schumacher Process).

Material handling systems should be designed to minimize dust emissions:

1. Conveyor sizes should be selected to minimize spillage.

2. Belt speeds should be properly set and maximum design inclinations should not be exceeded.

3. Hopper discharges onto belts should be properly sealed.

4. Where belt enclosures are used, they should be easily removahle and replaceable.

5. Bucket elevators should be sized large enough and operated at the proper speed.

Pneumatic conveying provides good system flexibility while facilitating dust control.

Vacuum cleaning systems provide for good housekeeping and cleanup of small sand spills.

The difficulty of controlling dust from shakeout is a function of the degree of mechanization and/or automation used to load and unload molding flasks. Manipulators have been used successfully allowing remote control of the shakeout operation from an enclosed booth.

\section{INTRODUCTION}

Foundries hare a reputation for being dirty and unpleasant places to work in, and this image is to some extent the result of the amount of dust and fume 
present in the atmosphere. To improve working conditions, it is imperative that foundries pay adequate attention to dust control, but improvement may be difficult because of the design and layout of existing equipment.

It is important that, when equipment and systems are designed and installed in foundries, proper consideration be given to dust control. A well designed plant from an environmental aspect will be higher in capital cost than one designed solely to produce acceptable castings, and this extra cost can only be justified when it makes possible the provision of effective dust control. The objectives of good design and equipment selection should be to reduce or eliminate the need for dust control, but when this is not possible, dust control should be at least capable of being applied effectively. The major point to be made is that foundry dust control does not consist of waiting for dust to be generated and then fitting an exhaust hood to remove it; it should consist of designing the foundry to make it as dust-free as possible in the first place. Since the handling of clay bonded sand is a major source of dust in foundries this paper considers some ways of reducing dust generation by good plant design.

\section{DESIGN OF PROCESSES WHICH GENERATE DUST}

Effect of Moisture on Sand Dustiness

The amount of dust generated when sand is disturbed depends on its moisture content; dry clay-bonded sands generate obvious dust clouds whereas no dust is generated by wet clay-bonded sand. Work carried out at BCIRA has shown that foundry sand containing not less than one-third of its working moisture level, which is evenly distributed, is unlikely to be a source of appreciable dust (1). Figure 1 shows the relation found between the amount of dust generated and moisture content of a typical green sand. The evenness of distribution is important, as sand containing an average of 2 percent moisture can contain pockets of wet and dry sand and the latter will generate dust if disturbed.

The practical implication of this work is that molding sand does not give rise to dust during its passage from the muller right up to the pouring station. It is only when sand in the molding condition is allowed to dry out that it becomes a source of dust. If the sand conveying systems allow sand to drop onto the floor from belts, transfer points, etc., the sand will dry out and be disturbed by traffic (human and mechanical), resulting in airborne dust.

Dust is always generated at the shakeout and from this operation onwards, therefore, the object should be to get sufficient, well distributed moisture back into the sand as quickly as possible to suppress the dust.

Sand Handling Design

Use of an Auxiliary Muller--

One method of introducing water is to utilize an auxiliary continuous pan muller immediately after the shakeout as shown in Figure 2. The muller is not intended to develop the "green" strength of the sand but merely to 


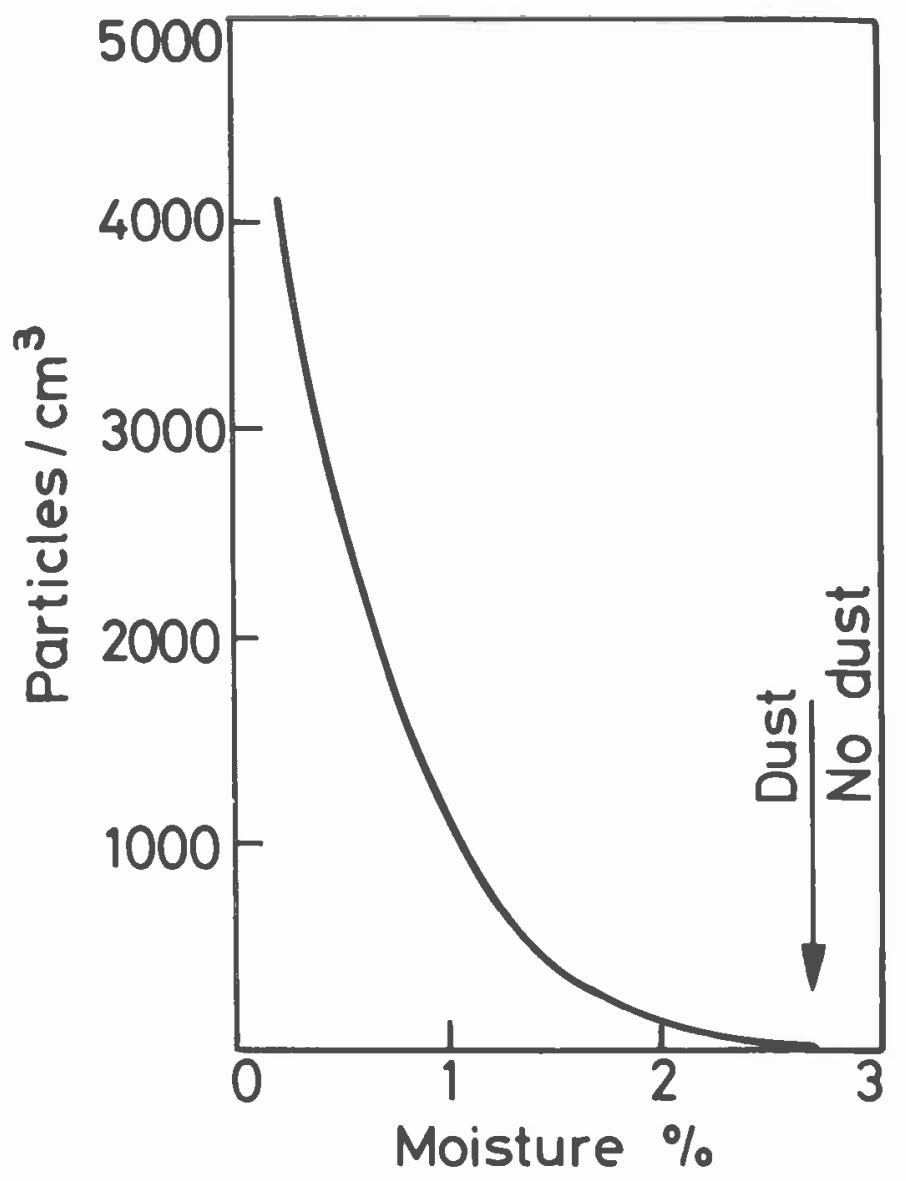

Figure 1. Dust generated by typical used green sand (1). 


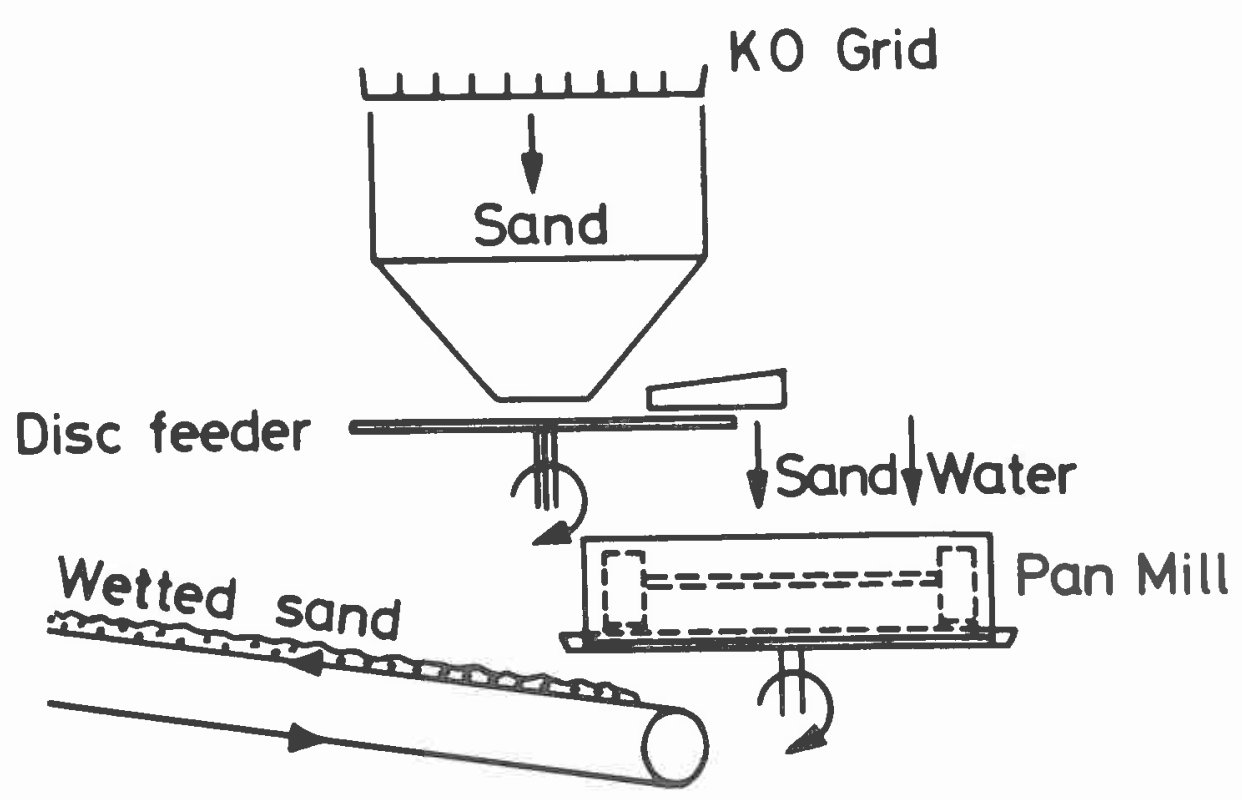

Figure 2. Use of Pan mill at knockout.

distribute sufficient water into the sand to make it non-dusting. In spite of the obvious disadvantages of such a system, e.g., the extra equipment required, more maintenance, increased space requirements, tramp iron problems, etc., such equipment has been installed and used successfully. Not only is dusting suppressed, but a useful degree of sand-cooling is obtained as the moisture can partially evaporate and thus cool the sand in subsequent parts of the sand plant (particularly the screen) (2). An aerator can serve a similar purpose and may be easier to accommodate.

Water Additions to Sand on Conreyor Belts--

Water added to a shakeout discharge conveyor belt should be added on the basis of the sand flow, its temperature, and its moisture content. In practice, the sand temperature after the shakeout provides a sufficiently accurate indication of the moisture content and thus the amount of water to be added can be based on sand throughput and temperature only. Various units for adding water to sand belts are available; throughput is based on the measurement of sand height by means of a mechanical arm and temperature is measured by one or more thermocouples trailing in the sand. Water is added by sprays over the belt (Figure 3) actuated from a control box which determines, according to the sand flow and temperature, the amount of water to be added (3). Water added in this manner is not evenly distributed and dry pockets will result, but they can be reduced by ploughs or fingers mounted over the belt to mix the sand and added water; these, however, can also act as sources of dust.

The Addition of Damp Sand--

An alternative method of adding water indirectly to shakeout sand is by addition of prepared molding sand. An excess of sand may be deliberately mulled greater than is needed for mold making, as in the Schumacher process. A layout of a sand clant using this system is shown in Figure 4. Depending 
on the metal:sand ratio, extra sand is mulled amounting to about the same as that required by the molding line. The surplus sand is diverted from the muller into the return sand system. The shakeout sand is thus buried in damp non-dusting sand and, until disturbed, no dust will be generated. The two sands are mixed at the earliest possible moment after shakeout. Normally magnetic separation is first required after which mixing is accomplished by one or more aerators mounted over the sand belt. Note that even distribution of moisture in the mixed sand is essential, and equipment to ensure that the sand is well-mixed is a necessary part of the dust suppression system. An aerator is shown after a magnetic sejarator añd it would be expected thât düst would be suppressed after this point. As with other methods of dust suppression, extra costs are involved. In this system, the extra costs are due to the need for increasing the mulling capacity and providing the larger belts required. It is also essential that mulled sand be available for addition to the shakeout sand during the whole period that shakeout takes place. The results of "before" and "after" airborne-dust surveys in foundries having installed the schumacher or a similar system are awaited with interest. It should be noted that a mulled sand addition is intended not only to reduce dust but also to provide cool sand at the molding line.

Clay and Coal Dust Additions--

The addition of dry coal dust and clay to a muller or to sand on a belt generates dust. Where possible the addition of both matexials should be made as a slurry. The use of slurry additions is possible when:

1. The amount of water added as an unavoidable component of the slurry is not in excess of that required to bring the sand up to molding moisture level. In practice this means that the sand-to-metal ratio needs to be low.

2. A continuously agitated slurry tank is installed with a recirculating main to prevent settling out of the slurry.

3. A non-gelling clay is used, e.g., calcium montmorillonite, otherwise the amount of clay in the slurry is restricted to about 6 percent by weight.

The dustless addition of clay has a further advantage in that "live" clay is not exhausted to the dust collector where, if it is of the usual wet design, it results in a slurry which cannot be settled and is difficult to dispose of.

Belt Conveyors--

A major reason why most mechanized foundries quickly become dirty is that sand is spilled from belt conveyors and falls onto gangways, overhead walkways, etc. Even if the sand is dustless as it falls from the conveyor it quickly dries out. Operators walk on the dried sand and transport vehicles drive over it and the result is the generation of dust which spreads throughout the foundry and collects on all horizontal or near-horizontal surfaces. Removal of this deposited dust by non-vacuum sweeping methods gives rise to more airborne dust and often results in part of it being 


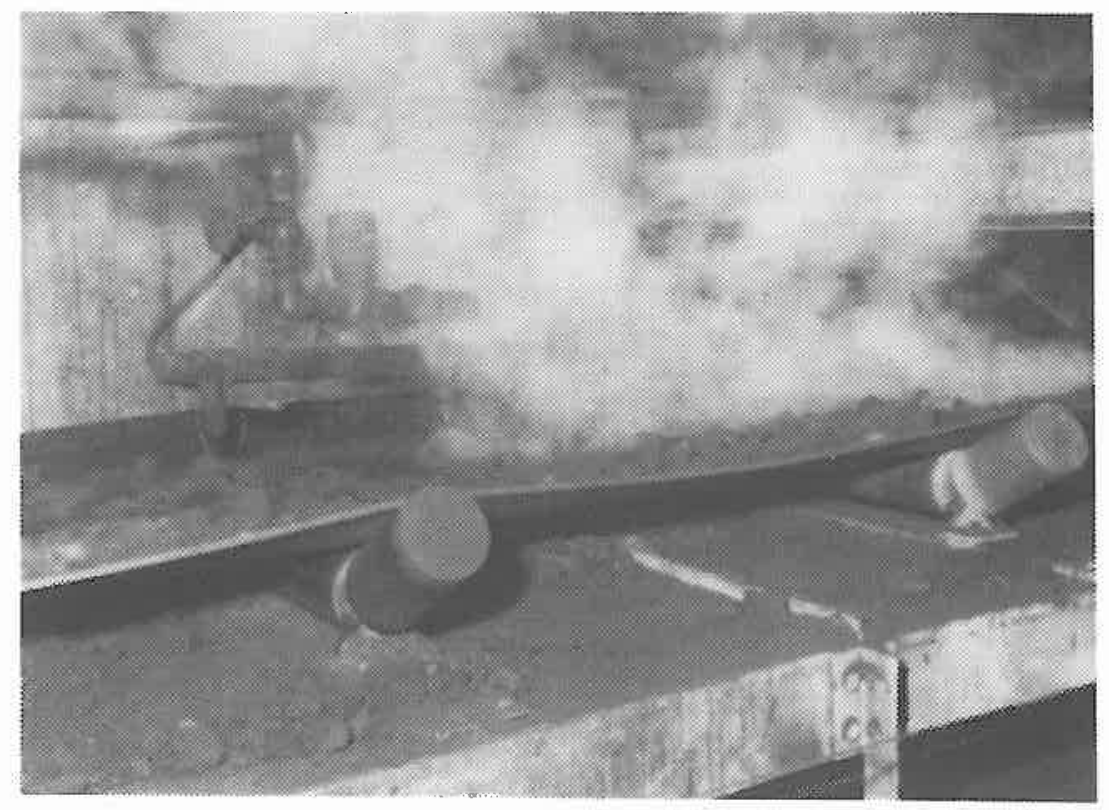

Figure 3. Water additions to sand on knockout belt.

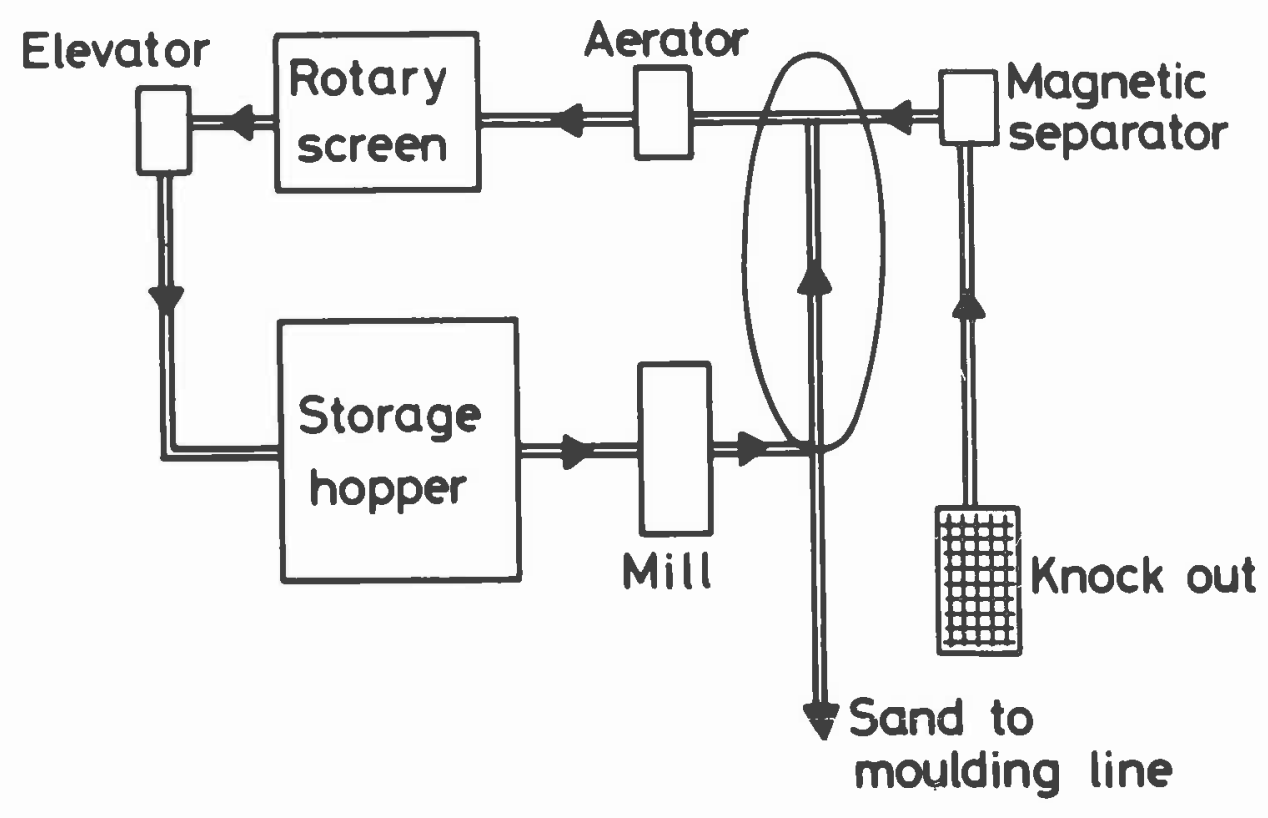

Figure 4. Schumacher system, 


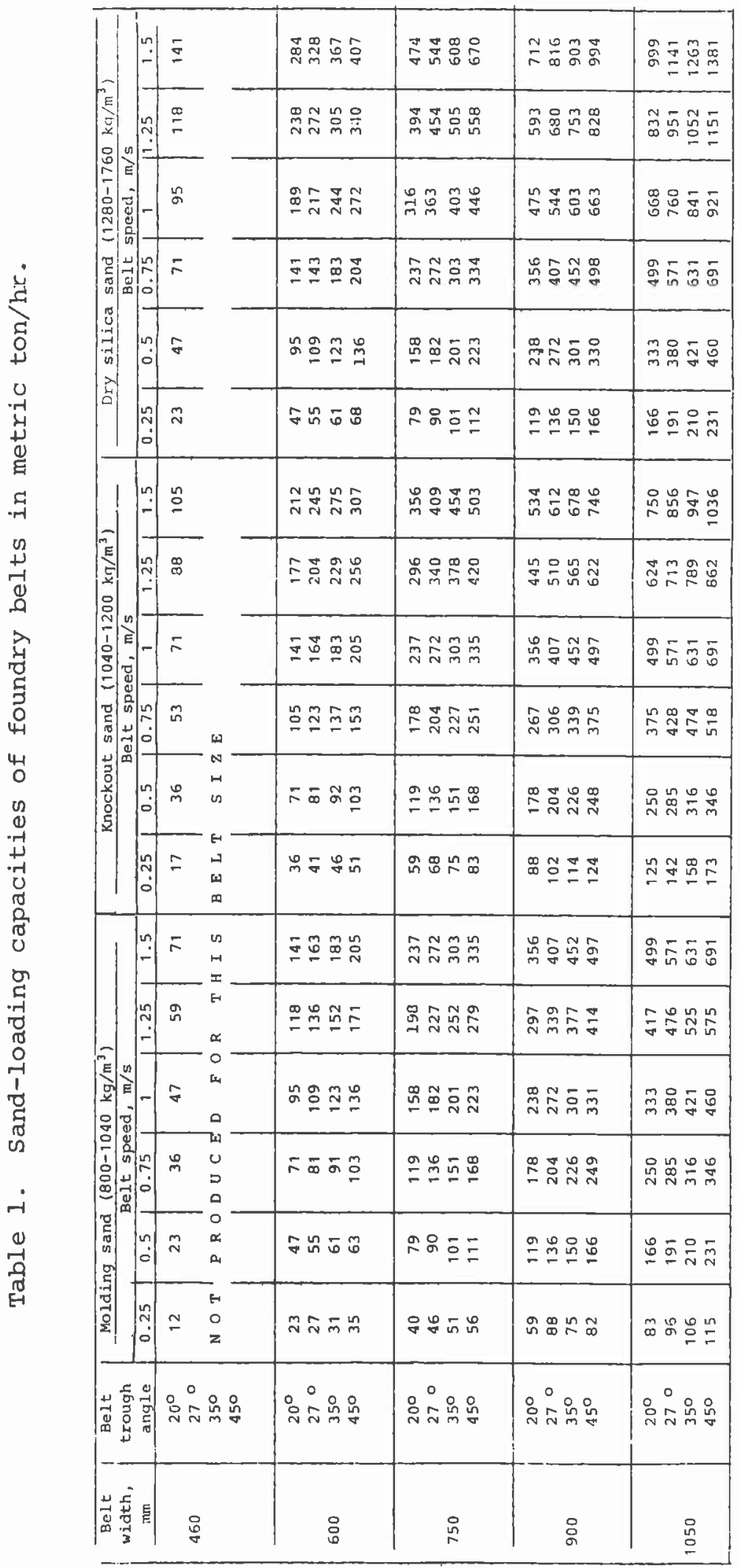


A reduction of belt spillage depends primarily on belt design. For the type of conveyor used most in foundries, there is sufficient data available to enable the belt and its ancillaries to be economically designed (4). Table 1 gives recommended belt sizes for various capacities of belt. Capacities vary for different sands because of varying bulk densities, e.g., sand in the molding condition is less dense than shakeout sand, and a belt will, therefore, carry a lower flow of molding sand than of shakeout sand.

Some design points which need to be considered to reduce spillage are given below:

1. A belt must be designed for the maximum capacity required of it even if this is only needed for short periods. Whenever possible surge hoppers should be used to even out sand surges and to allow for smaller and less expensive belts. In practice, the estimated peak loading is often taken as double the maximum sand flow needed for molding.

2. Troughed belts are normally run at speeds up to $1.5 \mathrm{~m} / \mathrm{sec}$ ( $300 \mathrm{st} / \mathrm{min}$ ). Speeds above this make the operation of ploughs and magnetic separators less satisfactory.

3. The trough ancle has been limited in the past to 20 degrees. The developrent of the nylon belt allows steeper angles - up to 45 degrees - to be used. The steeper the angle, the higher the carrying capacity of the belt and the lower the spillage for a given throughput.

4. Where flat belts are used or where troughed belts are run flat in some parts of the system (e.g., to allow ploughs to be fitted), the capacity of the belt should be taken as half that of the equivalent vidth of a 20 degree troughed belt, otherwise spillage will occur.

5. Belt inclination affects the amount of slipping and roll back which takes place. Excessive inclination leads to spillage and reduced belt capacicy. the maximum belt inclination should be 17 degrees for shakeout sand carried by 20 degree troughed belts. Even at this angle there may be some difficulty with sand lumps rolling back down the belt and eventually falling off. It may be prudent, therefore, to restrict the maximum inclination to 15 degrees for shakeout sand and 18 degrees for prepared molding sand.

Special belts with molded cross-bars and frilled edges forming a troughed section until the belt goes around a pulley, may be used at inclinations up to 50 degrees. Such belts may sometimes be used to supersede bucket elevators. 
6. Belt cleaners should be used whenever sand sticks to the belt. If they are not, sand will be dislodged from the return strand of the belt and give rise to a secondary form of spillage. Figure 5 shows a static scraper, and Figure 6 a rotary cleaner driven by its own motor. A modified trough conveyor where the belt runs in guides to retain its trough configuration is shown in Figure 7 . Covers to enclose the top are available which result in nearly complete enclosure.

7. Pulleys often build up with sand, and belt-wander results. Selfcleaning pulleys help to prevent this and one such design is shown in Figure 8. Belt-wander is one cause of sand spillage from conveyors.

8. The efficient sealing of hopper discharges onto belts reduces spillage. One method of sealing is shown in Figure 9. Poor hopper-to-belt sealing is a frequent cause of spillage, especially in underground pits where maintenance is unpleasant and often neglected.

9. Beneath hoppers, where rollers are subject to impact from sand falling on the belt, impact-resistant rollers are sometimes used. These also help to clean the underside of the belt.

10. The type of belt fastening used affects sand leakage. Only a vulcanized joint is leakproof and should be used in preference to mechanical belt fasteners.

Belt Enclosure--

Even with good design some spasmodic spillage of sand is likely to occur, especially from the underside of the return strand. It is possible to enclose a belt conveyor completely (Figure 10). The enclosure must be easily removable and replaceable for inspection and maintenance purposes. The system shown uses fabric stretched over a frame, but other systems are available.

Enclosure hinders the removal of spilled sand and some means of getting rid of it is necessary. This can be achieved by fitting shallow hoppers beneath the belt, equipped with nozzle outlets to which can be attached flexible exhaust tubes connected to a central vacuum-cleaning system.

Pneumatic Conveying--

Pneumatic conveying is a dust-free conveying system for all types of sand. Sand is conveyed by air pressure through small pipes which provide complete enclosure for the material being conveyed. Apart from being dustless (or at least very easily dust-controlled), pneumatic conveying allows complicated plant layouts and takes up little space. One possible layout is shown in Figure 11. The main advantage of the system apart from its cleanliness is the flexibility it provides in plant layout. Flexibility is not always possible with conveyor belts. 


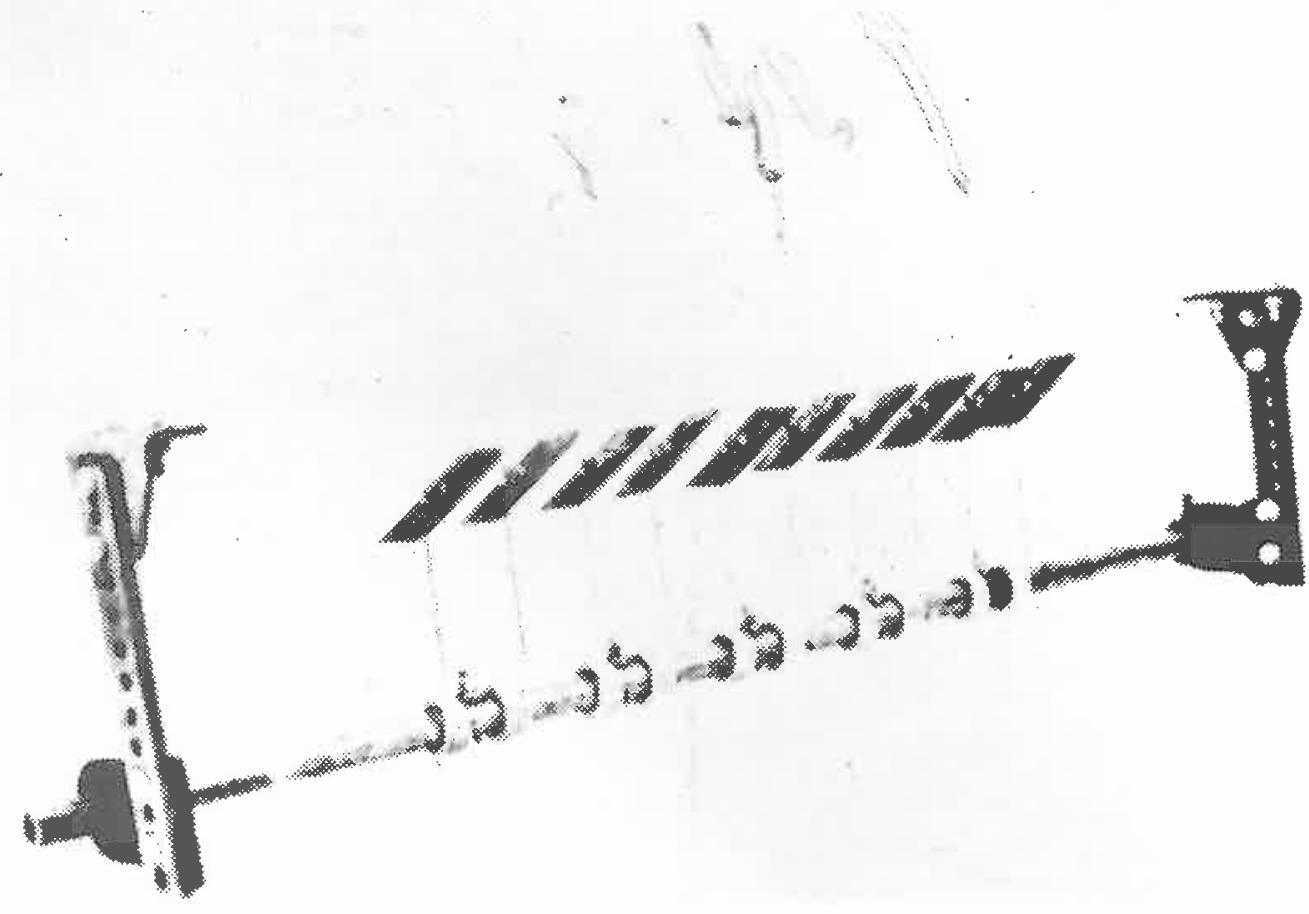

Figure 5. Stationary belt scraper.

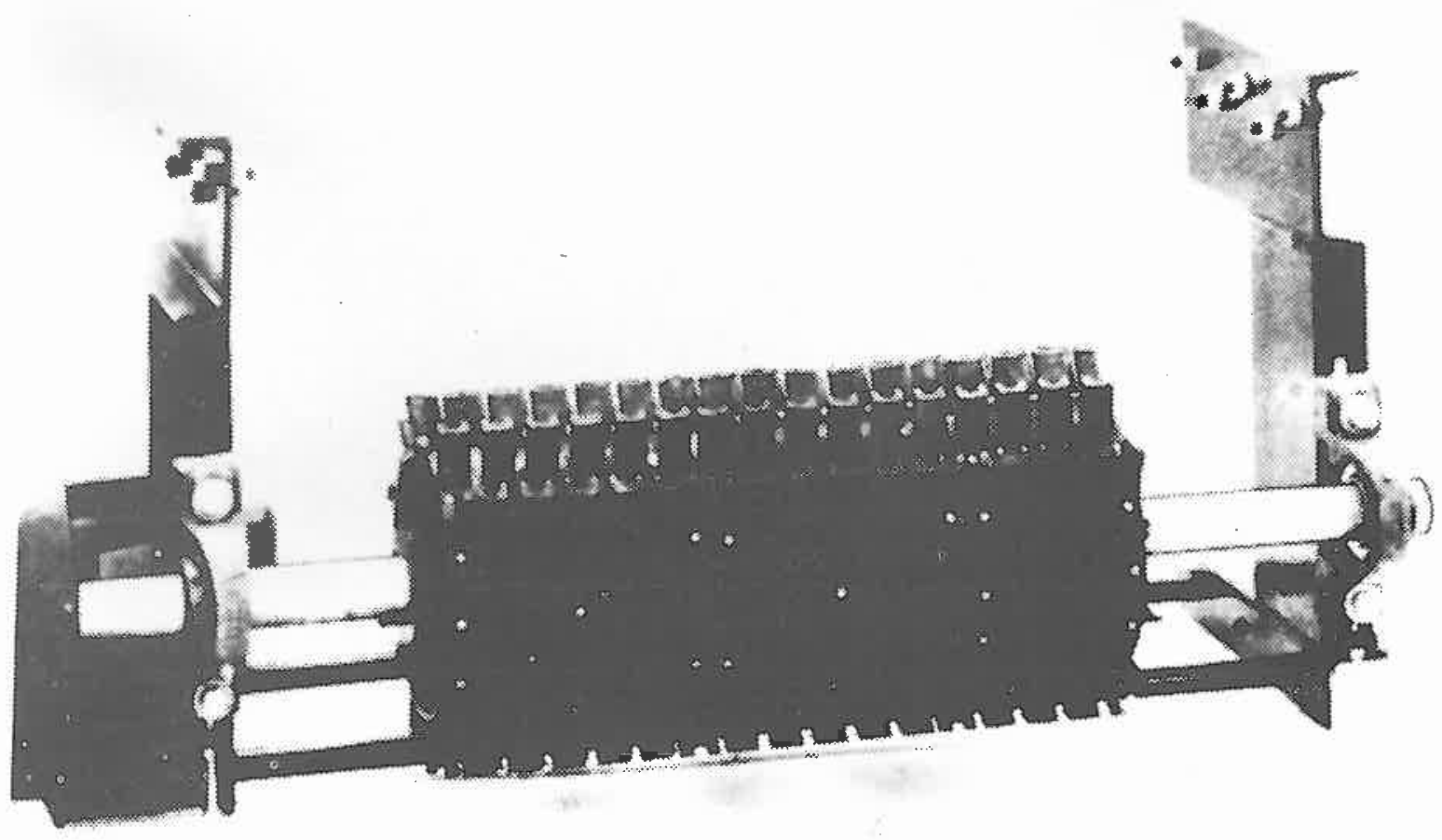

Figure 6. Rotary belt cleaner. 


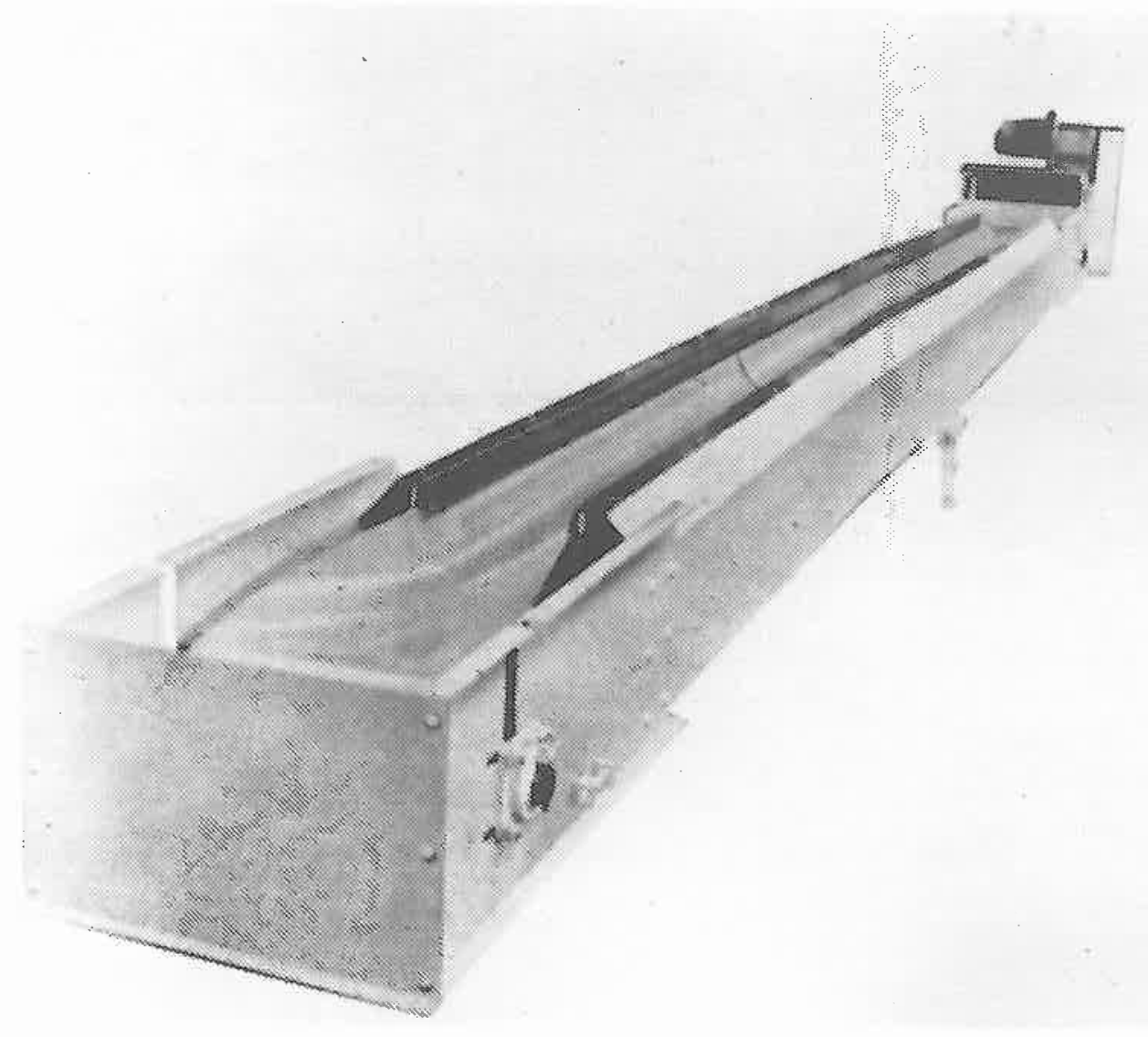

Figure 7. Formed trough conveyor.

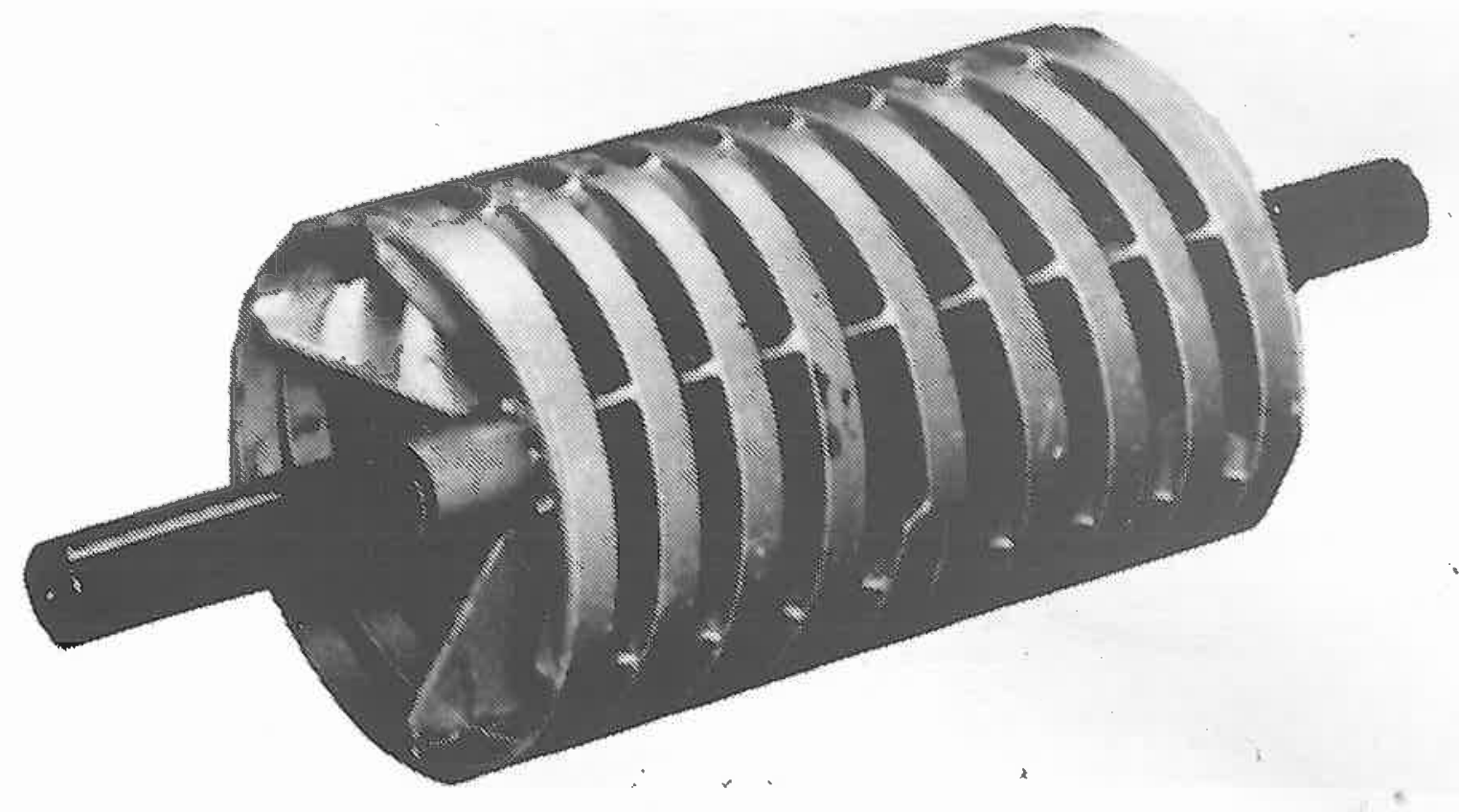

Figure 8. Self-cleaning pulley. 


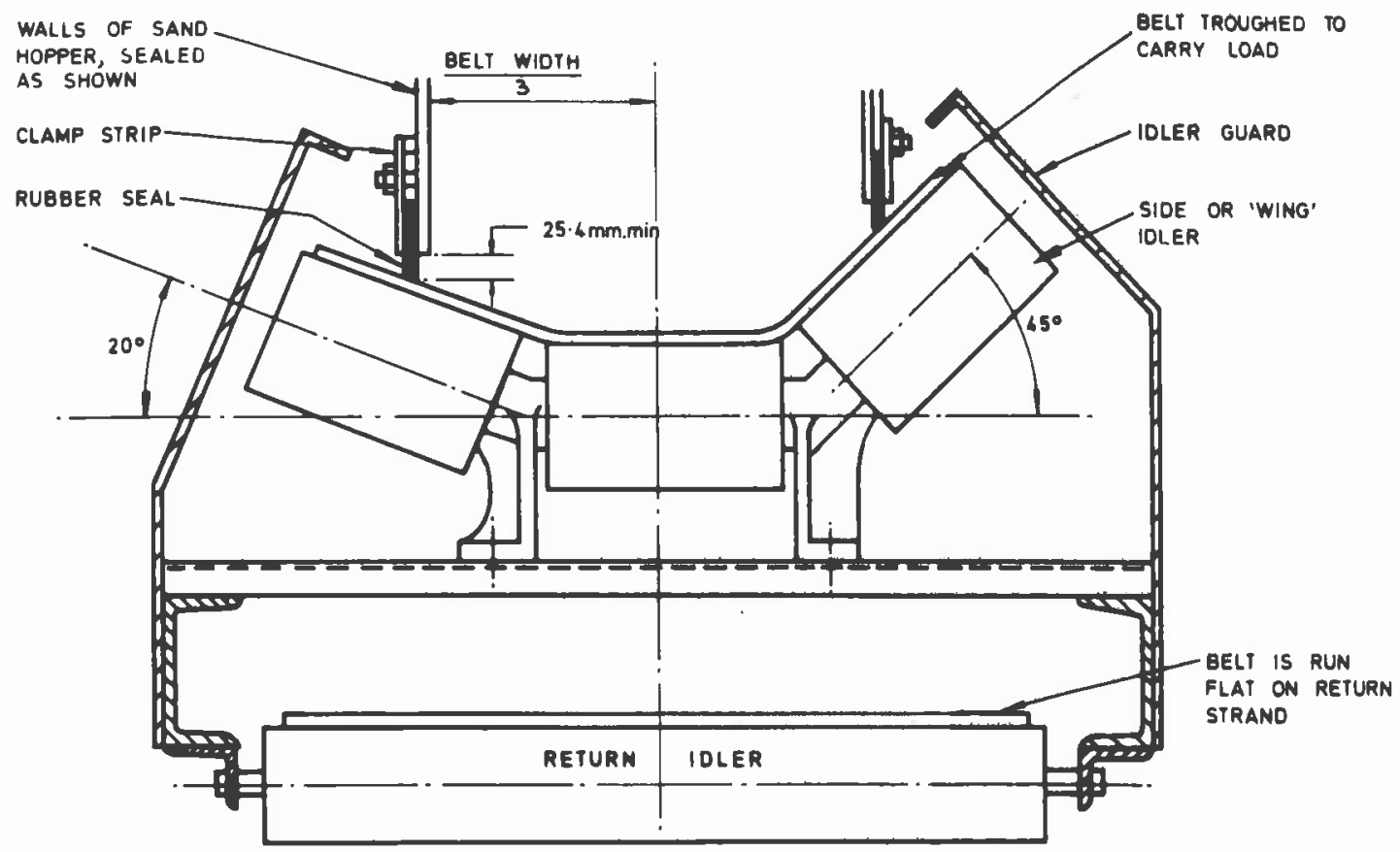

Figure 9. Section through conveyor showing a $20^{\circ}$ and $45^{\circ}$ troughing idler, chute, and sealing skirt with idler guard:
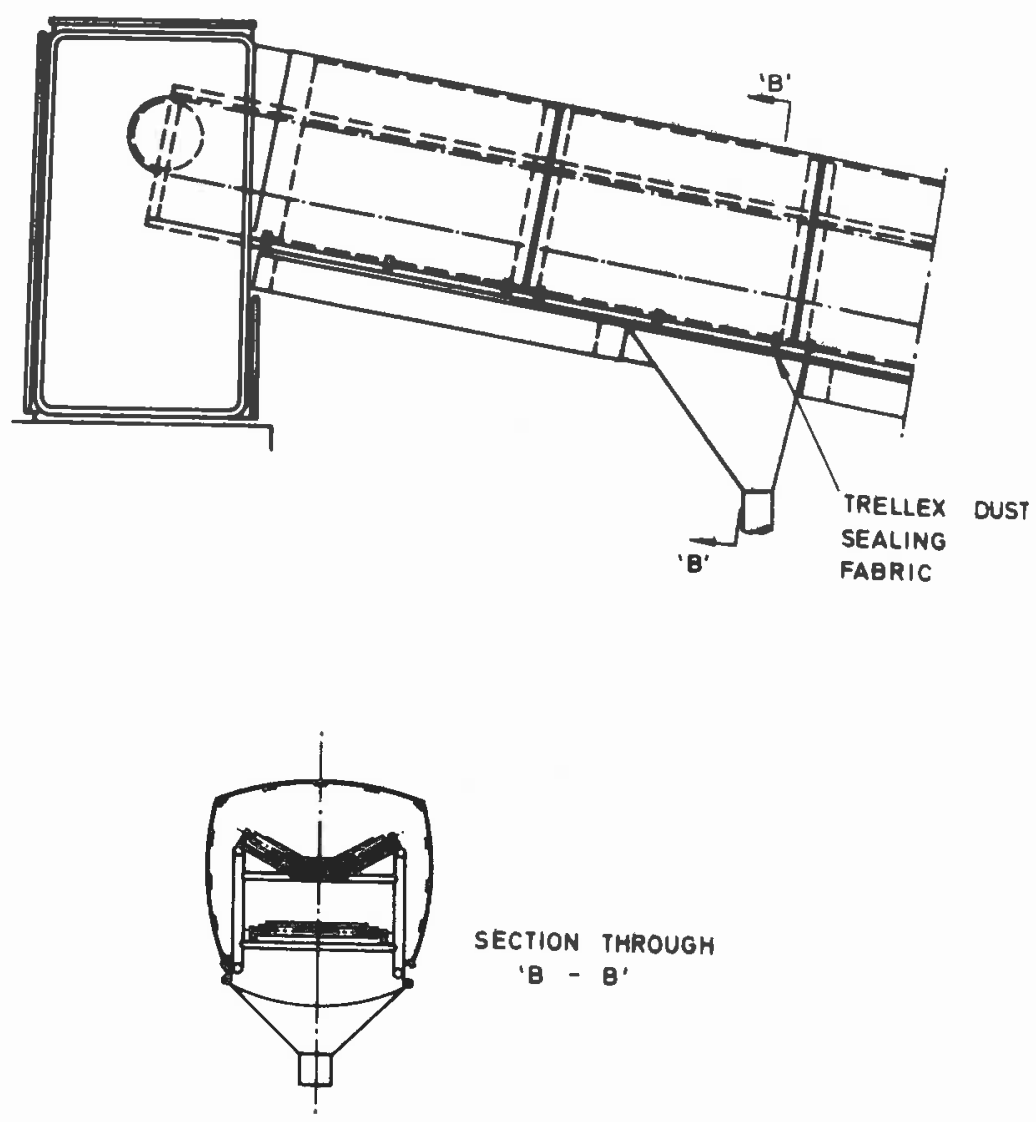

Figure 10. Enclosure of belt conveyor. 


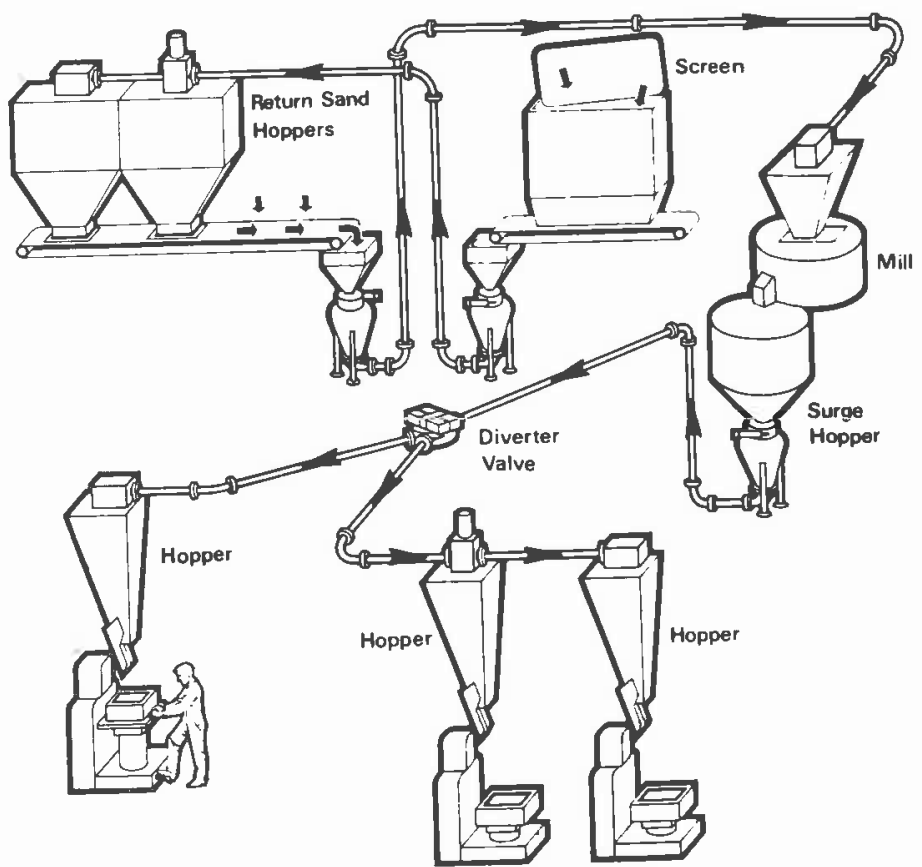

Figure 11. Pneumatic conveying of molding sand.

The disadvantages of pneumatic conveying are:

1. Power consumption. The conveying medium is air which is initially compressed to approximately $6.3 \mathrm{Kg} / \mathrm{cm}^{2}\left(90 \mathrm{lb} / \mathrm{in} .{ }^{2}\right)$. Depending on the vertical and horizontal distance of the sand conveyed, and number of bends in the conveyor, a power consumption of $3-5 \mathrm{~kW}$ per metric ton per hour capacity of sand conveyed can be expected. For example, to convey $20 \mathrm{t} / \mathrm{hr}$ of sand, approximately $80 \mathrm{~kW}$ will be needed at the compressor. A conveyor belt, in comparison, will only need some $11 \mathrm{~kW}$ or less for conveying sand at the same flow rate for a distance of $76 \mathrm{~m}$ (250 ft) horizontally and $10 \mathrm{~m}$ (33 it) vertically.

2. Maintenance costs may be higher than for equivalent belt systems. This is because pipe bends and diverter valves wear out and the air compressor needed to supply the motive power needs more maintenance than the electric motors used on belt systems.

3. Capital cost is likely to be higher than for a conveyor belt system, unless spare compressor capacity already exists.

Bucket Elevators--

Bucket elevators are widely used to raise sand from one level to another. They are frequently underdesigned and sometimes run at the wrong speed; both faults cause spillage. The capacity of the elevator should be the maximum capacity ever required. If necessary, surge loads can be reduced by surge hoppers. 
The capacity of the elevator should then be obtained by using the following formula (5):

$$
\begin{aligned}
& \text { Capacity, } \mathrm{kg} / \mathrm{h}=\frac{66 \text { BVND }}{\mathrm{P}} \\
& \text { Where: } \mathrm{B}=\text { Bulk density, } \mathrm{kg} / \mathrm{m}^{3} \\
& \mathrm{~V}=\text { Total bucket volume, } \mathrm{m}^{3} \\
& \mathrm{~N} \quad=\text { Speed of head pulley, rev/min } \\
& \mathrm{D} \quad=\text { Diameter of head pulley }+2 \text { (belt thickness), } \mathrm{m} \\
& \mathrm{P} \quad=\text { Pitch of buckets on belt, } \mathrm{m}
\end{aligned}
$$

The bulk density varies quite widely with the type and condition of sand (Table 2).

The fact that average bucket filling may be only 35 percent of total capacity has been allowed for in the capacity design formula. Wherever sand below a temprrature of $100^{\circ} \mathrm{C}$ is being handled, nylon buckets are recommended instead of metal. The service life of nylon buckets is longer and sand sticking is less, thus providing additional capacity and reducing the possibility of spillage.

Table 2. Bulk density of foundry sand in various conditions.

\begin{tabular}{lrc}
\hline & \multicolumn{2}{c}{ Bulk density } \\
\cline { 2 - 3 } Sand condition & $\mathrm{kg} / \mathrm{m}^{3}$ & $1 \mathrm{~b} / \mathrm{ft}^{3}$ \\
\hline Molding sand & $800-1040$ & $55-65$ \\
Shakeout sand & $1040-1200$ & $65-75$ \\
Free-flowing silica & $1280-1760$ & $80-100$ \\
$\quad$ sand & 2720 & 170 \\
Zircon sand & \\
\hline
\end{tabular}

The speed of the top pulley should ensure that sand is not carried around again by the bucket (too high a speed) and does not fall back down the elevator (too low a speed). Both these faults reduce elevator capacity.

The correct speed is given by:

$$
\mathrm{N}=\frac{42.3}{\sqrt{\cdot \mathrm{D}}}
$$

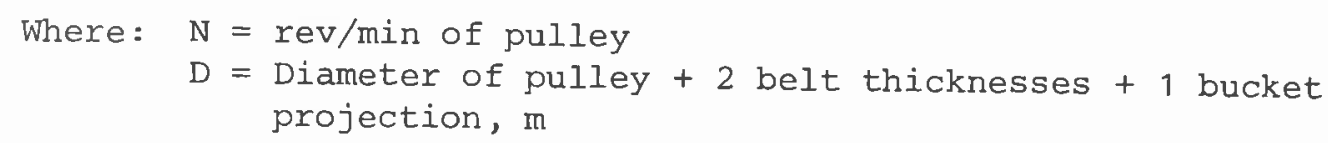

Vacuum Cleaning systems

Portable vacuum cleaning units or central suction systems are becoming more popular. They have the advantage that they can remove materials dustlessly even if it is dry sand. They are, however, not a replacement for good design of sand handling equipment. 
Some buyers of cleaning systems have been disappointed because the units are unable to quickly remove large sand spills. Vacuum systems are not suitable for this purpose but they do provide a very useful means of cleaning up minor spillages and for removing dust from surfaces.

\section{Shakeout}

Once the mold reaches shakeout it is partially dry due to the metal poured into it. As soon as molds are broken open to remove the solidified castings, dust and steam are generated.

Thermal currents from the hot castings and sand will carry dust for considerable distances unless controlled. A decreasing number of foundries still shake out over large areas of the foundry floor. Generally speaking, production rates in such foundries are low and the dust generated per unit area of floor is not high. To capture this dust as it is generated and keep it away from the operators is virtually impossible, and a high standard of general ventilation is relied on to improve conditions. Where this is unacceptable there is no real alternative to mechanization, so all shakeout operations will take place at one point and dust control can be applied. In other words, mechanical handling has to be installed to make a satisfactory solution possible.

Manual Shakeout--

In mechanized foundries, shakeouts loaded by workers using overhead hoists are still used in large numbers. When dealing with flasks of variable size having bars in either half it is difficult to use any other design of shakeout. Once the shakeout operation is confined to one place it is possible to fit it with reasonably efficient dust control.

Many early shakeout tables had downdraft exhaust through the perforated table since this allowed access on all four sides for the operators. Downdraft, however, is not recommended for shakeout for various reasons:

1. Even when shallow flasks [not more than $30 \mathrm{~cm}$ (12 in.) high for the assembled mold] are used the air flow required to control dust is very high, $5 \mathrm{~m} / \mathrm{sec}(1000 \mathrm{ft} / \mathrm{min})$ or more over the full grid area.

2. If deeper flasks are being knocked out [over $30 \mathrm{~cm}$ (12 in.) total] quite unacceptable exhaust rates would be required for control.

3. The exhaust air flow is drawn through the falling sand under the grid and results in a very high pickup of fines, sufficient in many cases to upset sand control and overload the dust collector.

It is more usual, if less practicable from a flask and casting handling standpoint, to use a sidedraft hood on the longest side of the grid. Given the correct exhaust rate, most dust can be kept out of the operator's breathing zone, but it remains a hot, unpleasant task which can only be improved by further mechanization. 


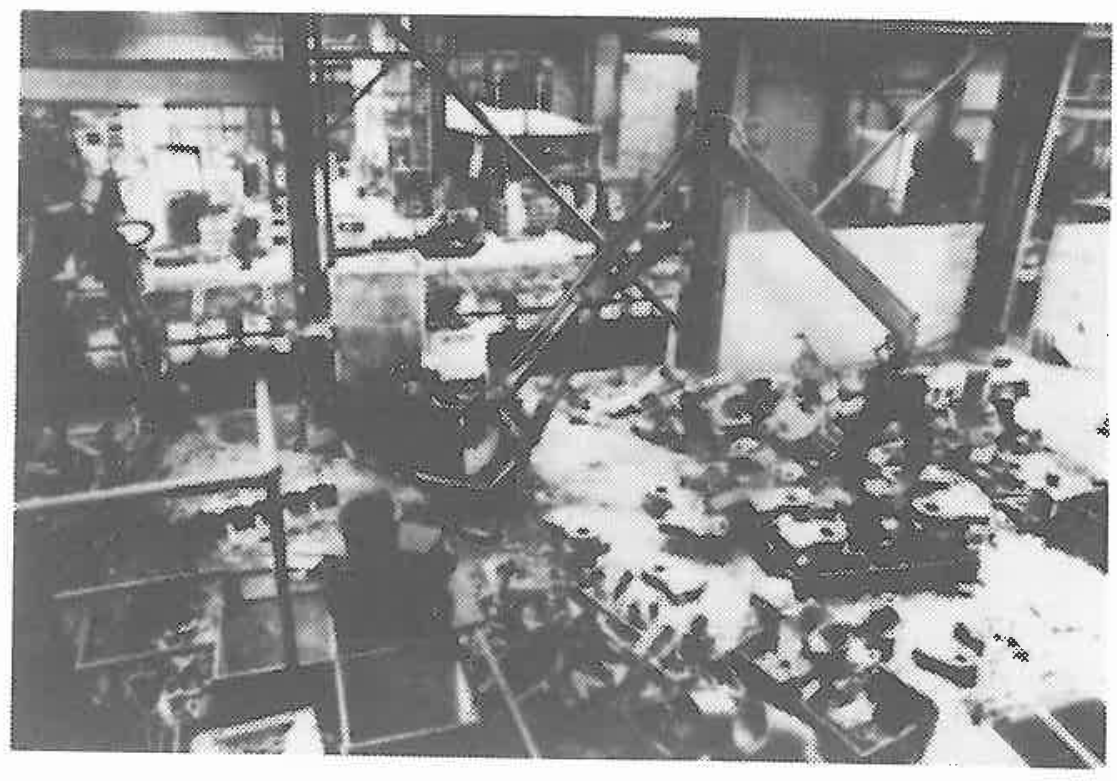

Figure 12. The use of a mechanical manipulator for shakeout.

Mechanical Manipulation Handing--

Automatic handling may be considered as an alternative to manual handling aided by hoists. This method allows full access to the shakeout table since exhaust hoods do not have to be as close-fitting. The operator is housed in a ventilated booth and handles castings and flasks using a powered manipulator. One such system is used in Sweden, and allows the simple system in Figure 12 to be used (6). It does not, however, eliminate the need for dust control. The shakeout needs to be ventilated to prevent dust from reaching other unprotected workers in other parts of the foundry, and to keep this foundry clean.

Automatic Shakeouts--

Vibrating shakeouts can be contained in an enclosure provided that they are made automatic, and this allows dust control to be effective with relatively
low exhaust air flows.

No successful automatic shakeout has yet been made which can deal with a variable flask size combined with bars in one or both halves. However, an ever increasing number of mechanized foundries now use standard size barless flasks anc', for these, enclosed automatic shakeouts are both economic and improve working conditions by:

1. Removing the operators from a hot, unpleasant job.

2. Allowing efficient dust control to be installed.

3. Providing the possibility of noise control.

Figure 13. shows a typical automatic shakeout layout and Figure 14 illustrates a successful early 1950 's mechanized foundry (now superseded) which had an
enclosed automatic shakeout. 
It is even possible to construct such a system above floor level where floor excavation is not possible. Figure 15 is a photograph of an above-floor level shakeout where the operators simply feed the unit with boxes via a lift.

Flaskless molds such as those produced by DISA machines readily lend themselves to automatic shakeout and a good example is shown in Figure 16. Here the molds at the end of the line enter a rotary drum which is well enclosed and discharges sand and castings separately. Note the heated and insulated exhaust duct to prevent condensation and consequent dust build-up inside the duct.

\section{REFERENCES}

1. Bright, J., and Shaw, F. M., The Effect of Moisture on the Amount of Dust Produced by Foundry Sand, BCIRA Journal of Research and Development, 1952, v. 4, December, pp. 426-429.

2. Godding, R. G., and McCormack, W., Hot Sand Cooling in Existing Handling Plant, British Foundryman, 1968, v. 61, March, pp. 95-103.

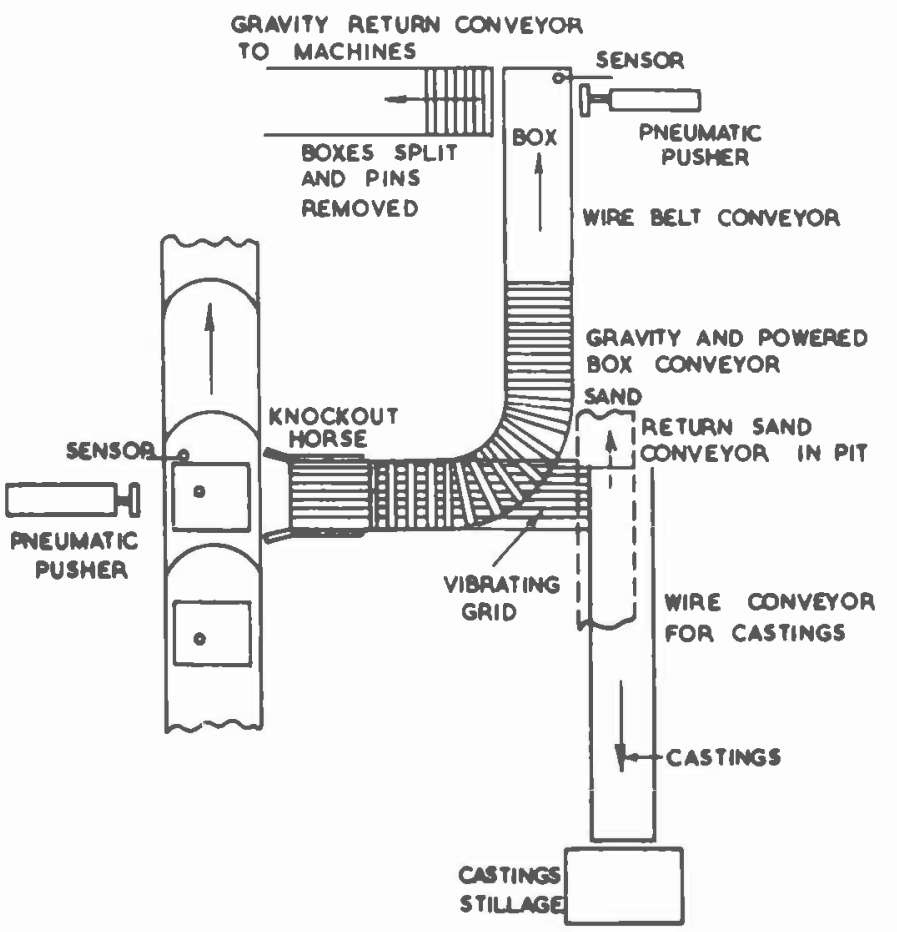

Figure 13. Automatic knockout plant. 


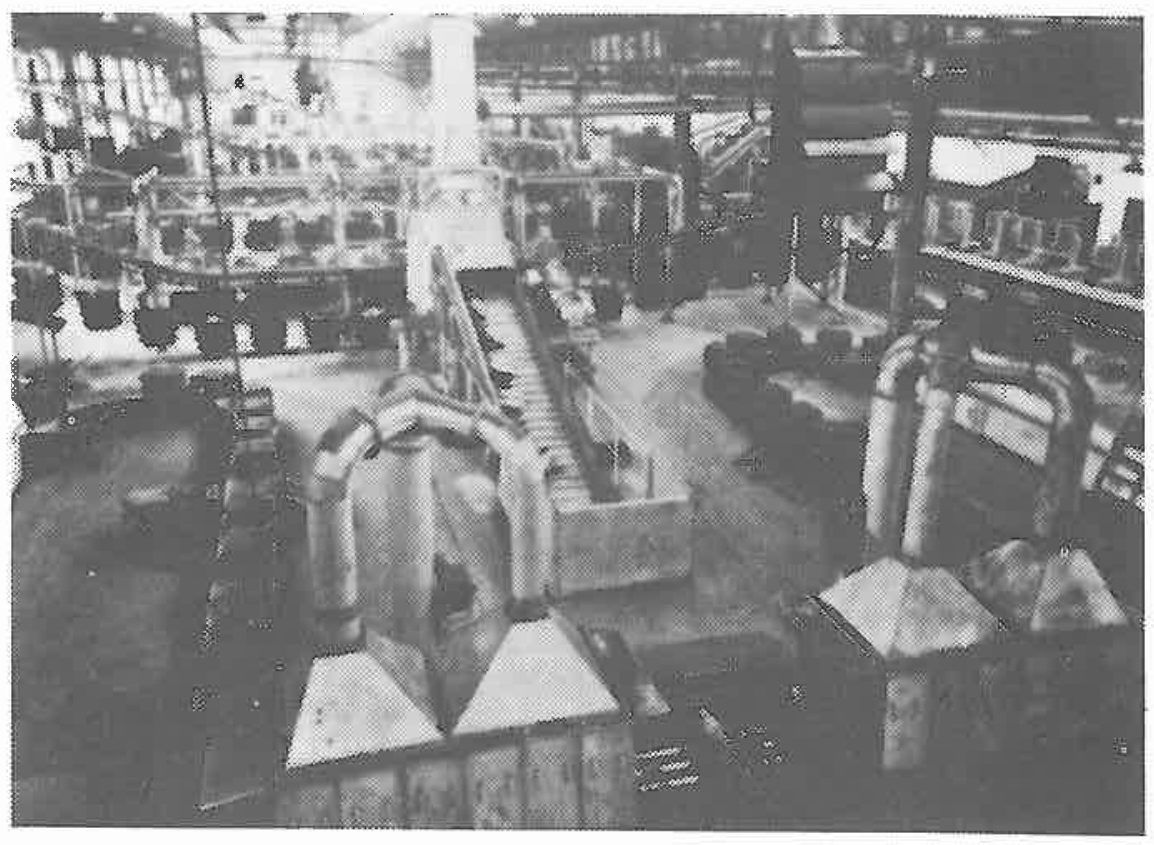

Figure 14. Automatic knockout of the $1950^{\prime} \mathrm{s}$.

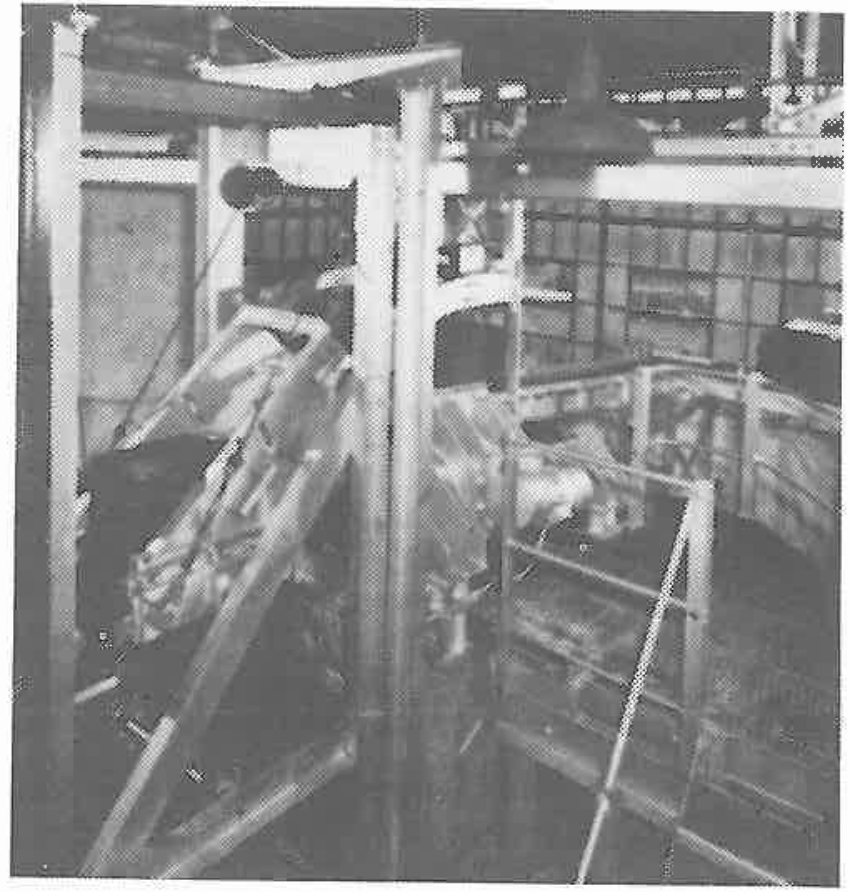

Figure 15. Above ground automatic knockout. 


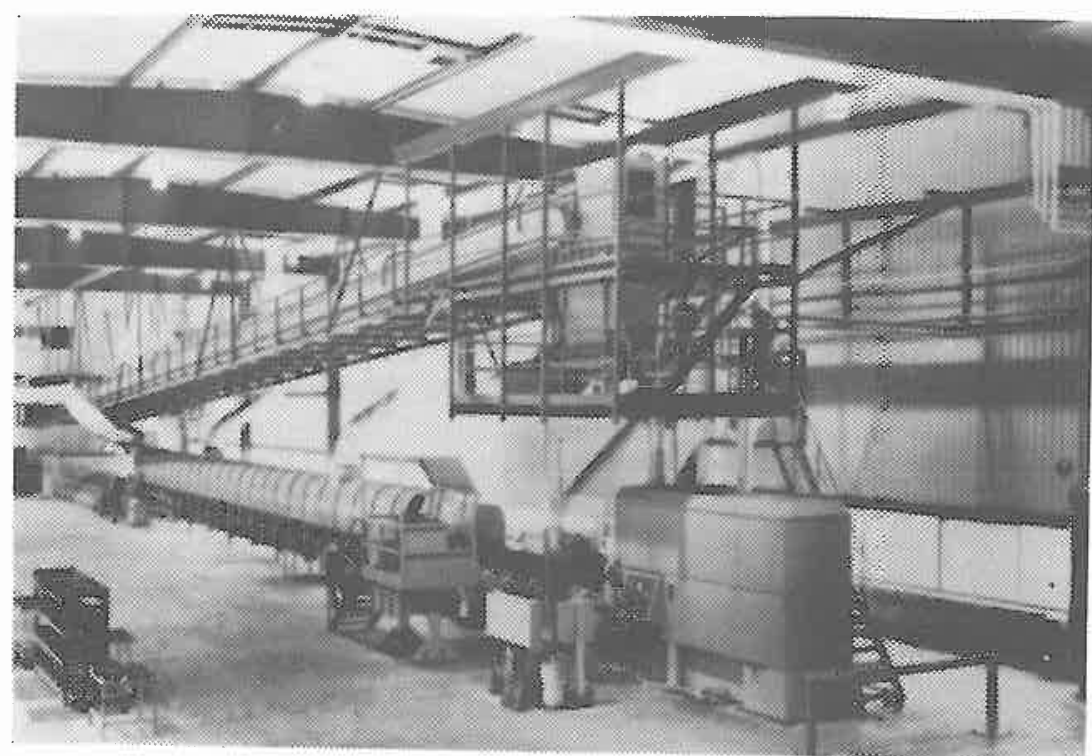

Figure 16. DISA plant using rotary drum knockout. 3. BCIRA, Fast Sand Cooling with Water Evaporation, BCIRA Broadsheet 51 ,
1972.

4. Pinfield, R. O., Unpublished Work at BCIRA.

5. Drywood, R. C., Unpublished Work at BCIRA.

6. Svensson, I., Manipulators and Industrial Robots in Sand Foundries, $43 r d$ International Foundry Congress, 1976, Bucharest, Paper 19, 12 pp.

QUESTIONS, ANSWERS AND COMMENTARY

Comment (R. Scholz, Rexnord Inc.):

The effectiveness of the Schumacher process in terms of worker exposure to dust has been documented in our NIOSH report on health hazard control technology in the foundry industry. There is also a reprint available of a presentation George Tubich gave at the American Industrial Health Conference in San Francisco in 1972, which includes dust measurements in three foundries employing the schumacher process.

Response (F. Shaw):

We have a number of Schumacher plants in the United Kingdom, and I'm waiting to see them in operation. Thus far, every time I've tried there have been problems with the systems which have delayed my visit. I don't believe anything unless I've measured it myself. I would appreciate the results of Mr. Tubich. 
Comment (J. Calhoun, White Consolidated Industries, Inc.) :

In regard to pneumatic conveying of foundry sand, we have two foundries which we have converted to no-bake molding. From the conclusions we've drawn there, there is a great hazard with conveying pneumatically. Whether or not this applies ilso to green sand shops I can't say.

It seems to me that a system that is relatively high pressured, as a pneumatic system must be, has a problem once a failure or a leak occurs. Leaks can appear anywhere in a bin or a problem may occur with the exhaust device that permits the air and not the sand to be exhausted from the bin or a leak may develop in any of many other places.

We seem to be able to convey sand with less airborne dust by belts than by pneumatic conveying. And we're a little bit soured on pneumatic conveying for that reason.

Response (F. Shaw):

Yes, I think I would agree. If a leak appeared in a pneumatic system, then dust would be discharged. But, then, of course, a leak in the pipework signals the fact that conveying was not being done properly and the system needs more repairs than just plugging the leak.

Normally speaking, the self-cleaning fabric air cleaners for hoppers are not a problem. I'm specifically talking, of course, about clay bonded sand. Furan sand may, in fact, be a better application for pneumatic conveying.

Question (D. Pullen, Pacific Steel Foundry):

McCarver has come out with a low-velocity high-pressure pneumatic transport system. Do you harre any experience with those systems?

Answer (F. Shaw):

To my knowledge it isn't any different than the systems we already have in Europe, where generally speaking, they're divided between high pressure, medium pressure, and low pressure. If there is anything different about it I would be interested to know. 


\author{
Johin iw. Davis \\ Assistant Professor of \\ Industrial Engineering \\ Center for Air Environment Studies \\ The Pennsylvania State University \\ Vernon C. Irwin \\ Research Assistant \\ Center for Air Environment studies \\ The Pennsylvania State University \\ Kenneth Knott \\ Assistant Professor of \\ Industrial Engineering \\ The Pennsylvania State University
}

\title{
ABSTRACT
}

This is the report of a study of four operating foundries conducted by The Pennsylvania State University. The overall purpose of this effort was to assess the occupational health problem associated with atmospheric free silica in the foundry workplace and to examine one solution to the problem, namely, the substitution of a non-silica based sand for silica sand in the molding area. Work began in 1976 and lasted a little over two years under the sponsorship of the participating foundries in cooperation with the office for Small Industries Research of the Pennsylvania State University.

Results indicate that the use of a silica sand substitute, olivine, which contains little or no free silica, does improve the air quality. Even in mixed silica and olivine sand systems improvements were noted. The number of standards violations was greatly reduced and there are indications that the levels of respirable particulate went down.

\section{INTRODUCTION}

There are many occupational health and safety problems associated with foundry operations. The one about which there has been continuing concern is airborne crystalline free silica. This substance is known to have a deleterious effect on human health. Studies indicate that persons exposed to silica dust over extended periods of time can develop silicosis and this disease can be disabling $(1,2,3)$. Control of this problem has been of primary concern to federal agencies and a vigorous program has been initiated to bring foundries into compliance with regulations. 
There are three major methods of control available to foundrymen. First, and most effective, is isolation. If the workers can be removed from those areas in which the silica dust is in the atmosphere, no exposure can take place. This solution requires complete mechanization so that the molding, pouring, shakeout and initial clean-up of castings is done with little or no human involvement. Economically, this is feasible for only a small group of foundries in the industry.

Air extraction is probably the most popular approach to control. Exhaust systems must be designed, installed and maintained so that the respirable particle matter is efficiently removed from those areas in which work stations are located. The design of such systems is critical. Large sums of money can be (and have been) spent and control of the respirable particulates still not be achieved. Systems improperly maintained or maintained only when inspectors are present may not provide continuing protection to foundry workers. The extraction systems are costly not only in the purchase of capital equipment, but also in the continuing expenses for energy and maintenance.

A third solution is to substitute for silica sand a molding material that does not contain free silica. Olivine is such a material. It has been used in scandinavian countries for many years in foundry operations. The health studies which have been done to date indicate that olivine is less injurious to health than silica sand $(4,5,6)$. Clearly, any air-borne particulate in sufficient respirable quantity is not desirable in the workplace, but one with minimal effects is to be preferred. Olivine is approximately five to six times more expensive than regular molding sand to purchase, but it does give excellent quality castings which require less'surface grinding. In addition, much less make up material is needed since it does not break down like silica sand.

A research study was initiated at the Pennsylvania State University to study the air extraction and sand substitution solution to the free silica problem in foundries. Work began in 1976 and lasted a little over two years under the sponsorship of the participating foundries and the office for Small Industries Research of the Pennsylvania State University. In most situations olivine would be introduced into a mixed system; that is, the foundry would not totally abandon the use of silica sand, but continue to use it in core-making and/or air-set mold (or no-bake) systems. This means that, since the silica sand cores are ground up and reconditioned with the molding material for re-use in molding, contamination of the olivine with silica is inevitable. The question was whether the respirable free silica levels would be reduced in such mixed systems to levels that would meet the regulations.

\section{DESCRIPTION OF PARTICIPATING FOUNDRIES}

Table 1 shows the basic characteristics of the foundries involved in the study. All four were gray iron foundries and produced a variety of different types of castings. While plant layouts and the amount of mechanization varied somewhat, the air quality problems were shared by all participants. Their collective concern over the occupational health problem was such that they were willing to invest funds in this research program. 


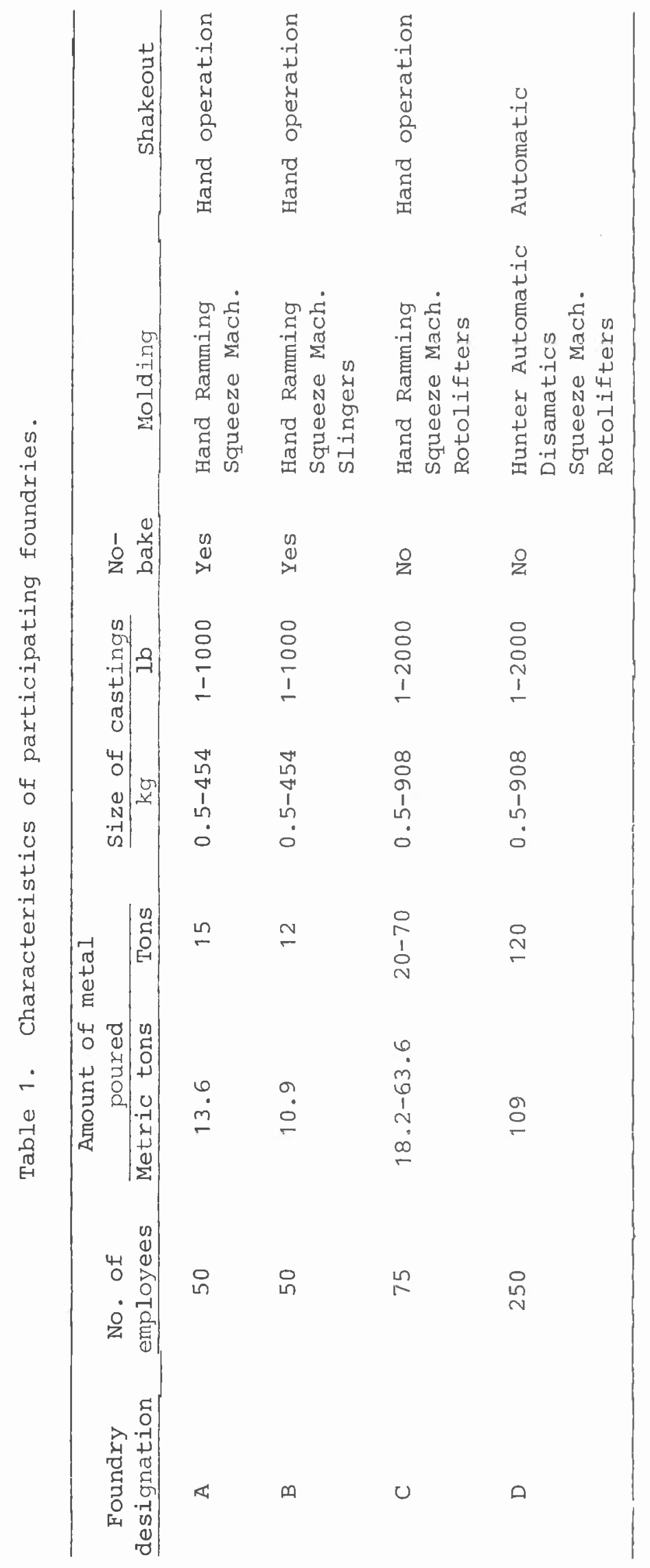


Foundry A substituted the mineral olivine for regular silica sand in the molding area. One test was conducted prior to the changeover and three afterwards. At Foundry $C$, olivine was in use and for technical reasons the operator decided to switch back to silica sand; one test was made at each condition. At the other two foundries only one set of tests was obtained. Foundry B was essentially an uncontrolled situation from a ventilation standpoint and Foundry D had installed a fairly large air extraction system.

NATURE OF THE AIR QUALITY STUDY

The major purpose of the study was to assess the impact on air quality of substituting the mineral olivine for the regular silica based sand. In addition, it was also of interest to examine the air quality in an uncontrolled shop and one which had tried to solve the free silica problem by air extraction. The economics of the solutions are discussed elsewhere (7).

Another aspect of the work discussed in the earlier stages was casting quality. It became apparent after the initial study in Foundry A that the quality of the castings made with olivine molds was quite comparable to those cast in silica sand molds. This particular parameter was best evaluated by the individual foundry with their own specific requirements.

Air quality was measured in three ways. The standard personal sampler was used on individuals. Cascade impactors, located at various points within the foundry were operated at random intervals in order to obtain particle size distributions. Tape samplers were located in five areas of the plant and were run continuously during the study; this permitted hour by hour evaluation of the air quality. In all cases, samples were taken over one week periods. Table 2 indicates when and how many samples were obtained of each type.

Table 2. Sampling summary.

\begin{tabular}{|c|c|c|c|c|c|}
\hline $\begin{array}{c}\text { Foundry } \\
\text { designation }\end{array}$ & Date & & $\begin{array}{l}\text { No. of } \\
\text { personal } \\
\text { samples }\end{array}$ & $\begin{array}{l}\text { No. of } \\
\text { impactor } \\
\text { samples }\end{array}$ & $\begin{array}{c}\text { Tape samplers, } \\
\text { continuous }\end{array}$ \\
\hline \multirow[t]{4}{*}{ A } & October, & 1976 & 35 & 24 & 5 \\
\hline & January, & 1977 & 30 & 21 & 5 \\
\hline & August, & 1977 & 28 & 16 & 5 \\
\hline & November, & 1977 & 15 & 18 & 5 \\
\hline B & February, & 1978 & 19 & 35 & 5 \\
\hline \multirow[t]{2}{*}{ C } & September, & 1978 & 18 & 23 & 5 \\
\hline & November, & 1978 & 19 & 21 & 5 \\
\hline D & October, & 1978 & 23 & 29 & 3 \\
\hline
\end{tabular}


The personal samplers used were from several manufacturers. Two types of samples were taken: 1) the standard procedure was to use the nylon cyclone with a back-up millipore filter and, 2) on occasion the filter holder was expanded to three sections and a sample taken without the cyclone to give a total dust reading. The data for each foundry was compiled by area. The percent quartz was determined by the Bumstead x-ray diffraction method.

In order to compare the air quality as measured by the personal samplers, the data are presented in two ways. Table 3 summarizes the number of Ostn violations - the measurements where the Time Waited Average (TWA) exceeded the Permissible Exposure Limit (PEL) for respirable silica dust* by area in each foundry. Within the table, the samples taken when Foundries $A$ and $\mathrm{C}$ were on olivine are shown separately. A second method of presenting the same data is shown in Table 4. In this case the averages of the ratio of TWA to PEL are shown for each area and each foundry. The larger the ratio, the more likely there is to be a violation. It should be noted that a ratio less than 1.0 does not mean that a violation is impossible, only that it is less likely. Numbers larger than 1.0 indicate the violations will definitely take place.

Table 3. Summary of personal sampler violations for respirable silica.

\begin{tabular}{|c|c|c|c|c|c|c|c|c|}
\hline \multirow[b]{3}{*}{ Foundry } & \multicolumn{8}{|c|}{ Using silica molding sand } \\
\hline & \multicolumn{2}{|c|}{ Molding area } & \multicolumn{2}{|c|}{ Grinding area } & \multicolumn{2}{|c|}{ Core area } & \multicolumn{2}{|c|}{ Shakeout area } \\
\hline & $\overline{\mathrm{N}}$ & Violations & $\overline{\mathrm{N}}$ & Violations & $\overrightarrow{\mathrm{N}}$ & Violations & $\overline{\mathrm{N}}$ & Violations \\
\hline$A$ & 9 & 1 & 10 & 4 & 10 & 3 & 6 & 2 \\
\hline B & 8 & 2 & 5 & 4 & 2 & 0 & 4 & 2 \\
\hline $\mathrm{C}$ & 9 & 8 & 3 & 1 & 1 & 1 & 5 & 3 \\
\hline \multirow[t]{2}{*}{$\mathrm{D}$} & 14 & 8 & 6 & 6 & 3 & 1 & & $\begin{array}{l}\text { separate } \\
\text { keout }\end{array}$ \\
\hline & \multicolumn{8}{|c|}{ Using olivine molding sand } \\
\hline A & $\overline{23}$ & 0 & 13 & 5 & 15 & 2 & 10 & 0 \\
\hline $\mathrm{C}$ & 11 & 1 & 3 & 0 & 3 & 0 & 2 & 0 \\
\hline
\end{tabular}

Table 3 indicates that these four foundries definitely have problems in violating OSHA standards when a silica molding sand is used. In Foundry D, where a large investment in air extraction equipment has been made, the problem is acute. It should be recalled that this foundry also has the highest degree of automation (see Table 1).

When olivine was used in Foundries $A$ and $C$, reductions in the number of violations were clearly achieved, but violations were not eliminated. Both foundries had a mixed system of silica sand and olivine. Silica sand was used for cores and, in the case of Foundry $A$, there was a large no-bake area adjacent to the molding floor where both air set cores and molds were made. If one looks at the use of sand substitution from the regulatory point of view, there is still a risk of OSHA violations, but the risk is somewhat reduced.

*OSHA PEL for respirable dust containing quartz is calculated as $\frac{10}{2+8}$ 
The grinding area is the exception to this rule because of the high particle concentrations in that area; if castings from air set molds are ground, the percent quartz can still be quite high. Foundry $\dot{C}$ had grinding booths and lower overall dust concentrations in that area than any of the other three foundries. The shape of the castings at Foundry $A$ made the use of booths somewhat impractical. The problem of violations in grinding was not controlled by changing to olivine for molding.

Table 4 indicates the same results in a numerical way. Note again that the foundry (D) with the highest level of automation had the most difficult control problem in both the grinding and molding areas. The value for TWA/ PEL ratio in the core area was similar to the ones found in Foundries $A$ and B. The single value for Foundry $\mathrm{C}$ in that area is probably erroneous.

Table 4. Summary of personal sampler results for respirable silica.

\begin{tabular}{|c|c|c|c|c|c|c|c|c|}
\hline \multirow[b]{3}{*}{ Foundry } & \multicolumn{8}{|c|}{ Using silica molding sand } \\
\hline & \multicolumn{2}{|c|}{ Molding area } & \multicolumn{2}{|c|}{ Grinding area } & \multicolumn{2}{|c|}{ Core area } & \multicolumn{2}{|c|}{ Shakeout area } \\
\hline & $\mathrm{N}$ & TWA/PEL & $\mathrm{N}$ & TWA/PEL & $\mathrm{N}$ & TWA/PEL & $\mathrm{N}$ & TWA/PEL \\
\hline A & 9 & 0.61 & 10 & 1.14 & 10 & 0.98 & 6 & 1.09 \\
\hline B & 8 & 0.90 & 5 & 2.13 & 2 & 0.88 & 4 & 1.22 \\
\hline C & 9 & 2.05 & 3 & 0.97 & 1 & 4.42 & 5 & 1.01 \\
\hline \multirow[t]{2}{*}{ D } & 14 & 2.70 & 6 & 3.25 & 3 & 0.92 & & $\begin{array}{l}\text { eparate } \\
\text { eout }\end{array}$ \\
\hline & \multicolumn{8}{|c|}{ Using olivine } \\
\hline A & 23 & 0.40 & 13 & 0.90 & 15 & 0.43 & 10 & 0.23 \\
\hline c & 11 & 0.44 & 3 & 0.50 & 3 & 0.60 & 2 & 0.28 \\
\hline
\end{tabular}

At foundries $A$ and $C$ the two areas which should be most affected by the use of olivine are molding and shakeout. When silica sand is the molding material, higher levels of quartz are found and the PEL is smaller as the result. The ratio of TWA to PEL would, therefore, be larger and should show a statistical difference when compared to the same ratio when olivine is in use.

To compare two sample means where the sample size is small ( $\mathrm{n}<30$ ) the student $t$ test is used. The null hypothesis

$$
\mathrm{H}_{\mathrm{O}}: \mu_{1}=\mu_{2}
$$

indicates that the means are equal. Clearly, this should be the case if the samples are drawn from the same population. A 95 percent significance level is used for the test.

The input information and the results are shown in Table 5 . Note that in three of the four cases the hypothesis that the means of the population are equal is rejected. In the case where the sample size is extremely small (2) the hypothesis cannot be rejected. 
Table 5. Statistical test.

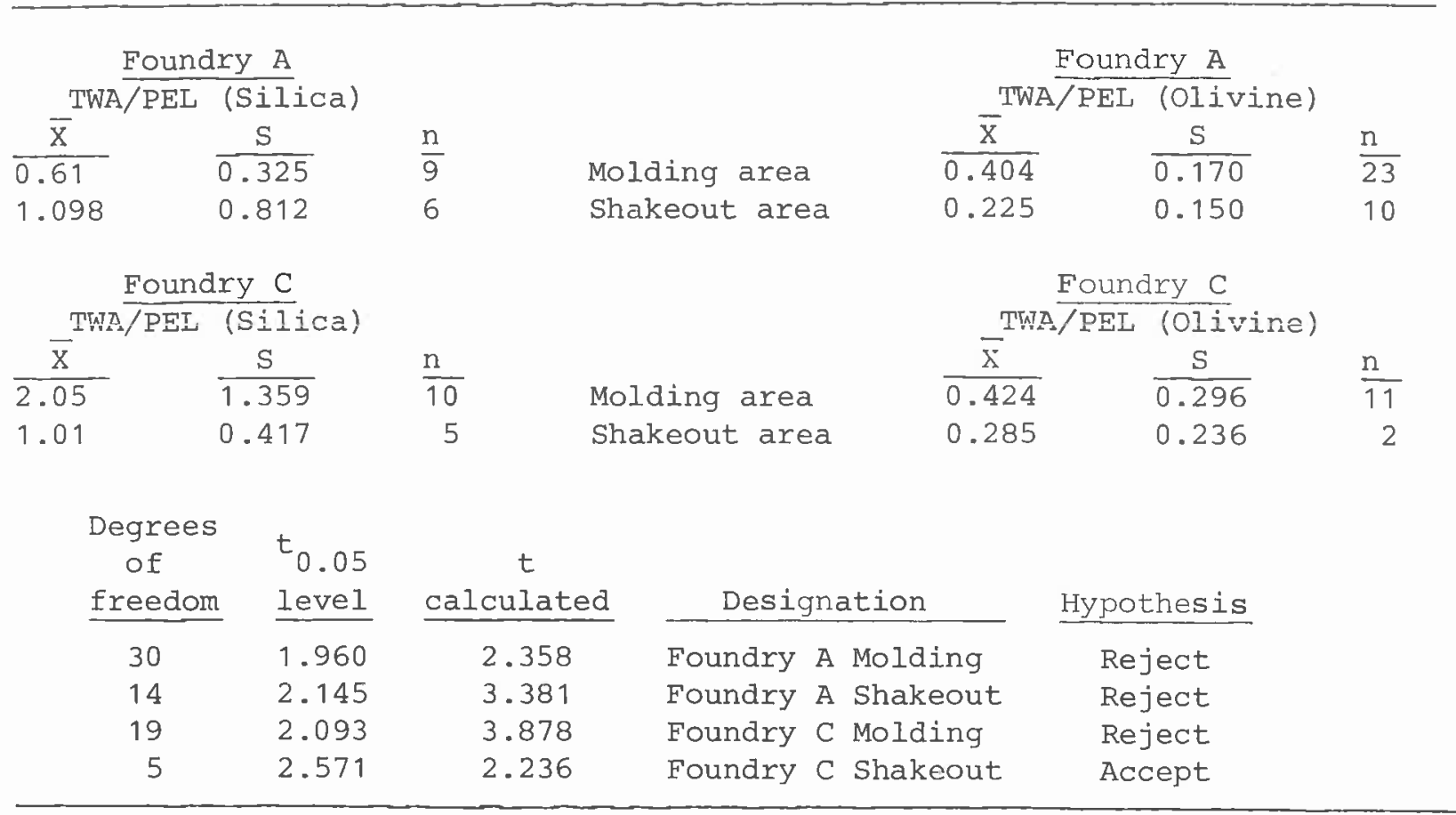

While this is not a conclusive test, it is an indicator that the introduction of olivine reduces the TWA to PEL ratio significantly. This in turn should reduce, but probably not eliminate, the possibility of a violation of OSHA regulations in the Molding and Shakeout areas or in any location in the foundry where olivine is in use.

\section{SUMMARY AND DISCUSSION OF IMPACTOR RESULTS}

The cascade impactor is an instrument that has been widely used in assessing air quality in all types of atmospheres. An Andersen unit was used in these studies. It was originally designed to simulate the human bronchial system. Particles are drawn into the device at a fixed flow rate and are fractionated into size ranges by progressively increasing the velocity and collecting a fraction at each stage. The collection media are weighed before and after exposure to determine the amount of material in each fraction. Results can be plotted in many ways. Differential plots were chosen since they present the data in a pictorial way.

Figure 1 shows the data from the molding area of all four foundries. Each curve represents at least five impactor samples taken at random intervals in each foundry. The similarity of the curves is obvious. The ordinate is labeled DM/D Log DP. This means the change in the percent mass divided by the change in the log of particle diameter. To put this more simply, the area under the curve between any two selected particle sizes on the abscissa represents the percent of the mass in that interval. 


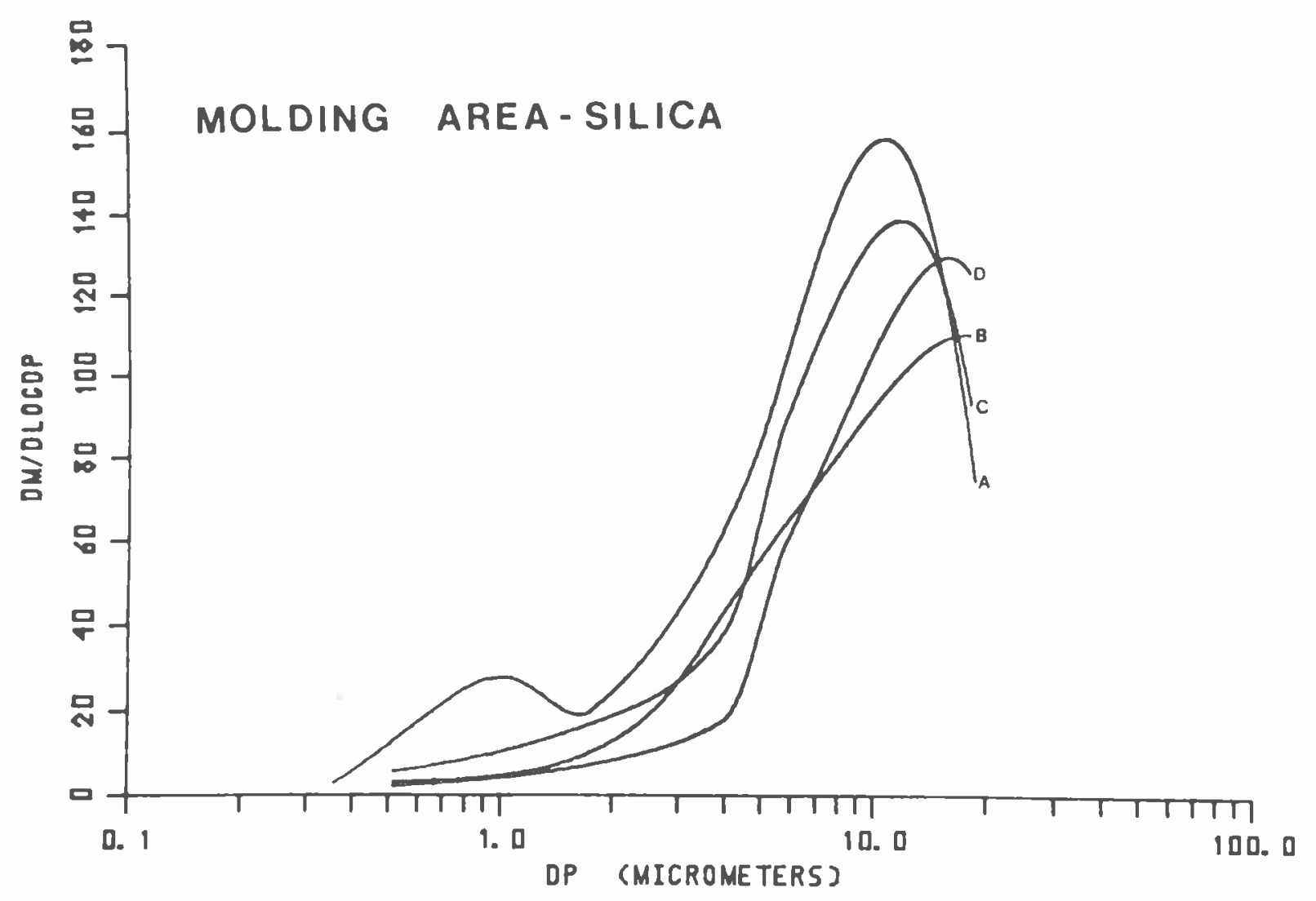

Figure 1. Molding area impactor plots.

The curves that are shown are characteristic of all areas of the foundry. In the complete report of this work the distributions by area for each of the participating companies are shown (7). These data indicate that the largest population by mass of the airborne raterial is larger than 4.0 micrometers. There is still a large fraction of the dust in the respirable region $(\sim<2.0 \mu \mathrm{m})$ and this, of course, constitutes the basic occupational health problem.

Since olivine is more dense than silica, it should tend to settle out more quickly. More importantly, because of its physical characteristics, it is also less likely to fracture at the mold surface where high temperatures are present. The point at which some of the free silica is generated in foundry operations is at the point where the hot metal comes into direct contact with the silica sand. Olivine does not fracture to the same extent at this surface and one would assume that the concentration of very small particles should be less in an olivine system than in a silica sand shop. In the two foundries which used both silica and olivine, the point at which this factor should be most noticeable is at shakeout. When the molds are broken to remove the castings, large amounts of fine particles become airborne.

Cascade impactor tests were taken at shakeout in Foundries $\mathrm{A}$ and $\mathrm{C}$ when both silica and olivine were in use. Figures $2 \mathrm{a}$ and $2 \mathrm{~b}$ are plots of these data. In this case the ordinate is labeled DC/D Log DP. 


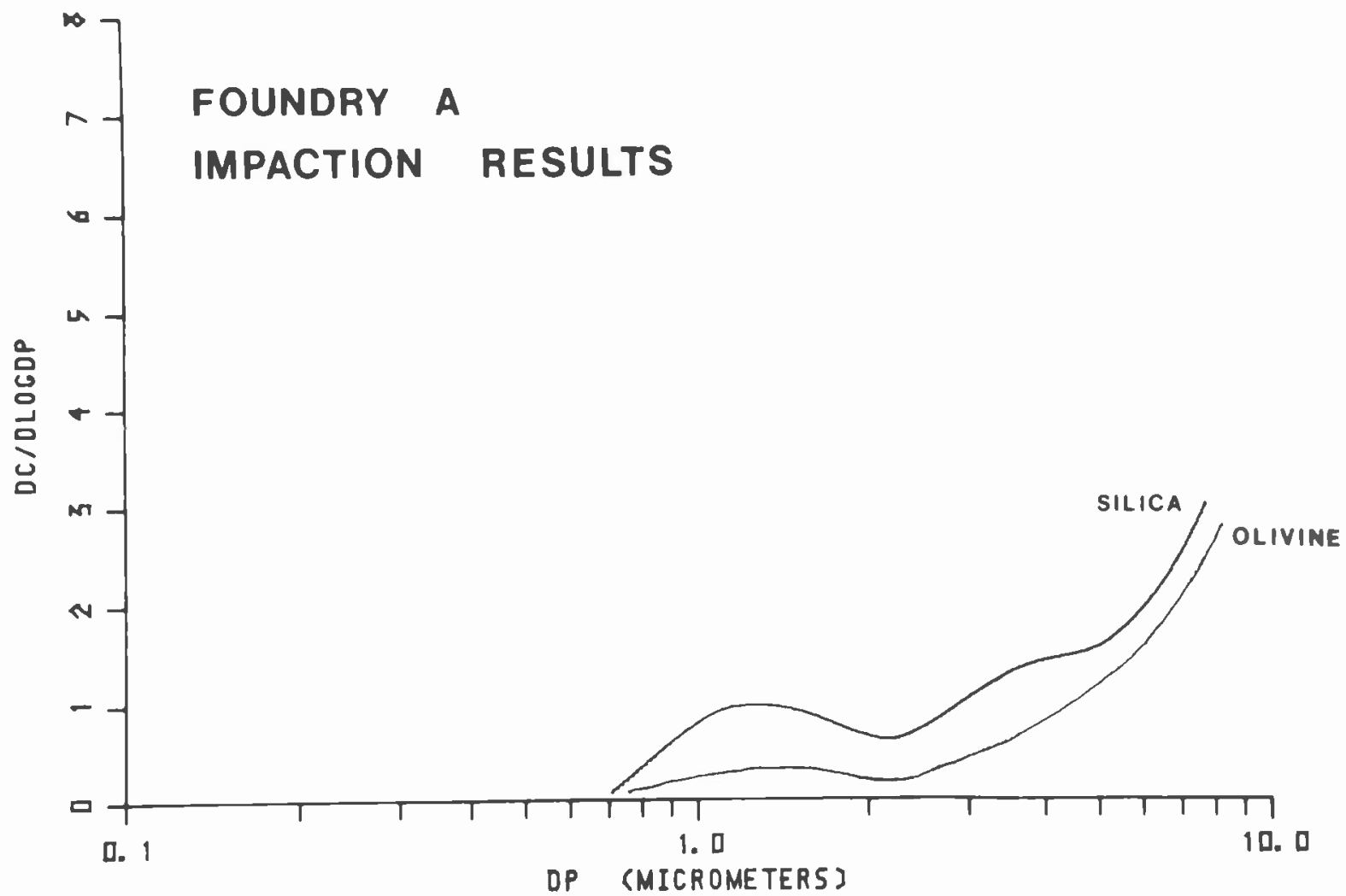

Figure 2a. Impaction results, shakeout area, Foundry A.

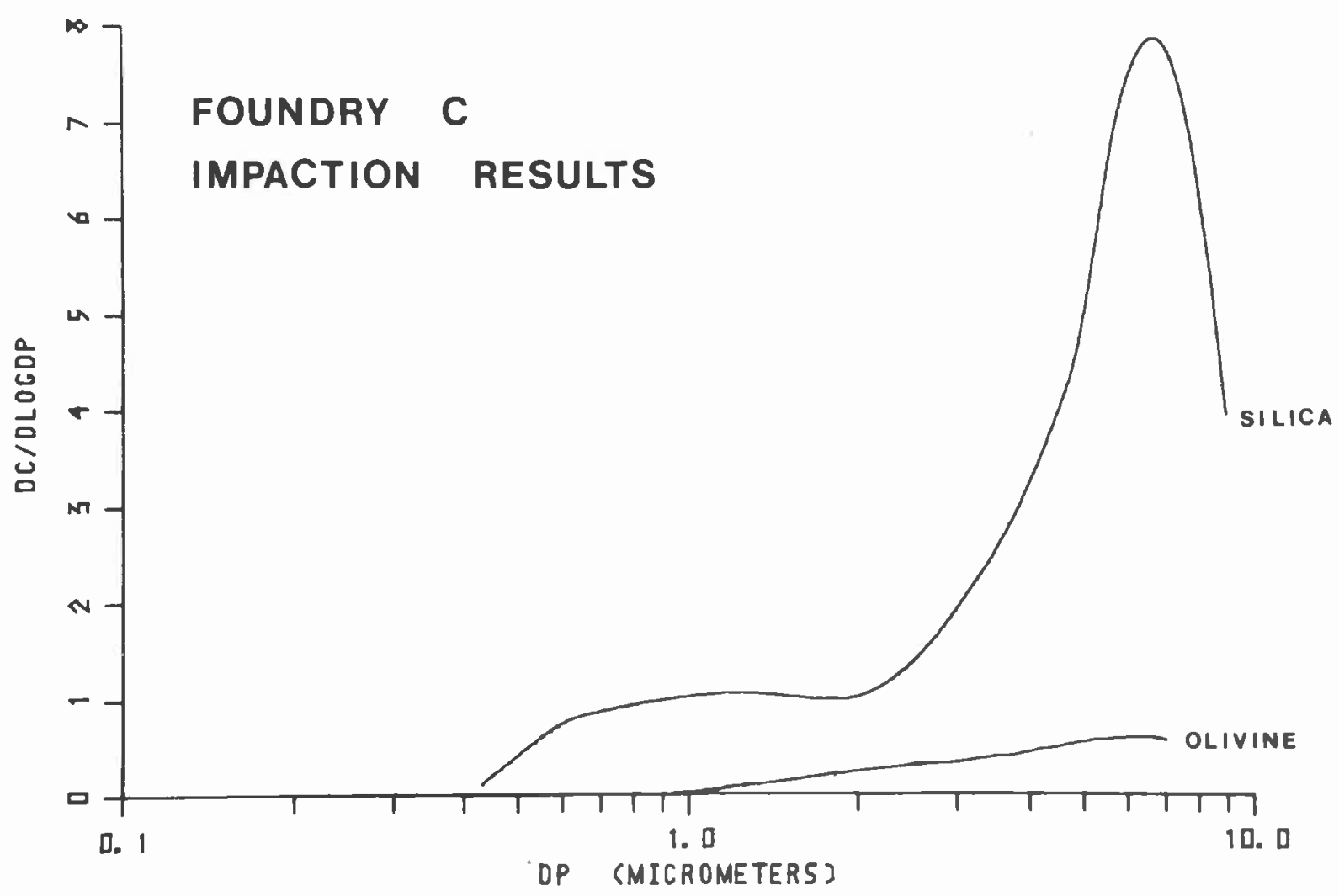

Figure 2b. Impaction results, shakeout area, Foundry C. 
This refers to the change in particle concentration divided by the change in particle size. The area under the curve between any two selected particle sizes represents the milligrams per cubic meter in that size fraction.

Note that in both cases the change is quite obvious. For respirable particles in the region $<2.0 \mu \mathrm{m}$ there is a reduction of about a factor of two for Foundry $A$ and considerably more than that for Foundry $C$. In the latter case there were some problems with the exhaust system which undoubtedly contributed to the extremely large variation. The olivine curves for both foundries are remarkably similar in the fine particles region. These two sets suggest that there should be fewer respirable size particles coming from the sand system in a foundry using olivine for molding sand.

SUMMARY AND DISCUSSION OF TAPE SAMPLER RESULTS

Tape samplers have been used for many years to determine the hour by hour variations of total particulate matter in the atmosphere. In the foundries visited in this series of tests, five were used and the samples were taken between $1.5-1.8 \mathrm{~m}(5-6 \mathrm{ft})$ above the ground. A sample is drawn through a filter tape at a fixed flowrate for one hour; the tape then automatically indexes to a clean spot and the process repeats. Operating inside a building with a fixed type of dust makes it possible for the spots on the tapes to be compared using a simple optical density meter. Comparisons could be made since each spot had a fixed amount of air drawn through it for the one hour period.

The devices were set up so that a one hour sample was taken each hour - 24 hours a day. The major information that could be determined from such a program was the variations during the day and the daily high and low points. One would expect that the particle concentration would begin at a relatively low point in the morning, build up over the day, and begin to taper off as the activity in the foundry was reduced toward evening. All four foundries were shut down from approximately midnight till 5:00am. Foundry B shut off all power in the building so that there is no overnight data for that foundry.

Figure 3 shows the results for all four foundries in the molding area while silica sand systems were in use. These data were obtained by taking the hour by hour optical density readings for each day during the testing period and averaging them together to get a composite picture of each area where the tape sampler was in use. Foundry A had the typical curve which had been expected. The other three foundries did not drop down to the expected low levels in the night-time hours and, therefore, started the day at a relatively high particle concentration level.

Foundry D, the most automated of the group, had an almost constant level, while Foundry A increased rapidly in the morning and dropped off from lunch time till about 3:00pm. The peak at about 4:00pm was probably due to the initiation of the shakeout procedures. 


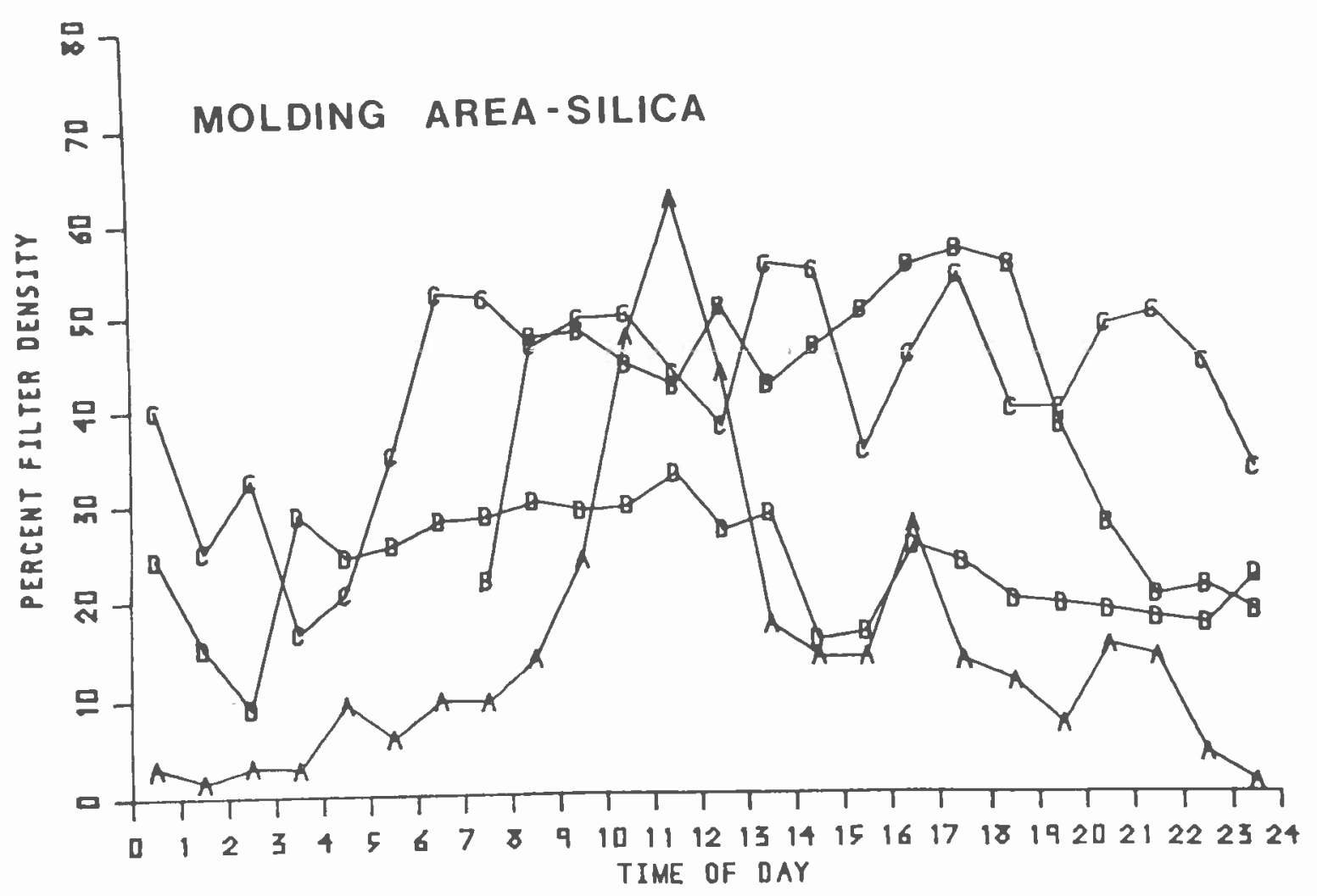

Figure 3. Molding area tape sampler graphs - silica.

Since the physical characteristics of olivine are similar to silica, one would not expect a great change in the measured parameters when the two materials were in use. Olivine is more dense and should settle out faster and perhaps dampen out some of the variations. Figure 4 shows the results for Foundries $A$ and $C$ when the two foundries used an olivine system. There is a rather large overall reduction indicated in the results from Foundry $C$. Unfortunately, since the ventilation system was not functioning properly when the silica sand system was in use, no definitive statement can be made. On the basis of Figure 4 it should be noted that the combination of ventilation and the use of olivine produced the lowest levels of particulate matter found in any foundry.

At Foundry $A$, the levels at the beginning and the end of the day are somewhat lower when olivine was in use and the large morning peak has been reduced. However, the levels at mid-morning and mid-afternoon are slightly higher. The reasons for this are not clear.

Only the molding area is discussed here because this is the area where the differences between olivine and silica systems should be most obvious over the 24 hour period. Shakeout, the other critical area, takes place at the two foundries (which used both materials) only at short time periods during the day. The area by area tape sampler results for each of the foundries is found in the complete report (7). 


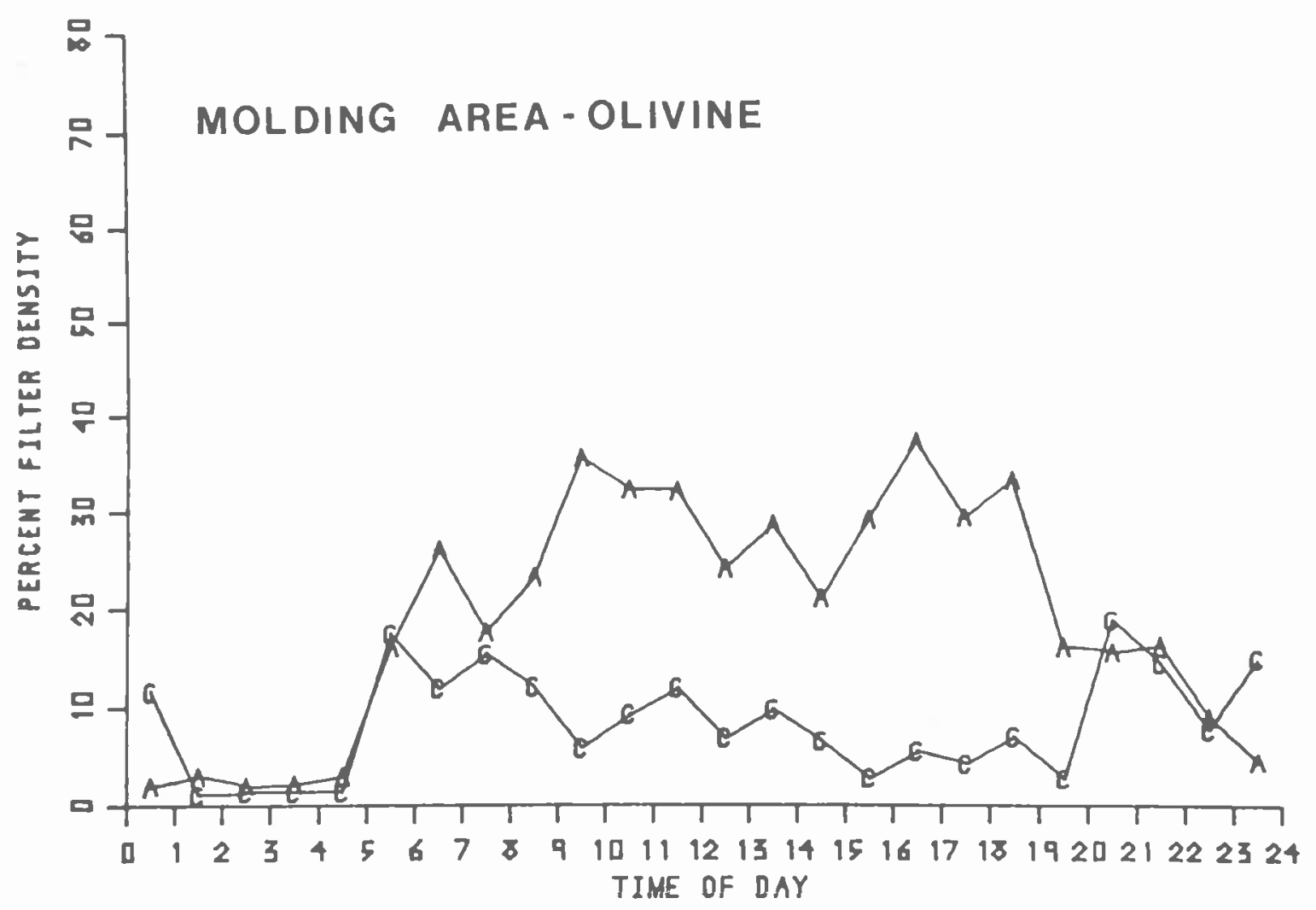

Figure 4. Molding area tape sampler graphs - olivine.

AIR QUALITY EVALUATION AND SUMMARY

In examining the data from these four foundries some generalizations can be made. First, the foundry industry must definitely make an effort to reduce not only the free silica, but also the total dust loadings in the working atmosphere. A second inference from the information yathered is that the use of the mineral olivine, even under a mixed system condition, can reduce the amount of free silica in the foundry atmosphere and reduce the possibility of an occupational health violation. Iastly, it can be stated with assurance that the most effective (and the most expensive) solution is a combination of ventilation and the use of olivine or some other non-free silica based material as the molding material.

The results presented in this study show rather vividly that the atmosphere in operating foundries contains levels of particulate matter which have been declared by regulatory agencies as unsuitable working conditions. Table 3 shows that at the four foundries, while using silica sand, $48 \%$ (46 to 95 ) of all samples taken were in violation of existing regulations. At Foundry D, which had spent a rather large sum of money on a baghouse and an exhaust ventilation system, 15 of 23 samples or 65 were at unacceptable levels. 
Results from Foundries $\mathrm{A}$ and $\mathrm{C}$ indicate that olivine, while not eliminating violations, clearly improved the situation. Impactor results show that the amount of respirable particulate is reduced when olivine is substituted for silica (see Figure $2 \mathrm{a}$ and $2 \mathrm{~b}$ ). This coupled with the knowledge that olivine contains less than $1 \%$ free silica should convince even the most skeptical that there is a health related advantage in substituting this mineral for silica sand. As stated earlier, experience in the Scandinavian countries supports this contention also. To date all the data available indicate that olivine is less toxic than silica but a definitive health study has yet to be made $(4,5,6)$.

Violations were reduced at Foundry A from 29 percent of all samples taken to 11 percent with the only violations occurring in areas where sand type was not a factor. At foundry $C$ the number went from 72 percent of all samples in violation when silica was in use to 5 percent when olivine was the molding material.

Foundry $c$, when using olivine, was shown to be the cleanest working atmosphere by all the measuring devices used in these tests. It had the fewest violations (1) and the lowest percentage of violations (5\%). The ratio of TWA to PEL never exceeded 0.60 in any area of the foundry (Table 4). The respirable particulate as measured by the impactor showed the lowest amount present (Figure $2 \mathrm{~b}$ ) and the particle levels as measured by the tape sampler were lower than any other foundry visited.

The reasons for the above would appear to be related not only to the use of olivine but also to the following factors:

1. The grinding area was separated from the rest of the foundry and was equipped with grinding booths.

2. There was less silica sand in use in this foundry than at Foundry A.

3. More care was taken with housekeeping than at any of the other foundries.

Observations indicate that all foundries would probably show improvements if the last factor, housekeeping, was taken more seriously. This would not bring them into compliance, but would improve the air quality. Periodic cleaning of beams and other ledges where particulate matter tends to collect, more careful use of forklift trucks and loaders, and the isolation of dusty areas from other parts of the plant are just three of the ways in which the situation could be improved.

This study has shown that olivine can improve the air quality in foundries not only by reducing the free silica present but also by reducing the respirable particle matter in the atmosphere. However, it is not the whole answer. Some areas of the foundry, e.g., grinding areas, will have to be equipped with exhaust ventilation and, most probably, isolated from other areas. It is also important to note that exhaust ventilation systems must be carefully designed and tested. The costs are high and the increased energy usage can be substantial. The economics of such decision making are discussed 
in the complete report but it is difficult, if not impossible, to predict in advance whether ventilation alone is going to bring the particle level in the working atmosphere to acceptable levels (7).

\section{REFERENCES}

1. Hermann, H., M.D. The Health of Ferrous Foundry Workers. Public Health Reports. Vol. 66. No. 8. P.H.S. Publication No. 31 . (1951).

2. Hunter, D., M.D. The Diseases of Occupations. Little Brown and Company. 5th Edition. pp. 915-1048. Boston, Massachusetts. (1975).

3. Silicosis and Diseases of Retired Iron Foundry Workers. Ind. Mag. $41: 32-38$. (1972).

4. Ahlmark, A. and A. Nystrom. Silicosis Risk in Steel Foundries and Its Prevention by Use of Olivine Sand. An Important Prophylactic Advance (in Swedish and English Summary). Svenska Läkartidn. 57:3057. (1960).

5. Davis, J. M. G. The Fibrogenic Effects of Mineral Dusts Injected into the Pleural Cavity of Mice. Brit. J. Exp. Path. 52(2):190-201. (1971).

6. King, E. T., Rogers. H., Gilchrist, M., Goldschmidt, V., and Nagelschmidt, G. The Effects of Olivine on the Lungs of Rats. J. Path. Bact. $57: 488-491$ (1945).

7. Davis, J. W., and Irwin, V. - Knott, K, and Herbe, D. Meeting Air Quality Standards in the Foundry Industry. Volume I - Summary of Air Quality Data (CAES No. 538-A-79)*. Volume II - Detailed Analysis of the Air Quality at the Four Cooperating Foundries (CAES No. 538-B-79*. Volume III - An Economic Evaluation of Alternative Methods*.

QUESTIONS, ANSWERS AND COMMENTARY

Comment (S. Hoenig, University of Arizona) :

It's well-known that silica, particularly the one micron size material, has a strong negative charge. Since the earth is also negatively charged you would expect this material to remain suspended in the air, which in fact it does. This has been observed by meteorologists and it's called the electrode effect. It's actually quite well-known.

\footnotetext{
* May be obtained from Small Industries Research office, 312 Willard Building,
University Park, PA 16802 .
} 
Question (G. Tubich, Tubich and Associates):

Has there been any attempt or work lately on separation of the silica from the olivine based on the differences in specific gravity?

Answer ( $\mathrm{J}$. Doninger, IMC Olivine Company):

This is an area of ongoing research, not only in separating olivine from silica sand but also from chromite sand and zircon sand. The results have been mixed - it just isn't that feasible to separate silica sand from olivine. You can do a good jỏ of separating chromite sand from either silica sand or olivine sand. But olivine is about a 3.3 specific gravity while silica sand, I think, is around 2.7 or 2.8 .

Question (R. Jacko, Purdue University):

bu said Foundry D was a very mechanized foundry and you found relatively high levels of dust. I am curious if you have any personal observations as to why.

Answer (V. Irwin):

Yes, I was at that foundry during the study. As I said, it was very highly mechanized. I have no idea why their dust loadings were so high. They had certainly spent a considerable amount of money on a new baghouse system but conditions were still terrible. You couldn't see for fifty feet in the place when they were operating.

Comment (J. Calhoun, white Consolidated Industries Inc.):

I would like to comment that Foundry D from your data was the most productive foundry by far. It had fewer employees per ton cast and it also had many, many more tons per day than the other foundries. For those two reasons it probably produced a large amount of dust and needed some ventilation work done to capture the dust. If you cast more tons per day, you'll certainly have more tons of dust per day.

Question (J. Calhoun):

What, if any, study was done at Penn State to determine the relative availability of olivine for the foundries that might be interested in using it. In other words, what is the supply and demand situation?

Answer (V. Irwin):

A continuing part of the study has been determining the economic feasibility of using olivine. Such information could be obtained by writing to Penn state University, Small Industries Research Office*. That particular information is just now being published.

\footnotetext{
* See footnote, previous page.
} 
Answer ( $\mathrm{J}$. Doninger):

George Tubich mentioned yesterday that there are ten million tons of silica sand being consumed and only about five hundred thousand tons of the specialty sands being consumed. Yes, there is more olivine sand available.

Comment (V. Irwin):

I would like to thank the IMC people who gave us some very valuable help in our analysis and provided us with some olivine. 


\author{
CHARACTERIZATION OF PARTICULATES AND LEAD IN A BRASS FUUNDRY \\ USING A CLOSE CAPTURE EXHAUST SYSTEM \\ Robert B. Jacko, Ph.D., PE \\ Associate Professor of Environmental Engineering \\ School of Civil Engineering \\ Purdue University \\ West Lafayette, Indiana \\ Robert C. Overmyer, President \\ Hawley Division \\ Envirotech Corporation \\ Indianapolis, IN
}

\title{
ABSTRACT
}

Housekeeping, work practices, layout of facilities, and ventilation controls have a substantial impact on lead levels in brass melting and pouring operations. The study reported here was undertaken to characterize lead levels in a brass foundry employing Hawley ventilation systems to control fume emissions during furnace operations, as well as hot metal transport and mold pouring of an alloy containing 5\% lead. Personal exposures ranged from $57-173 \mu \mathrm{g} / \mathrm{m}^{3}$, depending on the work task involved. The overall average personal lead concentration was $110 \mu \mathrm{g} / \mathrm{m}^{3}$. Measurements of particle size distribution and segregation of lead among the particle sizes in the samples are also reported.

\section{INTRODUCTION}

\section{General Considerations}

This paper will address the problems that brass foundries face in reaching the low lead level required by OSHA (time-weighted-average of $50 \mu \mathrm{g} / \mathrm{m}^{3}$ ). After many years of observing foundry and brass mill operations, we can point to many variables to be overcome in reducing airborne particulate to acceptable and safe levels.

The problem of housekeeping is a contributor to high lead levels: floors may be dust laden; lead-bearing dust can drift down from ceiling beams and overhead cranes.

The problem of work practices and layout of facilities presents a variety of difficulties that contribute to high lead levels. These can relate to widely separated pouring and melting operations, methods of ladle transport, ways of operating different kinds of furnaces or a variety of methods for charging furnaces (by hand, by shovel, by barrels, by chutes or by drop bottom buckets). There can also be difficulties caused by worker attitudes. 
When the term engineering control is used it usually relates to exhaust systems designed to capture and control airborne contaminants. In the past the foundry industry had little concern about the amount of air discharged from a building. Installation of a canopy hood or roof exhauster might have been considered as making progress in clearing away dust and smoke. Air was cheap; energy to power big fans was no problem; and fuel to heat make-up air was plentiful. Unfortunately, these things are no longer true. Today the cost of cleaning dirty air is very expensive. Consequently, we have learned how to conserve the amount of air being discharged that has to be cleaned on the outside and replaced on the inside.

The average cost of installing a complete hood and duct system five years ago together with air pollution control equipment on the outside cost $\$ 1.50 / \mathrm{m}^{3} / \mathrm{hr}(\$ 2.50 / \mathrm{cfm})$. Today, the expense of cleaning air has doubled and it is still increasing every year. Reducing the amount of air to be exhausted is important. If a company can save $34,000 \mathrm{~m}^{3} / \mathrm{hr}(20,000 \mathrm{cfm})$, it means $\$ 50,000$ to $\$ 100,000$ when the cost of air pollution control equipment is considered. This savings can be put back into capital budgets for productive equipment.

Canopy hoods for melting, pouring, and shakeout use many times more air than necessary and seldom are effective. Experience has shown that lead particulate levels can be controlled most effectively by capturing and exhausting brass fume at the source using close-capture, high velocity hoods with in-draft velocities sufficiently high to entrain fume which rises in the thermal draft.

Control of fume during both hot metal transport and pouring operations is possible with a close-capture hood coupled to a mobile exhau-t system. Only $3400 \mathrm{~m}^{3} / \mathrm{hr}(2000 \mathrm{cfm})$ per ladle may be needed to clean up an entire room, with subsequent shut down of most of the roof ventilators, thus reducing the waste of reheating outside air.

Reduction of lead levels can be obtained in ways that will save money on total systems by conserving on exhaust air volumes. It results in reducing the size and cost of air pollution control equipment and the amount of heated make-up air needed to make systems operate efficiently, thus lowering the cost of fuel and energy.

The last thing a worker wants to be wearing, when pulling or pushing a heavy ladle of hot metal, is a respirator. Keeping the exhaust systems, fans, and baghouses well-maintained and in good repair will help to assure the worker's personal protection and good health.

\section{A Study to Quantify Particulate and Lead Concentrations}

Remembering that good housekeeping, work practices, and plant layout also play a big part in holding lead levels to a minimum, we can ask how effective can engineering controls be? Keeping in mind the problems with many variables that exist from one foundry to another, Hawley wanted to know what results might be attainable under normal rates of foundry production. Therefore, Dr. Robert B. Jacko was asked to conduct a study to characterize 
the particulates and lead fume in a brass foundry employing a mobile ventilation system. The following measurements were made:

1. Workplace concentrations of total suspended particulates and lead fume by taking personal samples in areas of highest expected lead concentrations.

2. General area concentration of particulates and lead fume.

3. Particulate and lead aero-dynamic particle size distribution in two critical areas of the foundry.

PROCESS AND FACIIITY DESCRIPTION

The facility chosen for study was a modern brass foundry employing electric induction-type furnaces. The general layout of the furnace and pouring lines is shown in Figure 1. Molten metal is transported via $136 \mathrm{Kg}$ (300 1b) ladles to each of three pouring lines labeled as lines "A", "B", and "C" in Figure 1. The lead content in the alloy being melted and poured was $5 \%$ by weight during all tests.

The entire furnace and pouring area is controlled for particulates and fume with both a fixed and mobile arrangement of Hawley ventilation hoods. The fixed ventilation hoods are attached to each of the furnaces and control particulates during charging, meltdown and tapping.

A separate mobile ventilation system is employed to control fume from the individual ladles as they are charged at the furnace, transported to the mold pouring area, and poured at the mold pouring line. In this way total particulate control is maintained in the workplace for all molten metal operations.

EXPERIMENTAL PROCEDURE

Sampling Methodology

Eight-hour personal and area air samples were taken throughout the foundry where molten metal operations were in progress. In this area three tasks are carried out and have been identified as the furnace charger, ladle pourer and the pourer's helper. These workers perform tasks which place them in the areas of highest expected concentrations of lead fume.

The furnace charger is responsible for the electric furnace operation. This worker is, for the most part, adjacent to the furnace during the work day. Charging, meltdown, and tapping are his major functions.

The ladle pourer transports the ladle to and from the furnaces and molds. Throughout this operation a mobile ventilation hood travels with the ladle, thus reducing worker exposure to fume. The ladle pourer has assistance from a worker described as the pourer's helper. This involves movement of the ladle, slag removal and, depending on the work load, pouring. 

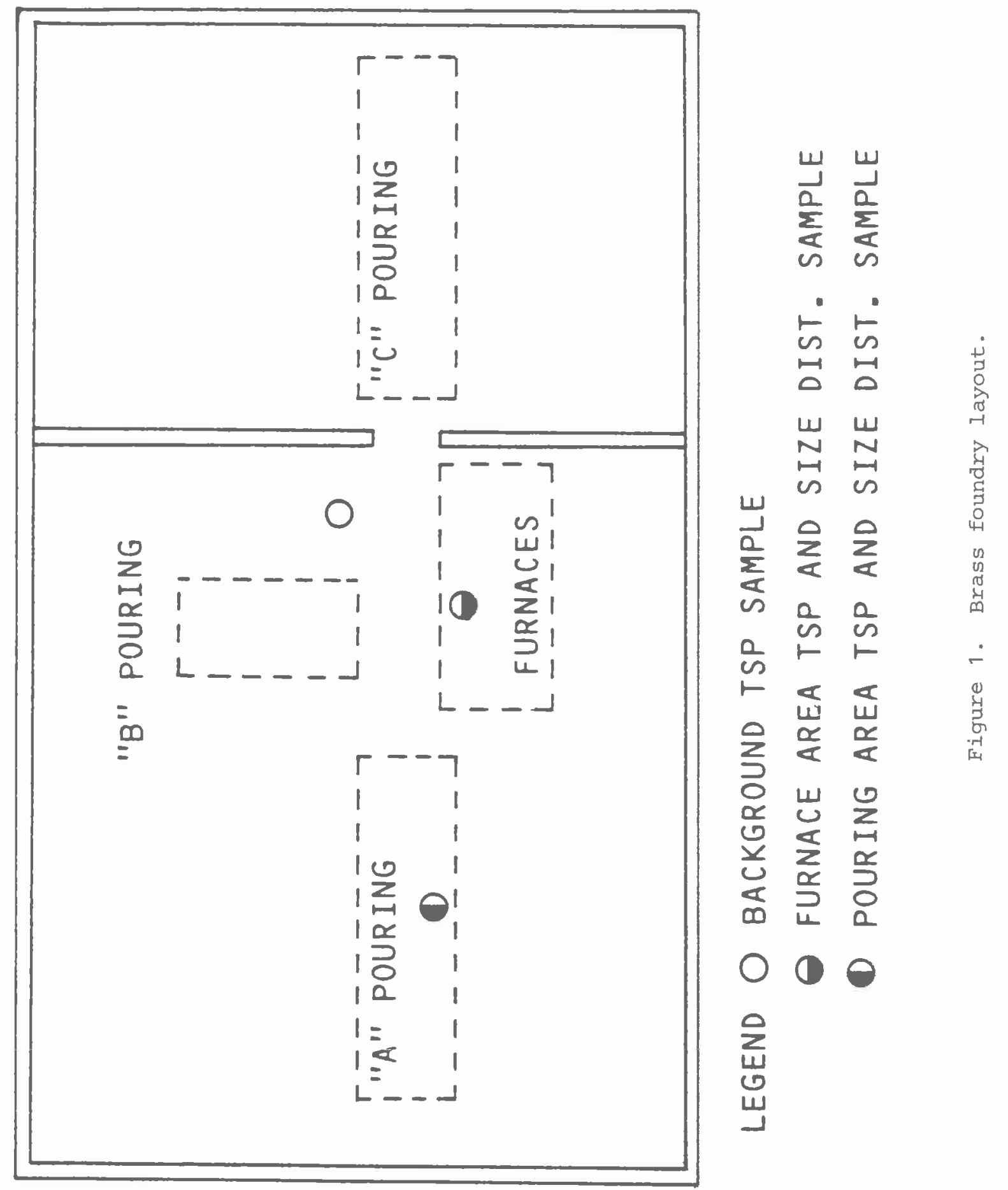
Personal samples were taken in accordance with NIOSH Method No. S341 for lead and inorganic lead compounds. Eight hour personal samples were taken at a flow rate of 1.5 liters/min. into a $37 \mathrm{~mm}$ diameter three piece cassette filter holder using $37 \mathrm{~mm} / 0.8$ micrometer mixed cellulose ester membrane filters. The filter was supported by a cellulose backup pad. Both RAC and MSA sample pumps and rotameters were utilized. The rotameters were calibrated with a soap film flowmeter prior to the testing program.

Sampling strategy was such that each of the worker categories defined earlier was sampled three times. In this way, a greater confidence can be placed on the averaged particulate and lead concentration values.

In addition to the personal samples, a number of area samples were taken at fixed locations. A high volume air sample was taken just north of the furnace area (refer to Figure 1). Particle size distribution samples were taken in the "A" pouring line area and the furnace area. Overall, three high volume total suspended particulate samples and two particle size distribution samples were taken.

The area sample taken north of the furnaces in the core storage area was taken over the 8 hour period of the first shift as were all samples. The sample flow rate was 14 liters/min and the $37 \mathrm{~mm}$ cassette filter holder inlet orifice was enlarged proportionally. In this way, the entrance velocity to the filter was the same as the personal samples and no particle size bias therefore occurred.

The size distribution samples in the furnace and "A" pouring line areas were taken with a seven stage Andersen impactor. The same sampling head and flow rates were used for both samples. The impactor was equipped with a backup filter. The average flow rate for the size distribution samples was approximately 20 liters/min.

The study was conducted in the fall and because of the cool temperatures, overhead and other access doors were closed. The foundry was in essence a "closed environment".

Sample Analysis

All filters were analyzed gravimetrically according to standard procedures. The handling of the $37 \mathrm{~mm}$ cassettes was in accordance with NIOSH Method No. S341.

The samples were prepared for lead analysis by digestion in nitric acid. Five milliliters of concentrated analytical reagent grade acid were added to each sample in a $125 \mathrm{ml}$ Ehrlenmeyer flask. Each flask was covered with a watch glass and heated at low temperature on a hotplate until complete digestion was observed, usually in about 12 hours. The resulting solutions were then filtered through 0.45 micron membrane filters and diluted to $100 \mathrm{ml}$ in volumetric flasks using glass distilled deionized water.

Measurement of the metals was accomplished using a Perkin Elmer atomic absorption spectrometer, model 5000, utilizing the background detection option. Five standards of lead prepared using Harleco (trademark) concentrated atomic absorption standards and dilute nitric acid solution, and a blank 
option. Five standards of lead prepared using Harleco (trademark) concentrated atomic absorption standards and dilute nitric acid solution, and a blank standard of the dilute acid solution were used in preparing calibration curves for lead. Solutions were diluted when necessary so that the resulting concentrations fell within the range of the standards. Concentrations were calculated using a least squares linear regression method. A clean filter pad, handled in the same way as the actual particulate filter pads, was also analyzed for lead.

The particle size samples were also analyzed gravimetrically for total particulates and then for lead. In this way total particulates as well as segregation of lead among the particle sizes could be determined.

\section{RESULTS AND DISCUSSION}

Personal Air Samples

Table 1 contains the results of the 8-hour personal samples for total suspended particulate (TSP) and lead fume concentration. All samples were taken during the first shift and reflect normal work activities under typical process load conditions. Note in Table 1 that the total suspended particulate concentration was relatively low, ranging from 1.05 to $5.36 \mathrm{mg} / \mathrm{m}^{3}$. The pourer receives the lowest average TSP concentration of $1.83 \mathrm{mg} / \mathrm{m}^{3}$ followed by the charger at $2.36 \mathrm{mg} / \mathrm{m}^{3}$ with the pourer's helper receiving the highest TSP concentration of $3.72 \mathrm{mg} / \mathrm{m}^{3}$.

The corresponding lead concentration in Table 1 shows that the charger receives the lowest average lead concentration of $90.3 \mu \mathrm{g} / \mathrm{m}^{3}$ followed by the pourer at $97.5 \mathrm{\mu g} / \mathrm{m}^{3}$. The highest lead concentration and the highest TSP concentration is received by the pourer's helper. The variations are attributed to a number of factors, among them: differences in ventilation at each work station, differences in production rates on each line, differences in task being performed, and differences in work habits of each employee.

In the case of the pourer's helper, as compared to the pourer and the charger, the higher exposure is probably due to a different work task. The helper is usually following the pouring ladle and as such comes into contact with any plume that is emitted from the ladle as it is moved.

Table 2 contains a summary of the personal TSP and lead concentrations. It is clear that the pourer's helper receives the highest concentration of 142 $\mu \mathrm{g} l e a d / \mathrm{m}^{3}$. It should be mentioned that the pourer's helper in this study is a unique work task not necessarily found in other foundries. The pourer and the charger are the more common work tasks found in most other brass foundries and it is interesting to note that both are below $100 \mathrm{\mu g}$ lead $/ \mathrm{m}^{3}$.

The overall average personal TSP and lead concentrations are $2.64 \mathrm{mg} / \mathrm{m}^{3}$ and $110 \mu \mathrm{g} / \mathrm{m}^{3}$, respectively, for the three worker categories sampled. 
Table 1. Secondary brass foundry

personal air samples for particulates and lead

\begin{tabular}{|c|c|c|c|}
\hline Task & $\begin{array}{r}\text { tal susp } \\
\text { late co } \\
\text { milli }\end{array}$ & $\begin{array}{l}\text { ended particu- } \\
\text { ncentration, } \\
\text { grams } / \mathrm{m}^{3}\end{array}$ & $\begin{array}{c}\text { Lead } \\
\text { concentration, } \\
\text { micrograms } / \mathrm{m}^{3}\end{array}$ \\
\hline \multicolumn{4}{|l|}{ Pourer: } \\
\hline "A" Line & & 3.20 & 141 \\
\hline "B" Line & & 1.05 & 57.0 \\
\hline \multirow[t]{2}{*}{ "C" Line } & & 1.25 & 94.5 \\
\hline & average & 1.83 & 97.5 \\
\hline \multicolumn{4}{|c|}{ Pourer's helper: } \\
\hline "A" Line & & 2.30 & 111 \\
\hline "A" モine & & 3.49 & 141 \\
\hline \multirow[t]{2}{*}{ "A" Line } & & 5.36 & 173 \\
\hline & average & 3.72 & 142 \\
\hline \multicolumn{4}{|l|}{ Charger: } \\
\hline Furnace area & & 1.61 & 84.8 \\
\hline \multirow[t]{2}{*}{ Furnace area } & & 3.10 & 95.8 \\
\hline & average & 2.36 & 90.3 \\
\hline
\end{tabular}

8-hour samples, 1st shift, per NIOSH method no. $\$ 341$.

Table 2. Secondary brass foundry

summary of personal air samples

for particulates and lead.

\begin{tabular}{|c|c|c|}
\hline Task & $\begin{array}{l}\text { Total suspended } \\
\text { particulates, } \\
\text { milligrams } / \mathrm{m}^{3}\end{array}$ & $\begin{array}{c}\text { Lead } \\
\text { concentration, } \\
\text { micrograms } / \mathrm{m}^{3}\end{array}$ \\
\hline Pourer & 1.83 & 97.5 \\
\hline Pourer's helper & 3.72 & 142.0 \\
\hline Charger & 2.36 & 90.3 \\
\hline Overal] & 1 avg. 2.64 & 110.0 \\
\hline
\end{tabular}

Area Samples

Table 3 contains ambient background concentrations of TSP and lead. Fixed in space samfles were taken in the core storage, furnace, and pouring areas as previously discussed and shown in Figure 1. These samples were taken over the 8-hour first shift at a relatively high sampling rate and, therefore, represent a relatively large volume of sampled air. For this reason, these samples are considered to be very representative of each respective area. Note that the TSP concentration was relatively constant, ranging from 2.53 to $3.23 \mathrm{mg} / \mathrm{m}^{3}$, with an overall average of $2.77 \mathrm{mg} / \mathrm{m}^{3}$. 
Table 3. Secondary brass foundry ambient area concentrations of total particulates and lead.

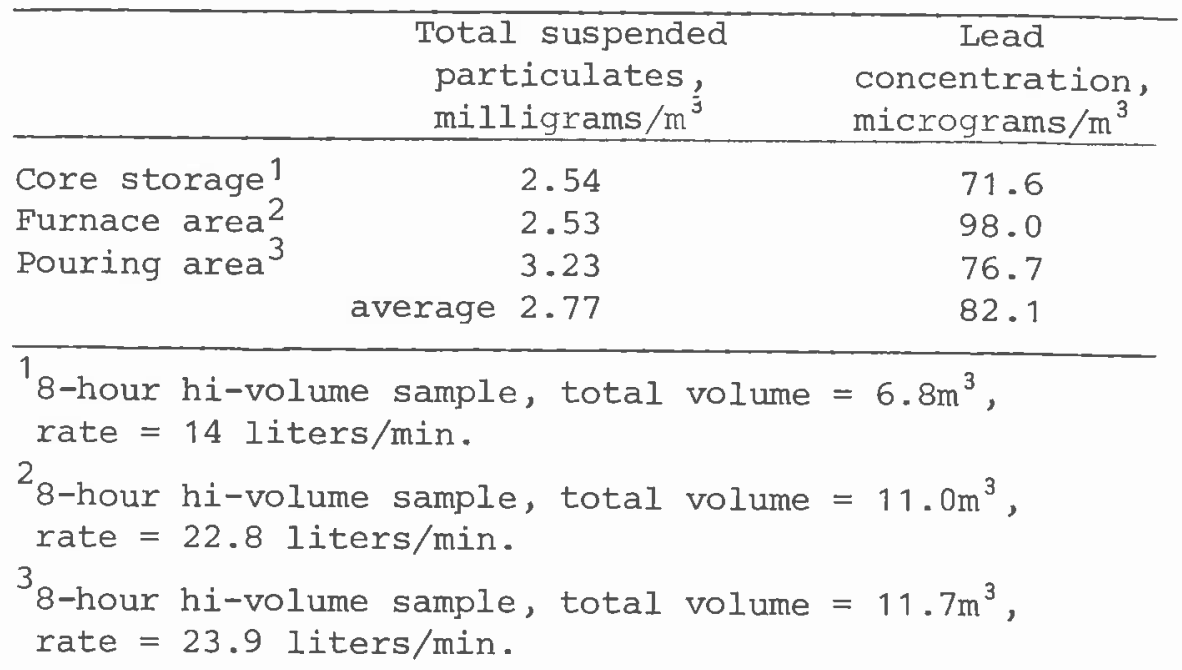

The lead concentration was highest in the furnace area at $98 \mu \mathrm{g} / \mathrm{m}^{3}$ followed by the pouring area at $76.7 \mu \mathrm{g} / \mathrm{m}^{3}$ and lowest in the core storage area with $71.6 \mu \mathrm{g} / \mathrm{m}^{3}$. These values suggest that the background lead concentration is highest near the furnaces and decreases as the distance from the furnaces increases, which is a reasonable expectation.

Aerodynamic Particle Size Distribution

Figures 2, 3, and 4 contain the aerodynamic particle size distributions of the suspended particulates in the pouring and furnace areas. These areas are shown in Figure 1, along with the sampling site location. In Figure 2, the TSP size distribution indicates that the mass median diameter is 8 microns in the pouring area. The size distribution in the furnace area (Figure 3 ) is very similar and shows a mass median diameter of 10 microns. The similarity of the two distributions is further evident in Figure 4 where the data from both distributions is plotted. The aggregate size distribution indicates a mass median diameter of 9 microns. The aggregate distribution indicates that $13 \%$ by weight of the pouring and furnace area particulate matter is less than 2 microns aerodynamic diameter.

The aggregate mass median diameter of 9 microns is relatively large considering that metallic fume is typically submicron in size. Since these background samples were taken not in the near vicinity of fume formation, agglomeration of the submicron particulate into larger sizes may be responsible for the high mass median diameter. In addition, since most of the fume is controlled in close capture hoods and the use of sand is prevalent throughout the foundry, the large diameter may reflect the general foundry sand particulate matter, although this is probably not the case as will be discussed shortly. 


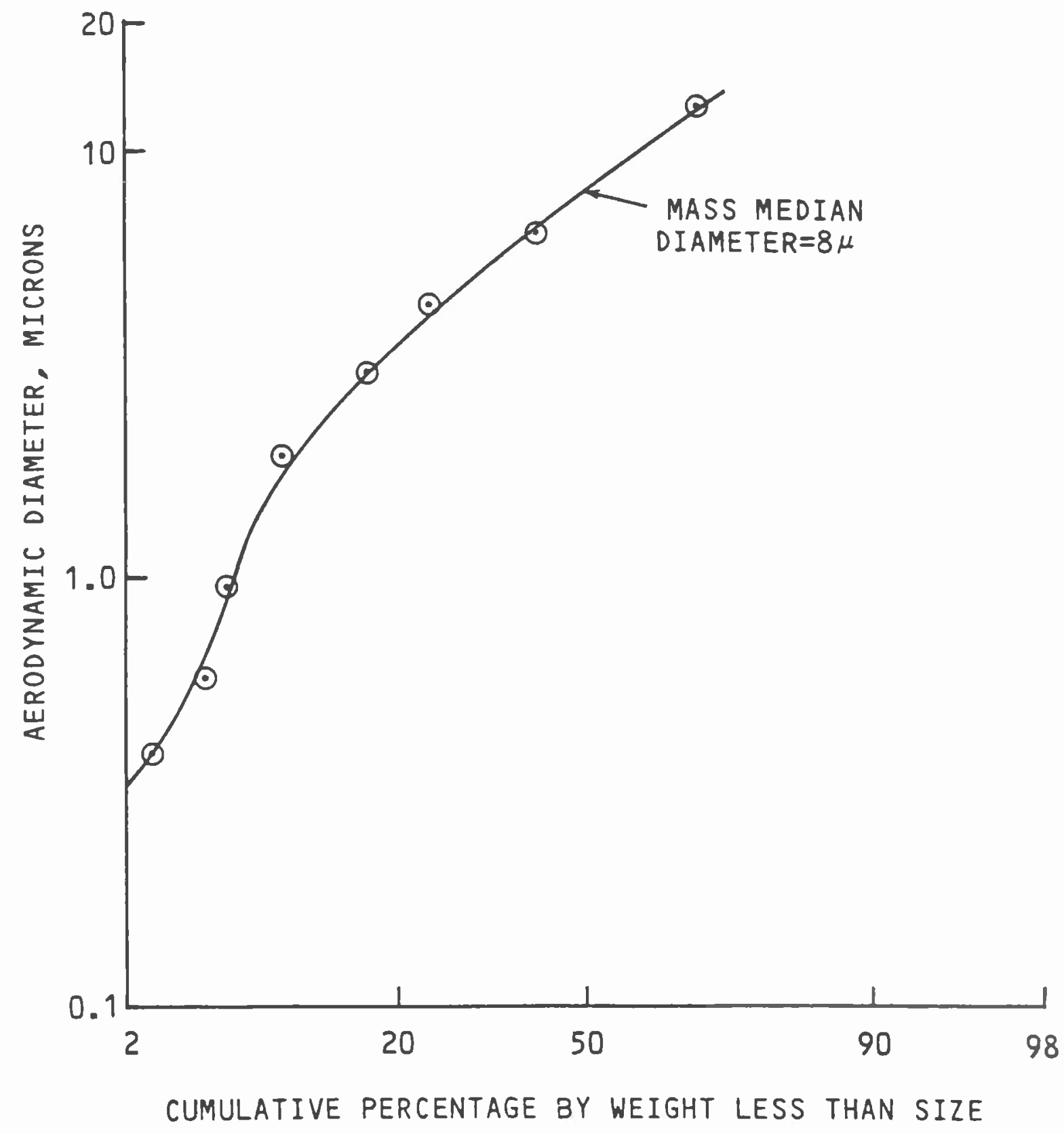

Figure 2. Aerodynamic particle size distribution in pouring area. 


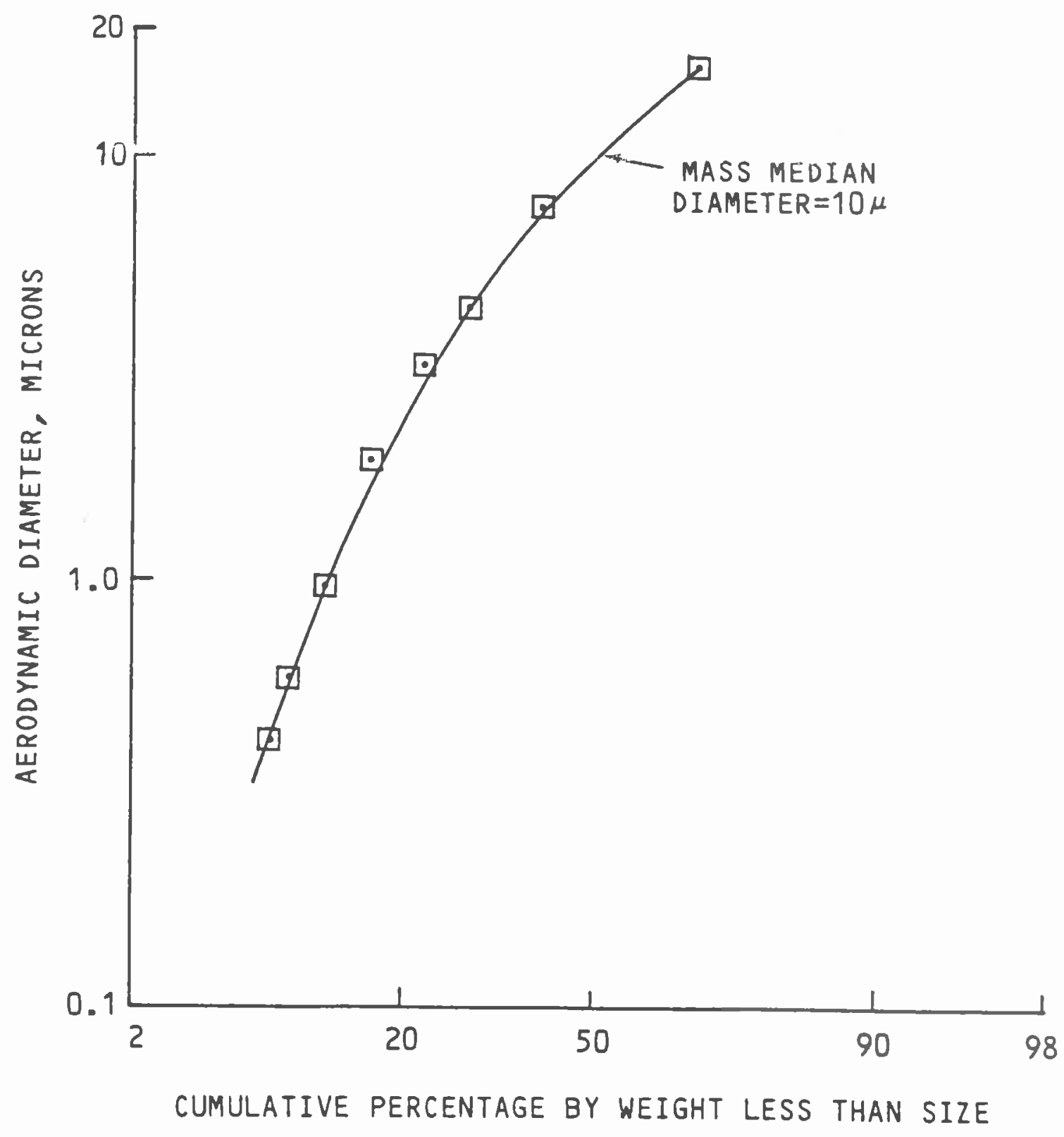

Figure 3. Aerodynamic particle size distribution. in furnace area. 


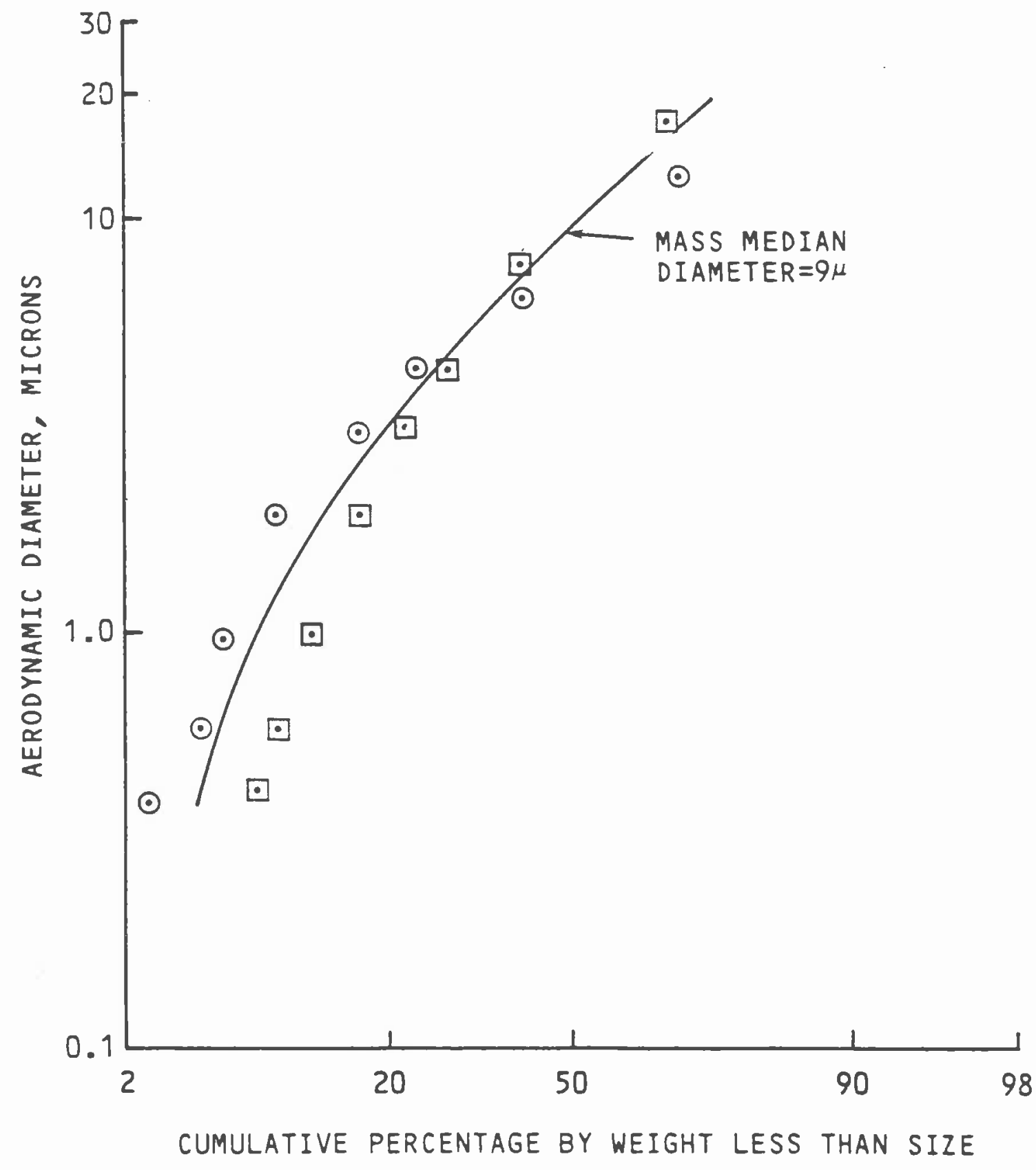

Figure 4. Aggregate aerodynamic particle size distribution of furnace and pouring area. 
Figure 5 shows the percentage of lead found at each particle size in the Andersen impactor. As a percentage of the total particulate, the lead is seen to increase markedly below a 2 micron aerodynamic diameter. Note that the lead percentage increases from about $2 \%$ at a 2 micron diameter to more than $20 \%$ lead at a 0.5 micron particle diameter. Lead fume is typically submicron in nature and, therefore, the smaller particulate matter would be expected to have a high percentage of lead. The second reason is that small non-lead particulate matter has a relatively high surface-area-tovolume ratio and acts as an effective adsorber for smaller lead fume and as nucleation sites for lead vapor condensation. This segregation of toxic metals in the smaller particle sizes has been found in other studies $(2,3)$.

Beyond a 2 micron aerodynamic diameter (Figure 5) the lead percentage appears to be on the increase in the furnace area and from 2 to 6 microns in the pouring area. This lead percentage increase may be due to agglomeration of the less than 2 micron particles of high $\%$ lead into larger apparent particles above 2 microns.

Expressing the lead as a concentration in air with the units $\mu \mathrm{g}-\mathrm{Pb} / \mathrm{m}^{3}-$ air and plotting these values versus aerodynamic diameter is shown in Figures 6 and 7. In addition to the sharp lead concentration increase below a 2 micron diameter, which has already been explained, a rapid increase is also evident above the 3 to 4 micron diameter range. This rapid lead concentration increase in the larger sizes is due to agglomeration of particles less than 2 microns in diameter into larger apparent particles. Furthermore, the unexpected large mass median diameter of 9 microns from the size distribution plot in Figure 4 is answered by this agglomeration phenomenon evident in Figures 6 and 7 .

\section{SUMMARY}

This study has shown that a close capture exhaust system can be relatively effective in reducing TSP and lead concentrations in a brass foundry. It must be pointed out, however, that the TSP and lead concentrations and particle size distributions reported here are unique to the brass foundry studied. Extrapolations or interpretations of this data to other foundries must be made with great care and a full realization that no two foundries are alike.

Specific results are as follows:

1. Personal samples indicated that total suspended particulates ranged from $1.05 \mathrm{mg} / \mathrm{m}^{3}$ to $5.36 \mathrm{mg} / \mathrm{m}^{3}$ depending on the worker task involved.

2. Personal lead samples indicated a range from $57 \mu \mathrm{g} / \mathrm{m}^{3}$ to $173 \mu \mathrm{g} / \mathrm{m}^{3}$, depending on the worker task involved. The overall average personal lead concentration was $110 \mu \mathrm{g} / \mathrm{m}^{3}$. 


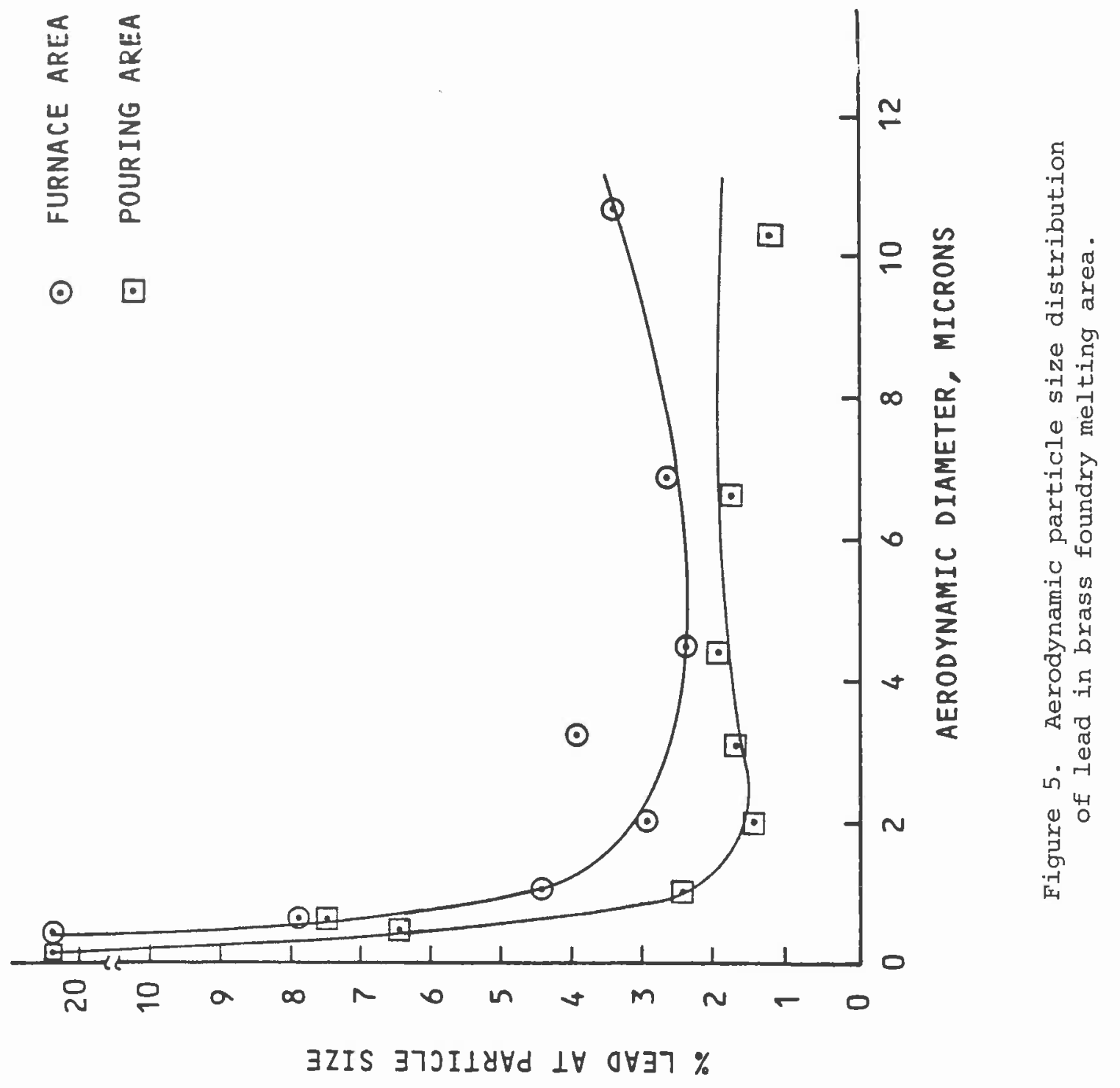




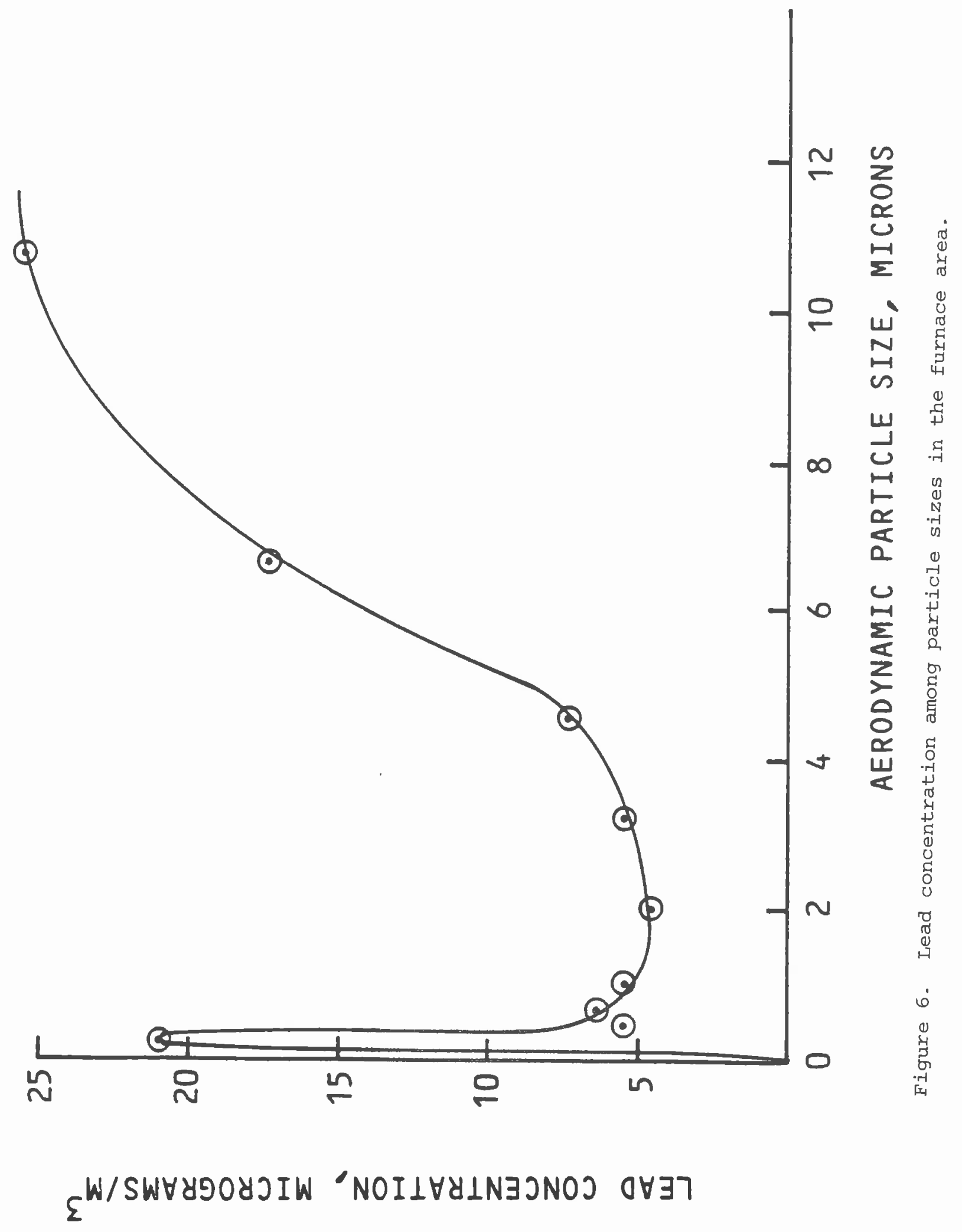




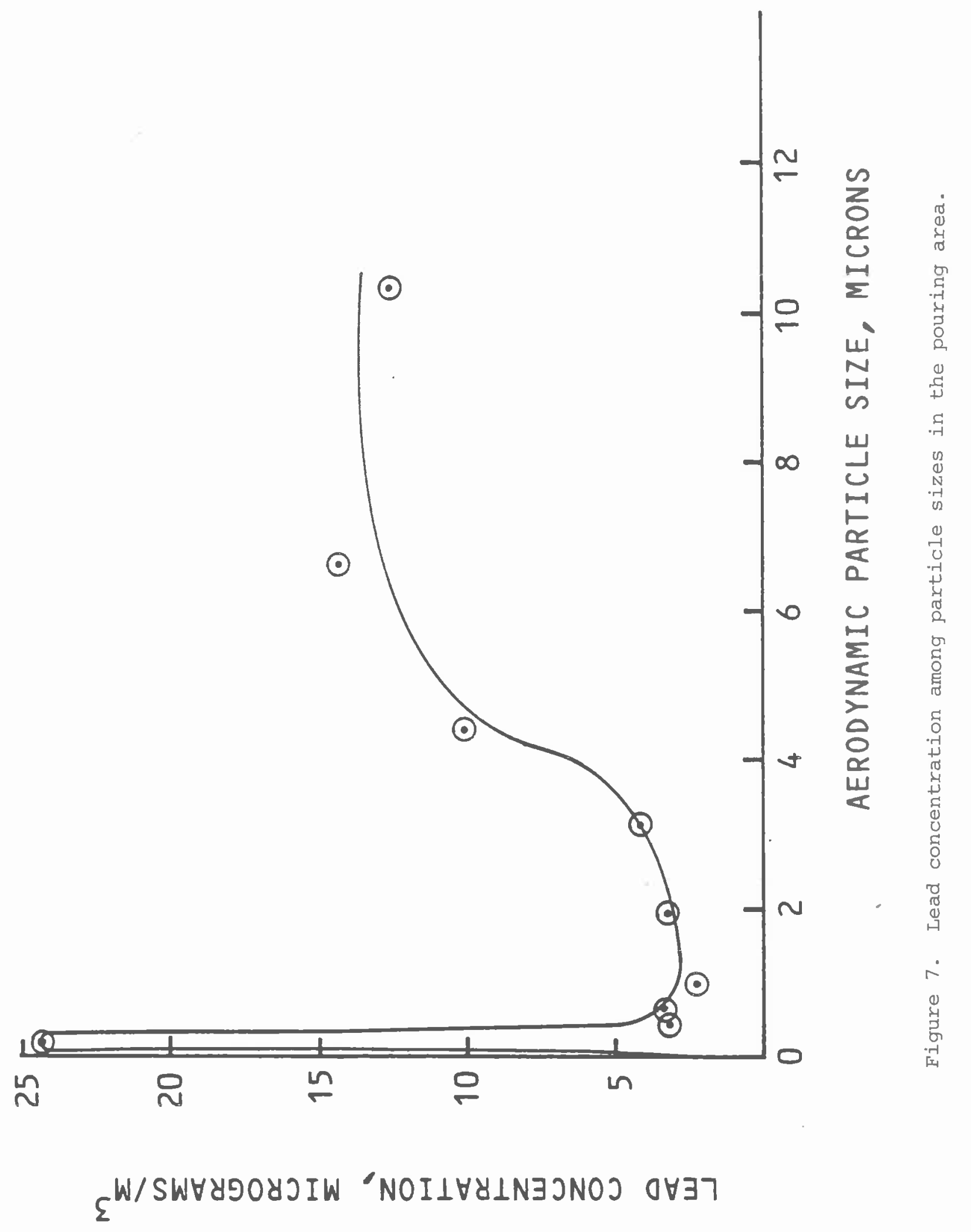


3. Area TSP concentrations ranged from $2.53 \mathrm{mg} / \mathrm{m}^{3}$ to $3.23 \mathrm{mg} / \mathrm{m}^{3}$ with an average of $2.77 \mathrm{mg} / \mathrm{m}^{3}$.

4. Background lead concentrations ranged from $71.6 \mu \mathrm{g} / \mathrm{m}^{3}$ to $98 \mu \mathrm{g} / \mathrm{m}^{3}$ and averaged $82.1 \mu \mathrm{g} / \mathrm{m}^{3}$. As expected, lead area concentrations were highest in the furnace area and decreased with distance from the furnace.

5. Area particle size distributions were very similar in the pouring and furnace areas. Aggregate particle size distributions indicated the aerodynamic mass median diameter to be 9 microns. The large mass median diameter was attributed to agglomeration of fine particulates.

6. The distribution of lead among the particle sizes expressed as a percentage by weight of the total particulate at that size indicated a strong segregation of lead in the particle sizes less than a 2 micron diameter. In the submicron size range the lead percentage exceeded 20\%. Submicron lead fume and effective adsorption of lead vapor and fume on the fine non-lead particulate are given as the reasons for this segregation.

7. Lead air concentration increased sharply at the submicron sizes and above the 3 to 4 micron diameter range. The rise in lead in the submicron sizes is attributed to lead fume and non-lead particulate adsorption of lead vapors and fume. The lead increase in the larger sizes is attributed to agglomeration of the submicron, high lead particulate into larger apparent sizes. This agglomeration also answers the unexpected large mass median particle diameter of 9 microns.

\section{REFERENCES}

1. NIOSH Manual of Sampling Data Sheets, 1977 edition, U.S. Dept. of H.E.W.

2. Jacko, R. B., and D. W. Neuendorf, "Trace Metal Particulate Emission Tests Results from a Number of Industrial and Municipal Point Sources", Air Pollution Control Assn. Journal, Vol. 27, No. 10, October 1977.

3. Greenberg, R. R., Gordon, G. E., Zoller, W. H., Jacko, R. B., Neuendorf, D. W., and Yost, K. J., "Composition of Particles Emitted from the Nicosia Municipal Incinerator", Environmental Science and Technology, Vol. 12, No. 12, November 1978 . 
Question (G. Mosher, American Foundrymen's Society) :

Was the same alloy poured during all of the air sampling or did the alloy
change?

Answer (R. Jacko):

I am not sure what the variation was, but the average lead content was 5\%. (Editor's note: The point was later confirmed by $\mathrm{R}$. Overmyer that the lead content in the brass was consistently $5 \%$ during all the tests. This statement appears in the technical paper submitted for publication).

Comment (R. Wilson, PEDCo Environmental, Inc.):

I have a comment for Mr. Overmyer and an admonition for the audience.

I'm glad to see people such as Hawley bringing out the close capture systems because they work extremely well. My admonition to the audience is to do a good job on your own system analysis. And I have a particular example.

This is not to cast any stones at Hawley or any other close capture manufacturer. But I'm working with a brass foundry right now that installed a close capture system and solved their lead problem very nicely. But the equipment manufacturer installed the fan right out in the middle of the foundry floor up on a pedestal, adding one more ninety-five dBA source into the room and bringing another OSHA citation.

The fan was put there to shorten the ductwork on the suction side of the fan so that they could get by with a less expensive fan. This worked fine for the manufacturer and not so well for the foundry.

My advice to foundry operators is to do your own inhouse work and consider putting your own very stringent noise and other requirements on your specification to the suppliers.

In other words, make them prove to you that they're not going to create another problem for you by solving one.

Editor's note: The next question is in regard to a concluding comment made by Dr. Jacko after presenting his summary results.

"Most of the brass foundry people that I've talked to using the close-capture system feel that enactment of standards below the levels that we have measured here with very good engineering practice, may well be unrealistic".

Question (M. Lane, Davy McKee Corp) •

You stated at the end of your conclusions, that you felt that lower lead levels were impractical from what was achieved. Do you feel that they're impossible or should we still strive to meet the $50 \mathrm{\mu g} / \mathrm{m}^{3}$ level? 
Dr. Jacko:

It would be ludicrous for me to say that anything is impossible. The term that I used was "unrealistic". After looking at the data and becoming intimately involved with the system and seeing how it operated, that it is a state-of-the-art technique, I felt that at this point in time it would be unrealistic to enact standards that would be much lower than the levels that I measured. This was my observation after analyzing the data. 
A NEW INCENTIVE: PAYBACK COSTS

OF ENVIRONMENTAL CONTROL IN THE MELTING SHOP

BY ADDING HEAT RECOVERY SYSTEMS

\author{
Joseph Gutierrez \\ Airecon Manufacturing Corp. \\ Cincinnati, Ohio
}

\title{
ABSTRACT
}

The high cost of fuel and environmental control systems make heat recovery a viable approach to reducing fuel use and costs in foundry melting operations. Although heat recovery systems are relatively new for this application in this country, they have been in use for some time in other countries where their practical use has been demonstrated.

Heat recovery has great potential for all foundry melting operations, but in particular, electric arc, gas-fired, and cupola furnaces. There are a number of arc furnace exhaust hood methods; the hood method most amenable to heat recovery is direct evacuation. Gas temperatures from the products of combustion of gas-fired furnaces are very high and quite stable which is an advantage for heat recovery. Heat recovered from cupolas can be put to a variety of uses including heating the blast air, preheating the afterburner combustion air, and providing a hot air curtain at the charge door. Heat recovery rates and payback analyses are presented for the furnace heat recovery systems described.

\section{HIGH COST OF EMISSION CONTROLS}

The control of airborne dust and fume is as important in the melt shop as in any other production area of the foundry. Free silica, metallic oxides including lead, various other particulates and carbon monoxide are present in the melting shop environment in varying degrees of concentration, according to metallurgy and practice. Melting furnaces, holding furnaces, alloying stations, open ladles, and metal troughs are some of the many sources of pollutants that require control devices in order to maintain an acceptable working environment in the melting shop.

The high cost of installing these necessary control devices is making many foundries limit production or make major changes in production methods, in order to reduce the cost of emission control systems. Some foundries that can't afford emission control systems are closing their doors. 
One way that the costs of emission control systems can be justified or even totally recovered is if waste heat can be recovered and utilized effectively.

In the past, fuel was cheap and plentiful and waste heat recovery was not considered. There were many justifiable reasons why heat recovery was not practical on emission control systems, in particular, high installation expenses, more troublesome and risky equipment to operate and maintain, and poor payback. Well, those days are gone: Every single BTU of waste heat recovered and reused today means energy conservation at a time when energy is becoming scarce and very expensive. Heat recovery is now affordable, practical, reliable, and has in many cases, excellent payback economics. For example, a discharge stack emitting a constant gas flow of $25,500 \mathrm{~m}^{3} / \mathrm{hr}(15,000 \mathrm{cfm})$ at $426^{\circ} \mathrm{C}\left(800{ }^{\circ} \mathrm{F}\right)$ will have a waste heat rate of $376,000 \mathrm{~g}-\mathrm{cal} / \mathrm{sec}(5,367,000 \mathrm{BTr} / \mathrm{hr})$. If only $60 \%$ of that heat were recovered and used effectively, a savings of $\$ 9.70$ per hour could be realized. Based on an 8-hour day, 5 day week, 50 week operation, the savings would total $\$ 19,400.00$ per year on that one stack alone.

Heat recovery systems applied to emission control systems on melting furnaces and other similar sources of waste heat have been used successfully for a long time in foundry applications in Europe, Australia, and Japan. Constant improvement over the years has resulted in a very high degree of reliability and practical operation.

To which sources of waste heat can recovery be applied? Any stack emitting a gas flow at temperatures higher than $65^{\circ} \mathrm{C}\left(150^{\circ} \mathrm{F}\right)$ has potential for heat recovery.

Emission control systems in the melt shop, curing ovens, annealing and heat treating furnaces, in short, any process where heat is present is a candidate. And the method is not just limited to situations where emission control systems are used.

The following sections of this paper will discuss the control of emissions and heat recovery methods for three types of furnaces that have the greatest potential for heat extraction: electric arc, gas-fired, and cupola furnaces. Only air-to-air heat exchangers will be discussed here, although heat recovery is not limited to this technique.

\section{ELECTRIC ARC FURNACES}

Electric arc furnaces are second only to the cupola as major producers of air pollution in the foundry. In order to provide the required air quality in the melt shop, as well as to clean up the emissions to the outside environment, the arc furnace requires an emission control system properly designed to capture all the particulates and gases generated during the various furnace operations, i.e., charging, melting, refining, and tapping.

The emission control systems will vary greatly according to the metallurgical practices and melt shop layout. The types of exhaust capture hoods in 
common use fall into the following categories:

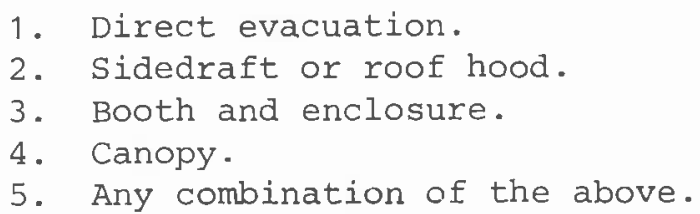

Of all of the above exhaust methods, direct evacuation has by far the greatest potential for heat recovery due to the higher temperature of the gases emitted. Sidedraft and roof-type capture systems may also have good potential, depending on the design of the hood and the exhaust rate required to capture the emissions generated by the furnace.

The other capture methods normally require large exhaust rates, which tend to reduce the gas temperatures to below the desired minimum for heat recovery $\left[65^{\circ \mathrm{C}}\left(150^{\circ} \mathrm{F}\right)\right]$.

Since most emission control systems on arc furnaces utilize a baghouse (fabric filter), the gas must be cooled below the limiting temperature of the fabric before entering the baghouse. Cooling is usually accomplished by introducing ambient air using a bleeder damper until the desired temperature is reached by mixture. The ideal location for the heat exchanger is upstream of the bleeder damper.

Figure 1 illustrates a hypothetical gas temperature record for two identical arc furnace operations at a steel foundry using different exhaust methods. Furnace $A$ is equipped with a direct evacuation control system; furnace B uses a sidedraft hood control system. The exhaust rate for furnace $A$ is $20,500^{3} \mathrm{~m} / \mathrm{hr}(12,000 \mathrm{cfm})$ and for furnace $\mathrm{B}$ is $44,100 \mathrm{~m}^{3} / \mathrm{hr}(26,000 \mathrm{cfm})$.

GAS FIRED FURNACES

Gas fired furnaces, e.g., rotary, reverberatory, open hearth, and crucible furnaces, have tremendous potential for heat recovery.

The control method for these furnaces is normally direct venting of the products of combustion from the melting chamber, with additional canopy or sidedraft hoods to control fume from charging and tapping operations.

The gas flow temperatures from the products of combustion are very high, and in most cases, quite stable. The exhaust volumes from the other hoods are used for dilution cooling of the gas stream to filtering temperatures.

The heat exchanger should be located in the hot gas stream from the melting chamber. This should not present any problems with most types of furnaces, however, in a crucible furnace the port venting the products of combustion must be ducted, and this ductwork must allow the furnace to tilt for pouring.

The higher quantity of heat that can be extracted from these furnaces can be used for many purposes, but, particularly important, the combustion air 


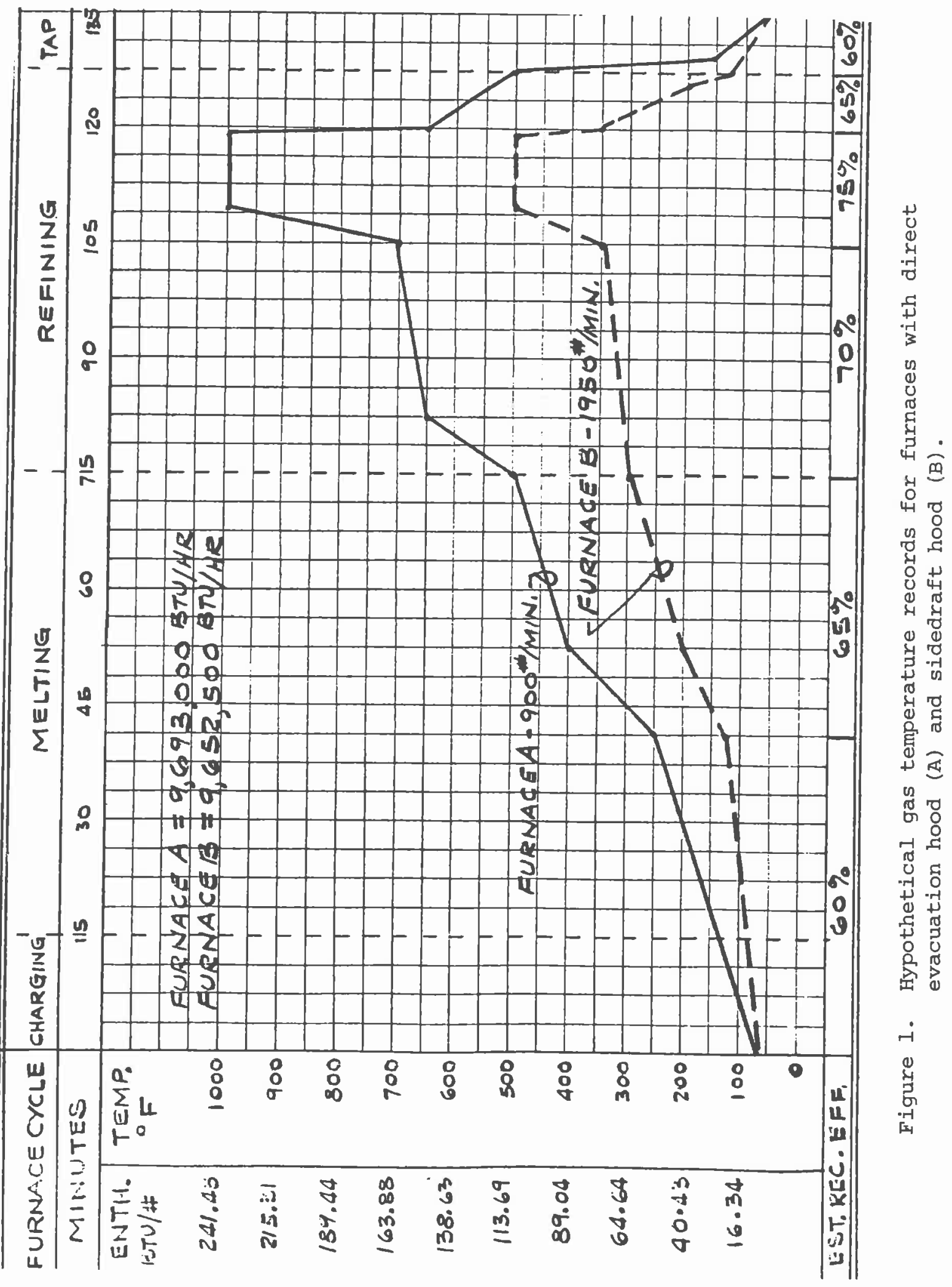


for the burner equipment could be pre-heated. Pre-heated combustion air can result in as much as a $20 \%$ or more fuel savings. In most cases, enough heat is extracted from these furnaces to pre-heat the combustion air and have large amounts left over for other uses.

Figure 2 shows a schematic diagram for a heat recovery system on a rotary smelter application. The heat and cost savings analysis for this system is presented below:

$$
\begin{aligned}
& \text { Heat content of flue gases } \quad 165,000 \frac{\mathrm{g} \text {-cal }}{\mathrm{sec}}(2,358,960 \mathrm{BTU} / \mathrm{hr}) \\
& \begin{array}{ll}
\text { Predicted heat exchanger effectiveness } & 70 \%
\end{array} \\
& \text { Heat extracted } \quad 125,000 \frac{\mathrm{g}-\mathrm{cal}}{\mathrm{sec}}(1,651,260 \mathrm{BTU} / \mathrm{hr}) \\
& \text { Cost savings per hour } 9 \$ 1.19 / 10,000 \mathrm{~g}-\mathrm{cal} \quad \$ 4.95 \\
& (\$ 3.00 / \mathrm{mill} \text {. BTU) } \\
& \text { Cost savings per year }(4,000 \mathrm{hrs}) \quad \$ 19,800.00 \\
& \begin{array}{lr}
\text { Est. cost of recovery system } & \$ 45,000.00
\end{array} \\
& \text { Payback period (at current cost) } 2.27 \mathrm{yr} \text {. }
\end{aligned}
$$

THE CUPOLA

The cupola has been one of the most economical and reliable melting furnaces ever used. Its popularity is confirmed by its use time and time again on new foundry construction. However, because of increasing prices for coke and natural gas and the requirement of an emission control system, the economical advantage is being diminished almost daily.

The emission control system for the cupola can be technically complex and costly both to purchase and operate. I would like to comment on one area that is always forgotten in a cupola emission control system, and that is the control of metallic fume from the cupola forehearth area and pouring ladles. This fume normally ends up in the melting shop, adding considerably to the levels of respirable particulates. Localized hooding could easily take care of this problem, and if properly designed, the hooding may not require large exhaust volumes.

But let's talk now about heat recovery for the cupola. Heat recovery, is one way to reduce the operating cost of the entire cupola melting shop.

Because the quantity of waste heat is so great, the cupola waste gases can provide heat for, among other uses: hot blast tuyere air, pre-heat afterburner combustion air; hot air curtain at the charge door.

A heat recovery system on a cupola can bring other benefits beside reducing the gas and coke consumption. These benefits include: 


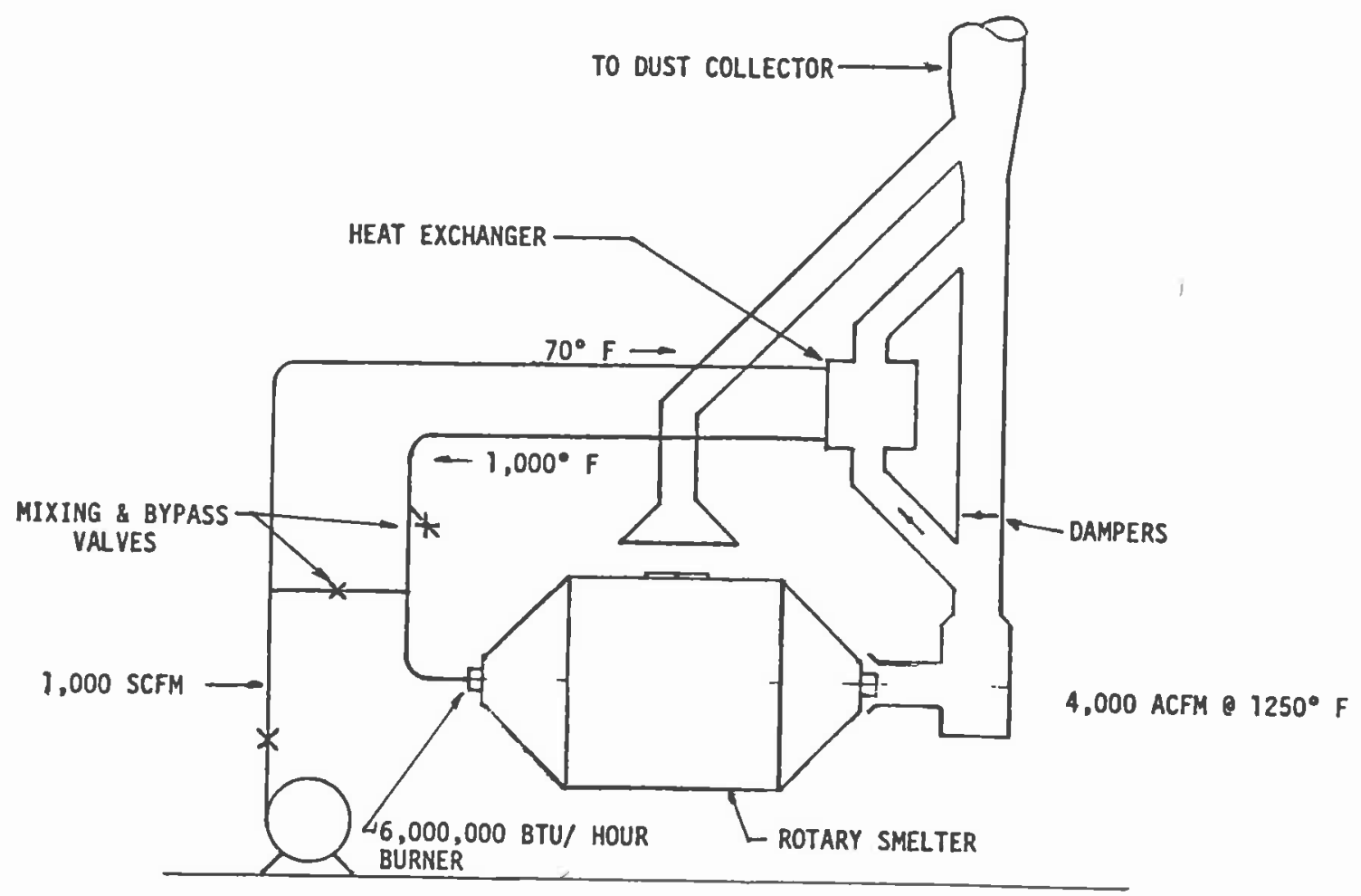

Figure 2. Heat recovery system on rotary smelter.

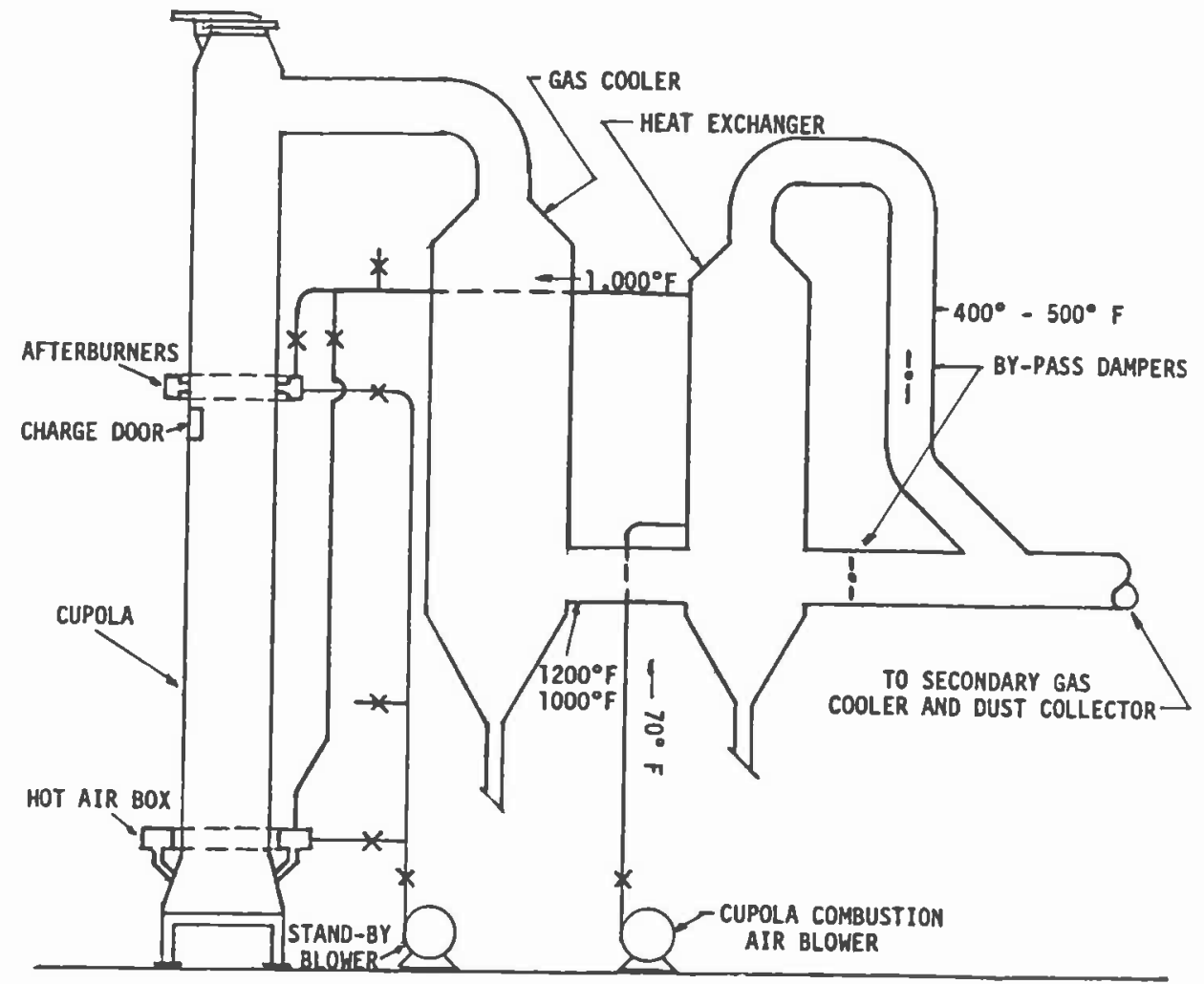

Figure 3. Heat recovery system on a $183 \mathrm{~cm}(72$ inch) diameter cupola. 
1. The high waste gas flow temperatures are maintained for a longer period of time. This is due to longer duct runs required to add the heat exchanger. This longer period of time at higher temperatures allows almost complete incineration of hydrocarbons. If a fabric filter is used as the dust collector, a lower resistance across the filter media is realized.

2. Since the heat exchanger will remove a great amount of heat from the waste gas flow, less water will be required for cooling to final filtering temperatures. This will lower the dewpoint of the gas flow, and a lower dewpoint may prevent condensation problems in the dust collector.

3. There will be better control of temperatures and gas flow in the emission control system. This, along with the other benefits listed above, will add to equipment life and refractory 1 ife.

Figure 3 shows a schematic diagram for a heat recovery system for a $183 \mathrm{~cm}$ (72 in.) diameter cupola. The payback analysis is presented below:
Cupola melt rate
10 metric ton/hr (11 $\mathrm{TPH})$
Coke usage (@8:1 ratio)
$1250 \mathrm{Kg} / \mathrm{hr}(2750 \mathrm{lb} / \mathrm{hr})$
Tuyere air required
$13,400 \mathrm{~m}^{3} / \mathrm{hr}(7900 \mathrm{SCFM})$
Afterburner combustion air required
$4,180 \mathrm{~m}^{3} / \mathrm{hr} \quad(2460 \mathrm{SCFM})$
Heat content of hot blast a $537^{\circ} \mathrm{C}$ $\left(1,000^{\circ} \mathrm{F}\right)$
$560,000 \frac{\mathrm{g}-\mathrm{cal}}{\mathrm{sec}}(133,715 \mathrm{BTU} / \mathrm{min})$
Heat content of afterburner comb. air
$175,000 \frac{\mathrm{g}-\mathrm{cal}}{\mathrm{sec}}(41,638 \mathrm{BTU} / \mathrm{min})$
Coke use reduction
$287 \mathrm{Kg} / \mathrm{hr}(632 \mathrm{lb} / \mathrm{hr})(23 \%)$
Gas use reduction
$386 \mathrm{~m}^{3} / \mathrm{hr} \quad(2271 \mathrm{cfm})$
Total savings [coke @ $\$ 178.00 /$ metric ton $(160.00 /$ ton $)$ and gas a $\left.\$ 0.117 / \mathrm{m}^{3}\left(3.00 / 1000^{3} \mathrm{ft}\right)\right]$
$\$ 229,480.00$
$57.37 / \mathrm{hr}$
Est. heat recovery system cost
$\$ 450,000.00$
Payback period (4000 hr. operation)
2 yrs

THE HEAT EXCHANGER

The application of heat exhangers to dirty gas streams is not new. Heat exchangers on cupola waste gases are numerous and have proven very successful.

It is very important, however, that the limitations of heat exchangers are recognized and the application is thoroughly studied prior to any attempt 
at heat recovery. It is also very important that all the conditions of the waste gases where the heat exchanger is to be applied are known. The chemical composition, the temperature range, volumetric flow, and dewpoints are all factors that must be taken into account when designing the heat recovery system.

The type of air to air heat exchanger that is normally applied to contaminated gas streams is an opposed flow tube type or slot type, having the heat recovery surfaces countercurrent or parallel to the waste gas flow, depending on the construction of the heat exchanger. The heat exchanger must be designed to meet the following requirements.

1. Operate at high temperature.

2. Operate under high air pressures that are required for cupola blast or combustion air.

3. Able to expand and contract without difficulty as the temperatures change in the system.

4. Have some protection against wear due to abrasion at areas blasted by the dust laden gas flow.

5. Self cleaning or equipped with cleaning jets to blast away any material buildup on the heat transfer surfaces. (Material buildup will greatly reduce the effectiveness of the heat exchanger).

We must remember that the heat exchanger is only one part of the heat recovery system. The other components and the actual design of the system are equally important if the system is to operate successfully. 
METHODS OF NOISE CONTROL IN THE FOUNDRY, PROBLEMS AND LIMITATIONS

\author{
William Ihde \\ Consulting Engineer \\ SV Engineering \\ Hinsdale, Illinois
}

\title{
ABSTRACT
}

Many available noise reduction approaches in foundries will not reduce noise levels below permissible exposure limits, but these approaches are still very worthwhile to take. A noise reduction of 5 dBA permits a doubling of the allowable time a worker can be exposed to the noise, and it reduces by $50 \%$ the possibility of an exposed worker losing his hearing. Three case histories of partial solutions are shown; in one of the three cases (arc furnace noise), a booth protecting the worker during the major part of the workshift was sufficient to bring the worker into compliance.

\section{INCENTIVES TO SOLVE NOISE PROBLEMS}

Upon entering an operating foundry, one is confronted with all sorts of noises, particularly around a cleaning room where many different noise sources are operating at the same time. Noise control seems like an insurmountable problem, and indeed it is a very difficult one, but the difficulty of the problem is no reason not to attempt to solve it.

What are some of the incentives that make management feel that an engineering effort in this direction is cost effective? OSHA is now considering excessive noise as a serious violation, and fines in excess of $\$ 200$ per violation are being levied. As the number of violations mount, so does the incentive. Of course, if nothing is done, and the violations become continued violations, then the fines apply on a daily basis. Such sanctions get management's attention.

Hearing loss due to excessive noise is beginning to be expensive. In Illinois, the maximum compensation for $100 \%$ hearing loss is $\$ 45,000$. It doesn't take many claims of $100 \%$ hearing loss before there is some real money involved.

EFFICACY OF PARTIAL SOLUTIONS

Not always is it necessary to solve a problem completely to realize a benefit. For example, if an operation in a foundry is producing 105 dBA of noise, and through some engineering procedures this noise level is lowered to $100 \mathrm{dBA}$, the benefit would be that 50\% fewer exposed people would suffer a 
hearing loss or that personnel could be legally exposed to the noise for two hours instead of only one hour without hearing protection. A $5 \mathrm{~dB}$ reduction is a substantial amount, and is very worth the effort particularly when many people are involved.

\section{METHODS OF NOISE CONTROL}

Some examples of partial solutions to noise problems will be discussed with data indicating some of the results. I don't have as much data as I would like to have the opportunity to take. Once I have completed my initial surveys and made my recommendations, it is hard to get a client to pay for a return visit to measure the improvement. If any measurement is made it is usually by the client himself to show the improvement to OSHA. Usually when the consultant is brought in again, it is to document the results of his effort for OSHA litigation.

\section{CASE HISTORY 1 - CLEANING ROOM NOISE}

A foundry had a problem with a cleaning room in which the castings were being chipped and shaped to meet certain dimensional specifications. As the castings were finished they were passed to the inspector for approval. of course, if the casting did not meet the standards it was returned to the operator who then corrected the problem.

It was found that the area was in excess of $90 \mathrm{dBA}$ for eight hours, and generally had a noise spectrum as shown in Figure 1 . You will note that there is a heavy concentration of energy in the bands above $500 \mathrm{~Hz}$.

Based upon this spectrum, and the method of chipping and inspecting, our decision was to protect those we could by engineering means, and to put hearing protection on the chipper-grinder operator. I know of no method to reduce noise of chipping. Metal against metal in a chipping operation is inherently noisy.

The approach to this partial solution was to construct a booth which had incorporated in it a work bench and a separation between the work area and the inspection area. This arrangement is shown in Figure 2.

What we accomplished was a reduction in noise for the inspector which was sufficient to put him in compliance on a time weighted basis. The noise reading was $87 \mathrm{dBA}$ at the inspector's station during chipping, while in the booth it was between 96 and $99 \mathrm{dBA}$. This 9 to $10 \mathrm{~dB}$ reduction is about what can be expected with a partial barrier.

CASE HISTORY 2 - ARC FURNACE NOISE

In a foundry producing steel castings melting was done with two direct electric-arc furnaces. They were cited for excessive noise in the furnace area and around the control console where the operators of the furnaces spent a lot of time. They were fortunate in that the only other people involved near the furnaces were ladle repair workers. 


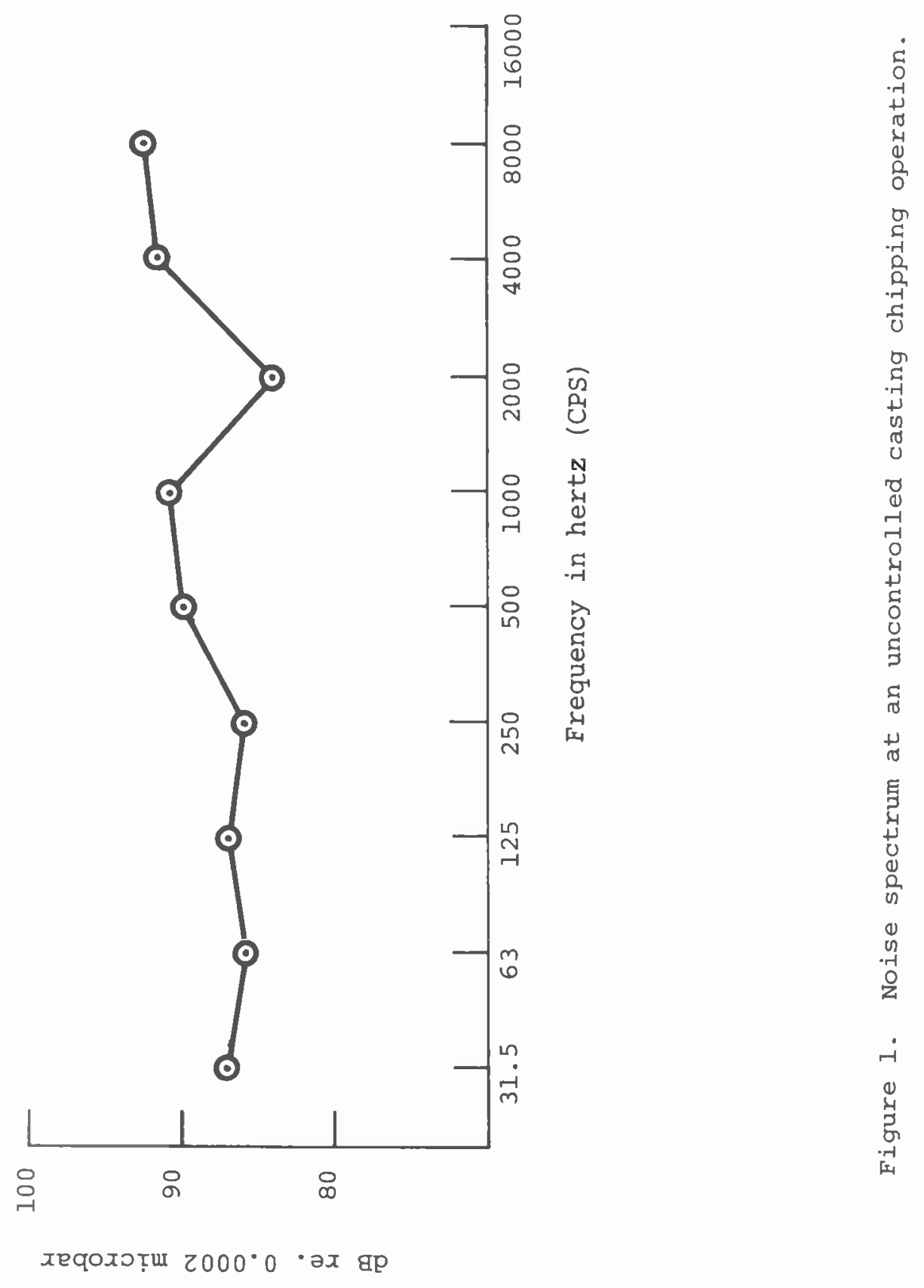




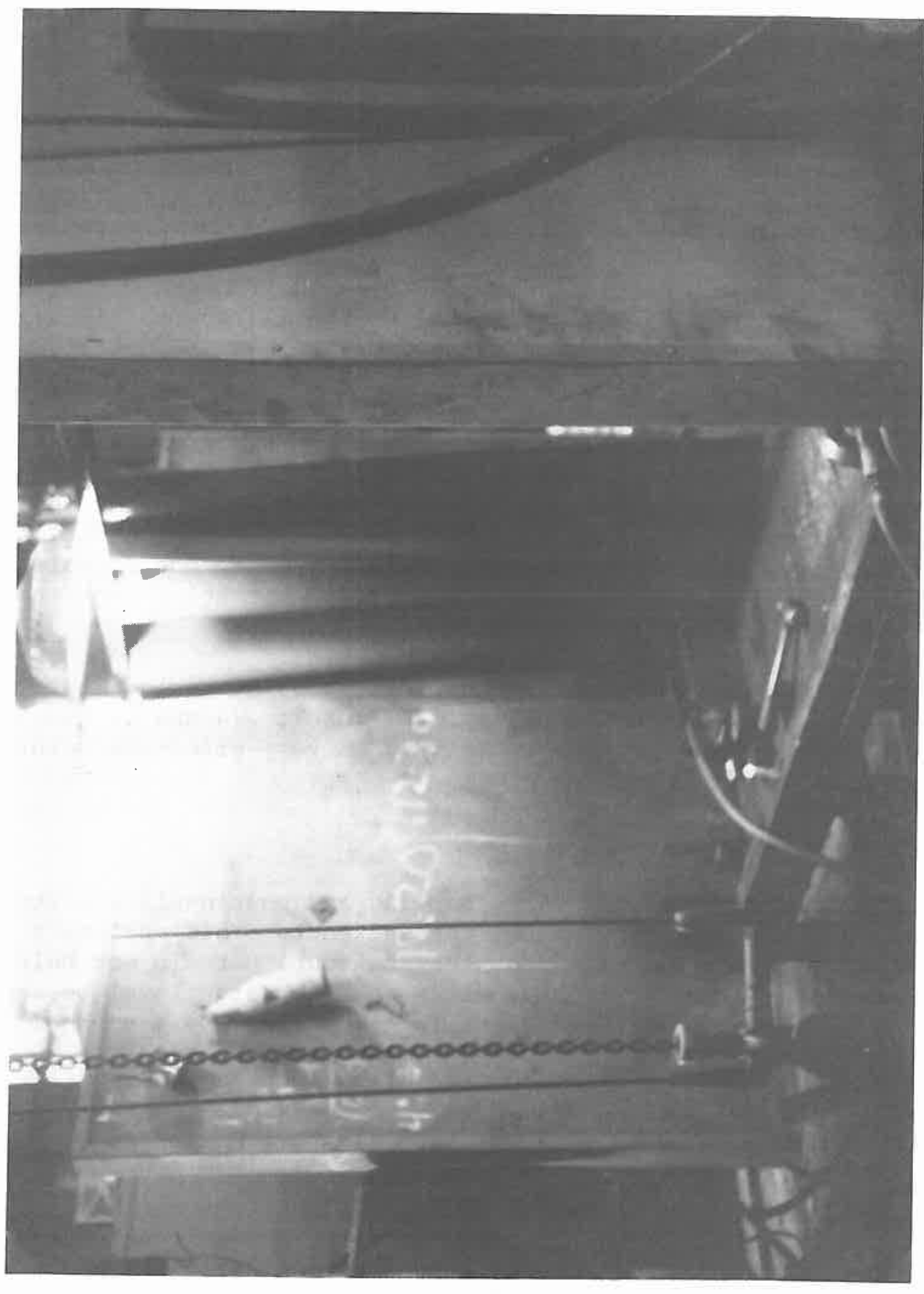

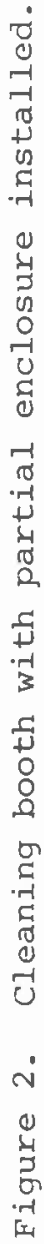


The type of noise spectrum found around the electric arc furnace is shown in Figure 3. You will note that during holding (idle condition) the noise level is about $94 \mathrm{dBA}$, with much of the noise in the middle frequencies $(125,250$ and $500 \mathrm{~Hz})$. At the start of a new heat the noise level increased to $100 \mathrm{dBA}$, and its spectrum shows increased energy in the $1 \mathrm{k}, 2 \mathrm{k}$, and $4 \mathrm{kHz}$ bands, which are the main bands affecting the dBA readings.

Trying to enclose two 15 megawatt furnaces with enough room inside the enclosure for the workers to move around and perform their job would have entailed the construction of a very large enclosure with complicated cooling and ventilation. It was decided to enclose the operators instead. This could be done with a much smaller and not nearly as complicated enclosure.

The ladle repair operation, which is separate from the furnace operation and did not need to be so close to it, was moved about $61 \mathrm{~m}(200 \mathrm{ft})$ further from the furnaces which lowered the ambient noise level enough for this operation to be in compliance.

With the addition of worker booths in which the furnace operators spent all of their time when they were not working directly at the furnace, the resulting exposure on the furnace operators was under $90 \mathrm{dBA}$. The dust free environment reduced their fume exposure and improved the conditions under which their console operated, so that maintenance on the console was dramatically lowered. This represented a benefit in operating cost that partially off-set the cost of the enclosure.

The noise level in the enclosure during the idle, holding period was $67 \mathrm{dBA}$, and when a new heat was started the noise level rose to $74 \mathrm{dBA}$ as levels reached $100 \mathrm{dBA}$ outside the enclosure. This was a very effective solution to their noise problem.

\section{CASE HISTORY 3 - SHAKEOUT NOISE}

At the discharge of an automatic osborne molding and pouring line a foundry had installed a partial enclosure around the shakeout. This enclosure was very effective for everyone working near the shakeout, but did not help the workers who were sorting the sprue and castings. The noise level on the aisle side of the enclosure was $88 \mathrm{dBA}$, while the sprue line personnel were exposed to $110 \mathrm{dBA}$.

It was felt that, even though hearing protection could be used, the noise level was high enough that excessive exposure was still possible even with ear plugs.

The layout of the line as it was originally constructed with the partial enclosure is shown in Figure 4 . The enclosure was not small and had represented a sizeable investment, but produced disappointing results.

After reviewing the various options that were available, it was decided to change the layout of the line by moving the workers who were sorting from immediately adjacent to the shakeout to a new location which was further removed. It did not require a lot of additional space and they were able to 

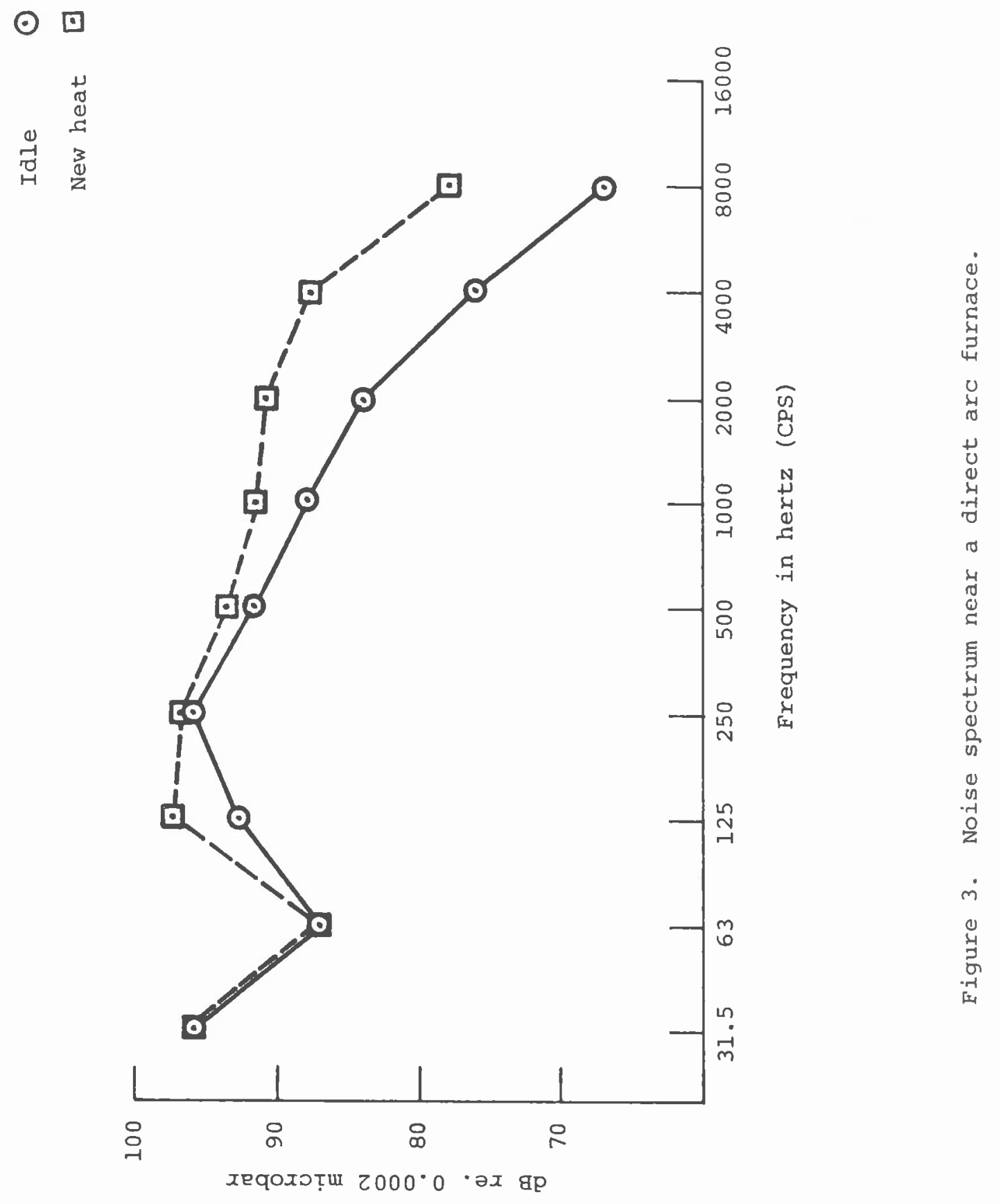


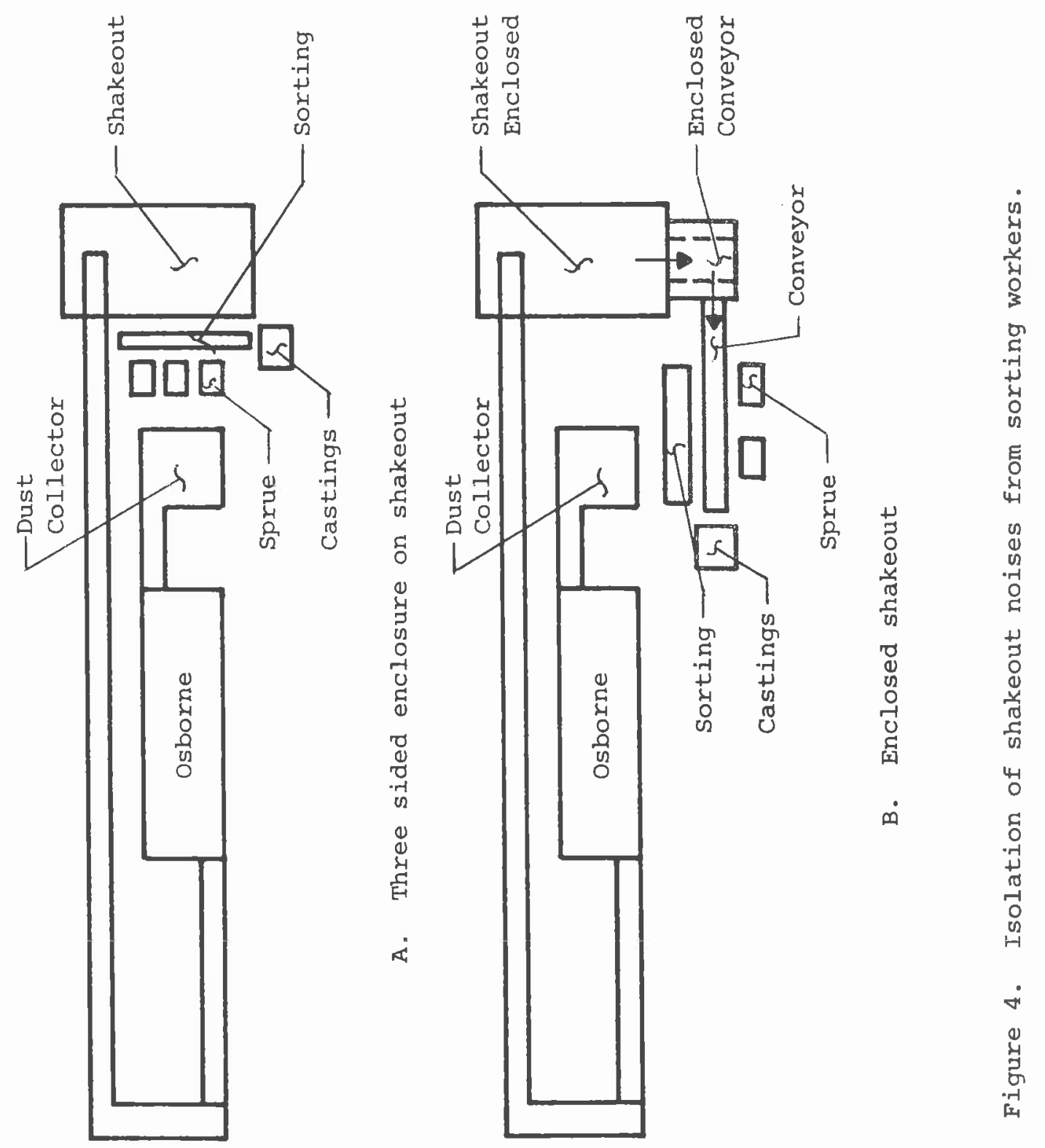


make use of an area where the noise level could be less than right in front of the shakeout.

A fourth wall was added to the shakeout enclosure along with some. necessary ventilation. Two new conveyors took the sprue and castings away from the enclosed shakeout and delivered the material to the sorting area. The use of the extra conveyors which carried the castings and sprue away from the shakeout made this arrangement successful.

\section{CONCLUSIONS}

We have discussed some approaches to noise control in the foundry. These approaches did not necessarily solve the noise problem by reducing the noise below $90 \mathrm{dBA}$; what they did was to provide some noise reduction which improved the environment. A noise reduction of $5 \mathrm{~dB}$ permits a doubling the time a man can be exposed to the noise or it reduces the possibility of a man losing his hearing by $50 \%$. Any such improvement is a worthwhile effort. 


\title{
A SUMMARY OF CHIPPING AND GRINDING NOISE RESEARCH AT RENSSELAER POLYTECHNIC INSTITUTE
}

\author{
H. A. Scarton, W. C. Kennedy, C. R. Caplan, J. A. Lacey, and K. R. Gaylo \\ Laboratory for Noise Control Research \\ Mechanical Engineering, Aeronautical Engineering and Mechanics Department \\ Rensselaer Polytechnic Institute, Troy, NY
}

\begin{abstract}
A summary of work on source noise control and a noise analysis of both a 15,000 RPM pneumatic horizontal grinder and a pneumatic metal chipping hammer is presented. The results of recent improvements in a 15,000 RPM horizontal extension grinder show a reduction in free running noise level of $5 \mathrm{dBA}$ to $84 \pm 1 \mathrm{dBA}$ measured at $61 \mathrm{~cm}(24 \mathrm{in.}$ ) in a small room with reverberant walls. The grinding noise level was reduced by $4 \mathrm{dBA}$ to $87+2 \mathrm{dBA}$. The grinder transient shutoff response was attenuated by 14 dBA to $92.5 \pm 0.5$

dBA. Data from a number three pneumatic metal chipping hammer are also presented. A comparison of anechoic data to actual cutting of heavy stock data implies that the noise results mostly from within the chipping hammer and, in particular, from the chisel. Although the dBA slow response readings were near $106 \mathrm{dBA}$, the peak readings went to $128 \mathrm{dBA}$. Detailed mechanical signature analysis of the complex chipping hammer signal is presented.
\end{abstract}

\section{INTRODUCTION}

In many instances the major sources of excessive noise in foundry related processes arise from hand held operations done on metal castings. If these castings are large, our research shows that the major acoustic sources emanate from within the tool and not the work piece. Although there can be a number of noisy operations occurring near these castings, such as arc-air metal gouging, electric arc furnaces, plasma cutting, metal chip blow-off nozzles, flame washing, chipping, and grinding, the subject of this report will be limited to the latter two. Although both chipping and grinding operations normally occur side by side in the preparation of castings, each tool noise signature and origin is unique so that each will be treated separately.

\section{NOISE CONTROL RESEARCH OF A PNEUMATIC HORIZONTAL GRINDER}

One of the primary tools used to finish the surface of large steel castings is the horizontal grinder. A pneumatic horizontal grinder powered by a sliding vane pneumatic motor generates siren-like simple source radiation under steady state grinding and free running conditions. When grinding is performed on large thics castings, this is the primary source of noise since the large size of the casting relative to the tool prevents it from imparting large quantities of energy. Additionally, more severe acoustic 
radiation is generated during the transient shutoff condition. The RPI Laboratory for Noise Control Research has developed a new muffler concept (patent pending) which greatly attenuates the pneunatic sound radiation from the tool.

The tool retrofitted for the new muffler is a DOTCO 15,000 RPM horizontal grinder. Figures 1 and 2 show this tool with the original and factory improved muffler. Figure 3 displays the RPI improved muffler. Table 1 shows the results of steady state free running, steady state grinding, and transient shutoff noise for the three mufflers. These measurements were made at a distance of $61 \mathrm{~cm}$ (24 in.) and at an angle of $90^{\circ}$ from the exhaust using a Bruel and Kjaer Type $213 \mathrm{H}$ calibrated sound level meter. The test was conducted in a small reverberant laboratory space (concrete ceiling and floor with painted cinder block walls). A running pressure of $586 \mathrm{kPa}$ (85 psig) on a $1.9 \mathrm{~cm}$ (0.75 in.) dia. airline were used. A free running noise level reduction of $5 \mathrm{dBA}$ to a new level of $84 \pm 1 \mathrm{dBA}$ measured at $61 \mathrm{~cm}$ ( $24 \mathrm{in.}$ ) in the reverberant room was realized. The steady grinding noise level was reduced by $4 \mathrm{dBA}$ to $87 \pm 2 \mathrm{dBA}$. The grinder transient shutoff response was attenuated by $14 \mathrm{dBA}$ to $92.5 \pm 0.5 \mathrm{dBA}$.

Table 1. Noise levels (dBA slow response) for DOTCO 15,000 RPM $2 \mathrm{HP}(1.5 \mathrm{KW})$ horizontal grinder (Model/10L4115C)*.

\begin{tabular}{llll}
\hline & $\begin{array}{c}\text { DOTCO } \\
\text { original } \\
\text { muffler }\end{array}$ & $\begin{array}{l}\text { DOTCO } \\
\text { improved } \\
\text { muffler }\end{array}$ & $\begin{array}{c}\text { RPI } \\
\text { muffler }\end{array}$ \\
\cline { 2 - 4 } 1. $\begin{array}{l}\text { Steady-state free } \\
\text { running in labora- } \\
\text { tory room. }\end{array}$ & $96 \pm 0.3$ & $89.5 \pm 0.5$ & $89 \pm 1$ \\
2. $\begin{array}{l}\text { Steady-state } \\
\text { grinding in } \\
\text { laboratory room. }\end{array}$ & $198.5 \pm 0.5$ & $91 \pm 1$ & $87 \pm 2$ \\
$\begin{array}{l}\text { Transient shutoff } \\
\text { peak response in } \\
\text { laboratory room. }\end{array}$ & $107 \pm 0.5$ & $106 \pm 0.5$ & $92.5 \pm 0.5$ \\
\hline
\end{tabular}

*All distances measured at estimated operator ear distance of $0.61 \mathrm{~m}$ (24 in.). The exhaust is 900 away from the Brliel and Kjaer type 2 $13 \mathrm{H}$ sound level metex. The grinding wheel was $8.9 \mathrm{~cm}(3.5 \mathrm{in.})$ dia., $1.3 \mathrm{~cm}$ (0.5 in.) thick, (85 psig running pressure).

A problem frequently encountered in the noise control of pneumatic vane motors under load is icing within the motor or muffler interior. This icing restricts air flow through the muffler, thus choking the tool and causing a power loss. Testing for this condition is usually accomplished by running the tool at its peak power output point for $3 \mathrm{~min}$. If no appreciable power loss is detected the test is considered successful. Preliminary testing of our muffler design has had the grinder running for well over $5 \mathrm{~min}$. without the power output dropping appreciably below peak levels. 
Figures 4 and 5 show the differences in spectra $(0-10 \mathrm{kHz})$ between the three mufflers under free running and grinding conditions. The grinding was done using a $8.9 \mathrm{~cm}$ (3.5 in.) dia. and $1.27 \mathrm{~cm}(0.5 \mathrm{in.})$ thick abrasive wheel on a large block of thick steel $6 \times 3 \times 24$ in. $^{3}\left(15.2 \times 7.6 \times 61 \mathrm{~cm}^{3}\right.$ ). Figure 6 shows the noise test conducted using the RPI improved muffler. The grinding noise was observed to be high frequency and starts to become unmasked as seen by comparing Figures $4 \mathrm{C}$ and $5 \mathrm{c}$. (Note the peak at $5 \mathrm{kHz}$ in Figure $5 \mathrm{c}$ vs. Figure 4c.)

Figure 7 dramatically displays time oscilloscope plots of the 14 dBA peak noise reduction ( $1 / 25$ th of the acoustic energy generated by both DOTCO models) achieved over the DOTCO improved muffler during the steady state free running to transient shutdown transition noise emission. The contrast is even more striking when one remembers that the capacitive microphone voltage is displayed so the sound intensity is proportional to the voltage squared.

Figure 8 shows the spark trajectories for the RPI muffler. Preliminary dynamometer tests show little loss of power caused by the RPI muffler.

\section{NOISE CONTROL RESEARCH OF A CHIPPING HAMMER}

The pneumatic metal chipping hammer is another tool used extensively in the foundry for removing metal waste from castings. When these castings are thick and heavy [such as those exceeding 100 tons and having a wall thickness in excess of $15.2 \mathrm{~cm}$ ( 6 in.)] our research has shown that the dominant source of sound comes from the tool itself. For the purpose of this paper, tests were performed on a Number 3 Chicago Pneumatic Metal Chipping Hammer. Figure 9 shows an assembled No. 3 hammer and a disassembled No. 2 hammer. The first series of tests were made under anechoic conditions [the $38 \mathrm{~cm}$ (15 in.) wedges used in our Eckel Anechoic Chamber correspond to a cut-off frequency of $250 \mathrm{~Hz}$, above which anechoic conditions are produced] Figure 10 shows the anechoic chamber and instrumentation with an RPI muffler applied to an Ingersoll-Rand riveting gun. A second series of tests were conducted by chipping on a $14 \mathrm{kN}$ ( 1.6 ton) test fixture in a large open area (Figure 11). The results of these two tests are shown in Table 2, and Figures 12-15. The sound level meter attenuator settings were held constant at $120 \mathrm{dBA}$ for all readings, which were made at a distance of $0.61 \mathrm{~m}$ (24 in.) after initial calibration using a Bruël and Kjaer 2209 sound level meter, with a $1.3 \mathrm{~cm}(0.5 \mathrm{in.})$ microphone. The running line pressure was $586 \mathrm{kPa}$ (85 psig) using a $1.9 \mathrm{~cm}(0.75 \mathrm{in.})$ dia. airline.

These tests clearly indicate that the origin of the sources of sound for heavy castings were from the metal chipping hammer and were independent of whether chipping of metal was actually occurring or not. In fact, somewhat higher readings were observed for the non-chipping case, as is shown by Figure 12. Figures $12 \mathrm{a}$ and $12 \mathrm{c}$ show a comparison between the operation noise of the non-chipping case (anechoic chamber) and of the actual open-area chipping conditions on a steel casting. Figures $12 \mathrm{~b}$ and $12 \mathrm{~d}$ show details of individual impact events from $12 \mathrm{a}$ and $12 \mathrm{c}$, respectively. Clearly the nonchipping case shows somewhat higher readings. It is noteworthy that tests 
performed in an anechoic chamber are typically $3 \mathrm{~dB}$ less than in an open area due to an absence of reverberation; thus, on this basis one would expect higher readings in a normal room. One can only conclude that the steel casting, is somehow acting as an energy sink for the vibrating chisel.

Table 2. Chipping hammer sound levels at $0.61 \mathrm{~m}$ (24 in.) with a $586 \mathrm{kPa}$ (85 psi) running pressure in a 1.9 $\mathrm{cm}$ (0.75 in.) dia. airline.

\begin{tabular}{lcc}
\hline & $\begin{array}{c}\text { Anechoic conditions } \\
\text { (with no chipping) }\end{array}$ & $\begin{array}{c}\text { Chipping on a 14 } \mathrm{kN} \\
(1.6 \text { ton) casting in } \\
\text { a large open area }\end{array}$ \\
\cline { 2 - 3 } & 106.5 & $104-106$ \\
Slow response & 105 & 106 \\
Fast response & 110.5 & $109-110$ \\
Impulse response & 111 & 110 \\
Impulse hold & 128 & $127.5 \pm 0.5$ \\
Peak hold & $\mathrm{dBA})$ & 127
\end{tabular}

Various chipping hammer parts were tested for resonant frequencies. Figure 13a shows the response of the barrel to a transverse impact; note the modulation effect due to the interaction of two close but distinct frequencies. The grip handle has a more complex response, as shown in Figure l3b. The retainer, on the other hand, rings with a pure bell tone, as shown in Figure 13c.

The chisel was studied in great detail and was observed to have three dominant resonant modes. The overall interaction of these modes is shown in Figure 14a; both the $5 \mathrm{~ms}$ and $1 \mathrm{~ms}$ sweeps are triggered by the initial (longitudinal) impact on the chisel. Figures $14 \mathrm{~b}, \mathrm{c}$ and $\mathrm{d}$ show the three modal frequencies individually.

It was also observed that each mode has a pair of close but distinct frequencies, as does the barrel. This is due to the geometry of the chisel; impacting the chisel parallel to the plane of the chisel flat produces a tone slightly higher in frequency to that heard when the impact is perpendicular to this plane. Similar reasoning applies to the barrel. The interaction of the second modal frequency pair is shown in Figure 15a. Note the modulation effect; this can actually be sensed by touch when the chisel is vibrating. Figure 15b shows the interaction of all (six) modal frequencies and is similar to Figure $14 \mathrm{a}$. 
A tabulation of the measured and computed values are given in Table 3 . The discrepancy can be related to the nonuniform chisel shape, which yields slightly different section properties in each of the directions perpendicular to the chisel shaft axis.

Table 3. Measured and computed transverse bending resonances for chipping hammer chisel. Overall chisel length, $24 \mathrm{~cm}$ (9.3 in.). Calculations made assuming a uniform cylindrical bar of radius $1.83 \mathrm{~cm}(.72 \mathrm{in.})$ and $24 \mathrm{~cm}$ (9.3 in.) long.

a. Actual frequencies

\section{Measured}

\begin{tabular}{cccc} 
Mode & $\begin{array}{c}\text { Impact parallel } \\
\text { to chisel flat, } \\
\mathrm{kHz}\end{array}$ & $\begin{array}{r}\text { Impact perpendicular } \\
\text { to chisel flat, } \\
\mathrm{kHz}\end{array}$ & $\begin{array}{r}\text { Calculated, } \\
\mathrm{kHz}\end{array}$ \\
\hline 1 & 1.94 & 1.99 & 2.97 \\
2 & 4.35 & 4.72 & 8.20 \\
3 & 7.41 & 8.36 & 16.08
\end{tabular}

b. Normalized frequency ratios

Measured

\begin{tabular}{lccc} 
Mode & $\begin{array}{l}\text { Impaet parallel } \\
\text { to chisel flat }\end{array}$ & $\begin{array}{r}\text { Impact perpendicular } \\
\text { to chisel flat }\end{array}$ & calculated \\
\hline 1 & 1.00 & 1.00 & 1.00 \\
2 & 2.24 & 2.37 & 2.76 \\
3 & 3.82 & 4.20 & 5.40 \\
\hline
\end{tabular}

The low frequency pneumatic acoustic pulsations require the use of an RPI designed minimum icing reactive muffler. Several preliminary prototype mufflers have been successfully tested. Further chipping hammer muffler development awaits the tool structural borne resonance problem that is now under study in the RPI Laboratory for Noise Control Research.

\section{ACKNOWLEDGEMENT}

We of the RPI Laboratory for Noise Control Research wish to express our thanks to the Large Steam Turbine-Generator Division of the General Electric Company, Schenectady, N.Y., for their continuing encouragement and generous support of this work. 


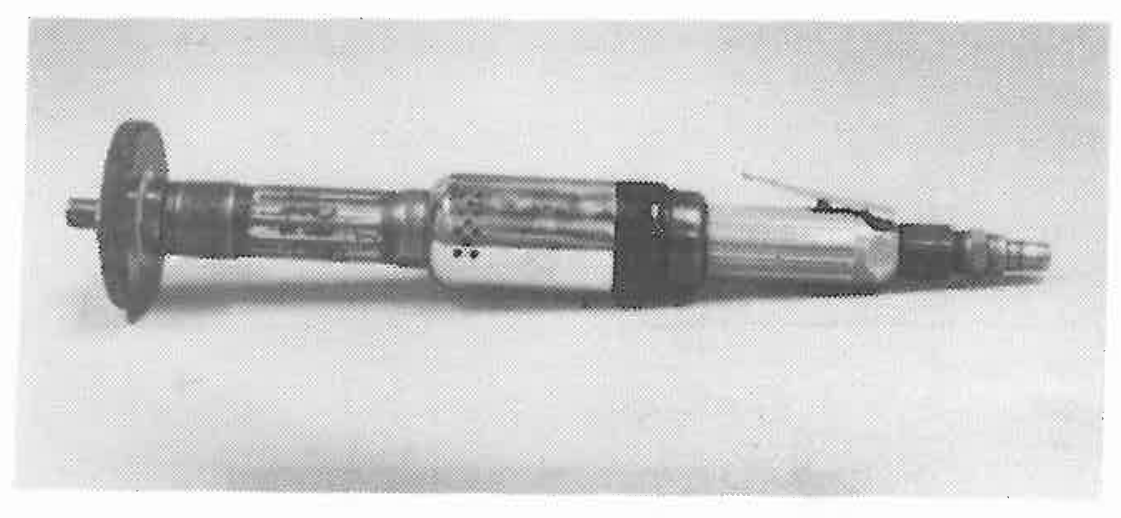

Figure 1. Side view of horizontal grinder with original muffler (DOTCO 15,000 RPM 2 HO $(1.5 \mathrm{~kW})$ Model 10L4115C)

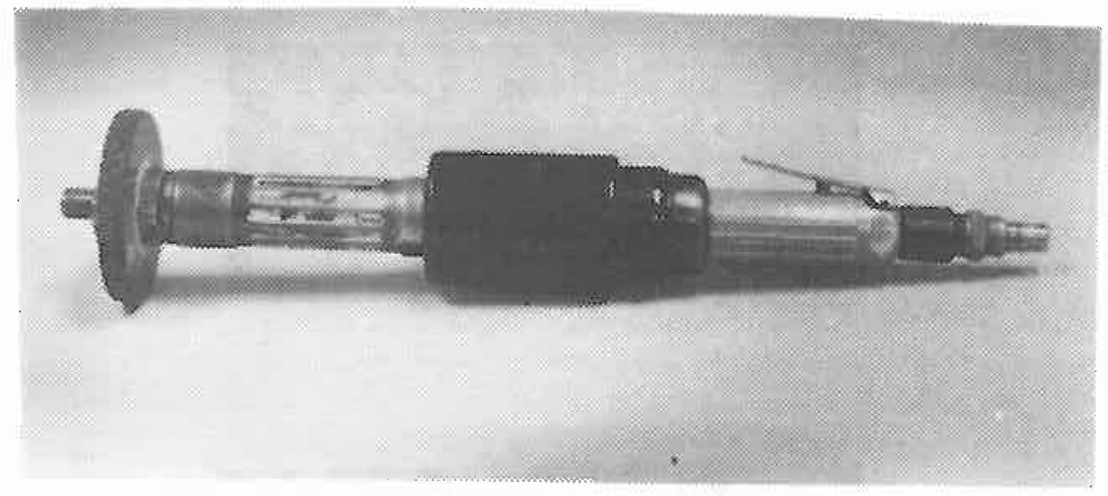

Figure 2. Side view of horizontal grinder with factory improved muffler (DOTCO 15,000 RPM 2 HP $(1.5 \mathrm{~kW})$ Model 10L4115C)

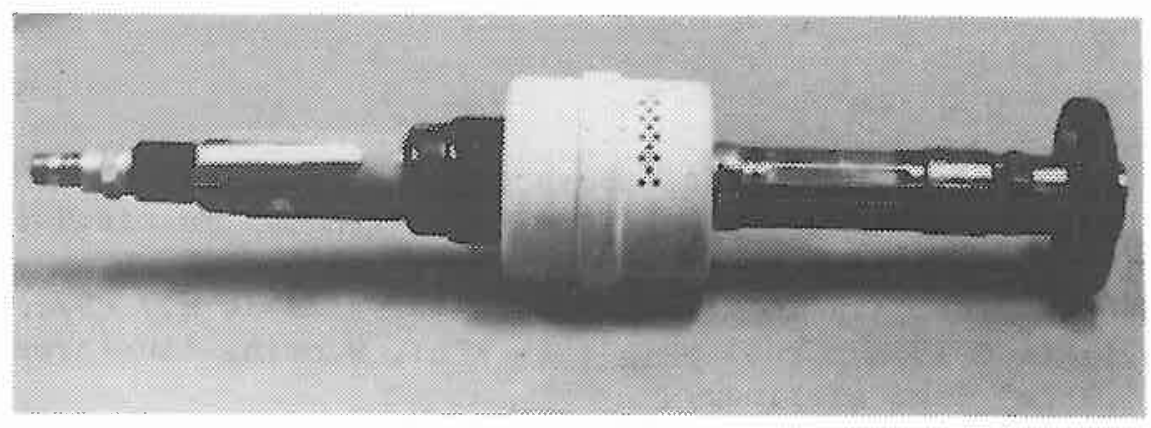

Figure 3. Side view of horizontal grinder with RPI muggler (DOTCO 15,000 RPM 2 HP (1.5 kW) Model 10L4115C) 
(a)

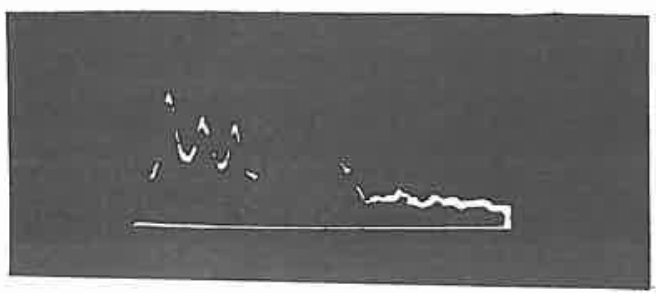

(b)

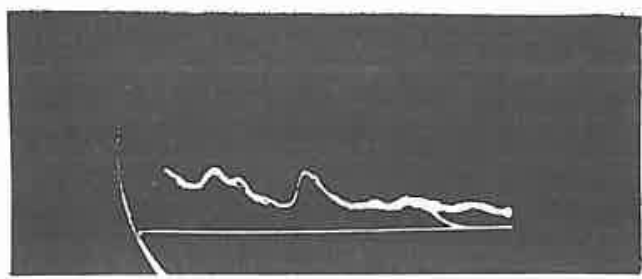

(c)

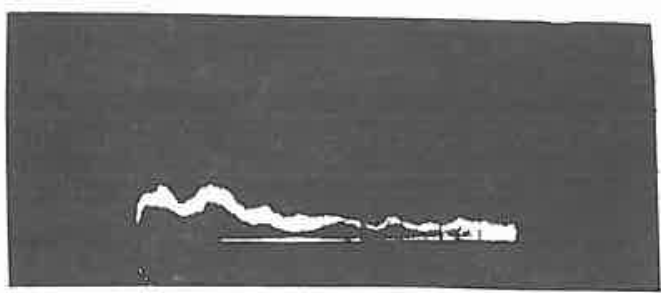

Figure 4 Free running spectra in laboratory for DOTCO 15,000 RPM $2 \mathrm{HP}(1.5 \mathrm{~kW})$ horizontal grinder (Mode1 10L4115C) with $3.5 \mathrm{in.}(8.9 \mathrm{~cm}) \mathrm{dia} .0 .5$ in. $(1.3 \mathrm{~cm})$ thick wheel at $24 \mathrm{in} .(0.61 \mathrm{~cm})$ and $90^{\circ}$ from exhaust. (A11 pad settings are identical. Vertical axis is $6.7 \mathrm{~dB} / \mathrm{cm}$. Horizontal axis is $0-10 \mathrm{kHz}$ ) [85 psig (586 kPa), running line pressure $0.75 \mathrm{in}$. $(1.9 \mathrm{~cm})$ dia. airline.) ]

a) DOTCO original muffler $(96 \pm 0.3 \mathrm{dBA})$,

b) DOTCO improved muffler $(89.5+0.5 \mathrm{dBA})$,

c) RPI muffler $(84 \pm 1 \mathrm{dBA})$. 

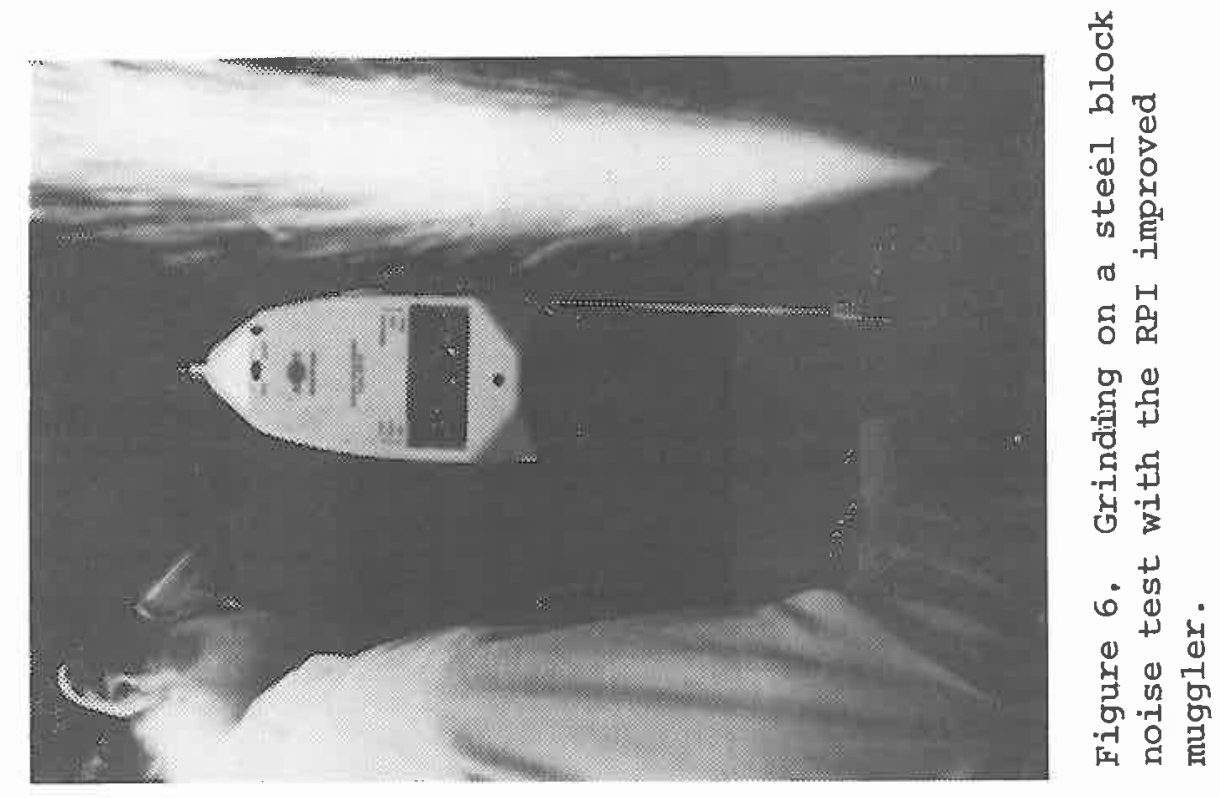
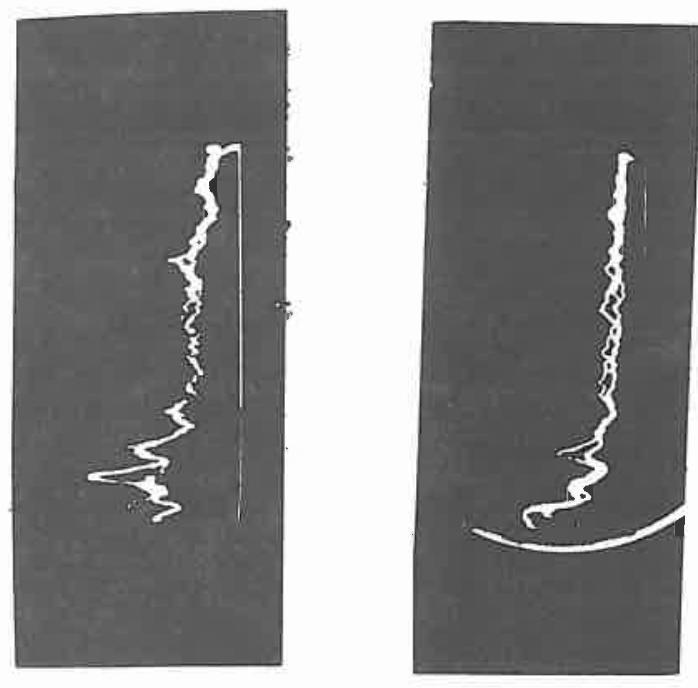

ชิ

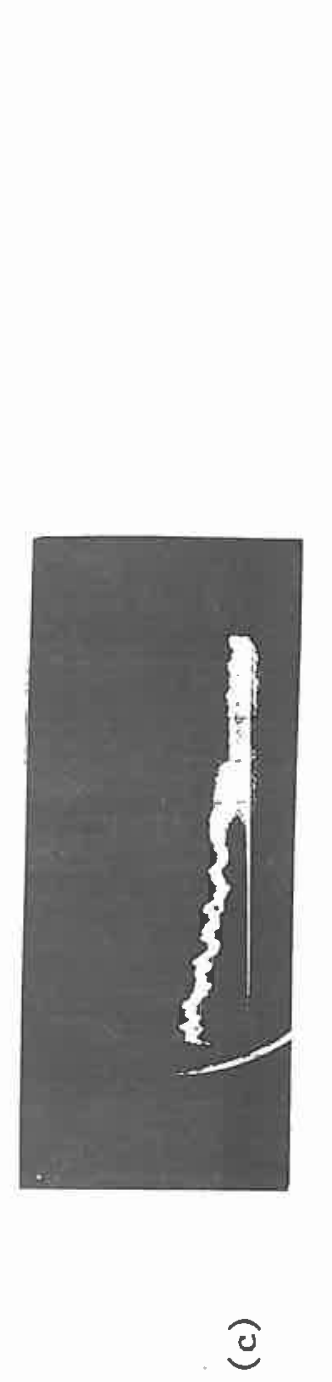


a)

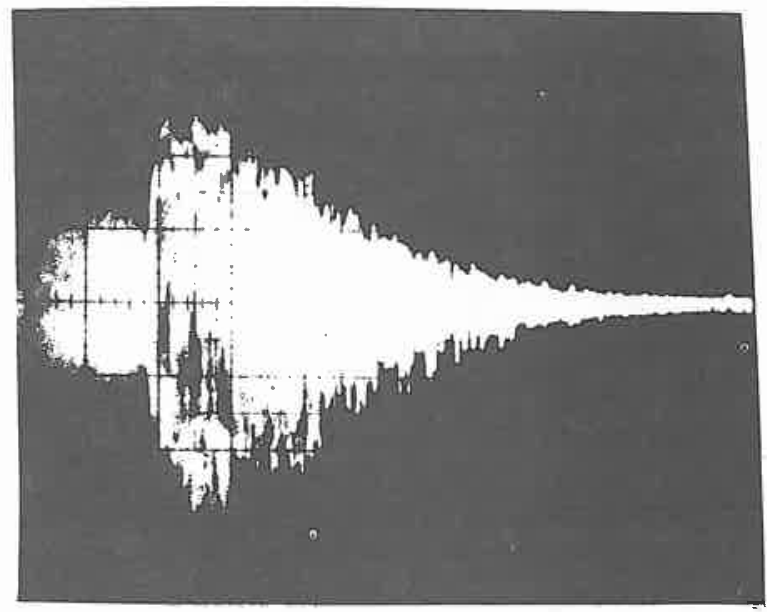

b)

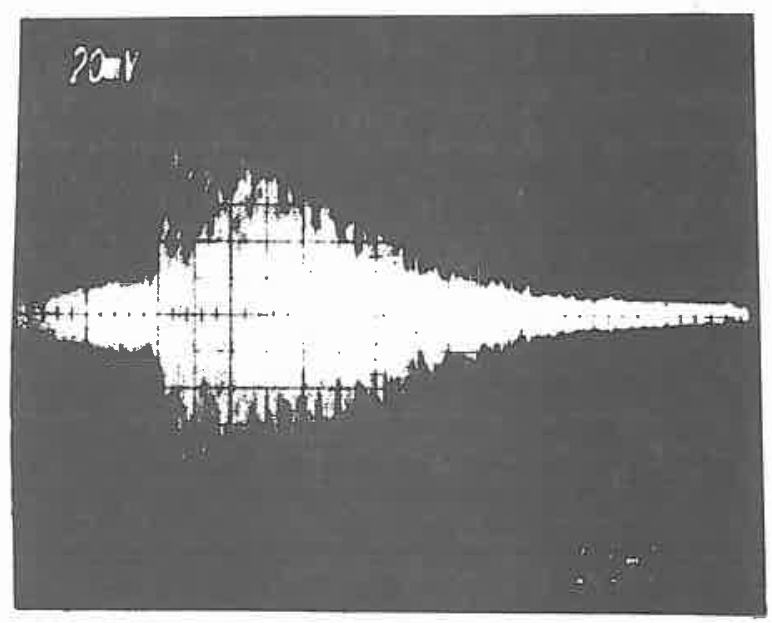

c)

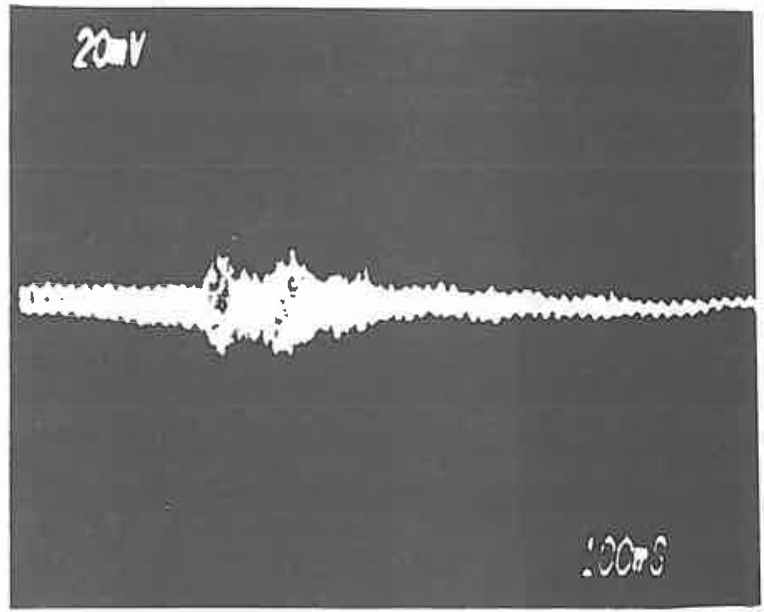

Figure 7 Transient shutoff preceded by steady state free running for DOTCO 15,000 RPM $2 \mathrm{HP}(1.5 \mathrm{~kW})$ horizontal grinder (Model 10L4115C) with $3.5 \mathrm{in} .(8.9 \mathrm{~cm}) \mathrm{dia} .0 .5 \mathrm{in} .(1.3 \mathrm{~cm})$ thick wheel at $24 \mathrm{in}$. $(0.61 \mathrm{~m})$ and $90^{\circ}$ from exhaust. (A11 pad settings are identical. Vertical axis is $20 \mathrm{mV} / \mathrm{div}$. Horizontal axis is $100 \mathrm{~ms} / \mathrm{div}$.) [85 psig $(586 \mathrm{kPa})$ running pressure with $0.75 \mathrm{in} .(1.9 \mathrm{~cm})$ airline.]

a) DOTCO original muffler ( $107+0.5 \mathrm{dBA}$ peak hold),

b) DOTCO improved muffler (106+0.5 dBA peak hold),

c) RPI muffler $(92.5+0.5 \mathrm{dBA}$ peak hold). 


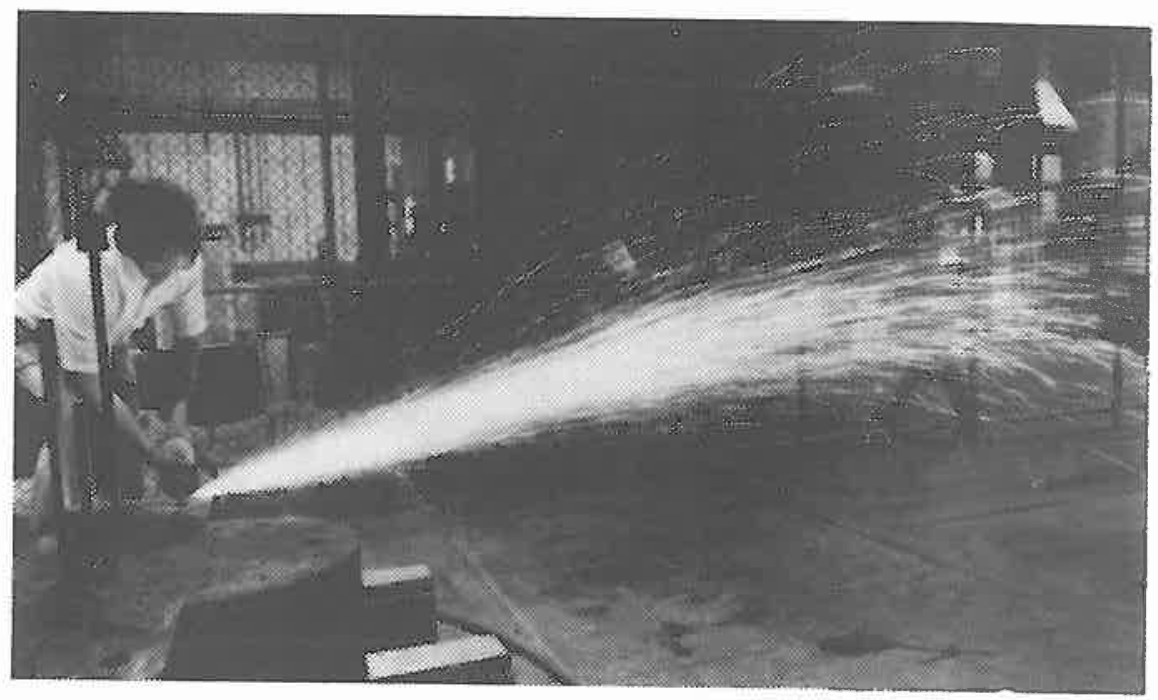

Figure 8 Spark trail for a horizontal grinder [DOTCO 15,000 RPM $2 \mathrm{HP}(1.5 \mathrm{~kW})$ Mode1 10L4115C] with RPI muffler and 3.5 in. $(8.9 \mathrm{~cm})$ dia. 0.5 in. $(1.3 \mathrm{~cm})$ thick grinding wheel [85 psig (586 kPa) running pressure 0.75 in. $(1.9 \mathrm{~cm})$ dia. airline $]$.

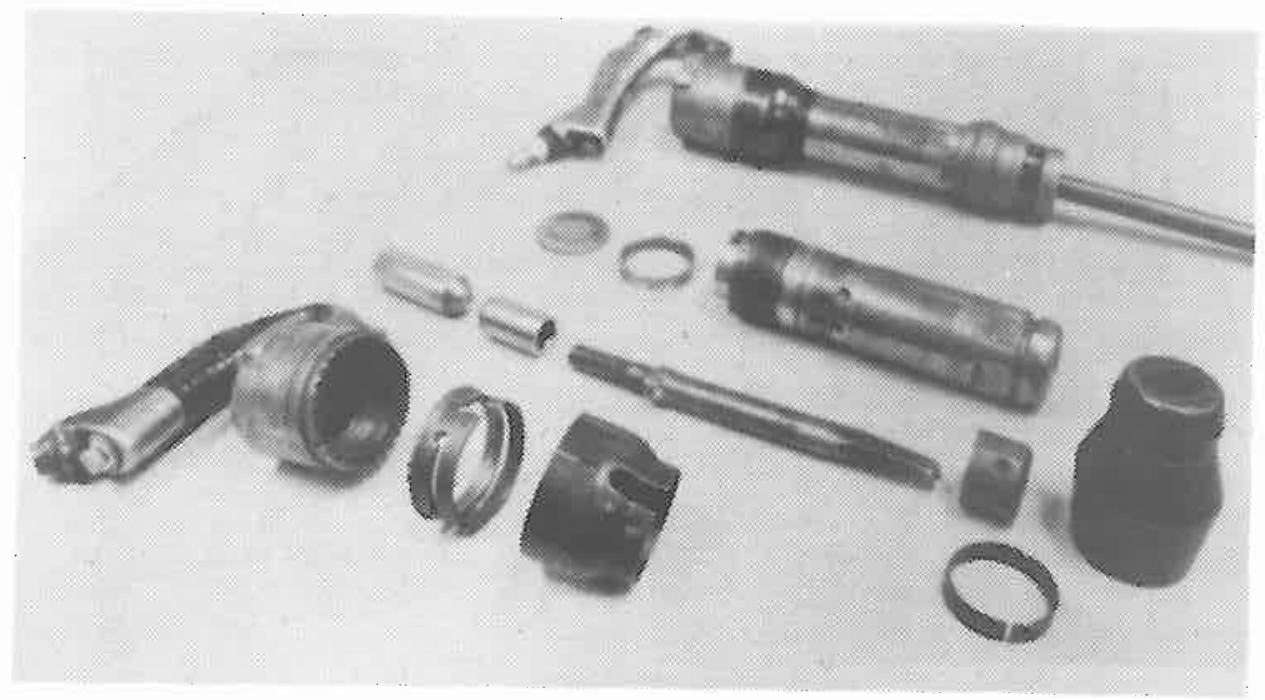

Figure 9 Chipping Hammer [Chicago Pneumatic No. 2 Model H118862 disassembled and No. 3 assembled]. 


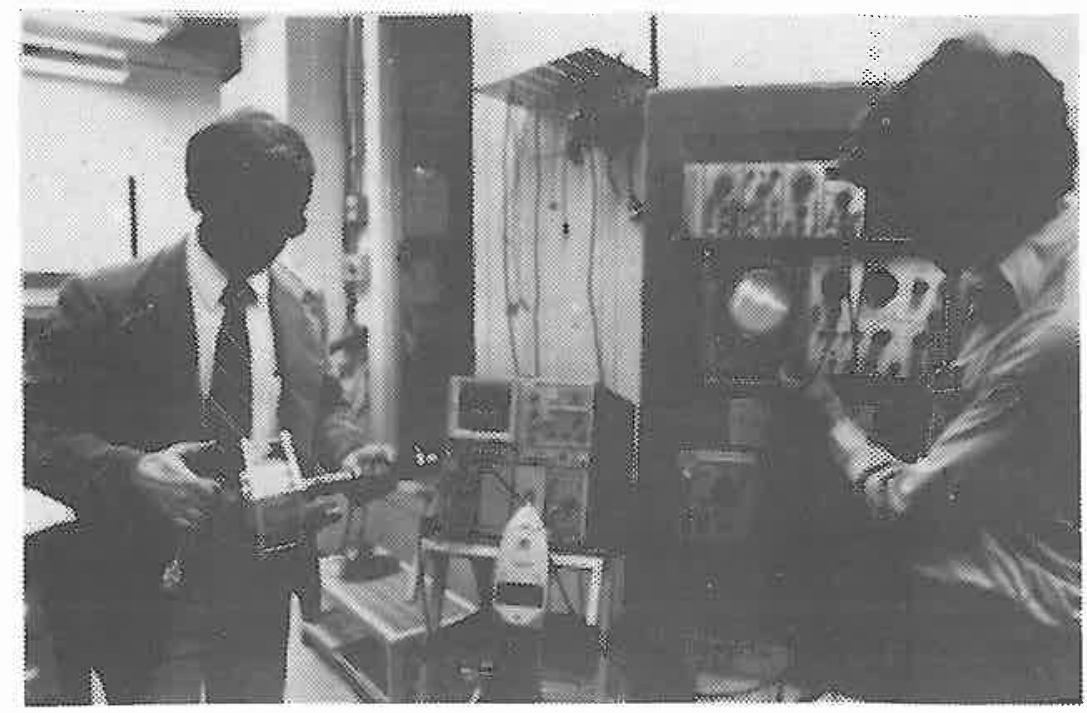

Figure 10. Anechoic Chamber and typical instrumentation used for acoustical measurement of an Ingersoll-Rand riveting gun.

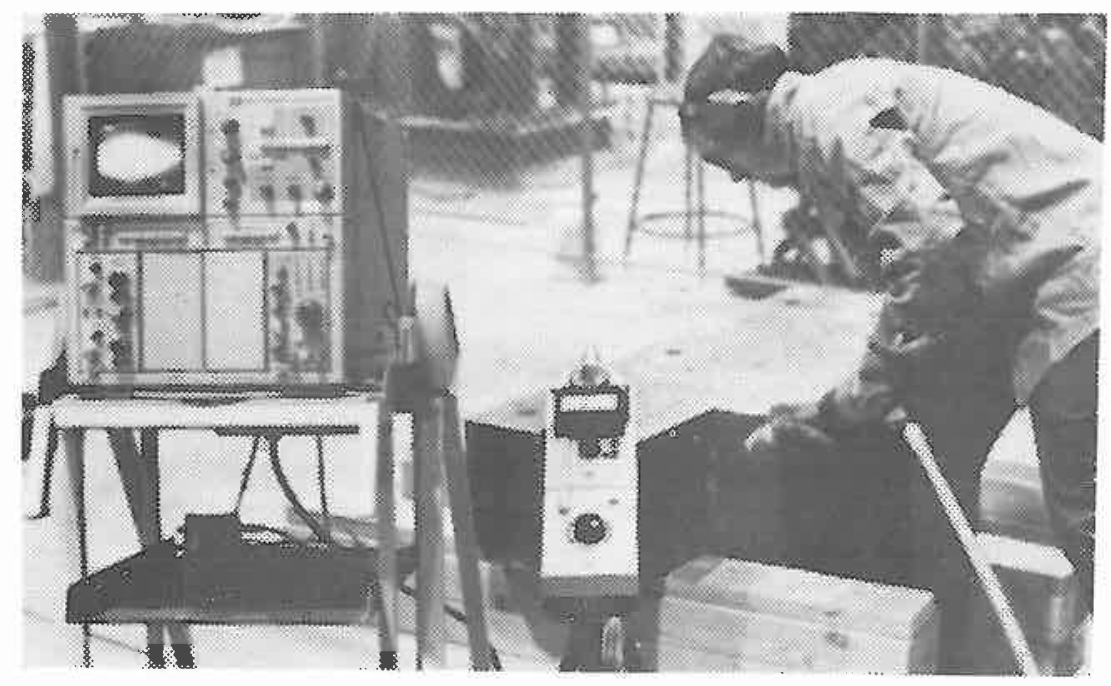

Figure 11 A chipping hammer [Chicago Pneumatic No. 3 hammer] chipping on a 1.6 ton $(14 \mathrm{kN})$ odd sized stee 1 block $5.6 \mathrm{ft.} 3\left(0.16 \mathrm{~m}^{3}\right)$ at $85 \mathrm{psig}$ $(586 \mathrm{kPa})$ running pressure through a $0.75 \mathrm{in.}(1.9 \mathrm{~cm})$ alrline. [The square portion of the block is $13.5 \times 11 \times 49$ in. $3(0.34 \times 0.28 \times$ $\left.1.2 \mathrm{~m}^{3}\right)$ with 12 in. $(0.30 \mathrm{~m})$ radius by 11 in. $(0.28 \mathrm{~m})$ thick appendage.] 


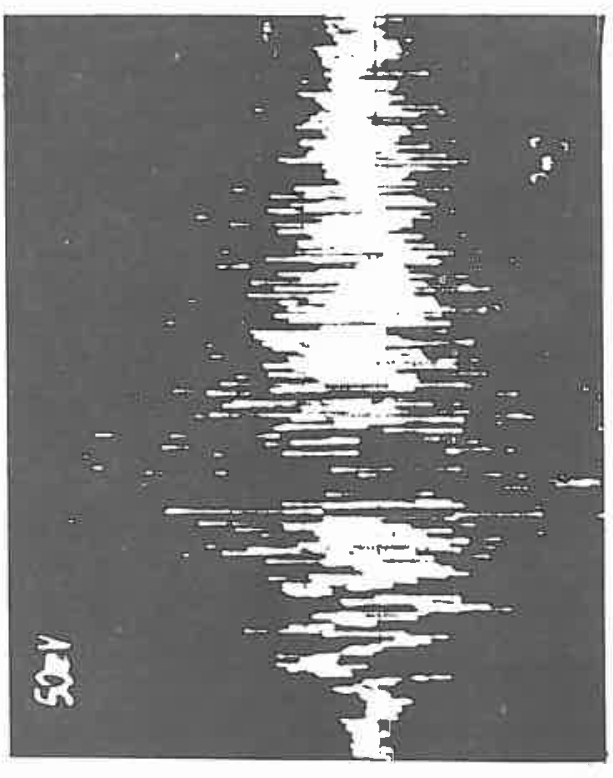

2

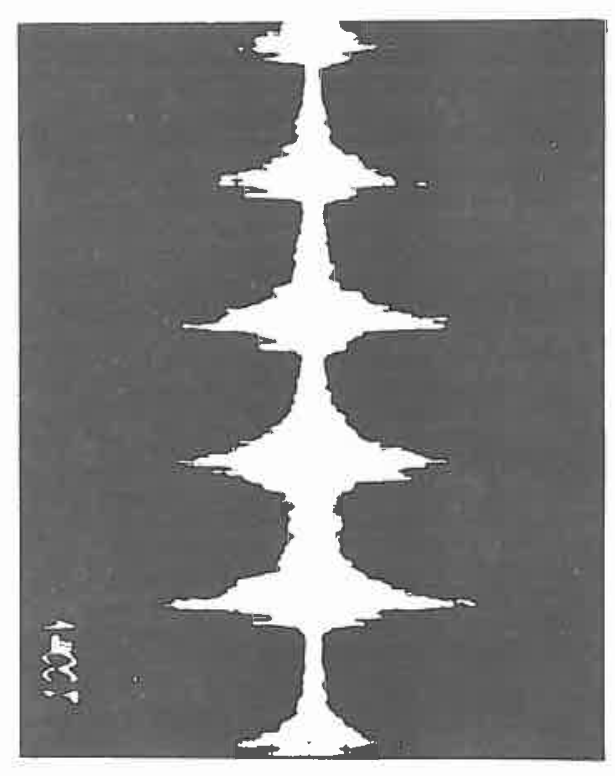

ฮ

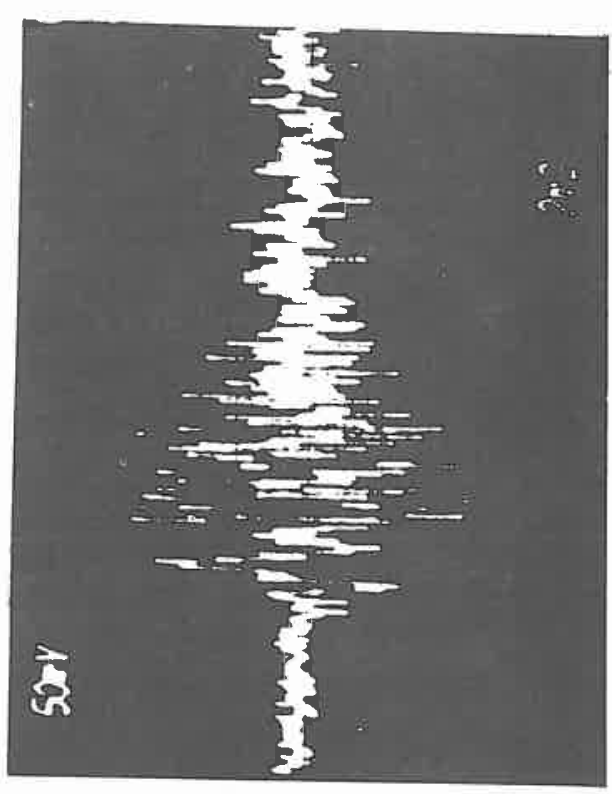

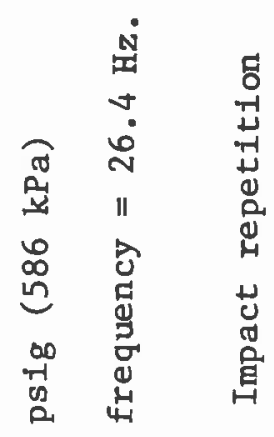

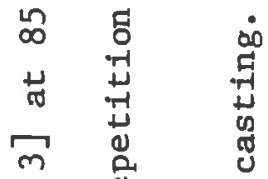

¿

$\dot{0} \quad \begin{gathered}0 \\ 0\end{gathered}$

堄皆

궁

点

自粦

$\widehat{\varnothing}$

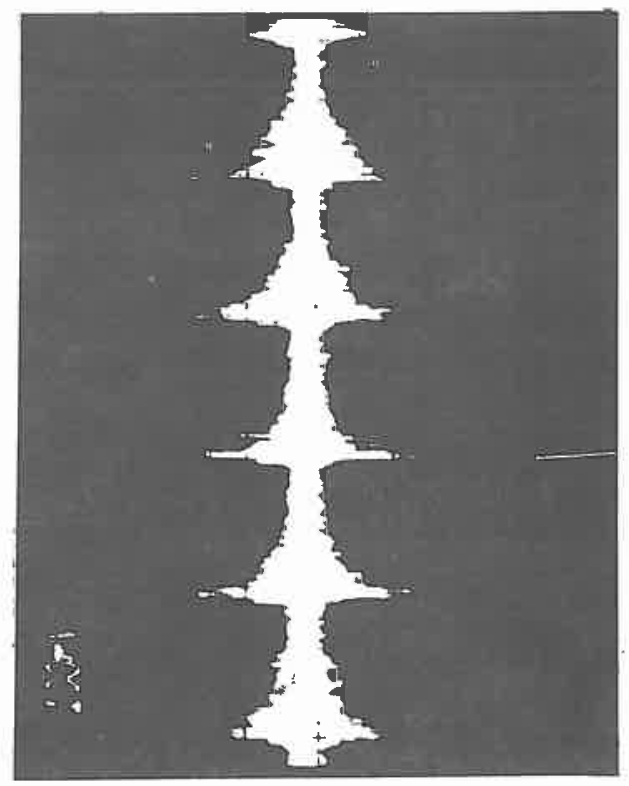

$\widehat{\jmath}$

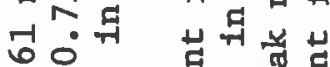
过 두 돔 a

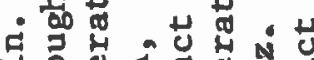

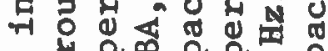

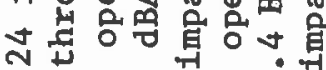
$4 \infty " 山 \dot{0}^{4}$

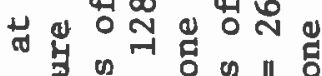
व के ब थ व

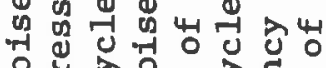

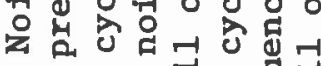
व 7

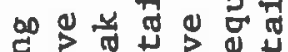

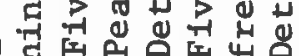

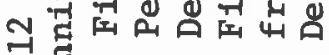
\% ه $\vec{a}$ 昰 


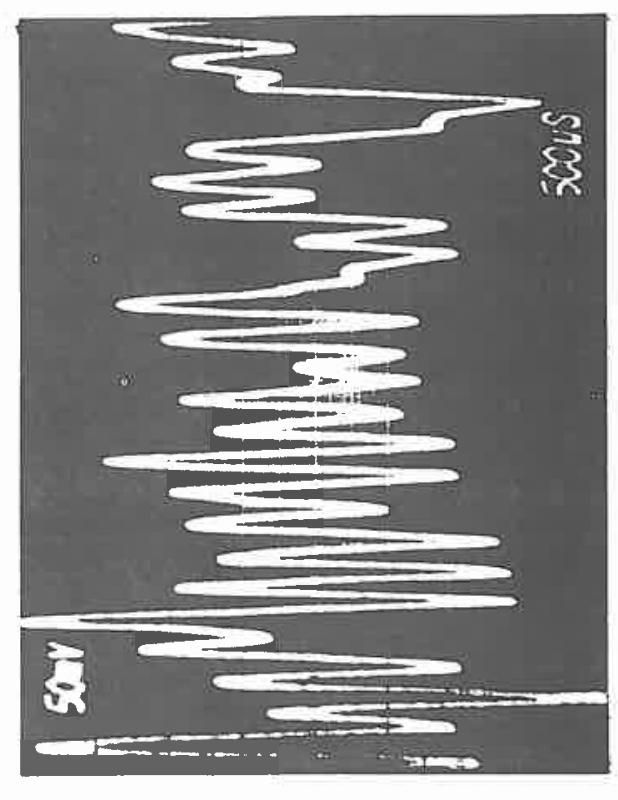

อ

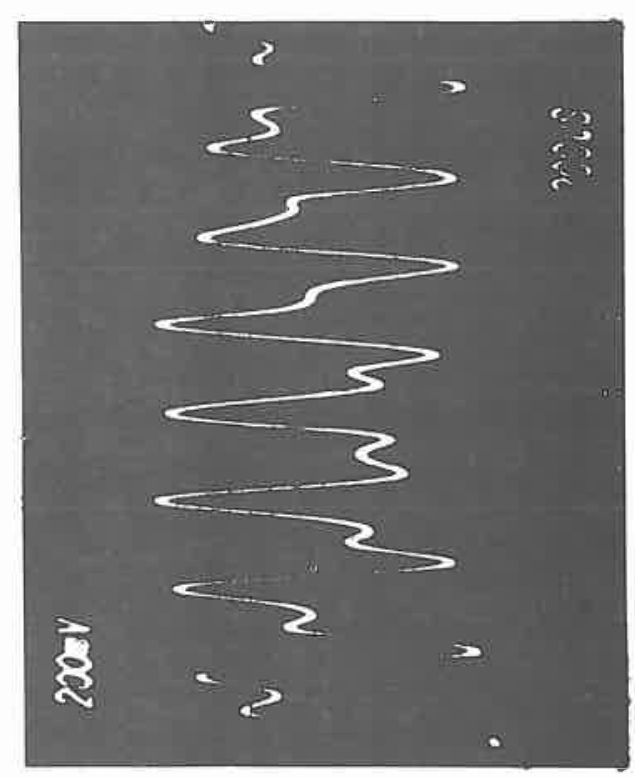

ฮ

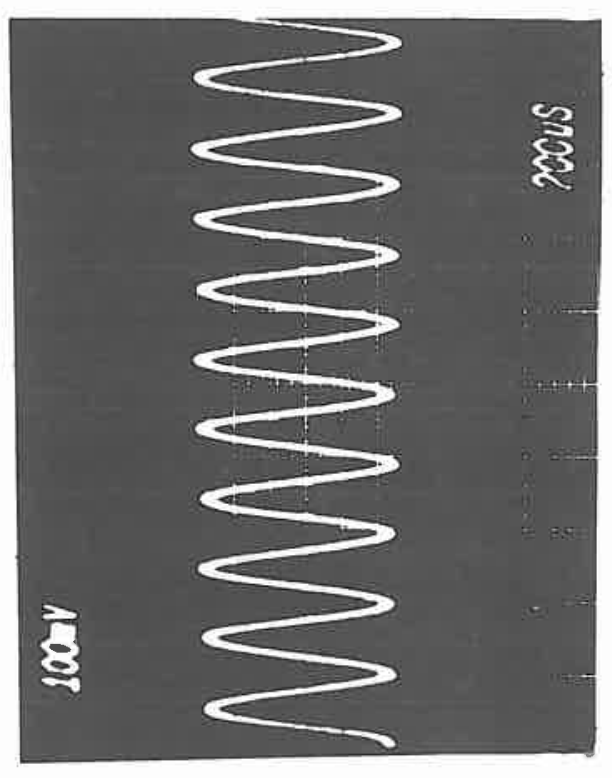

ว
ले

莒

总 N

$+$

용

ते

i

$\ddot{4}$

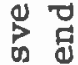

ב

갱

م

वै

is

刃

究些㟧

ธี

过貝

r $\nabla \ddot{g}$

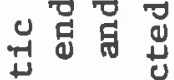

का

ठ 㟔合

武

. 自吾冠

里近出

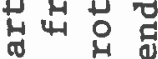

도

4 응

氙各。

界

可牙 काने Ф

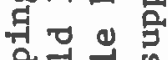

a $=1$

월

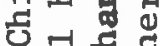

웜

4 겅

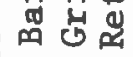

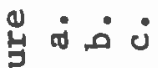

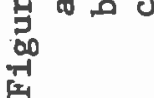




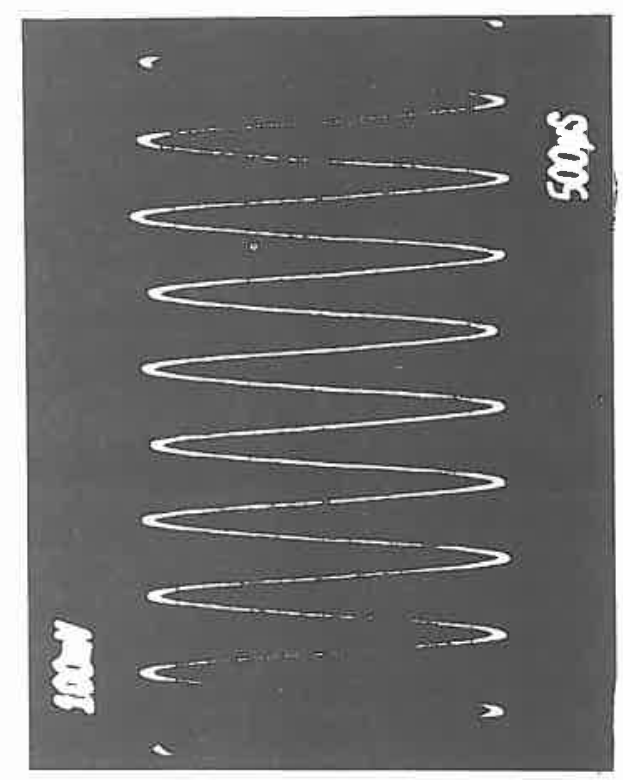

อิ

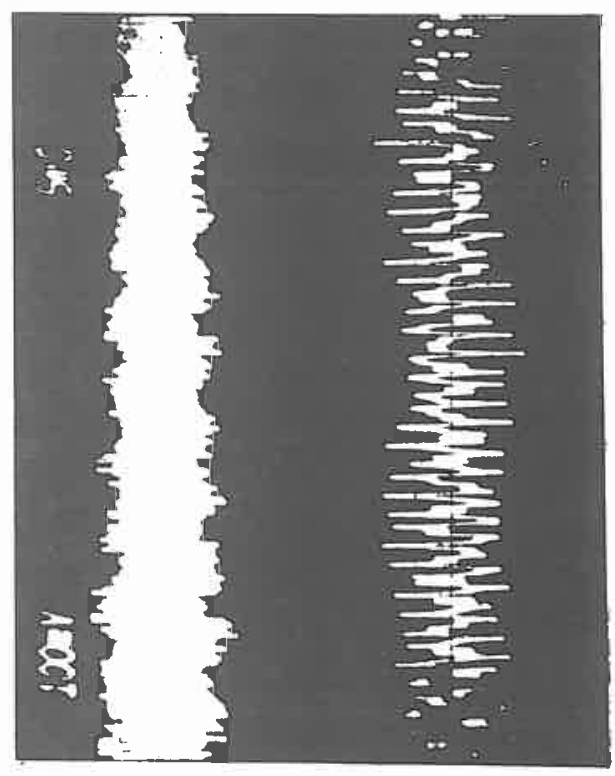

(ช)

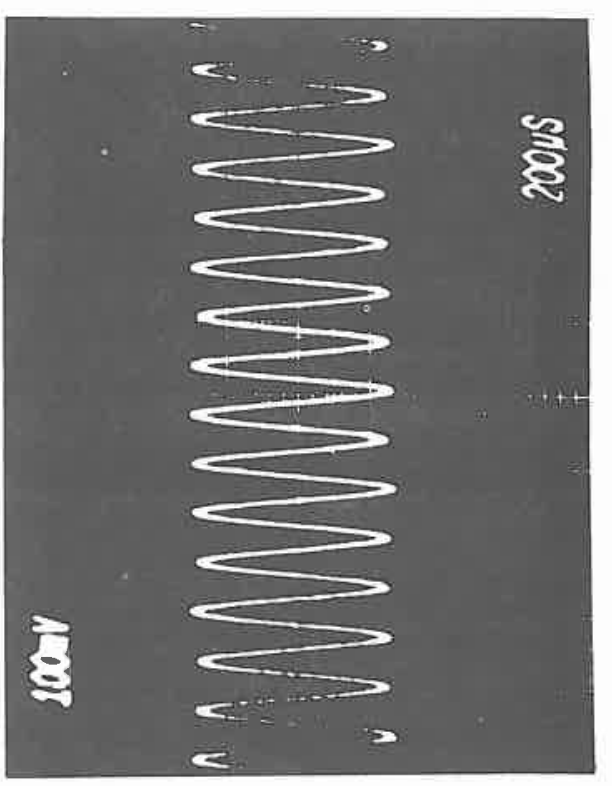

$\widehat{\nabla}$

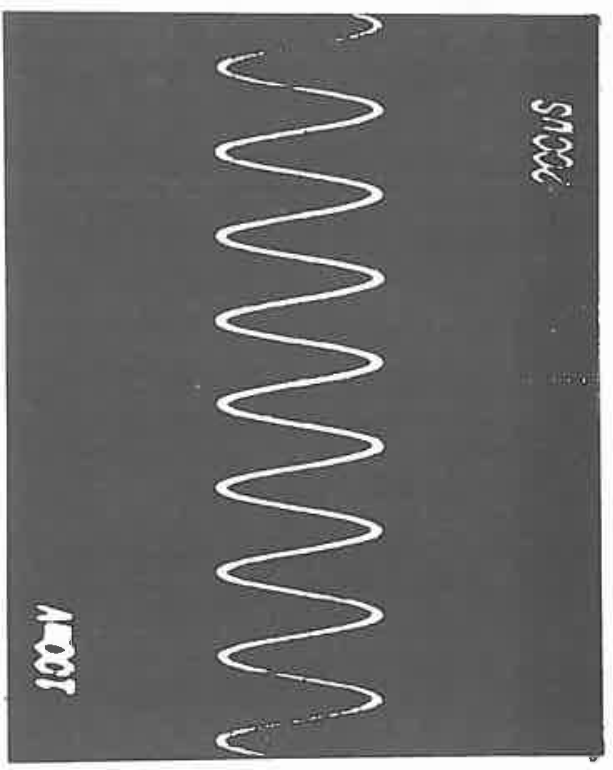

3
नें

$\because$ n

它过

文 응 त्न 늘 하 गै न्न $+\rightarrow$ on

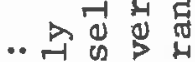
का नु का

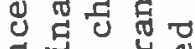
击 일 맹니 出 1) 纯出

(1)엉

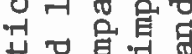
की व्न त्र 㟧 号

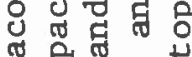
苜心 号的䔁 马 뭉융

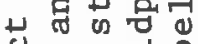
莳的可 员

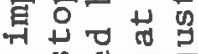
$\pi$ क य

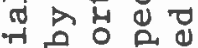
+ 只只 प्ति - 4 is of 낭 -10

.. 뭉 멈

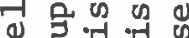

की की ट्टु न्ट है of $\cdots \cdots$

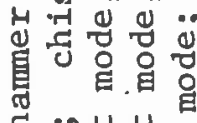
工 $\infty$ U 矛苛

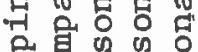
口. त् \& क क 간 हु 出 क

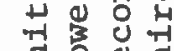
ナ占号品

ته ن 总 


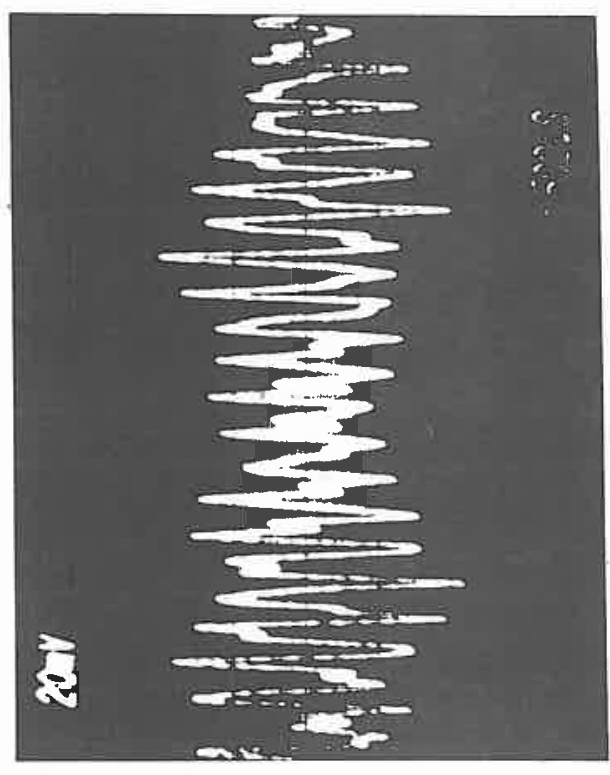

范

D્

空

을

24]

$+$

ब

壱

.. ลิ

ii

0

出

넉 국

ㄷㅇ잉

年

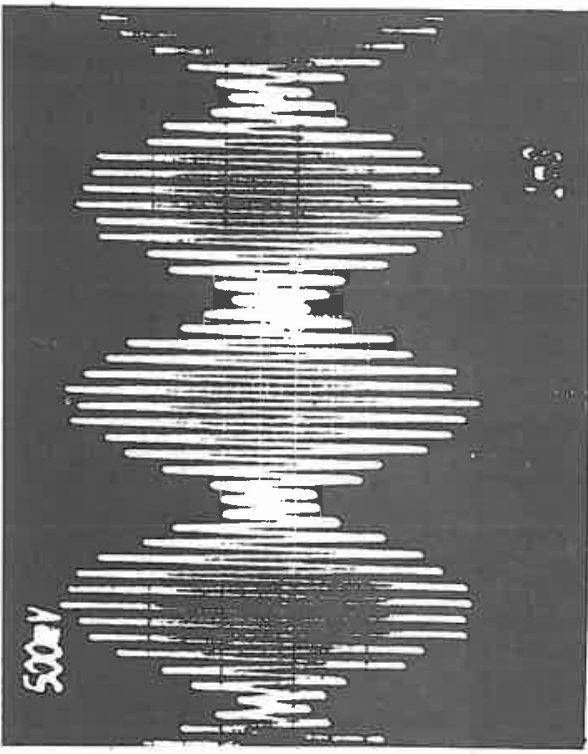

莤

焉。品

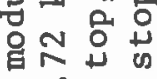

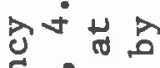

ज形

축웜

कू

出 लํํㅇ

¿ 导

-1

os $\rightarrow$

न तु ठี

टु क्त

- 仓े

狊苞落

बृ ब

工出置

品

哭焉

羿最山

डิ

응

के

근

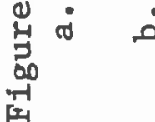




\title{
OCCUPATIONAL VIBRATION IN THE FOUNDRY
}

\author{
Donald E. Wasserman \\ Chief, Bioacoustics Section \\ Physical Agents Effects Branch \\ National Institute for Occupational \\ Safety and Health \\ Cincinnati, Ohio
}

\section{ABSTRACT}

Occupational exposure of workers to vibration in foundries is discussed, including hand-arm vibration during chipping and grinding and whole-body vibration in the mold shakeout areas. The use of various vibration transducers, measuring techniques, and methods of data analysis are briefly presented with practical examples cited. An interim work practices guide is suggested for workers*exposed to whole-body and hand-arm vibration.

\section{INTRODUCTION}

In the early 1970 's NIOSH was asked to help determine the health and safety effects of occupational vibration on workers. Before embarking on actual field, laboratory, and epidemiology studies it was necessary to first attempt to define the worker populations exposed to occupational vibration (1). In 1971, we conducted an extensive series of walkthrough plant and worksite tours. The results of these tours, together with population extrapolations using Department of Labor job statistics, indicate that some 8 million workers in the U.S. are exposed to occupational vibration. Of this number, some 6.8 million are exposed to "whole-body vibration" (head-totoe vibration as one might experience from a vehicle or plant floor); and the remaining 1.2 million are exposed to "hand-arm" or segmental vibration (as one might experience from a vibrating hand tool such as a chain saw, chipping hammer, or grinder) (2).

Three of the plant worksites toured in 1971 were foundries. A summary of our observations made at that time is as follows:

Two foundries manufactured large castings, the third manufactured smaller castings in volumes of 60 to 70 per hour. In all cases severe whole-body, segmental, and intermittent vibrations were observed. In particular, intermittent, whole-body vibration appeared during the mold shakeout operation where the special sand and other material surrounding the castings were removed. Workers were closely coupled to the vibration source in this operation. Acceleration levels appeared high. Segmental vibration was observed in the hand tamping, casting, and 
chipping operations. Workers in these operations were closely coupled to their hand tools. Finally, vibration was observed in the overhead cranes. Noise levels were high, but workers wore hearing protection

The 1971 job statistics indicated there were some 487,400 foundry workers at that time and we estimated that $40 \%$ of these workers (about 194,000) were exposed to occupational vibrations (3). The job categories included chippers and grinders, mold shakeout workers, workers operating overhead cranes, and lift-truck operators. Thus, there appears to be reasonable cause to conduct occupational vibration research in the foundry industry in conjunction with other industries in an effort to determine the health and safety consequences to foundry workers of occupational exposure to vibration.

The purpose of this paper is to familiarize and up-date the reader with NIOSH vibration activities related to foundries. This includes briefly describing measurement methods employed in foundry studies and suggesting a work practices guide.

\section{WHOLE-BODY VIBRATION}

Whole-body vibration is referred to as a generalized stressor which appears to affect multiple body sites and organs, depending on the vibration characteristics. The human body has a tendency to "resonate", that is, to act in concert with externally generated vibration and to actually amplify the vibration of certain frequencies and reject other frequencies. For example, the entire body tends to resonate at about $5 \mathrm{~Hz}$ and the head and shoulders can resonate in the 20 to $30 \mathrm{~Hz}$ range. The eyeballs can resonate in the 60 to $90 \mathrm{~Hz}$ range. The hand-arm system can resonate in the 100 to $150 \mathrm{~Hz}$ range. In general, the larger the system mass the lower the resonant frequency.

Little is known about the chronic effects of whole-body vibration on man. However, human studies have indicated such subtle effects as the inability to maintain posture, increased oxygen consumption, and increased pulmonary ventilation due to vibration exposure $(4,5,6,7)$. However, in the human performance area, with its possible safety implications, studies of vibration have shown that the lowest subjective-discomfort-tolerance level occurs around the $5 \mathrm{~Hz}$ resonant point. Manual tracking capability is also most seriously affected at this $5 \mathrm{~Hz}$ point. Visual acuity is severely impaired in the 1 to $25 \mathrm{~Hz}$ range.

On the other hand, performance of tasks such as those involving pattern recognition, reaction time, and monitoring appears not to be affected by exposure to vibration $(8,9)$. Simulated heavy equipment driving tests which compared the effects of a mixture of simultaneous vibratory frequencies (similar to actual occupational vibration) revealed that human subjects performed worse under the mixed conditions, gradually improving as the mixture was replaced by nonresonant single sinusoidal vibratory conditions $(10)$. 
Hand-arm or segmental vibration, unlike whole-body vibration, appears as a localized stressor creating injury to the fingers and hands of exposed workers using such vibratory hand tools as chain saws, and pineumatic and electrically operated rotary grinders. Extensive use of such tools (especially. in cold environments) has led to Raynaud's Phenomenon, i.e., "dead hand" or "vibration white fingers (VWF)". This condition is characterized by numbness and blanching of the fingers with probable loss of muscle control and reduction of sensitivity to heat, cold and pain (11). Medically, the occurrence of Raynaud's Disease (as distinguished from Raynaud's Phenomenon) in the normal population is about 6-8\% and is not necessarily associated with use of vibrating hand tools (12).

\section{INIOSH WHOLE-BODY VIBRATION FIELD STUDIES}

Past NIOSH whole-body vibration epidemiology and field studies have concentrated principally in the area of vehicular transportation (13, 14, $15,16)$. We have developed unique capabilities to measure vibration and other physiological and environmental factors which affect the worker in moving vehicles as well as in stationary situations such as plant environments. These studies have been concentrated in the area of heavy equipment operation $(17,18)$. To date we have not conducted a whole-body engineering study in a foundry situation.

Vibration is a vector quantity possessing both a magnitude and a direction and must be carefully measured. There are three quantities of interest in the quantification of vibration:

1. Displacement, the distance between the normal resting position of an object and its position at a given time in its vibratory cycle.

2. Velocity, the time rate of change of displacement.

3. Acceleration, the time rate of change of velocity.

Acceleration has been the most frequently used measure of vibratory magnitude because of readily available transducers and because both vibration velocity and displacement can be easily derived from this single measure with electronic integration. Acceleration is measured in gravitational ( $g$ ) units, expressed also in meters $/ \mathrm{second}^{2}$, where $1 \mathrm{~g}=9.8 \mathrm{~m} / \mathrm{sec}^{2}$.

Generally, in whole-body vibration measurements it is necessary to measure low Erequencies $(0$ to $100 \mathrm{~Hz}$ ) at low to moderate accelerations $(<10 \mathrm{~g})$, thus only lightweight piezoresistive or strain gauge type accelerometers should be used. These accelerometsrs are used singly or in multiples of three, mounted on a metal block, each mutually perpendicular to each other in three axes depending on the vibration source and direction. 
Measurement of jibration impinging on a person is not straightforward since vibration reaching a person is highly dependent on how the person is coupled to the vibrating source(s). Knowledge of such variables as grip strength, grip orientation, mechanical filtering, and characteristics of clothing are crucial elements. Accelerometers should not be mounted onto fleshy body parts, but rather should be fastened on the skin adjacent to external body bones using a stiff carpet tape.

Vibration measurements in themselves are insufficient to determine potential hazard and risk. These data must be tape recorded on an FM instrumentation tape system for later computer analysis. This analysis usually results in the form of a Fourier spectrum, which, simply stated, means that each vibration measurement has a characteristic "finger print" or spectrum. This spectrum indicates each and every frequency element composing the original composite vibration measurement and how much of each frequency element is present. From a knowledge of human response and resonance characteristics, exposure time and conditions, coupling elements, and spectrum, risk determination is attempted.

\section{NIOSH HAND-ARM VIBRATION FIELD STUDIES}

NIOSH hand-arm vibration field studies have concentrated on foundry chippers and grinders and miners who use the so called "jack-leg" drill. Studies in other countries have been conducted principally on chain saw operators where high prevalences of Raynaud.'s Phenomenon were discovered (11, 12). Eventually these studies resulted in the design of new "antivibration" chain saws which subsequently reduced the prevalence of the white finger problem. Little is known of the effects of pneumatic tools on workers. Thus, in 1975, the NIOSH International Conference on Hand-Arm Vibration emphasized the urgent need to:

1. Determine the effects of pneumatic tool exposure.

2. To minimize this exposure.

Before we performed these field studies it was necessary to:

1. Assemble a ten person international team of engineers, physicians, epidemiologists, physiologists, biostatisticians, and technicians who collectively represented many years of vibration study experience.

2. Develop a comprehensive, unique, and multidisciplined study protocol which consisted of: medical and physiological testing of workers; an epidemiological examination of their health records; an intensive work history record of their past vibrating tool exposure; and engineering assessment of the vibration parameters appearing on the vibratory tools measured under actual working conditions.

3. Develop and evaluate under laboratory conditions a series of specialized diagnostic tests suitable for field study usage $(19,20,21)$.

A field study was subsequently conducted on some 400 chippers and grinders along with other workers not exposed to vibrations in two large foundries and a shipyard. This was followed by a second study of 134 uranium miners. 
The study reports are now being prepared for publication. A preliminary examination of the study data on chippers and grinders indicated a Raynaud Pehnomenon (VWF) problem in the populations studied, refuting the claims of Pecora (22) that VWF did not exist in the United States.

Vibration measurements on hand-tools have proven to be extremely difficult and costly due to the tools' very high acceleration levels. The result has been a destruction of the crystal accelerometers used for measurements, especially at the chisel end of the chipping hammer where the worker's guide is placed (11). Our upcoming study report will elucidate this problem.

INTERIM VIBRATION WORK PRACTICES

Whole-Body Vibration: There is little epidemiological, medical, and engineering information available which defines safe and healthful operating levels. The exposure of workers to whole-body vibration should be minimized by :

1. Limiting the time spent on a vibrating surface to no more than is absolutely necessary to safely perform the job.

2. Having machine controls moved, wherever possible, off of the vibrating surface.

3. Mechanically isolating the vibrating source and/or the surface where the workers are stationed in order to reduce the exposure.

4. Carefully maintaining vibrating machinery to prevent excess vibration from developing.

I:=nd-Arm Vibration: Nearly all vibrating hand tools, including pneumatic and electrical tools, with the exception of some chain saws, present a potential hazard to workers using them. There is little epidemiological, medical, and engineering data available which defines and clarifies safe and healthful operating levels of vibratory hand tools for workers. Until the needed information becomes available, occupational physicians, industrial hygienists, management, labor, and workers are all confronted with the consequences of exposure to vibrating hand-tools. A work practice guide such as the one presented below is, therefore, suggested.

SUGGESTED WORK PRACTICES FOR WORKERS USING VIBRATING HAND TOOLS

1. Any worker who may encounter exposure of the hands to vibratory hand tools should, prior to employment, be physically examined and questioned as to:

a. Signs and symptoms of Raynaud's Disease or Raynaud's Phenomenon.

b. Detailed history of previous vibration exposure. These previous vibration exposure data should be recorded. Based upon present medical evidence, it is not advisable to allow workers with Raynaud's Disease or phenomenon to use vibratory hand tools. 
2. Vibratory hand tools should be carefully maintained according to manufacturers' recommendations.

3. Workers are advised to:

a. Wear gloves at all times when using vibrating hand tools.

b. Wear adequate clothing to keep body core temperature at a stable and normal level.

c. Warm the hands before starting the job and keep them warm during the job.

d. Not allow the hands to become wet and chilled. Should this happen, they should dry and warm the hands and insert them into a pair of dry warm gloves, This may require more than a single pair of gloves on the job.

e. Reduce smoking while using the vibratory hand tool since nicotine acts as a vasoconstrictor reducing the blood supply to the hands and fingers.

f. Let the tool do the work, grasping it as lightly as possible consistent with safe work practices and tool control, with the tool resting on the workpiece or support as much as possible.

g. Use the tool only when absolutely necessary.

h. See a physician promptly should signs of tingling, numbness, white or blue fingers occur.

4. It is known that the hazard of vibration white fingers (VWF) is reduced if continuous vibration exposures over long periods are avoided. Therefore, work schedules with rest breaks are recommended. 
1. Wasserman, D. E., and D. E. Badger, "The NIOSH Plan for Developing Industrial Vibration Exposure Criteria", J. of Safety Research, Vol. 4, No. 4 , pp. 146-154, December 1972.

2. Wasserman, D. E., D. W. Badger, T. E. Doyle, and L. Margolies, "Industrial Vibration - An Overview", ASSE Journal, Vol. 19, No. 6, pp. 38-43, 1974.

3. Employment and Earnings, Vol. 18, No. 3, Department of Labor, September 1971.

4. Duffner, L. R., L. H. Hamilton, and M. A. Schmitz, "Effect of Whole-Body Vertical Vibration on Respiration in Human Subjects", J. Appl. Physiol., Vol. 17, pp. 913, 1962 .

5. Ernsting, J., "Respiratory Effects of Whole-Body Vibration", Report No. 179, Royal Air Force, Institute of Aviation Medicine, Farnborough, England, 1961.

6. Hood, W. B., R. H., Murray, C. W. Urschel, J. A. Bowers, and J. G. Clark "Cardiopulmonary Effects of Whole-Body Vibration on Man", J. Appl. Physiol., Vol. 21, pp. 1725, 1966.

7. Guignard, J. C., and P. F. King, "Aeromedical Aspects of Vibration and Noise", AGARD-AG-151, Novembex 1972.

8. Grether, W. F., "Vibration and Human Performance", Human Factors, Vol. 13, pp. 203, 1971 .

9. Shoenberger, R. W., "Human Response to Whole-Body Vibration", Percept. Motiv. Skills, (Meno. Suppl. 1) Vol. 34, pp. 127, 1972.

10. Cohen, H. H., D. E. Wasserman, R. Hornung, "Human Performance and Transmissibility under Sinusoidal and Mixed Vertical Vibration", Ergonomics, Vol. 20, No. 3, pp. 207-216, 1977.

11. Wasserman, D. E., W. Taylor, and M. Curry (Editors), "Proceedings of the International Occupational Hand-Arm Conference", DHEW/NIOSH Publ. No. 77-170, April 1977.

12. Taylor, W., "The Vibration Syndrome", Academic Press, London, 1974.

13. Milby, T. M., and R. C. Spear, "Relationship Between Whole-Body Vibration and Morbidity Patterns Among Heavy Equipment Operators", DHEW/NIOSH Publ. No. 74-131, 1974.

14. Spear, R. C., C. Keller, V. Behrens, M. Hudes, and D. Tarter, "Moribidity Patterns Among Heavy Equipment Operators Exposed to Whole-Body Vibration", DHEW/NIOSH Publ. No. 77-120, 1977. 
15. Gruber, G. J., and H. H., Zipperman, "Relationship Between Whole-Body Vibration and Morbidity Patterns Among Motor Coach Operators", DHEW/NIOSH Publ. No. 75-104, 1975.

16. Gruber, G. J., "Relationship Between Whole-Body Vibration and Morbidity Patterns Among Interstate Truck Drivers", DHEW/NIOSH Publ. No. 77-167, 1977.

17. Wasserman, D. E., T. E., Doyle, and W. C. Asburry, and T. E. Doyle, "Whole-Body Vibration Exposure of Workers during Heavy Equipment Operation", DHEW/NIOSH Publ. No. 78-153, 1978.

18. Wasserman, D. E., W. C. Asburry, and T. E. Doyle, "Whole-Body Vibration of Heavy Equipment Operators", Shock and Vibration Bulletin, Part 2, No. $49, \mathrm{pp} .47-68,1979$.

19. Carlson, W., S. Samueloff, W. Taylor, and D. E. Wasserman, "Instrumentation for Measurement of Sensory Loss in the Fingertips", J. Occ. Med., Vol. 21, No. 4, pp. 260-264, 1979.

20. Wasserman, D. E., W. Carlson, S. Samueloff, W. Asburry and T. E. Doyle, "A Versatile Simultaneous Photocell Plethysmography System for Use in Clinical and Occupational Medicine", J. Med. Instr., Vol. 13, No. 4, pp. 232-234, 1979 .

21. Samueloff, S., R. Miday, D. E. Wasserman, D. W. Badger, T. E. Doyle, W. Asburry, and F. Dukes-Dobos, "Peripheral Vascular Insufficiency Test by Photocell Plethysmography", (In Press).

22. Pecora, L. J., "Survey of Current Status of Raynaud's Phenomenon of Occupational Origin", J. Am. Ind. Hygiene Assoc., Vol. 21, pp. 80, 1960. 
PERCUSSIVE TOOL NOISE AND VIBRATION CONTROL

\author{
Edward I. Auerbach \\ Manager, Acoustics and Vibration \\ Ingersol-Rand Company \\ Easton, Pennsylvania
}

\title{
ABSTRACT
}

Investigations are now being conducted to quiet the noise and reduce the amount of hand-arm vibration produced by chipping hamners.

Chipping hamrer noise comes from four sources: workpiece, chisel and housing excitation and air exhaust pulsations. Reduction of workpiece noise has proven difficult, expensive, and detrimental to productivity. Both external and internal damping methods can reduce noise from chisels; external darners, however, are vulnerable to damage. Air exhaust noises can be reduced by mufflers. Reduction of housing noises involves adding a barrier-type material to the outer surfaces of the housing or isolating the inner barrel from the outer housing.

Chipping hammer vibration results from resonances in the structure of the chipper, from recoil, and from chisel rebound. Recoil may be reduced by isolating the barrel from the handle or through an air reservoir technique. Vibration isolators have been under study for some time, but there has been difficulty in incorporating isolation in a tool suitable for production. Methods of chisel vibration reduction include damping the chisel or putting an isolating sleeve between the chisel and the hand which guides it.

Even with the above measures of noise and vibration reduction, levels will still be above those of other metal removal tools. Casting production changes to permit the use of quieter tools and automation of finishing operations are future ideas for solving the problem. For the present, investigations will continue into producing quieter, lower vibration, and more productive chipping hammers.

PERCUSSIVE TOOL NOISE AND VIBRATION CONTROL

INTRODUCTION

Chipping hammers have been used in foundry cleaning operations for many years. These tools often remove metal faster and easier than other types of hand-held power tools such as grinders. In the past, high sound and vibration levels have been tolerated as the price paid for higher productivity. Recent government noise regulations and studies of hand-arm vibration have led to 
new interest in quieting and reducing vibration of this tool. Investigations now being conducted will lead to a new generation of quieter, lower vibration chipping hammers that can be used until alternative nethods are developed.

The basic design of pneumatic chipping hammers has not changed since the turn of the century. A cross-section of a chipper is shown in Figure 1. A free running piston is driven in a cylinder by air pressure. At the end of its power stroke, the piston impacts a chisel imparting its kinetic energy to the chisel to do work. In its return stroke, the piston is kept from hitting the top of the cylinder by a cushion of trapped air. The flow of air into the cylinder is controlled by an air pressure activated valve, thereby controlling the operating cycle duration.

\section{CHIPPER NOISE}

Experimental investigations of sounds from chipping hammers have determined four main sources of noise. These are listed below in order of importance to the overall sound level:
a. Workpiece noise.
b. Chisel or steel noise.
c. Air exhaust noise.
d. Case or housing radiated noise.

Noise Evaluation Methods

Before considering individual chipper noise sources, the method of evaluating each of the pneumatic tool noises will be described. Sound was measured according to ANSI S5.1-1971. This test standard calls for measurement at five microphone locations one meter from the tool, as shown in Figure 2 . The five A-weighted pressure sound levels are logarithmically averaged to yield a single descriptive sound pressure level. The measurement room should have absorbant walls and ceiling and be large enough so that a $6 \mathrm{~dB}$ drop can be obtained at distances of two meters or greater from the tool. The floor must be reflective; i.e., made of concrete.

Each of the tool noise sources was evaluated by muffling or eliminating the other sources when measurements were taken. For example, chisel noise was evaluated with the chisel impacting on a steel I-beam totally immersed in sand to eliminate workpiece noise. The air exhaust was piped out of the room and the housing was covered with polyurethane lead septum foam to eliminate those two sources.

Workpiece Noise

The impact of the chisel on the undamped casting excites the workpiece to vibrate at its natural frequency. Airborne sound radiates from the surface of the casting to the operator's ear. The sound level of this ringing can often exceed $120 \mathrm{dBA}$. The actual sound level depends on the size, damping, and shape of the radiating surface. Reduction of this noise source has 


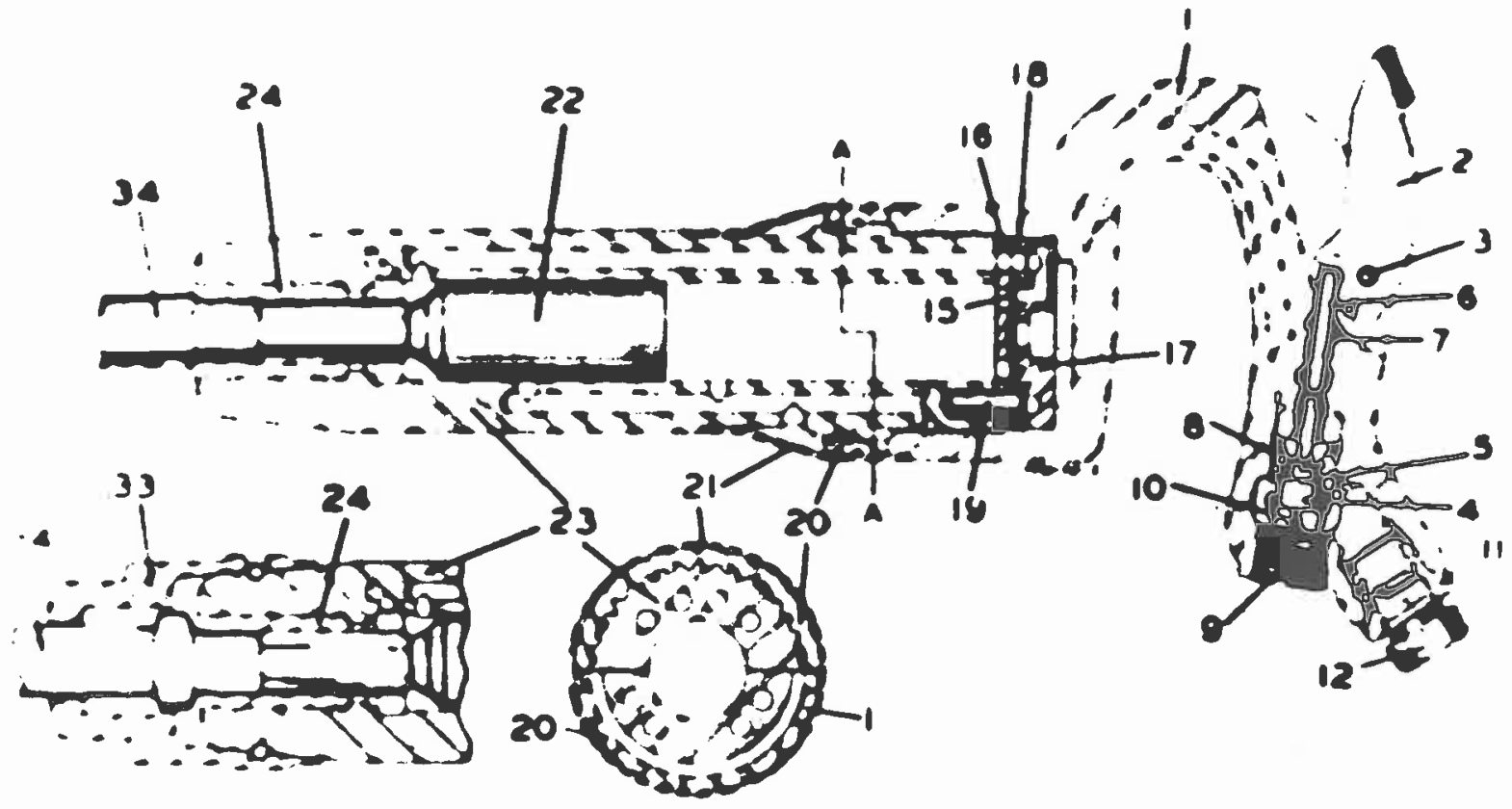

Figure 1. Cross section of typical chipping hammer.

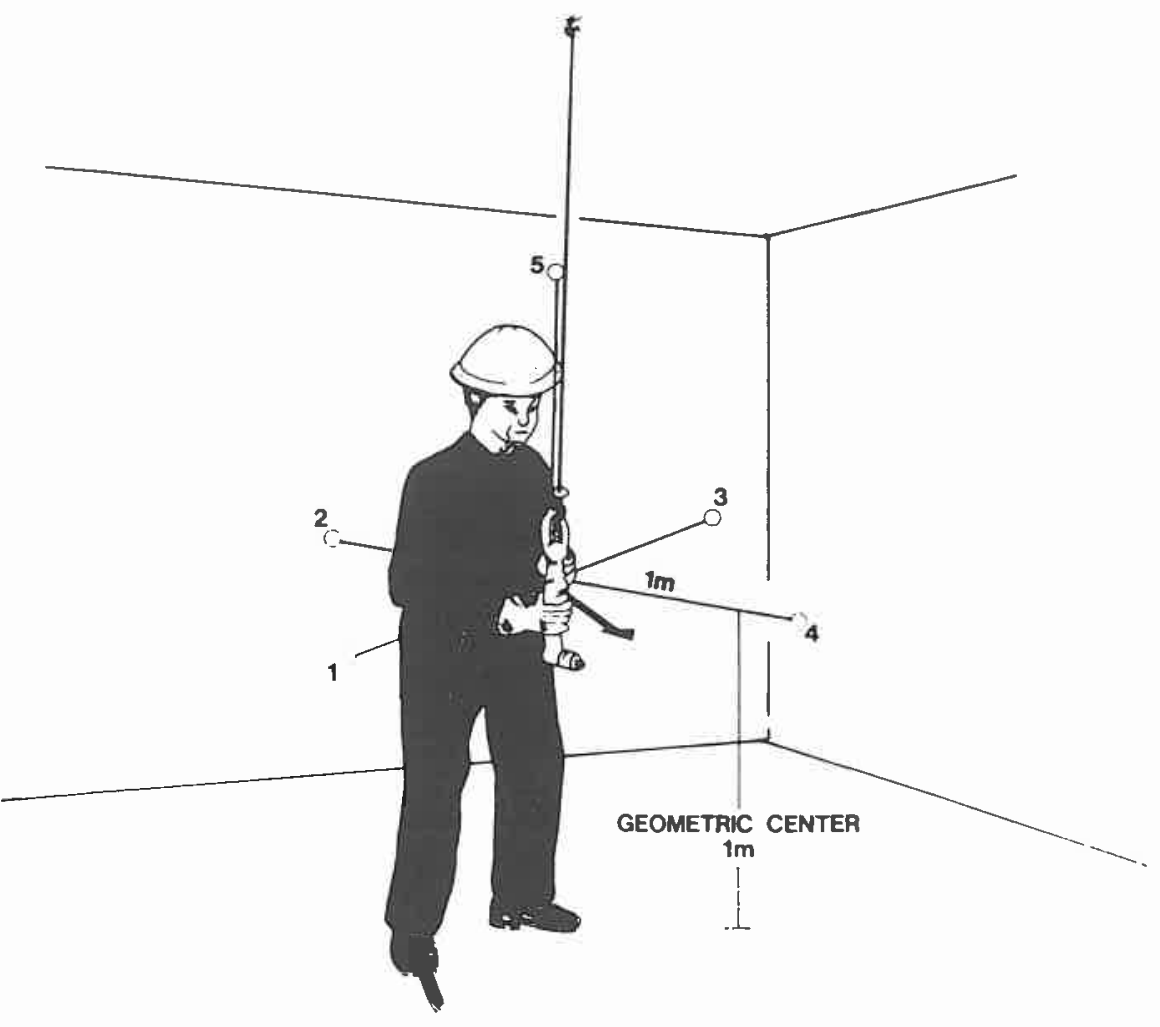

BOTARY AIRMACHINE RUNYING FREE

Figure 2. ANSI S5.1-1971 microphone positions. 
proven difficult, expensive, and detrimental to productivity. The major noise control method is to add damping to the casting. This involves immersing the casting in a damping media such as water or sand. Immersion can be a rather arduous procedure with large castings, especially in high volume operations. Small castings are usually rotated in many directions during cleaning operations. Each time the casting is rotated, it has to be immersed again. Therefore, cleaning time is increased. Other noise control methods, such as covering the workpiece with a low transmitting blanket, cannot be used effectively in many cases due to the complicated contours and sizes of castings.

When workpiece noise is high, the other noise sources have little effect on the overall sound level. However, if the workpiece noise is sufficiently damped, the other chipper noise sources become prominent.

Chisel Noise

The chisel may be considered a cantilever-hinged beam. When the chisel is struck by the piston, both longitudinal and flexural modes of vibration are induced. Short $10-30 \mathrm{~cm}$ (4-12 inch) chisels are used in most foundry operations. These chisels have relatively high natural frequencies. In many cases, the longitudinal model frequencies are above the audible range. In addition, longitudinal modes are poor sound radiators. Therefore, the audible chisel ring is due mainly to flexural vibrations. It has been observed that chisels with large exposed areas (longer chisels) yield higher sound levels than shorter chisels. Long chisel ring can generate sound levels as high as 110 $\mathrm{dBA}$ while shorter $10 \mathrm{~cm}$ (4 inch) chisels generate sound levels as low as $100 \mathrm{dBA}$.

The most frequently used method of reducing chisel noise is to add external damping to the chisels. Most of the dampers consist of a layer of rubber between the chisel and a protective outer shell as shown in Figure 3 . External dampers such as this are vulnerable to the heavy abuse of a typical foundry operation. In addition, high temperature will lead to rapid deterioration of the rubber layer.

A second method of damping chisels is to use internal damping. Ingersoll-Rand utilizes a Lanchester damper, otherwise known as an unturned dynamic absorber in its patented "muted chisel", as shown in Figure 4. A mass suspended by a viscous fluid or by air is free to move in a bore within the chisel. The inertia of the mass puts a force on the chisel that is out of phase with the vibratory forces. This damps out chisel ring and reduces chisel noise. The muted chisel reduces chisel noise by 10 dBA from that of a conventional chisel of the same size.

Air Exhaust Noise

Exhaust noise of chippers is caused mainly by the pressure pulses released to the atmosphere each time an exhaust port is opened. This noise consists of a series of discrete tones that are of. "firing" frequency and its harmonics. 


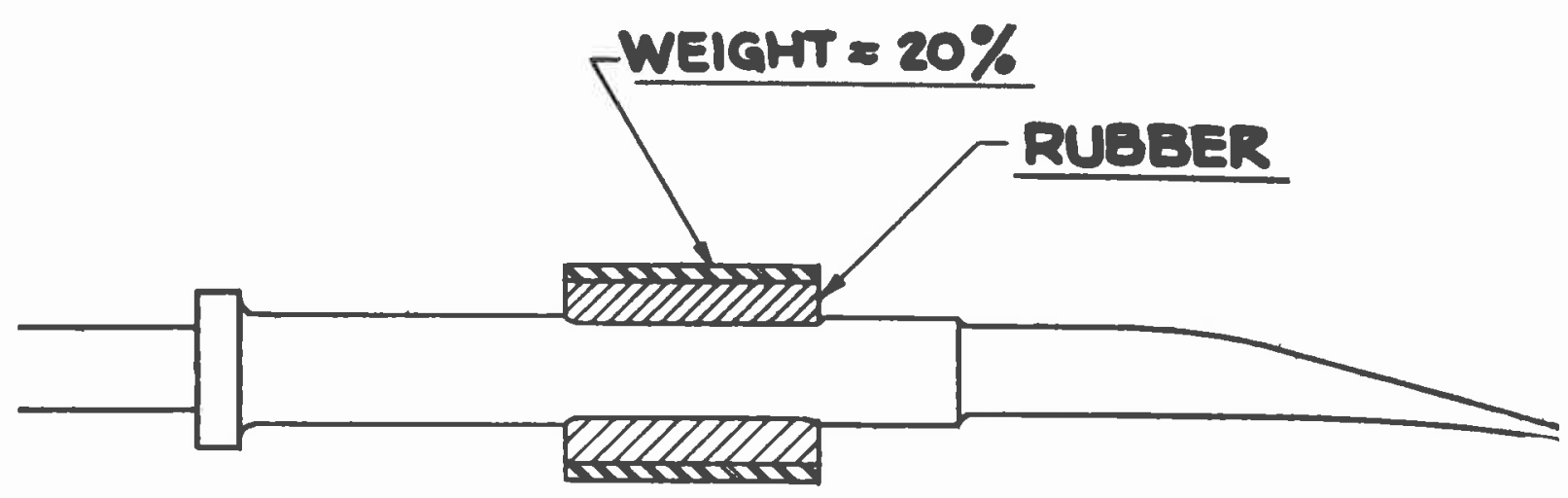

\section{EXTERNAL DAMPING (PATENT No. 3856107)}

Figure 3. Chisel with external vibration damper.

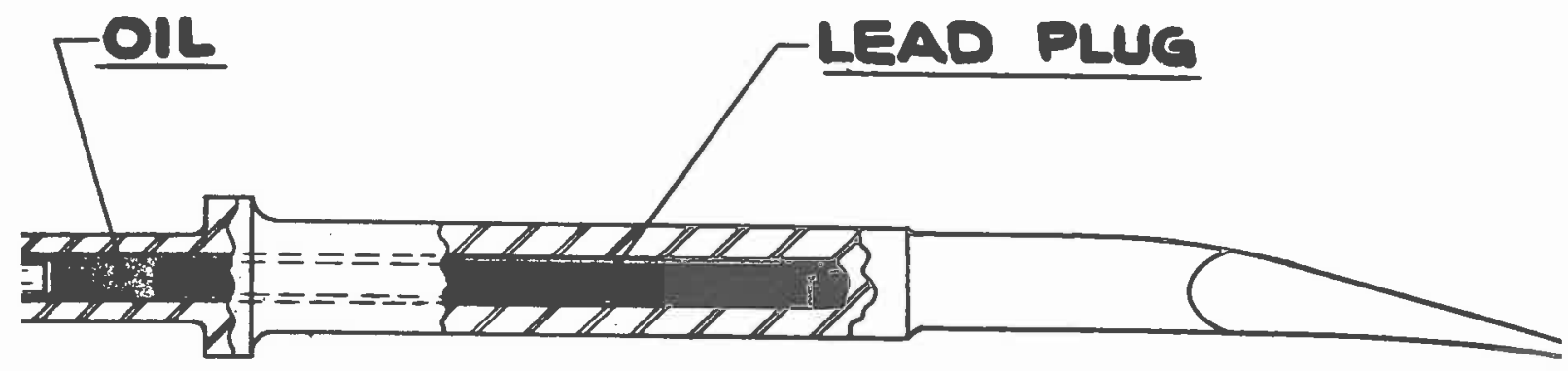

\section{INTERNAL DAMPING （I-R PATENT NO 3861494）}

Figure 4. Cross-section of "muted" chisel. 
The fundamental tonal frequency is generally below $42 \mathrm{~Hz}$ because most large chippers operate at 2500 blows per minute or less. Since A-weighting gives more emphasis to high frequencies, the effect of exhaust noise on the total A-weighted sound level is smaller than that of the outer high frequency noise sources. However, the large frequency spread between low frequency exhaust noise and the other high frequency noise sources makes the exhaust noise easily distinguishable. Subjectively, the chipper sounds quieter if the air exhaust is muffled. Air exhaust noise ranges from $95 \mathrm{dBA}$ to $105 \mathrm{dBA}$ and muffling can reduce this noise by 5 to $10 \mathrm{dBA}$, as indicated in Figure 5 . However, when the other chipper noise sources are present, muffling only reduces the total noise by 1 to $2 \mathrm{dBA}$.

Case or Housing Radiated Noise

When noise from the previously described sources is sufficiently reduced, case radiated noise must be considered before the sound level can be reduced further. Sounds generated internally by impacts of the piston on the chisel are transmitted through the housing and radiated to the atmosphere. In addition, the housing is also excited at its natural frequency and radiates sound. The sound level of this noise ranges from $95 \mathrm{dBA}$ to $100 \mathrm{dBA}$. Reducing this noise involves adding a barrier-type material to the outer surfaces of the housing or isolating the inner barrel from the outer housing.

In a foundry operation with the tool working on a damped workpiece, the sound level was reduced from $115 \mathrm{dBA}$ to $110 \mathrm{dBA}$ with the noise reduction methods described; i.e., exhaust air noise piped away, muted chisel, nonresonant workpiece, and non-transmittal case sheath; while in a paper box stripping operation, the chipping sound level was reduced from 105 dBA to $90 \mathrm{dBA}$. The lower levels in paper box stripping were due to the total lack of workpiece noise and the added damping effect of the paper on the chisel.

\section{CHIPPER VIBRATION}

Chipping hammer vibration has been found to be caused by resonances in the structure of the chipper, from recoil, and from chisel rebound. Recoil and rebound create vibrations along the axis of the tool that are transmitted through the throttle handle to the hand. In many cases, the operator holds the throttle handle with one hand while steadying and grinding the chisel with the other. This grinding hand is subjected to the flexural vibrations of the chisel. Investigations have shown that most cases of vibration-induced white finger (VWF) occur on the hand grinding the chisel, while problems further up the hand-arm system occur from holding the throttle handle; i.e., chipper's elbow.

Vibration Measurement Problems

There are problems involved with evaluating chipping hammer vibration. Most general purpose accelerometers have natural frequencies around $25 \mathrm{k} \mathrm{Hz}$. The impacting associated with chipper operation generates vibration with frequencies that can exceed $30 \mathrm{k} \mathrm{Hz}$. Therefore, the forced vibration at the accelerometer's natural frequency puts high loadings on the delicate 


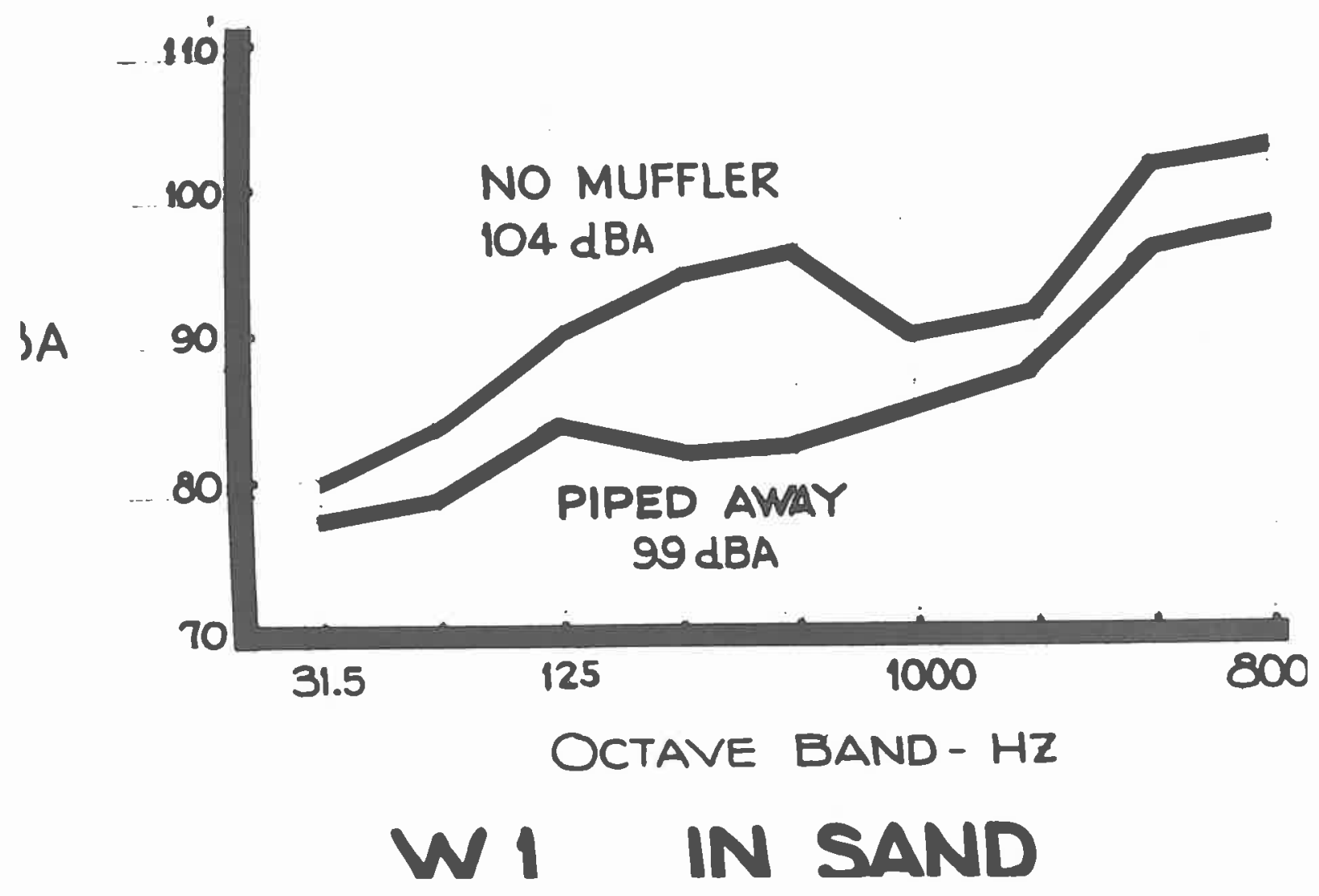

Figure 5. Sound spectra of chipping hammer with and without muffler.

internal parts of the transducer. This can lead to erroneous data and destruction of the accelerometer.

The European Committee of Manufacturers of Compressors, Vacuum Pumps, and Fneumatic Tools (PNEUROP) has been investigating the use of low pass mechanical filters between the chipper and the accelerometer to allow the use of general purpose accelerometers in chipper vibration measurement. The mechanical filter consists of a piece of rubber sandwiched between the steel mounting plates. The filter allows the useful data in the $0-1000$ $\mathrm{Hz}$ range to be measured while filtering out the high frequencies that could damage the accelerometer.

An alternative method is to use a shock accelerometer that has a high natural frequency above $60 \mathrm{k} \mathrm{Hz}$ and, sometimes, internal damping. The shock accelerometer works well when mounted solidly to the throttle handle. However, it has been demonstrated by Reynolds that even shock accelerometers cannot withstand high frequency vibrations when mounted solidly to the chisel. Therefore, a fixture for holding the accelerometer has been developed to measure chisel vibration. The fixture is held in contact with the chisel by the operator's hand, as shown in Figure 6 . This setup yields an accurate measure of the vibrational energy transfer from the chisel to the hand and provides protection for the transducer. 


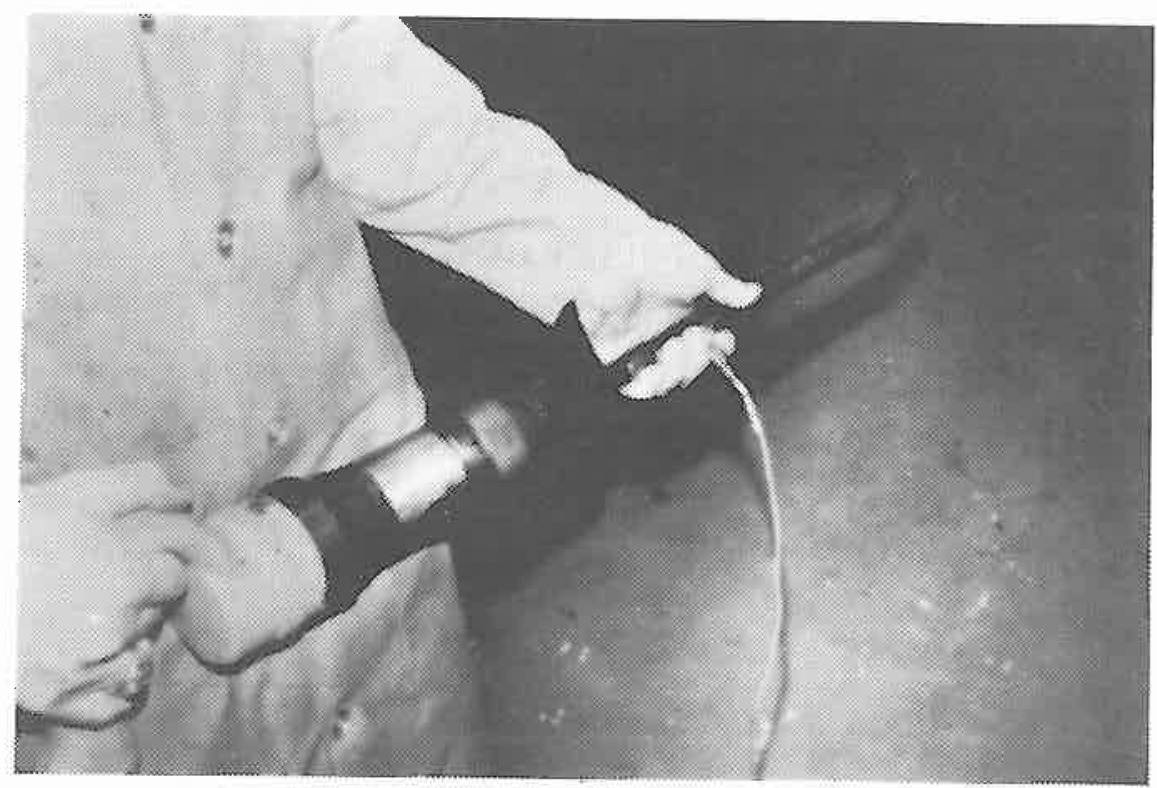

Figure 6. Measuring chisel vibration with a shock accelerometer in fixture.

\section{Recoil Vibration}

Recoil is caused by the acceleration of the piston within the barrel. The accelerations change the pressure of the gas in the barrel imposing a force on the tool in the opposite direction to the accelerations. The recoil may be reduced by isolating the barrel from the handle or by having a large reservoir of air in communication with the air in the barrel, such that the pressure changes will be smaller.

\section{Vibration Isolators}

Isolators for use in chippers have been under study for some time. However, there has been difficulty in implementing this system in a production tool. The vibrational frequencies of interest are below $1000 \mathrm{~Hz}$. The natural frequency of the isolator system should be below $10 \mathrm{~Hz}$ for the isolator to be effective in protecting the hand-arm system. A chipper weighs less than twenty pounds; therefore, the isolator stiffness has to be less than $200 \mathrm{lb}$ /in for an isolator resonant frequency of $10 \mathrm{~Hz}$. At low spring rates, under certain working conditions, instability can be induced in the isolator system. Relatively large oscillating motions between the handle and the barrel make it difficult to control the chisel. Chisel control allows an experienced operator to produce a continuous chip which yields a high metal removal rate and a smooth finish. Therefore, instability leads to a reduction in productivity and degradation of surface finish. Adding damping to the isolator reduces the instability but also reduces the effectiveness of the isolator. An experimental tool with a damped rubber isolator is shown in Figure 7. This isolator was effective in reducing high frequency vibrations, but had little effect on low frequency vibrations. 


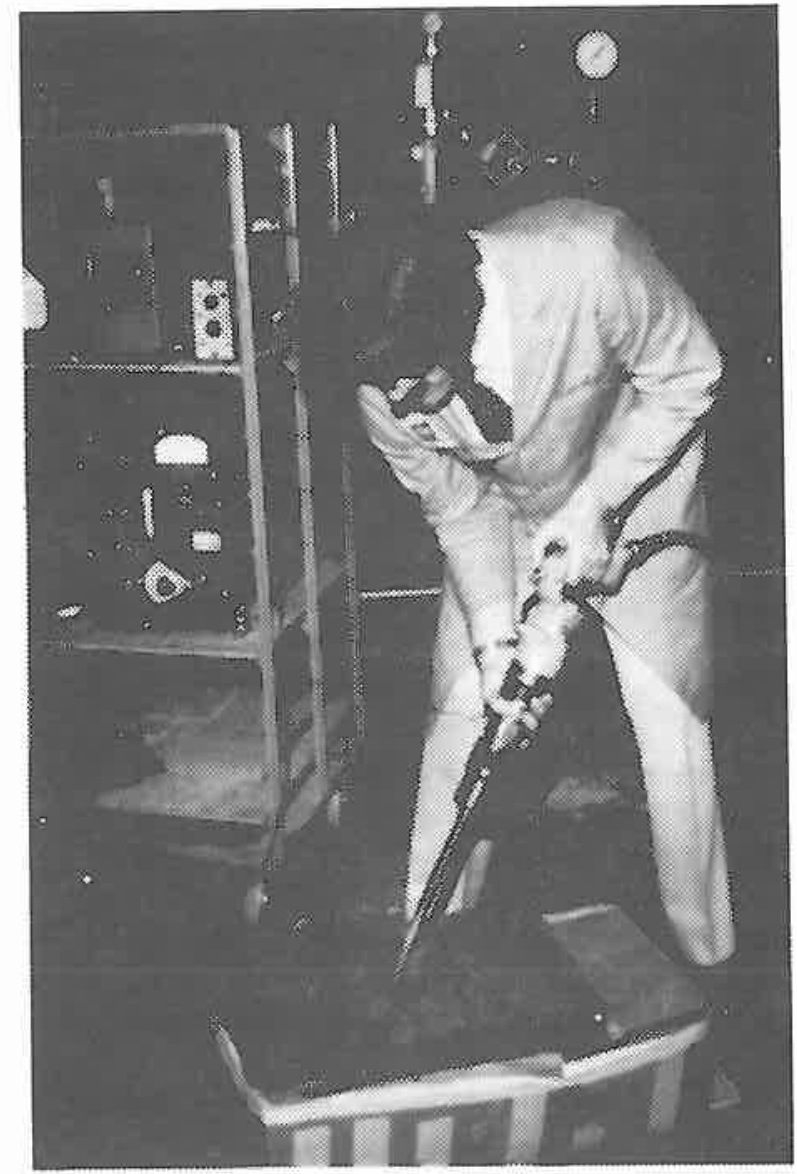

Figure 7. An experimental tool with a damped rubber isolator working in a non-resonant media.

Attempts have also been made to use a dynamic absorber to reduce axial vibrations. However, the limited space available for the secondary mass travel required the use of a secondary mass comparable to the mass of the tool itself to be effective. Doubling the weight of the chipper was, of course, unacceptable.

Some operators have observed a reduction in vibration when mass was added to the tool. This effect can be demonstrated by the equation below:

$$
X=\frac{F / K}{1-\frac{W^{2}}{K} M}
$$

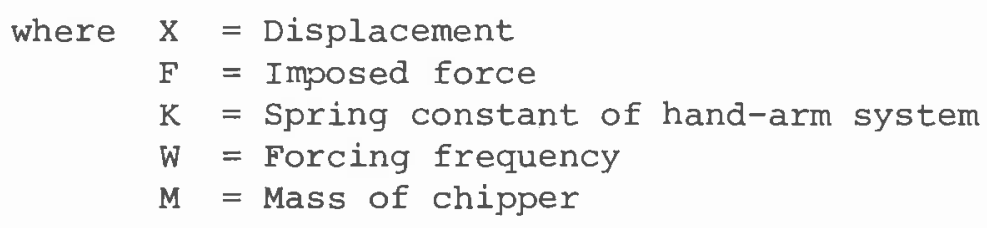


It can be seen that as the mass increases, the displacement decreases. In fact, a dynamic absorber acts as an increased equivalent mass. In both cases the added weight is unacceptable.

Rebound Vibration

Chisel rebound is common in foundry operations. The chipper bounces off the workpiece and impacts the front end of the chipper. This axial vibration can be reduced by isolating the barrel from the handle or by isolating the front end from the barrel. The problems associated with isolating the handle from the barrel have already been described. When isolating the front end of the chipper a performance problem is introduced. The small masses involved require an isolator with a low spring rate. When the operator bears down on the work, the front end will be moved rearward reducing the travel of the isolator and reducing the stroke and, therefore, the power of the chipper.

Methods of chisel vibration reduction include damping the chisel as described previously or by putting an isolating sleeve between the chisel and the hand. However, a sleeve adds width and length to the chisel and reduces what chipper operators call "feel". The muted chisel reduces vibration by the level of 6 to $10 \mathrm{~dB}$ in the frequencies of interest.

\section{ALTERNATIVES TO CHIPPING}

The methods of noise and vibration reduction described above are some of the latest being considered for chipping hammers. Even with the use of these measures, the sound and vibration levels will still be above those of other metal removal tools. Therefore, it may be necessary to seek alternative procedures in casting design to reduce exposure or to allow other types of metal removal tools to be used productively. These alternatives could include new designs of metal castings that would reduce amounts of flashing to be removed. Molds could be desiqned so that cleaning operations with quieter tools, such as grinders, could do the work instead of chippers. In addition, some cleaning room operations could be automated to remove the workers from the high noise and vibration regime. However, these techniques will take a long time to be initiated. In the short term, chippers will continue to be used for cleaning operations. Therefore, investigations into producing quieter, lower vibration and more productive chippers will continue. 


\section{BIBLIOGRAPHY}

1. Visnapuu, A. and Jensen, J., "Control of Pneumatic Chipping and Grinding Noise", Bureau of Mines, 1977.

2. Wilby, J., Kugler, B., and Wilby, E, "Occupational Noise and Noise Control in the steel Plate Fabricators Industry", BBN, Report 3700, 1978.

3. Reynolds, D, Unpublished Briefing on Hand-Arm Vibration, Presented at NIOSH Labs, Cincinnati, OH 1978.

4. Wasserman, D. (Ed.), "Proceedings of the International Occupational Hand-Arm Vibration Conference", DHEW (NIOSH), Publication No. 77-170.

5. Grego, T, "Sound Absorbing Device", U.S. Patent No. 3861494, 1975.

6. Koudelka, V., and Lada, M., "Pneumatic Impact Tool", U.S. Patent No. $3788404,1974$.

7. Atlas-Copco, "Silence Tool Bits", British Patent No. 1398693, 1975. 
ANNOUNCEMENT OF A NEW HEALTH STUDY ON NICKEL AND CHROMIUM EXPOSURE IN FOUNDRIES

\author{
William R. Dybvad, Corporate Director, Loss Control \\ The Duriron Co., Inc. \\ Dayton, Ohio
}

Gentlemen, I represent the Foundry Nickel Comittee (FNC), an ad hoc association of nickel and chromium-consuming foundries. FNC is developing scientific information to aid OSHA in setting reasonable, but safe regulations affecting foundrymen.

As you probably know, MIOSH has recommended to OSHA that both nickel and hexavalent chromium be controlled to very low airborne levels, and osHA is proceeding on a rulemaking path for both elements $(1,2)$. Good scientific and engineering data is needed as a basis for new standards; otherwise, the regulators will have to make their own guesses.

FNC has organized and funded a health study of nickel/chromium exposed foundrymen. Consultants from the University of Michigan School of Public Health are analyzing 1,000 death records submitted to FNC by 20 foundries. By comparing the data with suitable control groups, it is hoped to show whether there are adverse health effects from nickel or chromium exposures in the founciry industry.

Regarding foundry control technology, FilC is conducting an engineering study to predict the technical feasibility and costs for meeting the recommended OSHA nickel and chromium standards. The Environmental Research Center of Rexnord Inc., has been contracted to perform the work. The first task facing the study tean is to determine the effectiveness of today's ventilation techiliques in controlling worker exposures to nickel and chromium in foundries casting alloys. The recent NIOSH health hazard control technology assessment study documented the state-of-the-art of ventilation controls and the effectiveness with which this technology controls worker exposure (3). However, that study did not provide data on the effectiveness with which the state-of-the-art technology controls casting alloys with significant percentages of nickel and chromium. Thus, the study team is making this needed assessment through the use of information supplied by the foundries, as well as data to be gathered during field studies. The field studies will permit samples to be taken and analyzed for hexavalent chromium as well as for total nickel and chromium. very little information exists on exposure to hexavalent chromium in foundries. 
In the process of performing field studies in a representative number of foundries, the study team will evaluate the present ventilation methods to determine:

1. Whether or not the application of these methods could be improved.

2. What resultant reduction in worker exposure might be achieved.

3. What the costs of the methods might be.

It is hoped to be able to assess how low today's technology will permit foundries to go, taking them to the point where further reduction would require extensive process modifications o: research to develop a new generation of ventilation methods. The study team will document the findings and conclusions as related to technical and cost feasibility in a report to the Foundry Nickel Committee for presentation to OSHA.

Those of you that are involved in alloy operations and would like to get on our mailing lists, give me your business cards. At this point, we have no definitive data indicating that the metal nickel and its oxide is carcinogenic. If any of you have any information along that line, I would be most pleased to have it.

¿UESTIONS, ANSWERS, AND COMPENTARY

Cominent (F. Mirer, United Auto Workers):

We're happy to hear that an occupational health study is being done in the founary industry in the Unitea states. I think the only thing published on mortality in the last fer: vears has been a study by the Molders' Union on some death certificates that they have.

I have an observation about the study design. The observation is that, if we're doing a proportional mortality study on a thousand or so death certificates, we're going to have to have, under the best of circunstances, a thirty to forty percent increase in the proportion of cancer deaths

\footnotetext{
${ }^{1}$ NIOSH Criteria for a Recomnended Standard Occupational Exposure to Inorganic Nickel, May 1977. HEW Publication iNo. (NIOSH) 77-164, for sale by the Superintendent of Documents, US Government Printing Office, WAshington, DC 20402 (GPO Stock No. 017-033-00219-3).

2 NIOSi Criteria for a Recommended Standard Occupational Exposure to Chromium (VI), 1975. HEW Publication iNo. (NIOSH) 76-129. Out of print but may je obtained from iIOSH.

3 Envirex Inc. 1978. An occupational health hazard control technology assessment of the foundry industry. Deport of the National Institute for Occupational Safety and Health study. DHEW (NIOSH) Publication no. 79-114 for sale by the Superintendent of Documents, U.S. Government Printing Office, Washington, DC 20402 (GPO Stock No. 017-033-00366-0).
} 
for the result to become statistically significant. Under that circumstance we need a very close interaction between exposure histories of the individuals involved, and the mortality study in order to have any hope of getting useful information.

Response (F. Schaller, International Nickel Company):

I serve as secretary to the Foundry Nickel Committee and I'm with the International Nickel Company. We have been helping some of these ad hoc committees get organized.

We invited approximately 150 foundries to submit records, and it was only these twenty that came forward, and that was what led to the number of approximately a thousand. We were hoping to get more like four thousand so that we would have been able to say something about the occurrence of nasal cancer.

The early health problems occurred in the production of nickel in Canada, Norway, Russia and in England. There were high levels of nasal cancer. That has not been observed in any of the studies so far in the United states.

Question (F. Mirex):

Will the Rexnord foundry exposure control technology effort be correlated with the results of the mortality study?

And the second question is--Are any of these twenty foundries represented by the U.A.W.? And, if so, would the committee put us on their mailing list and give us an opportunity to have some input into the design of the study?

Answer (F. Schaller):

As far as correlating with the Rexnord study, we spoke to the consultants (University of Michigan School of Public Health) about that and they didn't think it was worth too much effort because the deaths occurring now that would be cancer-related are due to exposure some years ago and we're not sure really whether it would be worthwhile to go back and try to reconstruct this to get some sort of dosage/response relationship or something along those lines. So it's doubtful that we'll be able to do very much in correlating exposures with health problems that may be uncovered.

So that's something we'll have to see. If they request us to get some information, we'll try to do that, but ventilation systems and molding compounds, all these things have changed quite dramatically over the last 20-25 years. So it becomes very difficult to make any correlation.

Comment (F. Mirer):

I'm certain that when the charge was given to the Michigan School of Public Health they weren't told that they were supposed to demonstrate there was no adverse effect in the foundry industry. 
Response (F. Schaller):

In response to your statement, we most certainly conduct ourselves in a very ethical way. The consultants are the ones doing the study and they're under no instructions other than to analyze the death certificates.

Obviously, we're hoping the mortality study will not show any increased lung and nasal cancer compared to control groups of foundrymen where they were not exposed to nickel and chromium. But that remains to be seen. 
PANEL DISCUSSION ON HEALTH HAZARD CONTROL TECHNOLOGY

IN THE FOUINDRY INDUSTRY

\author{
Moderated by Dennis O'Brien \\ Industrial Hygienist \\ Control Technology Research Branch \\ NIOSH \\ Cincinnati, ohio
}

\title{
INTRODUCTION
}

The purpose of this panel, the last group function of the foundry symposium, was to provide a forum for comments, questions, and interchange of information concerning health hazard control technology in the foundry industry among all participants of the symposium. To highlight this discussion, five professionals with varied backgrounds, drawn from industry, an industry association, labor and government, but all with the common denominator of having interest and involvement in programs that affect the health of foundry workers, were selected as panelists to lead the discussion. Prior to the open floor discussion each of the panelists presented short introductory remarks. Panelists were not restricted in their remarks and were invited to make comments on one or more of the following topics:

1. Identification of worker exposure problems and types of control technology of immediate interest.

2. Critique of the NIOSH technology assessment.

3. Identification of research and development priorities and discussion of whose responsibility it should be to conduct this research and development.

4. Suggestion of ways in which better interchange of information concerning health hazards and control technology could be achieved among the groups represented.

5. Any other remarks concerning the various topics of health hazard control technology presented in the symposium.

To facilitate audience involvement and discussion, written questions had been requested from the audience from the beginning of the symposium. These were discussed first, followed by open discussion. The text of the panel incorporates both the introductory remarks of the panelists and the discussions, comments, and questions. 


\author{
PAINELIST'S REMARKS \\ William B. Huelsen \\ Director, Environmental Affairs \\ American Foundrymen's Society \\ Des Plaines, Illinois
}

\title{
COMPLEXION OF THE FOUNDRY INDUSTRY
}

A great deal has been said about control technology in the last two days. Very little has been said about the complexion of the foundry industry for those of you who are not intimately associated with it.

The foundry industry in the United States consists of approximately fortyfour hundred metal casting units. These are made up of iron, steel, brass, bronze, aluminum, and magnesium foundries. Eighty percent of the forty-four hundred foundries employ fewer than one hundred people.

Foundries for many years were labor-intensive; within the last one to two generations, they have become capital intensive。

A question is asked many, many times: Wouldn't the foundry industry be far more efficient if the smaller foundries were elininated so that there are fewer but larger foundries? Well, such is not the case and let me explain why .

NEED FOR LARGE AND SMALL FOUNDRIES

Approximately thirty-six thousand different metal alloys can be cast. In the iron segment we have foundries that cast gray iron, ductile iron, or both. There are malleable iron foundries and there are numerous foundries that cast just alloy irons of various compositions. In the steel foundry industry we have both low and high alloy steel producers. In brass and bronze there are literally hundreds of different alloys that can be cast. The same hoids true for aluminum. There are several alloys cast in magnesium, mainly for use by the aircraft and aerospace industries.

Not every part that's made in a foundry is made in large quantity. iNomally, when you think of the metal-casting industry you think of castings which are produced in large quantities, such as pipe fittings, plumbing ware and automotive castings. When we speak of large quantities we mean thousands and tens of thousands. 
But let's look at a different situation that we can all see. We have a slide projector out here on a table. The top of that table is an aluminum casting. The manufacturer of these tables may buy five hundred castings a month. A high-production foundry probably is not going to be called on to make this small quantity of castings; or a bed for an engine lathe or a base for a power press. These castings are made in small quantities. Let's even get to smaller quantities and larger castings: a hydroelectric project; for example, with six turbines. They require six sets of castings, specially engineered. So a foundry gets an order for six sets of castings, and this may be high production in that type of work.

The list goes on. We have repair parts; we have short-run castings; we have armaments that are required in relatively small quantity. How many tank holds, for instance, are required in a year's time? Just a matter of maybe one hundred fifty or two hundred.

\section{MINIMIZING THE NEED FOR CLEANING CASTINGS}

One of the questions that always comes to mind, and one that I have been asked two or three times since this symposium started is: Why are the foundrymen emphasizing problems in the cleaning room so much? Why can't a casting be made so that the cleaning requirement is essentially nonexistent?

Well, this is one of the main purposes of the American Foundrymen's Society and other sister societies. We don't want to clean castings; we're trying to make a casting that requires the minimum amount of cleaning. Unfortunately, the better we make our castings the tighter the customer specifications get. It becomes a neverending cycle. Believe me, if we could make castings that didn't require cleaning, we certainly would.

\section{CLOSE PROCESS CONTROLS}

The first thing a foundry can and should do in trying to control the environment is to exercise close process controls. I definitely prefer that a major and continuing effort be made in the process technology and process control categories.

\section{REPRESENTATIVE AIR SAMPLING}

One point I want to make to the foundrymen in particular is that one test of dust or fume at a foundry work station is not necessarily representative of the day-to-day situation in the workplace. It is only representative of the situation that existed at that particular work station during the time the sample was taken.

Before I recommend spending money for engineering controls, I would certainly like to see at least one or two tests that confirm the results of the first test. Certainly you want some statistical significance in the testing and I don't recommend relying on only one test. 
What we see with the test is the effect. We see an exposure of a particular employee to one or more things, such as noise, dust, fume, or carbon monoxide. The cause of that proilem right be many feet - two or three hundred feet sometimes - from that employee's workplace. So it's up to us as foundrymen, engineers and technical people to look at the effect, but then to go back and seek the real cause. 


\title{
PAINELIST'S REMARKS
}

\author{
James T. Williams \\ Vice President \\ Grede Foundries \\ Milwaukee, Wisconsin
}

REAL WORLD OF THE FOUNDRYMAN

The foundry business, in a very broad sense, is a huge process and material handling business. For even in a modest shop that ships 10,000 tons of castings per year, about 20,000 tons of metal must be charged into furnaces and melted; about 140,000 tons of sand must be mixed, delivered to mold machines, molded, shaken out, and recycled; and about 5,000 tons of cores must be made and set in molds. The total comes close to 700 tons per day, when all other necessary materials are included.

When a new employee finishes orientation and is introduced to his workplace and his job responsibility, he or she must first become accustomed to the things that go on around him as part of the process of handling large amounts of materials. In addition, he must become familiar with hot metal handling and the accepted practices of a safe worker. This is the "real world" of the foundryman. It is in this world that we must all apply the latest health hazard control technology known to the foundry industry.

As we see things at Grede Foundries, our gray iron, ductile iron, and steel foundries are most concerned with silica dust, noise, and carbon monoxide. Other hazards, such as products of combustion, lead, "white knuckles", and heat stress must be carefully considered, but appear to be of less importance at this time, at least in our particular case.

\section{SILICA PROBLEMS}

When this hypothetical foundry moves 145,000 tons of sand and cores in a year (much more if one of the recycling processes is used), it is easy to see how people could be exposed to silica dust at the mullers and the shakeout, along the return sand system, at the magnets and screen, and at the returned sand storage tanks. Even after shakeout and blasting, a thin layer of silica remains just within the surface of the casting and is the source of potential dust hazards in the cleaning room before the castings are shipped.

This silica contamination potential must be dealt with carefully, using all the knowledge we have of push-pull air flow, ventilation, cross drafts, and close capture collection to keep our plant atmosphere as clean as 
possible. This has been and is being done in our foundries and silica levels continue to improve. In areas where silica levels exceed TLV's, proper respiratory equipment is required, and is used.

We need to find a material to replace silica sand. Considering that the foundry industry uses 10 million tons of sand per year, this is no small order and most likely beyond the reach of zircon, chromite, and olivine sands. But, possibly a partial solution lies in a non-silica wash that would coat mold and core surfaces thoroughly enough to keep hot metal from silica grains.

In the absence of a silica sand substitute, adequate collection systems for stand grinding and large casting grinding would be very helpful. Some research has been done, but more is required for a successful conclusion.

\section{NOISE PROBLEMS}

Noise problems lie principally in the areas of casting chipping, tumbling, and fans. Process technology improvements have reduced the amount of chipping required on today's castings, and there are techniques that help reduce noise exposure or to limit exposures through enclosure. However, neither method controls noise below required levels. Therefore, at this time, our only alternative is the use of hearing protection devices in areas where required.

\section{CARBON MONOXIDE PROBLEMS}

Carbon monoxide has the potential of being a problem wherever combustion is taking place, e.g., in the cupola, near ladle drying areas, at mold cooling conveyors, and around shakeouts. Careful hooding and ventilation have been effective in eliminating carbon monoxide in our shops. Constant vigilance must be exercised to assure fans are on, and hoods are in place.

\section{FUTURE NEEDS}

The papers and discussions of the last two days have explored hazards and control technology as it exists today. Some suggestions have been made for research that would give foundries further controls and further improvements. However, our industry is a dynamic one; and as new products and processes are developed, we will use them and we will need to know how to control them.

As these new products and processes come to market, I would like to suggest that their originators and manufacturers thoroughly test them for their potential hazards and recommend acceptable control technology.

As people, we should not operate with a control level philosophy that says; "if one aspirin is good, two are better", nor should we, as people, take the opposite position. This kind of arbitrary action only increases the burden we must bear as we consume manufactured products. I would like to suggest that NIOSH could be of great assistance, if they would test and 
determine safe but realistic threshold limit values for materials suspected of being harmful.

The technical arm of our industry, The American Foundrymen's Society, has process teaching capability through its Cast Metals Institute, and laboratory analysis capability through its Knight Laboratory. By working along with the manufacturers and foundrymen, it can be a significant factor in aiding members to put new processes and products into operation in a safe and healthful manner.

INDUSTRY's DEDICATION

Foundrymen have worked hard and diligently to improve the environment in their shops. Their efforts have not gone without the investment of large sums of money. They are dedicated to operating safe and healthful workplaces and will continue their efforts to make further improvements as needed. 


\title{
PANELIST'S REIIARKS
}

\author{
Jane Brown \\ Industrial Hygienist \\ International Molders and Allied \\ Trades Union \\ Cincinnati, Ohio
}

\section{MOLDERS UNION CONSTITUENCY}

I want to talk first about the constituency of the molders union so that you can understand what types of foundries we cover.

The molders union was founded 120 years ago and represents some 70,000 workers in foundries and allied metal trades industries. We have about 890 shops, 83 percent of which employ less than 25 workers. So the average foundry in our constituency is one of those that's mentioned in the introduction of the control technology documents as being borderline. Whether or not they're going to stay in business is always a question both for the industry and for the union.

HEALTH CONCERIS

Economic issues often become more important than concerns for the worker's health and the worker's situation in the plant. This is unfortunate both for labor and for management and is something that we feel has to be turned around because of the fact that so many of our workers are ill and becoming ill due to problems in the foundries.

As a health professional assigned the responsibility of representing and assisting those workers suffering the consequences in the plants, it is unacceptable to me that we should ask people to sacrifice their lives and their health as part of the production process.

I know that those of our people who are ill with silicosis or emphysema or other job-related diseases feel the same way.

It's not enough to compensate a worker for the damage that we've already done. We have to look towards prevention. Compensation doesn't help that worker live a full life. It merely pays him off for things that we have caused to happen to him. And that is if he's fortunate enough to get compensation, which is not always easy.

Let me return to the typical foundry that we deal with. Because of their size those foundries in which our members work are generally those with 
absent or crude attempts at control technology. While what has been represented in this symposium is, admittedly, the state-of-the-art, what we generally see in use leaves a lot to be desired. We must all remember that research is of little value if we can't get the results of that research in use in the shops.

We have been asked to address the needs that we see as professionals involved in the various organizations that we represent. It's important to remember that my reflections and observations come from workers experiencing some real observable health problems. In other words, we generally tend to deal with symptoms rather than exposure levels due to the nature of the problems we deal with.

\section{PROBLEMS WITH CHEMICAL BINDER SYSTEMS}

As I mentioned yesterday during the discussion of chemical binder systems, our biggest single workload and most current problems arise from the use of these chernical binder systems. It is agreed that these systems, using applicable local exhaust ventilation, should not cause problems o However, we don't find such ventilation systems to be as widespread in use as it is assumed here. In many cases, mixing and molding operations are run with no ventilation systems other than an open window or a cooling fan used to blow the contaminants away from the operator, often towards other workers.

We receive complaints from workers on a regular basis of problems with the binders. Dermatitis, pulmonary sensitization, nausea, and visual disturbances are the most common things about which we hear. These symptoms can generally be linked directly to constituents of the chemical mix. More difficult to address are those symptoms reported by people on the pouring floor. Our people want to know what's causing the problems, and I quite honestly can't answer their questions.

Of greatest concern among these problems on the pouring floor are such things as mental confusion, impaired speech patterns, loss of memory in certain individuals for a period of as long as thirty minutes, and workers seeing colors of different types, either a green cast to the vision or actual colors in the visual field. I will repeat that these symptoms are generally coming from the pouring floor, not the mixing areas.

We get these reports from various parts of the country, not merely from one isolated plant. Use of chemical binders, as we all know, has become widespread. Little, if any, information is available on pyrolysis products of these binders.

We have employed a few students from the University of Cincinnati to help us look into these problems. But, again, it's a very difficult thing from my standpoint.

We have been told that we have to wait until these chemicals have been in use for at least one generation of people before we can address or research long-term effects. For me this resembles, a little bit, human experimentation, which is something that scares me, and I don't even work with chemicals. 
I don't mean to infer by this discussion of binders that they're our only problem. We still have problems with the more traditional health hazards in the foundries such as silica exposure and noise. New cases of silicosis still occur in our union, as well as cases of hearing loss.

Again, such problems as silica exposures have been discussed over and over in this symposium and the fact that the cleaning room is the problem. Chippers and grinders are the people that we see coming up with the new cases of silicosis. Many of our shops use grinding wheels with no ventilation at all and hand tools with no ventilation.

There's still a need for control technology in these areas, especially noise. There is a great need for a renewed emphasis in noise control technology. When we file third-party status in contested osHA citations, it is a thing that we lose most often due to the lack of any proof of feasibility of control.

CONTROL TECHNOLOGY DOCUMENTS IN LAYMAN'S TERMS

In closing I would like to address the usefulness of the NIOSH control technology document, in its present form, to workers and their representatives. Research on the state-of-the-art of controls is sorely needed regardless of who you represent. We use the research in several avenues both for review commission work and also to help keep the safety and health committee members more informed so that the things that they ask for will be more effective and useful.

I have to admit that the document in its present form is of limited use for our members. Generally, the way we have to deal with such documents is to translate them into lay terms so that those people who are not health professionals can more easily understand the information. It would be helpful to us if NIOSH would issue a concurrent document directed toward workers or lay people so that a much more widespread utilization of the document might be achieved. 


\section{PAINELIST'S REMARKS}

Zigmas Sadauskas

Industrial Hygienist

OSHA Training Institute

Des Plaines, Illinois

\section{NIOSH CONTROL TECHNOLOGY ASSESSMENT}

I firmly believe the NIOSH report on Health Hazard Control Technology for the Foundry Industry is a useful and needed report in that it presents some methods to control worker exposure to health hazards in foundries. However, it must be re-emphasized that, due to the wide variations in foundries, an idea presented in the report may not work for a foundry with a similar problem. Therefore, these recommended methods of control must not become dogma, but rather serve as points of debarkation for the thoughtful evaluation of solutions to very real problems. There is a great pitfall for a person with little foundry expexience to read a report like this and assume that the answers are known.

Although it may have been the intent of the report to only address control technology, generally I see an underemphasis on the importance of proper work practices. For all the most up-to-date control devices and the most modern technology is useless if not turned on, maintained, and properly used.

NEED FOR TRAINING AND EDUCATION

Personally, I feel that education offers the most dramatic breakthrough to be made in industrial hygiene. I believe that everyone involved -- management and worker alike -- must be responsible. The Government must also share a large part of this responsibility.

Congress, in drafting the Occupational Safety and Health Act, stated that one of the purposes of the Act is to stimulate employers and employees to institute new, and to perfect existing, programs for providing safe and healthful working conditions. Another goal of the Act is the dissemination of vital health and safety information and the development of necessary educational and training programs.

Recognizing these goals, Assistant Secretary of Labor Eula Bingham, has stated that the keystone of a successful health and safety program is knowledgeable workers and employers who can find and solve their own health and safety problems. 
To this end, OSHA, in its initial years, has not allocated proper resources directed toward appropriate education, training and control activities.

NEW DIRECTIONS PROGRAM

In an attempt to rectify these deficiencies in worker and employer education and training OSHA's New Directions Program of grants to employers and employees was developed. It is an attempt to deliver continuing information and educational programs to as many workers and employers as possible with a limited amount of financial resources. It was decided that institutions with proven competence in providing related services for employers and workers were the best sources for providing occupational safety and health assistance.

The objective of the New Directions Program is to assist in developing the long-term, internal capability of employer, labor and educational organizations, to provide continuing educational and related services for workers and employers thus enabling them to successfully address those workplace conditions that result in deaths, injuries and illness.

This year OSHA has allocated $\$ 11$ million dollars to strengthen the program of current grantees, and another $\$ 2.3$ million dollars for new grantees. Two recipients of such grants have been the Pennsylvania Foundrymen's Association and the International Molders and Allied Workers Union.

The Pennsylvania Foundrymen's Association grant stipulates a survey of foundries within Pennsylvania be conducted in conjunction with the James Company. They will use the James Company staff to conduct training seminars to persons who will thereafter be able to teach safety and health. There are 250 foundries in Pennsylvania employing over 27,000 workers.

The International Molders and Allied workers Union grant stipulates that the Union will employ an industrial hygienist and a labor educator in order to make safety and health services available to workers in the foundry and stamping industries. The Molders Union will increase the technical capability of their advisory committee through training; strengthen activities of safety and health committees; develop industry specific training material; train stewards and committee members and provide industrial hygiene technical assistance.

These grants will allow foundry organizations to plan an occupational safety and health program that will meet the specific needs of its members. It is my firm belief that the involvement of foundry organizations in programs such as the New Directions Program will not only contribute significantly to a safer and more healthful workplace, but will also contribute to better work practices and will stimulate ideas for improved control technology.

NEED FOR BREAKTHROUGHS IN CONTROL TECHNOLOGY

In closing, I would like to state that the NIOSH report entitled, "An Evaluation of Occupational Health Hazard Control Technology for the Foundry 
Industry" is useful and important. However, upgrading of worker and employee awareness and knowledge of health and safety problems is of paramount importance in the implementation of ideas presented in the NIOSH report. A program such as OSHA's New Directions Program is a step in the right direction.

Furthermore, I would like to suggest that there is a need for a program aimed at breakthroughs in control technology. I submit that what is needed is a program similar to OSHA's New Directions Program which will assist and support employer, labor and educational organizations in identifying hazardous conditions affecting the members they represent; and further support them in attacking and solving these specific foundry problems through effective controls on a "worst" hazard priority basis. This would provide specific answers to specific problems for a large population. 


\title{
PANELIST'S REMARKS
}

\author{
Franklin E. Mirer, Ph.D. \\ Industrial Hygiene Consultant \\ Social Security Department \\ International Union, UAW \\ Detroit, Michigan
}

\section{PROGRESS TO DATE}

The earlier, spirited discussion on research on health effects in the foundry industry revealed a good deal of defensiveness which must be overcome if we are to progress in eliminating hazards. While there are different roles for government, corporate, industry association, and union hygienists in this enterprise, we are all in it together.

I wish we could congratulate ourselves about our success in eradication of foundry health and safety hazards. We can't.

To my knowledge, the last published pulmonary disease study in foundxymen in the U.S. was 1947. The only U.S. mortality study published was a recent analysis of Molders Union burial benefit records. These findings, as well as British and recent Finnish data, were not optimistic.

\section{WIDESPREAD PROBLEMS}

The UAW canvassed OSHA for air sampling data and found that between 1972-5, just about every foundry had violations of silica limits, usually by many times, and the big foundries were worse than the little ones because they move more sand. Abatement hasn't been all that successful, and while this symposium has indicated that technological limits are primarily in the cleaning rooms, we still find many other workers overexposed, especially the unfortunate worker in the basement shoveling sand back on to the conveyor.

In the near future, the industry is looking at proposed two-fold reduction in limits for silica levels, a more than three-fold reduction in formaldehyde levels, and real enforcement of the noise standard. It is also going to be confronted with the need to examine and control the smoke cloud generated when the hot iron hits the core and mold binders.

This symposium comes at a rather peculiar time in the legal development of guidelines, standards, and regulations for exposure to occupational hazards. As engineers, industrial hygienists, and health professionals, we want worker exposure to air contaminants controlled to safe levels by engineering and process methods so that respirators are not needed. The combination of 
heat and heavy work make the foundry environment almost the last place a worker should be saddled with an air purifying respirator.

"ALL OR NOTHING" STALEMATE

Unfortunately, the Safety and Health Review Commission has left us with a peculiar legal doctrine of all or nothing. Recent decisions imply that partial engineering controls are not required if the government can't prove to a judge, who has no scientific training, that it is feasible (whatever feasible means) to control the air contaminant to below the permissible exposure limit (PEL). In other words, a 10-fold overexposure is no worse than a $10 \%$ overexposure and $101 \mathrm{dBA}$ is no different from 91, since respirators and earplugs will still be required.

Once the limit is ruled infeasible, the employex is effectively freed both from control development and from routine maintenance, housekeeping and work practice controls. If that's the legal framework, we have to work around it. It undercuts the program of the company safety and health staff as well.

A WAY TO GO FORWARD

Let me suggest a way to go forward. Government, industry, and labor should work together to classify unit operations and compile examples of unit operations which are in compliance. Often a plant will be in compliance in one area, e.g., sand mixing and molding, and in trouble in another, e.g., the cleaning room. In the next plant, the opposite might be true. The control technology report is a start, but it requires too much technical interpretation, and is too generalized to be immediately used. We need to have the fact of compliance, the location, the method, time schedule and even cost documented and in a data bank. The easiest way for a health professional to convince a corporate comptroller to approve a project, a judge to uphold a citation, or a local union president to hang in on a grievance, is to show these individuals that another company has done it and is still in business.

PRIORITY OF HEALTH CONCERNS

Trade secrets are likely to be a problem under this approach, but business rights must fall before health considerations. The comfortable way to think about controls is to retrofit ventilation or enclosures on existing equipment, and do everything else just as we do now. This is certainly true in the labor movement, when unionists see a loss of jobs in every process change, but it is equally true of health professionals and compliance officers who feel they have no control over, and no right to suggest, changes in product and process.

Real breakthroughs in control are likely to be made in other ways. Elimination of burned-in sand on- castings seems to be a much more effective way of solving cleaning roorn silica problems than ventilation. A solution to this problem will be worth a lot of money as would developments to reduce chipping needs or abate any number of noise, dust, or chemical hazards. 
Those present yesterday can judge from the discussion of binders the openness of transmission of information in this area. When compliance pressure gets heavy, the commercial value of techniques such as high-velocity, low volume hoods (HVLV) or charged fog, of complete engineering control strategies, such as sand system design, will be increasingly proprietory. This will place increasing pressure on management to judge competing claims without open, public, independent evaluation. The data needed will probably fit a legitimate definition of trade secrets or proprietory information, but the health needs of workers, and the interest of employers in protecting the health of their workers must come first. 
Moderator (D. O'Brien):

Before we begin our question and answer period I'd like to take a little poll just to see how adequately we were able to distribute our report on the foundry industry. I'd like each of you here who have a copy and have read at least part of it to raise your hand. I'd say a good seventy-five percent. I feel satisfied with that.

The following are questions from the question box. Several questions were submitted for Dr. Mirer. I'll ask them all at once because they're all in the general same vein:

What is the U.A.W. doing to inform its members about the necessity of working safely, using the safety equipment provided, and insisting that employees be disciplined for failure to comply with safety measures?

Why doesn't the U.A.W. spend money to provide research into effective means for understanding valid limits and/or reasonable solutions. What is the U.A.W. doing to insist that members not become involved in drug overuse, alcohol, smoking, or any other factors that could contribute to their poor health and safety?

Answer (F. Mirer):

We have a fairly active program, but I won't say it's as good as we'd like it to be in informing our members about how to work safely, how to recognize hazards on the job, and the like. We have an active program in our education department which includes having trained local union discussion leaders approximately thirty-five leaders - around the country who are now able to go out and teach courses to local unions and to the rank and file on health and safety including, among other things, the use of personal protective equipment.

When it comes to the question of employees being disciplined for not using their safety equipment, the analogy I like to use is the wearing of a respirator in the foundry. Wearing a respirator gives one the opportunity to experience the symptoms that you would have if you suffered silicosis, except that, instead of coming on over twenty years, you get the symptoms right at the time you put the respirator on.

We think that our members should wear the safety equipment; we encourage them to do it. In most cases when they're disciplined for not doing it, we find it to be unequal application and sort of a reign of terror in the plant to teach that "if they want health and safety, we'll give them health and safety".

On the question of spending money to do research, there's more obstacles than just money. I know of one case where we requested a health hazard evaluation in a foundry specifically for the purpose of determining whether relatively low levels of silica exposure were affecting the health 
of our members, and to find the effects of exposure to coremaking chemicals. When NIOSH visited the foundry to perform the evaluation, they requested medical records which the company refused to provide. Everybody went to court, where they're still deciding the case.

We're actively trying to promote research, however, we feel that the provision for funding research is primarily the responsibility of the corporations as workers are at risk, and the government has a public responsibility.

Finally, on the question of drug and alcohol abuse, we have over the space of nine years been promoting what we call substance abuse programs in all the plants where we have major contracts. And we think we're doing about as well in that as anybody can do. Nobody knows how to prevent drug and alcohol abuse. And as far as stopping smoking, I notice we haven't succeeded with the group here yet.

\section{Moderator:}

The next question from the question box isn't addressed to a specific panel member. Possibly, Mr. Huelsen or Mr. Williams would like to answer this one:

As mentioned by $\mathrm{Mr}$. Shaw, soft or sea coal, in premixed bond additives added to green sand, is one of the major problems causing excess dust. Has there been any scientific studies done on the effect of replacing sea coal in a premix with a carbon substitute?

Answer (J. Williams):

We're generally using sea coal substitutes in our sand. I know of several on the market. So I think it's possible to do this.

\section{Moderator:}

I know of a paper that was published in the proceedings of the British Cast Iron Research Association Conference, The Working Environment in Foundries several years ago. It discussed the merits of sea coal substitutes. The details of the paper are sketchy. I can tell you how to get ahold of it if you would like to see me.

Answer (W. Huelsen):

Starting fifteen or more years ago, sea coal substitutes were introduced into the foundry marketplace. There are a number of different ones available. And, again, this is a matter that goes into the area of competitive economy. First and foremost a foundry has got to make a good casting. We can have the most healthful sand system in the world, but if we can't produce a good casting using it we've got problems. So any product that we use, whether it's a sea coal substitute, a binder system, or what have you, has to contribute to making a good casting; it has to be salable from that 
standpoint. Of course we look for the minimum of environmental problems along with the quality considerations.

old timers in the foundry business know that every new product that's come on the market, has been introduced as the product that will replace all other sand binders or additives. Well, each one finds its place of best use, and as a result, we're still using most of the old systems as well as all of the new systems. Each one has its place, including sea coal substitutes. But, as far as complete elimination of sea coal is concerned, I don't think that will ever occur. Certainly it won't occur during my lifetime and probably most of yours.

\section{Moderator:}

The next question from the question box pertains to use of the method of recirculation of exhaust air. This question has several parts:

Can this method be used extensively in all dust-collecting systems? If so, what monitoring is required? Are downstream high efficiency filters required? And where can information on this be obtained?

I'll personally take the last item. NIOSH has done several studies on the recirculation of exhaust air. These reports are avilable either from NIOSH's Office of Publication Dissemination or the Government Printing Office. I know the American Foundrymen's Society has had a committee evaluating recirculation of exhaust air. Possibly Mr. Huelsen would like to comment on some of the other questions. And then Mr. Sadauskas on how OSHA reacts to some of these systems.

Answer (w. Huelsen):

For over two years, one of the technical committees of A.F.S. has been studying the recirculation of exhaust air. To date this committee, using A.F.S. research funds, as well as funds, labor, materials and engineering donated by members of the committee and their companies, has installed three dust collection units at one test site in the midwest for study purposes.

System 1 is an electrostatically augmented baghouse. System 2 has two baghouses in series. The first stage is a fabric filter similar to those that we use to meet the air pollution regulations; the second stage has a different filtration media, different air-to-cloth ratio, and a pre-coat on the bags. As a second phase in the test on system 2, the bags in the first stage were slit, representing a failure condition, and sampling of both inlet and outlet dust loading was done on the second stage collector. Then the fabric was changed in the second dust collector of system 2 and further tests were run.

The dust collector in system 3 has been installed, and if it's not already been tested within the last few days it's right on the verge of being tested. This system consists of a paper type filter which is capable of being cleaned. It reputedly doesn't pick up moisture in a humid atmosphere. 
I think that our work to date shows that it is possible to recirculate air back into the workplace and do it safely.

The thing that our committee is most concerned with now is a suitable instrument to monitor the quality of air being re-introduced into the workplace, such that if mechanical failure occurs, e.g., a bag rips, and the quality of the air deteriorates, the monitor will sense the failure within a matter of seconds or at most minutes, and will provide a warning or an output to initiate a control action, e.go, bypassing the air cleaner exhaust to the outdoors, to prevent overexposure of workers. I think the monitoring equipment is the key。

Answer (Z. Sadauskas) :

I'd like to say that from my experience as an OSHA compliance officer, I look at the recirculation of air with great suspicion. Except in a few situations where recirculation is explicitly forbidden, OSHA, as a general rule, does not forbid such practices. However, a compliance offieer will probably spend some extra time there evaluating the resulting conditions。

Moderator: I will now entertain comments and questions from the floor.

Comment (F. Boelter, OSHA):

I'd like to give a further statement of policy from this regional office on recirculation of exhaust air. We are quite concerned about it. I do know that there are any number of foundries in the region that are using recirculation, some effectively and some tremendously ineffectively. When measuring the worker's breathing zone exposure there is rather poor correlation except what work NIOSH has done to determine the relationship between what's being recirculated and what's being found in the breathing zone.

I'm a little cautious about telling people to embark on recirculation unless they are quite familiar with the theory behind such a design and are in a position to either contract a qualified consultant to do the work or are extremely knowledgeable in the area of industrial hygiene.

Comment (R. Hughes, NIOSH):

To reinforce what Bill Huelsen said, we've come to the conclusion from our work in recirculation that the most important component of any recirculation system is an adequate and reliable monitor. We have an ongoing project which is reviewing all available monitoring equipment and systems that are on the market and in use. This project includes a limited evaluation of some of these monitors. The goal is to make information on monitoring readily available for people to use. The project is underway now and will hopefully be completed in another eleven months.

We agree with OSHA that recirculation should not be installed and used without a good professional analysis both by engineering and medical people, on a case-by-case basis. If it's looked at that way it can possibly be safe. If people are concerned about a recirculation system failing and putting a lot of contaminants back into the workplace, I would submit that, 
if properly designed, failure of a recirculation system may not be any worse than failure of a normal exhaust system which is used, as you know, in hundreds of places in thousands of plants. It's just a matter of looking at these things very carefully on a professional basis.

Question (F. Boelter):

I have a question for the panel in general and it has to do with Dr. Jacko's presentation this morning. He tended to give a rather bleak outlook on the possibility of controlling lead in the workplace. I'm interested to know from the panel whether or not they tend to agree with the approach and attitude that was presented this morning. What type of a position are they taking?

Answer (W. Huelsen):

At A.F.S. we're trying to accumulate as much information from foundries as possible regarding controls that they have installed and samples they've taken to find out what is the best technology available. We're trying to find out why one system works and another doesn't and to accumulate as much technical information as possible for dissemination. The purpose of A.F.S. is the generation and dissemination of technical knowledge such as this.

I'd like to go on to comment on something else that's related to this. It was mentioned that along with the New Directions Program more evaluation should be done by NIOSH than is being done now. I submit to you, particularly OSHA, that the $85 \mathrm{~A}$ regulation (42 CFR 85 (a) published in the Federal Register, Vol. 41, No. 200, Thursday, October 14, 1976), in effect, reduced the amount of technical information available from the private sector to NIOSH. Information that was previously accumulated from companies for scientific purposes now becomes part of the public domain, including the identification of company names. I believe that that policy should be carefully reconsidered if we're to push the frontiers of knowledge back as rapidly as we'd like.

Answer (F. Mirer):

Just one comment, both about that and about Dr. Jacko's presentation and the lead standard.

Through the whole discussion of the lead standard during the proceedings in Washington, there were numerous pieces of testimony describing how absolutely infeasible a Permissible Exposure Limit of fifty micrograms per cubic meter would be in the battery industry. Since the standard has gone into effect we have become aware of at least two locations where company air sampling data has shown that they're in compliance in most of the unit operations of these battery plants. We're very happy to see that.

We also found it's just as hard to give out data showing underexposures as it is to give out data showing overexposures in an industrial plant. 
Answer (W. Huelsen) :

I'd like to point out that when we talk about lead standards and the capability of meeting them, we must remember that there are numerous alloys that could be involved. Some of the alloys have as much as forty percent lead in them. The melting and pouring temperatures are also important because, generally speaking, the thinner the wall of the casting the higher the melting and pouring temperature must be, resulting in a greater production of lead fume.

Lead in the cleaning room occurs because the lead is in solid solution within a metallurgical structure similar to dendrites. Abrasive wheel grinding and other mechanical cleaning tears lead particulates out and they become airborne.

So, just because a particular foundry may meet a fifty microgram per cubic meter lead standard does not mean that any other foundry or group of foundries can. In fact, there are copper-base alloys with no lead in them and I know of a couple of cases where air sampling has been done in these foundries and lead wasn't found. If you don't have lead present in the alloy, or very little, or if you are casting chunky castings, the probability or possibility of exceeding the lead standard is reduced.

Comment (F. Mirer):

I didn't make my comment clear. I was talking about the battery industry as establishment of an analogy to this situation where infeasibility was claimed and now it appears that the standard is feasible.

We're hoping to get more data about exposures in the nonferrous foundry and smelter industries to see how progress is being made. But, as I said before, industries loathe to expose themselves to scrutiny, even when they think they're doing okay. And it does seem to be as hard to get data of things that are in compliance as things that are out of compliance.

Comment (W. Huelsen):

I don't think that we as an industry loathe to undergo scrutiny. In 1971, a group from the American Foundrymen's Society headed by Newton Sachs, who was at that time chairman of the Environmental Division Executive Committee, went to NIOSH and through the good offices of the late Dr. Les Scheel, a group of scientists were assembled to meet with us. The foundry industry requested a detailed health hazard study for at least one disease cycle, i.e., ten years or more. And we offered our complete cooperation. This was turned down by NIOSH. Now is this lack of cooperation? I submit that it's not.

Comment (F. Boelter):

I have another comment which relates back to Bill Huelsen's introductory remarks on representative air sampling. I totally agree with him. However, I'd like to add that just because you don't find an overexposure doesn't mean that there isn't a problem. We at OSHA routinely are able to sample 
locations once and often further sampling is necessary to quantify the nature of the exposure and identify the cause. It's very important that this be done. Just because OSHA doesn't find any violation doesn't mean that it doesn't warrant further examination.

Question (Mr. De La Fuente, Molders Union, San Francisco Local):

Yes. I have a question for Mr. Huelsen from the American Foundrymen's Society, a question and a comment.

You mentioned during your presentation that you recommend at least two tests before you get into any type of a correction practice in the foundry. My question is: What can we do to try and convince some of your members to go along with the principles you are talking about? We are not asking for one test or two tests or three tests. We want to know if any companies will be willing to correct the problem if they know it's a problem.

We, as a union hear the complaints of the people we represent and then approach the company to get a test because we are not experts. We don't know if it's a problem or not. But we don't get the cooperation we really like to get.

I came to this conference and I have heard of all types of engineering control programs and of all types of safety committees and of all different plans and things that we can use. It appears that we have almost all the problems solved; but still we have a lot of problems.

Answer ( $W$. Huelsen):

The reason I made the specific point about not relying on just one test is that an anamoly can occur. This morning, the professor from Purdue University said that he threw out one set of data because it was so far different from the other two sets of data that he took that, even though he didn't know what exror might have occurred, the difference was so great that it should be disregarded.

We say workplace sampling is a science but then when you refer to the industrial hygiene field operations manual you see that there is a plus or minus twenty-five percent accuracy on silica dust sampling. Now let's say that you are at one hundred ten percent of exposure. Well, you should verify that and you should be sure over what range your exposure varies.

The design of any corrective measures that are taken is going to depend upon how reliable that data is. And this is strictly a technical point. Now as to how you go about doing it, I don't know what foundries you are talking about or what the situation is, and I really can't comment on that.

Answer (z. Sadauskas):

I'd like to answer in terms of OSHA's sampling policy and how we go about it. Mr. Huelsen mentioned the industrial hygiene field operations manual (IHFOM). 
It's quite explicit about what we're supposed to do. The twenty-five percent error is accounted for in the calculations. Basically what we're trying to achieve is a ninety-five percent confidence limit. In other words, we develop a lower confidence limit and an upper confidence linit. If the standard (PEL) falls between those limits it is OSHA's policy not to issue a citation, but to go back and resample. This policy is pretty well spelled out in Chapter 2 oI the IHFOM.

Comment (M. Cavanagh, OSHA):

Depending on where we come from and who we represent, we tend to take a different view on how long it will be till we solve our problems. But we all must concede to some degree that engineering controls are not going to save us today or in the very near future. I'd like to stimulate a little discussion with regard to such things as audiometric testing to insure that the hearing of employees is protected during the interim and also medical surveillance programs in backing up successful respiratory programs. .

Response (F. Mirer):

Our position is that, in negotiating with employers, we try to get engineering controls to eradicate the hazard and for any worker exposed to above eighty-five decibels we think he should have an audiometric exam yearly and get a copy of the results. Now, as a practical matter, we have had more success getting that requirement put in where the exposure is over ninety.

And with regard to medical surveillance, we interpret the respirator standard to require a medical examination including a lung function test on a yearly basis. And we also would make the same recommendation to any of our local unions that had a silica exposure that required respirator usage, an isocyanate exposure, and so forth. And we have been successful in negotiating the examination in a large number of plants, particularly the major plants.

Question (C. Brown, Motor Castings Co):

I have a question for Ms. Brown. From your approximately seventy thousand membership, how many verified cases of silicosis came up in 1978 or $77^{\prime}$ or $76^{\prime}$ ?

You just said a few minutes ago that so many of our workers are becoming ill. That's a pretty serious charge. So you must have some information to back

it up.

Answer (J. Brown):

There is no such thing as a silicosis registry. We're involved right now in trying to canvass our members for those new cases that have come up and also old cases that have been documented. We do get reports from some locals when there is a new case documented. We also deal with their problems as they come up in terms of OSHA citations and contested OSHA citations. I can only address the period since I have been with the Molders Union, which 
is the past year. We have been involved with a few particular plants where we have had nine cases in one plant, about five in another. We do have a study that was done by $\mathrm{NIOSH}$ on our mortality records, in which they looked at lung disease primarily as the cause of mortality. But they also addressed pneumoconiosis, which was very high.

Comment (J. Lake, OSHA):

I'd like to make an observation. I think there have been many personal positions and some policies put forth here. I think we should remember that we don't all speak for our particular groups on policy, and that many of the personal opinions put forth here are strictly based on the experience and knowledge of the person making the comment.

I would not want to hold any of our people here who have put forth something in a personal vein as having put forth OSHA policy. No more would I want to hold the speakers at the table accountable for any policy statements.

I think we ought to accept this conference for what it is: a platform in which to explore the technology in the foundry industry and the way to go insofar as controlling hazards and helping ourselves. And I think that we have gotten a little bit away from that in this discussion. I would like to repeat that I think we ought to differentiate between personal comments and experiences and the policies of the people we represent. 


\section{WELCOMING ADDRESS}

John T. Talty, P.E.

Chief, Control Technology Research Branch Division of Physical Sciences and Engineering, NIOSH Cincinnati, Ohio

On behalf of the National Institute for Occupational Safety and Health, I would like to welcome you to the smelter session of this symposium on occupational health hazard control technology in the foundry and secondary non-ferrous smelting industries.

In December of 1970, Public Law 91-496, the Occupational Safety and Health Act, was enacted "to assure safe and healthful working conditions for workers by authorizing, among other activities, research, information, education, and training in the field of occupational safety and health". To carry out this mandate, the Act also established the National Institute for Occupational Safety and Health within the Department of Health, Education, and Welfare. Within NIOSH, the Division of Physical Sciences and Engineering has the responsibility for evaluating and developing innovative methods, techniques and approaches, for the engineering control of occupational health hazards.

To expand the knowledge of available options for the engineering solution of occupational health problems, NIOSH has conducted a series of control technology assessment projects. The goal of the assessments is the documentation of the successful application of control measures and fostering research by identifying gaps in existing control technology. The studies are focused on the best control techniques practiced by industry and result in the dissemination of knowledge for use in solving industrial health problems.

Foundries and secondary non-ferrous smelters were among the first industries studied in this program, for several reasons. First, both industries employ processes using substances recognized as potential health hazards. Control measures for these hazards were known to exist, but no systematic study of the effectiveness of these methods had been undertaken. Secondly, many of the foundries and secondary smelters are small businesses, often lacking the resources to develop information on the prevention of occupational exposures on their own. Thirdly, major changes have taken place in the processes and equipment available for use in these industries both here and abroad. Lastly, both industries were significantly affected by current and proposed Federal regulatory activities. 
The NIOSH secondary smelter study began in late 1976 with our award of a research contract to the Radian Corp. The study was performed primarily through in-plant evaluations of functioning control techniques. We are particularly pleased to be able to provide you with a pre-publication copy of the Radian report today and hope you will find it to be a useful document. It is not in final form and will receive some editorial revision before issuance as a NIOSH publication.

As a follow-up to this study, NIOSH is conducting this symposium to enable representatives from industry, labor and government to contribute solutions to occupational exposure problems not investigated in the NIOSI studies, to assist in the dissemination and provide a vehicle for discussion of the NIOSH secondary smelter study, and, perhaps most importantly, to stimulate an interchange of ideas among participants. Our intention is that participation in the symposium should extend not just to the speakers, but to all who can contribute to a constructive exchange of information on these topics through floor discussions and the special panel discussions planned at the close of the day. Such discussion can lead to significant progress, and we hope that each participant will leave here with new ideas for solving the problems with which re are faced.

I would like to take this opportunity to thank the managers and employees of the secondary smelters who participated in the NIOSH control technology studies. Their cooperation is evidence of their commitment to the prevention of occupational disease, and has been of great assistance to NIOSH in the performance of its mission to protect the health of the working person.

I look forward to this day's presentations and your vigorous participation with the anticipation that not only will you be encouraged by the success of others but also that all will leave with the common goal of preventing occupational health hazards in the smelting industry. Only through a cooperative effort on the part of the industrial, labor and public sectors can this be accomplished. We are hopeful that today's gathering will be a major step in that direction. Thank you for coming. 


\title{
QUESTIONS, ANSWERS AND COMMENTARY \\ HEALTH HAZARD CONTROL TECHNOLOGY ASSESSMENT \\ OF THE SECONDARY NON-FERROUS SMELTING INDUSTRY
}

\author{
Robert Vandervort \\ Group Leader \\ David J. Burton \\ Manager \\ Occupational Safety and Health Division \\ Radian Corp. \\ Salt Lake City, Utah
}

Question (F. Boelter, OSHA):

My question relates to the use of a filtered air supply by the operator of a front-end loader at the Bergsoe Facility. I was a little surprised to see how high the lead levels were. Have you any reasons why that might be? Is it because of inefficiencies in the filtration or is it because of the activities of the operator?

Answer (R. Vandervort):

The air-filtered cab for the front-end loader at the Bergsoe facility was a prototype of a system developed at the plant. It was not a commercially available system. Some of the exposure may have related to the fact that the operator was required to leave the cab. Although the floor surfaces of the smelter were maintained in a wet condition, in some cases there were accumulations of small amounts of lead paste. which could be tracked into the $\mathrm{cab}$ on the shoes of the operator. During the normal operation of the cab with its air supply, these accumulations would dry out allowing the dust to be reentrained inside the cab. So it was not a completely successful operation.

I would personally like to see some work done with cabs of a similar nature, possibly in conjunction with equipment manufacturers in this country, to see just exactly how effective this control can be made.

Question (F. Boßlter):

Since your study was begun in 1976 and completed, from what I can tell, this past summer, do you see any technology which has become known to the industry since the completion of your study that would update your published findings? 
Answer (D. Burton):

Yes, there is a great deal of interest in additional control technology. Obviously, we've only scratched the surface here. And we have since seen other items, other interesting ideas, other approaches to the control of emissions and the employee's exposure in the secondary smelting industry. Radian and Charles River Associates of Boston have a joint contract with EPA and OSHA to identify economically and technically feasible control strategies for the primary and secondary lead smelting industry. We're coming across:a great deal of other ideas in control technology that eventually will become available.

NIOSH is also interested in pursuing contròl technology and would be interested through this forum to hear of other approaches.

Question (K. Caplan, Industrial Health Engineering Associates):

Is the condition of the Bergsoe plant due to the fact that it's a welldesigned new plant or is it due to the Bergsoe process?

I get the feeling in the description of the Bergsoe process and Bergsoe plant that hygiene and pollution conditions there, that are generally better than the industry as a whole, are due more to it being a new plant designed and laid out with these considerations in mind than really anything to do with the process per se.

Agglomerating flue dust is something that people have been doing one way or another for quite a while. One can even argue the various merits. The other major process difference that I'm aware of is the design of the blast furnace itself. I wonder how that significantly affects the hygiene problem.

Answer (R. Vandervort):

The answer to that question is multifaceted. I will start by saying that many of the control principles that Bergsoe has employed in the design of his smelter would be adaptable to new smelter designs here. The furnace that he has employed has the advantage of a fairly low blast rate and a low top temperature, which could be achieved here in the United States with slightly modified versions of our shaft furnaces。

The ventilation systems that he has used are simply examples of good ventilation practice. There is nothing magic about the ventilation control there; similar installations could be made here. We're not necessarily touting the process itself, but the system of controls as it works together was quite good. And, as Mr. Caplan mentioned, it is a relatively new smelter with new design technology.

Question ( $\mathrm{J}$ : Goulias, Goulias Associates):

Is the report available on control technology in the primary non-ferrous smelting industry? 
Answer (R. Hughes, NIOSH):

This report is a compilation of several volumes and that has been put into the National Technical Information Service (NTIS). It is not going to be published as a NIOSH report but it would be available through NTIS.

Question (J. Goulias):

In terms of the levels of lead in ambient air measured in the secondary smelters that you surveyed, can you give me the highest value that you found in the workplace?

Answer (D. Burton):

I don't recall the highest we saw, but it was probably on the order of $2000 \mu \mathrm{g} / \mathrm{m}^{3}$. 


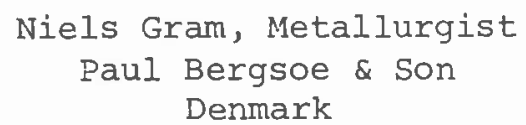

\section{ABSTRACT}

The need to produce a product more competitively while meeting regulations on worker health and the environment led to the design and construction of a new smelter at the firm of Paul Bergsoe \& Son in Denmark. The new design incorporates the use of a special blast furnace (the $S-B$ furnace) along with two or three short rotary furnaces. A number of design features built into the new plant help to reduce environmental pollution as well as worker exposure to air contaminants, particularly lead. These design features include:

1. Post combustion of furnace gases to incinerate soot and organic matter and to react $\mathrm{SO}_{2}$ with lead oxides to form a filterable material - lead sulphate.

2. Cooling of hot gases from the afterburner by mixing the gases with other exhaust air streams to reduce the cleaning problem caused by condensation of fume on the cooling surfaces.

3. Flue dust agglomeration to control dust discharge during handling, transport and recharging of material collected by the baghouses.

4. Flue duct and exhaust ventilation systems designed to avoid deposition of dust within the system.

5. Baghouses selected which allow filter replacement from the outside and long bag life.

6. Solid construction to prevent disuse of workplace control measures because of damage to ventilation hoods, doors and screens.

7. Separation of "clean" from "dirty" areas so that the greatest majority of jobs can be performed without personal protective devices or isolation into ventilated enclosures.

CHOICE OF SMELTING TECHNOLOGY

In the early 1970 's the Danish non-ferrous secondary metal smelter firm of Paul Bergsoe \& Son realized that its lead smelting section needed to be rationalized and modernized in order to avoid closure of the operation 
either by competition or by antipollution regulations, or by both. It soon became clear that this meant building a new smelting plant rather than modifying and extending an existing plant which comprised two comparatively small blast furnaces, one reverberatory furnace, and a number of conventional rotary furnaces (drum furnaces). Following experimental smelting of a variety of secondary raw materials in these furnaces, the decision was reached to select a special shaft furnace and the so-called short or deep rotary furnaces (Kurztrommelöfen) for installation and further development.

Special Shaft Furnace

Incorporating a number of special features, the special blast furnace (later called the S-B furnace) would be able to smelt unbroken batteries and would thus enable the company to operate more freely on the market, buying conventional battery scrap or unbroken batteries without having to resort to its own battery breaking. A variety of charge mixtures containing whole batteries, conventional battery scrap, lead dross, and recycled flue dust and slag can be smelted in the S-B furnace. It also offers good productivity because of its continuous mode of operation.

Short Rotary Furnaces

In the short rotary furnace, the flame coming from the burner at the aft end revolves inside the furnace, and the exhaust gases are again extracted at the rear. This furnace can also be used for smelting battery scrap, but to do this requires decased scrap. It is technically difficult to obtain a high yield simultaneously with a safe, disposable slag in this application. On the other hand, the deep rotary furnace is well suited for smelting secondary lead materials other than battery scrap. Solder and printing metal residues, and other tin-containing materials cannot be smelted economically in a blast furnace, and the variance in their composition makes batch-wise smelting more desirable.

It was felt that with the combination of an S-B furnace to smelt batteries, battery scrap and related materials, and two or three short rotary furnaces to smelt all other lead-based raw materials as well as a number of internal byproducts from the refining of lead and lead alloys, the company would have an adequate smelting capacity for many years to come and still possess the flexibility that is so necessary in the recycling
industry.

SAFETY AND HEALTH CONCERNS

The choice of these two smelting technologies was also governed by the demand for environmental protection and occupational safety. We have not been able to find other smelting systems that offer the same scope of protection. The deep rotary furnace is already a well-known process unit, well established in Europe and now also in Anerica. 
The use of the blast furnace for secondary lead smelting is by no means new, but the conventional type, frequently called the cupola, is not very acceptable from a pollution point of view, anci it is usually impossible to rebuild it into something acceptable today. Although working on the same principle, the $S-B$ furnace is a very widebodied type of shaft furnace, providea with air preheat and oxygen enrichment. Factors such as these allow a very low and compact smelting zone, a thorough preheating of the charge materials on their way down through the shaft, and an efficient cooling of the combustion gases on their way up. In this way, the battery case material can be effectively destroyed (burned) and the off-gases are much less loảed with flue dust and, therefore, easier to control and clean to a high standard.

\section{Design Guidelines}

Even with the inherent advantages of the furnaces selected, it took a lot of engineering to design these two types of furnaces into an occupationally acceptable smelting plant. To do so we developed and followed a number of guidelines, some of which are quite unusual in the metallurgical industry. Several of our design criteria seem related to the environmental protection rather than to work hygiene, but it will be pointed out how important they are also from that point of view.

Post Combustion--

All furnace gases are taken through post combustion where they are reheated to temperatures in excess of $900^{\circ} \mathrm{C}$, so that all soot and organic matter is effectively combusted. At the same time, gaseous $\mathrm{SO}_{2}$ is allowed to react with lead oxides to form lead sulphate that can be filtered away from the smoke. Both effects mainly improve the environmental protection.

\section{Gas Cooling--}

The hot gases from the afterburner are partially cooled by mixing with exhaust air from point sources of fume. Conventional gas cooling frequently leads to condensation of fume on the cooling surfaces, and the coolers therefore need regular cleaning. Cooling by mixing with cool exhaust air causes fume to condense "in suspension", so that the condensate can be carried by the gases to the baghouse filters. The important point is to reduce the need for cleaning. Inside cleaning of flues and gas coolers is necessarily a dirty operation and its frequency must therefore be reduced as far as possible.

Flue Dust Agglomeration--

Rather conventional baghouses are used to clean the gas, but the flue dust or filter dust is never handled as such. By means of screw conveyors, it is taken in a closed system to a patented agglomeration furnace in which the dust is continuously fused and transformed into a liquid slag that subsequently solidifies into a solid mass.

The flue dust from a lead smelting operation has a high metal content and therefore has to be collected and fed back into the smelting furnace. The handling, transportation and mixing of flue dust into other charge materials has always been a hazardous operation with a marked 
contribution to the workplace pollution and usually also to the fugitive

emissions from the plant. Both are eliminated by the use of the flash
agglomeration method.

Flue and Filter Design--

The entire flue system and the fabric filters are designed to avoid deposition of dust. By using steep flues near the furnace where hardly any dust will deposit and by carefully engineering the whole flue duct, the exhaust velocities can be closely controlled and deposition even in horizontal ducts minimized. Again this reduces the need for or frequency of cleaning operations.

Baghouses are now available in which exchange of bags can take place from the "clean" side and under suction, so that this otherwise very dirty operation can be carried out with minimal exposure. More important is the selection of a baghouse and filter type in which the bags have a long life and only need to be exchanged infrequently. We have had very good results with a reversed type of filter in which suction is inside the bag so that dust collects on the outside. Cleaning simply takes place by allowing atmospheric pressure or a slight overpressure inside the bag that then bulges out and dislodges the dust "cake".

Solid Construction--

Copious ventilation is installed at all fume sources in workrooms and all such equipment is constructed from heavy gauge material. The use of solid construction throughout ensures that the equipment continues to function the way it was designed and that ventilation hoods and protective screening continue to be used at all times. Dented hoods that no longer fit, and sliding and swinging doors or screens that do not move freely rapidly fall into disuse. Solid construction also reduces the need for repair work that is another serious source of exposure.

"Clean" and "Dirty" Areas--

Raw materials in a secondary lead smelter are dusty and all such material is received and stored indoors in "dirty" rooms which are also used for charge preparation. The "dirty" rooms are effectively separated from ordinary workrooms where the furnaces are operated and where it is unnecessary to use respiratory protection in the daily routine.

The under-roof handling of raw materials is primarily an environmental control but the separation of "dirty" rooms from "clean" rooms is an important factor in the work hygiene design. In the case of the S-B furnace, all handling, storage, charge preparation, and actual charging of the furnace takes place outside the workrooms from which the furnace is operated, nanely the control room and the tapping floor (Figure 1). Here lead in the atmosphere is controlled to below $100 \mathrm{\mu g} / \mathrm{m}^{3}$ and, according to Danish regulations, the people can work an 8-hour day without respiratory protection. The rest of the plant is not controlled this low, but the only person working there for any length of time is the machine driver who is isolated in a cabin with a filtered air supply. In the tapping bay around the furnace, copious ventilation is installed at all point sources, 
e.g., the lead siphon and the four slag tapping holes. There is also a general ventilation of the room and the floor is frequently wetted.

In the case of the short rotary furnaces, a similar system is adopted (Fiqure 2). Reception, storage and handling of raw materials takes place in a "dirty"

bay by means of a loading machine whose driver is isolated in a cabin ventilated with filtered air. The charging and tapping of the furnace, on the other hand, takes place in the furnace hall proper. To make this area acceptable from an occupational point of view, the furnace is well hooded, particularly at the front end where charging and tapping take place without fume escaping into the general background air. Furthermore, a system is used whereby skips are charged in an airlock between the "dirty" and "clean" rooms. Here they are first loaded from the "dirty" side, the airlock is then closed and exhaust is started before the airlock is opened from the "clean" side. On the "clean" side another truck with a tilting head feeds the skips one by one into the furnace, returning the empty skips to the same position again. A 20 ton charge is fed into the furnace in a matter of 12-15 minutes, virtually without polluting the atmosphere in the furnace hall.

A histogram of recent lead-in-blood measurements for all employees in the two smelting departments is presented in Figure 3, Most of these employees have a long history working with lead. Respirators are only used in emergency situations, and for repair and cleaning operations,

\section{QUESTIONS, ANSWERS AND COMMENTARY}

(Editor's note: The first question below was in regard to introductory remarks Mr. Gram made prior to delivering his paper. He said that a year or so ago East Germany had adopted a permissible exposure limit for lead, based on a time-weighted average of $5 \mu \mathrm{g} / \mathrm{m}^{3}$, with a maximum allowable exposure of $10 \mu \mathrm{g} / \mathrm{m}^{3}$. He said Russia, Poland and some other Eastern European countries had a similar standard).

Question (I. Tanenberg, R. Lavin \& Sons, Inc.) :

You made a remarkable statement about East Germany having such a low lead standard. Are they able to achieve it?

Answer (N. Gram):

I did say that East Germany has such a standard. I didn't say they had achieved this low level in their lead foundries or smelters.

I have visited one eastern smelter, the one that exists in East Germany. They don't meet the standard and they don't think at this time that they will ever be able to meet it. This very low standard for occupational hygiene was introduced in Russia some years ago, not only for lead but for all kinds of toxic substances. 
question (F. Boelter, OSHA):

Do you find that blood lead levels correlate at all with airborne lead exposures or do you find that the blood leads seem to be more related to personal hygiene?

Answer (N. Gram):

I can't say that we have found a correlation or seen a correlation. We have been doing blood leads for only three or four years. Before that we did basophillic testing, which was the screening method of those days in Denmark. And, during that period, we were always under the impression that personal hygiene and work practices were overriding.

I think it's true to say that there is an effect on blood lead levels by lowering the workplace lead in the air. But I can't say that we've found that that does the trick. I think it will be necessary to educate the workers (we have been doing that for some time), to do everything we can to reduce the workplace atmosphere's lead content, and to instruct and maintain good work practice and good housekeeping. The last two are very important and will remain so.

Question (F. Boelter):

What kind of locker room and showering facilities to you have?

Answer (N. Gram):

Our change room facilities have for many years been divided into "black" and "white" rooms. But our luncheon room facilities are not as good as they should be and they are now being revised. We can also improve on cleanliness of workclothes. We change people's clothes only weekly, except for very special jobs.

There is something else we could do that we don't want to do - we could give people respirators. This practice is not common or acceptable in Denmark. Our people work without personal protection, except for special jobs like relining or cleaning inside ducts and exchanging bags in dust collectors. All the daily routine jobs are done without respirators.

Question (D. Jackson, Chicago Inland Metals):

What effect, if any, would the introduction of the maintenance-free batteries have when they are comingled with the old batteries as regards wetting the floors?

Answer (N. Gram):

I'm afraid I can't answer shortly to that. I don't know whether we have time. I think there will be problems, and more so in the scrap trade than with the smelters. For details please refer to my article about arsine and stibine, published in "Lead Power News", No. 9 (Lead Development Assn., London, April, 1978). 


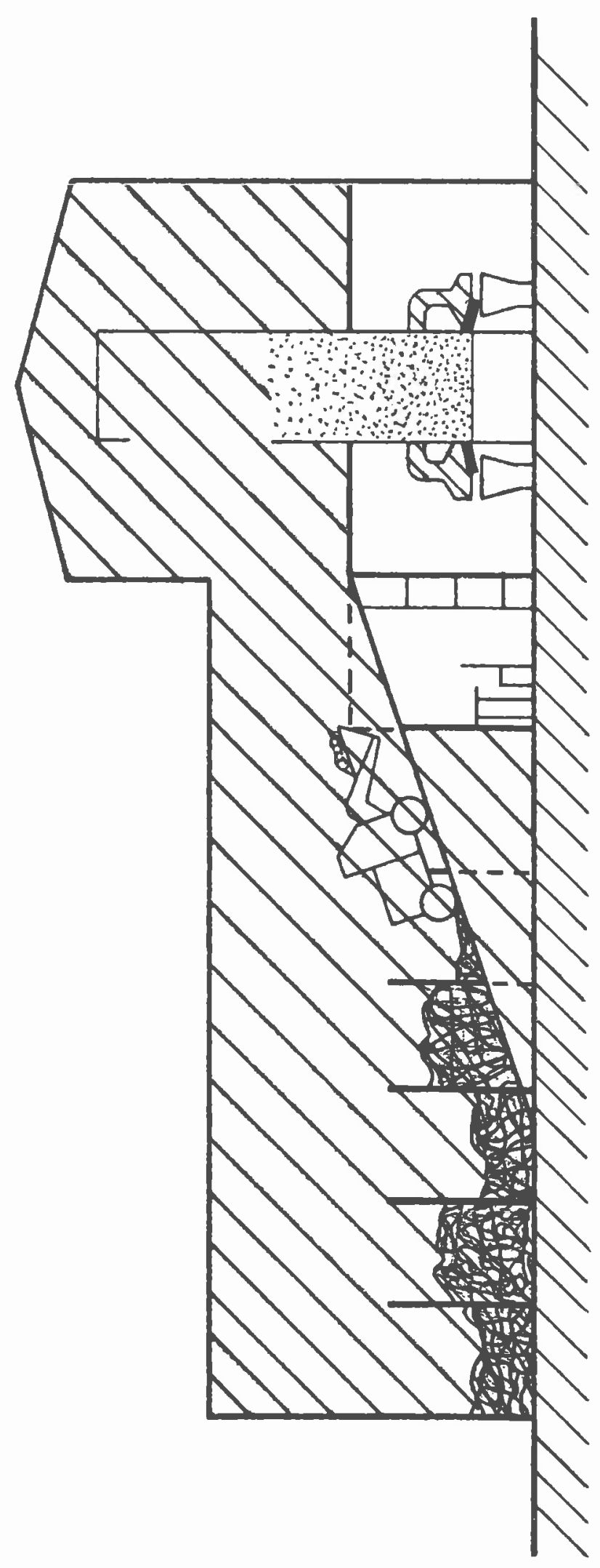

ํํำ

青

* न

क्ष

चु ब्न त

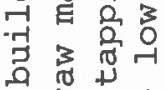

- 40

莒出 死

()

娄

- $\begin{array}{r}\text { I } \\ \text { U }\end{array}$

0

记 总

舟 $=\pi$

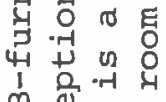

ज ठै

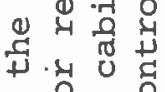

ช 4000

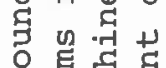

प्र

थ 4 ह

芯这究

담 त्ञ

시 0 견

学

ர नु

द्व

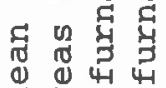

ปี प्र

- 吾

- 秃 ठ

(1) मे

널 옹

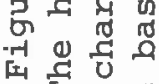

फ 岳焉 


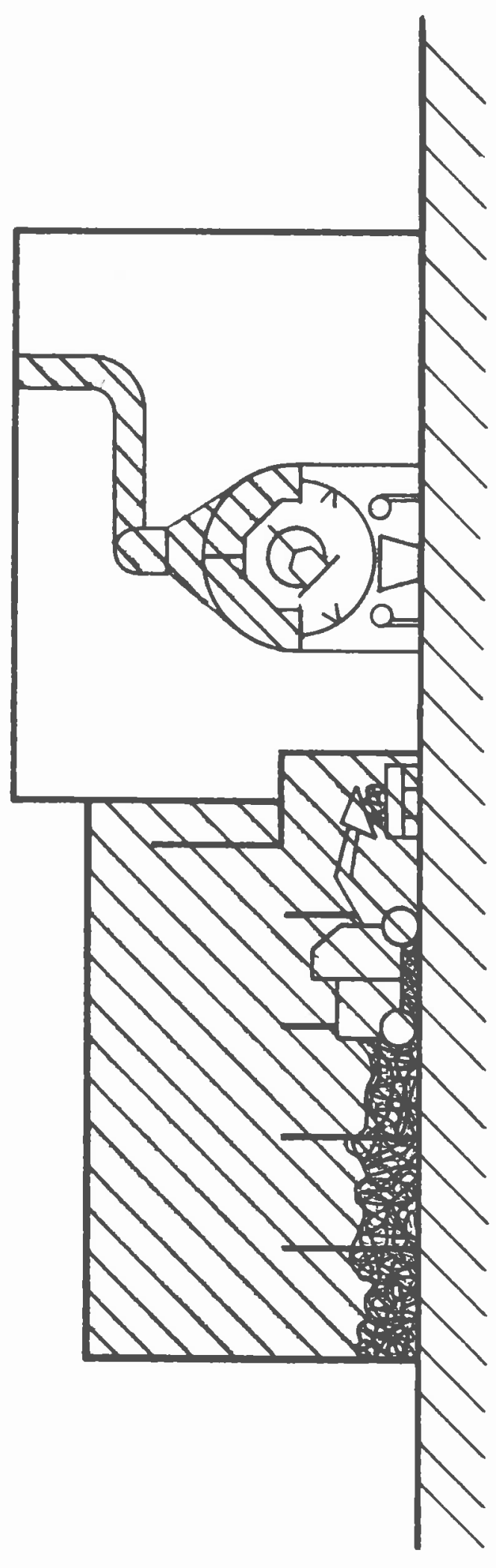

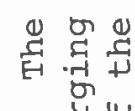

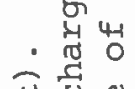

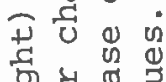

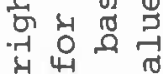

苗要这

ช

.

겅

न-

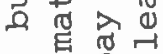

가 3 , 3

ॠ

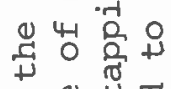

ए

.

- पू

论

范

通苗

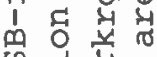

ल न म

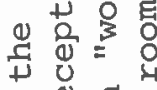

0 \%

马ु

वे टू न मे

तु 4 न्न

ص है

हूㅇํㅇ

प द U

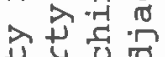

प्र

न्ठ त्ठ है

ن ํㅝㅁ

त 0

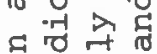

क्. है

ปี

U

- \begin{tabular}{rr}
0 \\
$-\pi$ \\
\hline
\end{tabular}

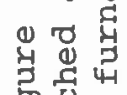

ดु

品枈 


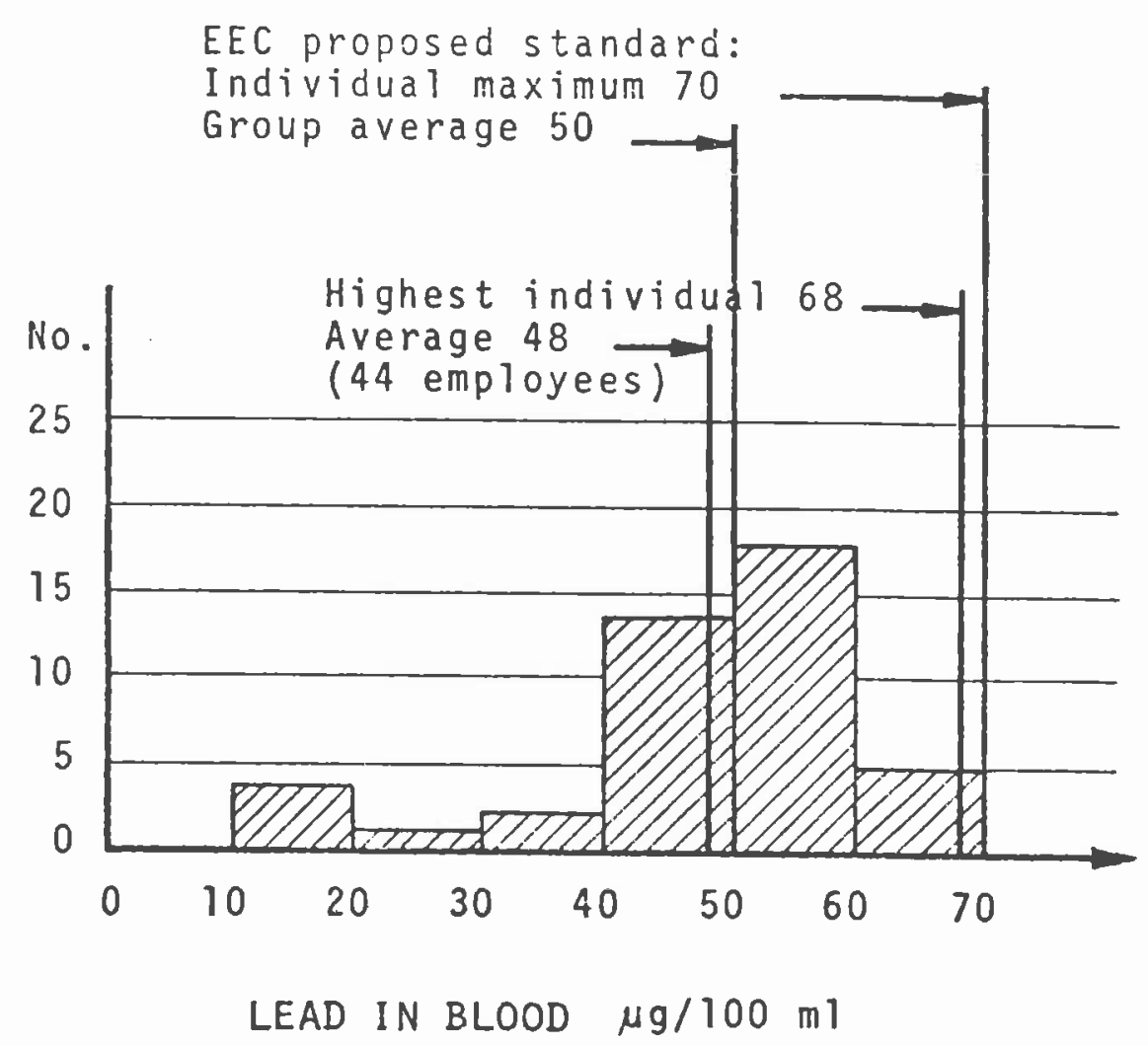

Figure 2. Clean and dirty rooms in the short rotary furnace department. The hatched area to the left is used for raw material storage and handling and the loading machine with its "clean" cabin is seen loading charge material into the charge skips in the airlock. Later another machine will take the skips from the clean side of the airlock and feed the contents into the rotary furnace under the hood (shown hatched to indicate the exhaust of fumes). 


\section{ENVIRONMENTAL AND OCCUPATIONAL PROTECTION IN THE SECONDARY LEAD INDUSTRY}

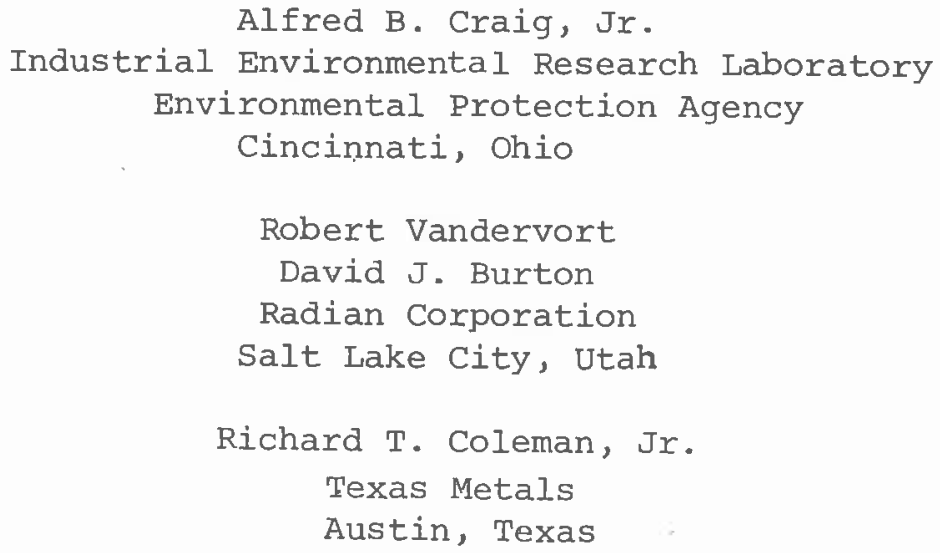

\section{ABSTRACT}

Test results from preliminary sampling studies performed at a secondary lead smelter are reported. The studies were performed before fugitive emission controls were installed. Some interim tests of the partially installed new control system have been completed. Additional work is scheduled.

In-duct air flows and hood capture characteristics were measured for the old ventilation system. Interim measurements indicate that order-ofmagnitude increases in some hood face velocities and air flow will be provided by the new exhaust system. A list of the installed engineering controls is presented. Work practice changes and other suggested improvements are also discussed.

Stack sampling tests were conducted to determine lead, antimony, sulfur, and chlorine emissions. Personal breathing zone and in-plant area samples were collected and analyzed for lead, antimony, and sulfuric acid. High volume ambient air monitoring for total particulate and lead completed the sampling effort. Company supplied blood lead data are also presented.

\section{INTRODUCTION}

The environmental Protection Agency (EPA) and the National Institute for Occupational Safety and Health (NIOSH) are engaged in a demonstration of the Bergsoe agglomeration furnaee and best management practices. The demonstration project is a test of these techniques for controlling fugitive 
and workplace lead emissions. The purpose of this study is to gather data regarding the reduction of both employee exposure to lead and fugitive lead emissions to the ambient environment which can be accomplished by retrofitting controls to an existing secondary lead smelter.

Like almost all secondary lead smelting facilities in the United states, the test smelter has had difficulty controlling both fugitive emissions and the resultant employee exposures to lead. The company is currently in the process of implementing a major exposure abatement plan which involves improved process enclosure and local exhaust ventilation, yard paving, modified materials handling, and agglomeration of flue dust. While engineering controls are being designed and installed employee exposures are being controlled through use of respiratory protective devices and work and hygiene practices.

The demonstration of the agglomeration furnace and best management practices involves before and after characteristics of the smelter. Additionally, the demonstration study provides for limited technical assistance during the final design and installation of engineering controls. This paper contains the data developed in the "before" study and through subsequent contacts with the smelter.

\section{BACKGROUND}

Flue dust handling has historically been a serious problem to secondary lead smelters in the United States and other parts of the world. Flue dusts generated by secondary lead blast and reverberatory furnaces contain appreciable amounts of lead. The collection, handling, storage, and reintroduction of this dust to the smelting process involves opportunities for the dust to enter the ambient, as well as the workplace environment. The Bergsoe flash agglomeration furnace is a means of helping to control emissions from the handling of flue dust beyond the point of its collection in a baghouse. The agglomeration furnace melts the flue dust into a slag-like material which can be handled in bulk form and reintroduced to the process without generating an appreciable amount of dust.

Flue dust handling, however, is not the only source of employee exposure at a secondary smelter. Emissions from furnaces and other smelting equipment also can contribute to workplace and ambient pollution if they are not properly controlled. The test smelter is the first U.S. secondary lead smelting firm to utilize the Bergsoe agglomeration furnace to help control fugitive dust. This smelter is also actively engaged in the installation of exhaust ventilation and improved management practices which should provide substantial red'uction in fugitive emissions and workplace exposures. The amount of improvement will be gauged by the work performed during this study and also by comparing the new conditions with those measured by the company during a two year period preceding this study.

\section{SMELTER DESCRIPTION}

At the test smelter, scrap batteries are broken using slow-moving shears. Battery plates, mud, plant scrap srom an adjacent battery manufacturing facility, drosses, and a variety of other lead scrap are fed to a vertical 
shaft blast furnace. This blast furnace is charged using a skip hoist and traditional slag-tapping and metal-tapping equipment is employed.

The smelter employs approximately 12 people per shift. Much of the work is manual. Charging the furnace and handling of crude and refined lead in the smelting building involve simple materials handling equipment. A small Bobcat loader is utilized to handle charge materials within the smelting building.

An open-air building houses the blast furnace, refining kettles and other smelting equipment. Several of the walls are open to allow movement of fresh air in and out of the building. The floor of the building is paved but rough. It is heavily contaminated with muas formed by water and paste from battery plates, as well as by other materials tracked in from the yard surrounding the smelting building. Housekeeping, at this particular smelter, is a difficult problem due to the rough surface of the floor and the lack of appropriate drains to flush accumulated lead-containing materials.

Local exhaust ventilation is provided for various emission points associated with the blast furnace and to some extent for the refining kettles. Figure 1 presents an overview of the original local exhaust ventilation system for the smelter building. Most of the system is serviced by a $4.7 \mathrm{~m}^{3} / \mathrm{s}$ $(10,000 \mathrm{cfm})$ baghouse and fan system. The slag tapping hood is connected to a separate $2.4 \mathrm{~m}^{3} / \mathrm{s}(5,000 \mathrm{cfm})$ baghouse and fan. Not included in this overview sketch is the blast furnace flue gas control system. Flue gases are ducted through knockout chambers and cooling tubes to a separate baghouse and fan duct collecting system. A new baghouse and fan system will collect exhaust gases from the local exhaust ventilation hoods. The slag tapping hood will continue to be served by the separate baghouse and fan.

Figure 2 presents a sketch of the skip hoist ground level loading station. Local exhaust pickups are provided at each side of the hoist enclosure. As indicated in Figure 2 the skip hoist dumping station at the top of the hoist shaft is exhausted via the skip hoist furnace charging hood.

Figure 3 presents a sketch of the local exhaust hood associated with slag tapping. As stated earlier, this hood is served by a separate dust collector and fan. This exhaust system is operated during slag tapping. The front door to the hood is raised by means of a cable and pulleys. The sides to the hood are hinged and swing away to allow access to the slag tapping port. Slag containers are moved via forklift trucks.

Figure 4 illustrates the relationship of the three local exhaust hoods which serve the molten lead tapping and molding operation. The tapping hood is stationary and is provided with fold-up side curtains to facilitate access to the tapping port. The launder hood moves with the launder which is supported from beneath by a pivoting mechanism. The sides to the launder hood fold up to allow cleaning of the launder. The mold filling hood is portable and is manually lifted into position over the mold being filled. Molds are contained in a tub filled with water. Finished ingots are removed from the molds through use of an overhead monorail hoist. 


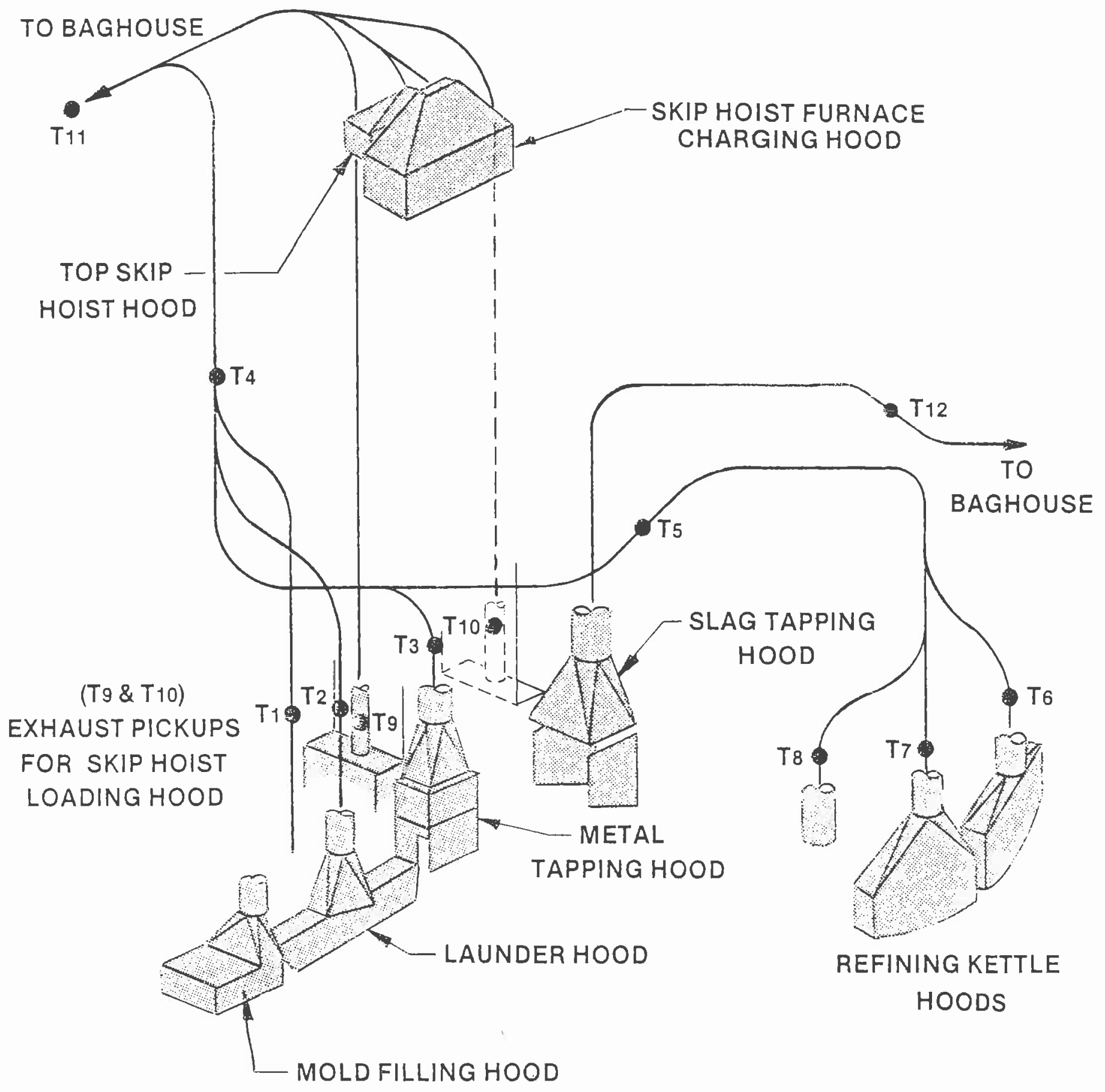

Figure 1. Overview of original local exhaust ventilation system. 


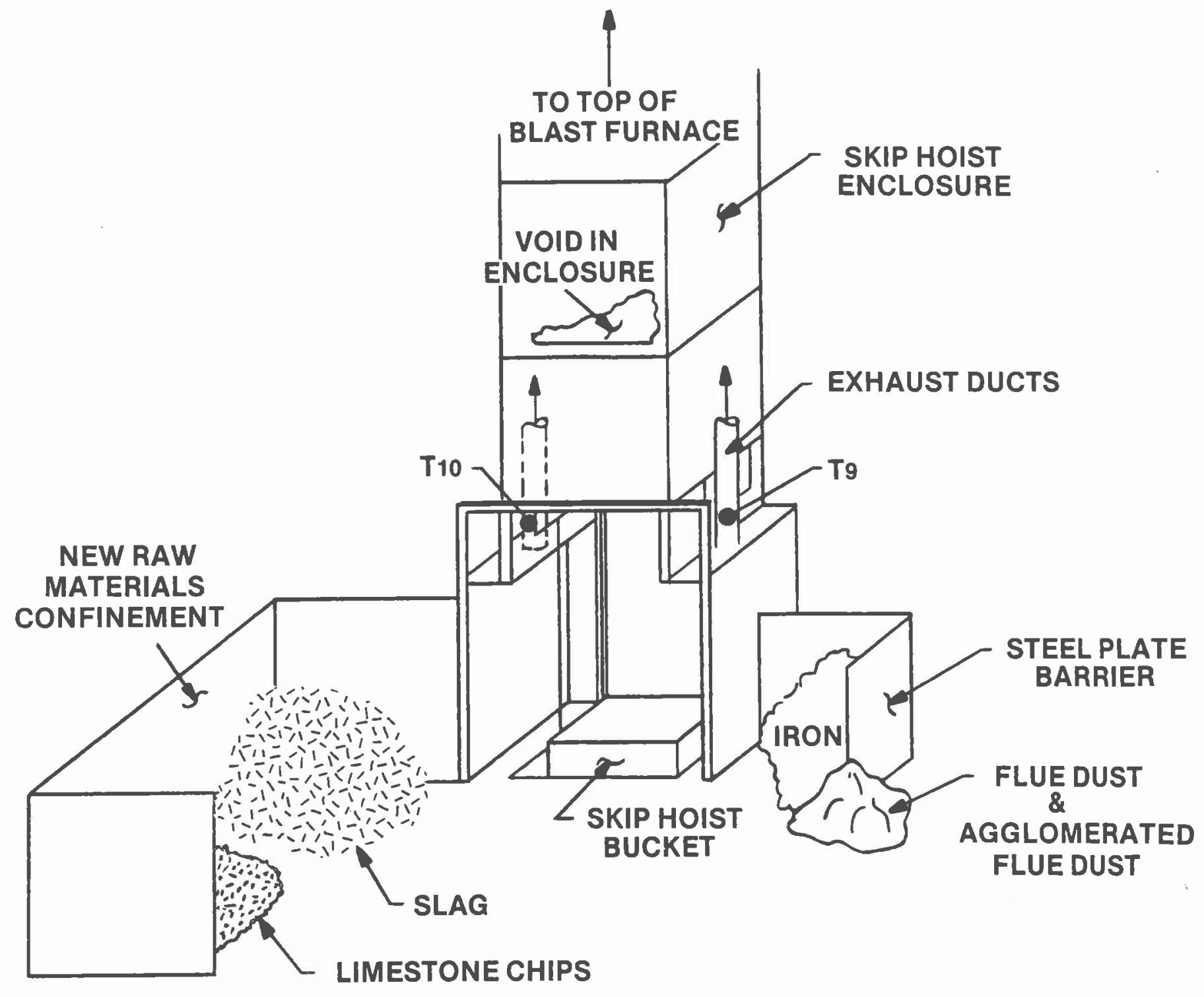

Figure 2. Skip hoist ground level loading station. 


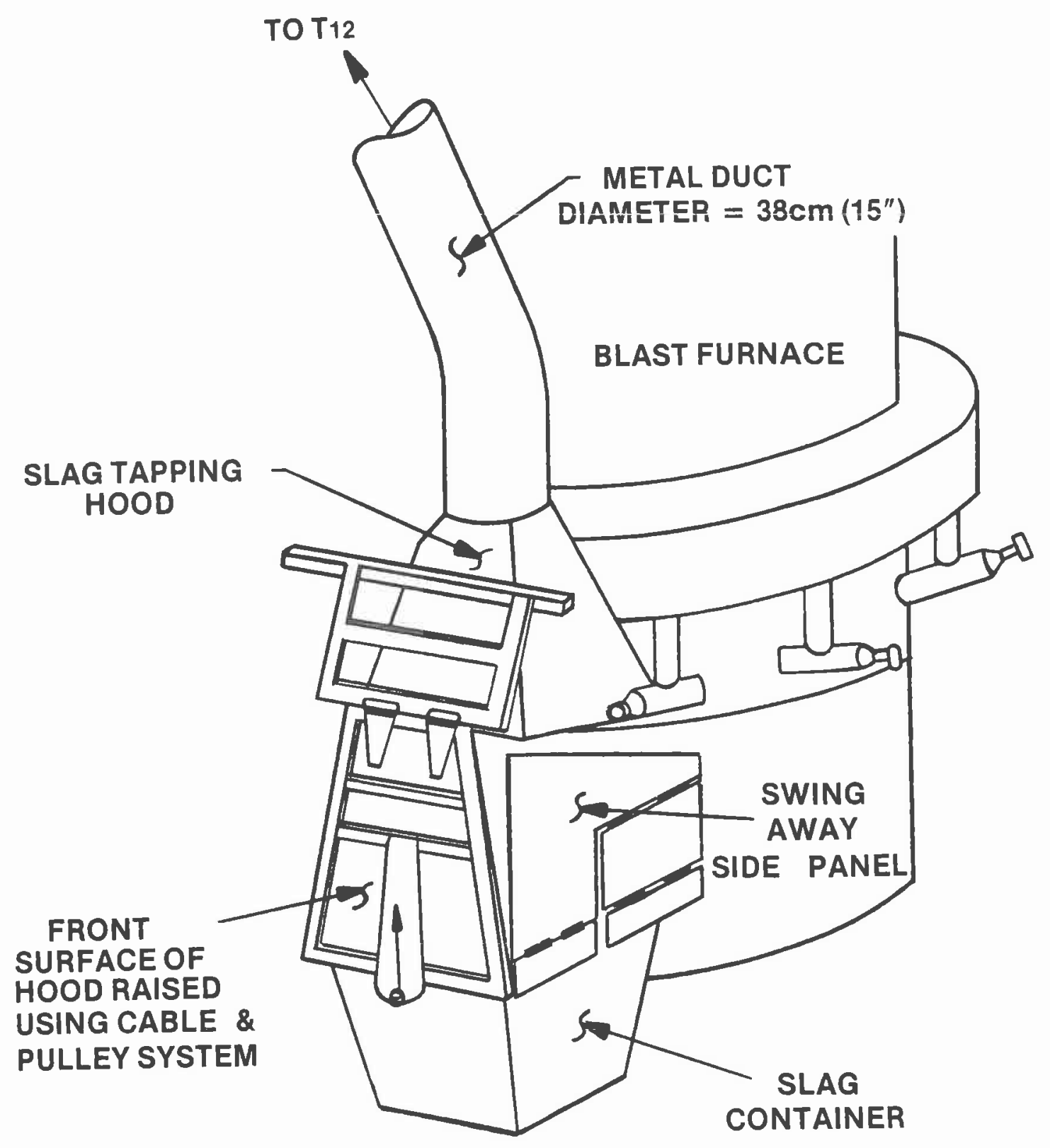

F.igure 3. Blast furnace slag tapping hood. 


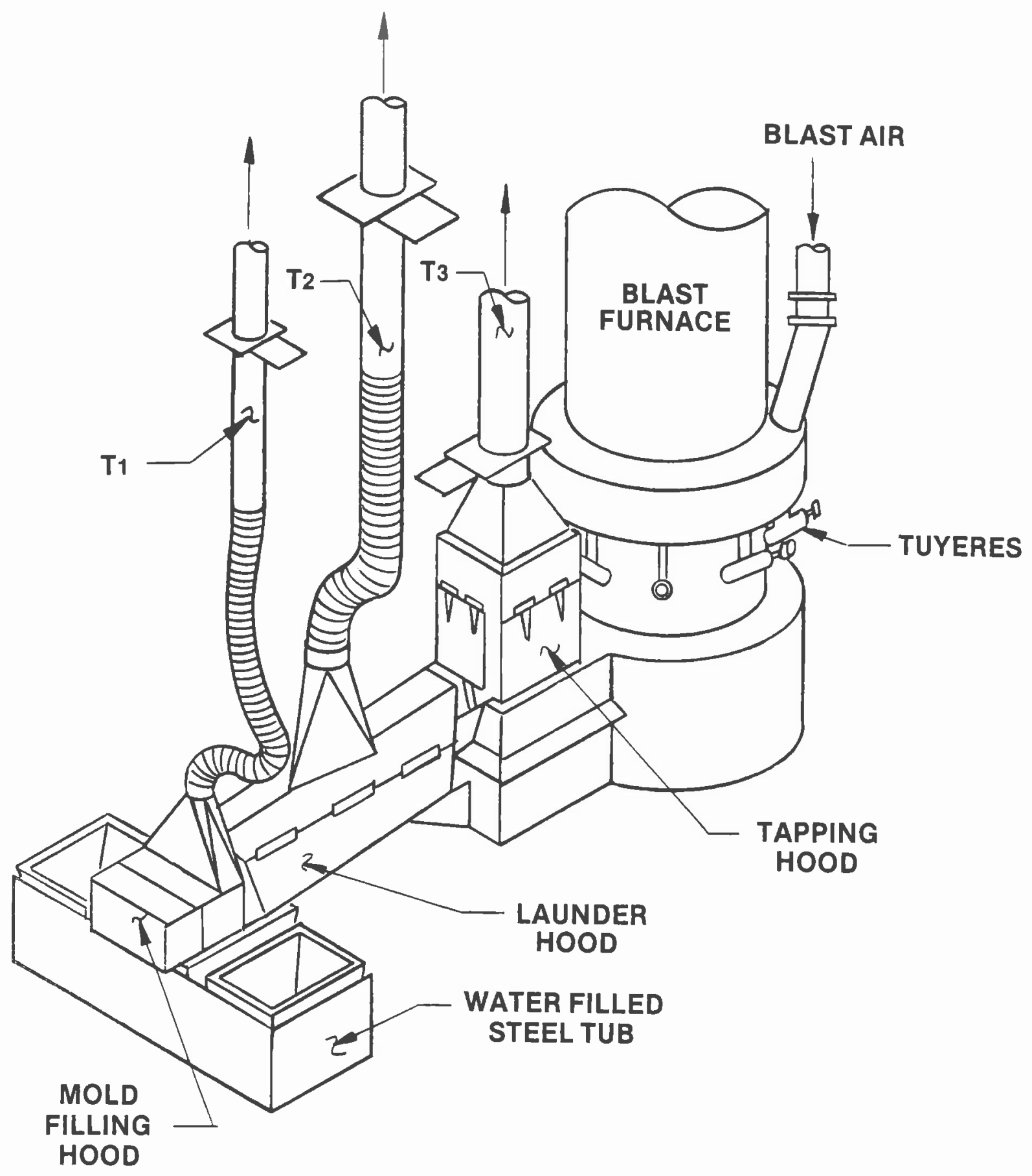

Figure 4. Local exhaust ventilation controls for molten lead tapping and molding. 
Following the initial characterization, the smelter building exhaust ventilation system was modified. These modifications are shown in part in Figure 5. The slag tapping hood is still served by the $2.4 \mathrm{~m}^{3} / \mathrm{s}(5,000 \mathrm{cfm})$ baghouse and fan. However, the remainder of the system is now served by a new baghouse and fan system with capacity in excess of $19.8 \mathrm{~m}^{3} / \mathrm{s}(42,000 \mathrm{cfm})$. An additional local exhaust ventilation hood has been provided at the top of the blast furnace to capture fugitive emissions leaking from side access doors to the furnace. Other local exhaust hoods have not been modified.

In addition to the local exhaust hoods and ductwork shown in Figure 5, the new ventilation system also serves the flue dust agglomeration furnace and associated flue dust handling equipment. As indicated in Figure 5, ductwork has been provided to serve the new refining kettle hoods which were in the final design stage at the time of the initial visit. Eventually both refining kettles will be provided with near total enclosure. The existing backdraft hoods will be removed and refractory chimneys installed to handle kettle burner exhaust gases.

Operating Conditions

The smelter operated normally during the entire initial test period. Battery plates were the major lead-bearing feed material charged to the blast furnace. Small amounts of flue dust and dross were also being recycled to the furnace. The plate material was generated by two men operating a hydraulic battery shear.

Rubber-cased automotive (SLI) and industrial batteries comprised a majority of the batteries processed. Some polypropylene-cased batteries were also present. All battery cases were removed and discarded prior to smelting. Only fragments of the rubber or plastic cases were included in the furnace charge.

Materials Handling and Housekeeping

The smelter began a major effort to clean up yard areas and improve housekeeping after the initial visit. Much of the large flue dust storage pile located adjacent to the process control baghouse system had been removed. Unpaved yard areas were being graded to begin removal of lead bearing dirt and rubble. Flue dust being collected in knockout chambers and baghouses was being fed to the agglomeration furnaces. However, since the agglomeration furnace was not completely online, some flue dust was being stockpiled. Tote boxes used to handle flue dusts collected in knockout boxes and small baghouses had been fitted with lids to prevent dispersal of lead bearing dust during transportation of the tote boxes.

During an interim visit, it was observed that the floors of the smelter building were visibly cleaner and wetter than during the initial vist. Major accumulations of dust had been removed from floor surfaces and additional physical barriers (low walls, partitions, etc.) had been provided to contain the spread of charge materials. Although simple in design, the raw 


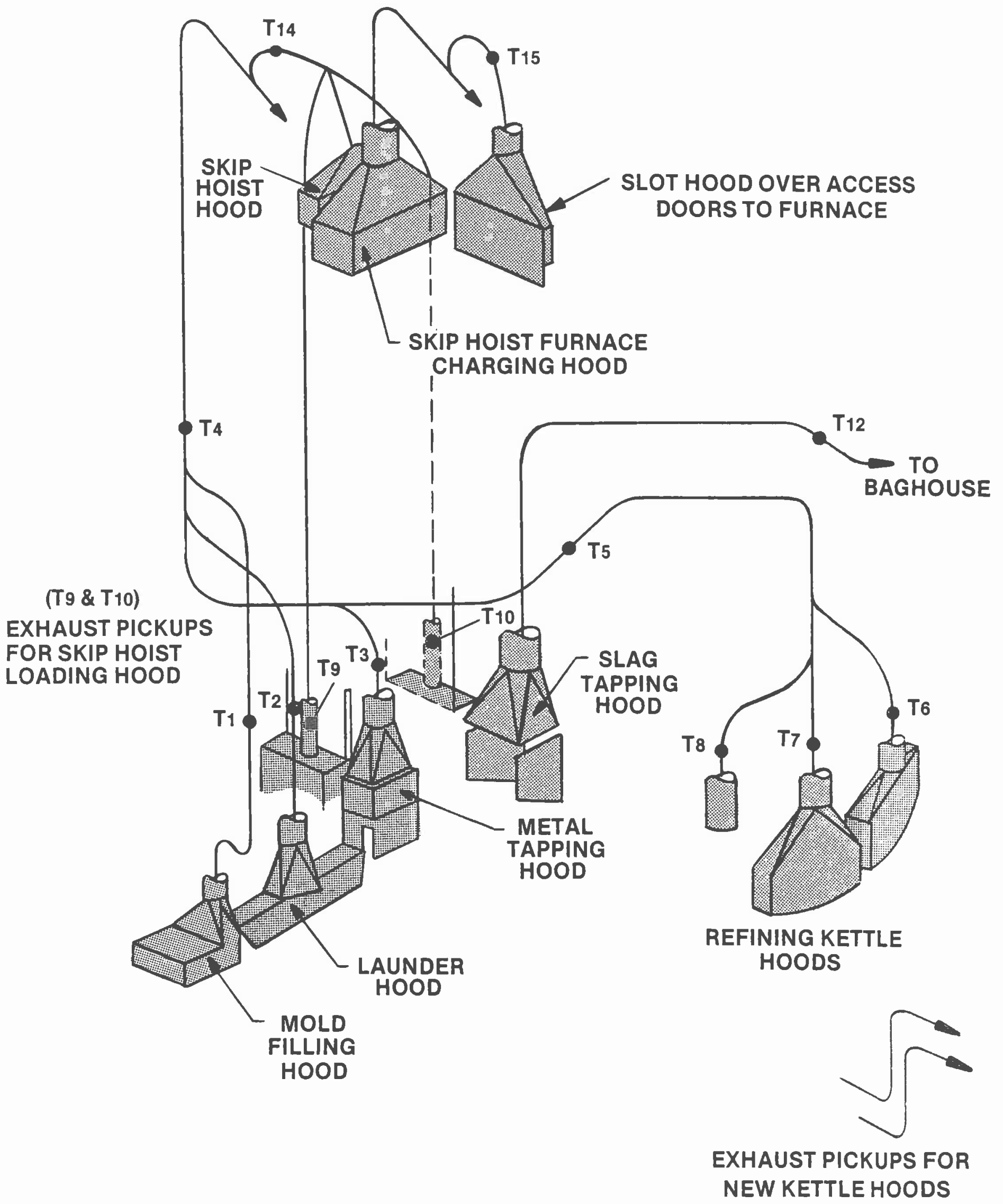

Figure 5. Overview of modified local exhaust ventilation system. 
materials confinement structure provided at the base of the skip hoist did appear to improve housekeeping in this work area.

The implemented improvements in housekeeping and materials handling were discussed with smelter management. Although major strides have been made to improve housekeeping, much work remains to be accomplished. Plans to improve enclosure of the smelter building and isolate raw materials handling were reviewed. A major housekeeping cleaning effort was completed during the sumner shutdown which concentrated on removing accumulations of lead particulates from ceilings, walls, girders, etc.

A major problem at this smelter involves the removal of flue dust from yard areas and floor surfaces. Lead bearing flue dust is difficult to wet. It has a slippery almost greasy property which causes water to bead up and enhances its ability to adhere to surfaces. At present, large unpaved areas of the yard are coated with compacted flue dust. Much of this lead contaminated earth will be excavated and replaced with clean fill and paving. Future contamination by flue dust should be greatly minimized by improved flue dust handling methods and agglomeration of flue dust into a slag-like material. However, paved areas beneath baghouses, U-tube coolers, and knockout chambers will be periodically contaminated by spills of flue dust. These spills could result in widespread yard area contamination if not promptly and completely cleaned up. Improved methods for cleaning flue dust from concrete and asphalt surfaces must be developed. Use of wetting agents and vacuum systems will be explored.

Housekeeping within the smelter building will be made easier with the elimination of flue dust handling associated with furnace charging. However, lead bearing particulate from battery plates, drosses, etc. will continue to contaminate the charge materials handling area. Isolation of this area from other work areas by means of a floor to ceiling partition may help isolate this problem. Maintenance of wet floors and prohibition of dry sweeping will also help if strictly implemented. Floor surfaces within the smelter building are rough and should be smoothed to facilitate cleaning.

Flue Dust Agglomeration

At the time the interim visit was made, the agglomeration furnace had been operating for several days. Several startup problems had been encountered which mainly dealt with furnace burner adjustment and furnace temperature control. These problems were nearly solved during the interim visit. A suitable furnace operating temperature must be found once the flue dust composition and dust generation rate stabilize.

A more difficult problem was encountered in providing a steady feed of flue dust to the furnace. After several days of operation it was determined that individual baghouse compartments released collected flue dust in highly irregular quantities following a bag shaking cycle. Since flue dust is fed directly from the baghouses to the agglomeration furnace, inconsistent feeding of the furnace was being experienced. Surges of flue dust would cause excessive charging of the furnace requiring operation at high heat 
to clear the furnace. These surges also created plugging at the slag tap which required almost continuous attention by an operator. Plans were being implemented to provide better control of furnace charging to eliminate these problems.

When uniformly fed, the agglomeration furnace did produce a steady stream of agglomerated material which was in appearance very similar to the material produced at the Bergsoe smelter in Glostrup, Denmark. However, the problem of emptying tote boxes of dust cleaned from the numerous dropout points in the system into the agglomerator has not been solved. This is one problem which could be avoided in a new smelter design. In this case, the retrofit of the agglomeration system did not include eliminating the dropout points. Thus, the tote box problem remains. Vacuum systems are being investigated as a means of emptying the tote boxes and charging the cleanout material to the agglomerator.

\section{CONTROL EVALUATION}

One major objective of the test work performed was to determine what contribution stack emissions make to ambient and workplace lead-in-air concentrations and what contribution fugitive emission sources make. To accomplish this, the following tests were performed: ventilation measurements, stack sampling, ambient air testing, and workplace monitoring.

In addition, the smelter provided blood lead data which had been collected over the previous three years. Similar data will be collected during a final smelter characterization once all the fugitive emission controls are installed.

The importance of these measurements to this particular smelter is evident when a plot plan of the smelter and the surrounding property is examined. As can be seen in Figure 6, the smelter actually extends beyond the company property line. This creates a significant problem when interpreting the new EPA ambient air quality standard for lead of $1.5 \mu \mathrm{g} \mathrm{Pb} / \mathrm{m}^{3}$. As a result, it is of particular interest to this smelter and EPA to determine what the ambient lead levels are and where they come from. The results of the testing are presented below.

\section{Ventilation Measurements}

Table 1 presents a comparison of exhaust air flows at several locations in the smelter building exhaust ventilation system. Several of the local exhaust hoods are now collecting two to three times the volume of contaminated air previously collected. Greatly increased quantities of air are being collected by the hoods serving the skip hoist and blast furnace charging operation. The slag tapping emission control system was measured to be collecting somewhat more air than in January. As indicated by measurements made in the new open ended ducts which will serve the refining kettles, approximately $4.0 \mathrm{~m}^{3} / \mathrm{s}(8,500 \mathrm{cfm})$ of exhaust capacity will be available for the new refining kettle hoods. 
Table 1. Comparison of exhaust air flows.

\begin{tabular}{|c|c|c|c|c|}
\hline \multirow[b]{2}{*}{ Fluw measurement location } & \multicolumn{4}{|c|}{ Volumetric flow rate, $Q$} \\
\hline & $\begin{array}{c}\mathrm{m}^{3} / \mathrm{s} \\
(1)\end{array}$ & $\begin{array}{l}\text { cfm } \\
(1)\end{array}$ & $\begin{array}{l}\mathrm{m}^{3} / \mathrm{s} \\
(2)\end{array}$ & $\begin{array}{l}\mathrm{cfm} \\
(2)\end{array}$ \\
\hline Mold filling hood $\left(\mathrm{T}_{1}\right)$ & 0.30 & 630 & 0.78 & 1650 \\
\hline Launder hood $\left(\mathrm{T}_{2}\right)$ & 0.39 & 820 & 1.2 & 2460 \\
\hline Metal tapping hood $\left(\mathrm{T}_{3}\right)$ & 0.65 & 1380 & 1.7 & 3660 \\
\hline Refining kettle hoods $\left(T_{5}\right)$ & 0.70 & 1480 & 2.2 & 4700 \\
\hline $\begin{array}{l}\text { Skip hoist hoods }+ \text { skip hoist } \\
\text { furnace charging hood }\end{array}$ & 2.8 & 5990 & 7.6 & 16030 \\
\hline Skip hoist furnace charging hood & & & 5.7 & 12100 \\
\hline Skip hoist hoods (top and bottom $\left(\mathrm{T}_{14}\right)$ & & & 1.9 & 3930 \\
\hline Slot hood over furnace access doors $\left(\mathrm{T}_{15}\right)$ & & & 0.91 & 1940 \\
\hline Slag tapping hood $\left(\mathrm{T}_{12}\right)$ & 1.8 & 3850 & 2.1 & 4540 \\
\hline $\begin{array}{l}\text { Exhaust pickups for new } \\
\text { kettle hoods }\end{array}$ & & & 1.4 & 2940 \\
\hline $\begin{array}{l}\text { Discharge from slag tapping } \\
\text { baghouse. }\end{array}$ & & & 2.4 & 5000 \\
\hline $\begin{array}{l}\text { Inlet to main exhaust fan for } \\
\text { smelter exhaust ventilation system }\end{array}$ & & & 20 & 41700 \\
\hline
\end{tabular}

(1) Measurements made $1 / 23-24 / 79$ with old exhaust system in operation. (Refer to Fig. 1).

(2) Measurements made 6/19-20/79 with new exhaust system in operation. (Refer to Fig. 5) 
The increased air volume being collected by each of the local exhaust hoods has increased hood face velocities. Face velocity measurements were made for several of the hoods using an Alnor $\mathrm{R}$ Velometer. As can be seen from the data in Table 1, substantial improvement has been realized and improved control was apparent by observation of fume capture. However, the degree of emission source enclosure offered by many of these hoods could be improved. Hood modifications are planned once more major modifications are complete. .

\section{Stack Sampling}

Stack sampling was performed in the exhaust duct leading to the main stack. Sampling personnel worked from a platform located approximately six meters from ground level. The duct was rectangular and was inclined at approximately a 30 degree angle from horizontal. The interior dimensions of the duct were $813 \mathrm{~mm}$ in height and $711 \mathrm{~mm}$ in depth.

At the platform level, the duct was equipped with three access ports on the vertical surface of the duct. These were located approximately $135 \mathrm{~mm}$ from the edge of the duct on $270 \mathrm{~mm}$ centers. The place in which the sample ports were located was approximately two equivalent diameters upstream and eight equivalent diameters downstream. of any flow disturbances. Velocity and sampling traverses were made at four points in each of these three ports, for a total of twelve points.

The EPA Method 5 sampling train was used to determine average duct temperature, velocity, and moisture content on January 21, 1979. These measurements were used to select the appropriate nozzle and isokinetic sampling rates for subsequent tests: Isokinetic sampling was performed at each point for the remaining tests conducted on January 22 and 23 .

On January 22 one Method 5 experiment was conducted. Isokinetic sampling was conducted at each point within each port for a period of five minutes. When all the points in all the ports had been traversed, sampling was repeated. This continued for approximately six hours so that sufficient sample for analysis could be obtained.

On January 23 , the experiment was repeated, however, each point was sampled over a fifteen-minute period to minimize sampling time. Sampling took approximately three and one-half hours.

Sampling was performed for $\mathrm{SO}_{\mathrm{X}}$ emissions using the Method 5 equipment as well. One thirty-minute sample was obtained at the center of the duct. Proportional sampling was conducted to obtain a $0.217 \mathrm{Nm}^{3}$ sample.

Stack particulates were collected on a glass fiber filter heated to $121^{\circ} \mathrm{C}\left(250^{\circ} \mathrm{F}\right)$ in a thermostated oven. Both the filter and probe were heated during sampling. Table 2 presents the results of this experiment for both test days. It is important to note that the average grain loadings for both days were nearly identical. This indicates that the baghouse was operating normally and was allowing a constant amount of fine particulate to pass through with the gas streams. 


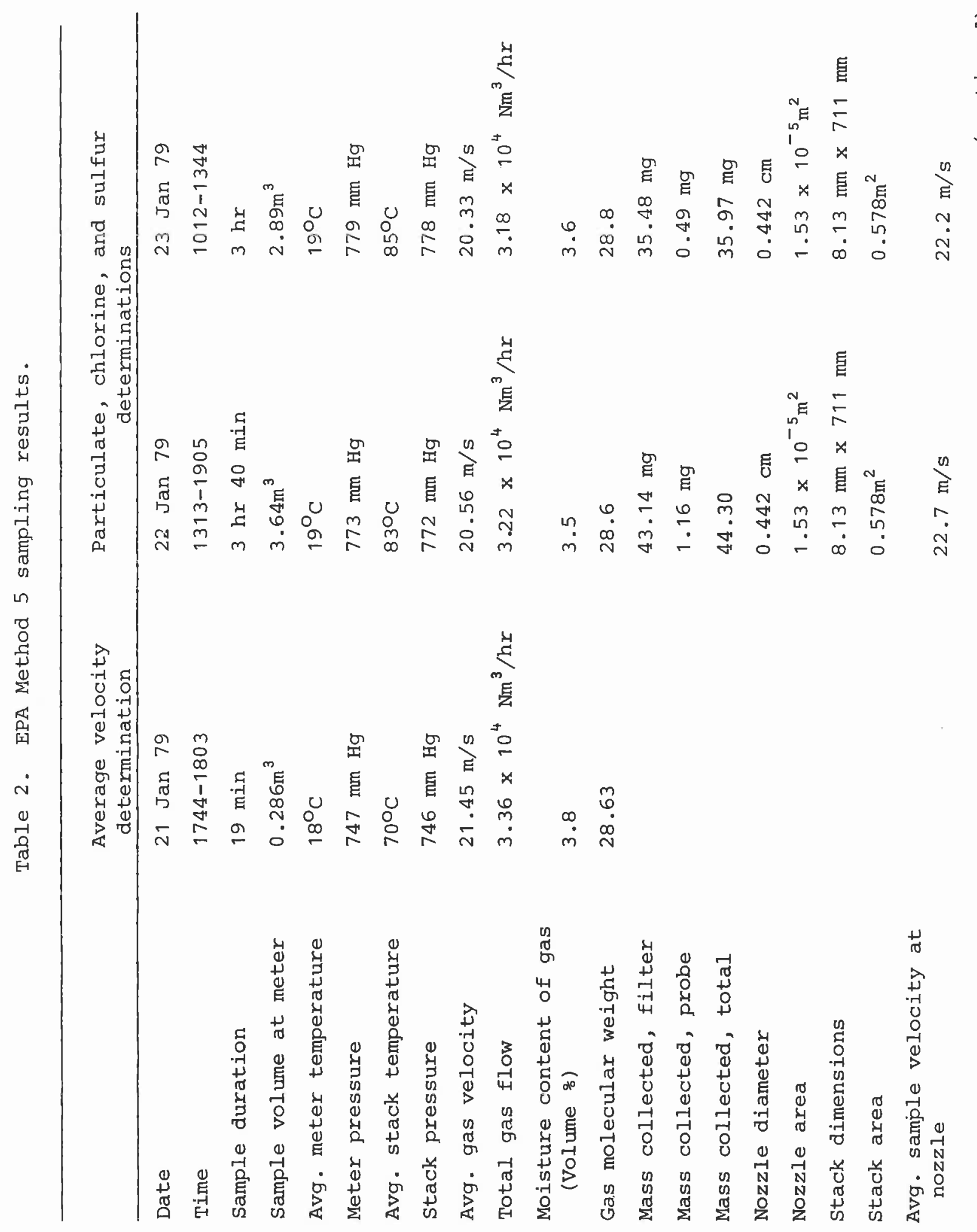




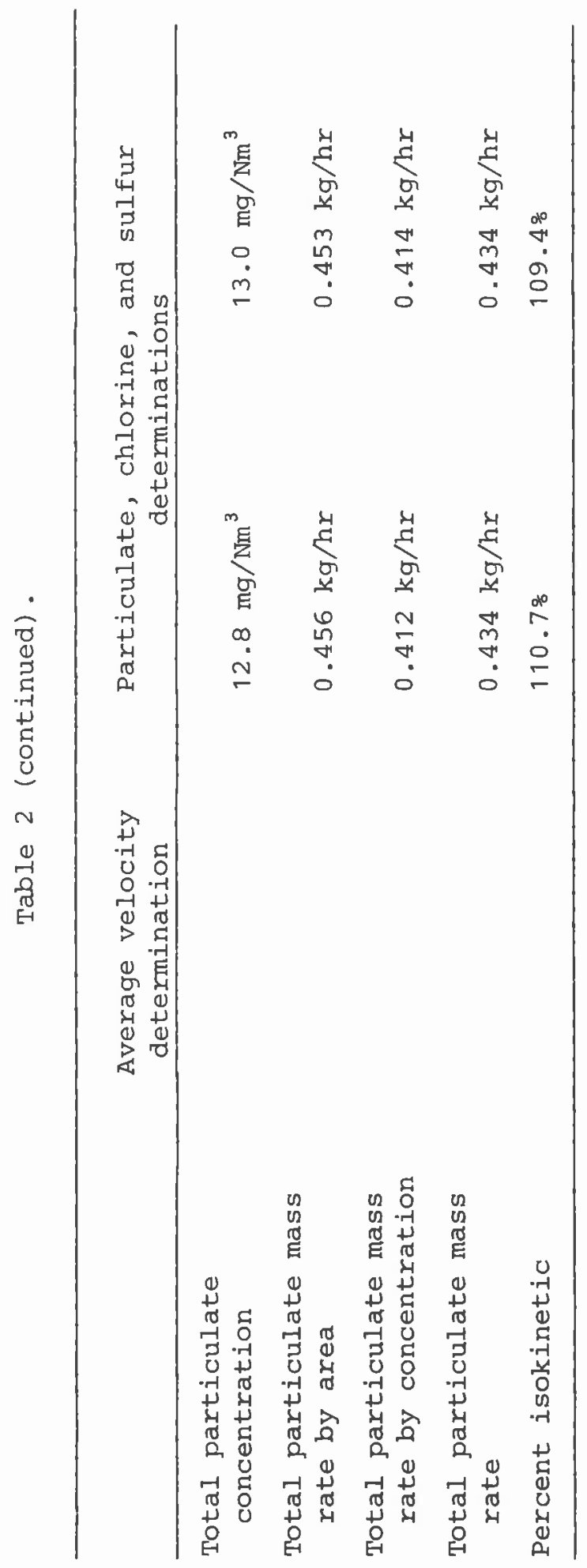


Sulfur and chlorine compounds were collected in a series of three impingers which were placed behind the heated filter in the Method 5 sampling train. Two impingers in series containing 1 percent $\mathrm{NaOH}$ followed by an impinger containing 6 percent $\mathrm{H}_{2} \mathrm{O}_{2}$ were used for the experiment. A Dionex $\mathrm{R}$ ion chromatograph was used for the sulfur determinations. A colorimetric determination using mercuric thiocyanate was used for the chlorine determinations.

An analysis of the matter collected as particulate and vapor was made for lead, antimony, sulfur, and chlorine. The results are presented in Table 3. These results indicate that both particulate and vaporous species are being emitted from the baghouse.

Lead is emitted mostly as particulate matter (99.99 percent). Antimony, however, is present mostly as a vapor (57 to 66 percent). It is likely that lead oxide $(\mathrm{PbO})$, lead chloride $\left(\mathrm{PbCl}_{2}\right)$, and antimony pentachloride ( $\mathrm{SbCl}_{5}$ ) are the compounds being emitted. The boiling point of $\mathrm{SbCl}_{5}, 79^{\circ} \mathrm{C}$, would account for the antimony being at least partially present as vapor.

Chlorine emissions were significantly higher on $1 / 23 / 79$ than on $1 / 22 / 79$. This might be due to a larger recycle of flue dust from the knockout chambers or because of a larger percentage of polyvinyl chloride separators in the feed materials that day.

Sulfur was emitted mostly as sulfur dioxide $\left(\mathrm{SO}_{2}\right)$. Some sulfur was detected in the collected particulate matter, perhaps present as calcium sulfate $\left(\mathrm{CaSO}_{4}\right)$. This compound is formed by the reaction of $\mathrm{SO}_{3}$ or sulfuric acid mist with the lime injected into the flue gas. The sulfur emission rates of 33,500 and $30,400 \mathrm{~g} / \mathrm{hr}$ were checked on 1/23/79 using the EPA Method 5 equipment with isopropyl alcohol in one impinger and hydrogen peroxide in another. The emission rate using this technique was $29,600 \mathrm{~g} / \mathrm{hr}$ which agrees closely with the Method 5 results.

Ambient Air Testing

Four high volume air samples were operating during the sampling study. Figure 6 shows the location of these four hi-vols (locations no. 5 through no. 4) and one other location measured by smelter personnel (location no. 5). Location no. 4 was also a smelter hi-vol. Two samples were collected from locations no. 1, no. 3 , and nò. 4 and one from no. 2 during the test period. Other data from location no. 4 and no. 5 were provided by the smelter. Table 4 presents the hi-vol test results.

The weather on January 22, 1979, was cold, clear and windy. Winds from the W-NW ranged from 9 to 16 meters per second (20 to $35 \mathrm{miles} / \mathrm{hr}$ ) during January 22. On January 23, 1979, it was clear, dry and relatively calm. The ground was snow-covered during the entire test period, however, the snow did not cover the flue dust pile behind the smelter.

The results presented in Table 4 are not conclusive, but they do show some trends. For example, location no. 3 shows a significantly higher lead-inair concentration on $1 / 22 / 79$, a windy day, than on $1 / 23 / 79$, a calm day. 


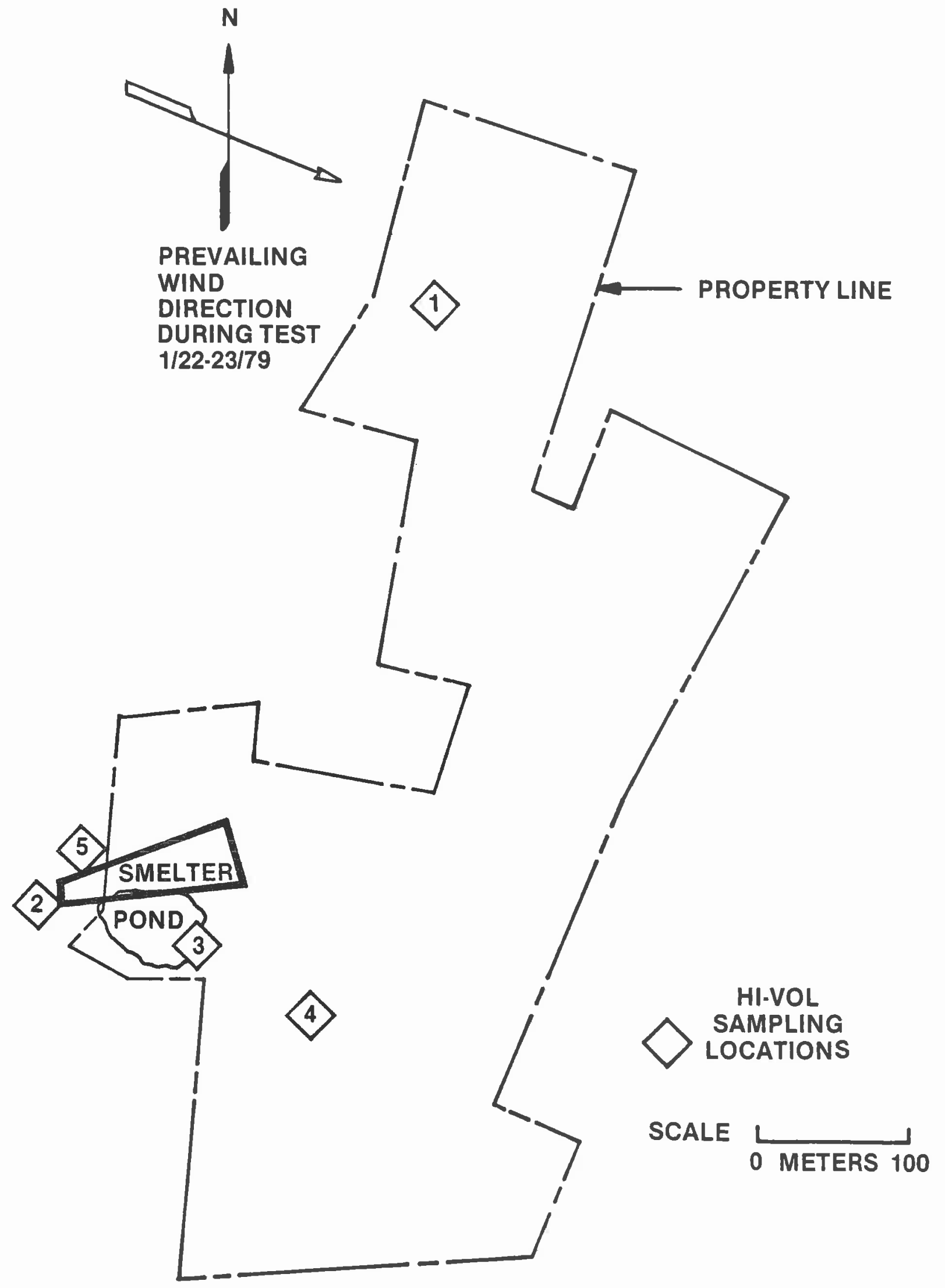

Figure 6. Pilot plan of smelter property. 


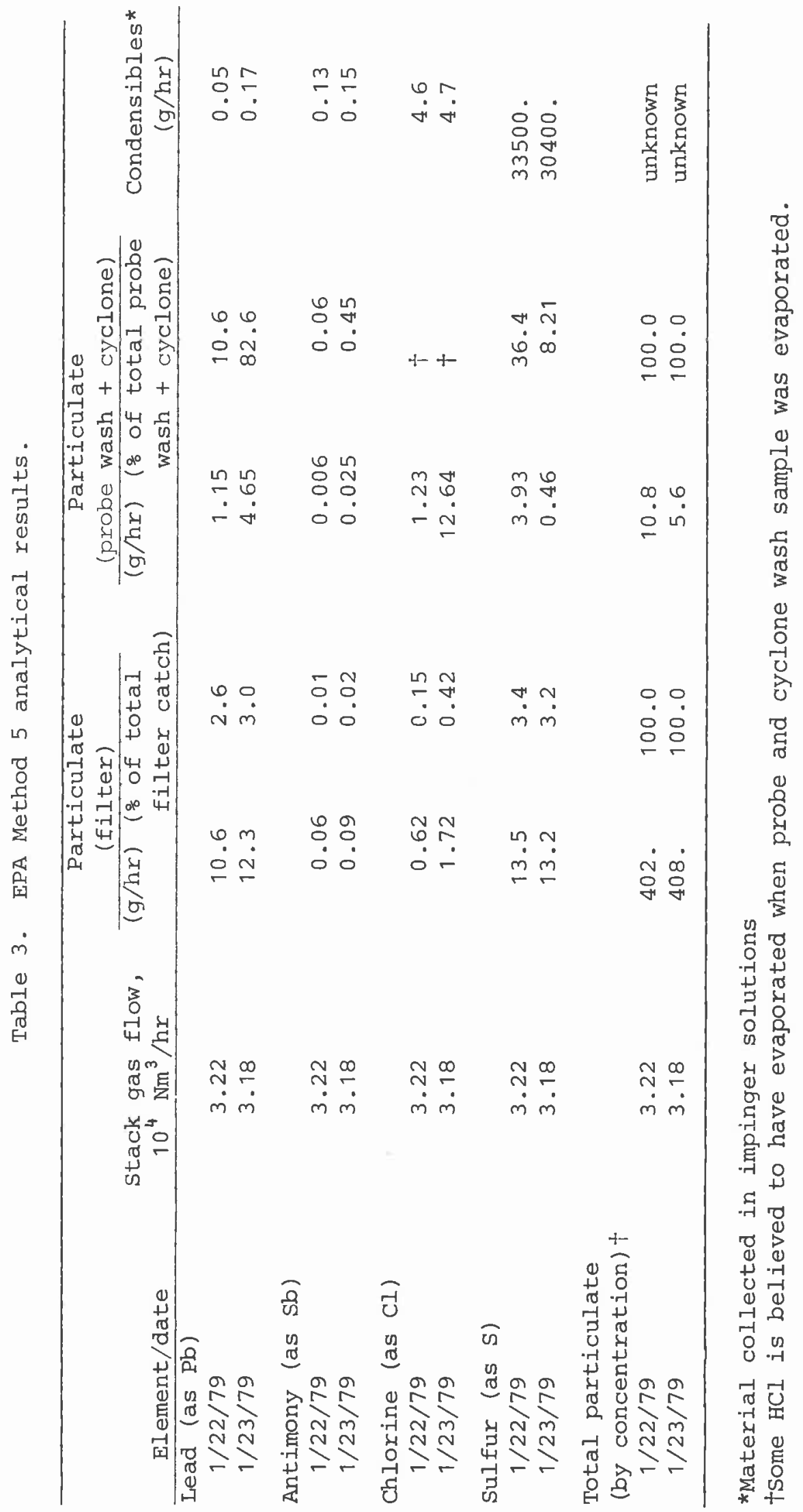


The calm conditions apparently reduced fugitive windblown dust from the smelter yard. Also, lead-in-air levels at location no. 4 remained fairly constant while location no. 3 varied by an order of magnitude. This indicates that the fugitive lead particulate from the smelter yard may be settling within a relatively short distance (location no. 3) while some constant background level, perhaps generated by the stack, accounts for conditions at location 4. The windy conditions on $1 / 22$ could thus cause an order- of-magnitude increase in lead concentrations at location 3 without seriously affecting location no. 4. Certainly more data are required before these trends can be substantiated.

Table 4. Hi-vol sampling results.

\begin{tabular}{|c|c|c|c|c|}
\hline Location & Date & $\begin{array}{c}\text { Total particulate } \\
\text { collected, } \\
\mu g\end{array}$ & $\begin{array}{l}\text { Total lead } \\
\text { collected, } \\
\mu \mathrm{g}\end{array}$ & $\begin{array}{l}\text { Ambient lead } \\
\text { concentration, } \\
\mu \mathrm{g} \mathrm{Pb} / \mathrm{m}^{3}\end{array}$ \\
\hline \multirow[t]{2}{*}{1} & $1 / 22 / 79$ & 54,000 & 1,750 & 0.88 \\
\hline & $1 / 23 / 79$ & 83,300 & 2,220 & 1.3 \\
\hline 2 & $1 / 22 / 79$ & 101,000 & 6,740 & 3.0 \\
\hline \multirow[t]{2}{*}{3} & $1 / 22 / 79$ & 106,000 & 29,500 & 16. \\
\hline & $1 / 23 / 79$ & 72,800 & 2,830 & 1.6 \\
\hline \multirow[t]{6}{*}{4} & $1 / 22 / 79$ & & & 9.3 \\
\hline & $1 / 23 / 79$ & & & 7.4 \\
\hline & $8 / 24 / 78$ & & & 1.1 \\
\hline & $8 / 30 / 78$ & & & 0.8 \\
\hline & $9 / 1 / 78$ & & & 1.0 \\
\hline & $9 / 5 / 78$ & & & 3.3 \\
\hline 5 & $5 / 22 / 78$ & & & 370 \\
\hline
\end{tabular}

Two Gaussian dispersion computer models were used to estimate the dispersion of particulates from the lead smelter. These two models are the Climatological Dispersion Model (CDM) and CRSTER. Both models employ the standard Gaussian plume assumption. These models assume that the pollutant concentration in a smokestack plume advects downwind with the ambient air while diffusing in both the horizontal and vertical directions. The pollutant distributions in the plume are assumed to obey Gaussian, or normal, distributions.

The emission data used in the two models are as follows:

$\begin{array}{ll}\text { Emission rate } & 0.126 \mathrm{~g} / \mathrm{sec} \\ \text { Stack height } & 16.8 \mathrm{~m} \\ \text { Stack diameter } & 8.6 \mathrm{~m} \\ \text { Stack gas velocity } & 20.5 \mathrm{~m} / \mathrm{sec} \\ \text { Stack gas temperature } & 84^{\circ} \mathrm{C}\end{array}$


Only total suspended particulate (TSP) was modelled. No attempt was made to separate the lead fraction of TSP from the total emission.

One significant assumption involved with Gaussian models is that no loss of mass occurs from the plume, e.g., settling or deposition. This is a conservative assumption for this analysis because the lead fraction of the particulate matter emitted by the smelter is dense and may settle rapidly. The result is that ambient concentrations predicted by the models will be higher than actual concentrations.

The CDM model predicts annual or seasonal concentrations due to pollutant emissions. It uses meterological information in the form of a joint frequency distribution of wind speed, wind direction, and atmospheric stability. For this analysis, ten years of meteorological observations at a nearby local airport were averaged together to yield the joint frequency distribution.

The CRSTER model predicts both short term and seasonal or annual concentrations based upon actual observed meteorological data. The CRSTER model calculates the hourly concentration at a grid of receptors for each hour of a year's worth of data. It then averages these concentrations together to yield average concentrations for periods of up to a year in length. Local meteorological data for 1964 were used and the model averaged concentrations over the winter months of January, February, and December to yield a seasonal average concentration.

Both the short term 24-hour average concentrations predicted by CRSTER and the seasonal average concentrations predicted by CDM are very small (Figure 7 ). Using a $200 \mathrm{~m}$ by $200 \mathrm{~m}$ grid, the highest concentration predicted by CDM for the winter season is $0.5 \mu \mathrm{g} / \mathrm{m}^{3}, 200 \mathrm{~m}$ east of the smelter. This is one-half of the concentration value used for point source dispersion (PSD) analysis to determine area of impact of a source. All other concentrations produced by the CDM model fall off rapidly with distance from the smelter and are at or below $1.0 \mu \mathrm{g} / \mathrm{m}^{3}, 600 \mathrm{~m}$ away from the smelter.

The 24-hour maximum concentration predicted by CRSTER is $0.9 \mu \mathrm{g} / \mathrm{m}^{3}$ at $5 \mu \mathrm{g} / \mathrm{m}^{3}$ level of significance used in PSD analysis for TSP.

Based upon these dispersion modelling results the conclusion can be drawn that particulate emissions from the test smelter stack have a negligible impact on ambient particulate concentrations in the vicinity $(<1 \mathrm{~km})$ of the smelter.

Workplace Lead-in-Air Contamination

The test smelter has monitored workplace lead-in-air contamination for a number of years. To assist this demonstration study, monitoring data covering approximately the last two years were submitted for review and evaluation. The results of this monitoring are summarized in Table 5. These data indicate that severe lead-in-air concentrations have accompanied operation of this smelting complex. Employee exposures have varied over a wide range and incorporate the expected seasonal and process fluctuations. 


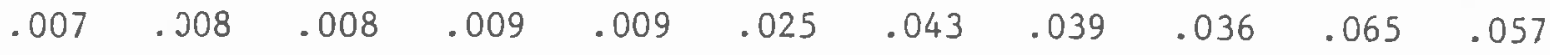

$$
\begin{aligned}
& \begin{array}{lllllllllll}
.008 & .009 & .010 & .010 & .011 & .031 & .053 & .048 & .085 & .074 & .065
\end{array} \\
& \begin{array}{lllllllllll}
.016 & .010 & .012 & .013 & .015 & .042 & .069 & .061 & .0100 & .085 & .085
\end{array} \\
& \begin{array}{lllllllllll}
.017 & .021 & .026 & .017 & .020 & .061 & .096 & .152 & .144 & .113 & .092
\end{array} \\
& \begin{array}{lllllllllll}
.019 & .023 & .029 & .040 & .032
\end{array} \begin{array}{llllll}
.114 & .296 & .229 & .162 & .124 & .100
\end{array}
\end{aligned}
$$

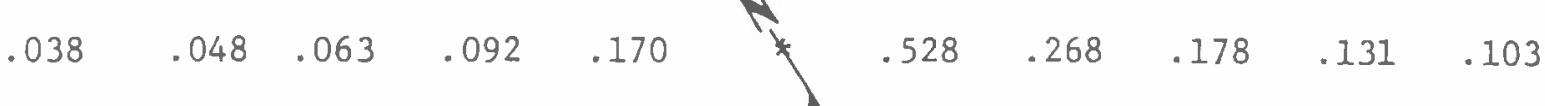

$$
\begin{aligned}
& \begin{array}{lllllllllll}
.082 & .101 & .129 & .179 & .204 & .141 & .183 & .172 & .121 & .092 & .073
\end{array} \\
& \begin{array}{lllllllllll}
.076 & .092 & .116 & .109 & .056 & .077 & .078 & .092 & .107 & .083 & .067
\end{array}
\end{aligned}
$$

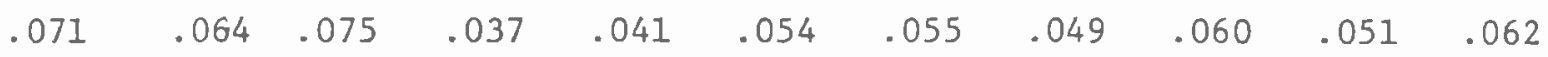

$$
\begin{aligned}
& \begin{array}{lllllllllll}
.050 & .056 & .064 & .030 & .033 & .041 & .043 & .039 & .051 & .044 & .038
\end{array} \\
& \begin{array}{lllllllllll}
.044 & .050 & .023 & .025 & .027 & .033 & .034 & .032 & .029 & .038 & .034
\end{array} \\
& \text { * stack } \\
& \text { L_- } 1 \text { kilometer } \\
& \text { Figure 7. Modelled map of TSP concentration (CDM model, no deposition, } \\
& \text { winter conditions) around test smelter stack in } \mu \mathrm{g} \mathrm{TSP} / \mathrm{m}^{3} \text {. }
\end{aligned}
$$




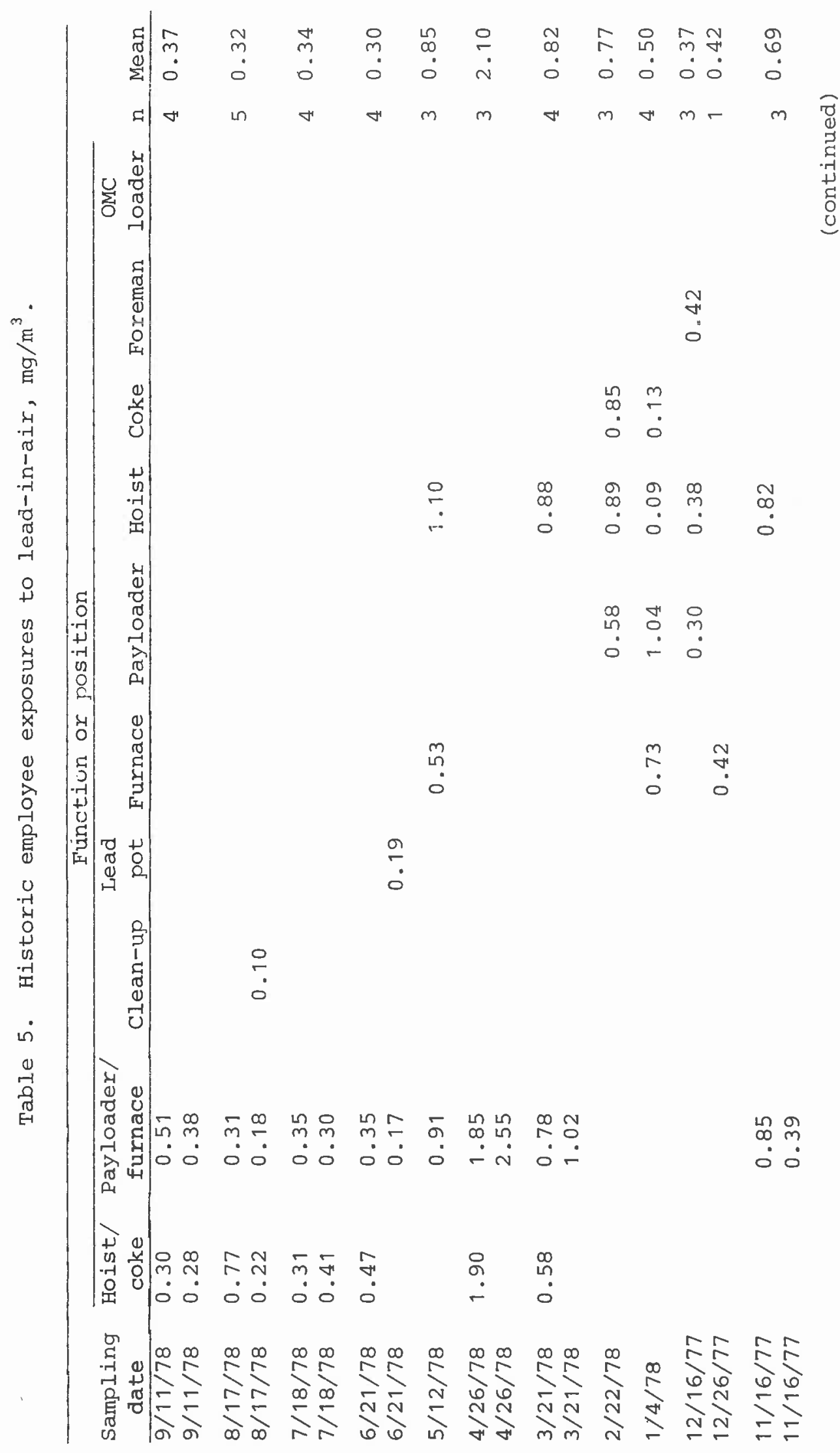




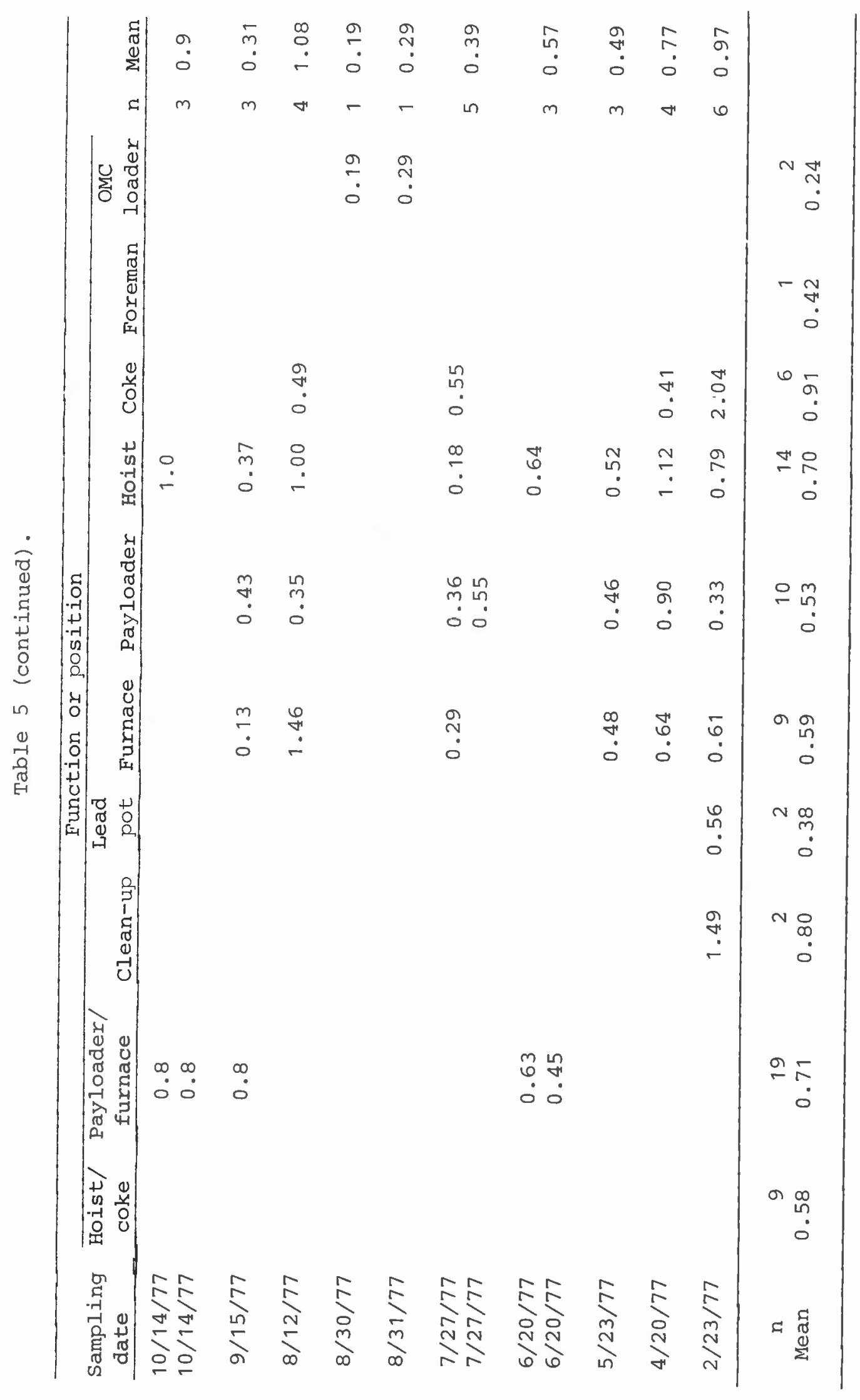


As part of the "before" study of this smelter a limited amount of breathing zone and work area air sampling was conducted. The purpose of this sampling was to 1) corroborate the sampling performed previously by the smelter, and 2) define employee exposures during a known set of smelter operating and ambient weather conditions.

Resource limitations of the study confined air sampling to two consecutive operating days. The selection of an optimum time for sampling was constrained by the fact that the smelter was actively engaged in a major modification program. To obtain air contaminant information before the agglomeration furnace and other controls were operational required sampling at the site during midwinter.

Breathing zone and work area sampling for lead and antimony were performed on January 23 and 24, 1979. January 23, 1979, was a relatively normal operating day at the smelting complex. The weather was sunny and cold with light winds blowing from several compass directions. Employees at the smelter performed normal tasks and rotated jobs at the halfway point in the work shift as is indicated by the change in employee initials associated with each of the jobs or operations shown in Table 6. January 24, 1979 was a relatively unusual day at the smelter complex. Heavy rains and strong winds were present throughout the period monitored. The strong gusty winds caused vigorous drafts through the smelting building which dist irbed the capture characteristics of local exhaust ventilation hoods and resulted in the introduction of dust into the atmosphere from building surfaces. By the afternoon of January 24, large volumes of runoff water were entering the smelting complex and leaving on the downhill side. The smelting building itself was very wet with pools of water in most of the work areas. Several of the employees did not show up for work on this day due to flooded roads in the countryside. The sampling conducted on these two days indicates that exposures were generally higher on the second day. This result is possibly due to the strong air currents which entrained contaminants from the captu:se zone of the local exhaust ventilation hoods. As stated earlier, the smelting work area was very wet, however, the production of fume from slag tapping, metal tapping, and refining operations was still present. On both days, the amount of antimony in the air was very low by comparison to the current OSHA permissible exposure limit of $0.5 \mathrm{mg} / \mathrm{m}^{3}$.

Several employees were found to have very high exposures $\left(>500 \mu \mathrm{g} \mathrm{Pb} / \mathrm{m}^{3}\right)$ during portions of work shifts on each day sampled. Battery breakers on the first day sampled showed high exposures to lead and the hoist operator encountered very high lead exposure during the afternoon of the second day sampled. It is possible that relatively large particles of lead entered the filter cassette during the sampling period in each of these operations. In the case of battery breaking, a splash of lead laden solution may have caused excessive contamination. In the case of the hoist operator, the handling of flue dust as it is charged to the hoist could have caused the deposition of lead particles onto the filter. However, in each of these cases, the measured exposure may not have been adversely influenced by artifact particulate and may represent the actual lead exposure. 
Table 6. Results of breathing zone sampling for lead and antimony.

\begin{tabular}{|c|c|c|c|c|c|c|}
\hline \multirow[b]{2}{*}{ Job/operation } & \multicolumn{3}{|c|}{$1 / 23 / 79$} & \multicolumn{3}{|c|}{$1 / 24 / 79$} \\
\hline & $\begin{array}{l}\text { Sampling } \\
\text { interval }\end{array}$ & $\begin{array}{c}\mathrm{Pb}^{*} \\
\mathrm{mg} / \mathrm{m}^{3}\end{array}$ & $\begin{array}{l}\mathrm{Sb} * * \\
\mathrm{mg} / \mathrm{m}^{3}\end{array}$ & $\begin{array}{l}\text { Sampling } \\
\text { interval }\end{array}$ & $\begin{array}{c}\mathrm{Pb} * \\
\mathrm{mg} / \mathrm{m}^{3}\end{array}$ & $\begin{array}{l}\mathrm{Sb} * \star \\
\mathrm{mg} / \mathrm{m}^{3}\end{array}$ \\
\hline \multicolumn{7}{|l|}{ Furnace } \\
\hline$(\mathrm{LW}) /(\mathrm{DH})$ & $0758-1232$ & 0.51 & 0.051 & $0803-1212$ & 0.62 & $<0.030$ \\
\hline$(\mathrm{NH}) /(\mathrm{LW})$ & $1300-1547$ & 0.38 & $<0.044$ & $1234-1559$ & 0.87 & 0.047 \\
\hline \multicolumn{7}{|l|}{ Hoist } \\
\hline$(\mathrm{DH}) /(\mathrm{LW})$ & $0803-1205$ & 0.37 & $<0.031$ & $0801-1233$ & 0.87 & $<0.027$ \\
\hline$(\mathrm{RH}) /(\mathrm{JM})$ & $1300-1547$ & 0.20 & $<0.044$ & $1238-1558$ & 7.8 & $<0.037$ \\
\hline \multicolumn{7}{|l|}{ Payloader } \\
\hline$(\mathrm{NH}) /(\mathrm{RH})$ & $0807-1300$ & 0.78 & $<0.025$ & $0807-1300$ & 1.2 & $<0.025$ \\
\hline$(\mathrm{LW}) /(\mathrm{NH})$ & $1258-1547$ & 0.48 & $<0.044$ & $1343-1557$ & 0.83 & $<0.025$ \\
\hline \multicolumn{7}{|l|}{ Coke } \\
\hline$(\mathrm{RH}) /(\mathrm{NH})$ & $0828-1233$ & 0.18 & $<0.030$ & $0818-1342$ & 0.66 & $<0.023$ \\
\hline$(\mathrm{DH}) /-$ & $1205-1547$ & 0.25 & $<0.033$ & & & \\
\hline \multicolumn{7}{|l|}{ Lead pot } \\
\hline$(W E) /-$ & $0807-1206$ & 0.21 & $<0.031$ & & & \\
\hline$(W E) /-$ & $1206-1425$ & 0.37 & $<0.064$ & & & \\
\hline \multicolumn{7}{|l|}{ Foreman } \\
\hline$(\mathrm{CS}) /(\mathrm{CS})$ & $0825-1207$ & 0.27 & $<0.033$ & $0821-1205$ & 0.66 & $<0.033$ \\
\hline$(\mathrm{CS}) /(\mathrm{DH})$ & $1207-1547$ & 0.28 & 0.037 & $1214-1603$ & 1.2 & $<0.032$ \\
\hline \multicolumn{7}{|c|}{ Industrial battery breaker } \\
\hline$(\mathrm{JM}) /(\mathrm{JM})$ & $0805-1300$ & 0.43 & $<0.025$ & $0815-1237$ & 0.73 & $<0.028$ \\
\hline$(\mathrm{JM}) /-$ & $1300-1615$ & 0.35 & $<0.029$ & & & \\
\hline \multicolumn{7}{|l|}{ Yardmen } \\
\hline$(D S) /-$ & $0817-1235$ & 0.69 & $<0.029$ & & & \\
\hline$(\mathrm{DS}) /-$ & $1235-1615$ & 0.25 & $<0.034$ & & & \\
\hline$(\mathrm{RM}) /-$ & $0818-1236$ & 0.37 & $<0.029$ & & & \\
\hline$(\mathrm{RM}) /-$ & $1236-1615$ & 0.23 & $<0.034$ & & & \\
\hline \multicolumn{7}{|l|}{ Battery breaking } \\
\hline$(\mathrm{KA}) /(\mathrm{KA})$ & $0833-1209$ & 2.5 & $<0.034$ & $0823-1200$ & 0.26 & $<0.034$ \\
\hline (WD) $/-$ & $0826-1211$ & 3.5 & $<0.029$ & & & \\
\hline$\left(K^{\prime} A\right)-$ & 1210 & 0.18 & $<0.040$ & & & \\
\hline$-/(W D)$ & & & & $1203-1520$ & 0.20 & $<0.037$ \\
\hline
\end{tabular}

*Time-weighted average lead-in-air concentration for the period sampled.

${ }^{* *}$ Time-weighted average antimony-in-air concentration for the period sampled. OSHA permissible exposure limit $0.5 \mathrm{mg} / \mathrm{m}^{3}$ 
The general conditions described at this smelter are similar to many other secondary smelters. The employee exposures which result from relatively unsophisticated materials handling procedures and marginally controlled emission sources are high by comparison to the recommended limits for employee exposure. Many secondary smelters in this country found difficulty in complying with the historical $0.2 \mathrm{mg} / \mathrm{m}^{3}$ OSHA lead standard. The new OSHA lead standard will require significant changes to be made in all existing facilities to approach compliance. The test smelter, at present, has a severe employee lead exposure problem. Exposures monitored during the initial part of this survey confirm smelter sampling results and indicate that the smelter does operate with workroom lead-in-air concentrations well above, or many times, currently accepted exposure limits. There is no apparent reason to discount the values measured by the company and they are assumed to characterize exposures (without regard to the use of respirators) during the period monitored.

The work area sampling results shown in Table 7 indicate the same trend from the first to second day of sampling. Sampling results of the second day are generally higher than those of the first. Work area concentrations tend to be much lower than breathing zone concentrations and reflect the fact that employees are much closer to the sources of emission within the smelting building than were the stationary area samples.

Area sampling results do indicate that the employee break room or lunchroom is significantly contaminated with airborne lead. This condition offers the distinct possibility for employees to eat food and use smoking and chewing materials which are contaminated by lead. The contamination of the lunchroom area may result from lead from an industrial battery department which may give rise to infiltration of lead contaminated air. A more obvious source of contamination is the traffic of employees dressed in work clothing to and from the lunchroom. Lead particulate lodged on clothing, hardhats, etc., may be dislodged while these materials are removed or during normal movement within the lunchroom.

Table 8 indicates the results of air sampling for sulfuric acid mist which was performed in the battery breaking operation. Exposures were measured at well below the OSHA permissible exposure limit for sulfuric acid mist of $1.0 \mathrm{mg} / \mathrm{m}$. Observation of work performed in the battery area indicated the very distinct possibility of employee eye and skin contact with battery electrolyte (sulfuric acid).

\section{Biological Monitoring Data}

The development of biologic monitoring data was outside the scope of this demonstration study. However, the test smelter did supply blood lead monitoring data covering a period of approximately two years directly preceding this study. Tables 9 and 10 contain summaries of these data.

The majority of blood lead concentrations fall in the range of 0.06 to $0.07 \mathrm{mg}$ or 60 to $70 \mu \mathrm{g}$ of lead per 100 grams of whole blood. This is true 
Table 7. Results of work area monitoring for lead and antimony.

\begin{tabular}{|c|c|c|c|c|c|c|}
\hline & \multicolumn{3}{|c|}{$1 / 23 / 79$} & \multicolumn{3}{|c|}{$1 / 24 / 79$} \\
\hline & $\begin{array}{l}\text { Sampling } \\
\text { interval } \\
\end{array}$ & $\begin{array}{l}\mathrm{Pb} * \\
\mathrm{mg} / \mathrm{m}^{3}\end{array}$ & $\begin{array}{l}\mathrm{Sb} \star \star \\
\mathrm{mg} / \mathrm{m}^{3}\end{array}$ & $\begin{array}{l}\text { Sampling } \\
\text { interval }\end{array}$ & $\mathrm{mg} / \mathrm{m}^{3}$ & $\mathrm{mg} / \mathrm{m}^{3}$ \\
\hline $\begin{array}{l}\text { Employee breakroom/ } \\
\text { lunchroom (refer to } \\
\text { Figure 6) }\end{array}$ & $\begin{array}{l}0838-1214 \\
1215-1559\end{array}$ & $\begin{array}{l}0.15 \\
0.17\end{array}$ & $\begin{array}{l}<0.034 \\
<0.033\end{array}$ & $0739-1145$ & 0.11 & 0.030 \\
\hline $\begin{array}{l}\text { Location no. } 1 \text { (refer } \\
\text { to Figure 1) }\end{array}$ & $0852-1219$ & 0.050 & $<0.034$ & $0745-1144$ & 0.37 & 0.031 \\
\hline $\begin{array}{l}\text { Location no. } 2 \text { (refer } \\
\text { to Figure 1) }\end{array}$ & $0854-1222$ & 0.089 & $<0.036$ & $0755-1142$ & 0.33 & 0.033 \\
\hline $\begin{array}{l}\text { Location no. } 3 \text { (refer } \\
\text { to Figure 1) }\end{array}$ & $0910-1224$ & 0.18 & $<0.038$ & $0749-1144$ & 0.25 & 0.031 \\
\hline $\begin{array}{l}\text { Location no. } 4 \text { (refer } \\
\text { to Figure 1) }\end{array}$ & $0901-1222$ & 0.12 & $<0.037$ & $0758-1158$ & 0.30 & 0.030 \\
\hline
\end{tabular}

Table 8. Results of breathing zone sampling for sulfuric acid mist.

\begin{tabular}{lllll} 
& \multicolumn{2}{c}{$\frac{1 / 23 / 79}{2}$} & \multicolumn{2}{c}{$1 / 24 / 79$} \\
Jampling & $\begin{array}{l}\mathrm{H}_{2} \mathrm{SO}_{4}{ }^{*} \\
\mathrm{mg} / \mathrm{m}^{3}\end{array}$ & & $\begin{array}{l}\text { Sampling } \\
\text { interval }\end{array}$ & $\begin{array}{c}\mathrm{H}_{2} \mathrm{SO}_{4}{ }^{*} \\
\mathrm{mg} / \mathrm{m}^{3}\end{array}$ \\
\hline $\begin{array}{l}\text { Battery breaking } \\
-/ \text { (WD) } \\
-/ \text { (KA) }\end{array}$ & & & $0821-1200$ & 0.18 \\
$($ WD $) /-$ & $1211-1515$ & 0.10 & $1203-1520$ & 0.067 \\
\hline
\end{tabular}

*Time-weighted average sulfuric acid mist-in-air concentration for the period sampled. OSHA permissible exposure limit $1.0 \mathrm{mg} / \mathrm{m}^{3}$. 
Table 9. Blood lead concentrations -smelter employees.

\begin{tabular}{|c|c|c|c|c|c|c|c|c|c|c|c|c|}
\hline $\begin{array}{c}\text { Sampling } \\
\text { date }\end{array}$ & $\frac{\text { Numb }}{.03}$ & $\frac{e r \text { of }}{.04}$ & $\frac{\text { perso }}{.05}$ & $\frac{.5 \mathrm{wit}}{.06}$ & $\frac{\text { blood }}{.07}$ & $\frac{\text { lead }}{.08}$ & $\frac{\text { conc }}{.09}$ & $\frac{\text { entra }}{.10}$ & $\frac{\text { tions }}{.11}$ & $\frac{\text { t. of : }}{.12}$ & $\mathrm{n}$ & mean* \\
\hline $12-04-78$ & & 1 & 5 & 8 & 5 & 1 & & & & & 20 & .06 \\
\hline $10-30-78$ & & & 5 & 7 & 3 & 3 & 1 & & & & 19 & .06 \\
\hline $10-02-78$ & & 1 & 3 & 3 & 4 & 1 & & & & & 12 & .06 \\
\hline $09-05-78$ & & & & 3 & 9 & & & & & & 12 & .07 \\
\hline $06-31-78$ & & & & 2 & 6 & 4 & 1 & & & & 13 & .07 \\
\hline $06-27-78$ & & & 1 & 1 & 3 & & & & & & 5 & .06 \\
\hline $05-30-78$ & & & 3 & 6 & 12 & 2 & & & & & 23 & .07 \\
\hline $04-24-78$ & & & 1 & & 2 & & & & & & 3 & .06 \\
\hline $04-04-78$ & & & 1 & 7 & 10 & 1 & & & & & 19 & .07 \\
\hline $02-07-78$ & & & 4 & 10 & 5 & 5 & & & & & 24 & .06 \\
\hline $01-03-78$ & & & & 1 & 2 & 1 & & & & & 4 & .07 \\
\hline $12-06-77$ & & & 4 & 8 & 7 & 1 & & & & & 20 & .06 \\
\hline $11-07-77$ & & & 2 & & 2 & 3 & & & & & 7 & .07 \\
\hline $10-04-77$ & & 1 & & 11 & 3 & 2 & 1 & & & & 18 & .06 \\
\hline $09-06-77$ & & & 1 & & 2 & 4 & & 1 & & & 8 & .08 \\
\hline $08-01-77$ & & & 6 & 6 & 3 & 4 & 2 & & & & 21 & .06 \\
\hline $06-29-77$ & & & & 5 & & 1 & 1 & & & & 7 & .07 \\
\hline $05-31-77$ & & & 2 & 6 & 7 & 7 & & & & & 22 & .07 \\
\hline $05-03-77$ & & & & 2 & 2 & 3 & & & & & 7 & .07 \\
\hline $03-29-77$ & & & 4 & 7 & 6 & 2 & & 1 & & & 20 & .06 \\
\hline $02-01-77$ & & & 4 & 4 & 4 & 3 & 1 & 2 & & & 18 & .07 \\
\hline $01-04-77$ & & & & & 2 & & 2 & 1 & & & 5 & .08 \\
\hline $12-07-76$ & 2 & & 2 & 7 & 6 & 3 & & 1 & & 1 & 22 & .07 \\
\hline $\mathrm{n}$ & 2 & 3 & 48 & 104 & 105 & 51 & 9 & 6 & & 1 & & \\
\hline$\%$ of Total & 0.6 & 0.9 & 14.5 & 31.6 & 31.9 & 15.5 & 2.7 & 1.8 & & 0.3 & & \\
\hline
\end{tabular}

*Milligrams lead per 100 graes whole blood 
Table 10. Blood lead concentrations - battery breakers.

\begin{tabular}{|c|c|c|c|c|c|c|c|c|}
\hline $\begin{array}{l}\text { Sampling } \\
\text { date }\end{array}$ & $\frac{\text { Number }}{.03}$ & $\frac{\text { of persons }}{.04}$ & $\frac{\text { with b1 }}{.05}$ & $\frac{\text { lood lead }}{.06}$ & $\frac{\text { concent }}{.07}$ & $\frac{\text { rationst of }}{.08}$ & $\mathrm{n}$ & mean* \\
\hline $10-30-78$ & & $i$ & 1 & 1 & 2 & & 5 & .06 \\
\hline $09-05-78$ & & & 1 & 2 & 1 & & 4 & .06 \\
\hline $05-30-78$ & & 1 & 1 & 1 & 2 & & 5 & .06 \\
\hline $03-i 3-78$ & & & & & & 4 & 4 & .08 \\
\hline $02-07-78$ & & & 1 & 1 & 1 & & 3 & .06 \\
\hline $12-06-77$ & & 1 & & & 2 & & 3 & .06 \\
\hline $10-04-77$ & & 2 & & & 2 & 1 & 5 & .06 \\
\hline $09-06-77$ & & & & & 1 & & 1 & .07 \\
\hline $08-01-77$ & & & 1 & & & & 1 & .05 \\
\hline $06-29-77$ & & 1 & & 1 & & & 2 & .05 \\
\hline $05-31-77$ & & & & 2 & 1 & & 3 & .06 \\
\hline $12-07-76$ & & 1 & 1 & 1 & & & 3 & .05 \\
\hline $\mathrm{n}$ & & 7 & 6 & 9 & 12 & 5 & & \\
\hline$\%$ of Total & & 17.9 & 15.4 & 23.1 & 30.8 & 12.8 & & \\
\hline
\end{tabular}

ᄎMilligrams lead per 100 grams whole blood. 
for both employees working in the smelter building and in the battery breaking area. A significant number of measured blood lead concentrations have indicated even more serious lead absorption.

The elevated blood lead concentrations measured by the company indicate that existing employee exposures to lead are significant despite use of respiratory protection devices. There are many possible sources of insufficiently controlled lead exposure. The contaminated lunchroom facility and improper use of respirators by employees are perhaps the major sources of exposure. Improved hygiene facilities and practices would be expected to help reduce continued excessive contact with lead.

\section{CONTROL CRITIQUE AND RECOMMENDATIONS}

Planned Improvements

The test smelter management has recognized the serious lead exposure problem associated with the secondary lead smelting complex. The company is in the process of making major modifications to its smelting complex to better control emissions to the ambient environment and workplace exposure of employees. An important element in this modernization program is in the Bergsoe flash agglomeration furnace. The furnace will work in concert with a new baghouse facility. The new baghouse system is of much greater capacity than the system which has served the smelter historically. The new baghouse exhaust ventilation system will provide the capability to exhaust between 68,000 and $93,500 \mathrm{~m}^{3} / \mathrm{hr}$ of air from the smelter building. This exhausted air volume will be gathered from strategically located exhaust ventilation hoods which will serve major sources of emission associated with the smelting facility. The following list of major emission sources will be served by the new ventilation system:

1. The charging location at the top of the blast furnace.

2. The skip hoist charging elevator.

3. The lead tapping and pouring station.

4. The refining kettles.

5. Flue dust tote box dumping station associated with the agglomeration furnace feed.

The existing slag-tapping exhaust ventilation system will not be modified since it is quite effective in capturing emissions. It will still be serviced by a separate $8640 \mathrm{~m}^{3} / \mathrm{hr}(5000 \mathrm{acfm})$ baghouse.

The final hood designs for local exhaust ventilation of these emission sources are in the development stage at present. The first step in implementing the new exhaust ventilation control program will be to attach existing exhaust ventilation hood structures to the new system. The next stage in implementation of the total control program will be to complete the installation of the flash agglomeration furnace. Once the flash agglomeration furnace is operating in concert with the dust collecting system, attention will be given to the final design of local exhaust ventilation hoods for refining kettles, etc. Completion of this control program will consume several months. The data collected in this "before" study describe 
employee exposures and engineering controls at a point in time when the plant was being serviced by its historical exhaust ventilation system and local exhaust hoods located within the smelting facility.

Minimizing employee exposure and fugitive emissions will require more than simply increasing the amount of air exhausted from the smelting building and installing better local exhaust hoods. The smelter has plans to improve paving of outside yard surfaces; to enclose portions of the smelting building (cutting down cross drafts which would interfere with contaminant capture); and to make materials handling modifications which should help to control escape of contaminants into the work environment.

\section{Recommended Control Considerations}

Following the field work associated with this "before" study, a list of recommendations was developed to assist the test smelter in controlling the lead exposure problem. These recommendations were made within the framework of retrofitting controls to existing process equipment. This constraint ruled out some more radical changes that could be incorporated in a new plant construction. Examples of changes which cannot be accomplished at the existing smelter are:

Complete removal of existing smelter building floors and replacement with elaborate washdown and water collection sumps and drains.

Complete separation of all raw materials handling from the furnace operating and refining areas of the smelter.

The recommendations which have been forwarded to the test smelter are described below. They are organized by smelting operation and other industrial hygiene control considerations. During the interim while engineering controls are being designed and installed, it is imperative that employees be afforded maximum protection from exposure through use of respiratory protective devices and rigorous personal hygiene. Several recommendations are included which pertain to respiratory protection, hygiene facilities and practices and employee training.

Battery Breaking--

A suitable eye fountain and emergency shower station should be provided in close proximity to the battery shearing work station.

Lead mud deposits should be cleaned from all surfaces in the battery breaking area (walls, roller conveyor, shear, floor, etc).

Plexiglas or other transparent barriers or enclosures should be installed at the shear to prevent splashing of battery acid and mud onto employees.

A means of periodically washing mud and acid from the transparent barrier or enclosure should be provided.

A means of periodically washing down the battery breaking work area to remove accumulations of caked-on mud, etc., should be provided. 
Depending on the reduction in employee exposures afforded by the above recommendations, an exhaust ventilation system should be designed and installed to serve the battery shears.

Employees should be instructed to clean accumulations of battery mud from their protective aprons at periodic intervals. Water and a sponge should remove most of this material and prevent it from becoming dry and entering the air in the breathing zone of the worker.

Skip Hoist Charging and Materials Handling--

Improved materials handling should be instituted in association with skip hoist charging.

a. Raw materials stored (piled) in the charging area should be kept damp. Sprinklers or hoses with spray nozzles could be utilized.

b. Deliveries of plant scrap such as reject battery plates, etc. should be brought to the smelter in covered tote boxes or other covered containers. Before dumping into a storage pile, dry materials should be thoroughly wetted.

c. The floor area near the skip hoist should be kept as clean as possible and wetted to help limit dust generation.

d. Cross drafts through the furnace charging area should be minimized by closing sliding doors.

e. Sweeping and shoveling of dry lead bearing materials should be prohibited. Shoveling of wetted materials or vacuuming of dry materials is preferred.

f. Charging of flue dust should cease once the agglomerator is operational. Until agglomerated material is available, any dry flue dust should be wetted before handling and should be stored wet in an area protected from cross drafts.

Improved local exhaust ventilation should be provided at the skip hoist loading station.

a. Initially the new exhaust system should be attached to the existing exhaust ducts serving the loading station.

b. Extensions from the side of the loading station should be considered to create better dust control in front of the loading station.

c. Tapered entries to exhaust ductwork should be considered for the exhaust pickups on each side of the loading station enclosure. 
The materials storage area should be kept as clean as possible. Splashes of mud should be cleaned from surfaces to prevent drying and entrainment into the air.

Mechanized materials handing equipment (Bobcat) should not be allowed to track mud into other smelter areas.

muyere Punching--

A hood should be considered for above all tuyeres to control emissions when tuyere covers are removed.

Blast Furnace Charging--

Improved local exhaust ventilation of the blast furnace charging port should be provided.

a. Initially the new ventilation system should be attached to the charging hoods provided at the top of the furnace.

b. Capture characteristics at the charging hood should be evaluated to determine whether improved enclosure or otherwise altered hood designs are necessary.

Slag Tapping--

The slag tapping hood should be repaired to correct damaged ductwork.

Better enclosure of the taphole and receiving vessel should be provided.

a. The hood front and side pieces should be made to fit together better reducing gaps where sparks, etc., may escape.

b. The hood sides and front should fit more tightly around the slag receiving vessel to better contain sparks, splashes, etc. which drop to the floor at the base of the receiving vessel.

c. A means of clearing the slag taphole with the front portion of the slag tapping hood in its lowered position should be investigated. Possibly a small opening in the hood front would allow sufficient access.

Sweeping and shoveling of dry particulate materials resulting from slag tapping should be discontinued. Fugitive settled particulate should be wetted before being cleaned up. Alternatively, it could be picked up using vacuum methods.

The slag tapping work area should be protected from strong wind currents. Doors leading to the yard area should be closed during windy conditions.

The filled slag receiving vessel should remain under the slag tapping hood until it has cooled sufficiently to prevent fuming. 
Crude Metal Tapping from Blast Furnace--

Initially the new exhaust ventilation system should be hooked up to the existing local exhaust hoods provided for the lead well, launder and molding line.

Improved local exhaust ventilation enclosures should be designed and installed for the crude metal tapping/pouring operation.

a. A stationary hood could be constructed which would enclose the lead well, launder and molding line. This hood could be provided with access panels for inspection and service. The launder could remain stationary with the ingot molds passed in front of the pouring station by means of a rolling molding car at the pouring station. The hood over the pouring station should accommodate the mold being poured and the one cooling after pouring.

b. A movable hood similar in some respects to the existing three-hood system could be constructed. This movable hood should be of one or two piece construction. The hood system should be self supporting (supported on pivots, etc.). The hood(s) should enclose the lead well, launder, the mold being poured and the mold in the cooling position.

c. A combination of fixed and movable hoods could be applied. Any movable hood should be self supporting. The hood system should enclose the mold being poured and the one in the cooling position. Transitions between hoods should overlap with no gaps in local exhaust coverage.

Sweeping and shoveling of dry particulate materials resulting from metal tapping and pouring should be discontinued. Settled fugitive particulate should be wetted before being cleaned up, or vacuumed.

Kettle Refining--

Local exhaust ventilation hoods should be designed and installed for the refining kettles.

a. Sufficient enclosure should be provided to capture heated air from kettle firing and fume from the surface of the molten lead in the kettle.

b. The local exhaust hood should be designed to permit charging of the kettle with large crude lead ingots.

c. The local exhaust hood should be designed to permit insertion of a mechanical stirring apparatus used during drossing. Sufficient enclosure during drossing and stirring should be provided to control fume and particulate emanating from the molten lead. 
d. The local exhaust hood should accommodate the pigging operation. Swing-away doors could provide reasonable access for the molten lead pumping device.

Depending on the final design of refining kettle hoods, varying configurations of additional local exhaust ventilation for the skimming operation will be necessary.

a. Fume from kettle skimmings ("pies") should be controlled near the source.

b. The present practice of building pies on a pallet should be reviewed to determine whether a more compact method of handling skimmings can be devised.

c. The auxiliary local exhaust ventilation for skimming should take advantage of the enclosure (swing away doors, etc.) of the kettle refining hoods. It may be possible to control skimming emissions by attaching local exhaust ductwork to the swing-away portion of the hood, thus eliminating the need for extra equipment.

d. Any additional local exhaust ventilation for skimming operations should be easily operated by employees. Complicated ductwork, hoisting, and moving systems should be avoided.

Removing skimmings from the kettle could be accomplished by a long handled implement supported at a pivot point at the center of the handle. The increased length of handle would give more mechanical advantage to the skimming operator than using a flat point shovel. Also the skimming operator would no longer have to reach out over the molten lead, thereby decreasing his potential exposure to fume.

Sweeping and shoveling of dry particulate materials resulting from kettle refining and skimming operations should be discontinued. Settled fugitive particulate should be wetted before being cleaned up or vacuumed. Splashes of molten lead and skimmings will require manual removal from surfaces and placement into scrap containers.

During windy weather, doors should be closed to help minimize cross drafts within the smelting building. These cross drafts can entrain contaminants which would otherwise be captured by kettle and skimming hood enclosures.

Pigging--

Exhaust enclosure for the pigging machine should be designed and installed on the machine.

a. Of primary importance is the portion of the pigging machine where the reservoir of molten lead and pouring of lead into the ingot molds occurs. 
b. An enclosure of the "hot" end of the pigging machine could be made with hinged side access doors. The hood could be supported by metal extensions from the machine framework.

c. The hood could be made a permanent part of the traveling pigging machine. Drops of flexible ductwork from the overhead local exhaust ductwork could be attached to the hood when the machine was positioned beside either refining kettle.

During windy weather, cross drafts past the pigging machine should be minimized by closing the large sliding doors. This will help to minimize entrainment of contaminants from under the pigging machine exhaust hood.

Hous ekeeping--

A smelter-wide cleanup should be undertaken. Lead dust and mud should be removed from yard surfaces, building surfaces, equipment, etc. Settled particulate which has accumulated on building structural members should be removed.

Dry sweeping and shoveling should be discontinued. Shoveling of wet materials or vacuum methods are preferred.

Hygiene Facilities and Practices--

Smoking and food and beverage consumption should be strictly prohibited in the smelter building and yard area. Smoking and chewing materials should not be carried by employees into the smelter building and yard area.

Use of the existing smelter lunchroom facility should be discontinued. Smelter employees should be required to use the main plant lunchroom or outside food establishments.

Smelter employees should not enter lunchroom facilities with protective work clothing or equipment unless surface lead dust has been removed. Alternatively, smelter employees could be provided with overalls which can be worn over their work clothing and removed before entering lunchrooms, breakrooms, or food establishments. Clean smocks could be provided to put on over work shirts and trousers.

A shoe/boot cleaning station should be provided at the entrance to the locker room and to areas where food and beverages are consumed.

Smelter employees should be required to thoroughly wash their hands, forearms, face and neck before consuming food or drink. As a minimum, hands and face should be washed before smoking or chewing materials are utilized.

Smelter employees should be provided with clean work clothing each day. The employee locker room should be frequently cleaned and mopped on all shifts of the working day. 
Smelter employees should shower and change into street clothing at the conclusion of the workshift. Work clothing should not be taken home. It should be deposited in closed containers.

Employee Training and Information--

Employees should be informed in organized training sessions of the following :

a. OSHA requirements as set forth in 29 CFR 1910.1025.

b. The hazards associated with exposure to lead and how they can be controlled.

c. The purpose, proper selection, fitting, use and limitations of respirators.

d. The purpose and description of the medical surveillance program.

e. The engineering controls and work practices associated with controlling employee exposure to lead associated with a particular job.

f. The contents of existing compliance plans.

g. The dangers of chelating agents.

Privately each employee should be told what his measured lead-in-air exposure is (without regard to use of respiratory protection) and what the results of his blood lead monitoring are. These results should be explained in terms of compliance with OSHA standards and related to potential adverse health effects.

Respiratory Protection Program--

Plant management should review OSHA's respiratory protection requirements (29 CFR 1910.134 and 29 CFR 1910.1025). Appropriate updating and improvement of the existing program should be instituted.

Specifically, attention should be placed on the following items:

a. A respiratory protection training session should be presented to employees. The intent of the session should be to refresh workers' knowledge with regard to the fitting, use, care and limitations of the respirators they are required to wear.

b. A determination should be made whether all smelter employees can obtain a proper face fit from the respirators in use. It may be necessary to obtain respirators of another manufacturer to accommodate all variations in facial size and shape. All respirators utilized should carry appropriate NIOSH approvals. 
c. A determination should be made whether all employees who are required to wear respirators can perform their normal duties wearing the respirator. Employees who cannot effectively breathe through the respirator during normal work activity should be identified. The plant physician can assist in this determination. A different form of respiratory protection, e.g., powered air-purifying respirator, may be supplied or the employee could be transferred to an area where respirators are not required.

d. Special emphasis should be given to impressing the employees that respirators must be worn at all times while working in the smelting building and yard area.

e. Employees should be instructed to prevent contamination of the respirator when it is removed at breaks or during lunch. Paper towels or soft clean cloths should be provided to wipe off the respirator facepiece before it is reused after a break.

Medical Monitoring--

The existing blood lead monitoring program should be continued.

The OSHA medical monitoring requirements of 29 CFR 1910.1025 should be implemented.

Recordkeeping--

The OSHA recordkeeping requirements of 29 CFR 1910.1025 should be implemented.

QUESTIONS, ANSWERS AND COMMENTARY

Question ( $J$. Goulias, Goulias Associates):

Are your paper and reports available now or can you let me know when they will be available?

Answer (A. Craig):

The report that was done on the Danish facility should be out, I would expect, within a month or a month and a half, which talks about tie engineering and additive controls. The paper and discussion here will be in the symposium proceedings .

Question (J. Goulias):

Was all of the sampling outside the premises hi-vol sampling? 
Anstier (A. Craig):

Yes.

Question (J. Goulias) :

Was anything analyzed from the filters besides total lead? Was there any compound identification or particle size characterization?

Answer (R. Coleman):

We had some analysis done for chlorine, antimony and sulphur.

Answer (A. Craig):

When we go back and retest this facility after installation of controls, we'll be using particle sizing to get some information on the percent of this material is in the respirable range.

Question (J. Goulias):

It's my understanding at this point that neither NIOSH nor EPA have sponsored any work that involves a fundamental change in any pyrometallurgical processing technology. Is that correct?

Answer (A. Craig):

No, we have not. We've forused on add-on technology. The Bureau of Mines has done some work on hydrometallurgy, but this is in the pilot plant stage. 
WORK PRACTICES AND ADMINISTRATIVE CONTROLS - LESSONS

LEARNED FROM BATTERY MAKING AS APPLIED TO SMELTING

\author{
William M. Pallies \\ Director of Environment, Safety and Health \\ ESB Ray-O-Vac Management Corp. \\ Philadelphia, Pennsylvania
}

\title{
ABSTRACT
}

The author has drawn a parallel between the need for effective work practices that he experienced during his career in battery making with the need that exists in smelters. In battery making operations he found through observation of workers with low breathing zone and blood lead levels that these individuals appeared to be more aware of potential hazards than other workers and worked in such a way as to minimize those hazards. A study at General Battery Corp. is cited documenting real differences in air and blood leads among workers rotated through similar jobs.

Identification of specific work practices which are effective is made difficult because of the masking effect of respirators and the variability inherent in sampling the workplace air.

Effective engineering controls should not be pursued while excluding research into work practices because any future engineering improvements which the author anticipates at this time could be undone by poor work practices. Work practices will only be effective if management is committed to providing a safe and healthy workplace and stressing to the workers the need for following good practice.

\section{INTRODUCTION}

I have been in the battery business for thirty years and have been associated with secondary smelters for fifteen years. I don't have solid data on the effectiveness of work practices in controlling blood lead levels in smelting which I could present to you and for some reason my experience in smelting didn't produce solutions to lead exposure problems the way it did in battery making so I was reluctant at first to give this presentation. When I learned that others weren't anxious to take on this task it occurred to me that I probably wasn't the only one who lacked data. In thinking about this I discovered that there are reasons why the effectiveness of work practices in reducing air and blood concentrations of lead is so difficult to document and evaluate. In this presentation, besides stressing the importance of work practices in achieving control of lead, I will cite some of the complicating factors in the evaluation of their effectiveness. 
Twenty-five years ago after repeated visits to 20 or more battery plants, I decided that if I could have my choice of people from all the plants I could run a plant with minimal ventilation and have few lead absorption problems. For unexplained reasons some people seemed less susceptible to lead than others, and/or they were cleaner than others and/or they worked more carefully than others and didn't generate as much dust or absorb as much lead. Personal air sampling has shown that these same people breathe less air contamination so it seems that while susceptibility and hygiene may be important, work habits are the key. My personal observations also bear out this conclusion.

In one case I became aware that there was a problem with high lead in air when plates were being burned in forming tanks in preparation for the charging process. Yet one of the people doing this burning had consistently low lead in his breathing zone and in his blood. I decided to go out and watch this man and stay with him until I found the reason. He used the same equipment as everyone else and seemed to work in a normal manner. After observing from all angles I suddenly noticed that this man, when he breathed out, pursed his lips slightly and blew the smoke away. Any lead or arsenic fume was also blown away and was sufficiently diluted by the air in the room to be at safe levels.

A room full of forming tanks requires complex and expensive local exhaust ventilation which wasn't needed when the OSHA Permissible Exposure Limits (PEL) for lead and arsenic were 200 and $500 \mathrm{\mu g} / \mathrm{m}^{3}$, respectively. It isn't needed now if we could institute the proper work practices. Unfortunately, it may be asking a little too much of work practices to expect the operator to supply his own dilution ventilation:

A further example of the effectiveness of work practices in reducing lead exposure was presented by Dr. Ralph Smith for the General Battery Corp. (GBC) at the OSHA lead standard hearings. John Bitler, Vice President of GBC, had studied 17 identical (as far as can be measured) stack and burning stations. The stack and burn crews rotated among the stations and measurements were made of all crews at different stations. It became obvious that certain stackers and burners had high air or blood leads no matter which stations they used. Others could work at any station and maintain low air and blood leads. The engineering controls were satisfactory for most people but a few were doing things which the ventilation could not control.

\section{EFFECTS OF WORK PRACTICES HIDDEN AMONG OTHER VARIABLES}

It was in thinking about this stack and burn report that I suddenly realized why we have a problem in analyzing for effects of work practices in secondary smelting. No one lines up 17 identical blast furnaces and rotates furnace crews among them. I have had experience with four or five furnaces but there were enough differences among them that any effects of work practices were hidden. 
Another problem in isolating effective work practices is the use of respirators. Air lead levels have been high in smelters and respirators have been used routinely. If a respirator is worn properly it will mask much of the effect on blood lead levels of varying work practices.

John Tibbels, of Exide's Refined Metals Corporation, is now investigating the case of a furnace crewman who has maintained a blood lead level in the $40^{\prime} \mathrm{s}(\mu \mathrm{g} / 100 \mathrm{ml})$ for months when others are lucky to be at 60 or 70 and some go to 80 and have to be removed from exposure. In this and other similar situations, the effects of respirator usage must be sorted out and then studies made which will pin-point the beneficial work practices.

It was a disappointment to me to see OSHA make respirator use mandatory when breathing zone lead levels exceed $50 \mu \mathrm{g} / \mathrm{m}^{3}$. Blood lead can be controlled to 70 or $80 \mu \mathrm{g} / 100 \mathrm{ml}$ with air leads closer to $200 \mathrm{\mu g} / \mathrm{m}^{3}$ than to $50 \mathrm{\mu g} / \mathrm{m}^{3}$ and we were getting to the point where $200 \mathrm{\mu g} / \mathrm{m}^{3}$ looked possible. There is very little benefit in reducing air lead to $200 \mu \mathrm{g} / \mathrm{m}^{3}$ as far as respirator usage time is concerned when the time-weighted average (TWA) exposure has to be kept below $50 \mu \mathrm{g} / \mathrm{m}^{3}$. At $200 \mu \mathrm{g} / \mathrm{m}^{3}$ the respirator must be worn for more than six hours of an eight-hour shift to reach a TWA of $50 \mu \mathrm{g} / \mathrm{m}^{3}$.

As more air samples are taken the effects of work practices are going to become more evident. But it will take a great many samples because air sampling is so highly variable. The same amount of variability does not occur in blood sampling provided minimal precautions are taken against contamination. The principal errors are usually associated with the analysis. In air lead measurements, on the other hand, the principal variability is associated with the lead content of the air, which varies widely.

EFFECTIVENESS OF ENGINEERING CONTROLS IS TIED TO WORKER INVOLVEMENT

There is a lot of work to be done in the area of effective work practices and one can ask, why bother? Wouldn't it be better to concentrate on studying and improving engineering controls? I think that in the forseeable future, any engineering improvements I can visualize will be capable of being undone by poor work practices. There is no way present day safety, health and environmental requirements can be met without the full cooperation of the smelter worker. In a reasonably well-engineered smelter the worker can do more to control blood lead level than can any of the foremen, engineers or plant managers. The first step is to get every smelter worker interested in what his or her blood lead level is and which way it is going. However, to do this the worker must first be given a reasonably clean place in which to work. There is no use exhorting everyone to work safely in poorly maintained, dirty plants. But not only does the worker have to have a decent working environment, the worker must also be convinced that it is decent. If the worker is not, it will affect attitude and work practices. The worker should be consulted on what he or she thinks can be done to reduce exposure and blood lead. Often management will have to explain why a particular idea won't work or is impractical or too expensive, but it gives management the opprotunity to explain why certain things have or haven't been done. On the other hand, when ideas are 
freely exchanged between workers and management, the potential for new solutions is always there.

MANAGEMENT COMMITTMENT TO SAFETY AND HEALTH

I have had the opportunity to spend some time in a very finely engineered smelter - one of the Bergsoe smelters. I was there with Mr. Bergsoe and during our visit he noticed a violation of a minor safety practice. He immediately went over and very briefly counseled the man about this safety practice. Here was something extremely important. To this worker there was no question that in the Bergsoe organization committment to safety starts at the very top.

It is important for managers to ask themselves how committed they and their company are. When there is a breakdown and a choice must be made between lead exposure and producing a product, what does the furnace crewman think the choice will be? I fully agree that our objective is to produce a product because it puts "bread on my table" and sends my kids to college too but this objective has to be tempered by other important concerns, especially for the health and well-being of workers. It can't be, "make lead at any cost" because without a properly motivated, cooperative workforce, it will be more difficult and expensive (if not almost impossible) to achieve the mandated legal requirements.

QUESTIONS, ANSWERS AND COMMENTARY

Question (M. Lane, Davy McKee Corp):

Have you noticed any correlation between the people who have good work practices and low blood lead levels with the fact that they smoke or not?

Answer (w. Pallies):

I've seen information on both sides of that question. In a presentation later, Don Lynam is going to present some very interesting correlations between exposure to another metal and smoking. Certainly there is something to it. 


\author{
USE OF DONNDRAFT BOOTH DESIGN \\ IN REMOVING TOXIC DUSTS FROI PROTECTIVE CLOTHING \\ Curtis E. Dungey, Environmental Specialist \\ ASARCO \\ Tacoma, Washington
}

\title{
ABSTRACT
}

Recently promulgated OSHA lead and arsenic standards require the removal of dust from protective clothing before workers enter lunch and change areas if the particular vorkers are exposed to concentrations of these contaninants above prescribed levels. The arsenic standard requires the use of vacuuming to do the cleaning, a process which is cumbersome, time-consuming, and not always effective. A prototype downdraft booth was developed and tested at a large copper smelter to determine whether it would be a feasible alternative for vacuuming of arsenic dusts. The booth utilized downdraft ventilation to collect dust particles dislodged from clothing by a series of air nozzles. Respiratory protection was needed during the process, which took about a minute. The effectiveness of this method was demonstrated by evaluation of airborne and settled arsenic levels in the lunchroom; the vacuuming method was evaluated in similar fashion. The results showed very small differences in contamination of the lunchroom between the two methods. The downdraft booth had the advantages of being a faster method, was more acceptable to workers, and visually did a better job.

\section{INTRODUCTION}

Both of the recently promulgated OSHA lead and arsenic standards require employees to remove dust from their protective work clothing before entering the Iunchroom/changehouse areas. Although the aim of these respective provisions is to reduce levels of contamination in such facilities, the specific requirements are different. The arsenic standard requires that protective clothing be cleaned when airborne exposures exceed $0.100 \mathrm{mg} / \mathrm{m}^{3}$. (The eight-hour permissible exposure limit for arsenic is $0.010 \mathrm{mg} / \mathrm{m}^{3}$ ). Vacuuming is the only method that can be used in removing such dust. The lead standard, on the other hand, requires that all employees exposed above the permissible exposure limit of $0.050 \mathrm{mg} / \mathrm{m}^{3}$ clean protective clothing before entering lunchroom and hygiene facilities. Removal of dust can be accomplished by either vacuuming, a downdraft booth, or "other cieaning method". When a situation is encountered where employees are exposed to both arsenic and lead, vacuuming, the method dictai-ed by the arsenic standard must be chosen as the method of surface dust removal. 
One such situation was encountered at a large copper smeltex located in the Pacific Northwest. Before the arsenic standard, it was already recognized that arsenic and lead dusts could be a source of contamination in the lunchroom. The common practice for many years was to remove dust from protective clothing with an air hose before leaving the work area. Respirators were always worn when performing this task. With the advent of the arsenic standard, it was resolved that vacuuming would have to be substituted for this practice. However, it was soon realized that there were some aspects c.f vacuuming that made it less than desirable. Undesirable aspects $0:$ vacuum cleaning include:

1. Vacuuming tends to be cumbersome and time-consuming. Employees were found to take up to five minutes to do an adecuate job.

2. Some types of smelter dusts tend to be "sticky", and are especially hard to remove with a vacuum when clothes are damp from perspiration or rain.

3. It is difficult for an employae to vacuum his back adenuately by himself, making it almost essential that two employees to the job.

4. Vacuuming does not receive much employee acceptance in the plant; the major complaints are that it takes too long, and that much of the visible dust would not come off the clothes.

An alternative to this method would be to use a downdraft booth, as mentioned in the lead standard, with compressed air nozzles for cleaning clothes. However, to be in compliance with the arsenic standard, it would be necessary to obtain a variance from the vacuuming requirements. It was decid d that to accomplish this goal, it would be important to design, construct, and evaluate such a booth for its efficiency in cleaning protective clothing as compared to the vacuuming $m$ thod.

\section{DOWNDRAFT BOOTH DESIGN}

One such booth has been built outside the lead and arsenic work areas of the cottrell Department at the copper smelter, arjacent to a lunchroom/ changehouse facility. This department's function is to collect dust by electrostatic precipitation before process gases are exhausted to the main stack. Arsenic content in the dusts handled here may run as high as $50 \%$.

The prototype booth was constructed of plywood, $2.24 \mathrm{~m}$ (8 ft) high by $1.52 \mathrm{~m}$ (5 ft) square (Figure 1). Air is drawn through the booth at approximately $0.94 \mathrm{~m}^{3} / \mathrm{sec}(2,000 \mathrm{cfm})$ by a fan located outside the structure. This results in an average air velocity of $1.02 \mathrm{~m} / \mathrm{sec}(200 \mathrm{fpm})$ through the booth. Air enters the booth through openings in the ceiling. After passing a steel grating raised $15 \mathrm{~cm}(6 \mathrm{in.})$ from the floor, air is exhaustea from the booth through openings located opposite each other at the bottom of the enclosure. Exhausted air is fed into a duct leading to the plant's main stack, located about $9 \mathrm{~m}$ (30 ft) away. This takes advantage of the natural draft already present in the stack and eliminates the need for an 


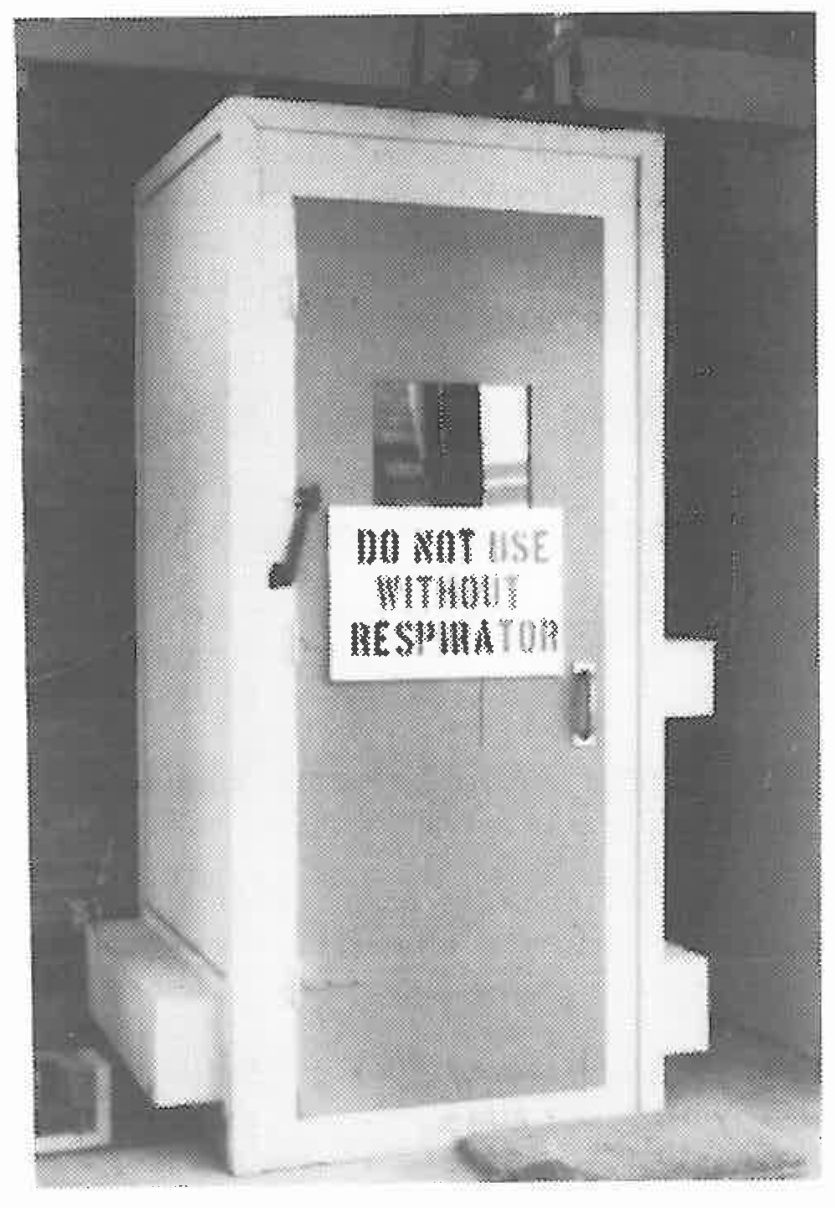

Figure 1. Outside view of downdraft booth. Air is exhausted from the booth through the lower protrusions on either side of the enclosure.

individual dust collector next to the booth. Although booth intake air is unternered, it is not felt to cause a significant draft on workers, because of the relatively mild climate of the area.

In conjunction with the downdraft system are eighteen air nozzles (Figures 2 and 3) arranged on the wall opposite the door of the booth. The nozzles are located at different levels and at 45 degree angles to the worker's body. Average air velocity through each of the air nozzles is about $51 \mathrm{~m} / \mathrm{sec}$ $(10,000 \mathrm{fpm})$. A regulator in the air line ahead of the nozzles ensures that the pressure does not exceed $2.1 \mathrm{Kg} / \mathrm{cm}^{2}(30 \mathrm{psi})$.

USE OF THE DOWNDRAFT BOOTH

After the prototype downdraft booth was constructed, a specific procedure was adopted for use of the booth. Upon leaving the work area, the employee determined to have an airborne arsenic exposure above $0.100 \mathrm{mg} / \mathrm{m}^{3}$, or a lead exposure above the permissible exposure limit of $0.050 \mathrm{mg} / \mathrm{m}^{3}$ is instructed to use the booth before entering the lunchroom/changehouse facility. Before using the booth, the worker must check to make sure he has 


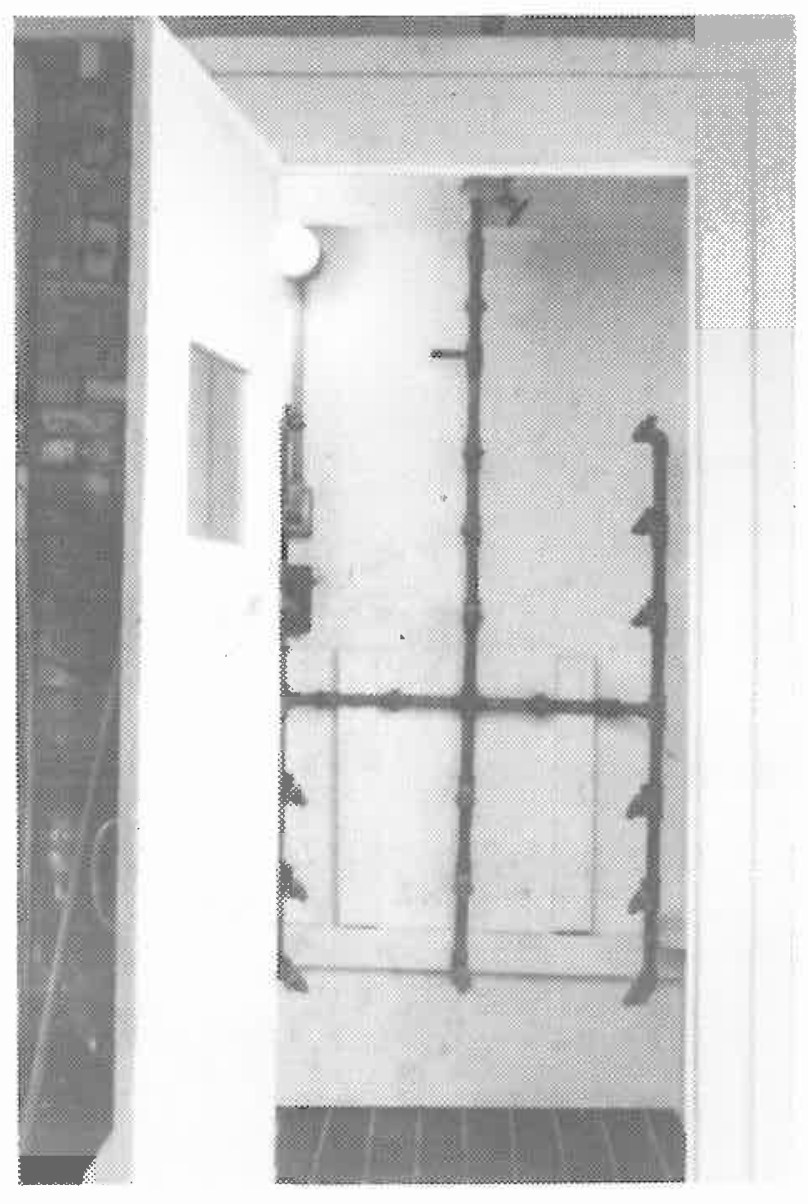

Figure 2. Inside view of downdraft booth. Banks of compressed air nozzles can be seen, with steel grating at floor level.

on all the required personal protective equipment, including respiratory protection. Protective equipment includes all that is worn in the work area: coveralls, shoes, gloves, hat, and appropriate respirator. Some of the employees use powered air-purifying respirators, which can pose a special problem when using compressed air in the downdraft booth. Since the filter/blower assembly unit is carried on the waist, the somewhat delicate high-efficiency filters are vulnerable to rupture by any compressed air directed at the unit. Therefore, a plastic guard was designed by the maintenance department to slip over the unit while the employee is in the booth cleaning his clothes. This guard protects all exposed openings of the filters from the direct impact of compressed air, but still allows air to be drawn through the filters and into the facepiece.

After properly adjusting the respirator to ensure a good face-to-facepiece seal, dust on the shoes is loosened by a foot brush located over a grating adjacent to the booth. After entering the booth, the downdraft fan pulling air through the grating at the bottom of the booth is first turned on, followed by the compressed air nozzles. Clothes are cleaned by moving body 


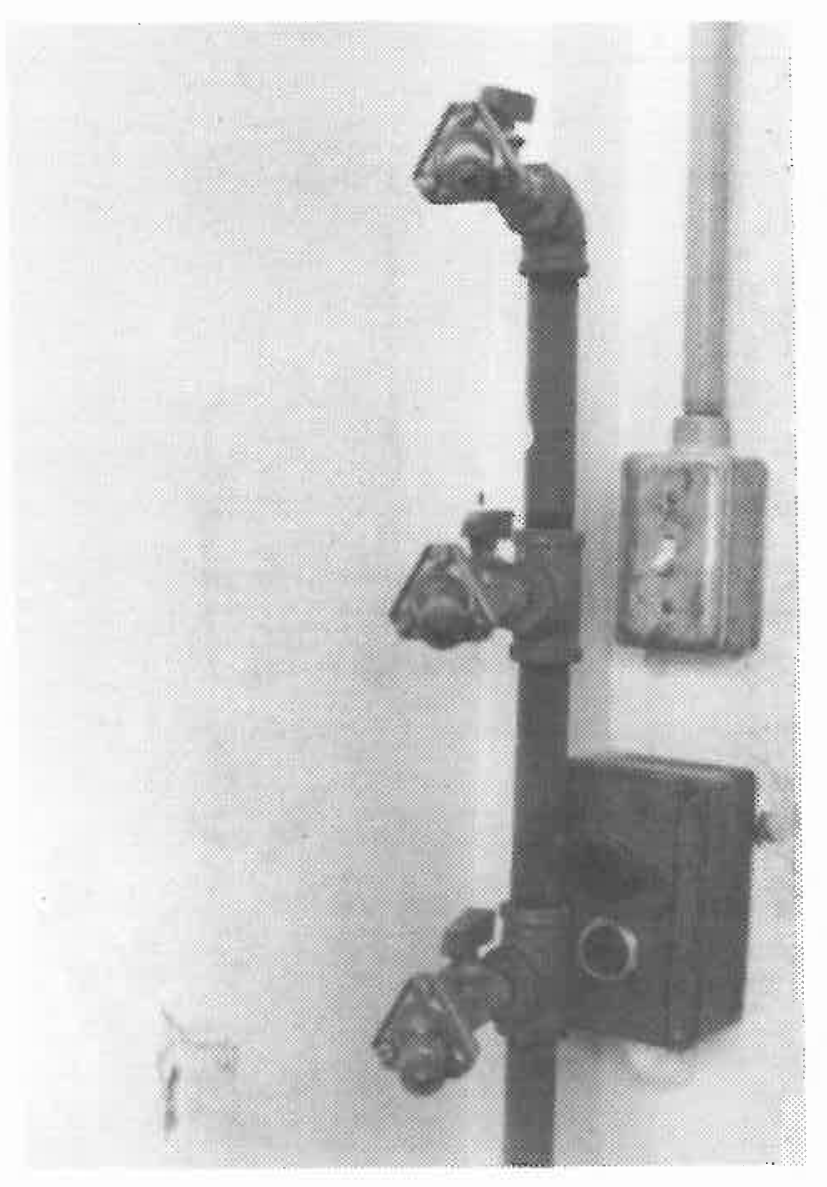

Figure 3. Close-up of air nozzles. Switch for light and on/off buttons for downdraft fan also can be seen.

and clothing past the bank of nozzles in vertical and horizontal motions. After clothing and shoes are cleaned, which usually takes no more than a minute, the nozzles are turned off. Before leaving the booth, the employee turns off the downdraft fan.

\section{EVALUATION}

Because the OSHA arsenic standard limits the cleaning of work clothing to vacuuming only, it was necessary to determine if the downdraft method is as effective as the method prescribed by this standard. Arsenic contamination in the lunchroom was selected as the criterion for effectiveness, since one of the main objectives of cleaning work clothes by either method is to reduce arsenic levels in this area. The lunchroom used for sampling in this test is pressurized by filtered air. Airborne and settled arsenic levels were monitored for two weeks on day shift while employees used the downdraft booth, and for two weeks while employees vacuumed their clothes. 
Vacuuming was conducted in the open, and averaged about 4-5 minutes per employee. Cleaning clothes with the downdraft booth averaged about one minute per employee. During the test period, eight of the fourteen employees using the lunchroom cleaned their clothes before entry, based on their measured airborne arsenic exposure.

For each of the two week periods, full shift air samples were collected on a daily basis at three locations in the lunchroom. Short term air samples were obtained during the lunch period. On several occasions, breathing zone samples were collected from an average of three individuals per sample, while employees either vacuumed or blew their clothes off in the downdraft booth. Wipe samples were collected for four lunch counter locations in the lunchroom for each of the two week periods, before and after the lunch period.

All airborne samples were collected with MSA Model G portable pumps and closed-face millipore filter casettes ( $0.8 \mu$ pore size). Settled arsenic samples were obtained in the form of wipe samples. Each wipe sample was collected on a four-inch whatman 41 filter, moistened with distilled, deionized water. All samples were analyzed by a colorimetric method, based on the reaction of arsine with a pyridine solution of silver diethyldithiocarbamate, producing an intense red color.

\section{RESULTS}

Results of airborne arsenic sampling conducted in the lunchroom during periods of vacuuming and downdraft booth use indicate very small differences in contamination levels when using either of the two methods (Table 1). A t-test shows the differences between all sets of data not to be significant.

Table 2 shows that breathing zone air samples collected while employees used the booth were higher than during vacuuming. This, however, could be expected, since in dislodging dust with compressed air, some of it is liable to drift into the breathing zone before it can be swept out of the booth. It is interesting to note that airborne arsenic breathing zone levels were above the eight-hour permissible exposure limit of $0.010 \mathrm{mg} / \mathrm{m}^{3}$ when the prescribed method of vacuuming was used.

Table 3 summarizes the results of the wipe samples. The means given in the table are the differences in the samples taken after the lunch period minus the samples taken before lunch. Although increases in lunch counter contamination were noted in most cases after employees had finished lunch, these samples are not viewed as being too valuable, since results were, for the most part, erratic. It is felt that the qualitative nature of this test and the uneven distribution of arsenic contamination on the counters limited its effectiveness. In spite of these problems, a t-test again shows that no difference could be found between those collected during vacuuming and those collected during downdraft bnoth use. 
Table 1. Average airborne arsenic levels in Cottrell lunchroom.

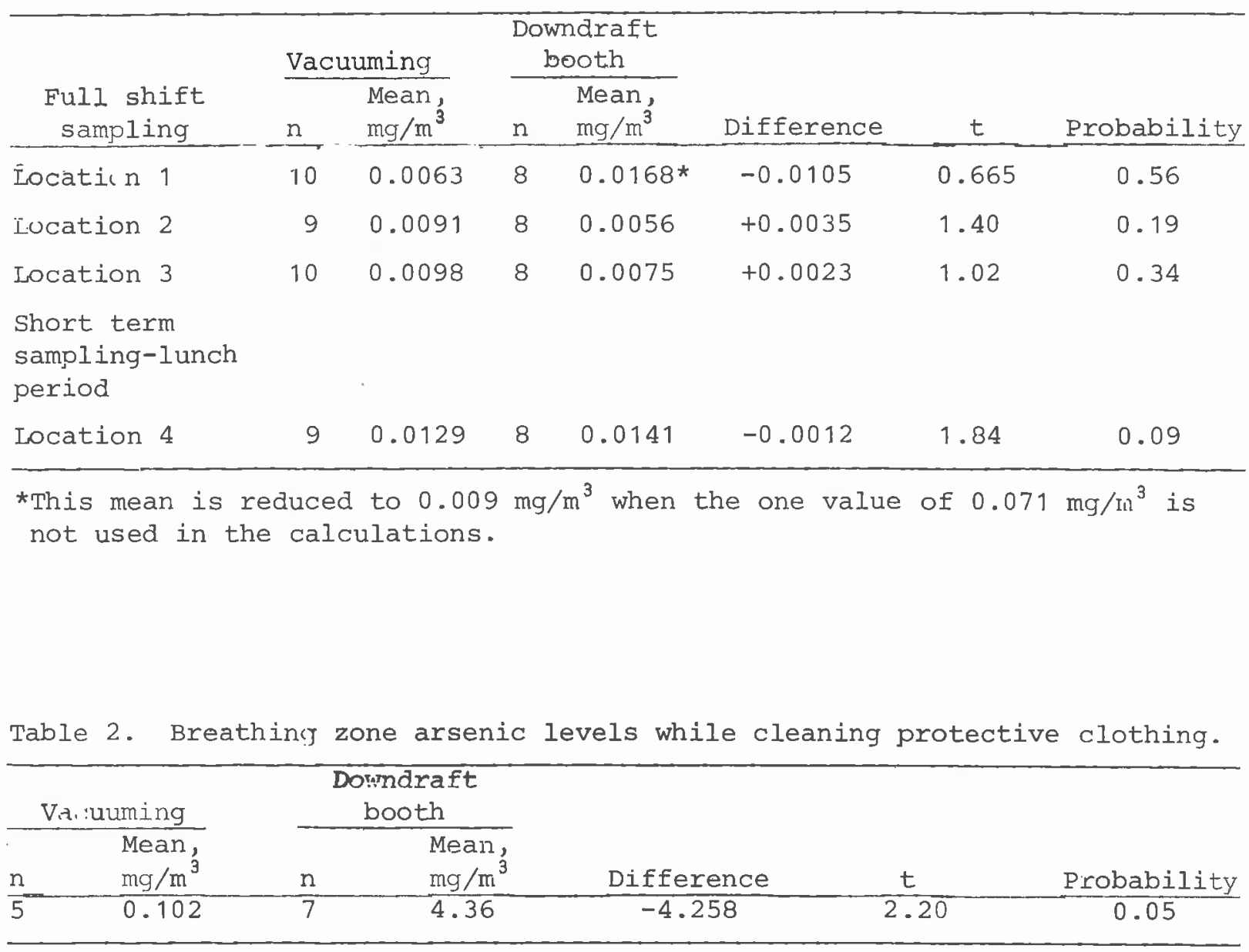


Table 3. Wipe samples analyzed for arsenic.

\begin{tabular}{|c|c|c|c|c|c|c|c|}
\hline Location & Va & $\begin{array}{l}\frac{\text { uuming }}{\text { Mean, }} \\
\mu g^{*}\end{array}$ & $n$ & $\begin{array}{l}\text { ondraft } \\
\text { Dooth } \\
\text { Mean, } \\
\mu g^{*}\end{array}$ & Difference & $t$ & Probability \\
\hline $\begin{array}{l}\text { Northwest section } \\
\text { of counter } \\
\text { (after-before) }\end{array}$ & 9 & 12.81 & 8 & 18.33 & -5.52 & 0.24 & 0.42 \\
\hline $\begin{array}{l}\text { Southwest section } \\
\text { of counter } \\
\text { (after-before) }\end{array}$ & 9 & 14.12 & 8 & -37.4 & 51.52 & 1.36 & 0.11 \\
\hline $\begin{array}{l}\text { Northeast section } \\
\text { of counter } \\
\text { (after-before) }\end{array}$ & 9 & 25.56 & 8 & 3.3 & 23.26 & 1.13 & 0.15 \\
\hline $\begin{array}{l}\text { Southeast section } \\
\text { of counter } \\
\text { (after-before) }\end{array}$ & 9 & 11.46 & 8 & 5.18 & 6.28 & 1.20 & 0.13 \\
\hline
\end{tabular}

* Mean of the differences in arsenic samples taken after lunch minus samples taken before lunch.

SUMMARY

The data presented above demonstrate that the downdraft booth can be as effective as vacuuming in accomplishing the goal of reducing arsenic contamination in the lunchroom/changehouse area. It takes less time than vacuuming, and also has the advantage of greater employee acceptance and better removal of visual dust that adheres to the clothing.

QUTSTIONS, ANSWERS AND COMMENTARY

Comment (L. Bullock, Globe Union):

I think you failed to mention that the part of the lead standard you are dealing with in regard to employee vacuuming of clothes has been stayed as of right now.

Answer (K. Gerecke, OSHA):

It was stayed initially for a month, but it hasn't been stayed since then, so it's in effect. 
Comment (L. Bullock):

You are more or less presuming that dirt on clothes affects airborne lead readings. You could also assume that dirt on clothes could also affect dirt on hands, and thus ingestion of lead which may or may not be shown by wipe and air samples.

Question (J. Dionne, Gould Inc., Metals Div.):

What was the average residence time the individual stayed in the booth and how many people can go through the booth at the same time?

Answer (C. Dungey):

It was about one minute. Only one person can fit in the booth at a time. If there are, for example, eight people that need to use the booth before lunchtime, it will only take about ten minutes to get everyone through. Often they don't all come at one time. If the number is larger than this multiple booths may be required, just as multiple vacuuming stations would be required.

Question (J. Dionne):

Or perhaps a longer booth?

Answer (C. Dungey):

A longer booth used simultaneously by a number of employees is a possibility. 


\author{
Vincent C. Jacobson \\ Gopher Smelting Co., Inc. \\ St. Paul, Minnesota \\ Knowlton J. Caplan, President \\ Industrial Health Engineering Associates, Inc. \\ Minneapolis, Minnesota
}

\title{
ABSTRACT
}

Designing and installing engineering controls to protect the health of workers is one thing, making them fully functional and reliable is quite another. The authors list four reasons for installing control measures which may be related to the ultimate success of their use: product recovery, protection of employee health, satisfaction of government mandates and survival. A case history is presented to show the progression of management acceptance starting with the plant's efforts to protect the health of workers on their own, through the upheaval of a court ordered compliance program, and ending with the establishment of a management plan to provide a comprehensive program of protection.

\section{FACTORS THAT AFFECT CONTROL EFFECTIVENESS}

When engineering controls are discussed in the technical literature, the subject of the discussion is usually the beginning, i.e., application, design, installation and evaluation. Obviously, the design must be good or the results cannot be good, but let's go on from there.

The continuation of engineering controls, i.e., proper operation and maintenance, is usually lumped into the general category of maintenance and considered separately. Improper operation or poor maintenance are usually blamed for inadequate performance of engineering controls whether or not the design was good. The design obviously can influence the ease of operation and maintenance, but even the best design by no means assures the continued effectiveness of the control.

While effective engineering controls can frequently be provided by expenditure of enough money and talent, the real difficulty of implementing engineering controls is in gaining worker acceptance and in assuring continued operation and maintenance. This problem can be substantially reduced through skillful design of controls with both worker and maintenance 
in mina*. However, with very few exceptions, the presence of an engineering control will in some way interfere with the worker's performance of his job. Unless the health hazard is immediate and severe--a "life hazard"--it is well-known that production will not stop if this piece of equipment malfunctions. The only way the controls will be assured of performing their function on a continuing basis is if the entire plant management is sincerely committed to assigning a high priority to them--equivalent to that for production.

\section{REASONS FOR INSTALLING CONTROL MEASURES}

For the purpose of this talk, engineering controls may be divided into four classes based on the reasons for implementing them:

Class 1. Those desired for the purpose of product recovery-This class results in product value and is therefore given a priority equivalent to production. This type of control usually functions as consistently as other production equipment in the same facility, at least in its product recovery aspects.

Class 2. Those perceived by management as being required to protect employee health--

This class is the second highest priority in the plant. The number of controls included in this group and the relationship of their priorities to that of production varies broadly depending on objectives of management and profitability of the company.

Class 3 - Those perceived as important by outside authorities and implemented through the use of force--

This class is often considered unnecessary, ineffective, and/or unworkable by management. The situation is made worse by the stance of some agencies, frequently requiring controls for their own sake regardless of effectiveness or cost, as a "policy" or "political" position. It receives lowest priority and is doomed to failure. It may be doomed anyway because of basic infeasibility, but that is a different problem. The only hope for this class of control is that, where the facts warrant, management can be persuaded to change it to Class 2 or Class 4 .

Class 4 - Those considered by management to be effective and workable and perceived to be in the best interests of the company based on the survivor syndrome--

Controls in this group include, for example, those that the manager feels are possible to implement and are required to meet the osHA standards, even though this manager may feel a particular osHA standard is unreasonably restrictive and not required to protect the employee's

*Caplan, K. J., "Philosophy and Management of Engineering Controls", Vol. III, Chapter 18, Patty's Industrial Hygiene and Technology, 3rd ed. Wiley Interscience, New York 1979. 
health. Priority is placed on these controls because if they are not functional, the legal ability to operate will be affected, which in turn will affect the plant's competitive position in the long run.

\section{CASE HISTORY EXAMPLE}

\section{Background}

A first-hand case history will be illustrative of a progression of management acceptance and incorporation of the different classes of controls just described. I will begin by characterizing the management of the company which in this case is a secondary lead smelter. The organization, not at all unusual for small companies including many in the foundry and secondary lead industries, comprises a minimum management staff. It is a paternal organization run by well-meaning people who place a very high value on their employees and have a far-reaching reputation as legitimate businessmen. They have, however, a poor reputation with local health officials, probably because they have dealt for some time with a product known to be toxic (lead) and have largely ignored interference by outsiders.

At the plant being described, the situation at the reginning of the case history relative to controls was as follows:

Class 1 controls included filtration and recovery of flue dust which had been used for many years. In this industry, recovery of product from furnace flue dust is required to maintain a competitive position in the marketplace.

Class 2 controls had been installed for some time and were reasonably well maintained as evidenced by the fact that there was rarely a case of lead poisoning occurring. Such controls relied heavily on personal protective devices and were not complete solutions in an engineering sense. Biological monitoring had been in effect for some time and the list of controls included in Class 2 was continually growing as a result of concern over blood leads.

Management had done a good job - from their point of view - of keeping on top of the situation. They regularly visited the plants of competitors to keep abreast of what others were doing in this area. They worked hard to keep theix plants "better than most" as it relates to employee health.

\section{Government Mandate}

With this background, it is understandable that management was upset when OSHA cited them, stating that they were "seriously" endangering their employees' health in most areas of the plant. Not only did they disagree, but they were insulted that anyone would think they would deliberately risk their employees' health. They listened to the ideas suggested by OSHA for coming into compliance, attempted to incorporate what they considered workable, and disposed of the rest. Following expiration of the abatement date, they discovered that OSHA was not satisfied. Under pressure from OSHA for compliance, they indicated that they had done everything they could, that they were on par with most smelters in the 
industry, and that further engineering controls were not feasible.

OSHA brought court action against the company, and retained an industrial hygiene engineering consultant for an independent opinion. The consultant produced a report documenting feasible engineering controls required to achieve OSHA compliance. After some negotiation, the consultant's report was adopted as the basis for settlement of the case, and was issued in the form of a court order. The company proceeded to hire an engineering consultant in an attempt to implement the court order, with all the lack of fervor described above for Class 3 controls.

Implementing the Mandate

In the initial investigation, upon which the recommendation of feasible controls was made, the consultant had had to accept management statements as to the existing and reserve capacity of the baghouses. It later developed that management had been badly misled by equipment vendors as to the capacity that could be achieved by modifications. This posed special hardships in attempting to fulfill the court mandate.

I (Vincent J. Jacobson) had the good fortune to be assigned this task on behalf of the consulting firm, Industrial Health Engineering Associates. It was a truly exciting experience to work with this company and to watch our relationship grow from mistrust to trust to belief in a common goal as the project progressed. The work done has been substantial, and is briefly outlined as follows:

The battery saw has been replaced with a low speed saw which produces a much lower emission.

Plate storage has been relocated to inside a new building resulting in drastically reduced fugitive emissions (an EPA consideration) and also in reduced exposure to employees working in the general area. The entice plate handling end of the operation has been physically isolated from the rest of the plant. The plate handling operator running a payloader has been supplied with either an air supplied respirator or a clean air cab enclosure.

The dry sweeper which was used throughout the plant. and which produced substantial amounts of dust in operation has been supplemented by a central vecuum cleaning system.

Blast furnace and reverberatory furnace tapping have been provided with improved enclosure and ventilation.

The refining kettles have been provided with hoods having significantly improved capture.

Flue dust recycling from the baghouse to the furnaces has been mechanized using a well sealed screw conreyor system. 
Gravity roof ventilators have been provided above the reverberatory furnaces to exhaust contaminants from the upper building air spaces.

Make-up air introduced at low velocities to produce a clean air "island" effect has been provided in the blast furnace area.

Limited Effectiveness Achieved

Upon installation of these controls, the OSHA court order was satisfied and officially closed. However, the effectiveness of many of the installed control meisures was limited.

The material handling isolation included a number of access openings which were usually left open, negating the effectiveness of the isolation. The air-supplied respirators for the payloader operators never did work properly as they were quite cumbersome and suffered from many breakdowns.

The vacuum cleaning system worked extremely well, but due to a manpower shortage and the labor intensiveness of manual vacuum cleaning, it was not performed frequently enough to improve overall plant housekeeping.

The furnace hoods were reasonably well designed and functioned quite well when adequate baghouse capacity was available and access openings were maintained closed, which they routinely were not. Another furnace hood problem was consistency of exhaust capacity which was disrupted by a plugging problem. The original flue gas cooling system was a radiant tube type system with receiver kettles at the ground level junctions. As flue dust settled out of the cooling tubes, the kettles plugged, resulting in dramatically varying system pressure drops and ventilation rates and inadequate performance of furnace hoods.

The flue dust handling system was very satisfactory where it was installed, however, the cooling tube kettles were periodically cleaned using a payloader and that source had not been controlled.

The gravity roof ventilators and make-up air system were also satisfactory where installed, but additional make-up air systems were needed in other areas of the plant.

It could be shown that the lead exposure of virtually every job description in the plant was less than $200 \mu \mathrm{g} / \mathrm{m}^{3}$-when things went right. Conversely, workers with virtually every job description had exposures exceeding $200 \mu \mathrm{g} / \mathrm{m}^{3}$ when things went wrong. This is a case of a complete set of engineering controls having been almost installed and almost implemented. The project was successful in the Class 3 sense in that the terms of the court order had been satisfied. 
A decision point had been reached. Management now realized that they could significantly delay the effects of furnace OSHA involvement by hiring a good lawyer and playing legal games. Instead, they chose to become survivors, and began by attacking their most obvious weakness - lack of management coverage. They hired key staff members to improve coverage and expertise in the areas of safety and health, engineering and personnel. As a result, they have been able to improve the stability of the work force which in turn makes training efforts more productive, and makes it possible to more effectively enforce personal hygiene and work practice controls and to implement a comprehensive respirator program.

Hygiene and lunchroom facilities have been rearranged and improved. A new U-tube cooler has been designed and is nearly in operation to improve baghouse capacity and dramatically reduce flue dust handling exposure. Each of the existing engineering controls is in the process of being reassessed and the required detailed changes to make them perform adequately will be implemented.

Long range planning is being done, especially in the area of mechanization of material handling, to reduce employee involvement and, therefore, exposure. A long range compliance plan will soon be developed to provide for plinned progress toward the objective of implementation of all feasible engineering controls. It is crucial, however, when discussing these plans to remember that they really are--only the beginning.

QUESTIONS, ANSWERS AND COMMENTARY

Question (J. Talty, NIOSH):

How do you distinguish between Class 2 and Class 4? What would be an example of a Class 2 engineering control?

Answer (V. Jacobson):

The difference I see between Class 2 and Class 4 is the belief that is really required to protect the employee's health. And with the proposed lead standard in the courts, I think it's obvious to everyone that we don't all believe that a standard as low as $50 \mu \mathrm{g} / \mathrm{m}^{3}$ is required to protect the health of workers. 
PREVENTION OF HIGH LEAD LEVELS THROUGH EMPLOYEE TRAINING PROGRAMS

Lee Norman, Director

Industrial Safety and Health Consultants

Jackson, Tennessee

\section{ABSTRACT}

Extensive analyses of blood lead levels in smelter workers with and without initial employee training programs has lead to the conclusion that initial blood lead levels can be controlled by special training, briefings, and follow-up meetings with new employees. Prevention is much more effective than trying to reduce levels once they are elevated. The pre-employment physical presents an opportunity to identify individuals with initial high blood lead. Blood lead data is presented to show the trends in new employee levels during their first months with and without worker training programs in effect. Guidelines are presented for administering a suitable worker training program. For the program to be maximally effective, accurate blood lead analyses are required to prevent fluctuations in accuracy of the analyses from confusing the periodic evaluation of the worker's performance or incorrectly signalling the need for medical removal.

NEED FOR TRAINING NEW EMPLOIEES

I recognize the purpose of this symposium is to present technical information concerning control methods for reducing worker exposure to air contaminants and that, for the most part, the presentations made here today will all have to do with engineering control technology. However, I would like to discuss the opportunity the smelting industry has to prevent high blood lead levels by using effective training techniques during the employee's first sixty days on the job.

After reviewing approximately 10,000 blood lead analyses of new employees over the past three years, I am convinced that initial blood lead levels can be controlled by special training, briefings and follow-up meetings with new employees.

I realize that what I am suggesting is a complete reversal of the approach many employers have been taking up to this time. I am aware that employers spend a great deal of time with those workers who have already experienced high levels of lead in their total body system and I am also aware of the work employers do to reduce these levels. Sooner or later, however, it is necessary to "prevent" rather than "cure". 
The new employee's blood lead level must be an important issue from the first pre-employment physical. The initial blood lead level should be in line with the normal lead level in the area. Without prior industrial lead exposure a new worker in Chicago may have an initial lead level of $26 \mathrm{\mu g} / 100 \mathrm{ml}$, whereas the initial blood lead level of a person who has spent the last 10 years in the rolling hills of Nebraska may be as low as $8 \mu \mathrm{g} / 100 \mathrm{ml}$. Once the normal range for new employees in an employment area has been established any abnormally high lead levels on pre-employment physicals should be questioned. Careful consideration should certainly be given to any potential employee who has not had any significant contact with lead in the past but who has an initial lead level greater than $30 \mu \mathrm{g} / 100 \mathrm{ml}$. Such levels may indicate the employee's inability to discharge lead from his or her system.

There have been only a very limited number of clinical studies concerning lead exposure for new employees. Most of this research was performed by Kehoe in the late 40 's and early 50's. In all reported cases, the blood lead levels of subjects appeared to rise rather rapidly after the initiation of the lead exposure, then stabilize as the worker adjusted, and finally slowly fall after the end of the exposure period.

My experience with more than 10,000 blood lead samples from new employees has indicated the same trend. However, I recently began to see a change in this trend as certain employers began to implement strong employee briefing and training programs for new workers. I now believe the rapid increase of new employee's lead levels can be controlled by strict enforcement of employee training programs that include careful follow-up sessions for the first sixty days the employee is on the job.

The new OSHA lead standard requires an employer to provide information and training programs for all employees exposed to lead. At the minimum the employer must inform employees of specific hazards associated with their work environment and of protective measures which can be taken. If worker training is approached as a program to control high lead levels rather than just to satisfy minimum requirements, I know that good results will be achieved.

\section{LEAD LEVEL MEASUREMENTS}

I will now present a few samples of what happens to controlled and uncontrolled blood lead levels for new employees. Table 1 shows actual analyses of blood lead levels during the first several months on the job for employees of two secondary lead smelters before training programs were implemented.

The first group of smelter workers (Smelter 1, Table 1) had average preemployment lead levels of $25 \mu \mathrm{g} \%$ * which quickly jumped to highs of $50-60 \mu \mathrm{g} \%$ after only one month or the job. The second case (Smelter 2, Table 1) shoes similar large increases during the first month with exceptional jumps in two cases up to 78 and $98 \mu g$ g levels.

* $\mu \mathrm{g} \%$ is synonomous with $\mu \mathrm{g} / 100 \mathrm{ml}$. 
Table 1. Blood lead levels of new workers in the first months of employment at two smelters without training programs.

\begin{tabular}{|c|c|c|c|c|c|}
\hline \multirow[b]{2}{*}{ Employee } & \multicolumn{5}{|c|}{ Month of employment } \\
\hline & 1 & 2 & 3 & 4 & 5 \\
\hline \multicolumn{6}{|l|}{ Smelter 1} \\
\hline A & $16 \mu g \%$ & $50 \mu \mathrm{g} 8$ & $51 \mu \mathrm{g} 8$ & & \\
\hline B & $27 \mu g 8$ & $63 \mu \mathrm{g} \%$ & & & \\
\hline $\mathrm{C}$ & $21 \mu \mathrm{g} \%$ & $53 \mu \mathrm{g} \%$ & $57 \mu g \%$ & & \\
\hline D & $26 \mu \mathrm{g} \%$ & $49 \mu \mathrm{g} \%$ & $54 \mu g \%$ & $53 \mu \mathrm{g} \frac{\circ}{6}$ & $54 \mu \mathrm{g} \%$ \\
\hline$E$ & $16 \mu \mathrm{g} \%$ & $37 \mu g \%$ & & & \\
\hline F & $29 \mu \mathrm{g} \%$ & & $66 \mu \mathrm{g} \%$ & $68 \mu \mathrm{g} \%$ & $56 \mu \mathrm{g} \%$ \\
\hline G & $25 \mu \mathrm{g} \%$ & $39 \mu \mathrm{g} \%$ & $38 \mu \mathrm{g} \%$ & & \\
\hline $\mathrm{H}$ & $17 \mu g 8$ & & $29 \mu \mathrm{g} z$ & $55 \mu \mathrm{g} \%$ & \\
\hline$I$ & $26 \mu \mathrm{g} \%$ & $58 \mu \mathrm{g}$ 웅 & & & \\
\hline $\mathrm{J}$ & $21 \mu g 8$ & $54 \mu \mathrm{g} \%$ & $63 \mu \mathrm{g} \frac{8}{8}$ & & \\
\hline \multicolumn{6}{|l|}{ Smelter 2} \\
\hline $\mathrm{A}$ & $14 \mu \mathrm{g}$ 용 & $54 \mu \mathrm{g} z$ & $53 \mu \mathrm{g} 8$ & $50 \mu \mathrm{g} 8$ & \\
\hline B & $16 \mu \mathrm{g} 8$ & $78 \mu \mathrm{g} \frac{2}{8}$ & $121 \mu \mathrm{g} \%$ & & \\
\hline $\mathrm{C}$ & $22 \mu g^{8}$ & $35 \mu \mathrm{g} 8$ & $43 \mu \mathrm{g} \frac{8}{8}$ & & \\
\hline $\mathrm{D}$ & $18 \mu \mathrm{g} \%$ & $98 \mu \mathrm{g} \%$ & $75 \mu \mathrm{g} \frac{8}{8}$ & $72 \mu \mathrm{g} \frac{8}{6}$ & \\
\hline $\mathrm{E}$ & $14 \mu \mathrm{g} \%$ & $50 \mu \mathrm{g} \%$ & $48 \mu \mathrm{g} \%$ & $48 \mu \mathrm{g} \%$ & \\
\hline $\mathrm{F}$ & $11 \mu \mathrm{g} z$ & $47 \mu \mathrm{g} \%$ & & & \\
\hline G & $24 \mu g q$ & $34 \mu \mathrm{g} \%$ & & & \\
\hline $\mathrm{H}$ & $10 \mu \mathrm{g} \%$ & & $28 \mu \mathrm{g} \frac{8}{8}$ & $35 \mu \mathrm{g} \%$ & \\
\hline
\end{tabular}


Table 2 shows the results of blood lead levels in new employees taken both before and after a smelter instituted a good training program.

ELEMENTS OF THE TRAINING PROGRAM

Each employee should receive an initial briefing session including a description of the hazards of working with lead, explanation of preventive methods, and the symptoms of lead poisoning. The worker should be both told and shown how to use all of the protective equipment he or she will be issued and have the engineering controls demonstrated at the work station.

The initial briefing is only one part of the overall program and this can be done verbally or with slides or films. The more important part of the program is the follow-up with each employee. After the third day on the job, the immediate supervisor should reaffirm to the new worker points from the initial briefing and answer any questions the employee may have.

An appraisal of the probationary employee should be made at the end of two weeks and a written report prepared by the supervisor on the ability of the new employee to handle a job in a contaminated area.

The supervisor must make daily checks to observe hygiene habits and to be sure the new employee is observing company policy of washing before eating, drinking or smoking and of restricting these activities to the approved areas.

The personnel department should hold a follow-up briefing at the end of each 30 day period for the first three months, and conduct a training session when the employee's blood lead levels are received from the lab, repeating at each session those items the employee can do to reduce lead levels.

In summary, I recommend the following guide for your use in setting up a training program:

-Pre-employment briefing and training format.

-Two-day follow-up by supervisor.

-14 day re-briefing by safety director, nurse, or personnel director.

-30 day appraisal of probationary employee with discussion of blood lead levels.

-45 day employee appraisal by supervisor.

-60 day re-briefing and discussion of blood lead results.

It should be manditory for all new employees to attend a safety program for one hour each month for the first three months on the job in addition to te the schedule listed above.

It is my belief that such a program can prevent employees from rapidly developing high lead levels. Lead levels can be more adequately controlled during the first six months on the job than at later periods. 
Table 2. Blood lead levels of new workers in the first months of employment at a smelter before and after a training program was implemented.

\begin{tabular}{|c|c|c|c|c|c|}
\hline \multirow[b]{2}{*}{ Employee } & \multicolumn{4}{|c|}{ Month of employment } & \multirow[b]{2}{*}{5} \\
\hline & 1 & 2 & 3 & 4 & \\
\hline \multicolumn{6}{|c|}{ Before implementation of training program } \\
\hline A & $19 \mu \mathrm{g} \%$ & $52 \mu \mathrm{g} \%$ & & $49 \mu \mathrm{g} \%$ & \\
\hline B & $19 \mu \mathrm{g} \%$ & $56 \mu \mathrm{g} \%$ & & $66 \mu \mathrm{g} \%$ & $55 \mu \mathrm{g} \%$ \\
\hline $\mathrm{C}$ & $18 \mu \mathrm{g} \%$ & $64 \mu \mathrm{g} \%$ & $52 \mu \mathrm{g} \%$ & & \\
\hline $\mathrm{D}$ & $26 \mu \mathrm{g} \div$ & $54 \mu g \%$ & $40 \mu \mathrm{g} \%$ & & \\
\hline $\mathrm{E}$ & $16 \mu \mathrm{g} \%$ & $63 \mu \mathrm{g} \%$ & & & \\
\hline $\mathrm{F}$ & $5 \mu \mathrm{g} \%$ & $43 \mu \mathrm{g} \%$ & & & \\
\hline G & $17 \mu \mathrm{g} \%$ & & $44 \mu \mathrm{g} \%$ & $50 \mu g \%$ & $49 \mu \mathrm{g} \%$ \\
\hline $\mathrm{H}$ & $15 \mu \mathrm{g} 8$ & $27 \mu \mathrm{g} \%$ & $51 \mu \mathrm{g} \%$ & $59 \mu \mathrm{g}$ 웅 & $61 \mu \mathrm{g} \%$ \\
\hline I & $10 \mu \mathrm{g}$ 응 & $56 \mu \mathrm{g} \%$ & $52 \mu \mathrm{g}$ 웅 & & $93 \mu \mathrm{g} \%$ \\
\hline \multicolumn{6}{|c|}{ After implementation of training program } \\
\hline A & $13 \mu \mathrm{g} \%$ & $18 \mu \mathrm{g} \%$ & & $39 \mu \mathrm{g} \%$ & \\
\hline B & $22 \mu g$ 웅 & $33 \mu \mathrm{g} \%$ & $37 \mu \mathrm{g} \%$ & $34 \mu g \%$ & \\
\hline $\mathrm{C}$ & $29 \mu \mathrm{g} \%$ & & $33 \mu \mathrm{g} \%$ & $34 \mu g \%$ & \\
\hline $\mathrm{D}$ & $20 \mu \mathrm{g} \%$ & $20 \mu g \%$ & $51 \mu \mathrm{g} \%$ & & \\
\hline $\mathrm{E}$ & $18 \mu \mathrm{g} \%$ & $29 \mu \mathrm{g} \%$ & $45 \mu \mathrm{g} \frac{2}{2}$ & $53 \mu \mathrm{g}$ 웅 & \\
\hline $\mathrm{F}$ & $19 \mu \mathrm{g} \%$ & $66 \mu \mathrm{g} \%$ & $43 \mu g \%$ & $32 \mu \mathrm{g}$ 응 & $37 \mu \mathrm{g} \%$ \\
\hline G & $16 \mu \mathrm{g} \%$ & $26 \mu \mathrm{g} \%$ & $65 \mu \mathrm{g} \%$ & $47 \mu \mathrm{g}$ 용 & \\
\hline $\mathrm{H}$ & $17 \mu \mathrm{g} \%$ & & & $40 \mu \mathrm{g} \%$ & \\
\hline I & $19 \mu \mathrm{g} \%$ & $26 \mu g \%$ & & & \\
\hline
\end{tabular}


There are good resource materials that can assist an employer in establishing an adequate training program. Visual aid materials include films such as Lead in Motion and Lead Poisoning - it needn't be by the Lead Industry Association (IIA)*, or Recite Industrial Training Program by Resource Consultants**. An employer could even develop an in-house color slide/tape program.

\section{IMPORTANCE OF LABORATORY SELECTION}

The data which the above recommended training program relies on to provide information about the program's effect as well as the effectiveness of all the exposure control measures in the smelter is the measurement of blood lead level. It should be obvious that the accuracy of these measures is very important to prevent peaks and valleys from month to month which add confusion to the employee training program results.

Currently there are 145 certified laboratories involved in the Center for Disease Control (CDC) blood lead proficiency testing program. In the third quarter of 1979 only 57\% of these labs had satisfactory proficiency testing results. Ten labs failed to get within plus or minus $50 \%$ of the target value.

Less than $30 \%$ of the certified laboratories are able to produce sample results that meet OSHA's lead standard requirement of 95 percent accuracy. OSHA recently attempted to change these requirements when it published the following statement in the Federal Register on October 23, 1978: "Under CDC standards, $75 \%$ of blood lead determinations are not to vary from reference values by more than $6 \mu \mathrm{g} / 100 \mathrm{ml} "$.

I urge you to continue to require laboratories to meet the $95 \%$ accuracy goals rather than be satisfied with $75 \%$. This difference could be significant in the medical removal program when the levels drop to $70 \mu \mathrm{g} / 100 \mathrm{ml}$ on March 1, 1980.

\section{QUESTIONS, ANSWERS AND COMMENTARY}

Question (S. Smith, OSHA):

In your examples of elevated blood lead levels in the first sixty days on the job, were those employees wearing respirators?

Answer (L. Norman):

Yes . 
Question (S. Smith):

Although you didn't mention it, do you recommend that employees wear respirators in the beginning when they're setting up the work practices and procedures of doing a job?

Answer (L. Norman):

Yes

Question (F. Boelter, OSHA):

If a person has greater than 30 $\mathrm{g} \%$ (blood lead level) and has had a prior lead exposure, does this automatically prevent this individual from iecoming an employee?

Answer (L. Norman):

If the potential employee has an answer for his high lead levels, i.e., if this person has worked for another lead facility or in a situation which would explain the above thirty blood lead levels, then I think this should be taken into consideration and, if all things fall into line, employment offered.

Question (F. Boelter):

Do you feel that people who have never had a prior lead exposure at $30 \mu \mathrm{g} \%$ should be informed of this or how do you go about treating that information?

Answer (L. Norman):

In the discussion with the employee after the return of the pre-employment blood lead level measurements, the personnel director should take some time to find out why the employee's lead levels were elevated over thirty. The person may have been involved in a job that gave the person lead exposure that the person was not aware of. I think that:

1. The employee needs to know that.

2. Some effort should be made to determine what created the excessive lead levels.

Question (F. Boelter):

When somebody retains your services to set up a program for doing blood monitoring as well as employee training, do you find that management itself is always fully cognizant of the problems that it is faced with? And, secondly, what type of efforts do you do to train management as to what it should be doing and what is its responsibility? 
Answer (L. Norman):

I'm fortunate that most of my clients have been longtime clients, and we have been dealing with this problem for quite a while. But I recognize where your question is leading. There are many, many people in the lead industry today who aren't even aware that a lead standard has been published. These people certainly need some assistance in that area.

Question (F. Boelter):

Where do the partially or at least presently stayed sections of the lead standard dealing with $A L A D$ and $Z P P$ fall into your recommended programs for monitoring an employee's health?

Answer (L. Norman):

My laboratory does a zinc porta porphyren (ZPP) test on every blood sample we receive in our lab regardless of whether it's requested from the client company or not. We do this as a crosscheck for ourselves to determine if there is a potential problem.

Of course, we also automatically do complete blood counts (CBC) in our lab to determine if anemia is a problem. We feel that you don't get all the answers simply by doing a blood lead level determination.

Question (M. Bergner, OSHA):

Have your observations of the fluctuations in blood levels taken into account bone deposition of lead as a total body burden or are you just looking at the free-lead levels in blood? Do you measure hemoglobin? I think you had just mentioned that in one of your answers.

Answer (L. Norman):

Yes. In the data that I presented earlier, we were looking only at lead levels found in the blood at the time of testing. However, I feel confident that, should we go back and check zinc porta porphyren levels, we would not see the rapid advancement of zinc porta porphyren as we would see in blood lead levels. I seriously doubt that we would start to see advancement of zinc porta porphyren in new employees until the worker had been on the job four to six months.

Question (M. Bergner):

What recommendations do you make to your clients as far as hiring women to work in lead contaminated areas? 
Answer (I. Norman):

My recommendation is that they not hire women to work in lead contaminated areas. I agree with OSHA in their findings at the hearings that they must protect the fetus, not only the adult worker. Recognizing that the two hundred microgram level* may or may not be safe, depending on interpretation, for the adult worker either male or female, when we have the fetus to contend with we must aim towards that fifty microgram level of air exposure**. In today's smelters we may or may not be at the fifty microgram level at work stations. However, we have until 1984 in which to get down to the fifty microgram level. I feel that until we reach that fifty microgram level we should not expose the fetus of the woman at the workplace.

Question (D. Lynam, International Lead-Zinc Research Organization):

I have a question with regard to the zinc porta porphyren evaluations.

Do you use the hematofluorimeter?

Answer (L. Norman):

Yes.

Comment (D. Lynam):

For the benefit of the audience I think it should be pointed out that there is good indication that the hematofluorimeter gives bad results on old blood and that the results are only reliable on fresh blood. If samples of old blood are being transported by mail then you should be using a wet chemical digestion process.

Response (L. Norman):

I recognize this. And along with this, I'll say that we've run the same sample every day for a thirty-day period, and found no drastic change. We are getting change, but we're not getting any drastic change in the first fourteen days. The difference may be twelve to twenty points, e.g., a zinc porta porphyren test that may be 296 on the first day might go to 319-320 on the fourteenth day.

\footnotetext{
*Former OSHA Permissible Exposure Limit (PEL) of $200 \mu \mathrm{g} / \mathrm{m}^{3}$ in the worker's breathing zone.

**New OSHA PEL of $50 \mu \mathrm{g} / \mathrm{m}^{3}$ in the worker's breathing zone.
} 
PANEL DISCUSSION ON HEALTH HAZARD CONTROI TECHNOLOGY

IN THE SECONDARY NON-FERROUS SMELTING INDUSTRY

\author{
Moderated by Robert Hughes \\ Chemical Agents Control Section \\ Control Technology Research Branch \\ NIOSH \\ Cincinnati, Ohio
}

\title{
INTRODUCTION
}

The purpose of this panel, the last group function of the secondary non-ferrous smelting symposium, was to provide a forum for comments, questions, and interchange of information concerning health hazard control technology in the industry among all participants of the symposium. To highlight this discussion, four professionals with varied backgrounds, drawn from an industrial association, labor, government, and a consulting firm, with the common denominator of having interest and involvement in programs that affect the health of workers, were selected as panelists to lead the discussion. Prior to the open floor discussion each of the panelists presented short introductory remarks. Panelists were not restricted in their remarks and were invited to make comments on one or more of the following topics:

1. Identification of worker exposure problems and types of control technology of immediate interest.

2. Critique of the NIOSH technology assessment.

3. Identification of research and development priorities and discussion of whose responsibility it should be to conduct this research and development.

4. Suggestion of ways in which better interchange of information concerning health hazards and control technology could be achieved among the groups represented.

5. Any other remarks concerning the various topics of health hazard control technology presented in the symposium.

To ficilitate audience involvement and discussion, written questions had been requested from the audience from the beginning of the symposium. These were discussed first, followed by open discussion. The text of the panel incorporates both the introductory remarks of the panelists and the discussions, comments, and questions. 
PANELIST'S REMARKS

Donald R. Lynam, Ph.D

International Lead Zinc Research Organization, Inc. New York, New York

IMPORTANCE OF WORK PRACTICES AND PERSONAL HYGIENE

I would like to comment specifically on one of the recommendations for further research and development in the NIOSH report, "Control Technology Assessment - The Secondary Non-Ferrous Smelting Industry". The technology assessment identified "one particularly important research need - with regard to lead exposure which this study did not address, that is: the need to correlate the effect of worker personal hygiene with blood lead levels at varying lead-in air concentrations". The authors of the control technology assessment recommended "that a study be conducted to develop these correlations so that the expected effect of control technology (designed to reduce lead-in-air levels) on worker health can be better established". I would certainly agree with this major recommendation.

There is much discussion about the importance of work habits and personal hygiene in lead exposure situations, unfortunately there are few "hard" data which provide guidance on the significance of these factors. Today I would like to present a limited amount of data supporting the position that work habits and personal hygiene can represent significant routes of exposure.

\section{RESEARCH REPORT ON LEAD}

The first set of data comes from a study by Tola and Nordman, "Smoking and Blood Lead Concentrations in Lead-Exposed Workers and an Unexposed Population", which appeared in Environmental Research, Vol. 13, pages 250255, 1977. Blood lead concentrations were measured and the smoking history was recorded for 355 men representing the general population and 2209 men occupationally exposed to lead. Data from the Tola and Nordman study are presented in Table 1. In the general population, with no occupational exposure to lead, there was no association found between blood lead level and smoking. The reported blood lead levels were $10-11 \mu \mathrm{g} / 100 \mathrm{ml}$ regardless of the amount of smoking. These results are similar to most studies in the literature, indicating that smoking does not result in a change in blood lead levels. For the group of 2209 men occupationally exposed to lead, there was a relationship betwien the amount of smoking and the blood-lead concentrations. Smokers had statistically higher blood lead levels than non-smokers. Also, the differences between smokers and nonsmokers increased as the degree of occupational exposure to lead increased from slight exposure to heavy exposure, i.e., from $38.4 \mu \mathrm{g} / 100 \mathrm{ml}$ for 
non-smokers to $55.8 \mu \mathrm{g} / 100 \mathrm{ml}$ for smokers for heavy exposure and from $19.3 \mathrm{\mu g} /$ $100 \mathrm{ml}$ to 22.7 for slight occupational exposure to lead. While not completely ruling out the effect of smoking on lung clearance, the authors state that this result can probably be attributed to the contamination of fingers and cigarettes in the lead exposed work places. The carrying of and smoking of cigarettes on jobs involving exposure to lead certainly seems to result in increased lead absorption.

Table 1. Blood lead levels of people with or without occupational exposure to lead in different smoking categories.

\begin{tabular}{ccccc}
\hline \multirow{2}{*}{$\begin{array}{c}\text { Smoking category } \\
\text { (cigarettes daily) }\end{array}$} & \multicolumn{4}{c}{ Mean blood lead level, $\mu \mathrm{g} / 100 \mathrm{ml}$} \\
\cline { 3 - 5 } & None & Non occupational exposure to lead \\
Slight & Moderate & Heavy \\
\hline 1 - 20 & 10.8 & 22.7 & 29.1 & 55.8 \\
Stopped smoking & 11.4 & 22.5 & 26.3 & 47.4 \\
Never smoked & 10.8 & 20.7 & 25.1 & 43.8 \\
& 10.2 & 19.3 & 24.6 & 38.4
\end{tabular}

*From Tola and Nordman, Environmental Research (1977).

\section{RESEARCH REPORT ON CADMIUM}

The importance of this route of exposure is further emphasized in a study of cadmium workers by Piscator and colleagues of Karolinska Institute in Sweden. This report, "Pulmonary and Gastrointestinal Exposure to Cadmium Oxide Dust in a Battery Factory", appeared in Environmental Health Perspectives, Volume 28, pages 219-222, 1979. The investigators had previously shown that cigarettes and pipe tobacco of workers occupationally exposed to cadmium were contaminated by cadmium metal dust. However, the investigators looked further into the problem of contamination and personal hygiene in workers exposed to metal dust. The study had as its aim to find out to what extent cadmium entered the gastrointestinal tract of cadmium exposed workers. The results are presented in Table 2. The elimination of cadmium in feces averaged $619 \mu \mathrm{g} /$ day for smokers and $268 \mu \mathrm{g} / \mathrm{day}$ for non-smokers. The average dietary intake of cadmium for the general population in Sweden with no occupational exposure to cadmium is less than $20 \mathrm{\mu g} /$ day. Therefore, there are great differences between the amount of cadmium eliminated in feces between the general population and both smokers and non-smokers occupationally exposed to cadmium oxide dust. In addition, in the cadmium exposed population smokers had much higher cadmium fecal levels than did non-smokers. These differences between the general population and cadmium exposed population (smokers and non-smokers) and between smokers and non-smokers in the cadmium exposed population cannot be explained by differences in dietary habits or in air cadmium concentrations, which were very low. Even at 50\% lung retention and $100 \%$ absorption, the contribution of inhaled cadmium transferred to the gastrointestinal tract would be less than approximately 50 $\mathrm{\mu g}$. The authors concluded that the most probable explanation for the large amounts of cadmium found in feces is that the workers easily contaminate their clothes, hands, and other body surfaces and that additional oral exposure takes place when 
cigarettes or pipes are surface-contaminated with cadmium oxide dust.

Table 2. The effect of smoking on air, fecal, and blood levels of occupationally exposed workers*.

\begin{tabular}{lcccc}
\hline $\begin{array}{l}\text { Smoking } \\
\text { category }\end{array}$ & $\begin{array}{c}\text { Ca in air, } \\
\mu \mathrm{g} / \mathrm{m}^{3}\end{array}$ & $\mu \mathrm{g} /$ day & $\begin{array}{r}\text { Fecal cd, } \\
\mu \mathrm{g} / \mathrm{g} \text { dry wt. }\end{array}$ & $\begin{array}{c}\text { cd in blood, } \\
\mu \mathrm{g} / 100 \mathrm{ml}\end{array}$ \\
\hline Smokers & 10.1 & 619 & 25.4 & 2.0 \\
Non-smokers & 7.0 & 268 & 8.1 & 0.7
\end{tabular}

*From Adamsson, Piscator, Nogawa, Env. H. Persp., Feb., 1979.

I believe that the data from these studies clearly demonstrate the importance of good hygiene and work practices in reducing exposures. Clearly, few if any operations will involve exposures to levels as low as $10 \mu \mathrm{g} / \mathrm{m}^{3}$ of metal dusts as measured in the cadmium oxide battery plant. Yet, in this very clean plant, significant levels of dust were evidently ingested.

AWARE_TESS NEEDED OF VARIOUS ROUTES OF EXPOSURE

While it is not my intent to reduce the importance of engineering controls, I believe that it is important to be aware of the routes of exposure and the significance of the various routes of exposure. As pointed out in the Radian control technology assessment, this type of information is needed so that the effectiveness of control technology on worker health can be better established. In addition, the types of data which I have discussed are needed if workers and supervisory personnel are to seriously consider programs designed to improve hygiene practices and work habits and as a result significantly reduce absorption of metal dusts. 


\author{
PANELIST'S REMARKS \\ Melvin E. Cassady \\ Industrial Hygienist \\ U.S. Department of Labor/OSHA \\ Salt Lake City, Utah
}

HEALTH RESPONSE TEAM

First I'd like to explain the function of the Health Response Team. We are a group of industrial hygienists assigned to the OSHA Directorate of Technical Support, Washington, DC, but stationed in Salt Lake City, Utah. We have several functions, among them technical support and response to occupational health hazard emergencies. We also support compliance officers in investigations involving unusual and complex occupational health problems. A large portion of our work involves control technology assessment.

There are several ways that we come in direct contact with control methods:

1. We are often requested to provide technical assistance to area and regional offices. In the process of doing that we're able to do some evaluation of engineering controls.

2. We are consulted in some cases where petitions are submitted for modification of abatement to see if there is any other approach which could be taken in an operation to bring it into compliance.

3. If we hear through other agencies, through industry, or through engineering and sales firms of unique control technology, we then contact the plant and request a visit to observe the control method in operation.

LEAD SMELTER PROBLEMS

From my experience, the major problems in secondary lead smelters are involved with material handling, storage of material, and housekeeping. Smelters with dirt floors have a particularly severe problem after lead dust has accumulated over a number of years. Dry sweeping of material is a problem and vacuum cleaning should be used where possible. Not utilizing control equipment that is already in place is a problem. Hygiene facilities, which include the lunchrooms and the showering facilities, can be problem areas. 
A universal problem is poor maintenance. It is also common to find inspection doors on hoods open or to find that covers over launders have not been replaced. After removal for maintenance, some ventilation hoods are never replaced.

INNOVATIVE CONTROL METHODS

Over the last six months to a year we have seen some unique or innovative control technology in smelters. Among them are:

1. A charging mechanism on a blast furnace with a hooding system that seemed to do an effective job.

2. Flash agglomeration furnaces.

3. Removal of dross into an enclosed and exhausted container.

4. Totally enclosed battery breaking operations with little or no emissions.

5. Change rooms utilizing the Atomic Energy Commission (AEC) or beryllium industries methods, where a worker has to go through a shower to get from a contaminated area to a clean area.

6. Different methods for removing lead from shoes before going into a lunchroom area.

7. Curt Dungey mentioned today about the air wash system for removing contaminant from clothes. I know of several of those that are in use right now.

8. Good general ventilation as recommended by the American Conference of Governmental Industrial Hygienists (ACGIH).

SOURCES OF INFORMATION AND ASSISTANCE

Many companies are not presently making use of all the help that is available to them. There are many EPA and NIOSH publications available and the trade associations are a close-at-hand source of information. NIOSH has a program of heat hazard evaluations which is open to employee and employer both. Manufacturers of protective equipment can help in setting up a good respirator program. 
PANELIST'S REMARKS

Knowlton J. Caplan, President

Industrial Health Engineering Associates

Minneapolis, Minnesota

I'm going to talk about one or two slightly different aspects than have been touched on by the other panelists.

THE BASICS ARE THERE - THE PROBLEM COMES IN APPLYING THEM

My personal feeling is that for the secondary non-ferrous industry most of the basics of engineering controls are available. The problem is paying for them and getting them designed right and getting them adapted so they are workable and maintainable.

IMPROVEMENTS NEEDED IN FLOOR SWEEPING TECHNOLOGY

There is one area, however, where the technology has not kept up with the need. And that is in the area of keeping the floors clean - or housekeeping. Sweeping machines do clean the surface, but they are designed and built for ordinary floor sweeping or ordinary street sweeping and their air filtration systems are not designed to adequately filter a toxic substance.

In one case, we tested the clean air discharge of the vacuum system of a sweeping machine while it was cleaning a floor in a secondary lead smelter. The dust concentration was measured at $18 \mathrm{mg} / \mathrm{m}^{3}$.

We suspected there might be something wrong so we suggested that they overhaul that machine, make sure the filters were in good shape, and so forth - which they did. A second test showed a reduction by one-half to something like eight or nine milligrams per cubic meter.

You can see what this does to the time-weighted average if a sweeper is putting out $0.24-0.28 \mathrm{~m}^{3} / \mathrm{sec}(500-600 \mathrm{cfm})$ of air containing eight or nine milligrams of dust per cubic meter. The sweeper creates this problem while running up and down keeping the floor clean so that the fork truck doesn't kick up a cloud of dust!

One obvious alternative is an inhouse manually-operated vacuum cleaning system, which does work if properly designed. The problem is they're awfully labor-intensive; it takes a lot of manhours to clean the open areas of the floor by hand. On the other hand, the inhouse vacuum cleaning system is needed for the more inaccessible areas, especially overhead, 
that require periodic cleaning. What is needed is a better ride-on vacuum cleaner/sweeper that covers a lot of area per hour to do this job
economically.

I think some extra attention placed on this problem would be helpful because the people who manufacture those units would have to invest a fair amount in the development of a really effective and salable machine. The problem, from their point of view, would be the small size of the market because the number of secondary lead smelters in the country is small. The industry could stand some kind of an incentive to develop the right kind of floor cleaning equipment. 


\author{
PANËLIST'S REMARKS \\ Paul Hitcho \\ Industrial $\mathrm{Fj}$; gienist \\ United Steelworkers of America \\ Pittsburgh, Pennsylvania
}

\title{
SYMPOSIUM ACHIEVED OBJECTIVE
}

The purpose of this symposium was to present up-to-date information on control technology to reduce or eliminate worker exposure to chemical and physical agents in foundries and secondary non-ferrous smelters. After attending these sessions I believe that this purpose has been achieved. However, I also believe that much more than the exchanging and discussion of technological information has been accomplished.

This symposium, which has brought together representatives of industry, labor, and government, has provided a forum, albeit at times a heated one, where all could discuss both common and individual problems.

\section{NEED FOR A COMPREHENSIVE APPROACH}

One of those problems which I would like to discuss is a failure in the past and present to recognize that a comprehensive approach must be taken to implement a successful control program.

I'm glad to see that the need for a comprehensive approach was one of the conclusions of the Radian study. I also heard it from other speakers who shared the platform with me today. However, the problem still exists and let's try to solve it by using a technique suggested by Edward Hodnett, who has said that a good problem statement includes: a) what is known, b) what is unknown and $\mathrm{c}$ ) what is sought. By using this metnod we can attempt to solve our problems.

\section{WHAT IS KNOWN?}

1. Workers are exposed to agents that are hazardous to their health. I fully realize that there is not complete agreement among all of us here as to what levels of these agents are harmful.

2. The workers' occupational health must be protected.

3. In most cases the state-of-the-art is sufficient to control or reduce the hazard. However, there are still specific instances where the state-of-the-art must be refined. 
4. In many cases where controls have been installed workers are still being overexposed and are still contacting occupational diseases.

WHAT IS UNKNOWN?

In spite of the advances in control technology and the increasing number of companies with installed control systems, why are workers still being overexposed?

WHAT IS SOUGHT?

1. The best system should be used that will afford adequate protection for workers.

In deciding what is the best system many factors must be taken into account. A discussion of these factors follows.

Cost

The cost of control must be taken into account, however, economics must not be used as a primary reason for deciding on whether controls should be installed or not. Rather, cost should play a role in deciding which control systems should be installed. Hopefully, as control technology advances, the costs will become lower.

Efficiency

The control must accomplish what it was designed to do.

Maintenance

The system must not be so complex that regular plant maintenance personnel can't service it. As a corollary to this, there must be a continuing preventive maintenance program.

Worker Acceptance

All too often controls fail either because workers do not use them at all or do not use them effectively. Workers may not understand or appreciate the need for the controls, how they work, or what the rorker's role is in making these controls successful. Much time and research has been spent on the technical aspects of controls but little has been done in educating and training the workers for whom these controls were designed. After the control program has been installed and made operational the project is only one-half completed. An educational program for the workers must be undertaken.

Worker Input

There are very few people who know more about the process than the person who has operated that process for a good many years. You would be surprised at 
the ideas that these people come up with. A control program, to be successful, should take into account the ideas that workers put forth.

ESSENTIALS OF A WORKER TRAINING PROGRAM

Workers must be told and made aware of:

1. The hazards to which they are exposed.

2. The extent of these hazards, i.e., their personal exposure.

3. The health effects of these hazards.

4. What has been done, is being done, and what will be done in the future to control their exposure.

5. How the instituted controls work.

6. Their role in the program so that the control system can function properly.

7. How they can determine if the control is malfunctioning and what procedures they should follow to get it repaired.

8. The procedures to be followed in case of an emergency.

9. If there is a medical surveillance program, an explanation of what it is, and what their role is in it.

It has been our experience that worker cooperation is much easier to obtain from an educated work force as opposed to an uneducated one. A comprehensive approach must be undertaken to make any control technique successful. This approach must take into account worker cooperation and acceptance, as well as technological and economical feasibility.

After attending these sessions for three days I'd like to make two personal observations. The first observation is that it is the company's responsibility to provide a safe and healthful workplace. It is required by federal statute.

And the second observation is this: During the past day we heard about work practice controls and classification of workers as good or bad. A good worker is a worker who, for some unknown reason, does not expose himself to these agents and therefore, has a low biological monitoring result. A bad worker is a person who for whatever reason has a high biological monitoring result. In all my contact with labor I've yet to meet a worker who would purposely expose himself to a harmful substance or purposely cause himself to be injured on the job.

The Steelworkers, leadership and the rank and file, take occupational health very seriously. As a matter of fact, the wage policy committee that makes recommendations to the leadership on contract negotiations for the basic steel industry has placed improved contract language on occupational safety and health number four on their list of priorities. This is out of a total of fifty-five demands that will be negotiated with the basic steel industry.

And, finally, the Steelworkers do not subscribe to the philosophy that unsafe workers or unsafe acts cause injuries or illnesses. It's unsafe conditions, and these conditions must be corrected. 
Moderator (R. Hughes):

The following are questions from the question box. The first question is a rather general one which reads:

"I have seen a plant which calls itself a foundry but uses no sand, and I have seen another plant which melts scrap and extrudes brass logs which calls itself a brass mill. Please clarify the difference between a mill, a foundry, and a secondary smelter".

Ansẉer (M. Cassady):

There's not a really good definition of a secondary lead smelter. We have been using what the SIC code indicates for secondary smelter. But in terms of lead, that's all encompassing, and includes a lot of facilities that really aren't secondary lead smelters. I would consider a secondary lead smelter to be one that utilized materials such as batteries and reclaimed material in a blast furnace operation. It does make a difference in terms of compliance but I'm not sure that OSHA has clearly defined that at this point. (A definition of secondary lead smelter, supplied by Mr. Cassady from the Federal Register, appears at the end of the questions and answers).

Moderator :

The second question is: Why is there a hazard from arsine formation with some furnaces but not with blast furnaces?

Answer (K. Caplan):

The reason there is a hazard from some furnaces and not from blast furnaces is that arsine is formed when there is a reducing condition, i.e., when the arsenic-containing material is subjected to a chemically reducing condition, typically when there is hydrogen being formed.

For example, finely divided aluminum or magnesium will react with water to form hydrogen. And if there is any arsenic present, arsine will be formed.

In a blast furnace, hydrogen is not generated at the same time when arsenic is present. Instead, the arsenic is oxidized.

I would say a good rule of thumb is to watch out for reducing conditions when arsenic or antimony is in the mixture and, in case of doubt, to consult a chemist.

Moderator:

Does the secondary non-ferrous smelting industry have any noise problems? And, if so, what are they? 
Answer (M. Cassady) :

The problem, from my experience, that immediately comes to mind is burner noises.

Moderator:

Another question from the question box reads: "Mr. Gram commented on the unacceptability of respirator use as a final solution to hazardous situations in Denmark. I notice a definite difference of philosophy with American Industrial Management. Why can't industry address the issue of pooling education regarding health hazards, work practices, and engineering control to minimize these hazards with the same vigor with which they address production quotas"? If I understand the question, the objection is that in this country there is a greater reliance on respirators than on engineering controls.

Answer (D. Lynam):

I don't agree that the philosophy of management in the U.S. is different. I think the lead industry at the present time is forced into complete respirator usage in order to meet a $50 \mathrm{\mu g} / \mathrm{m}^{3}$ time-weighted average.

I think Mr. Gram, in his comments this morning, pointed out that the Bergsoe operation was certainly not meeting a $50 \mu \mathrm{g} / \mathrm{m}^{3}$ level. He also indicated that, while the average blood lead was something like $48 \mu \mathrm{g} / 100 \mathrm{ml}$, most of the values were in the $60-70 \mu \mathrm{g} / 100 \mathrm{ml}$ range. Under the OSHA standard industry will eventually be required to go to a $40 \mu \mathrm{g} / 100 \mathrm{ml}$ blood lead level. EPA has stated that in order to keep 99.5 percent of the blood leads in the general population below $30 \mu / 100 \mathrm{ml}$, the mean value would have to be $15 \mathrm{\mu g} / 100 \mathrm{ml}$. If essentially 100 percent of the people are to be controlled below $40 \mu \mathrm{g} / 100 \mathrm{ml}$ then certainly the mean level is going to be much lower than that.

Moderator :

I will now entertain questions from the floor.

Question (F. Boelter, OSHA):

Dr. Lynam, my question is based on the data you presented indicating the high levels of cadmium that were excreted from the body. Do you think that the ingestion hazard of cadmium is great enough in a lunchroom to warrant a very clean environment, such that on a wipe sample you would essentially find zero or non-detectable levels of cadmium?

Answer (D. Lynam):

I really don't know how to interpret some of the values on wipe samples. I think the conditions under which these data were collected indicate that most of the contamination occurred for reasons such as the carrying of 
smoking materials into work areas in which they become contaminated, resulting in oral ingestion when smoking occurs. These data did not refer to contamination within a lunchroom, but I would say that a lunchroom should be relatively free of contamination.

Question (F. Boelter):

Mr. Caplan, I totally agree with you on the inadequacy of housekeeping equipment not only for the non-ferrous smelting industry but also for the foundry industry. You stated that the vacuuming systems that are currently available tend to be high manual labor items. Even though it requires a lot of labor is it still not a worthwhile investment and effort to make to keep the facility clean since there really is no other alternative for a broom and a shovel?

Answer (K. Caplan):

Depending on what the problem is, sometimes it may be and sometimes it may not be. The point I am trying to make is that cleaning the open areas of the floor with an inhouse vacuum cleaning system is a slow, laborious, and menial task. What is needed is a good ride-on sweeper that does not itself generate more dust than we'd like to get in the air. Then all the areas where the vehicle can go can be cleaned efficiently, rapidly, and safely. It's a need for further development.

Question (H. Scarton, Rensselaer Polytechnic Institute):

Would not a hammer mill be a potential noise source? And, if it is, is there anything being done to quiet this machine down?

Answer (M. Cassady):

Yes, it would be a source. I think the NIOSH Technology Assessment Report has something on quieting down aluminum hammermills.

Answer (K. Caplan):

Yes, it's a source but it can be fixed.

Moderator :

Is that technique used for battery breaking?

Answer (K. Caplan):

Yes.

Question (K. Gerecke, OSHA):

Mr. Caplan, do you anticipate any process changes in the near future? Earlier you seemed to indicate that what we've really been talking about today is add-on controls, not basic process changes. 
Answer (K. Caplan):

The Bergsoe process is new in several aspects. As I understand it, the process differences are helpful in achieving better hygiene control but are by no means key or new or different in kind than existing processes. The real reason, in my opinion, that the Bergsoe plant has controlled exposures to lead in the blast furnace area to around $100 \mu \mathrm{g} / \mathrm{m}^{3}$ is because it is a new plant that was well designed, not because it's a slightly different process. The design included their best efforts in hygiene and air pollution.

I haven't seen any significant new process technology on the horizon, except the one that was mentioned, which is an electrowinning process. It doesn't look too good, in fact, it's got a more serious potential hazard than the present process, which is chlorine gas. Of course, I'm not aware of private development efforts which may be going on.

Comment (I. Tanenberg, R. Lavin and Sons, Inc.) :

I have a feeling here today that there has been an oversimplification of the problem and the cure. Industry is now trying to correct within a short space of time problems that are eight decades old.

Response (K. Caplan):

Yes, I agree. I think that, unfortunately, the approach that's frequently taken is overly simplified and its's difficult to know what to do about it.

In the current lead standard, for example, OSHA said that in their opinion a control to $50 \mathrm{\mu g} / \mathrm{m}^{3}$ would be feasible for industry as a whole. Assuming it may be feasible for industry as a whole, is it therefore going to be feasible for every member of industry? Probably not.

Part of the problem, as I see it, is the strictly legal enforcement/penalty approach which requires it to be clearcut, black and white and, therefore, it becomes oversimplified.

Response (M. Cassady):

Most of the control technology that has come out of this symposium has been related to generally-accepted ventilation practice. Much of it is in the Industrial Ventilation Manual of the American Conference of Governmental Industrial Hygienists (ACGIH). This manual was around for a long time prior to the promulgation of the new lead standard. We are finding a lot of industries that haven't even applied some of the older technology to their facilities, and they don't even meet the $200 \mu \mathrm{g} / \mathrm{m}^{3}$ standard, for example.

Comment (M. Lane, Davy McKee Corp):

I'd like to add to the view that has been taken throughout the whole conference: that it appears that the only way that industry can come 
close to meeting the OSHA regulations is by an overall package of control, not only engineering but administrative. This comprehensive approach also relates to the design of new plants where all of the governmental regulations must be taken into account.

A comprehensive approach is something that I don't think the governmental agencies have addressed the way that they should.

Response (R. Hughes):

I do think that there is an effort within government for agencies to talk to each other. I know in NIOSH's efforts we're trying to coordinate with EPA what we're looking at in our studies. Hopefully, that can lead to a more coordinated effort.

Question (R. Coleman, Texas Metals):

I think we might agree that the OSHA regulations are technology forcing and that when new controls are installed there is going to be a period during which people will have to find out whether or not they work.

Has either NIOSH or OSHA come up with plans for funding some of the tests of the new control technology?

Answer (R. Hughes):

NIOSH is currently conducting control technology assessments. The assessment effort is not necessarily trying to find the "best" technology, but rather exemplary, workable, effective controls that are in place and functioning. As a result of these studies a lot of areas where controls are not effective or not as effective as they need to be have been identified and recommendations for research and development programs have been made.

It is our intention to initiate demonstration grants or find some other way to stimulate development of new technology.

I'm not sure that we are going to do it ourselves. I'm not sure that government should go out and develop a new smelter because we don't know how to do it. We've been told that many times and we agree with it.

Answer (M. Cassady):

There are three of us within three different organizations that are working together to see if we can come up with some things that might be worth funding. These individuals include Mr. Fred Craig of EPA, Mr. Robert Hughes of NIOSH, and myself (OSHA). Within OSHA I don't think we've ever tried that before and I'm not sure the mechanism is there for that funding. But we're going to take a shot at it. 
Response (R. Hughes):

We're looking for the mechanism.

Question (Ralph Allan of the University of California-Irvine):

One of the unique ways that we're addressing the control of some of the work stations in the secondary smelting industry as well as the battery industry is by addressing positive air systems to the work stations and the problem of housekeeping. Is there any work that has been done in addressing the effect of these positive air-moving systems on the re-entrainment of settled dust? Is there anything at all to show the effectiveness of the positive air-moving systems versus the exhaust systems?

Answer (K. Caplan):

The positive systems that I'd like to talk about first are the enclosed, pressurized work booths. If there is enough pressurizing air and if it is adequately filtered and especially if the air is exhausted through the floor or at the floor level of a reasonably small booth, the air in that booth will be reliably clean. If there are problems with such a booth they are the result of not supplying enough air or not using an efficient filter or a powerful enough blower.

When clean air is blown on workers in open plant areas and the distance cf travel of the air from the discharge port to the worker is more than $1-1 / 2 \mathrm{~m}$ (3-5 ft), the air will have mixed with some background air in the plant by the time it reaches the worker. As a result the air will not be as clean as it was at the discharge point.

We've actually done some small experiments, and the profile of the contamination looks just like the classic picture of the blue flame and the purple flame coming out of a Bunsen burner. The pure air quickly gets contaminated a fairly short distance from the clean air port.

Question (L. Norman, Industrial Safety and Health Consultants):

I'm concerned about what took place back in the original hearings. There seems to be a strong effort to say that the Bergsoe system is the best available control technology in the secondary lead smelting industry. There was that approach in the hearings, and we're starting to get that approach in the industry again, not only from the meeting today but also from the fact that there has been federal money spent to investigate the Bergsoe system in Denmark, and to actually construct a flash agglomeration furnace in the United States to see if it would work.

Are we being told in a roundabout way or maybe even directly that the Bergsoe system is the best available technology for the industry? 
Answer (R. Hughes):

It was our branch in NIOSH, cooperating with the EPA, that investigated it. The investigation was performed as part of our smelter study, whose objective was to evaluate installations that were reported to be effective. That was the basis for looking at the Bergsoe system. There were other operations that were also looked at in our study that were reported as being good.

I think it was also brought out earlier today that the Bergsoe process is not being pushed. Jeff Burton addressed that quite well and I think Mr. Gram from Bergsoe addressed it also.

Comment (D. Lynam):

If you look closely at the OSHA standard and the basis for it from a technological standpoint, OSHA is saying that the Bergsoe process is a demonstration that indastry can meet a $50 \mu \mathrm{g} / \mathrm{m}^{3}$ standard.

In fact, it was very clearly spelled out in a letter on the lead standard from the OSHA solicitor, Richard Gross, to Mr. Bergsoe. Mr. Gross thanked Mr. Bergsoe for testifying at the OSHA hearing, and stated that his testimony was used as the basis for showing that the industry can meet a $50 \mathrm{\mu g} / \mathrm{m}^{3}$ limit. It was very clearly pointed out by $\mathrm{Mr}$. Bergsoe in a return letter to $M r$. Gross that he said no such thing, and that what he was saying was that he felt that they could come close to a $100 \mu \mathrm{g} / \mathrm{m}^{3}$, but they certainly were not proposing that their process and their technology could meet a $50 \mu \mathrm{g} / \mathrm{m}^{3}$ level.

Comment (K. Caplan):

I think it was completely appropriate for NIOSH and EPA to investigate the Bergsoe process at the Bergsoe plant because there was so much information and misinformation about it.

Now, concerning the appropriateness of seeing if flue dust will melt in the United States just like it will in Denmark, that's a different question.

Comment (N. Gram, Bergsoe and Son):

The question of entirely new processes was raised a while ago. In the United States there are 800,000 tons of lead recycled per annum by secondary smelters. No new process is going to replace smelting in the production of that volume of material in the near future.

I have another comment as regards respirator use. I would confirm wh=.t Dr. Lynam said: We are not working today under a $50 \mu \mathrm{g} / \mathrm{m}^{3}$ standard in Denmark, we're working under a $100 \mu \mathrm{g} / \mathrm{m}^{3}$ standard and we have not had to use respirators in the daily routine. If we were to meet a $50 \mathrm{\mu g} / \mathrm{rm}^{3}$ standard all of a sudden we might have to look to respirators. But I don't think we'll get our people to use them. 
The Danish OSHA, which I know quite well but do not represent (I can't speak for them), would never make such a regulation all of a sudden. They would stay with the $100 \mu \mathrm{g} / \mathrm{m}^{3}$ standard for another number of years, seeing that our blood lead levels are creeping down. They would watch to see how far we can get and then decide whether another step should be taken and what it should be. That's the way the Danish regulatory agency usually works.

Finally, one comment about vacuum cleaners. We have tried them and now try to avoid using them except in areas where we have to work dry, for instance, because of the arsine or stibine problem. In other areas, outdoor and indoor, we use wash-down wherever we can.

Question (G. Mitchell, OSHA):

It seems that the furnace mechanism and ingot handling are high contributors to noise. Are there any engineering controls to reduce or any other means to reduce employee exposure to these processes?

Answer (K. Caplan):

Yes, there are ways to control burner noise. Whether they can be retrofitted to a given furnace or not depends on various things.

As regards the second noise source jou mentioned, I didn't realize that ingot handling was a significant noise source.

Answer (M. Lane, Davy McKee Corp.):

There a:e ways of decreasing burner noise. The main source of the noise comes from the blower itself. Isolating the blowex in a room by itself or putting it outside the wall of the workplace are effective ways to take care of the problem.

Definition of secondary lead smelter from the Federal Register (29 CFR 1910.1025):

"Secondary smelters recycle lead from discarded batteries and other waste materials. This recycling involves two phases: smelting of the old material to recover crude lead and in some operations, refining of the crude lead to produce pure lead and alloys for reuse.

Secondary lead smelting plants take scrap lead material from many sources, but the majority (61\%) comes from scraped lead-acid batteries. Lead cable covers, linotype, and recovered fume and drosses are other major sources. Some scrap is reprocessed to remove lead and other materials. Battery plates and terminals, for example, are mechanically separated: and lead-copper cables are heated to melt off the lead. Materials containing lead oxide may be processed through a blast furnace to reduce the proportion of oxide to lead metal. Lead from the blast furnace and scrap 
containing lead metal may be melted in refining kettles and treated by drossing to remove copper and other impurities. Following the drossing, the lead may be "softened" by removing antimony that has been previously added to give the lead hardness and strength. This removal is done by air oxidation in a reverberatory furnace or by oxidative slagging with sodium dioxide or sodium nitrate fluxes. Once the lead has been refined to a desired composition, it is cast into various shapes or fabricated into wires, pipes, sheets, or solders". 


OFFICIAL BUSINESS

PENALTY FOR PRIVATE USE. $\$ 300$
Special Fourth Class-Book

POSTAGE AND FEES PAID U.S. DEPARTMENT OF HHS

HHS 396 